COLUMBIA LIBRARIES OFFSITE

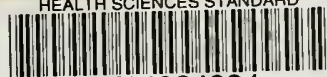

HX64084094

QM601 .H36

RECAP 


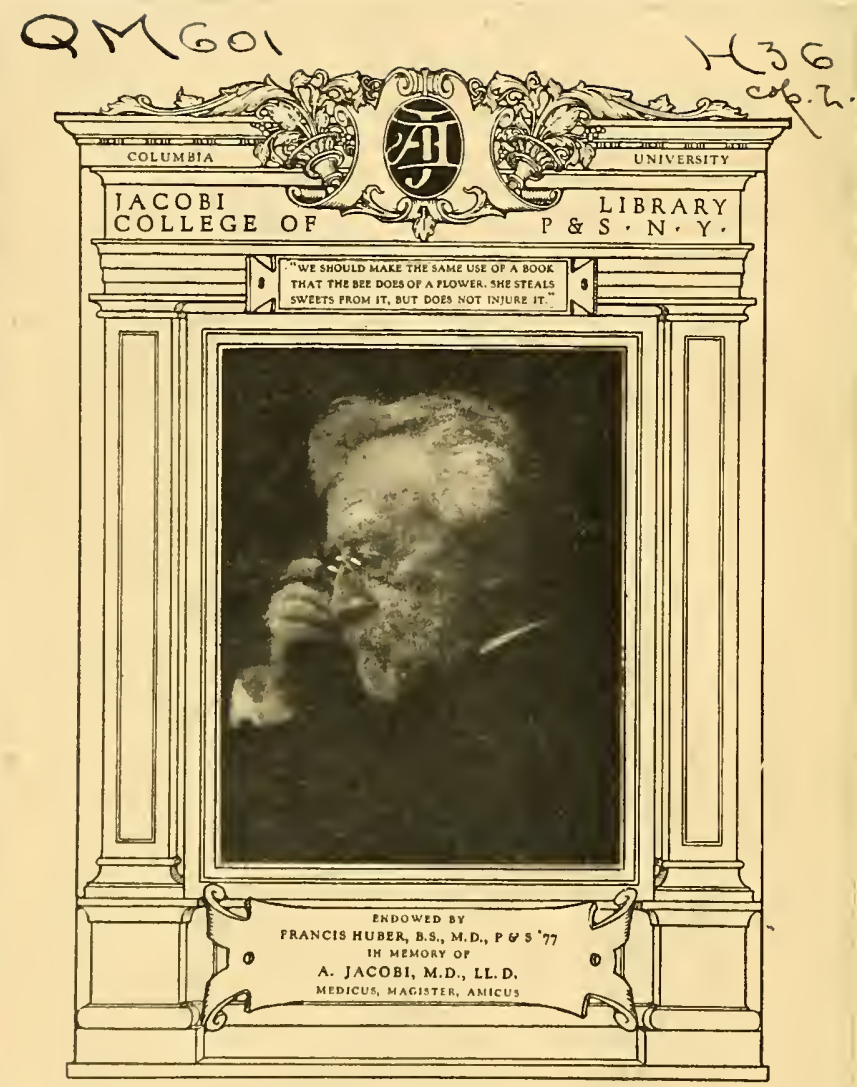







Digitized by the Internet Archive in 2010 with funding from Columbia University Libraries 



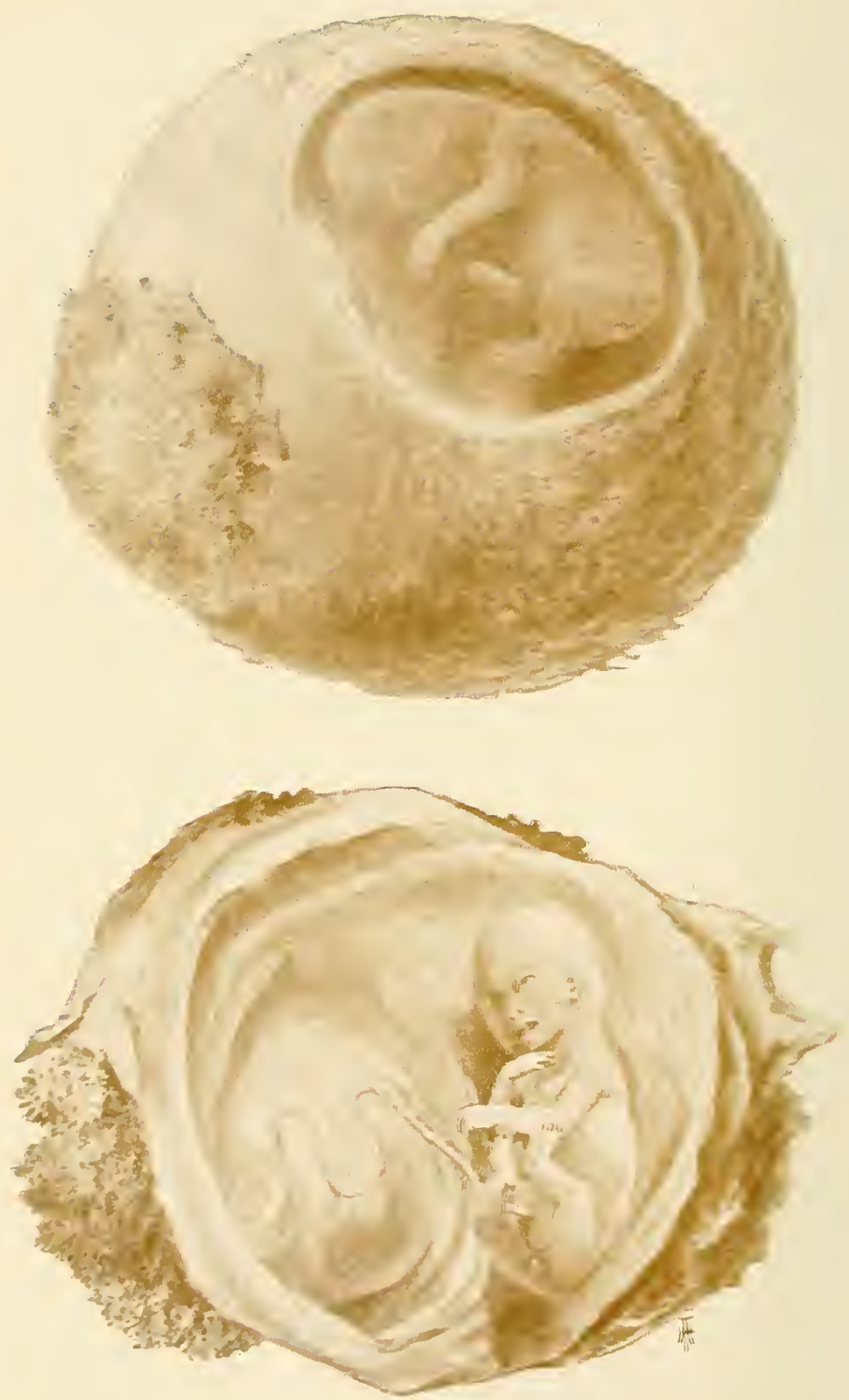

Fetus of third month, with fetal nembranes and newly-formed placenta (natural size). In the upper figure the chorion is eut, showing the fetus through the annion; in the bower figure the membranes are laid open. 


\title{
A TEXT-BOOK
}

\section{OF \\ E M B R Y O LOG Y}

\section{FOR STUDENTS OF MEDICINE}

\author{
BY \\ JOHN CLEMENT HEISLER, M.D. \\ Professor of Anatomy in the Medico-Chirurgical College, \\ Philadelphia
}

WITH 190 ILLUSTRATIONS, 26 OF THEM IN COLORS

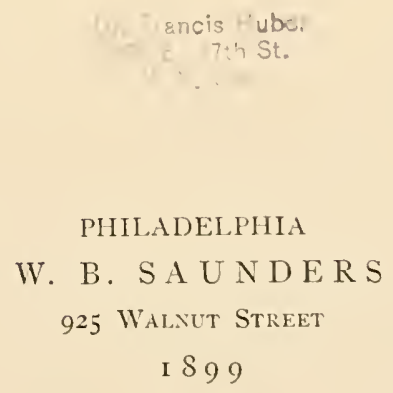


Copyright, i899,

By W. B. SAUNDERS.

ELECTHOTYPEO BY WESTCOTT \& THOMSDN. PHILADA.
PRESS OF

W. B SAUNDERS, PHILADA. 


\section{PREFACE}

The facts of embryology having acquired in recent years such great interest in connection with the tcaching and with the proper comprehension of human anatomy, it is of first importance to the student of medicine that a concise and yet sufficiently full text-book upon the subject be available. It was with the aim of presenting such a book that this volume was written, the author, in his experience as a teacher of anatomy, having been impressed with the fact that students were serionsly handicapped in their study of the subject of embryology by the lack of a text-book full enough to be intelligible, and yet without that minuteness of detail which characterizes the larger treatises, and which so often serves only to confuse and disconrage the beginner.

In the arrangement of the subject-matter of the book, it has been the ain not only to present a comnected story of human development, hut also to make each chapter as nearly as possible complete in itself, for the sake of convenience of reference. It is for this reason that some repetitions occur in the text. The frequent allusions to eertain ficts of comparative embryology are rendered necessary by the very nature of the subject, but it has been the writer's aim to make these allusions as simple and ats easily intelligible as possible.

In the selection of the illustrations, great care has been exercised to employ those of the greatest teaching value, and to arrange them, with reference to any one chapter, as nearly 
as possible in proper chronological sequence. Due acknowledgement is made in each case for every illustration borrowed from other works.

With few exceptions, no attempt has been made to cite authorities in the text, and the anthor would here express his obligations to the writings of His, O. Hertwig, Kölliker, Schultze, Bonnet, Balfour, Marshall, Piersol, Minot, Tourneux, and many others.

3705 Powelton Ave,

J. C. H.

Philadelphia. 


\section{CONTENTS.}

CHAPTER 'I.

PAGE

The Male and Female Sexual Elements; Maturation; Ovu=

lation; Menstruation; Fertilization ........ 17

The Spermatozoon . . . . . . . . . . . . . 20

The Ovun . . . . . . . . . . . . . . . . . . . 22

The Hen's Egg . . . . . . . . . . . . . 25

Oogenesis . . . . . . . . . . . . . . . . 27

Maturation of the Ovum . . . . . . . . . . . . . . . 30

Ovulation . . . . . . . . . . . . . . . . . . . 32

Menstruation . . . . . . . . . . . . . . . . 35

The Relation of Menstruation to Ovulation and Conception . . 37

Fertilization ..................... 38

CHAPTER II.

The Segmentation of the Ovum and Formation of the Blas= todermic Vesicle ... . . . . . . . . . 41

Segmentation . . . . . . . . . . . . . . . . 4 41

The Stage of the Blastula .......... . . . 45

CHAPTER III.

The Germ=layers and the Primitive Streak . . . . . . . . 46

The Stage of the Gastrula . . . . . . . . . 46

The Embryonal Area . . . . . . . . . . . . 50

The Primitive Streak . . . . . . . . . . . . 51

The Development of the Mesoderm . . . . . . . . . 54

The Derivatives of the Germ-lavers . . . . . . . . 58

CHAPTER IV.

The Beginning Differentiation of the Embryo; the Neural

Canal; The Chorda Dorsalis; the Mesoblastic Somites 61

The Neural or Medullary Canal . . . . . . . . . . . 62

The Notochord or Chorda Dorsalis . . . . . . 65

The Neurenteric Canal . . . . . . . . . . . . . 66

The Somites or Primitive Segments . . . . . . . . 67 
CHAPTER V.

The Formation of the Body=wall, of the Intestinal Canal, and of the Fetal Membranes . . . . . . . . . . 70

The Formation of the Body-Wall and of the Intestinal Canal of the Embryo . . . . . . . . . . 70

The Anvion . . . . . . . . . . . . . . . 74

THE YolK-SAC.................... . . . 78

The Allantors . . . . . . . . . . . . . . . 80

THE CHORION . . . . . . . . . . . . . . 82

CHAPTER VI.

The Decidua ; the Placenta ; the Umbilical Cord . . . . . . 85

The Decride . . . . . . . . . . . . . . . 85

The Placenta . . . . . . . . . . . . . . . 87

The Umbilical Cord ................. . . . . 91

Condition of the Fetal Membranes at Birth . . . . 93

CHAP'TER VII.

The Further Development of the External Form of the Body 94

The Stage of the Ovum . . . . . . . . . . . . . . . 95

The Stage of the Eurbryo . . . . . . . . . . . . 96

The Visceral Arches and Clefts . . . . . . . . . . 100

The Stage of the Fetus . . . . . . . . . . 106

CHAPTER VIII.

The Development of the Connective Tissues of the Body, and of the Lymphatic System . . . . . . . . . . . . 113

The Connective Tissues . . . . . . . . . . . . . 113

The Development of the Lympinatic System. . . . . . 116

CHAPTER IX.

The Development of the Face and the Mouth Cavity . . . . 118

The Evolution of the Face . . . . . . . . . . . 118

THE Mouth . . . . . . . . . . . . . . . 122

The Teeth . . . . . . . . . . . . 125

The Salivary Glands . . . . . . . . . . . . 131

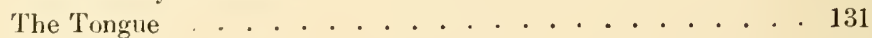

TIIE NOSE ............................ 133

CHAPTER $\mathrm{X}$.

The Development of the Vascular System . . . . . . . 135

Trif Vttelline Crrculation and tile Origin of the Blood 135

The Devitopment of tue Hent . . . . . . . . . 138

The Netanorphosis of the Single into the Double Heart . . . 142

The Valves of the Heart . . . . . . . . . . . . 144 
PAGE

The Allantolc and tme Placental Circulation . . . 148

The Fetal Arterial System . . . . . . . . . . . 149

The Fetal Venous System . . . . . . . . . . 153

The Formation of the Pericardium, the Pleurd, and the

DiAPHRAGMI . . . . . . . . . . . 158

The Portal Circulation . . . . . . . . . . . 161

The Final Stage of the Fetal Vascular System a . 165

CHAPTER XI.

The Development of the Digestive System . . . . . . 168

The Month . . . . . . . . . . . . 175

The Pharyt . . . . . . . . . . . 176

The Tonsil . . . . . . . . . . . . . 177

The ANe'. . . . . . . . . . . . . . 178

The Differentiation of the Almmentary Canal into Sep-

ARATE Regions . . . . . . . . . . . 180

Increase in Length and Further Subdivision . . . . . . . . . 184

Alteration in the Relative Position of Parts and Further Devel-

opment . . . . . . . . . . . . . . . 155

Histolngical Alterations . . . . . . . . . 188

Meckel's Diverticulum . . . . . . . . . . . 190

The Develophest of the Liver . . . . . . . . . 190

The Development of the Pancreas . . . . . . . 194

The Development of the Spleen. . . . . . . . 194

The Eyolution of the Peritonetar . . . . . . . 195

CHAPTER XII.

The Development of the Respiratory System . . . . . 204

The Thyiond and Thrmes Bodies. . . . . . . . . 207

CHAPTER YIII.

The Development of the Genito=urinary System . . . . . 212

The Developuent of the Kinvey and the Ureter . . . 212

The Mesonepliros or Wolffian Body . . . . . . . . . . . 213

The Metanephros or Permanent Kidney . . . . . . . . 217

The Suprarenal Bontes . . . . . . . . . . . . 218

The Developinext of the Interxal Generative Organs. 220

The Indifferent Type . . . . . . . . . . . . . . 220

The Male Type . . . . . . . . . . . . . . . . 222

The Female Type. . . . . . . . . . . . . . 226

The Blander axd the Prostate Gland . . . . . . 232

The External Orgaxs of Generation . . . . . . 234

The Female External Genitals . . . . . . . . . . 236

The Male External Genitals . . . . . . . . . . . 237

SumMary . . . . . . . . . . . . . . 240 
CHAPTER XIV.

PAGE

The Development of the Skin and its Appendages . . . . . 245

The Skiv . . . . . . . . . . . . . . . 245

The Appendages of the Skin . . . . . . . . . . 247

The Nails . . . . . . . . . . . . . . . 247

The Hair . . . . . . . . . . . . . . . . . 248

The Sebaceous and Sweat Glands . . . . . . . . . 250

The Mammary Gland . . . . . . . . . . . . . . 251

CHAPTER XV.

The Development of the Nervous System . . . . . . , 254

The Development of the Spinal Cord . . . . . . . . 257

The Development of the Brain . . . . . . . . . . 262

The Fifth Brain-vesicle . . . . . . . . . . . . . 264

The Hind-brain Vesicle . . . . . . . . . . . . . . . . 268

The Mid-brain Vesicle . . . . . . . . . . . . . . 270

The Inter-brain Vesicle . . . . . . . . . . . . 272

The Fore-brain Vesicle . . . . . . . . . . . . . 278

The Development of the Peripheral Nervous System . 292

The Development of the Sympathetic System . . . . . 300

\section{CHAPTER XVI.}

The Development of the Sense Organs . . . . . . . . 302

The Develotuent of the Eye . . . . . . . . 302

The Retina and Optic Nerve . . . . . . . . . 304

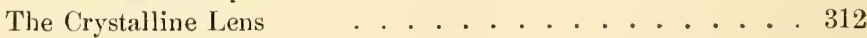

The Vitreous Body . . . . . . . . . . . . . 314

The Midlle and Outer Tunies of the Eye . . . . . . . 315

The Eyelids and the Lacrimal Apparatus . . . . . . . . 318

The Development of the Organ of Hearing . . . . 321

The Internal Ear . . . . . . . . . . . . . . 321

The Middle and External Ear . . . . . . . . . . . 331

The Develophent of the Nose........... . . 334

CHAPTER XVII.

The Development of the Muscular System . . . . . . . . 339

The Striatrid or Voluntary Musclis . . . . . . . . 339

The Muscles of the Trunk I'roper . . . . . . . . . . . . . . 339

The Metamorphosis of the Muscle-plate . . . . . . . . 342

The Jirunchial Muscles . . . . . . . . . . . . . 344

The Museles of the Extremities . . . . . . . . . . . . 345

The Invoiduntary or Unstriated Muscular Tissue . . . 346 
The Axial Skeletox . . . . . . . . . . . . . . . 348

The Derelopment of the Trunk . . . . . . . . . . . 348

The Stage of the Chorda . . . . . . . . . . 348

The Membranous Stage . . . . . . . . . . . . . . 349

The Cartilaginous Stage . . . . . . . . . . . 351

The Osseous Stage. . . . . . . . . . . . . 354

The Development of the Ribs and Sternum . . . . . . 356

The Development of the Head Skeletor . . . . . . . 358

The Membranous Cranium . . . . . . . . . . . . . . . . 359

The Cartilaginous Cranium . . . . . . . . . . . . . . 360

The Osseous Stage . . . . . . . . . . . . . . 363

The Appendicular Skeleton . . . . . . . . . . . . . 376

The Pectoral and Pelvic Girdles . . . . . . . . . . 377

The Bones of the Extremities . . . . . . . . . . . . 37s

The Development of the Limbs . . . . . . . . . 380

Tabulated Chronology of Development . . . . . . . 383

Index . . . . . . . . . . . . . . . . . 391 



\section{CHAPTER I.}

\section{THE MALE AND FEMALE SEXUAL ELEMENTS; MATURATION; OVULATION ; MENSTRUATION ; FERTILIZATION.}

Embryology is that department of biology whieh treats of the generation and development of organisms. It may refer to the development of the race or stock-Phylogeny-or to that of the individual-Ontogeny; again, it may treat of animal or of vegetable development.

Sinee no observations have been made upon human embryos of an age less than twelve or thirteen days, and but few upon those younger than sixteen or eighteen days, we eannot be said to possess definite knowledge of the very earliest processes of development in man. There is, however, suffieient analogy between the known facts of human development and those of corresponding stages in allied groups of animals, as well as between the various groups of animals themselves, to establish certain broad general prineiples of agreement in essential features. In traeing the history of human development, therefore, frequent recourse must be had to the development of animals, since in this way only is it possible at present to fill up the gaps in our knowledge of human embryology.

That a new individual may be ealled into existenee, the union of the male element, or spermatozoön, with the female element, or ovum, is necessary. Snch union is varionsly called fertilization, fecundation, and impregnation.

Prior to the beginning of the present eentury, little or nothing was definitely known coneerning reproduction and development. The opinions of the biologists of early times found expression in a theory which was then called the theory of unfolding or of evolution, but which more recently has 
been designated the preformation theory. According to this doctrine, the egg or germ contained all the parts of the adult organism in an exceedingly minute condition, and development consisted in the simple growth or unfolding of already formed parts. As the theory of unfolding implied the preformation not only of the immediate but of all subsequent offspring, its votaries were able to compute that the ovary of Eve contained 200,000 millions of human germs.

With the discovery of the spermatozoön in 1677 by Hanm, a pupil of Lenwenhoeck, a eontroversy arose as to whether it was the spermatic filament or the ovum that contained the germ. Those who maintained the former view were known as cmimalculists; those who held the latter, as ovists. According to the opinions of the animalculists, the spermatozoon was the complete organism in miniature, and it required for its growth the soil or environment which the ovum alone could furnish.

The enumciation by Wolff, in 1759, of his doctrine of epigenesis completely overturned the preformation theory. Wolff maintained that the germ was unorganized matter, and that the union of male and female material was essential to reproduction. While Wolff's theory was in the main correct, it remained for later investigators to show that the ovum did not consist of unorganized matter, as he thought, but that it possessed definite structural characteristies. Thus, the germinal vesicle of the hen's egg was discovered in 1825 by Purkinje, and the germinal spot in $1826 \mathrm{by}$ Wagner. Soon after the enunciation of the cell-doctrine by Schleiden and Schwann, it was seen that the ovum was in reality a typical cell, possessing all the parts of such a structure.

It was not, however, until about the year 1840 that it was shown, by Kölliker, Reichert, and others, that the spermatozoa are the active agents in fecmudation. Previonsly it had been held, since the refutation of the preformation theory, that the seminal fluid performed this function, and that the spermatozoa were parasitic organisins.

'The length of time necessary for the development of the new individual varies aceording to the species; in man it 
oeeupies nine ealendar months or about ten lunar monthsthat is, from 273 to 280 days. The period of human gestation is arbitrarily divided by $\mathrm{His}$ into three stages: (1) The

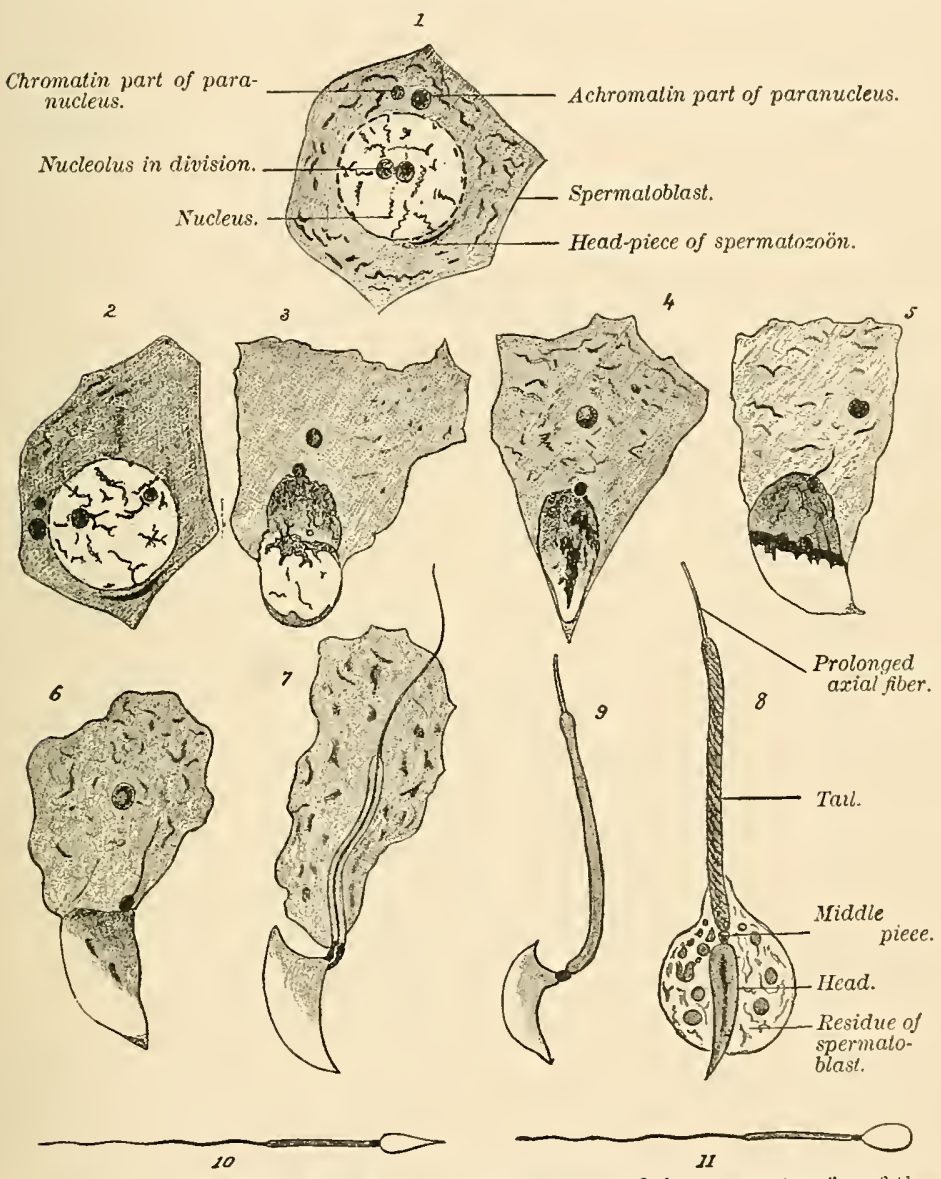

FIg. 1. -1 to 8 , Various stages of the development of the spermatozoon of the mouse; 9 , the spermatozoön of the mouse (after F. Hermann); 10 and 11, spermatozoa of the $\mathrm{dog} ; 10$, as seen from the side; 11 , as seen from the broader surface (after Bonnet).

stage of the ovum, comprising the first two weeks of development; (2) The stage of the embryo, extending from the end of the second week to the fifth week, during which time the germ begins to assume definite form; and (3) The stage of 
the fetus, which includes the remainder of the term of intrauterine existence.

It may be pointed out that the term ovum, as employed in embryology, has three different signifieations: it designates the female sexual cell prior to its impregnation ; it is used in the sense noted above to designate the fertilized egg; and it is somewhat loosely applied to the product of conception during various stages of development.

\section{THE SPERMATOZOÖN.}

It is noteworthy that both spermatozoa and ova-that is, both sexual cells-are products of metamorphoses taking place in epithelial structures, the former being derived from the spermatogenic cells found in the seminiferous tubules of the testicle, while the latter come from

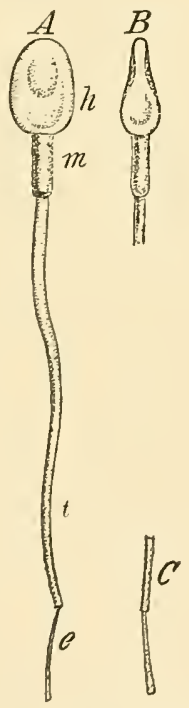

Fig. 2.-1Iunan spermatozoa (after Retzius): 1, spermatozoön secn en face; $h$, head ; $m$, midalepiece; $t$, tail ; $r$, end-picec; $b, C$, seen from the side. the germinal epithelium of the ovary.

The form of the seminal filament varies greatly in different species (Fig. 1). The human spermatozoön (Fig. 2) is an elongated body, about $0.05 \mathrm{~mm}$. ( $\frac{1}{500}$ inch) in length, consisting of three parts, a head, a middle piece, and a tail or flagellum.

The head is much thickened as compared with the other segments, appearing egg-shaped as seen upon its broader surface, the smaller extremity being connected with the middle piece; seen in profile, it is convex on onc side and concave on the other. The middle piece is somewhat longer and much thinner than the head, while the tail is a slender filament slightly more than four-fifths of the entire length of the spermatozön. Lying in the center of the spermatozoön, and extending throughout its entire length, is the slender axial fiber, which is prolonged slightly beyond the tail. 
The power of locomotion which the spermatozoön exhibits is conferred by the ribratile movement of its tail, accompanied by a rotation about its long axis through an arc of 90 degrees. The rate of progression is about 0.05 or $0.06 \mathrm{~mm}$., or its own length, per second.

Spermatozoa possess remarkable vitality, remaining active in the male genital tract for sereral days after death. In the genital passages of the female, they may retain their activity for several weeks, and when mounted and protected from evaporation they have been known to show vibratile motion after the lapse of nine days (Piersol). Weak alkaline solutions render them more acrive, while acids, even quite dilute, destroy them. The spermatozoa of the bat, being deposited in the female genital passages in the autumn, retain their power of fecundating ova until the following spring.

Spermatogenesis.-The details of spermatozoön-formation, or spermatogenesis, vary in clifferent animals. A cross section of a seminiferous tubule (Fig. 3) shows a layer of

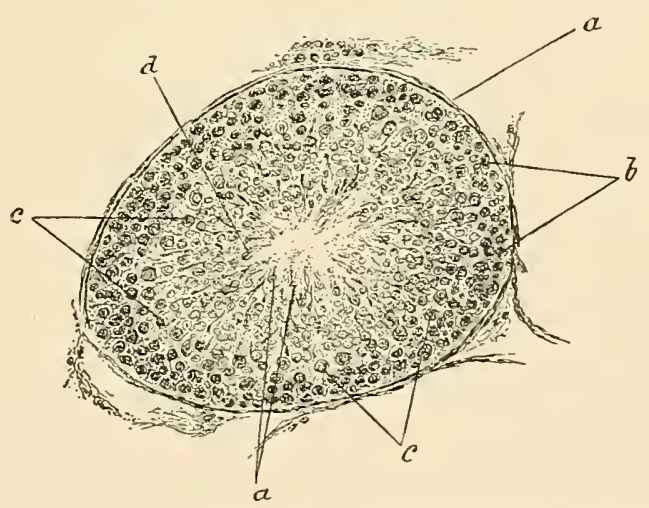

FIG. 3.-Section of testicle of musk-rat; seminiferous tubule seen in cross section: $a$, wall of tubule; $b$, parietal cells; $c$, mother-cells ; $d$, spermatoblasts.

cuboidal cells called parietal cells, lying in contact with the hasement membrane of the tubule wall. This layer consists of the so-called Sertoli's columns, or sustentacular cells, and of the spermatogenic cells. The sustentacular cells are merely supporting; the spermatogenic cells give rise to the spermatozoa. The immediate offspring of the spermatogenic 
cells are the mother-cells, a group lying in contact with the spermatogenic cells, on the side toward the lumen of the tubule. The multiplication of the mother-cells results in the production of the smaller daughter-cells, whose nuclei are the spermatoblasts, or spermatids of some authors. The round spermatoblast soon becones oval, and later pear-shaped, and its chromatin accumulates in the onter half of the nuclens, giving rise to a dark, deeply-staining zone in this position, and a elear zone on the side toward the lumen of the tubule. At the same time the nucleus or spermatoblast escapes from the daughter-cell. A little later the spermatoblast shows three zones-an outer elear band, a middle dark area, in which the chromatin has become localized, and an inner clear region. A slender filament or spine of chromatin, the rudiment of the tail, now grows from the middle dark zone into and through the inner clear area (that is, toward the lumen of the tubule), projecting slightly beyond the limits of the nuelear membrane. With the disappearance of the nuclear membrane and the progress of further changes-which ehanges consist in the formation of the head from the outer elear band, of the tail and middle piece from the middle dark zone, and of the delicate sheath for the tail and the mirldle piece from the inner clear band-the development of the spermatozoön is practically completed.

The spermatozön has been regarded as a metamorphosed cell, the head representing the nucleus, and the cilium or tail the protoplasm. This view, however, is controverted by certain anthorities (Kölliker, Biondi, Niessing, Piersol), and the weight of the evidenee is in favor of regarding the entire spermatozoön as having been developed from a cell-nucleus.

\section{THE OVUM.}

The female sexual eell or ovum is remarkable among animal cells for its size, it being a rule, to which there are no known exceptions, that it is much larger than any other cell in the borly of the parent. 'The human ovum measures, in the mature state, 0.2 ınm. in diameter.

In structure, the ovum presents the parts of a typical cell; 
namely, a cell-wall, here called the vitelline membrane, the cell-contents, or vitellus or yolk, a nucleus or germinal vesicle, and a nucleolus or germinal spot.

Surrounding the ovum is a somewhat loosely-fitting transparent, elastic envelope, the zona pellucida, and outside of this is the corona radiata. These two layers are often re-

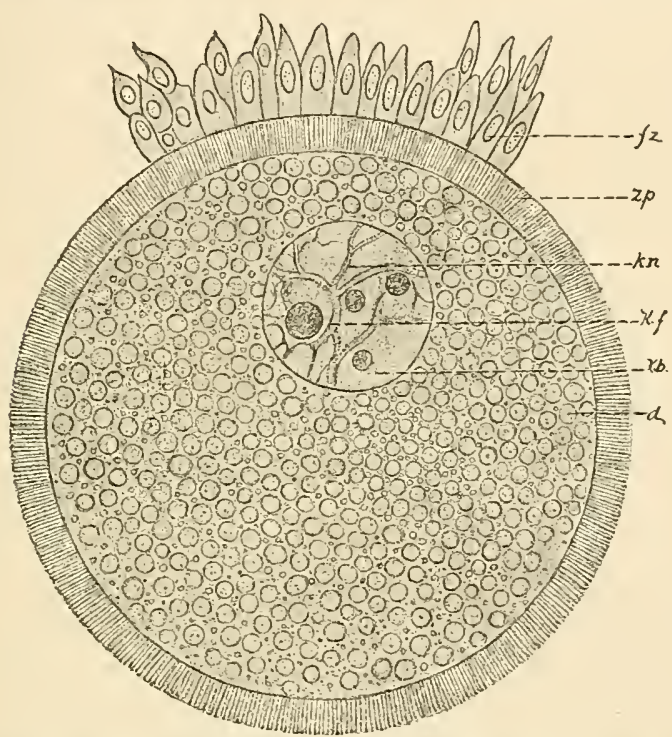

FIG. 4.-Egg from a rabbit's follicle which was $0.2 \mathrm{~mm}$. ( $\frac{1}{125}$ ineh) in diameter (after Waldeyer). It is surrounded by the zona pellueida ( $z . p$.$) , on which there$ rest at one place follicular cells $(f . z)$. The yolk contain deutoplasmic granules $(d$.$) . In the germinatire resiele (k, b$.$) the nuclear network \left(k, n_{*}\right)$ is especially marked, and contains a large germinative dot $(k . f$.$) .$

ferred to as the egg-envelopes; and since they are contributed by the discus proligerus of the Graafian follicle, it must be remembered that they are not, properly speaking, a part of the ovum. Between the zona pellucida and the orum is the small perivitelline space. The radial striation of the zona is gencrally regarded as dne to the presence of minute cunals opening into this space. The canals are thought by some to facilitate the ingress of spermatozoa, thus corresponding in function to the micropyle, a small aperture found in the less easily penetrable egg-envelopes of many invertebrates and of some fishes. 
The vitelline membrane does not call for extended description. It may be regarded as a slightly specialized condensation of the peripheral part of the cell-contents.

The vitellus, or cell-contents, here, as in other cells, is essentially protoplasm, to which is added material called deutoplasm, designed for the nutrition of the ovum at the beginning of development. The protoplasm is also called the formative yolk and the egg-plasm, while the deutoplasm is known as the nutritive yolk. In the human ovum these elements are more or less uniformly distributed ; there is, however, a differentiation into an inner, slightly less clear region, containing more yolk-granules (deutoplasm), and a peripheral, clearer zone. The characteristic transparency of the human egg-cell is due to the fact that the dentoplasmic particles found in it are not cloudy as in the ova of other mammals. The following classification of ova by Balfour is based upon the arrangement of these constituents :

1. Alecithal ova are those in which the protoplasm and

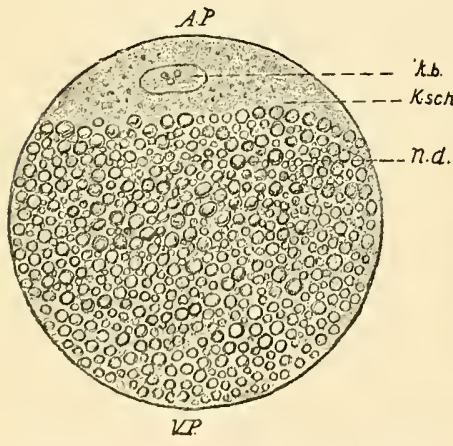

Frg. 5,-Diagram of an egg with the nutritive yolk in a polar position. The formative yolk constitutes at the animal pole (A.P.), a germ-disk $\left(\boldsymbol{K}^{*} . \mathrm{sch}\right.$.) in which the germinative vesicle $(k, b$.$) is en-$ choser. The nutritive yolk $(n, d$.) fills the rest of the egg up to the vegetative pole (I:P.) (llertwig).

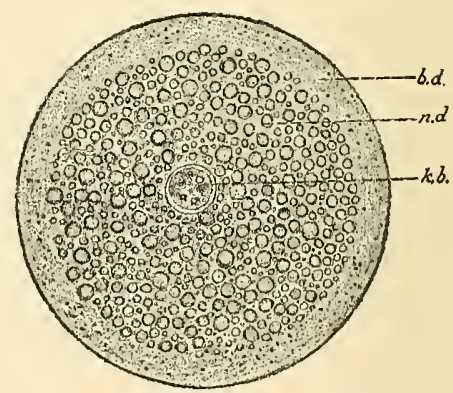

Firi. 6.-Diagram of an egg with the nutritive yolk in the center. The germinative vesicle $(k, b$.$) oeenpies the$ middle of the nutritive yolk $(n . d$.$) ,$ which is enveloped in a mantle of formative yolk (b.d.) (llertwig).

dentoplasm are uniformly distributed, as in the ova of Mammalia including man), and of amphioxus (Fig. 4).

2. Telolecithal ova are those in which the relatively abun- 
dant deutoplasm is aceumulated at one side of the ovum, called the vegetative pole, while the protoplasm appears as a flat germ-disk at the animal pole on the opposite side. Here belong the eggs of birds, reptiles, and bony fishes (see Fig. 5).

3. Centrolecithal ova are those in which the deutoplasm is central, the protoplasin completely surrounding it, as in the eggs of arthropods (Fig. 6).

Ova are classified also according to their method of segmentation. This will be rlescribed later.

The germinal vesicle or nucleus is the most important part of the eell, since, as will be seen hereafter, it is essentially by the conjugation, or more accurately by the fusion, of the nuclei of the male and female parent-cells that generation is effected. As a rule, there is but one nucleus, though there may be two. Its position is usually-if not universallyeccentric, this being more marked where there is a distinct differentiation into animal and regetative poles, in which case it is found always near the animal pole. It is nearly spherical in shape, and like the nueleus of any other typical cell, it is composed of a network of nuclear fibrils or chromatin substance, and nuclear juice or achromatin, the former containing the latter within its meshes. Surrounding the nueleus is the well-marked nuclear membrane, while within it is the nucleolus or germinal spot. The latter may be single or multiple, according to the species, though the number is fairly constant for each species. Nagel ascribes ameboid movement to the germinal spot.

Polarity.-The polarity of the egg has been incidentally referred to. Apparently it owes its existence to the eccentric position of the nucleus, the animal pole being that print on the surface to which the nucleus is nearest. Polarity bears a significant relation to the specific gravity of the ovum, since the nucleus reaches the surfice of the latter at the animal pole and there extrudes the polar globules; and it is also related to the segmentation of the fertilized egg.

The Hen's Egg.-As the hen's egg is so largely utilized for the study of development, it will be profitable to consider briefly its structure. The ovum or egg-cell is represented by 
the yolk or yellow of the egg, the albumen or white, as well as the shell and shell-membrane, being egg-envelopes contributed by the oviduct. As in other ova, the egg proper is a single cell, having a vitelline membrane and a germinal vesicle. The enormous size of the cell is due to the large quantity of nutritive material or deutoplasm present, this contributing by far the greater part of the bulk, while the much smaller formative yolk or protoplasm, containing the germinal vesicle, is so eccentrically placed that it seems to float upon the surface of the deutoplasm. The little whitish spot on the surface of the yolk, known as the cicatricula or germinative disk, consists of the germinal vesicle with the surrounding formative yolk. It is in the germinative disk alone that segmentation takes place, and it is for this reason that eggs of this class are designated meroblastic, or partiallydividing eggs.

The deutoplasm is made up of white and of yellow yolk

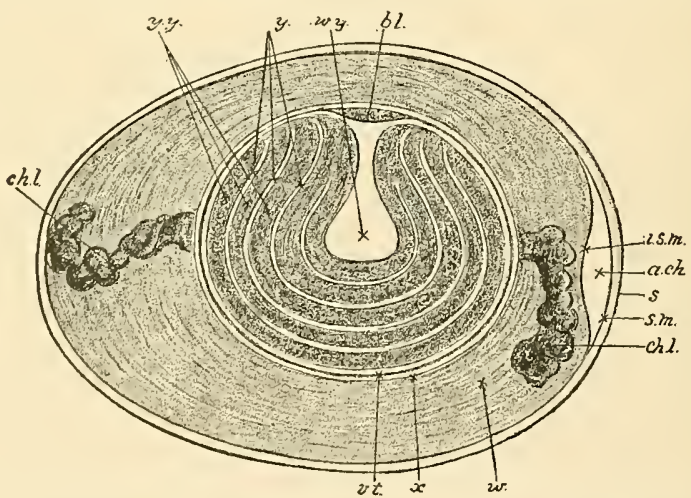

FIG. 7.-Diagrammatic longitudinal section of an unineubated hen's egg (after Allen Thomson). (Somewhat altered): $b . l$, germ-disk; $w, y$, white yolk, which consists of a central flask-shaped mass, and a number of coneentric layers surrounding the yellow yolk $(y . y.) ; v . t$, vitelline membrane; $x$; a somewhat fluid albuminous layer which immerliately envelopes the yolk; w, albumen, eomposed of alternating layers of more and less fluid portions; $c h . l$, ehalazæ; a.ch, airchamber at the blunt end of the egg-simply a space between the two layers of the shell-membrane; $i, s, m$, inner, $s, m$, outer layer of the shell-membrane; $s$, shell.

(Fig. 7). The former consists of a thin layer spread over the surface of the latter; of a small mass, known as Pander's 
nucleus, situated under the germinative disk; of a larger mass, the latebra, more deeply placed; and of several concentric layers separated from each other by the yellow yolk.

Such is the egg as it leaves the hen's ovary. In the beginning of the oviduct it is fertilized by the spermatozoa already there. After fertilization it passes into the longitudinally furrowed second part of the tube, where it receives a copious coating of albuminous material, the white of the egg; thence it goes into the villous third part of the oviduct, where it acquires a calcareous coating, the shell; finally, passing through the fourth part of the canal, it is "laid."

The layer of albumen immediately surrounding the yolk is relatively dense; it is prolonged to either extremity of the egg, somewhat spirally twisted, as the chalazæ. Enclosing the albumen is the thin tough shell-membrane. This consists of two layers, which separate at the blunt pole of the egg soon after it is laid, giving rise to the air-chamber. The shell, composed largely of lime salts, is very porous and thus readily permits of the necessary gas-interchange between the contents of the egg and the external air during incubation.

Ova do not possess the remarkable vitality which is characteristic of spermatozoa. An unimpregnated ovum perishes in from seven to nine days.

Oogenesis.-The formation of ova takes place throughout the greater part of fetal life and continues for a short time (two years, according to Waldeyer, Bischoff, and others) after birth. Their number is estimated to be abont seventy thousand.

The ovum, the direct derivative of the germinal epithelium covering the free surface of the ovary, is situated in the cortical part of the latter organ, being enclosed in the Graafian follicle. As a rule, each Graafian follicle or ovisac contains but one ovum, though sometimes two, and more rarely three are present.

The Graafian follicle, in its mature condition, is a vesicle from 4 to $8 \mathrm{~mm}$. in diameter, which is surrounded by a sheath, the theca folliculi or tunica vasculosa, consisting of a condensation of the ovarian stroma. The outer, more fibrous 


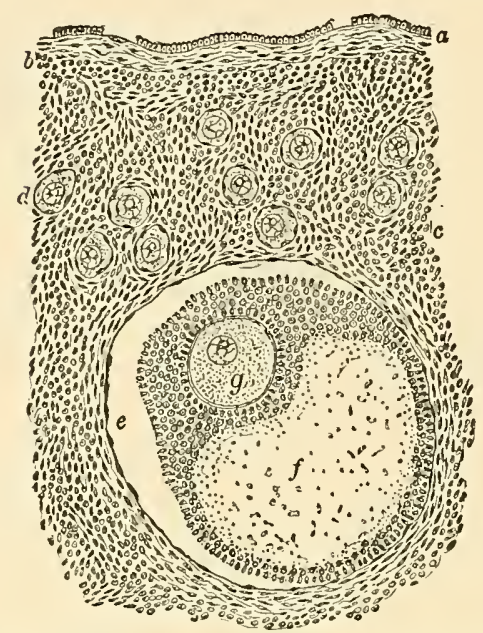

FIG. 8.-Section of human ovary, including cortex : $a$, germinal epithelium of free surface; $b$, tunica albuginea; $c$, peripheral stroma containing immature Graafian follicles $(d)$; $e$, well-advanced follicle from whose wall membrana granulosa has partially separated; $f$, cavity of liquor folliculi; $g$, ovum surrounded by cell-mass constituting discus proligerus (Piersol).

zone of the theca, containing large blood-vessels, is distinguished as the tunica fibrosa; the inner more cellular layer, rich in small vessels and capillaries, as the tunica propria.

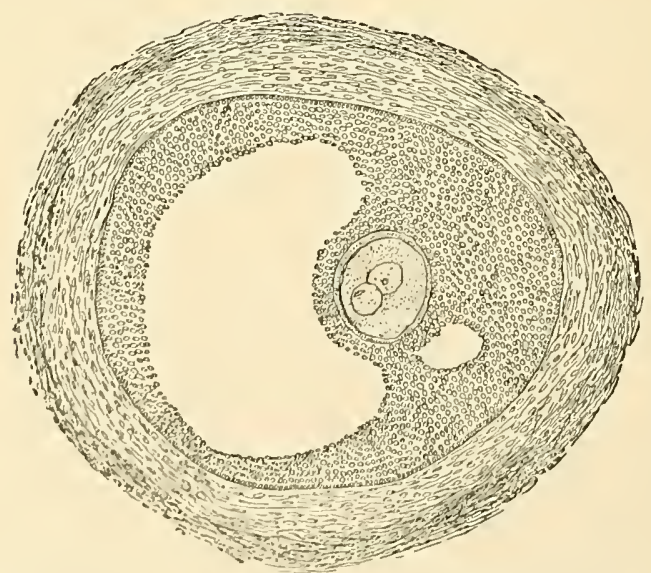

F16. 9.-Section of well-developed (iruatian follicle from human embryo (Von IIeril): the enclosed ovum contains two nuelei. 
The fibrous wall of the follicle is lined by the membrana granulosa, which consists of many layers of epithelial cells; these, at the point of contact with the ovum, project in such a manner as to surround it completely, the cellular envelope thus formed constituting the discus proligerus. The inner cells of the discus are arranged in two layers, the individual elements having their long axes radially directed. From the appearance of radial striation, conferred partly by this circumstance, the inner zone has been called the zona radiata or zona pellucida, and the outer the corona radiata. The cavity of the Graatian follicle is filled with fluid, the liquor folliculi.

The stigma, or hilum folliculi, a yellowish-white spot devoid of blood-ressels on the free surface of the Graafian follicle, indicates the point at which rupture will take place. After this event, which occurs when the ovum is "ripe," the latter passes into the Fallopian tube.

The ultimate origin of the egg is to be sought in that important group of cells on the surface of the ovary to which Waldeyer gave the name germinal epithelium. This first appears at about the fifth week of intra-uterine life, as a localized thickening of the cells of the structure that subsequently becomes the peritoneum. The thickened areas comprise two longitudinal elevations on the dorsal side of the future abdominal cavity, one on each side of the median plane of the body; these are the genital ridges. Owing to the development of connective tissue beneath the epithelium, the ridges increase in thickness, and, with the progress of other changes, finally become, in the female, the ovaries. At about the sixth or serenth week-the germinal epithelium now consisting of several layers of cells instead of being a single stratum thick, as at first-cord-like processes, the sexual cords, or primary egg-tubes, or egg-columns, grow from the surface into the underlying connective tissuc, carrying with them certain of the surface-cells (sec Fig. 112). Conspicuous among these are the large sexual cells, or primitive ova; while smaller cells, likewise from the germinal epithelium, are also present. The sexual cords bccome divided into groups 
of cells, each group containing one or more primitive ova and many of the smaller cells. Gradually, the small cells of the group surround the primitive ovum, at first as a single layer of flattened cells, which are succeeded by several layers of polygonal cells. From these enveloping cells come the membrana granulosa and the theca of the Graafian follicle.

The primitive ova become fully formed eggs upon the assumption by their rather ill-defined nuclei of the characteristic shape and structure of typical nuclei, coincidentally with the occurrence of other changes of secondary importance in other parts of the cell.

The youngest ova are found nearest the suriace of the ovary, the eggs as they develop advancing toward, but never entering, the medulla of the organ. Finally, in the fullydeveloped condition of the ovum and the follicle, the size of the latter is such that its diameter equals or exceeds the thickness of the ovarian cortex, its position being usually indicated by a small prominence on the surface of the ovary.

\section{MATURATION OF THE OVUM.}

By maturation or ripening is meant that series of changes by which the ovum is prepared for fertilization and without which the latter process is impossible. In nearly all mammals, including man, it occurs while the orum is still in the Graafian follicle; in some other groups it takes place after the egg has reached the oviduct.

Briefly, maturation may be said to consist in the extrusion from the cell of a part of its nucleus and of a small part of its protoplasm. The nucleus undergoes changes practically identical with those of ordinary cell-division. First, the nuclear membrane disappears, the nucleolus disintegrates, the nuclear juice becomes mingled with the surrounding protoplasm, and the uncleus moves toward the periphery of the eggr (Fig. 10). There is now formed a muclear spindle from the achromatin substance of the nuclens. The long axis of the spindle lies parallel with one of the radii, and its direction is determined by the position of the pole-corpuseles. Each pole-corpuscle is surrounded by a radiation, the attrac- 
tion-sphere or polar striation. These bodies exercise a controlling influerce upon the nuclear spindle, so that it assumes
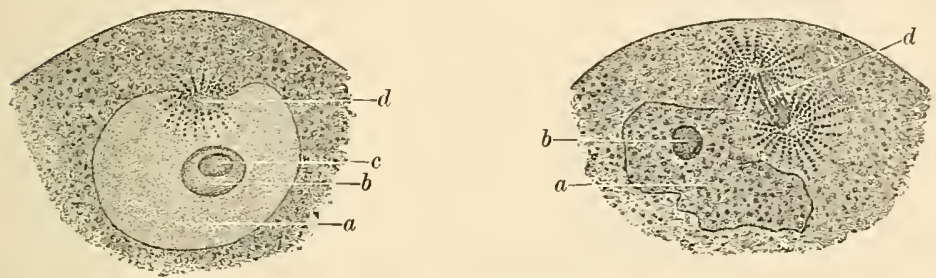

FIG. 10.-Portions of the ova of Asterias glacialis, showing changes affecting the germinal vesicle at the beginning of maturation (Hertwig): $a$, germinal vesicle; $b$, germinal spot, composed of nuclein and paranuelein $(c) ; d$, nuclear spindle in process of formation.

such a position that each of its apices points toward a polecorpuscle.

The outer extremity of the nuclear spindle, being made to protrude by the continued onward movement of the nucleus, becomes detached (Fig. 11); this separated piece, with the
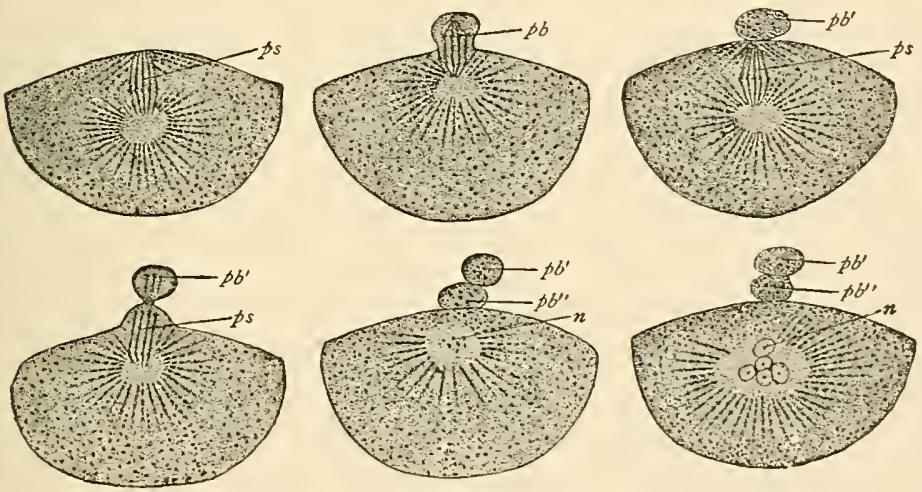

Fig. 11.-Formation of the polar bodies in the ova of Asterias glacialis (Hertwig): $p s$, polar spindle; $p b^{\prime}$, first polar body ; $p b^{\prime \prime}$, second polar body; $n$, nucleus returning to condition of rest.

small surrounding constricted-off mass of protoplasm, constitutes the first polar body. From the remmant of the first nuclear spindle, a second one is formed, which in the same manner extrules the second polar body. What remains of the nucleus now moves toward the center of the cell and 
temporarily disappears, soon to reappear as the female pronucleus. The position of the female pronucleus is nearly or absolutely central. The protoplasm surrounding it is radially striated (Fig. 12). The egg is now ready for fertilization.
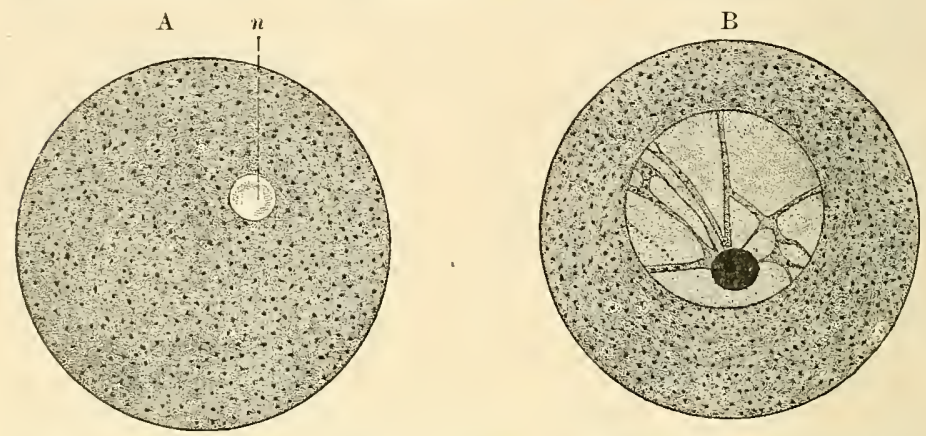

Fig. 12,-A, mature ovum of echinus ; $n$, female pronucleus; B, immature ovarian ovum of echinus (Hertwig).

The fate of the polar bodies is undetermined. For some time after their extrusion, and pending their final disappearance, they are to be seen lying in the perivitelline space. The formation of polar globules is probably almost universal throughout the animal world, although in reptiles and birds and in some fishes and amphibians they have not as yet been demonstrated. It is of interest to note that in some parthenogenetic eggs - that is, eggs capable of developing into a new individual without contact with the male element, as for example the summer eggs of plant lice and of some other arthropods-only one polar globule is said to be formed.

One of the theories advanced to explain the phenomenon of maturation is that of Minot. This theory assumes that the ovum is at first hermaphroditic-that is, that it contains both male and female elements, and that the extrusion of the polar bodies is a casting-off of the male element. Hertwig and others believe, however, that the formation of the polar bodies is an abortive cell-clivision, the bodlies being aborted cells.

\section{OVULATION.}

Extrusion of the ovum from the Graatian follicle, or ovulation, oecurs upon the completion of the process of matura- 
tion. As the time for this event approaches, the wall of the follicle at the site of the stigma becomes much thinned and finally ruptures, and the ovum passes into the Fallopian tube (Fig. 13). If, instead of passing into the tube, the

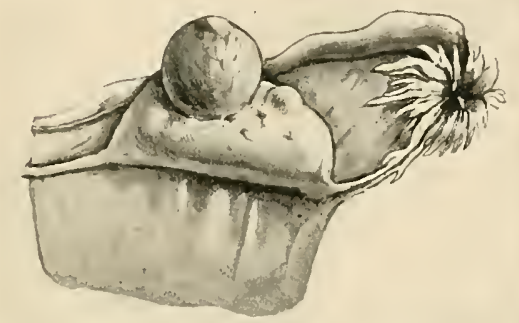

Fig. 13.-Ovary with mature Graafian follicle about ready to burst (RibemontDessaignes).

ovum drops into the abdominal eavity and is fertilized there, it undergoes partial or complete development in situ, this condition being known as extra-uterine pregnancy or ectopic gestation.

Ova are extruded from the ovary, one or more at a time, at regular, generally monthly, intervals, from puberty to the climacteric.

After the escape of the orum, hemorrhage into the empty follicle oceurs, the resulting clot being the corpus hemorrhagicum. According to Leopold, if rupture occurs during the intermenstrual period instead of at the time of menstruation, hemorrhage will be small or entirely wanting, the resulting corpus luteum being ealled then atypical, to distinguish it from the typical body formed in the ordinary manner.

The blood-clot is soon permeated by cells originating in the wall of the follicle, some of which are fusiform connective-tissue cells, while others are large cells containing the yellow pigment, lutein. Meanwhile, the follicular wall thickens and becomes plicated. Later, upon the replacement of the mass of clot and cells by fibrous tisine and the development of capillaries within it, the body assumes a yellowish cicatricial appearance and is known as the corpus luteum. (Fig. 14). The color of the corpus varies considerably in 
different species of animals, the rellow color being eharacteristic for the human subject.

If the ovum is not fertilized, the corpus lutem attains its maximm development in less than a week and begins to shrink at about the twelfth day, becoming eompletely absolbed in a few weeks. If fertilization occurs, it continues to grow for two or three months and alequires a size onefourth or one-third that of the entire ovary; persisting till
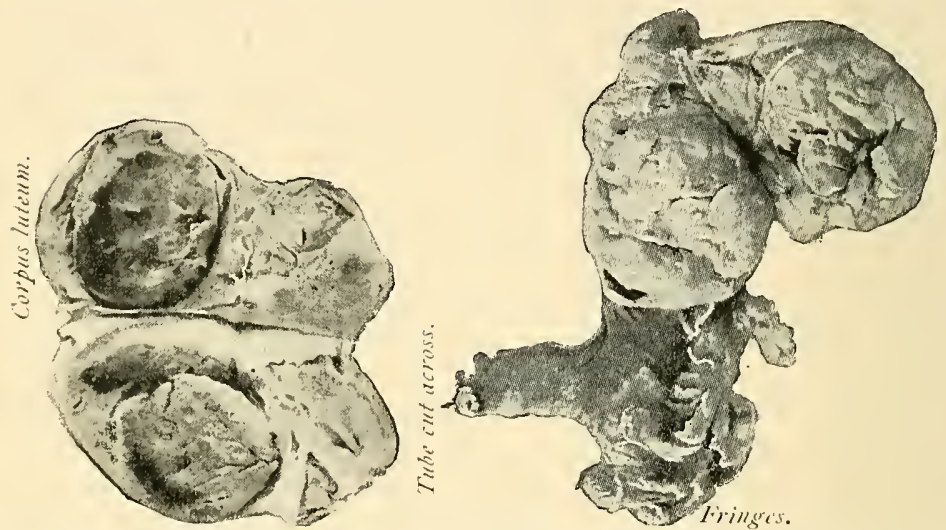

FIG. 14.-Ovaries of two virgins, showing large corpora lutea, resembling those of pregnancy (Hirst).

toward the end of gestation, it finally shrinks to a small white sear, which may not totally disappear until a month or more after labor.

It has been eustomary to designate the larger, better developed yellow body, the true corpus luteum, or the corpus luteum of pregnancy, in contralistinetion to the so-called false corpus luteum of menstruation, and to regard the presence of the former as absolute proof of previous impregnation. This view is no longer temable, since boties identieal in appearance with trne corpora lutea have been found in virgin ovaries (Hirst).

'The relation of ovulation to the menstrual funetion has been much discussed. While the two processes usually oceur at the same time, they are not to be regarded as dependent omo "umon the other. It has been shown by Coste, whose 
observations have been contimed by Leopolel, that ats a rule Graafian follicles burst during menstruation, though they may rupture before or after this event. It has also been shown that in the rabbit sexual intercourse hastens the rupture of the follicle.

\section{MENSTRUATION.}

Menstruation, or the eatamenial flow, is considered here because of its natural association with the function of ovulation.

Menstruation may be defined ats a periodical discharge of hlood and disintegrated epithelium and other structural elements of the mucous membrane of the body of the uterus, mixed with mucus from the uterine glands and the vagina, occurring normally about every twenty-eight days, and associated with more or less disturbance of the entire sexual system. The inanguration of the function marks the age of puberty, the beginning of the sexual life of woman ; its cessation, known as the climacteric, or menopause, indicates the termination of the child-bearing period.

In temperate climates, the menses are established between the thirteenth and seventeenth years and cease between the ages of forty and fifty. In the tropies, they appear somewhat earlier; in cold climates, somewhat later. The function is suspended during pregnancy and, usually, during lactation.

The quantity of the discharge, though subject to considerable variation, is usually from 4 to 6 fluidounces. The blood is venous in character, and, owing to atlmixture of alkaline mucus, does not coagulate unless present in excessive amount.

The menstrual cycle of twenty-eight days may be divided into four periods: the constructive stage, comprising from five to seven days; the destructive stage, lasting about tive days; the stage of repair, eovering a period of three or four days; and the stage of quiescence, including the remaining twclve to fourteen days.

In the constructive stage, which occupies the six to seven days preceding the discharge, the mucous membrane of the 
uterus becomes markedly swollen, the normal thickness of from 1 to 2 millimeters being more than doubled. The uterine glands become wider and longer and also more branched. The blood-vessels, especially the capillaries and veins, undergo great increase in size, and the connective-tissue cells are increased in number. The thickened mucous membrane resulting from these alterations is the decidua menstrualis. The term "constructive" is applied to this series of changes for the reason that their apparent purpose is the preparation of the womb for the reception of a fertilized ovum.

The destructive stage, corresponding to menstruation proper, lasts from three to five days. It consists essentially in the partial destruction of the hypertrophied mncous membrane, the menstrual decidua, accompanied by hemorrhage. The initial step is the infiltration of blood into the subepithelial tissue; according to Overlach, this takes place, not by rupture of eapillaries, but by diapedesis. In a day or two the superficial layers of the mucous membrane disintegrate and are cast off, those portions of the enlarged uterine glands inchuded within this stratum sharing the same fate. By the loss of the epithelium and the subjacent strata, the bloodvessels are exposed. Subsequently these rupture, giving rise to the characteristic hemorrhage. Fatty degeneration accompanies the death of the east-off tissue, and was thought by Kundrat and Engehman to be the direct canse of the hemorrhage; it is probable, however, that fatty degeneration is not present until after the flow of blood has begun. ${ }^{1}$

The stage of repair, comprising the three or four days following the period of the discharge, witnesses the return of the uterine mucosa to its usual eoudition. With the gradual subsidence of the swelling, the superficial layers, which were lost, are replaced by the growth of new tissue from the deeper layers, which persisted. The formation of the new epithelium begins at the months of the uterine glands.

The stage of quiescence extends from the close of the pre-

${ }^{1}$ Marshall's "Vertebrate Embryology;" Minot's "Human Embryology." 
ceding stage to the end of the cycle, or, in other words, to the beginning of the next constructive stage.

Other parts of the sexual apparatus, including the ovaries, the Fallopian tubes, and the mammary glands, show more or less sympathy with the uterus during menstruation, the changes in them consisting chiefly in swelling, hyperemia, and tenderness.

\section{The Relation of Menstruation to Ovulation and} Conception.--The function of menstruation and the extrusion of ova from the Gratian follicles, though closely associated, are not dependent upon each other. Ovulation occurs perhaps most commonly during the time of the menstrual discharge, but it may take place before or after this event. While it is now generally accepted that the two functions are not mutually interdependent in the sense that one is a necessiry part of the other, yet, since the turgescence incident to sexual intercourse has been shown to hasten the rupture of the follicles, it seems reasonable to suppose that the ovarian hyperemia attendant upon the menstrual epoch would exert a like influence.

Since the function of menstruation is normally suspended during pregnaney, the relation between menstruation and ovulation, and of these to conception, are of practical interest in determining the date of labor. 'The duration of pregnancy is from 270 to 280 days, nine calendar, or ten lunar, months, and it dates from the moment of conception. But since the ovum retains its vitality for about a week after its extrusion from the Graatian follicle, and since the activity of the spermatozoa ma continue for several weeks after their entrance into the female genital tract, it is impossible to fix accurately the date of conception even in those eases in which there has been but one coitus. It is now believed by most embryologists that the ovum is fertilizable only while it is in the Fallopian tube, a period probably of about seven days ; if this be true, it follows that conception must oceur within a week after ovulation, althongh it may be effected as late as two weeks after coitus. Since the orum is usually discharged from the ovary during the menstrual period, it is evident that 
the time most faroralle for eonception is the week following menstruation; and inasmuch as the latter function is suspended during pregnancy, it is obvions that the most reliable basis for calculating the probable date of conception is the last menstruation. The method usually employed is to count nine months and seven days from the first day of the last menstruation. After what has been sain it is perhaps needless to remind the reader that this can furnish only alproximately the date of labor. In a case where conception occurred a few days prior to the first omitted period, there would be a discrepancy of several weeks between the actual, and the calculated, termination of pregnancy.

\section{FERTILIZATION.}

Fertilization is that peculiar union of spermatozoön and egg-cell which initiates the phenomena resulting in the formation of a new individual. As implied in a preceding section, impregnation is possible in the higher organisms only after the completion of maturation, while in others, as for example the maw-worm of the horse, spermatozoa enter the ovum before the extrusion of the polar bodies, and thus one process overlaps the other.

The more primitive method of fertilization is that effected without copulation of the parent organisms, or external fertilization; this oceurs in osseons fishes, in some amphibians, and in many invertebrates. In these groups, both ova and semen are discharged into the water and there meet. In frogs, however, there is a quasi-copulation, the male embracing the female during the breeding season and depositing semen upon the eggs as they are evacuated. In all higher animals, internal fertilization oceurs, this being effected by sexual congress.

In man, fertilization normally ocens in the onter third of the Fallopian tube. 'The semen having been deposited in the vagina, or the uterus, or even upon the volva, the spermatazoa make their way into the oviduet by the vibratile motion of their tails. Meeting the ovmm, they swarm around it, and some of them pass through the zona pellueida into 
the perivitelline space. It is helieverl by many investigators that the canals of the zoma constitute the aremes of entrance for the spermatozoa. In the rather firm egerenvelopes of insects and some fishus, there is a small aperture, the micropyle, through which the spermatozoa gain entrance.

While many spermatomon may pass thromgh the zoma, only one-that one whose heald first impinges against the vitelline membrane-enters the ovem. II hy others do not or amunet enter is nuknown; possibly becuuse the egg's power of attratetion is amnulled (Minot). Polyspermia, or the penetration of several spermatozoa, may ocenr, however, if the ovmm is unhealthy; and in some lower types it is said to be normal.

As the spermatozoin is abont to strike the vitelline membrane, the protoplasm swells up at the point of contact into the receptive prominence (Fig. 15). Through this the sper-
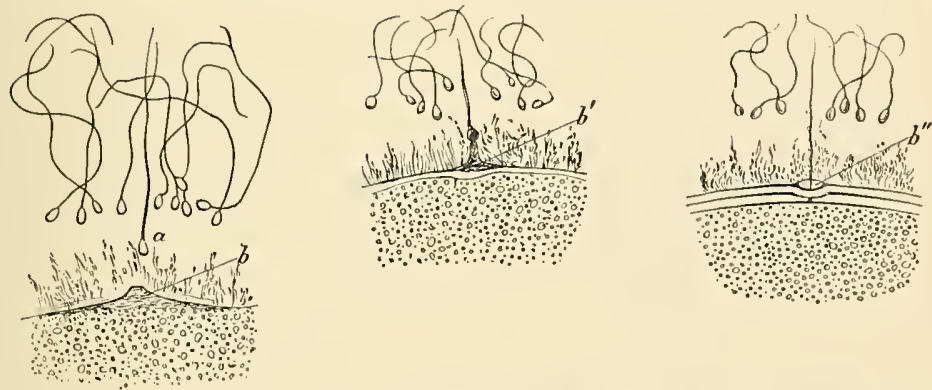

FIg. 15.--Portions of the ova of Asterias glacialis, showing the approach and lusion of the spermatozoön with the ovum (Hertwig): $a$, fertilizing male element; $b$, elevation of protoplasm of egr; $b^{\prime}, b^{\prime \prime}$, stages of fusion of the head of the spermatozoön with the ovim.

matozoin bores its way, losing its tail in the process, and thus becoming the male pronucleus. The female prontrelens, it will be remembered, lies in or near the center of the cogg. The two pronnclei now approach each other, and, upon meeting, fuse and temporarily disappear. Soon they reappear, and now constitute the segmentation-nucleus or cleavage-nucleus (Fig. 16).

Since the spermatozoön is the metamorphosed meleus of a cell formed in the testicle, and since the female pronuclens is a part of the nucless of the ovmm, it follows that the seg- 
mentation-nueleus consists of chromatin substanee derived from each parent. As this fact has been thought to explain, anatomically, the off'spring's inheritanee of both paternal and
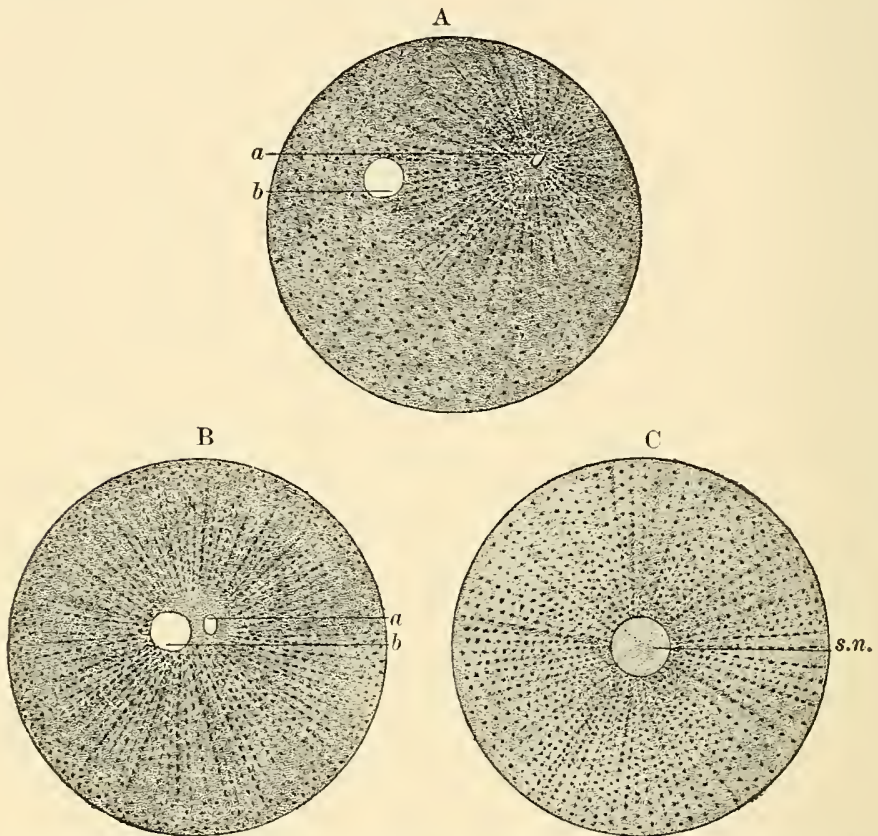

Fig. 16.-A, fertilized ovum of echinus (Hertwig): the male (a) and the female pronucleus $(b)$ are approaching; in $\mathrm{B}$ they have almost fused; $\mathrm{C}$, orum of echinus after completion of fertilization (Hertwig): s.n., segmentation-nucleus.

maternal eharacteristics, it has been made the basis of a theory of heredity formulated by Hertwig and independently advaneed by Strasburger. 


\section{CHA P'T R I I.}

\section{THE SEGMENTATION OF THE OVUM AND FORMA= TION OF THE BLASTODERMIC VESICLE.}

Wrinte the fertilized orum is passing along the Fallopian tube to the uterus-a journey believed to require seven or eight days in man-it undergoes repeated segmentation, or clearage, becoming a more or less globular mass of eells or blastomeres. This mass is the mulberry-mass or morula.

The details of the process of division correspond closely to those of ordinary indirect cell-division, or karyokinesis. The first indication of approaching clearage is seen in the segmentation-nucleus, just as, in other cells, the sequence of changes leading to cell-division is inangurated in the nucleus.

The achromatin-substance of the segmentation-nucleus forms a nuclear spindle in the ordinary manner, with a centrosome or pole-corpuscle at each apex. The centrosome is surrounded by the polar striation or attraction-sphere. After the usual preliminary changes, the chromatin-substance assumes the form of $V$-shaped loops arranged around the equator of the spindle in such a manner as to produce the wreath or aster. Each ehromatin loop splits longitudinally, and the resulting halves of each move to opposite poles of the spindle, where they become grouped about the pole-corpusele to constitute the daughter-wreaths of the new nuclei. The vitellus now begins to divide, the first step being the formation of an encireling groove on its surface; this groove deepens more and more until finally division of the cell is complete. In like manner, each daughter-cell divides into two, and each of these two into other two, the cell-division continuing until there results the mass of cells, or morula, already mentioned (Plite I, Fig. 1).

These processes have been followed the most accurately in 
the exg of the sea-mrehin; in reptilian eggs, as well as in those of the rabhit and other nitmmals, they have been studied also and have been fomm to agree with the former in all essential, respects. Curtain modifications dependent upon the relations and proportions of formative-yolk and food-yolk will be pointed out hereafter.

While no one has seen the segmentation of the human orum, there is no reason to suppose that it differs materially from that of other mammals.

An interesting and probably significant modification of the method of cleavage as just described has been observed by Van Benerlen in the ova of the maw-worm of the horse. In this case male and female pronuclei do not fuse but merely lie close together. At the beginning of segmentation, the chromatin of each pronucleus assumes the form of a convoluted thread, which divides transversely into two sisterthreads. In this manner are produced four loops of chromatin from each pronucleus, which become grouped around the equator of the nuclear spindle just formed. In the migration of the segments that now ensues, each pair of sister-threads separates, one thread going to one pole of the spindle, one to the other. Hence, at each pole, and taking part, therefore, in the formation of each new nucleus, are two male and two female threads of chromatin. Thus the male and female pronuclei contribute equal shares of chromatin to each daughter-nucleus.

Very suggestive in this connection is the observation of Nussbaum, that if the same principle should be found to apply to all subsequent cell-division, then every eell of the adult organism would consist of equal amounts of material from each parent.

Cleavage-planes.--The direction of the planes of cleavage is determined by certain laws. The direction of the plane of the first eleavage bears a definite relation to the long axis of the muclear spindle, whose position, in turn, depends upon the mamner of distribution of the exce's protoplasm, its direction coinciling with the longest diameter of an oval egg, but lying in any diameter of a spherical one. 
The first cleavage-plane always ents the axis of the nuclear spindle perpendiculanly at its center; the second bisects the first, also perpendieularly ; and the third is perpendienlar to the two others, and passes through the middle of their axis of intersection.

Kinds of Cleavage. - The mode of cleavage of the ovum is influenced by the relation of the protoplasm and the deutoplasm to each other, and by their relative proportions. The classification of ova accorling to their method of eleavage is as follows:

1. Holoblastic ova are those in which segmentation is total -that is, the entire ovum undergoes division. If the resulting cells are of equal size, there is said to be

(a) Total equal cleavage; to this class belong the alecithal ova of mammals (Fig. 4) and of amphioxus, to the segmentation of which the above description may be said to appl!: Strietly speaking, the eells are not of exactly equal size, those in the region of the regetative pole of the egg being slightly larger than those at the animal pole. Contrasted with this is

(b) The total unequal cleavage of amphibian ova, whose segments are of unequal size (Fig. 17). These eggs being
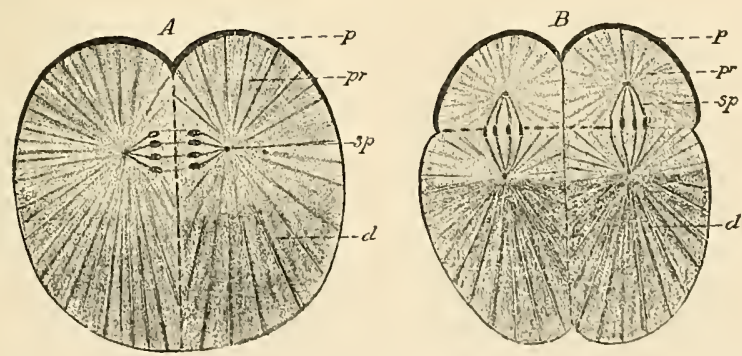

Fig. 17.-Diagram of the division of the frog's egg: $A$, stage of the first division. $B$, stage of the third division. The four segments of the second stage of division are beginning to be divided by an equatorial furrow into eight segments; $p$, pigmented surface of the egg at the animal polo; $p r$, the part of the egg which is richer in protoplasm; $d$, the part which is richer in dentoplasm ; sp, melear spindle.

telolecithal, the lighter protoplasmie animal pole is directed upward, while the dentoplasmic vegetative pole is underneath. The inequality of the resulting segments, as woll as 
the direction of the clearage planes, may be appreciated $b y$ reference to Fig. 17, which represents a frog's ovum.

2. Meroblastic ova are those in which the segmentation is partial, division being limited to the formative yelk, or protoplasm.

(a) Partial discoidal cleavage is the variety of meroblastic cleavage that occurs in those telolecithal ova having a germdisk (Fig. 7), to which latter the segmentation is limited. This method of segmentation is seen in the eggs of birds, reptiles, and fishes. In the egg of the bird, which may be taken as a typical example, the germ-disk, in whatever position the egg may be placed, floats on the top of the yolk. The beginning of the first segmentation is indicated by a furrow in the center of the surface of the germ-disk (Fig. 18). This furrow deepens, eutting vertically from the
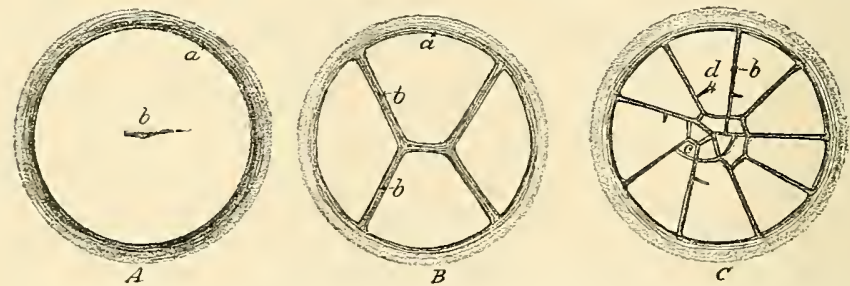

FIG. 18.-Surface riew of the first stages of cleavage in the hen's egg (after Coste) : $a$, border of the germ-disk; $b$, vertical furrow ; $c$, small central segment; $d$, large peripheral segment.

upper to the lower surface of the germ-disk, dividing it into two equal parts. Another groove, crossing the first at a right angle, bisects each of the two segments, and each of these is in turn bisected by a radial furrow, so that the germ-disk now eonsists of eight sector-shaped cells. Cross finrrows, appearing near the center of the disk, ent off the apices of the sectors, adding small central segments. Celldivision continues until the germ-disk consists of a flattened mass of cells, several strata thick, lying on the surface of the yolk.

The second method of meroblastic segmentation is

(b) Peripheral cleavage, which occurs in the centrolecithal ova of arthropods (Fig. 6). In these eggs, it will be remem- 
Plate I.

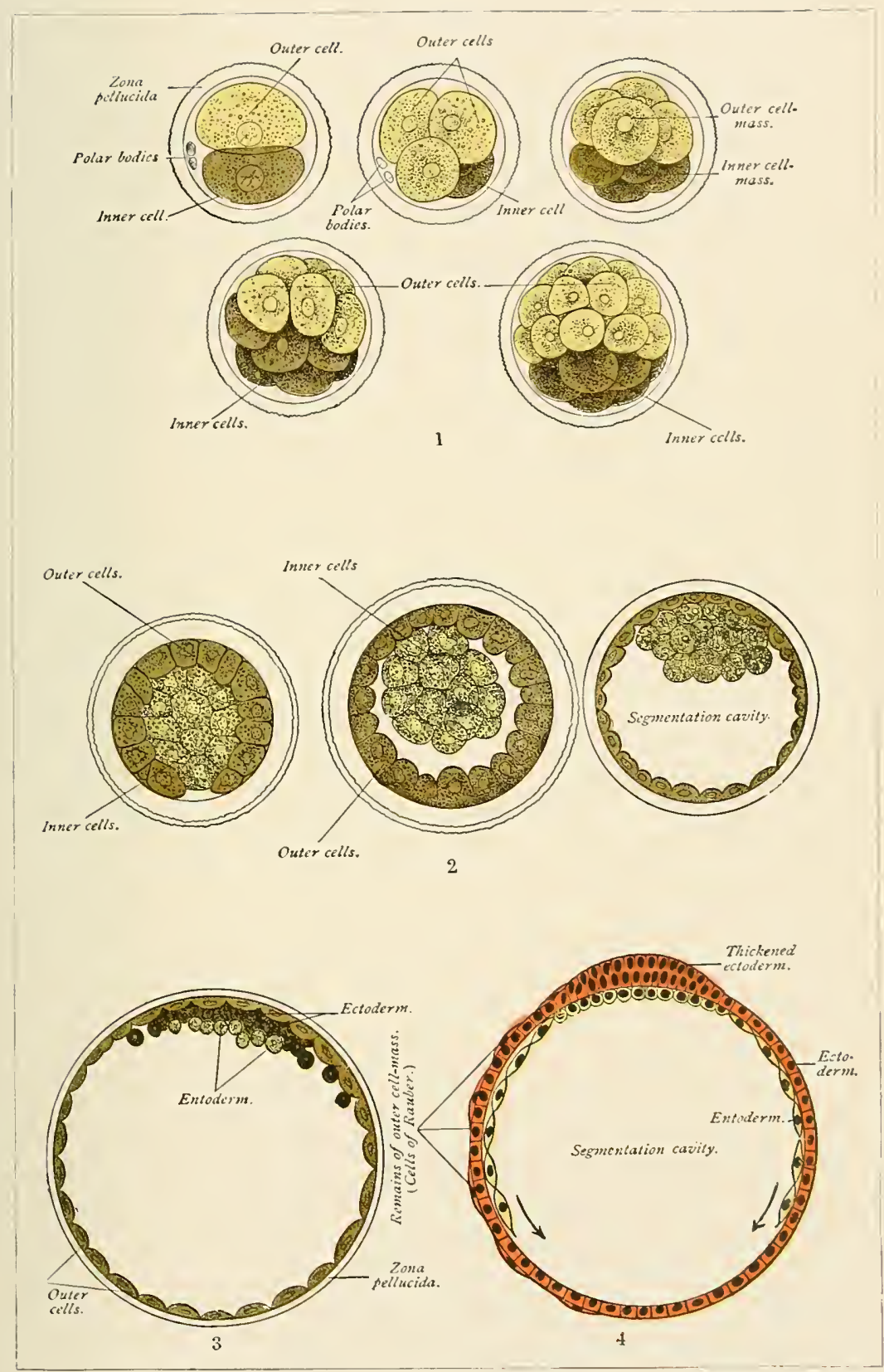

1, 2, 3. Diagrams illustrating the segmentation of the mammalian orum (.1len Thomson, after yon Beneden). " 4 . Hingram illustrating the relation of the primary layers of the blastoderm, the segmentation-cavity of this stage correspunding with the arehenteron wimphioxus (Bounct). 

bered, the nutritive-yolk is centrally placed and is surrounded by the formative-yolk. The segmentation-nueleus lies in the center of the nutritive-yolk, and in this position undergoes division and subdivision. The new nuclei now migrate into the peripherally placed formative-yolk, when the latter divides into as many parts as there are nuclei, and thus the central unsegmented nutritive-yolk becomes enclosed in : sac composed of small cells.

\section{THE STAGE OF THE BLASTULA.}

Very soon there appears in the interior of the morula or mulberry mass referred to above, a little fissure-like space, called the cleavage-cavity or segmentation-cavity. When this space has inereased somewhat in size, the germ is said to have reached the blastula stage, or the stage of the blastodermic vesicle (Plate I., Fig. 2).

What may perhaps be regarded as the primitive form of the blastula is that of the lancelet, or amphioxus lanceolatus, one of the lowest vertebrates, a fish-like animal several inches in length inhabiting the Mediterranean Sea. The blastula in this case is a simple sac composed of cells which surround the eleavage-cavity as a single layer (Fig. 21, A). The cells in the region of the vegetative pole are larger and more turbid, beeause more dentoplasmie, than those at the animal pole, as shown in the same figure.

The mammalian blastula is a hollow sphere, whose wall is a layer of eells, the outer cell-mass, and into whose eentral space, the cleavage-cavity, projects an irregular mass of granular cells constituting the inner cell-mass (Plate I., Fig. 2). The cleavage-cavity contains an albuminons fluid. It is during this stage that the germ, in the case of mammals, reaches the uterus. As a peculiarity of the mammalian orum, the blastula now increases greatly in size, the cleavage-cavity becoming dilated. The zona pellucidla, which still surrounds the ovum, is by this time quite attenluated, and is ealted the prochorion. The outer cell-mass, likewise much thinned-ont, constitutes Rauber's layer (Plate I., Fig. 4). 'The significance of the cells of Rauber's layer is nu- 
known. After a time they disappen, probably by disintegration (Kölliker). The form of the hlastula of amphibians and of the Samropsida (birds and reptiles) is greatly modified by the relatively abundant nutritive yolk with which their

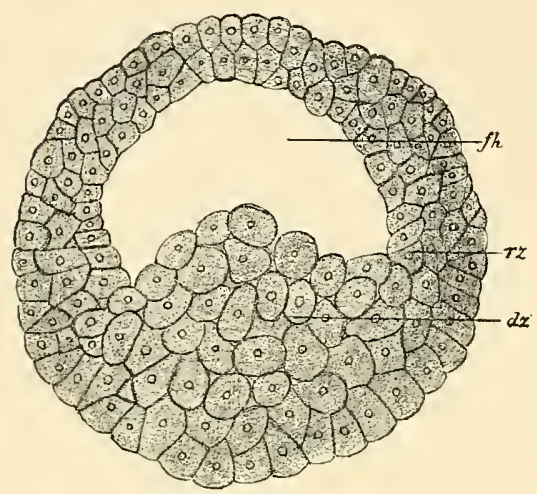

Fig, 19.-Blastula of triton tæniatus: $f h$, segmentation-eavity; $r z$, marginal zone; $d z$, cells with abundant yolk (Hertwig). ova are endowed. In amphibian orum in the blastula stage is shown in Fig. 19. It will be seen that its walls consist of several layers of eells, and the eleavagecarity is encroached upon to a considerable extent by the large and abundant cells of the regetative pole, which are especially rich in deutoplasm. In the eggs of birds and reptiles-that is, in the telolecithal eggs that undergo partial discoidal segmentation-the blastula form is so markedly modified as to be searcely reeognizable. In this case, as shown in Fig. 20, the eleavage-cavity is a narrow fissure

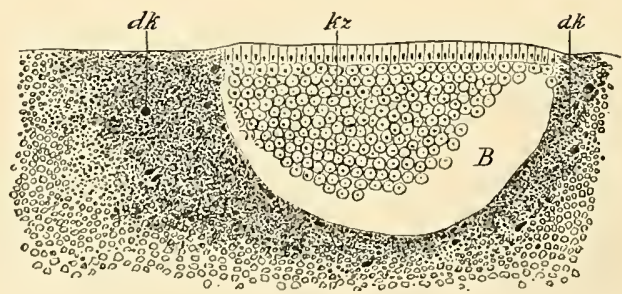

Fig. 20.-Median seetion through a germ-disk of pristiurus in the blastula stage (after Rickert): $B$, eavity of the blastula; $k$, segmented germ ; $d k$, finely gramular yolk with yolk-nuclei.

whose roof is the germ-disk, and whose floor is the unsegmonted mutritive-yolk, which latter eorresponds therefore to the large vegetative cells forming the floor of the amphibian egge shown in Fig. 19. 


\section{CHA P'TER I I I.}

\section{THE GERM=LAYERS AND THE PRIMITIVE STREAK.}

\section{THE STAGE OF THE GASTRULA.}

$B y$ the conversion of the one-layered germ, the blastula, into the germ with two larers, the gastrula stage is attained. The gastrula, in its typical form, consists of two layers of cells surrounding a central carity, which latter communicates with the exterior by means of a small aperture, the blastopore. The cavity is the archenteron or colenteron or intestino-body cavity. The outer laver of cells is the ectoderm or epiblast; the inmer layer is the entoderm or hypoblast. This form of the germ is seen in holoblastic invertebrate, as well as in some vertebrate ora, and is typically exemplified in the development of the amphioxus. The blastula of this animal is a simple sac, the wall of which is a single layer of epithelial cells surrounding the cleavage-cavity (Fig. 21, A). By a pushing-in of the vegetative cells, the cleavage-cavity is encroached upon and finally is completely obliterated, being replaced by the arehenteron (Fig. 21, C). From this it is obvious that gastrulation occurs here by a simple process of invagination. In ova with a large amount of food-yolk, as in those of frogs, birds, and fishes, the process is modified and complieater by this condition.

According to the so-called gastrula theory of Haeckel, all metazoa-that is, multicellular animals as distinguished from protozoa, or unicellular organisms-pass through a typical gastrula stage in the course of their development.

It has been held as a general principle that the higher animals during their development repeat, to a greater or less extent, the embrronic or the larval forms of the lower members of the group to which they belong. Huxley has pointed ont the morphological iclentity of the arlult form of the celen- 
terata with the two-layered gastrula. This principle is one of importanee as applying to the developmental history of the various organs.

It must not be understood, however, that we find in mammals such a gastrula as that of amphioxus; some embryologists, indeed, do not employ the term gastrula in connection

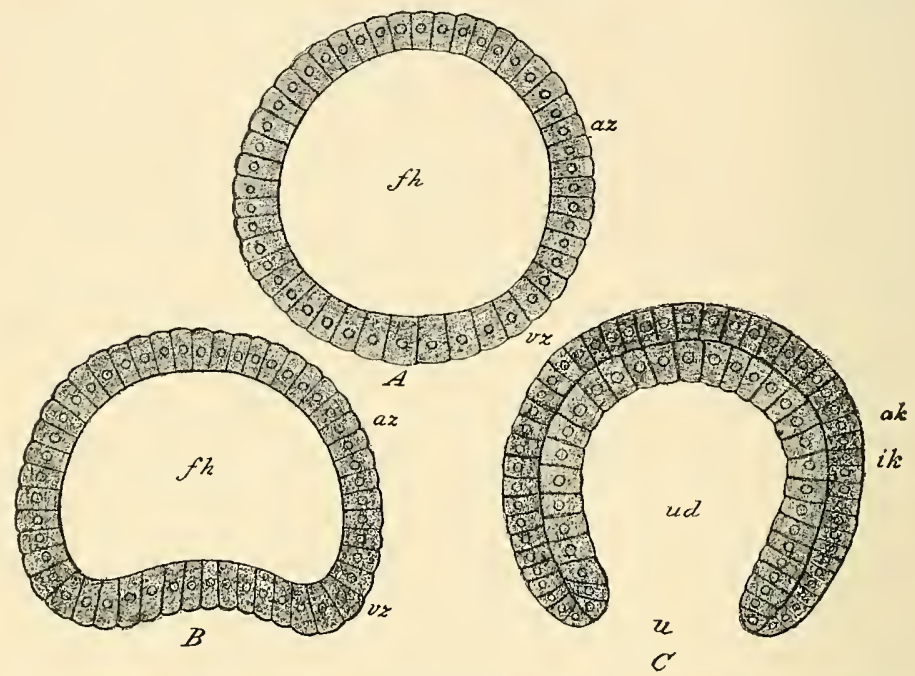

F1G. 21.-Gastrulation of amphioxus (modified from Hatschek). A. Blastula : $a z$, animal cells; $v z$, vegetative cells; $f h$, cleavage-cavity. B. Beginning invagination of vegetative pole. $C$. Gastrula stage, the invagination of the vegetative eells being eomplete: $a k$, outer germ-layer; $i k$, inner germ-layer; $u d$, archenteron; $u$, blastopore.

with mammalian development, but eall the germ a blastodermie vesiele even after it has become two-layered.

The mammalian "gastrula" (Plate I., Fig. 4) is a vesicle whose wall, for the most part, is a single layer of flattened cells, known as Rauber's layer; this layer has been referred to above as the attennated outer cell-mass of the blastula. Throughout a limited area, the germ-wall is composed of two other layers of cells in addition to the layer of Rauber. The inner of these layers, eomposed of flattened cells, is the entoderm; the outer, lying next to Rauber's layer, and consisting of cubical cells, is the ectoderm. $\Lambda t$ a later stage both layers take part in the formation of the entire wall of the vesiele. 
The ectoderm and the entoderm are produced from the inner cell-plate of the blastula. This mass gradually flattens, becoming at first lens-shaped; spreading out peripherally on the inmer surface of Rauber's layer, it is at length differentiated into the two primary germ-layers, the ectoderm and the entoderm.

The eavity of the vesicle is the archenteron, or cœlenteron. As previously stated, the process of gastrulation and the form of the gastrula are modified in the case of ova possessing a large proportion of dentoplasm. In the ease of the frog, for example, as well as in other amphibians, the blastula has the form shown in Fig. 19. By an invagination of the blastula-wall at the place of transition from the animal cells to the vegetative cells, all of the latter and a part of the former are carried into the interior of the blastula to form the lining of the archenteron (Fig. 22). Compare this with the amphi-

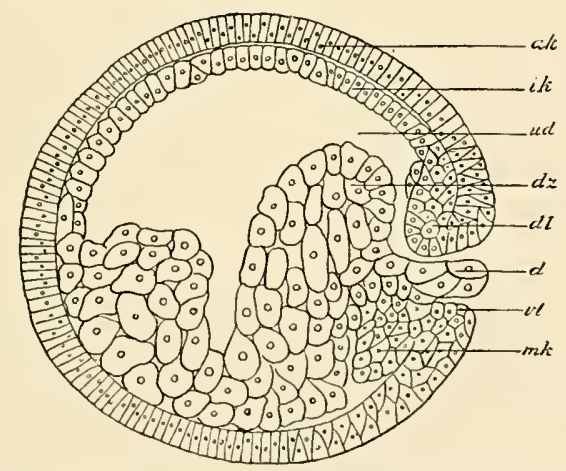

Frg. 22.-Sagittal section through an egg of triton (after the end of gastrulation): $a k$, outer germ-layer; $i k$, inner germ-layer; $d z$, yolk-eells ; $d l$ and $v l$, dorsal and ventral lips of the colenteron; $u d$, calenteron; $d$, vitelline plug; $m k$, middle germ-layer (Hertwig).

oxus gastrula as shown in Fig. 21. In the bird's egg, the form of whose gastrula is shown in Fig. 23, an infolding or invagination occurs, as in the frog's egg, at the place of transition from the animal eells to the vegetative cells, or, in other words, at the margin of the germ-disk. The gastrula thus formed is represented in Fig. 23. Its arehenteron is a 
narrow fissure, and its blastopore, situated at the posterior margin of the germ-disk, is exceedingly small.

The Embryonal Area.-Upon the surface of the germ at the beginning of gastrulation-that is, at about the fifth day of development in the case of the rabbit's germ-there is

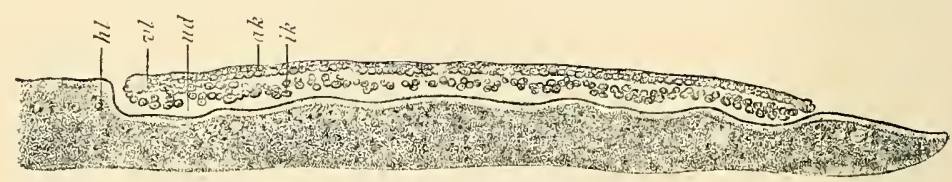

FIG. 23.-Longitudinal section through the germ-disk of a fertilized unineubated egg of the nightingale (after Dural): $a k$, outer, $i k$, inner germ-layer; $u d$, colenteron; $v l$, anterior, $h l$, posterior lip of the blastopore (crescentic groove).

a round whitish spot, the embryonal area. Its position corresponds to that formerly held by the inner cell-plate of the blastula, as shown in Plate I., Fig. 2. It is only in this region that the wall of the vesicle is, at this particular stage, composed of more than a single layer of cells, the ectoderm and the entoderm not extending much, if at all, beyond its periphery.

The embryonal area, soon becoming oval (Fig. 2t) and, later, pear-shaped, exhibits, at its posterior margin, a trans-

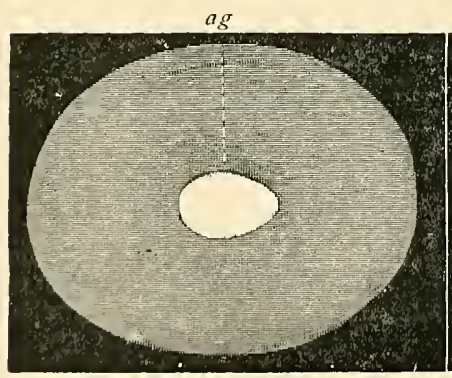

$A$

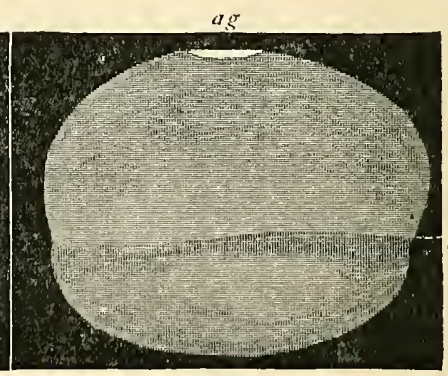

$B$

Fig. 24.-Blastala of the rabbit seven days old without the outer egg-membranes. Length $4.4 \mathrm{~mm}$. (after Kölliker). Magnified ten diameters. Seen in $A$ from above, in $B$ from the side: $a g$, embryonic spot (area embryonalis); $g e$, the line up to which the blastula is two-layered.

verse thickening called the terminal ridge, which is believed to be the anterior lip of the blastopore. It may be not amiss to say that the terms anterior and posterior are used with 
reference to the future body, the narrow end of the area embryonalis corresponding to the posterior pole or caudal extremity of the fetus.

In the chick's egg, the embryonic area (Fig. 25), or embryonic shield, appears while the egg is yet in the oviduct.
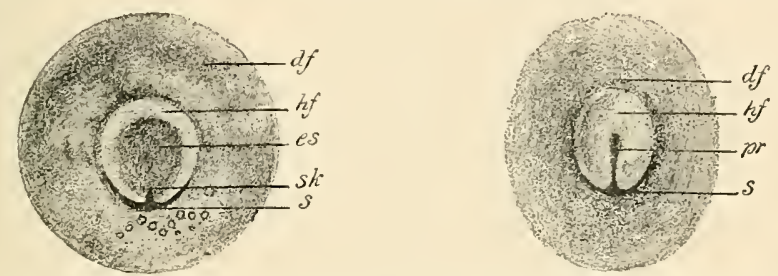

FIG. 25. -Two germ-disks of hen's egg in the first hours of incubation (after Koller) : $d f$, area opaca; $h f$, area pellncida ; $s$, crescent; $s k$, crescent-knob; $e s$, embryonic shield; $p r$, primitive groove.

Its embryonic crescent corresponds to the mamalian terminal ridge. Segmentation being limited to the germ-disk in the chiek's egg, the resulting blastorlerm, which is not a resicle, but a flattened mass (Fig. 23) composed of several layers of cells, rests by its margin upon the partially liquefied yolk. The central region of the blastoderm, which overlies the liquefied portion of the yolk, from its translucence is known as the area pellucida (Fig. 25), while the dark opaque rim, resting upon the yolk is the area opaca. The inner rim of the area opaca is the area vasculosa. These regions are observed also in the mammalian egg.

It is in the embryonal area alone that the borly of the embryo is developed; the other parts of the germ produce extra-embryonic structures, such as the amnion, the yolksac, ete.

Partial longitudinal division of the embryonic area during development results in the production of some form of double monster; its complete cleavage gives rise to homologous or homogeneous twins, which are twins of the same sex and of almost absolntely identical structure. Ordinary twins are developed from separate ova, which may or may not have come from the same orary.

The Primitive Streak. - The primitive streak is a linear 
median marking lying in the long axis of the embryonal area and containing a median furrow, the primitive groove (Fig. 26). A transverse section through the primitive streak

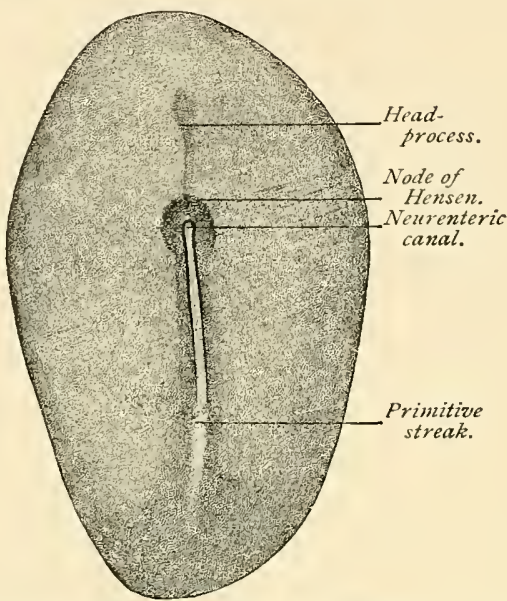

FIG. 26.-Embryonic area of rabbit-embryo (E. v. Beneden) : primitive streak beginning in cell-proliferation known as the "node of Hensen."

(Figs. 27 and 28) shows that this surface-marking is produced by a thickening of the ectoderm along the median line, owing to a proliferation of cells from its under side. The length of the streak is about two-thirds of that of the embryonal area. In the rabbit's ovum it is seen at about the seventh day; in the human germ the time of its appear-

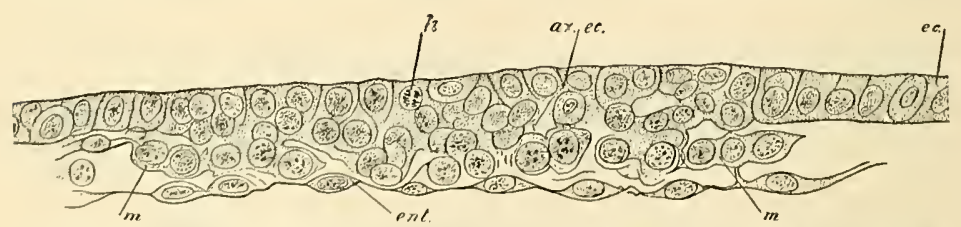

Fig. 27.-Section aeross the primitive streak of rabbit-embryo (Kölliker): $e c$, cetroclerm; $a x$. $p c$, axial ectoderm undergoing proliferation, as shown by karyokinctic figures $(k)$; ent, entoderm; $m$, nesoderm.

ance is not known, but is probably about the twelfth or thirteenth day. In the case of such a gastrula as that of the amphioxus (Fig. 21), the lips of the blastopore approach each 
other and fuse in a line corresponding to the median longitudinal axis of the future embryonic area, the fusion or conerescence beginning at the anterior extremity of this line and proceeding toward its caudal end. The surface-marking produced by the apposition and partial union of the blastoporic lips was called the primitive streak, and its median furrow was known as the primitive groove, long before their true significance was appreciated. Since the edge of the blastopore marks the place of transition from the entoderm to the ectoderm (Fig. 21), the two germ-layers after the

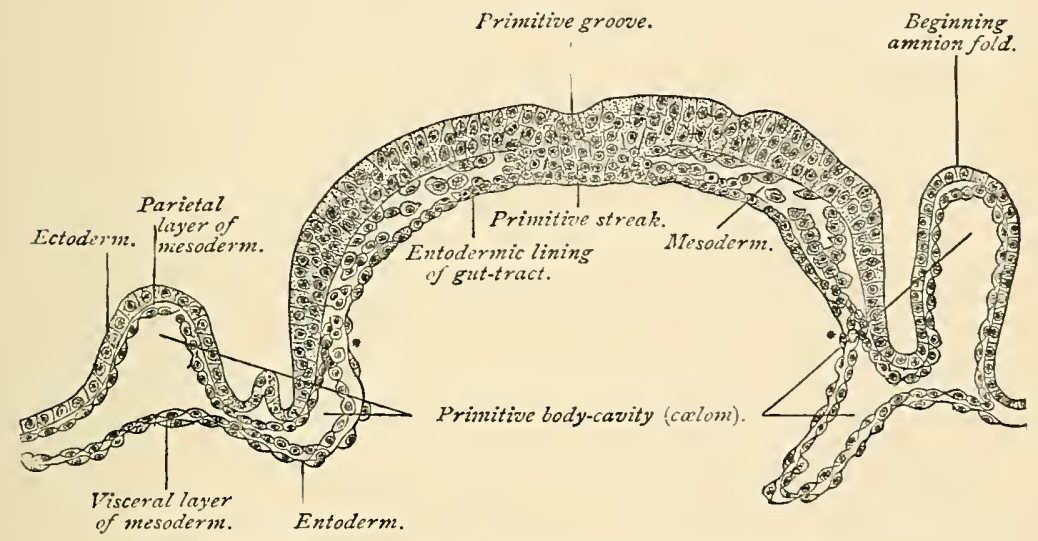

FIG. 28.-Transverse section of the embryonic area of a fourteen-and-a-half-day ovum of sheep (Bonnet).

union of the edges of this opening are in intimate association under the primitive streak, as shown in Fig. 28.

Morphologically the primitive streak of the higher vertebrates is regarded as the fused and extended blastopore of lower types. The terminal ridge of the mammalian embryonic area, as well as the crescent of the embryonic shield of avian and reptilian eggs, represents, as stated above, the anterior lip of the blastopore. Since the embryonal area is increasing in circumference while the lips of the blastopore are undergoing union or concrescence, the transversely directed terminal ridge, which lies at the posterior edge of the embryonal area, and which remains a fixed point, becomes a 
longitudinal marking, and this marking or primitive streak comes to lie, therefore, behind the site of the blastopore. Reference to Duval's diagram (Fig. 29) will make this clear.
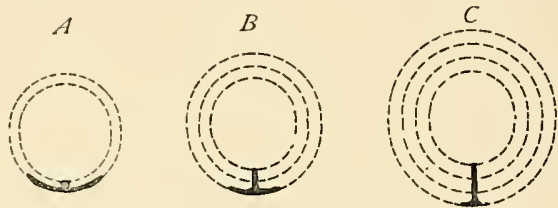

FIG. 29,-Diagram elueidating the formation of the primitive groove (after Duval). The increasing size of the germ-disk in the course of the development is indieated by dotted circular lines. The heavy lines represent the erescentic groove, and the primitive groove which arises from it by the fusion of the edges of the crescent.

After the development of the primitive streak, there is seen, in the median line of the embryonal area, anterior to the streak, another marking, the head-process of the primitive streak. This is almost identical with the primitive axis of Minot, which that investigator describes as a median band of cells comnected with the entoderm and extending forwarl from the blastopore.

Hensen's node is an accumulation of eells on the under surface of the ectoderm at the anterior end of the primitive streak. It is important because of its relation to the neurenterie canal, which will be deseribed later.

Althongh the primitive streak and blastopore play no part in the later stages of derclopment, it is worthy of note that the former lies in the line of the longitudinal axis of the future body, and that the position of the blastopore marks the posterior or caudal end of the embryo.

The Development of the Mesoderm.-The mesoderm or mesoblast is a strueture composed of several layers of cells lying between the ectoderm and the entoderm. It is earliest formed in the vicinity of the front end of the prinitive streak, the position formerly held by the blastopore. From this point it grows laterally and posteriorly and, later, anteriorly as woll. It is not, however, mntil other important changes have taken place that it extends completely aromel the germ. 
The terms gastral mesoderm and peristonal mesoderm are nsed to designate respectively that portion developing from the region of the head-proeess of the primitive streak and that portion growing from the region of the blastopore.

Concerning the origin of the mesodern much difference of opinion prevails. 'The simpler and more primitive method is seen in the amphioxus, in which it develops as two evanginations from the dorsal wall of the archenteron, one on each side of the mid-line. These entodemic folds, containing each a cavity, the enterocel, grow out laterally between the inner and the onter gem-layers. By transverse constriction, each fold divides into a series of segments, the somites, which lie on either side of the median line from the head-end to the tail-end of the embryo. Each somite divides into a dorsal part, the "protovertebra," and a ventral part, the lateral plate. By the fusion of the lateral plates of each sicle their several cavities bccome one, the body-cavity or cœlom.

The origin of the middle germ-layer in higher vertebrates is far less elearly made out. Some investigators hold that it arises in essentially the same mammer as does that of amphioxus-that is, by evagination or outfolding of the entoderm bounding the coelenteron; the investigations, however, of Bomnet and of Duval respectively upon shcep and chick embryos, point to a different conclusion. Bonnet's obscrvations show that the mesodermic tissue, starting from Hensen's node, grows out laterally between the ectoderm and the entoderm, and that at some distance from the median line of the embryonic area there is a delamination or splitting-off of cells from the entoderm; and, further, that these two primitive areas grow toward each other and unite to form one continuous sheet of mesoderm. It may be said, therefore, that the mesoderm origimates from a double source, rhiefly from the entoderm, but also fiom the ectoderm, since the cells giving rise to the part that grows from the region of Hensen's node are ectodermic. A section of the germ transverse to the long axis of the embryonic area (Figs. 27 and 28) shows the mesoderm to be a distinct and independent layer, sharply defined from the other gem-layers everywhere except 
in the region of the mid-line, in which position the three layers are so closely related as to constitute one structure. The mesoderm does not extend completely around the germ at this stage, being defieient on the side opposite the embryonic area.

The mesoderm, after its formation, grows by the proliferation of its own cells, independently of the ectoderm and the entoderm.

If the expansion of the mesoderm, as indicated by the surface appearance of the germ (Fig. 30), be noted, it will

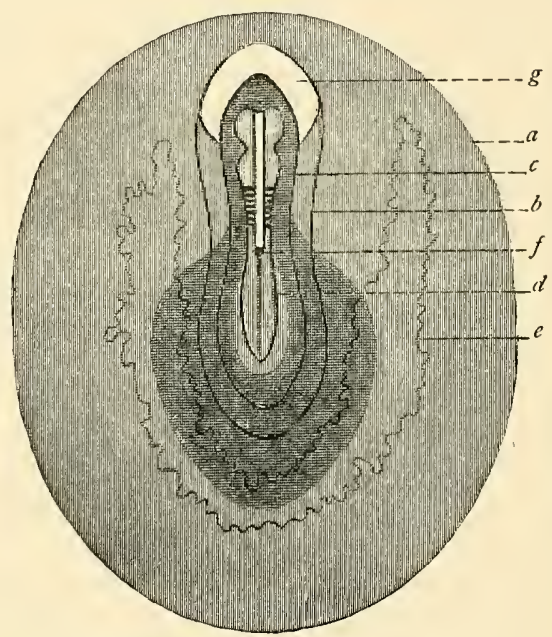

FIG. 30.-Diagrammatic surface view of rabbit's ovum of 205 honrs (after Tonrneux). The darkly shaded area indicates the extent of the mesoderm. $a$, Peripheral limit of area opaea; $b$, of area pellucida; $c$, of parietal zone; $d$, of stem-zone; $f$, Hensen's node; $g$, proamnion.

be seen that at first it is present throughout a pear-shaped area whose narrow end is direeted forward. Somewhat later, two wing-like expansions grow forward from the front end of this area (Fig. 31); these wings, meeting at their tips, enclose a space, the proamnion, which is devoid of mesoderm.

Referring again to the transverse section (Fig. 28), it is evident that the middle germ-layer in the vieinity of the median line is composed of a somewhat irregular mass of cells, while farther away it constitutes a lamina on each side. 
As development advanees, these two portions beeome more differentiated from each other, although they are not entirely separated until much later. The thick mass adjacent to the median line is the vertebral plate, or primitive segment plate, or paraxial mesoderm; the more flattened lateral portion is the lateral plate. The mesoderm at this stage, therefore, consists of four parts-the two paraxial masses, lying one on each side of the median line, and extending from the head-

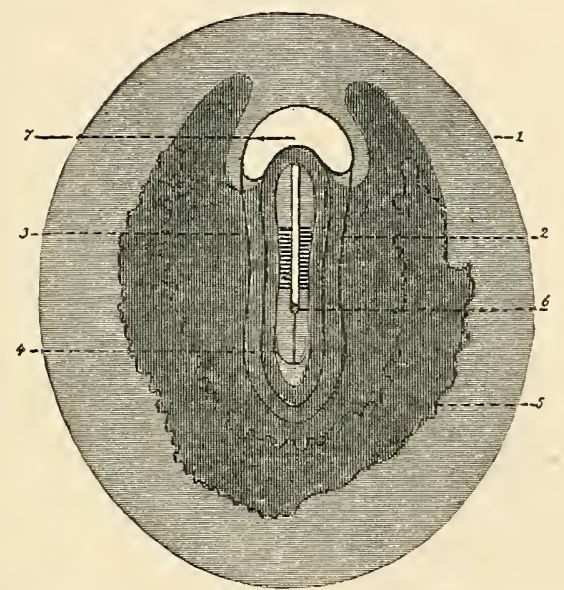

Fig. 31.-Diagrammatic surface view of rabbit's ovum of 211 hours (after Tourneux). The darkly shaded area indicates the extent of the mesoderm. 1, Peripheral limit of area opaca; 2 , of area pellucida; 3 , of parietal zone; 4 , of stem-zone; 6, Hensen's node; 7 , proamnion.

end to the tail-end of the embryonal area, and the two lateral plates, situated upon the outer sides of the paraxial columns.

Each primitive segment plate undergoes transverse division into a number of irregularly eubícal masses, the mesoblastic somites, or primitive segments, often improperly called the protovertebræ. The presenee and position of the primitive segments are indicated by transverse parallel lines on the surface of the grerm, which constitute a series on either side of the primitive streak and its head-process (Figs. 31 and 37 ). The formation of the somites begins at the cephalie end of the embryo and progresses tailward.

The lateral plate of the mesoderm splits into two lamellæ, 
of which the outer or parictal layer is the somatic mesoderm. and the inner or visceral layer is the splanchnic mesoderm. The somatic mesoderm mites with the ectoderm, forming the somatopleure; the splanchnic mesoderm unites with the entoderm, forming the splanchnopleure. The tissure-like cavity between the somatopleure and the splanchnoplenre is the cœlom, or body-cavity, or pleuroperitoneal cavity (Fig. 36). The great serons cavities of the adult borly-pleural, pericardial, and peritoneal-are later suldivisions of the colom.

The mesodermic cells bounding the body-cavity become flattened and endothelioid in character, and constitute the mesothelium; from them are descended the varions endothelial cells lining the serous cavities of the mature organism. Accorling to some authorities, among whom Hertwig may be especially mentioned, there levelop from the mesothelium at an early stage certain cells whose particular function is the formation of the lifferent kinds of comnective tissue, such as bone, cartilage, fibrous tissue, etc.; these elements are often distinguished as mesenchymal cells, or collectively, as mesenchyme. According to this classification, the importance of which is insister upon by Minot, the mesenchyme includes all the mesodermic tissue except the flattened cells, the mesothelium, lining the body-eavity.'

His claims a donble origin for the mesoderm. He maintains that the mesothelium and the smooth musculatme of the body are of intra-embryonic origin, and these structures he terms the archiblast; while all other parts of the mesoderm, which he designates the parablast, have, in his opinion, an extra-embryonic souree, being derived possibly from the granulosa cells of the ovary. These views are not shared, however, by the majority of embryologists.

The Derivatives of the Germ-1ayers.-From the three primary enerm-layers are developed the various tissues and organs of the body by metamorphoses which may be

I Minot holds with Goette that the mesenchymal cells are the product of the mesothelium. Ifertwig maintains that the mesenchyma arises from all the other germ-layers by the emigration of isolated cells. 
referred to the two fundamental processes of specialization, or the adaptation of structure to function, and of mequal growth, which latter results in the formation of folds, ridges, and constrictions.

From the ectoderm are produced :-

The epidemis and its appendages, including the nails, the epithelium of the sebaceous and sweat-glands and their involuntary muscles, the hair, and the epithelium of the mammary glands.

The infoldings of the epidemis, including the epithelium of the mouth, with the enamel of the teeth, the epithelium of the salivary glands, and the anterior lobe of the pituitary body :

The epithelium of the nasal tract with its glands and communicating cavities:

The epithelial lining of the extemal anditory canal, including the outer stratum of the membrana tympani :

The lining of the anus and of the anterior part of the urethra :

The epithelium of the conjunctiva and of the anterior part of the cornea, the crystalline lens.

The spinal eord, the brain with its outgrowths, including the optic nerve, the retina, and the posterior lobe of the pituitary body.

The epithelium of the internal ear.

From the entoderm are produced :-

The epithelium of the iespiratory tract.

The epithelium of the digestive tiact, from the back part of the pharynx to the anus, including its associated glands, the liver, and the pancreas.

The epithelial parts of the middle ear and of the Eustachian tube.

The epithelium of the thymus and thyroid bodies.

The epithelium of the bladder, and of the first pait of the male urethra, and of the entire female urethra. 
From the mesoderm are developed:-

Connective tissue in all its modified forms, such as bone, dentine, cartilage, lymph, blood, fibrous and areolar tissue.

Muscular tissue.

All endothelial cells, as of joint-eavities, bursal saes, lymph-sacs, blood-vessels, pericardium and endocardium, pleura, and peritoneum.

The spleen.

The kidney and the ureter.

The testicle and its system of excretory ducts.

The ovary, the Fallopian tube, the uterus, and the vagina.

From the foregoing tabulation it may be seen that, generally speaking, all epithelial structures originate from either the ectoderm or the entoderm, the notable exception to this rule being that the epithelium of the sexual glands and their duets, and also that of the kidney and of the ureter, proceed from the mesoderm. 


\section{CHAPTER I V.}

\section{THE BEGINNING DIFFERENTIATION OF THE EM= BRYO; THE NEURAL CANAL; THE CHORDA DORSALIS; THE MESOBLASTIC SOMITES.}

The germ, in the stages thus far eonsidered, has the form of a hollow sphere or vesicle. It will be seen, in following the further history of development, that the layers of cells constituting the walls of the vesicle give rise to the alterations of external form and to the rudiments of the various organs of later stages by processes which, though seemingly complex, are referable to certain simple fundamental principles. It is, namely, in the unequal growth of rifferent parts of the germ, in ontfoldings and infoldings, and in the furrowing and constricting-off of parts, as well as in the adaptation of structure to function, that we find an explanation of the various developmental processes.

The first indication of the formation of the embryo and of its differentiation from the parts of the germ that are destined to produce, wholly or in part, the several extra-embryonic structures, is the marking ont of the embryonic area by the thickening of the cells of the vesicle-wall in a definitely circumscribed region. The structures designated as extra-embryonic are the umbilical vesicle, the amnion, the allantois, and the fetal part of the placenta. The development of these and the production of the external form of the body of the embryo will be considered in the next chapter.

The primitive streak and its head-process have been already described. After their appearance the further evolution of the embryonic body is closely associated with three fundamentally important processes-namely, the formation of the neural canal, of the chorda dorsalis, and of the mesoblastic somites. 
The Neura1 or Medullary Cana1.-The nenral canal is an elongated tube lying beneath the ectoderm in the median longitudinal axis of the embryonic body, its position corresponding to that of the future spinal canal. Its walls are composed of eylindrical epithelial eells.

To follow the development of the medullary canal, it is necessary to study the surface appearance of the ovum at the stage when the mesoderm is beginning to grow out from the region of the head-process of the primitive streak. Upon the surface of such a germ (Fig. 26), one may see the primitive streak and, in front of it, also in the median line of the embryonic area, the head-process of the primitive streak. The ectodermic cells overlying the head-process thicken so as to

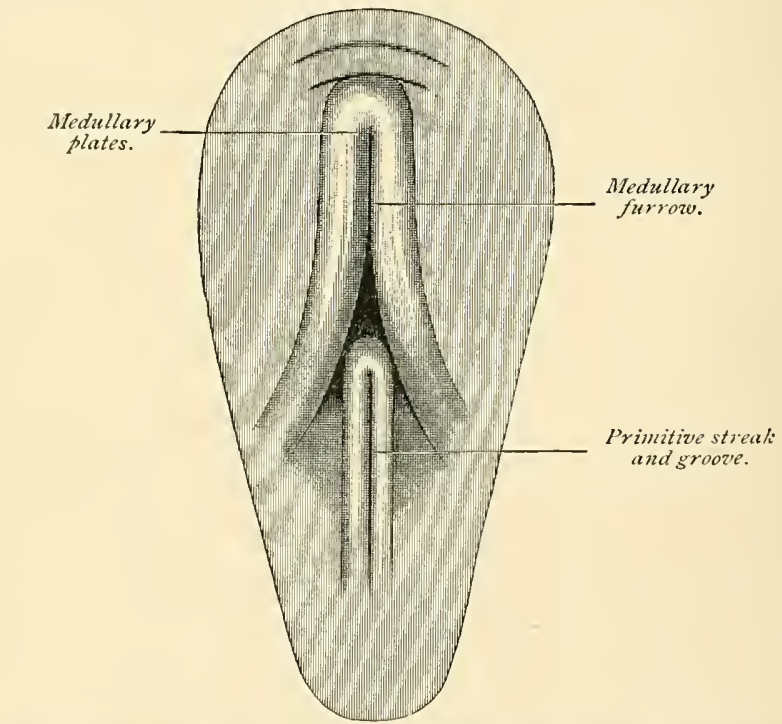

FIG. 32.-Surface view of area pellucida of an eighteen-hour chick-embryo (Balfour).

become columnar, while those on each side of it become flattened. This differentiation results in the production of a relatively thick axial plate of cetoderm, the medullary plate, which is present at the begimning of the eighth day in the rabbit's germ, and in the human germ at about the fonrteenth 


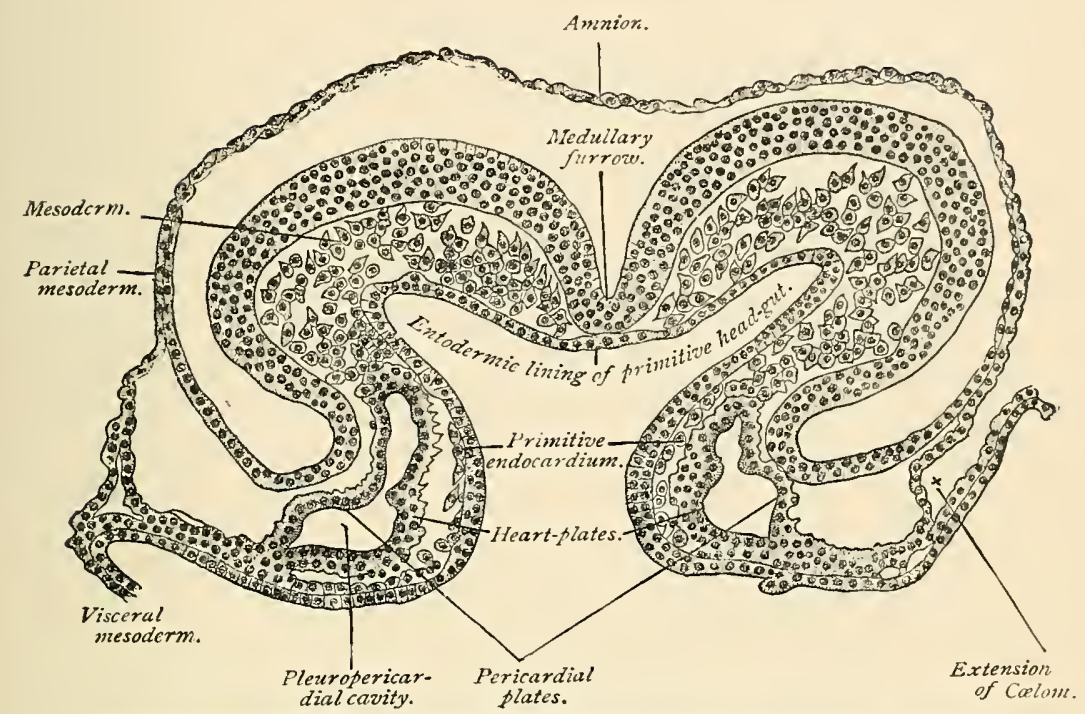

Fig. 33.-Transverse seetion of a sixteen-and-a-half-day sheep-embryo (Bonnet).

day. Almost as soon as the plate is formed, its lateral and anterior edges begin to curl up, producing the medullary fur-

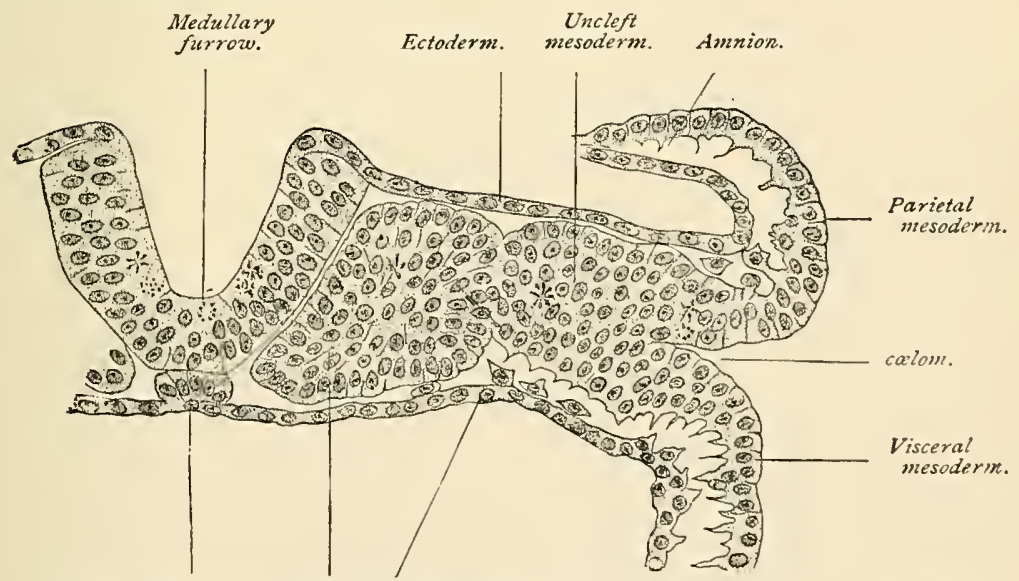

Notochord. Somite. Gut entoderm.

FIG. 34.-Transverse seetion of a sixteen-and-a-half-day sheep-embryo possessing six somites (Bonnet).

row or groove (Fige. 32, 33, and 34). The curling margins of the plate carry with them, as they rise, the arljacent 
thinner ectoderm ; these projections constitute the medullary folds. A surface view shows the medullary folds to be continuous with each other in front, while their posterior ends are separated and embrace between them the front end of the primitive streak (Fig. 32). Since the formation of these structures is always more advanced in the anterior part of the embryonic area, their posterior extremities are not sharply defined but fade away (Fig. 32). The edges of the medullary plate continue to curl until they meet, when they unite, forming the medullary or neural canal (Figs. 35 and

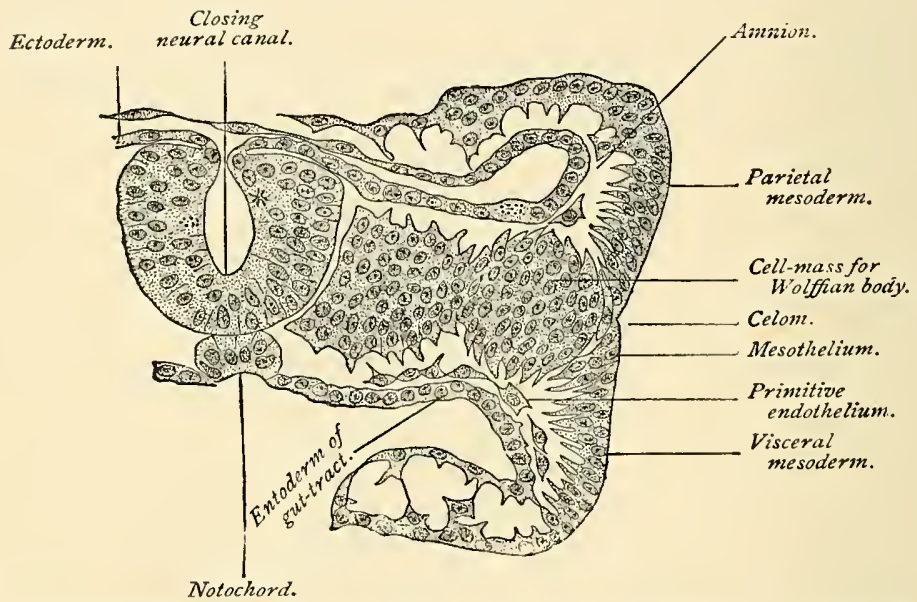

FIG. 35.-Transverse section of a fifteen-and-a-half-day sheep-embryo possessing seven somites (Bonnet).

36). The medullary folds and plate continuing to advance toward the tail-end of the embryonic area, and the closure of the tube taking place from before backward, the entire primitive streak is made to disappear by being included within the neural tube.

The medullary folds having grown toward each other a short time before the union of the edges of the medullary plate now unite over the partially formed nenral tube. By the growth of the medullary folds and their subsequent coalescence, the completed neural tube comes to lie under the surface ectoderm, its connection with which is afterward lost. 
It is apparent, therefore, that the neural tube is a structure whose walls are composed of ectodermic cells, and that it has originated from the ectoderm by what may be called a process of infolding.

The medullary canal is the fundament of the entire adult nervous system. The first step in the conversion of a structure so simple into one so complex consists in the dilatation of the cephalic end of the neural tube and the subsequent division of this dilated extremity into three imperfectly separated compartments, named respectively the fore-brain, the mid-brain, and the hind-brain vesicles. It is by the multiplication and

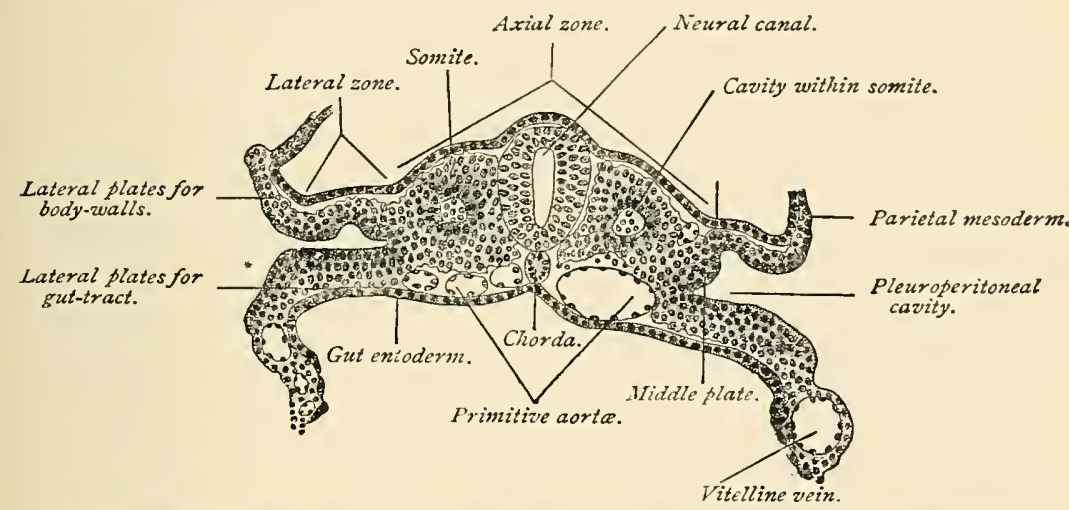

FIG. 36.-Transverse section of a seventeen-and-a-half-day sheep-embryo (Bonnet).

specialization of the cells composing the walls of the medullary tube that the cerebrospinal axis is produced, the brainvesicles giving rise to the brain-mass, while the remainder of the tube produces the spinal cord. Approximately one-half of the length of the tube is devoted to the formation of the brain, the other half forming the spinal cord.

The neural tube eloses first in the future cervical region, the cephalic part of the canal remaining open for a time. From the neck region the closure of the tube progresses toward either end of the embryo.

The Notochord or Chorda Dorsalis.-The notochord is a solid cylindrical column of cells lying parallel with the medullary tube, on the dorsal side of the archenteric cavity. 
Its position is that of a line passing through the centers of the bodies of the future vertebræ. The development of the chorda oceurs at the same time as that of the neural tube, and in a very similar manner. A thickening of the cells of the entoderm in a longitudinal line extending along the dorsal aspect of the coelenteron produces the chordal plate. Along either edge of the chordal plate a small fold of entoderm projects rentralward. By the curling around of the edges of the chordal plate, the latter becomes a solid eylinder of cells, which is separated from the entoderm proper by the union of the chordal folds, as shown in Figs. 35 and 36.

The appearance of the notochord is the first indication of the axis of the embryo, since around it the permanent spinal column is built up. The relative size of the chorda is less in the higher vertebrates than in the lower members of this group. It is one of the distinctive features of a vertebrated animal.

The chorda is essentially an embryonic structure, since it gives rise to no adult organ. Its only representative in postnatal life is the pulpy substance in the centers of the intervertebral disks. It is a permanent structure in one vertebrate only, the amphioxus. In this animal it is the representative of the spinal colmmn of higher vertebrates. The notochord affords another illustration of the principle that higher organisms repeat, in their development, the structure of the lower members of the group to which they belong.

The Neurenteric Cana1.-The neurenteric canal is closely associated with the development of the medullary canal and with the disappearance of the primitive groove. We have learned that the blastopore is the orifice through which the coclenteron opens to the exterior, and also that in birls and nammals the position of the blastopore, as indicaterl by the prescence of the terminal ridge, corresponds to the anterior end of the primitive streak, and therefore of the primitive groove. Reference to Fig. 32 will show that the medullary folds have extended so far posteriorly that they embrace between them the primitive groove; therefore when 
they unite to form the neural canal, the primitive streak falls within its limits.

In a gastrula with an open blastopore, such as that of the amphioxus and those of amphibians, the blastopore is included between the medullary folds, and, after the completion of the neural canal, it constitutes an avenue of communication between the latter and the celenteron or primitive enteric cavity; this communication is the neurenteric canal. In mammals, as also in birds, reptiles, and selachians, classes in which the primitive streak is the representative of the closed blastopore, a small canal is found at the anterior end of the primitive groove, passing through Hensen's node, and opening into the coelenteron. With the covering in of the primitive groove by the medullary folds, this canal becomes the neurenteric canal. According to Graf Spee, a neurenteric canal is found in the human embryo, as well as in the groups above mentioned. The canal is a temporary structure and gives rise to no organ of the adult.

The Somites or Primitive Segments.-The mesoblastic somites are cuboidal masses of cells, arranged in two parallel rows, one on each side of the notochord, extending the entire length of the body of the embryo. They are sometimes called protovertebrce, but this term if used at all should be restricted to a subdivision of them that appears later.

The development of the somites was incidentally referred to in the description of the mesoderm. As mentioned in that connection, the paraxial plates of mesoderm, lying as parallel longitudinal columns, one on each side of the notochord, break up, each one into its corresponding series of primitive segments. The division throughout the entire length of the body takes place not simultaneously, but consecutively, beginning at the head-end.

The segmentation of the axial mesoderm is indicated by certain surface markings. The surface of the embryonal area, at the stage when the primitive streak and the medullary groove are present, shows a dark zone on either side of the median line, the so-called stem-zone, which marks the 
limits of the axial plate of mesoderm (Fig. 37 ); the position of the lateral plates is indicated by the peripheral lighter parietal zone. The stem-zone soon exhibits, on each side of the primitive streak and medullary groove, a series of parallel transverse lines, produced by the transverse furrowing of the axial plates, preparatory to their division into the primitive segments. The first pair of somites is formed in the future cervical region, before the medullary folds have united to form the neural tube, and when the primitive streak is yet present. After the appearance of the first pair, the forma-

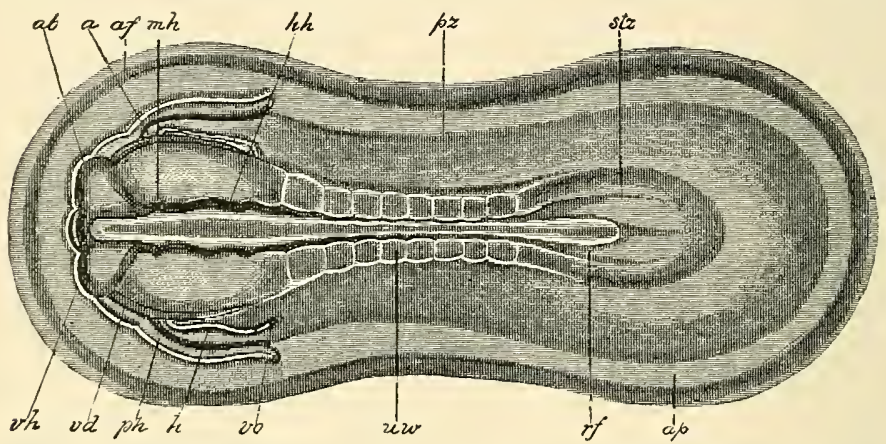

Fig. 37.-Rabbit embryo of the ninth day, seen from the dorsal side (after Kölliker). Magnified 21 diameters. The stem-zone (stz) and the parietal zone ( $p z)$ are to be distinguished. In the former 8 pairs of primitive segments have been established at the side of the chorda and neutral tube; $a p$, area pellucida; $r f$, medullary groove; $v h$, fore-brain ; $a b$, eve-vesicle; $m h$, mid-brain; $h b$, hind-brain; $u w$, primitive segment: $s t z$, stem-zone; $p z$, parietal zone; $h$, heart; $p h$, pericardial part of the body-cavity; $v d$, margin of the entrance to the head-gut (vordere Darmpforte), scen through the overlying structures; $a f$, amniotic fold; $v o$, vena omphalomesenterica.

tion of other segments proceeds headward and tailward. In selachians the number of head-segments has been shown to be nine; in higher vertebrates the number is possibly less. The trunk-segments are added in regular order from the neck-region to the tail-end of the embryo.

The first somites appear on the eighth day in the rabbit, and between the twentieth and twenty-second hours in the chick. While they are forming, the neural eanal is closing, the notochord is differentiating from the entoderm, and the lateral plates of mesoderm are splitting to form the bodycavity or coclom. 
In structure the primitive segments of lower vertebrates consist of columnar cells arranged around a central carity (Figs. 34 and 36). The eavity, in the amphioxus, communicates for a time with the colenteron, since the segments are in this case developed as entodermic evaginations; in selachians, the method of formation of whose primitive segments may be regarded as the primitive method for vertebrates, the cavity is for a time in communication with the body-cavity, since the segments in these animals derelop as if by evagination from the dorsil side of the mesoderm after it has separated into its parietal and visceral layers and before it has divided into the axial and lateral plates. The size of the cavity is quite variable; in some cases, as in the Amniota, it is almost if not entirely obliterated by the encroachment of the cells of the ralls of the somite.

Belonging to the somite, though not apparent on the surface, is a mass of eells which connects, for some time, the somite proper with the lateral plate (Fig. 36). This is known as the intermediate cell-mass or middle plate. Later, the separation of these is effected, the mesial part of the somite being the myotome, the intermediate cell-mass becoming the nephrotome. Each one of these parts contains a cavity, that of the myotome being called the myocœl. From the inner, mesial side of the myotome, embryonic comnective-tissue cells (mesenchyme) derelop, constituting the sclerotome, or skeletogenous tissue. The sclerotomes, made up of loosely-arranged embryonal connective tissue, grow around the medullary canal and chorda dorsalis, spreading out and fusing with each other. Subsequently this tissue produces the rertebral column and its associated ligamentous and eartilaginous structures. The outer part of the myotome, sometimes called the cutis plate, gives rise to the corium of the skin of the trunk. The remaining part of the myotome, that situated dorsolaterally, constitutes the muscle-plate or myotome proper; it gives rise to the voluntary musculature of the trunk.

The segmentation of the body of the embryo is an embryological process of great significance. 
The segmented condition is common to the developmental stage of all true vertebrates, and in some invertebrates it persists throughout adult life. The development of the axial skeleton and of the muscular system, it will be seen later, bears an important relation to the process of segmentation, as does also the evolution of the genito-urinary system.

Upon reflection, it will be seen that in the region of the embryo corresponding to the future neek and trunk, the segmentation affects only the dorsal part of the body, while the ventral mesoderm, the so-called lateral plate, which contains the colom, remains misegmented. On the other hand, in the head-region, the segmentation is both dorsal and ventral, the former being in series with the trunk-segments, while the latter, affecting the ventral mesoderm, and therefore also, in the corresponding region, the coelom, produces the structures known as the visceral arches (see Chapter VII.).

The relation of the primitive segments to the differentiation of the skeleton and of the musculature of the trunk, and also of the visceral arches to the muscles of the jaws, will be considered in subsequent chapters. 


\section{CHAPTER V.}

\section{THE FORMATION OF THE BODY=WALL, OF THE INTESTINAL CANAL, AND OF THE FETAL MEMBRANES.}

The formation of the fetal membranes occurs coincidentally with the production of the external form of the body of the embryo. These changes mark the division of the hollow sphere or vesicle of which the germ consists up to this stage into two essentially different parts-namely, the embryonic body and the fetal appendages, the latter of which are destined for the nutrition and protection of the growing embryo. Although the several processes by which are produced the different parts of the embryo and its varions appendages go on simultaneously, it is necessary, for the sake of clearness, to consider successively the development of each structure from its inception to its completion.

\section{THE FORMATION OF THE BODY=WALL AND OF THE INTESTINAL CANAL OF THE EMBRYO.}

In the stages of development thus far considered, the part of the ovum that is to become the embryo-that is, the embryonic area-is represented by a localized thickening of the wall of the blastodermic vesicle, of the shape and relative size shown in Fig. 24, which presents a surface view of the germ. On each sile of the embryonic axis, represented by the notochord, is the paraxial mass of mesoderm, which has undergone partial segmentation to form the somites; on the distal side of the paraxial column, the mesoderm has split into the somatic or parictal, and the splanchnic or visceral lamellæ, between which is the body-cavity or cœlom. The cavity of the germ until the occurrence of the transforma- 
tions about to be described is one undivided compartment which is bounded by splanchnopleure; and a conspicuous feature of the changes nnder consideration is the division of this cavity into two by the folding in of the splanchnopleure composing its walls.

The first indication of the foldings that lead to the differentiation of the embryo from the fetal appendages is seen upon the surface of the germ at a very early stage. A surface view of the germ-in the case of the chick on the first day of ineubation-shows, at what becomes the head-end of the embryonic area, a transverse crescentic groove, with its concavity looking backward (Fig. 32); a similar groove is seen at the opposite extremity of the area, and also one at each lateral margin. These marginal grooves are depressions in the somatopletre. The elerated onter edges of the grooves form folds of somatopleure, designated respectively the head-fold, the tail-fold, and the lateral folds of the amnion. As these marginal grooves increase in length they meet each other and now constitute one continuous furrow, which encircles the embryonic area; its outer elevated edge is the amnionfold. This furrow, which may be ealled an inverted fold composed of splanchnopleure and somatopleure, progressively deepens and at the same time its bottom is carried inward toward a point vertically under the eentral region of the embryonic area; that is, a fold composed of somatopleure and splanchnopleure grows from all parts of the periphery of the embryonic area toward the point indicated above, a point which corresponds to the site of the future umbilicus. By the ingrowth of the edges of the fold, the eavity of the archenteron is more and more constricted (Plate II., Figs. 2 and 3), until finally, with the completion of the infolding, it becomes divided into two parts of unequal size; the smaller of these spaces is the gut-tract, or intestinal canal of the embryo, while the larger is the yolk-sac or umbilical vesicle. The constricted canal through which the gut-tract communicates with the yolk-sac is the vitelline duct (Plate II., Figs. 4 and 5).

While the splanchnopleuric layer of the ingrowing fold 
PLATE 1 .

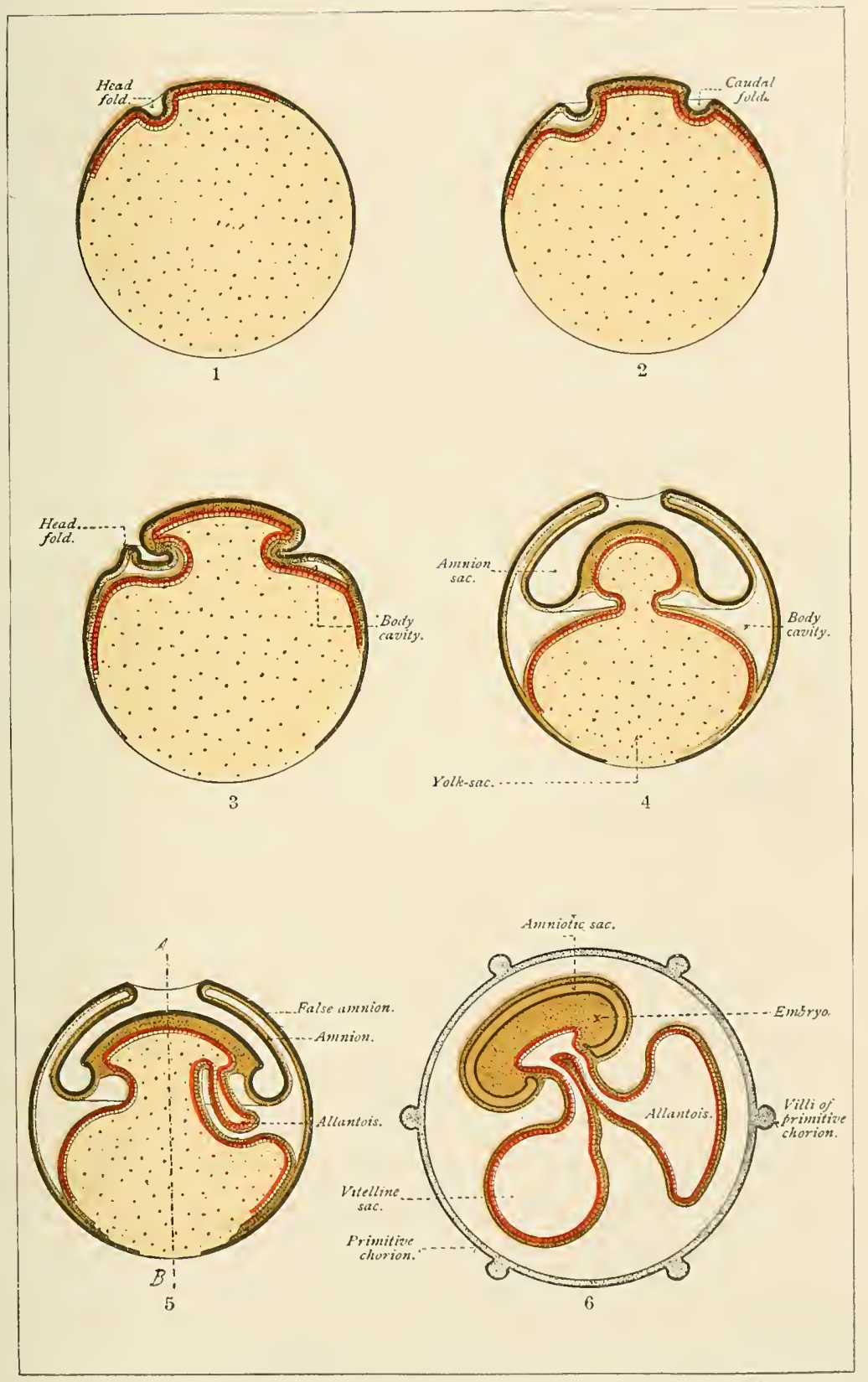

Diagrams illustrating the formation of the marnmalian fetal membranes (modified from Route). 

thus outlines and forms the walls of the intestinal canal, the somatopleuric layer, which accompanies it, constitutes the lateral and ventral body-walls of the embryo. During the progress of this infolding of the splanchnopleure and the somatopleure, the part of the latter membrane that forms: the outer wall of the groove becomes lifted up to constitute the amnion-fold (Plate II., Fig. 3) ; by the continued upward growth of this amnion-fold and the simultaneous settling down of the embryo upon the yolk-sac, the margins of the fold come to lie above the embryonic body, and, approaching each other, they fuse over its back, in this manner enclosing it in a cavity. It is obvious that the fold just described is a double layer of somatopleure. After the union of its edges, the two layers become completely separated, the inner one constituting the amnion, while the outer layer is the false amnion, or serosa (Plate II., Figs. 4-6).

Since the infolding of the splanchnopleure begins at the periphery of the much elongated embryonic area, the resulting gut-tract has the form of a straight tube extending from the head-end to the tail-end of the embryo (Plate III.). When the candal and the cephalic portions of the splanchnopleuric fold have advanced but a comparatively short distance, in consequence of which the communication between the gut-tract and the umbilical resicle is still widely open, as shown in Plate II., Fig. 5, there is a cul-cle-sac or pocket formed of splanchnopleure at the head-end of the embryo and a similar one at its tail-end; these recesses are respectively the foregut and the hindgut, the orifices of which are designated the intestinal portals. At this particular stage, therefore, the eavity of the gut-tract is incompletely closed off from that of the nmbilical vesicle.

It is evident that the gut-tract, being a tubular cavity enclosed by splanchnopleure, is lined with entodermal cells; this simple straight tube develops subsequently into the adult intestinal canal and its associated glandular apparatus.

It has already been pointed out that the layer of somatoplenre which is folded under the embryonic area in company with the splanchnopleure constitutes the lateral and the ven- 
tral walls of the body of the embryo. When the fold has grown in only far enough to form the sides of the embryonic body, the latter has the shape of an inverted boat. The fold continues to advance from each side and from each end, and its edges come together and fuse in the median line of the ventral surface of the body.' At one place, however, fusion of the edges of the fold does not oceur; this region corresponds to the umbilieus and is often designated the dermal navel. Here the part of the somatopleure that forms the body-wall is continuous with that part of this membrane which constitutes the amnion (Plate II., Fig. 6). By the infolding of the somatoplenre the body-cavity or pleuroperitoneal space becomes divided into an intra-embryonic and an extra-embryonic portion, the two communicating for a time through the small annular space that encircles the proximal end of the vitelline duct; this is represented in the accompanying figures.

By this simple process of folding, associated with the unequal growth of different parts, the leaf-like fundament constituted by the embryonic area is differentiated into the body of the embryo; the ventral portion of this body now consists of two tubes, one within the other, of which the smaller, bounded by the splanchnopleure, is the intestinal canal, and the larger, enclosed by the somatopleure, is the body-cavity, the walls of which are the walls of the body of the embryo. In the dorsal region is a third tube, the medullary canal; between it and the dorsal wall of the intestine is the notochord, on each side of which are the somites (Fig. 35). The further evolution of this body and the clifferentiation of its various organs and systems will be described in subsequent sections.

\section{THE AMNION.}

The amnion is a membranous fluid-filled sac, which surrounds the fetus of eertain groups of vertebrate animals

1 Failure of union of the somatopleuric folds in the median line of the thorax produces the deformity known as cleft sternum; while lack of fusion of the lateral halves of the abdominal wall results in an extra-abdominal position of the intestines, or, if in lesser degree, in exstrophy of the bladrler. 
during a part of their period of development. In man, it is found as early as the fourteenth day, before the medullary groove has closed to form the neural canal; it attains it maximum size by the end of the sixth month and persist. until the end of gestation. It constitutes a loose envelope for the fetus, being attached to the abdominal wall of the latter at the margins of the umbilicus, and loosely enveloping the umbilical cord (see Plate III., Fig. 2).

An amnion is found in birds, reptiles, and mammals, these groups being classed together as Amniota, while fishes and amphibians, which are without an amnion, constitute the class Anamnia.

The first indication of the growth of the amnion is apparent at a comparatively early stage of development. A surfaceview of the blastodermic vesicle of the first day of incubation in the case of the chick, or of about the eighth day of development in the rabbit, shows a curved line or marking at the anterior edge of the embryonic area (Fig. 32); this is the anterior marginal groove, in front of which is another marking, the head-fold of the ammion. Very soon the lateral and posterior marginal grooves appear at the sides and posterior edge respectively of the embryonic area; the outer elevated edges of these marginal grooves constitute the lateral folds and the tail-fold of the amnion. The grooves and folds increase in length in each direction until they meet, when they form one continuous furrow, which circumscribes the embryonic area, and the outer elevated edge of which is the amnion fold. The groove involves both the somatopleure and the splanchnopleure, constituting the inverted fold of these two structures that grows in to form the body-wall and the wall of the gut-tract, while the ammion fold is composed of somatopleure alone (Plate II.). This separation of the somatopleure and the splanchnopleure enlarges the extraembryonic portion of the bodly-arity. The amnion fold continues to grow upward, and finally its edges meet and fuse over the back of the embryo, the line of union being the amniotic suture; the suture closes first at the head-end of the embryo and last at the tail-end. After the union of the edges 
of the fold, its inner layer, consisting of eetoderm and parietal mesoderm, separates from the outer layer to constitute the true amnion, whose enclosed space is the amniotic cavity; the outer layer, which is merely a part of the general somatopleure, is the false amnion or serosa. It is apparent from this description that the amniotic cavity is lined with ectodermal epithelium and that its walls consist of somatopleure - that is, of ectoderm and parietal mesorlerm.

While the amnion fold is growing upward, the embryonic area-now undergoing differentiation into the embryonic body-is sinking down upon the yolk-sae. The amnion fold does not grow uniformly in all parts of its periphery. The head-fold is prodneed first and constitutes a eap or hood covering the head of the embryo, which is forming simultaneously by the ventrad growth of the somatopleure at the bottom of the marginal groove. It is only after the development of the lead-fold is well advanced that the lateral, and, later, the eaudal, portions of the amnion-fold grow up to meet it. The head-fold is, for a time, destitute of mesodermie tissue, since it corresponds to that region of the wall of the blastodermic vesicle describer on page 56 as the proamnion.

The amnion of man presents an important variation from that of all other Amniota, since the inner layer of the amnion-fold does not entirely sever its connection with the onter layer, but remains attacher to it over the caudal pole of the embryo. In conseqnenee of this attachment the true amnion is eonnected with the false amnion, and since the true amnion is eontinuous with the body-wall of the embryo, the caudal end of the embryonic body is attached to the false amnion and, consequently, to the later chorion, by a mass of tissne ealled the allantoic stalk or belly-stalk, as seen in Fig. 38. The relation of the belly-stalk to the development of the allantois will be pointed out hereafter.

The space within the amnion-the amniotic cavity-is filled with the amniotic fluid or liquor amnii.

The amnion at first envelops only the sides and dorsum of the embryonic body, occupying the upper part of the eavity enclosed by the chorion, as shown in Plate II., Figs. 5 and 
6 ; the groove, or furrow, however, of which the amnion fold is the peripheral or onter elevated edge, becomes deeper, and the bottom of the groove is carried toward the middle of the future ventral surface of the embryo, its ventrad growth contimning until it reaches the position of the future umbilieus. This is represented in transverse seetion in Plate II., Fig. 4, and in longitudinal section in Plate II., Figs. 5 and 6 . The layer of somatopleure constituting the inner wall of the groove - that is, on the side toward the embryonic area-beeomes the lateral and rentral walls of the body of the embryo, as described above; in this manner is effected the transition from the flattened or layer-like embryonic area to the definite form of the embryonic body. The ventral body-wall is continuous at the margins of the umbilieus with the amnion, sinee the somatopleure, forming the outer boundary of the original groove, is a part of that membrane. After its completion, therefore, the ammion enrelops the body of the embryo on every side, lying closely applied to it, since the amniotic cavity is at first very small. With the progress of development and the inerease of the amniotic fluid, the amnion requires more room, milil, in the third month-in man-it fills out the entire space within the chorion, with the inner surface of which membrane it at this time acquires a loose conneetion. The umbilical resiele and the allantois have meanwhile undergone regression. The walls of the amniotic sac contain contractile fibers; it is to these that the rhythmical contractions observed in the amnion are dne. Its lining is, for the most part, a single laver of flattened epithelial cells.

The liquor amnii is a watery fluil having a specific gravity of 1.007, and containing about 1 per cent. of solids (albumin, urea, and grape sugar). The origin of the fluid is believed to be in the blood of the mother, the liquid portion of which transudes into the amniotic eavity. The amniotic fluid increases in quantity until the sixth month of pregnancy ; from this time until the elose of gestation it generally diminishes about one half. A pathological excess of the fluid constitutes the condition of hydramnios.

The function of the amniotic fluid is two-fold; it serves as 
a buffer for the fetus, protecting it from mechanical violence, and it supplies the fetal tissues with water, since portions of it are from time to time swallowed. Evidenee that the fetus swallows the fluid is afforded by direet observation of ehieken embryos, and by the presence of epidermal cells, hairs, and fatty matter in the fetal alimentary canal. After the development of the bladder, the urine of the fetus is from time to time evacuated into the amniotic cavity.

The epidermis of the child in utero is protected against maceration in the amniotic fluid by the presence of a fatty coating, the vernix caseosa, which is a modified sebaceous secretion.

At the end of pregnaney, the amnion is loosely united with the chorion and the deeiduæ; during birth it ruptures, and its fluid eseapes.

\section{THE YOLK=SAC.}

The yolk-sac, or umbilical vesicle, as seen in the higher vertebrates, is a capacious sae attached by a narrow pedicle, the vitelline duct, to the ventral surface of the embryonic intestinal canal, the duet passing through the umbilical aperture (Plate II., Fig. 6).

In order to appreciate more fully the function and the morphological relations of this strueture, it is necessary to glance at the enditions that ohtain in the several classes of vertebrate animals. In ova that develop outside of the body of the parent organism, a special dower of pabulum is provided for the nutrition of the embryo; this dower is represented by the deutoplasm so abundant in telolecithal ova. In the case of amphibians, whose cleavage, it will be remembered, is holoblastie or total, the eells richest in deutoplasm are aceumulated, after segmentation, in the floor of the archenteron; this aeeumulation produces on the future ventral surface of the embryo a marked bulging, which constitutes the amphibian yolk-sac. As the embryo grows, it draws upon this store for its nutrition, in consequence of which the sac gradually shrinks, its cells being, for the most part, 
liquefied and absorbed, while some of them contribute to the lining of the intestinal canal.

In a higher type, as exemplified in sharks and dog-fishes, the yolk-sac is produced by a folding-in of the splanehnopleure and the somatoplenre, the walls of the sac being therefore constituted by both of these layers; this folding-in divides the archenteron into a smaller part, the intestinal canal, lying within the body of the embryo, and a larger eavity, the yolk-sac, situated outside of that body. The splanchnopleuric layer of the yolk-sae is eontinuous with the wall of the intestinal canal, while its somatopleuric layer is continuons with the body-wall. A system of blood-vessels develops upon the yolk-sac, their function being to convey the nutritive material into the body of the embryo. These blood-vessels constitute the so-called vascular area, which :ppears, in surface views, as a zone encircling the embryonic area, and, later, the embryo, sinee the latter reposes upon the proportionately much larger yolk-sac. As the contents of the sac become absorbed, the latter shrinks, the splanchnopleuric layer slipping into the abdomen of the embryo through the umbilical opening, the somatopleuric layer contracting to close that aperture.

In the Amniota-that is, in reptiles, birds, and mammalsthe development and structure of the yolk-sac are modified by the presence of the amnion. In these groups the umbilical vesiele and the gut-tract are produced out of the cavity of the archenteron by the folding-in of the splanehnopleure alone, since the formation of the amnion-fold by the somatopleure carries the latter structure away from the splanchnopleure and prevents its forming a complete investment for the yolk-sac, although covering it in part (Plate II., Fig. 4).

Sinee the yolk-sac contains the store of food destined for the nutrition of embryos that develop outside of the maternal body, and since the mammalian embryo, which leads an intrauterine existence, is endowed with a relatively small quantity of such store, the yolk-sac of mammals would seem to indicate the descent of the latter from oviparous ancestors. Further and stronger cvidence of such descent is found 
in the fact that the eggs of the lowest order of mammals, the Monotremata, comprising the echidna and the ornithorhynchus, are "laid" and undergo extra-uterine development.

In the human embryo the umbilical vesicle is found partially constricted off from the intestinal canal by the end of the second week; by the end of the third week the separation of the two cavities has advanced to such an extent that the vitelline duct is present, the sac attaining its maximum size by about the fourth week.

The function of the umbilical vesicle, as above intimated, is to serve as the organ of nutrition for the embryo during a certain period. The manner in which its blood-vessels develop will be considered in treating of the vascular system. Their growth precedes that of the intra-embryonic portions of the vascular apparatus, the vascular area of the yolk-sac being the seat of the earliest blood-vessel formation. The vessels find their way into the body of the embryo along the vitelline duct, and consist of two vitelline arteries and two vitelline veins.

With the development of the allantois the yolk-sac retrogresses, the allantois succeeding it as the organ of nutrition and respiration. By the end of the sixth week the sac has shrunk to a narrow stalk, which is surrounded by the enlarged amnion, and which terminates in a knob; at birth, the knob lies near the placenta (Plate IV., Fig. 2), and the atrophic remnant of the stalk is one of the constituents of the umbilical cord.

\section{THE ALLANTOIS.}

The allantois is an embryonic structure which is found in those vertebrates possessing an amnion. Its growth is correlated with the retrogression of the umbilical vesicle, which structure it supplants as the organ of nutrition and respiration for the embryo.

Appearing at first as a little evagination or out-pocketing of the ventral wall of the gut-tract, the allantois finally becomes a pedunculated sac lying in the extra-embryonic part of the coelom (Plates II. and III.), its stalk leaving the 
PLATE III.

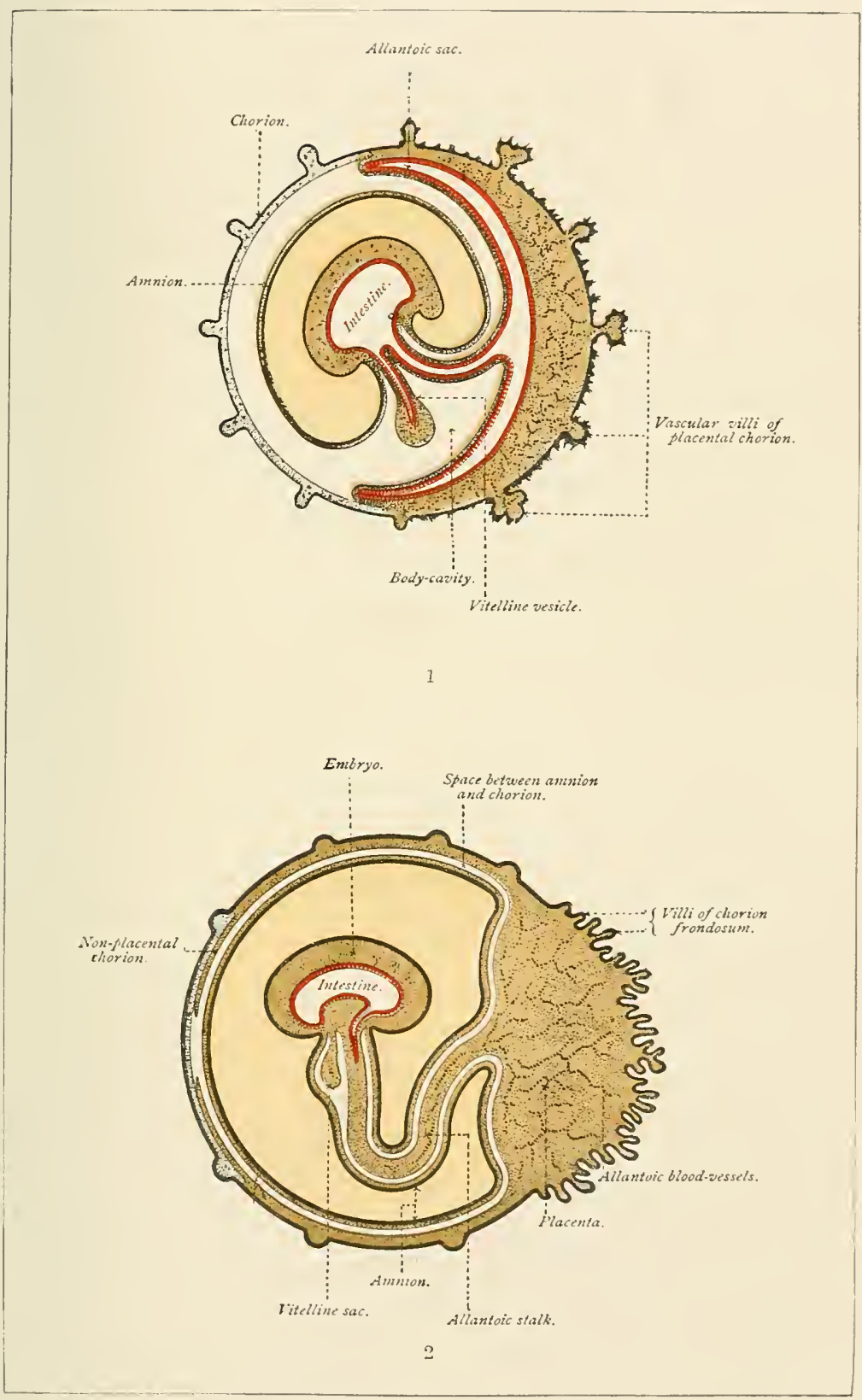

Diagrans illuntrating the later stages of the formation of the mammalian fetal membranes moditied from koule). 

body-cavity proper through the umbilical opening. Being an outgrowth from the intestinal canal, the walls of the allantois are made up of splanchnopleure-that is, of entoderm and visceral mesoderm. Blood-vessels develop in the mesodermic stratum, the principal trunks, the two allantoic arteries and veins, being connected at their proximal ends with the primitive heart; this system of ressels constitutes the allantoic circulation and is the avenue through which the growing embryo is supplied with mutritive material and oxygen. As the fundus of the allantois increases in size, it spreads itself out upon the inner surface of the false amnion (Plate III., Fig. 1), into whose villi its vascular tissue penetrates, and with which it becomes intimately blended. The union of the allantois and the false amnion produces the true chorion.

The human allantois presents a striking peculiarity as compared with that of birds and reptiles; in man, the allantois
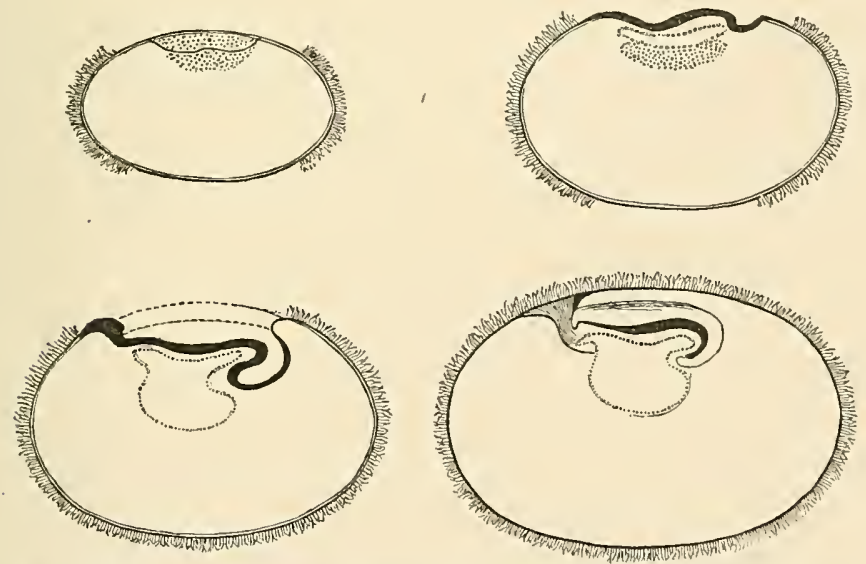

FIG. 38.-Diagrammatic sections representing growth and arrangement of the amnion in the earliest stages of the human embryo (His).

develops not as a free sac projecting into the extra-embryonic borly-cavity, but as a mass of splanchnopleuric tissue which contains only a rudimentary cavity and which grows into the abdominal stalk (Fig. 38 and Fig. 47, bst), being guiderl by that structure to the filse amnion. 
The function of the allantois is to serve as a nutritive and respiratory organ until the formation of the placenta, its period of activity extending from about the fifth or sixth week to the thirr month; it also eonstitutes a reeptacle for the fetal urine.

The part of the allantois contained within the body of the embryo produces three structures of the adult organism: 1 , the urachus, an atrophic cord extending from the summit of the bladder to the umbiliens $;^{1} 2$, the urinary bladder; and 3 , the first part of the urethra of the male, or the entire female urethra. The extra-embryonic portion shrinks after the appearance of the placenta and forms one of the constitnents of the umbilical cord, its blood-vessels becoming the umbilieal arteries and veins.

\section{THE CHORION.}

At the time when the false amnion is forming, the zona pellucida, very much thinned-out, still surrounds the embryonic vesicle, forming the so-called prochorion. The prochorion unites with the false amnion, producing the primitive chorion. After the allantois has grown forth from the guttract and has spread itself over the inner surface of the primitive ehorion, it becomes blended with the latter. to eonstitute the true chorion. The chorion may then be defined as the membrane which encloses the germ at the stage following the appearance of the amnion and the false amnion, and which has resulted from the fusion of the allantois with the primitive chorion ; or, ignoring the presence of the zona pellucida, the chorion results from the fusion of the allantois and the false amnion. ${ }^{2}$ The chorion consists of an outer ectodermic layer, an inner entodermic stratum, and an intermediate lamella of mesodermic tissne contributed conjointly by the allantois and the false amnion.

'If the urachus remains patulous, instead of becoming impervious, urine inay escape at the umbilicus, and the condition is a variety of urinary fistula.

${ }^{2}$ Minot defines the elorion as all that part of the extra-embryonic somatopleure which is not used in forming the true annion. 
The surface of the chorion is beset with numerous little projections-the villi-a very early development of which is characteristic of the human chorion (Fig. 39 and Plate II., Fig. 6). At first the villi, either covering the entire surface
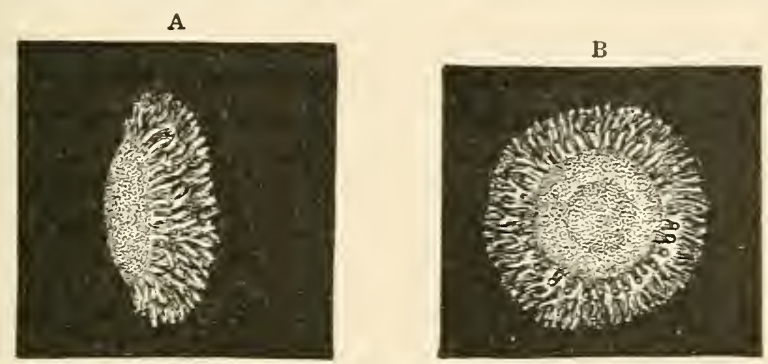

FIG. 39.-Human orum of about twelre days (Reichert): $A$, side view; $B$, front view. The villi are seen to be limited in distribution, leaving the poles free.

of the chorion or leaving the two opposite poles free, are of uniform size; at the beginning of the third month, howerer, there begins to be a differentiation into a region containing smaller, and one having larger, projections. The difference between the two areas beeoming more marked, the relatively smooth part of the membrane, possessed of rudimentary villi, is designated the chorion læve, while the region provided with well-dereloped villous projections is distinguished as the chorion frondosum (Plate III., Figs, 1 and 2); the latter acquires a close relation with the mueous membrane of the uterus and becomes the fetal part of the placenta. The villi in their earlier condition are somewhat club-shaped elevations, which later become branched. Each villus consists of a core of mesodermie tissue, covered with epithelium and containing lolood-ressels (Plates II. and III.). Their microscopic appearance is so characteristic that they afford a means of positively determining whether a mass discharged from the uterus is or is not al product of conception.

The blood-vessels of the chorion are derived from the allantois, whose vessels penetrate into the villi already present on the serosa when the two structures come in contact.

A chorion is present, ats a rule, in those animals whose embryos develop within the uterus; this would include the 
entire class Mammalia, with the exception of the lowest order, the monotremes, whose eggs undergo extra-uterine development, and the marsupials, whose embryos, though nourished in the womb, never acquire villi on the serosa, nutriment being absorbed by simple contaet of the latter with the uterine mucous membrane. The Mammalia are therefore divided into two groups, one, the Achoria, comprising the monotremes and marsupials; the other, the Choriata, ineluding all other mammals. 
CHA PTER VI.

\section{THE DECIDUAE. THE PLACENTA. THE UMBILICAL CORD.}

\section{THE DECIDUAE.}

THE deciduæ, or the deciduous or caducous membranes, are the hypertrophied mucosa of the nterus' so developed as to form not only a lining for the uterine carity, but also an envelope enclosing the orum, and a sprecially thickened part which serves as a bond of connection between the ovum and the womb.

During the four or five days preceding menstruation, the socalled constructive stage of the menstrual cycle, the mucous membrane of the womb becomes much thickened and unnsually vascular, the purpose of these changes being evidently the preparation of the nterus for the reception of the orum in the crent of impregnation. If impregnation has not occurred, the thickened mucosa, the decidua menstrualis, is in great part cast off as a part of the menstrual discharge; if, on the other hand, conception has taken place, the muenus membrane undergoes still greater hypertrophy. On section, it is seen to consist of a super-

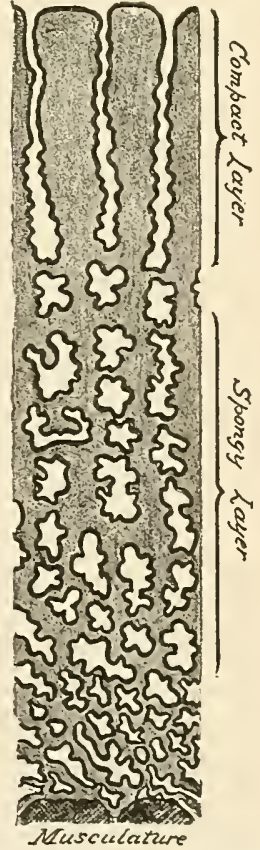

Fig. 40.-Cross seetion through the mucous membrane of the uterus at the beginning of pregnancy (after Kundrat and Engelmann). 
ficial compact stratum and a deeper spongy layer reposing directly upon the muscular wall of the uterus. In the compact layer are the necks of the much enlarged uterine glands, while in the spongy layer are their greatly branched and often tortuous bodies (Fig. 40). The tortuosity and division of the deeper extremities of the glands produce the characteristic appearance of a section of the spongy stratum.

The alterations necessary to convert the menstrual decidua into the deciduæ of pregnancy take place while the orum is still in the Fallopian tube; when it reaches the uterus it becomes attached to the mucous membrane of the latter, usually along the upper part of the posterior wall toward one or other side of the median line. The mucous membrane grows up around, or is said to be reflected over, the ovum, so as to enclose it in a distinct envelope (Fig. 41). The part of

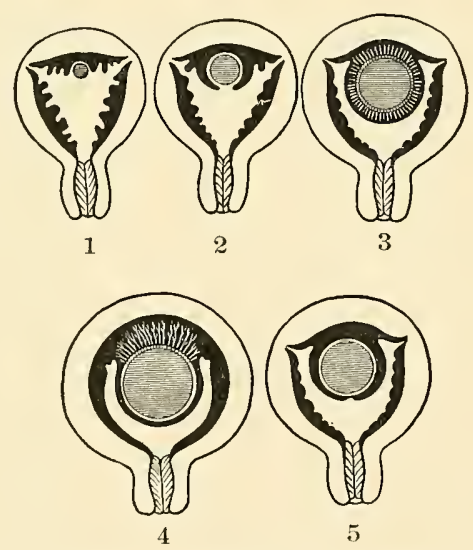

FIG. 41--Series of diagrams representing the relationship of the decidua to the ovum at different periods. The deciduæ are colored black, and the ovum is shaded transversely. In 4 and 5 the vascular processes of the chorion are figured (copied from Dalton). 1, ovum eutering the congested mucous membrane of the fundusdeciclua serotina; 2 , decidua reflexa growing around the ovum: 3 , eompletion of the decidua around the ovum; 4 , general growth of villi of the ehorion; 5 , special growth of villi at placental attachment, and atrophy of the rest.

the uterine mucosa which is reflected around the ovmm is the decidua reflexa; the part still lining the eavity of the womb is the decidua vera; the part that is in contact with the chorion frondosum is the decidua serotina. The decidua 
serotina afterward becomes the maternal part of the placenta, intimately uniting with the chorion frondosum.

The ciliated epithelimm of the uterine mucous membrane disappears by the end of the first month of pregnancy (Minot); somewhat later, that of the uterine glands is also lost. By the end of the fifth month the fetus and its appendages have increased in size to snch an extent that they completely fill the carity of the womb, and the space between the decidua vera and the decidua reflexa is obliterated. After the fifth month the pressure of the growing fetus induces regressive changes in the decidna rera and the decidua reflexa. These consist chiefly in the obliteration of the gland-cavities, the alteration of the cells from the columnar type to the cubical or flattened form, and a great decrease in the thickness of the membranes as a whole. At the end of pregnancy the vera and reflexa are closely blended with the chorion. After birth the membranes are cast off, separation taking place in the spongy layer, the deeper part of which latter remains to form a new mucosa.

\section{THE PLACENTA.}

The placenta, in certain groups of mammals, including man, is the organ of nutrition for the fetus during about the latter two-thirds of the period of gestation. In its most highly dereloped form it is a discoid structure attached by one surface to the wall of the womb and connected on its opposite aspect with the fetus through the medium of the umbilical cord.

The human placenta represents the highest specialization of an apparatus for bringing the fetal blood into intinate relation with the blood of the mother. In eggs that develop ontsicle of the body of the mother, snch as those of reptiles, birds, and the lowest ordel of manmals, the Monotremata, the growing embryo necessarily acquires no connection with the uterine mucous membrane, but draws npon its original dower of mutriment, the deutoplasm, until its derelopment is completed, when it breaks through the shell and secks its own fond; in these groups the false ammion does not develop 
villi. In the marsupials, a group of mammals one stage higher than the monotremes, the ovum, although developing in the uterus, forms no close connection with it, but obtains its nourishment by simple imbibition from the nterine mucous membrane. On the other hand, in all mammals higher than monotremes and marsupials, the false amnion, as previously shown, fuses with the allantois to form the chorion, a membrane distinguished by the presence of villi upon its surface.

The chorionic villi become highly developed in a certain region, constituting the chorion frondosum, which, uniting with the decidua serotina, contributes to the formation of the placenta. Between the human placenta and the smooth nonvillous false amnion of the marsupials, certain definite graditions exist; for example, in pigs, whales, and some other groups, there is no proper placenta, the villi being evenly distributed over the surface of the chorion; while in ruminants (the cow, sheep, deer, etc.) the villi are gromped into little clusters or tufts callerl cotyledons, which are easily detachable from the mueous lining of the womb. Owing to this loose connection, the uterine nucous membrane is nondeciduous-that is, it is not east off after the birth of the young. The foregoing clisses are therefore styled Mammalia indeciduata, in contradistinetion to the Mammalia deciduatacomprising man, rorlents, apes, bats, and Insectivores-in which there is a loss of the greater part of the mneous membrane of the womb after the expulsion of the fetus. In the Carnivora the placenta has the form of a zone or ringplacenta zonaria-while in man and certain allied mammals, as apes, rodents, and some others, it is diseoid in shapeplacenta discoidea.

The human placenta is formed in the third month of pregnancy by the mion of the chorion frondosum with the decidua serotina; it eonsists, therefore, of a fetal and a maternal part. The organ is discoid in form (Fig. 42, and Plates III. and IV.). Its uterine surface (Fig. 42) is divided into tufts or cotyledons; the fetal surface is somewhat concave and is covered by the loosely adherent am- 
Plate IV.

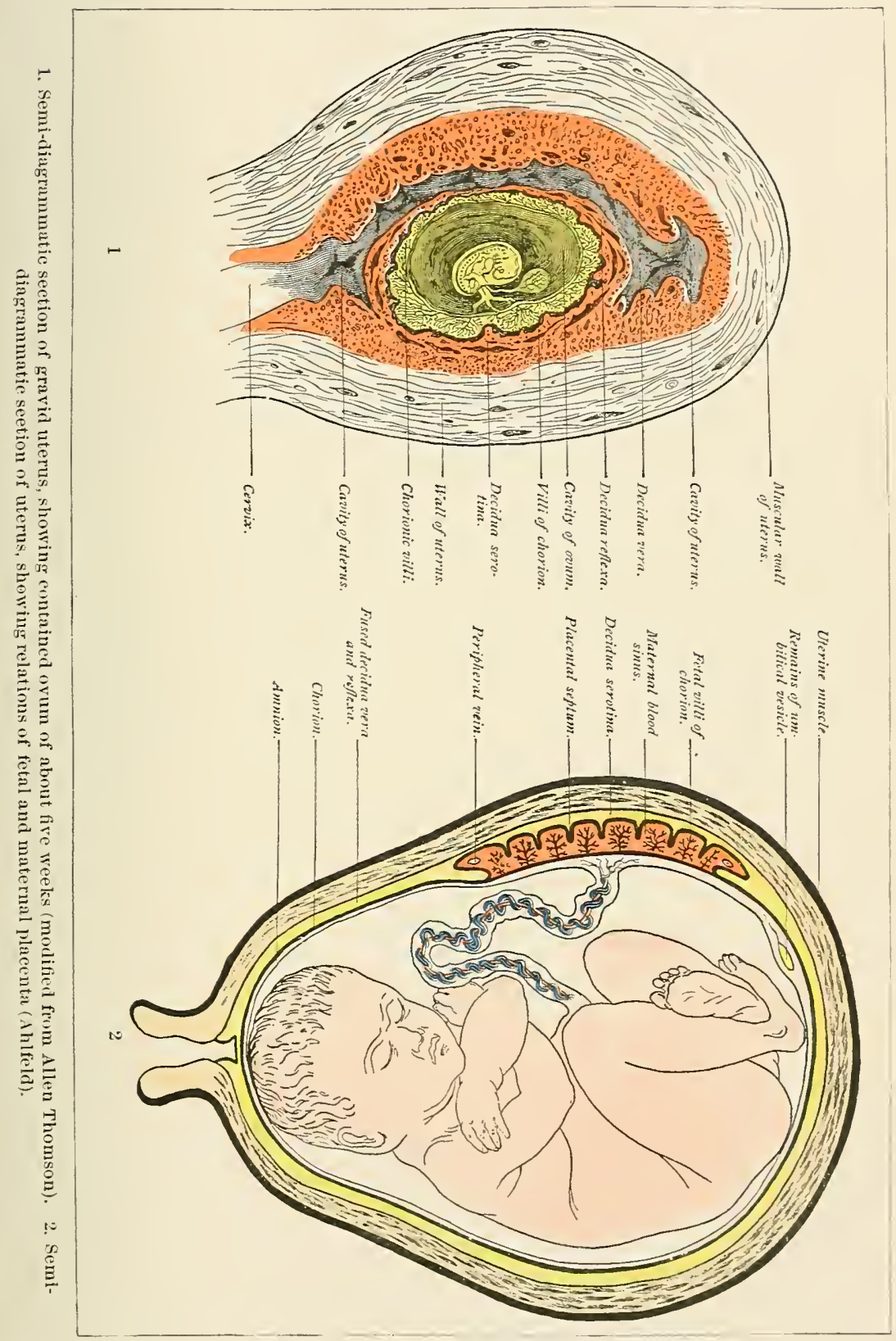



nion. 'To some point on the latter surface, usually not its center, the umbilical cord is attached, by the vessels of which the fetal blood is conveyed to and from the placenta. The diameter of the mass is from 15 to 20 centimeters, aud its thickness is from 3 to 4 centimeters. The fetal part of tho plicenta (Plate $\mathrm{V}$.), constituted by the chorion frondosum,

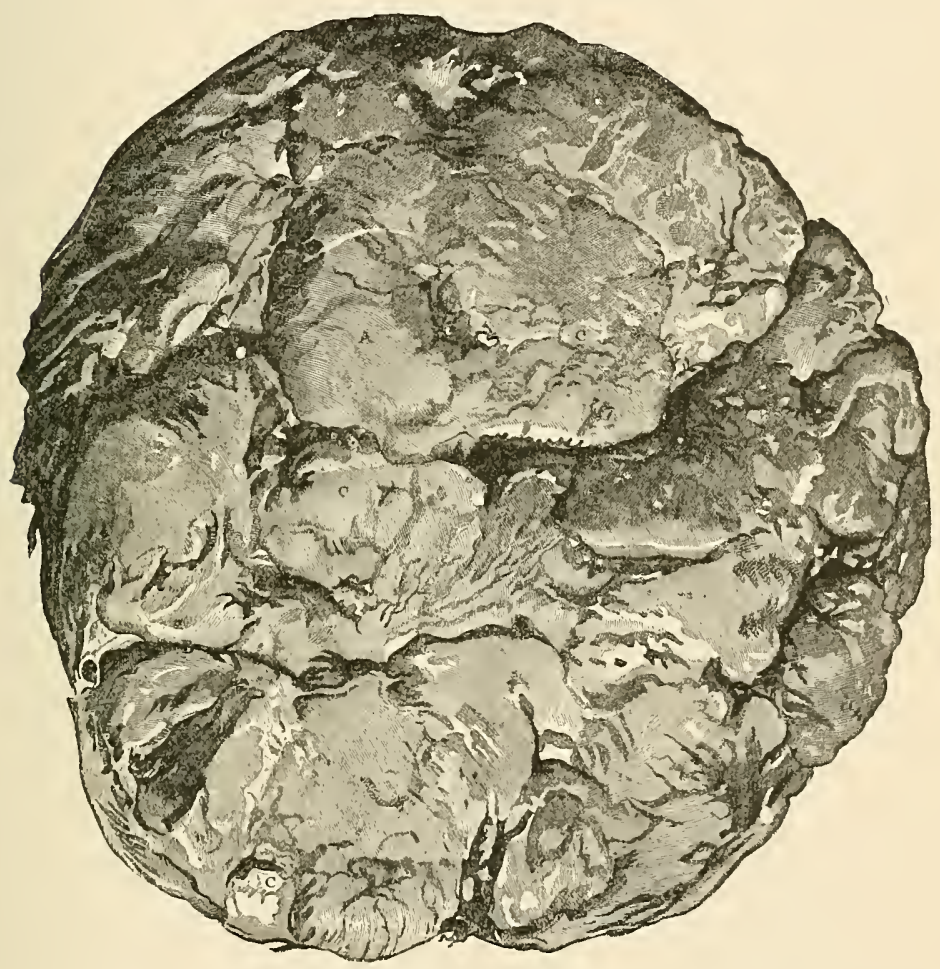

Fig. 42.-Placenta riewed from uterine surface of attachment, showing divisions into cotyledons (Bidloo).

consists of highly developed villi situated upon the membiana chorii. Each villus contains a core of gelatinous connective tissue and numerous blood-ressels and is beset with secondary villi. Blood is conveyed to the villi by the umbilical or allantoic arteries and is returned from them to the fetus through the umbilical vein. The maternal part of the pla- 
centa, the decidua serotina (Plate V.), exhibits a deeper spongy layer and a superficial compact stratum. In the compact region are cavities, the placental spaces, which are separated from each other by the septa placentæ, and into which dip the villi of the placenta fetalis. These spaces must be looked upon as the greatly dilated capillaries of the decidua serotina (Waldeyer, Keibel); they are lined by endothelial cells, and into them is poured the blood of the uterine arteries. The villi, projecting into the spaces, are bathed in the maternal blood, and thus the blood of the mother, containing oxygen and nutriment, is brought into intimate relation with the blood of the child (Fig. 43). It should be especially noted, how-

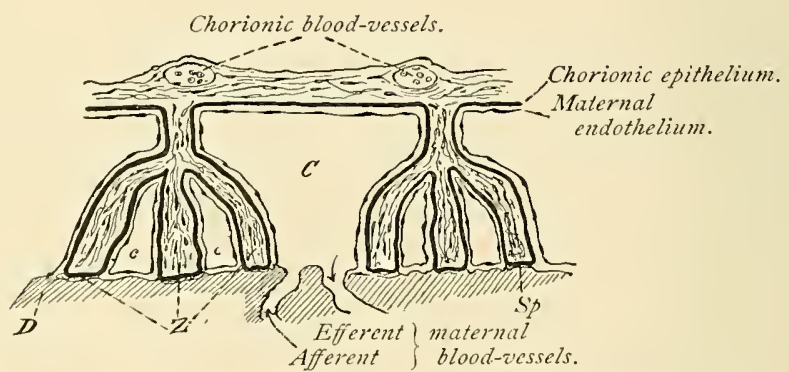

FIG. 43.-Diagram of the structure of the human placenta from an embryo four weeks old (after Kiebel): $Z$, ehorionic villi; $S p$, attacnment of tips of the same in the maternal decidua $(D)$; $C$, cnlarged nuternal blood-capillaries.

ever, that there is no intermingling of the respective bloodcurrents, since the two fluids are separated by the single layer of cells forming the walls of the capillaries of the villi. In the early stages of the development of the placenta, the earities resulting from the enlargement of the eapillaries of the serotina are separated from the chorionic villi by the most superficial part of the decidua as well as by the enclothelium of the spaces themselves; owing, however, to the compression exerted by the growth of the fetus and its appendages, this intervening decidual tissue and, later, the endotheliun atrophy and disappear, so that the spaees are bonnted on the side toward the fetus lyy chorion and villi alone. $\Lambda$ t the periphery of the maternal placenta is a venous chanmel, the marginal 

sinus or vein; this is not a vein in the proper sense of the word, but a series of communicating spaces.

The site of attachment of the placenta to the uterus is usually the upper part of the posterior wall, to one or other side of the median line. Under certain circumstances it may become attached lower down, even extending partly or wholly over the moutl of the wonb; the latter constitutes the condition known as placenta prævia.

After the birth of the child, the placenta, in common with the decidua vera, becomes detached from the uterine wall and is expelled from the womb. The separation takes place in the deeper region of the deep or spongy layer of the serotina or maternal placenta. That part of the maternal placenta which still adheres to the placenta foetalis is the basal plate of Winkler (Plate V.).

\section{THE UMBILICAL CORD.}

The blood-vessels through which the fetal blood finds its way from the fetus to the placenta and back again to the fetus, together with the atrophic vestiges of certain structures associated with the development of these vessels, constitute the structure known as the umbilical cord. In considering the growth of the human allantois it was pointed out that the latter structure, as it grows from the ventral wall of the guttraet into the so-called allantoic or abdominal stalk, becomes the seat of development of the two allantoic arteries and of an equal number of allantoic veins. With the metamorphosis of a part of the chorion into the placenta, the abdominal stalk becomes more slender and at the same time much elongated, and the allantoic blood-ressels are henceforth the umbilical vessels. The two umbilical veins fuse, so that, at birth and for some time before, there is but one vein, though there are still two arteries. The umbilical vein, entering the body of the fetus through the umbilicus, passes directly to the under surface of the liver, where it unites with the fetal portal rein and gives off a branch of communication, the ductus venosus, to the inferior vena cava, after which it enters the liver through the transverse fissure. 'The umbilical 
arteries, whose intra-embryonic portions are called the hypogastric arteries, are the direct continuations of the superior resical arteries of adult anatomy. They leave the body of the fetus at the umbiliens.

The umbilical cord, while consisting essentially of the three blood-vessels mentioned, contains also the remnant of the allantoic stalk and of the umbilical vesicle, these structures being surrounded and held together by a quantity of embryonic connective tissue, the jelly of Wharton, which makes up the chief part of the mass of the cord; upon the surface is a layer of epithelium, continuous, at the distal end of the cord, with the epithelium of the amnion.

The umbilical cord has an arerage length of $55 \mathrm{~cm}$, or 22 inches, but varies between the extremes of $15 \mathrm{~cm}$. ( 6 inches) and $160 \mathrm{~cm}$. (6t inches); its thickness is abont $1.5 \mathrm{~cm}$. ( $\frac{2}{5}$ inch). The cord presents the appearance of being spirally twisted; it is probable, however, that the appearance of torsion is conferred by the spiral or coiled arrangement of its arteries, due to their excessive growth, rather than by a twist of its entire mass. There may be one or more true knots in the cord, produced by the slipping of the fetus through a loop.

The position of attachment of the cord to the placenta is usually near, but seldom exactly in, the center of the fetal surface of that organ; rarely it may be found attacherl to its edge, and still more rarely to the fetal membranes themselves at some little distance from the edge of the placenta, with which, in the latter ease, it is connected by its bloodvessel:.

The great length of the human umbilical eord is thought to be due to the relatively large quantity of amniotic fluid present in the human sulject.

After birth, the portions of the hypogastric arteries extending from the upper part of the lateral wall of the bladiler to the umbilicus undergo atrophy, becoming impervions fibrous cords; the intra-abdominal part of the umbilical vein likewise becomes atrophic and impervious, constituting the so)-called round ligament of the liver. 


\section{CONDITION OF THE FETAL MEMBRANES AT BIRTH.}

When the quantity of the amniotic fluid reaches its maximum degree-at about the end of the sixth month-it requires so much space that it presses the amniotic membrane everywhere closely against the chorion, which latter, covered by the decidua reflexa, is in turn forced into intimate relation with the decidua vera (Plate IV.). By the end of gestation the vera, reflexa, and chorion have become practically one membrane, since their union is so firm that it is impossible to separate them. The amnion, while adhering to the inner surface of the chorion, is so loosely associated with the latter that it may be peeled off from it. The membranes, which constitute a fluid-filled sac surrounding the fetus, are ruptured by the contractions of the uterus at some time during parturition. Through this rent the child is forced during birth, the placenta and the membranes remaining behind. After the expulsion of the child, the decidua vera and the placenta detach themselves from the uterine wall, and, with the decidua reflexa, the chorion, and the amnion, constitute the after-birth, which is expelled shortly after the expulsion of the child. The separation of the after-birth takes place in the deeper region of the deep or spongy layers respectively of the decidua vera and of the nterine placenta. The thin stratum of the spongy layer remaining serves for the regeneration of the uterine mucosa. 


\section{CHA PTER VII.}

\section{THE FURTHER DEVELOPMENT OF THE EXTERNAL FORM OF THE BODY.}

Having traced the growth of the germ to the time when the body of the embryo becomes definitely differentiated from the embryonic appendages or fetal membranes, the development of the individual organs and tissues may be taken up. The discussion of this latter subject, especially of that part of it pertaining to the structures on the exterior of the body, involves a consideration of the external form of the embryo and fetus during the successive stages of growth.

In the preceding chapters it was pointed out that the cells of the segmented ovum arranged themselves in such a manner as to form a hollow sphere, the blastodermic vesicle (Plate I.); that this vesicle, having at first a single-layered wall, came to consist of two layers of cells, the ectoderm and the entoderm; and that, finally, a third, intervening layer, the mesoderm, made its appearance. It was shown, further, that the thickened portion of the vesicle wall, the embryonic area, became more and more differentiated from the remainder, and that, by eertain processes of folling, this area was made to assume the definite form of the embryonic body, while from the other parts of the vesicle-walls the fetal membranes were produced (Plate II.). It may be well to remind the reader again that when the body of the embryo has become closed off from the fetal membranes, this body is an irregularly tubular structure whose walls are the somatoplenre and whose enclosed space is the body-cavity, and that within it are two other tubes, a larger, the gut-tract, formed by the splanchnoplenre, and a smaller ectodermic tube, the nenral canal.

While, as a matter of convenience, the description of 
the individual organs is taken up after tracing the course of development to this stage, it should be borne in mind that the rudiments of some of them are already distinguishable before the germ-layers become infolded to form the body-wall and the gut-tract. It will facilitate a comprehension of the general principles concerned in the origin of the different parts of the body to refer to the tabulated statement of the derivatives of the three primary germ-layers as presented in Chapter III.

In considering the external form of the product of conception, one may adopt the classification of His, referred to in the first chapter. This anthor divides the period of development into three stages, of which the first, the stage of the ovum, or the blastodermic stage, comprises the first and second weeks of intra-uterine growth; the sccond, the stage of the embryo, extends from the second to the fifth week; and the third, or the fetal stage, includes the time between the fifth week and the end of gestation.

THE STAGE OF THE OVUM.

During the fortnight allotted to this first stage of development occur the various changes by which the impregnated

A

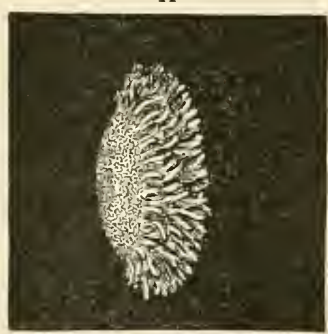

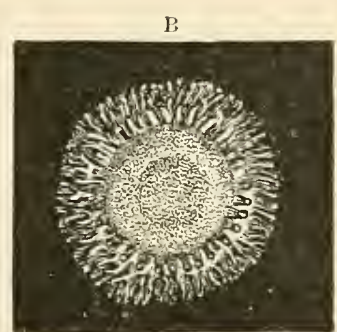

FIG. 44.-Human ovum of alout twelve days (Reiehert); A, side view; B, front riew. The villi are seen to be limited in distribution, leaving the poles free.

orum aequires the form of a hollow sphere, designated the cmbryonic or blastodermic vesicle. The series of transformations has been deseribed in Chapter IT. In this place it will be sufficient to refer to the extermal characters of the blasto- 
dermic vesicle as depicted in Fig. 44, which represents the ovum deseribed by Reichert. This ovum was estimated to be about twelve days old and was probably the youngest human orum ever described. Its form was that of a sphere somewhat flattened, its short and long diameters measuring respectively $3.3 \mathrm{~mm}$. and $5.5 \mathrm{~mm}$. The flattened surfaces were smooth, while the equatorial zone was beset with villi. The early appearance of villi is charaeteristic of the human ovum.

\section{THE STAGE OF THE EMBRYO.}

It is during the early part of the second stage, at about the fourteenth day, that the somatopleuric layer of the blasto-

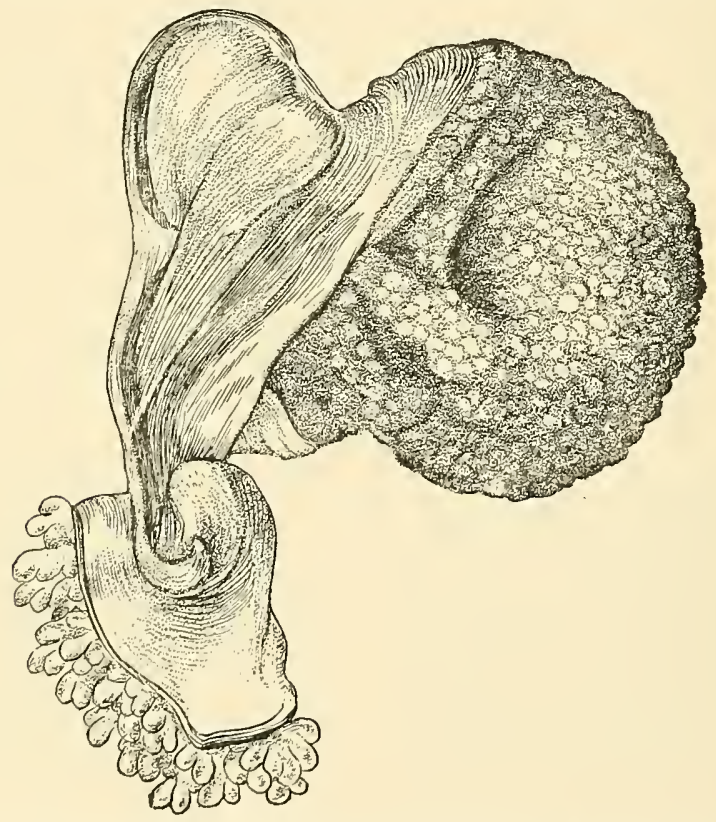

FIG. 45.-Human embryo of about the thirteenth day (His). The caudal pole of the embryo is connected with the blastodermic vesicle by means of the abdominal or allantoie stalk; the amnion already eompletely eneloses the embryo, and the large vitclline sac communieates throughout the greater part of the mitral surface by means of the unclosed gut-tract.

dermic vesicle becomes folded in to produce the walls of the cmbryonic body. Fig. 46 shows a human embryo of about 
the fifteenth day, whose form is as yet imperfectly differentiated, the ventral wall of the body being incomplete, since the gut-tract is still in communication with the umbilical vesicle throughout almost the entire length of the embryo. The back and sides of the embryo are enveloped by the amnion, and the dorsal outline is concave. The caudal pole

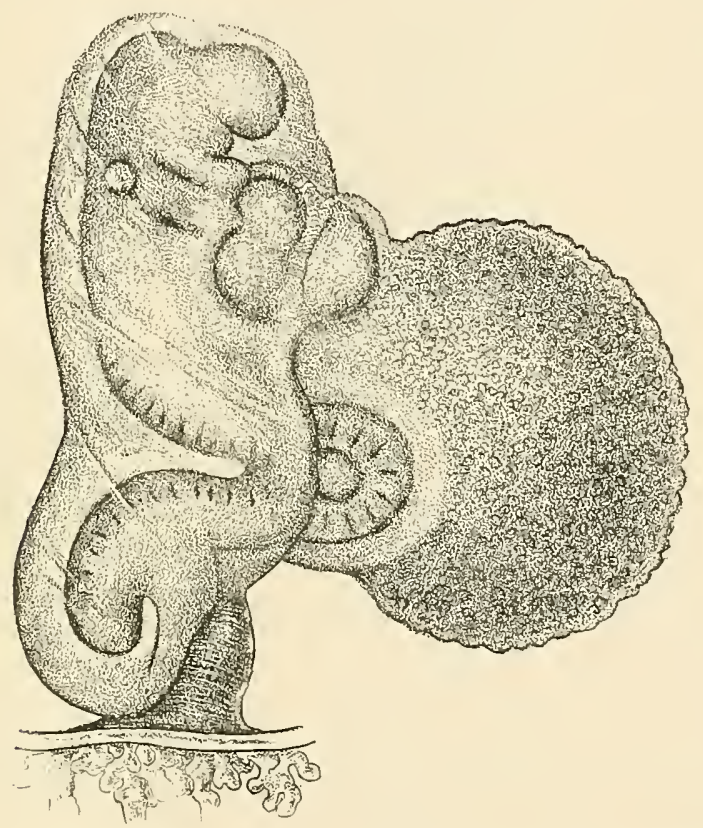

FIG, 46.-Human embryo of about the fifteenth day (His). The embryo is attached to the wall of the blastodermic vesiele by means of the umbilical or allantoic stalk, and is enclosed within the amnion; the large vitelline sac freely communicates with the still widely open gut.

is seen to be comnected by means of the allantoic stalk with the primitive chorion, which latter structure, however, is not represented in the figure. The concavity of the chorsal ontline is peenliar to the human embryo of this stage. The development of the head is elosely associated with the dilatation of the cephatic end of the nenral tube and the subsequent division of this dilated extremity into the three primary brain-resicles, the fore-brain, the mid-brain, and the hind- 
brain. The oral pit, the first indication of the future mouth, is present in the early part of this stage; it is a depression between the prominent fore-brain vesicle and the cardiac dilatation (Fig. 47).

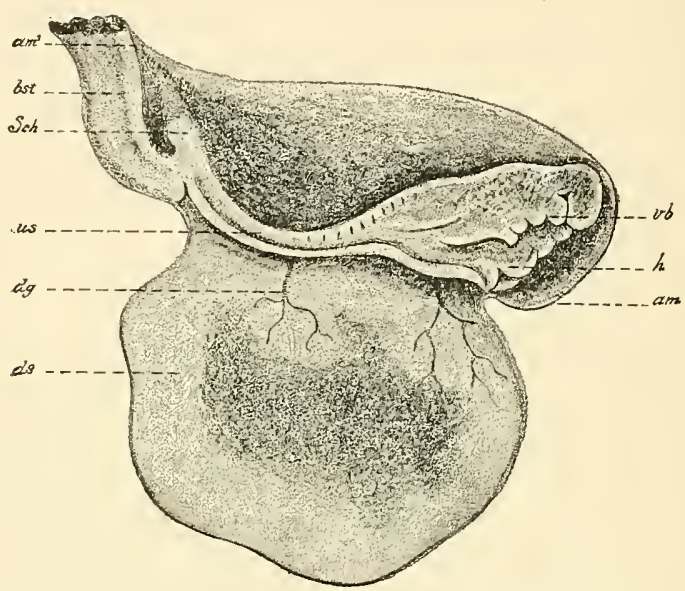

Fig. 47.-Humau embryo with yolk-sac, amnion, and belly-stalk of fifteen to eighteen days (after coste). The chorion is detacherl at $a m^{\prime}: a m$, amnion; $a m^{\prime}$, the point of attachment of the amnion to the chorion drawn out to a tip; bst, bellystalk; Sch, tail-end; $u s$, primitive segment; $d g$, vitelline blood-vessels; $d s$, yolksac; $h$, heart ; $v b$, visceral areh.

Between the fifteenth and the twenty-first day, the lensvesicles and the otic vesicles are formed by invaginations of the surface ectoderm (Fig. 48, 7 and 8), these saes being the rudiments respectively of the erystalline lens and of the membranous internal ear; at this time also the visceral arches and clefts first become distinguishable. On the twenty-first day, the rudiments of the limbs appear as little bull-like processes springing from the trumk. The eonspieuous projection on the ventral surface between the now almost eompleted yolk-sie and the eephalie end of the borly is produced by the primitive heart (Fig. 48, 10, 11, and 12).

Until the twenty-first day the embryonic body is erect. Between the twenty-first and twenty-third day's a marked alteration in the appearance of the germ is brought about by a pronounced bending of the long axis of the embryonic 

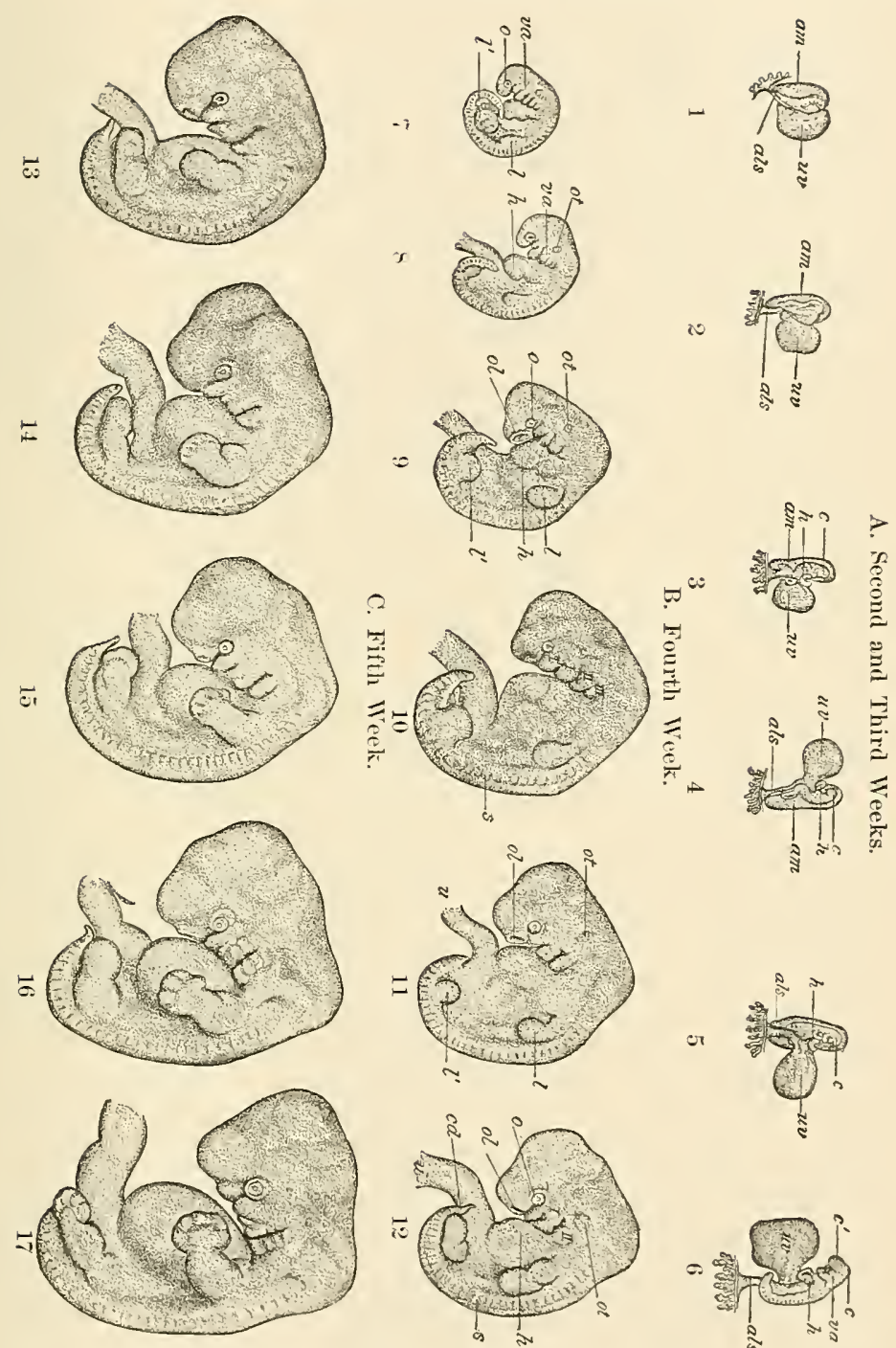

Fig. 48.-Early human embryos, all enlarged ubout two and a half times (His): $1-4$, from twelfth to fifteenth day ; 5,6 , from eighteenth to twenty-first day : 7,8 , from twenty-third to twenty-tiftl day; ?-12, from twenty-seventh to thirtieth day; 13-17, from thirty-first to thirty-tourth day. am, amnjon; $u 2$, umbilical or vitelline vesicle; als, allantoic or abdominal stalk; $c, c^{\prime}$, brain-resicles; $h$, heart ; $a$, visceral arehes; $o$, optie vesicle; $o t$, otie vesiele; ol, olfactory pit; $l, l$, upper and lower extremities; $s$, somites ; $c d$, caudal process; $u$, primitive umbilical cord. 
body (Fig. 48). The degree of eurvature is such that the caudal and cephalic extremities overlap. The flexion reaches its maximum degree by the twenty-third day. The curved dorsal outline is referable to four well-marked flexions, the position of the most anterior, or cephalic flexure, corresponding to that of the future sella tureica and being indicated by the projection of the mid-brain vesicle (Fig. 51, III.) ; at this point the anterior part of the head is bent almost sufficiently to form a right angle with the posterior half. A second or cervical flexure is found in the future neck-region, while further caudad are seen the less pronounced dorsal and coccygeal curves.

The fourth week marks the period of the most active growth of the embryo. After the twenty-third day, the body as a whole uncoils somewhat, although in the latter half of the fourth week the individual flexures noted above become more conspicuons.

The Visceral Arches and Clefts.-The visceral arches, with the intervening visceral clefts, constitute a conspicuous feature of the external appearance of the embryo during this stage. These arehes are a series of five approximately parallel ridges appearing upon each side of the future neck-region and extending obliquely downward and forward toward the ventral surfuce of the embryo (Figs. 49 and 51). The four furrows lying between the five viseeral arches are the visceral clefts. A coronal section of the neckregion (Fig. 50) - a section in a plane parallel with the ventral surface-shows that the furrows seen on the ectodermic surface correspond in position to a like number of deeper grooves on the inner or entodermic surface. The inner furrows are ont-pocketings of the entoderm lining the pharyngeal region of the fore-gnt; they are referred to as the pharyngyeal pouches or throat-pockets to distinguish them from the onter clefts. At the bottom of the clefts the ectoderm is in contact with the entorlerm, the mesoderm being absent; these two layers constitute the closing membrane. The visceral arehes or rirlges consist of thickened masses of mesodermic tissue covered outwarlly and inwardly respectively 


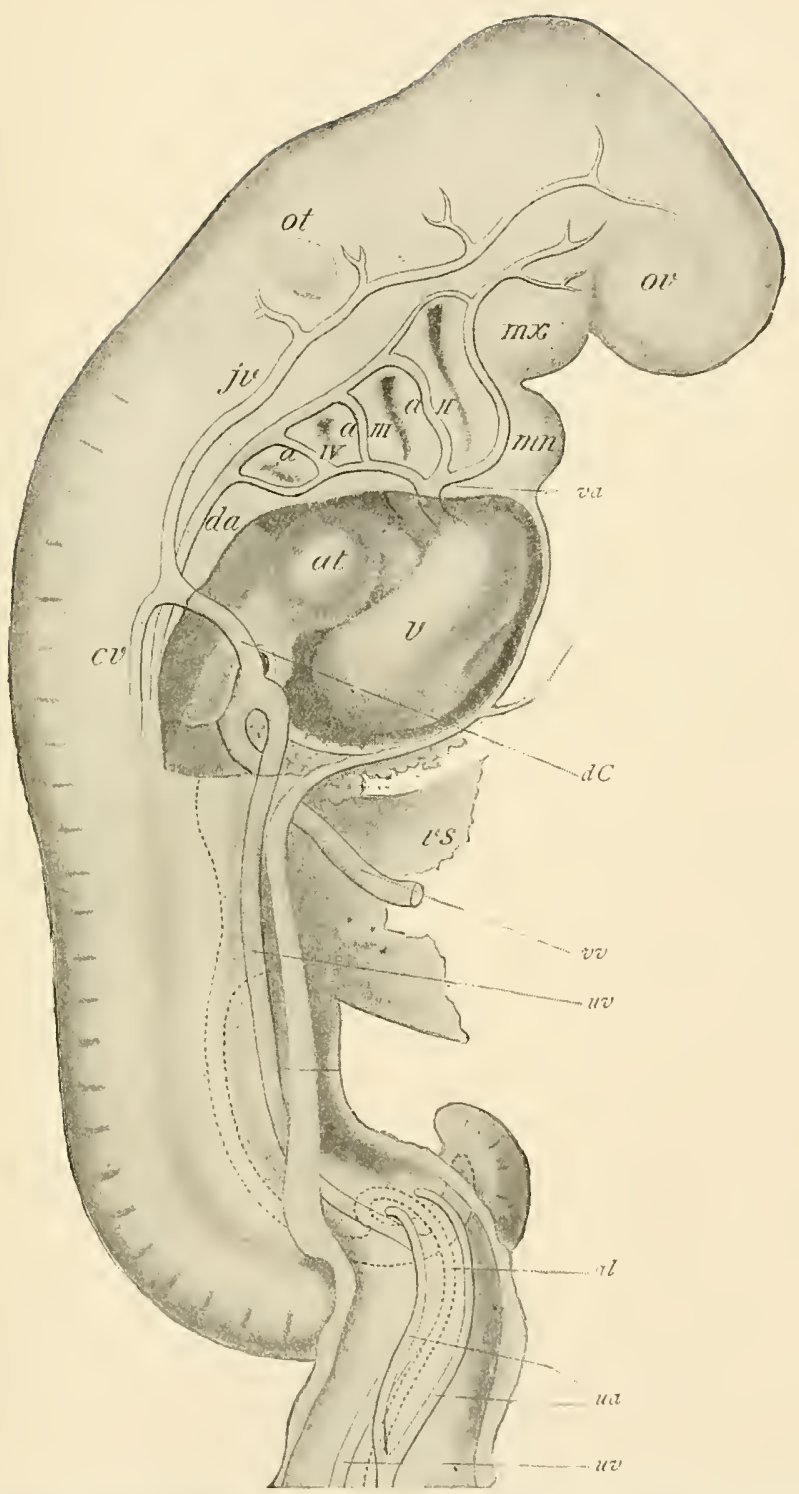

Fig. 49.-Human embryo of about three weeks, showing viseeral arehes and furrows and their relations to aortic arches (His): $m x, m n$, maxillary and mandibular processes of first viseeral areh : a $I-a I \mathrm{I}$, tirst to fourth aortic arehes; $j v, c a$, primitive jugnlar and eardinal veins ; $d C$, duet of Cuvier; $a t, v$, atrium and ventricle of primitive heart; $v s$, vitelline sae ; $v a$, da, rentral and dorsal aortx; $o v, o t$, optie and otic vesicles; $u v, u u$, umbilical veins and arteries; $v$, vitelline rein; al, allantois. 
by the ectoderm and the entoderm. Each arch contains an artery, the visceral-arch vessel. These five pairs of visceralarch vessels arise by a common stem, the truncus arteriosus, from the primitive heart. ${ }^{1}$

The morphological significance of the visceral arches and clefts may be appreciated by a comparison of the conditions
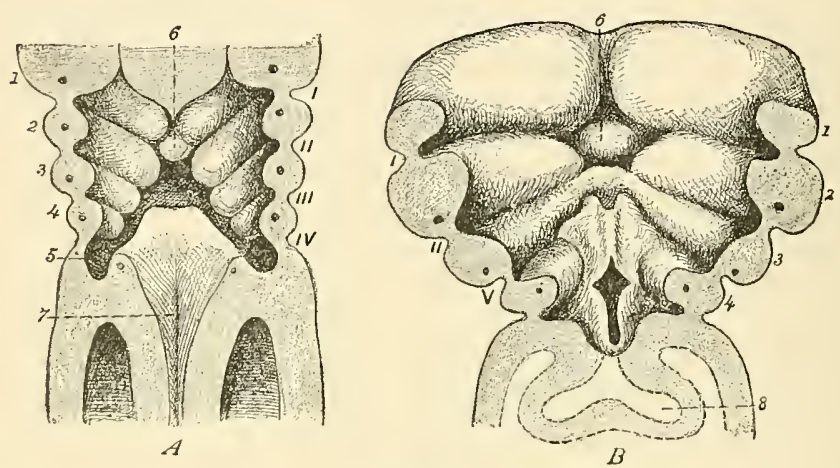

FIG. 50.-Coronal sections of two human embryos, showing ventral wall of pharyngeal end of gut-tract from behiud (from Tourneux, after His). $A$, from embryo of $3.2 \mathrm{~mm}$; $B$, of $4.25 \mathrm{~mm}$. (ubout 25 to 30 days). $I, I I, I I I, I \mathbf{J}$, outer visceral furrows; $V$, sinus præcervicalis, comprising third and fourth outer furrows; $1, \Omega, 3,4$, visceral arches, each with its visceral-arch vessel; 6 , tuberculum impar; 7 , orifice of larynx; 8 , pulmonary evagination.

obtaining in lower types. While in birds and mammals the number of the clefts is four, in reptiles, amphibians, and bony fishes, five elefts appear, and in some fishes (selachians) the number is six. In all aquatic vertebrates, the thin epithelial closing membranes rupture, thus establishing communications between the alimentary tract and the exterior, through which openings water passes in and ont. The margins of the elefts-cxcept the first or hyomandibular cleftbecome the scat of a rich supply of capillary blood-vessels, the blood of which obtains oxygen from the water and yields to the latter its carbon dioxid; while the visceral arches, excluding the first and second, become known in these classes as branchial arches from their producing bony arches which

${ }^{1}$ For an accomt of the metanorphosis of the visceral-arch vessels into the adult arteries of the throat and neck the reader is referred to Chapter $\mathrm{X}$. 
support the branchire or gills. With the exceptions noted, the visceral arches and clefts with their capillary plexuses therefore functionate in these classes as a respiratory apparatus.

When, in the course of evolution, certain of the vertebrates assume an aerial existence, in consequence of which they acquire a breathing meehanism adapted to such a morle of life, the respiratory function of the clefts or branchiae ceases, and they either disappear entirely or constitute mere? rudimentary structures of the adult. The so-called clefts in man are never actual openings, the closing membrane always being present (His, Kölliker, Piersol, Born). To express the morphology of the visceral clefts briefly, they are permanent structures in fishes and in tailed Amphibia; they are present during the larval stage of other Amphibia, while in birds and mammals they are found only in embryonic life.

The growth of the visceral arehes and elefts bears an intimate relation to the differentiation of the head- and the neckregions of the embryo. They first make their appearance at about the twenty-third day and attain their greatest development by the end of the fourth week. Both the arehes and the clefts appear earliest and are best developed at the cephalic end of the series, the fifth arch being exceedingly illdefined. During the fifth week the obliteration of the arches and elefts as such begins, since certain of them become metamorphosed into permanent structures while the remainder undergo regression.

The Metamorphosis of the Visceral Arches and Clefts.The first visceral arch becomes divided into an upper part, the maxillary arch, and a lower portion, the mandibular or jaw-arch (Fig. 51). The maxillary arches or processes of the two sides unite, at their anterior ends, with the intervening nasofrontal process (Fig. 56), and in this way is formed the upper boundary of the month-cavity; the mandibular processes become joined with each other anteriorly and constitute the inferior boundary of this cavity. The maxillary processes becone the superior maxills, while the mandibular processes become the lower jaws. The mesodermic core of 
104

TEXT-BOOK OF EMBRYOLOGY.

the mass of tissue constituting the mandibular arch divides into three sections, of which the two situated at the proximal

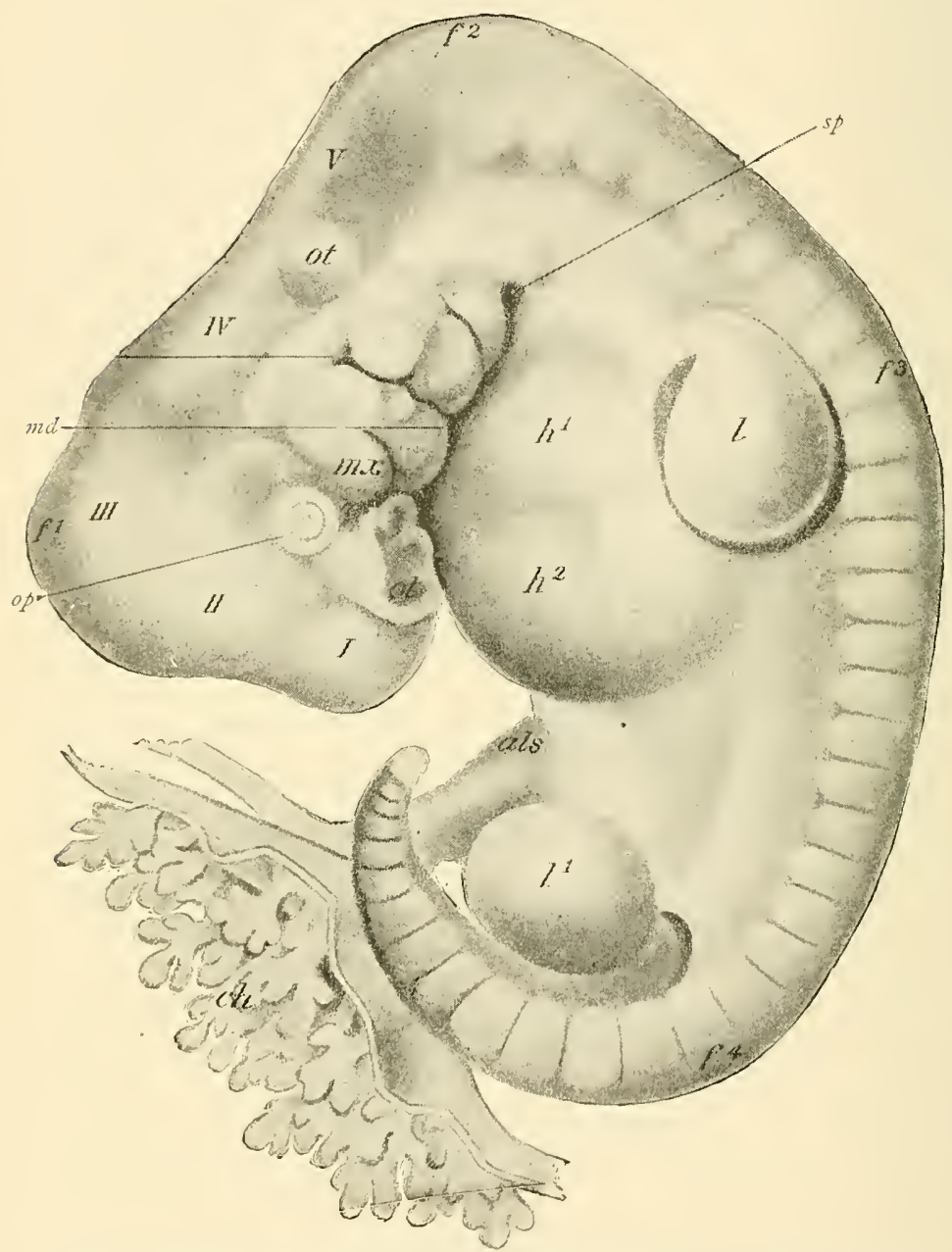

FIG. 51.-IJ oman embryo of about twenty-eight days (1 Iss) : I-1, brain-vesieles; $f^{1}, f^{2}, f^{3}, f^{4}$, cephalic, cervical, dorsal, and lumbar flexures; op, eye; ot, otic vestce; al, olfactory pit; $m x, m d$, maxillary and mandibular processes of first visceral arch; sp, sinus procervicalis ; $h^{1}, h^{2}$, heart ; $l, l^{1}$, limbs ; $a l s$, allantoje stalk; $c h$, vilJus chorion.

end of the arch are quite small and give rise respectively to the incus and the greater part of the malleus; the large distal 
segment is a slender cartilaginous rod, Meckel's cartilage, whose proximal extremity becomes the processus gracilis of the malleus (see Chapter XTITI.).

The second visceral, or anterior hyoid arch becomes obliterated as such, although a bar of cartilage which it containsReichert's cartilage_gives rise by its proximal extremity to the stapes, while the remaining portion becomes metamorphosed into the styloid process, the stylohyoid ligament, and the lesser cornu of the hyoid bone.

The third or posterior hyoid arch, which corresponds with the first branchial arch of fishes, likewise loses its identity as a surface marking, while the bar of cartilage it contains becomes the body and greater cornu of the hyoid bone.

The fourth and fifth arches coalesce with the adjacent tissues, producing no special struetures.

The first outer cleft, known as the hyomandibular cleft, suffers obliteration except at its dorsal extremity, where the tissues forming its margins produce the external ear. The remaining three outer clefts disappear in the following manner : the fourth outer cleft becomes covered and hidden by the fourth arch, and the third and second clefts are successively buried by the growth of the third and second arehes. The siuking-in of the lower arehes and clefts (Fig. 50) results in the formation of a fossa or fissure on the lateral surface of the neek, the sinus præcervicalis, (Fig. 51, sp) which subseqnently is made to disappear by the coalescence of its edges. Occasionally this sinus, instead of becoming completely obliterated, persists, and the thin layer of tissue forming its bottom ruptures-possibly spontaneously or perhaps more probahly as the result of explolatory probing-constituting the anomaly known as cervical fistula. Such a fistula establishes an opening into the esophatgus.

The first inner cleft or first pharyngeal pouch becomes metamorphosed into the middle ear and the Eustacliau tube, the closing membrane, which separates it from the outer eleft, forming the membrana trmpani. The second pharyngeal

'Reichert, (regenbaur, Hertwig; or to the ring of the stapes according to Salensky, Gradenigo, and Rabl. 
pouches produce no special structures, but the adjacent tissues give rise to the epithelial parts of the middle lobe of the thyroid body and to the posterior third of the tongue, in the manner more fully indicated on pp. 131 and 207. The third inner cleft produces the thymus body, while from the fourth results the lateral lobes of the thyroid body.

The configuration of the face, depending as it does so largely upon the development of the boundaries of the nose and of the month, is elosely associated with the growth of the first pair of visceral arches. The earliest indication of the month, the oral pit, appears at about the twelfth day as a shallow repression on the rentral surfuce of the embryonic borly between the fore-brain vesicle and the prominence caused by the primitive heart (Fig. 48, 3 to 5). This depression is deepened by the growth of the tissues surrounding it, as also by the flexure of the head, which occurs at the twenty-first day. In the third week, therefore, the oral pit is a five-sided fossa, being bounded above by the nasofrontal process, which has grown down from the elevation of the fore-brain, laterally by the maxillary processes, and below by the mandibular arches (Fig. 56, A). The pharyngeal membrane, which consists of opposed ectoderm and entoderm and which separates the primitive oral cavity from the gut-tract (Fig. 55, $r h$ ), ruptures at the time of the appearance of the third branchial areh.

By the end of the third week, the communication between the yolk-sac and the gut-tract has become reduced to the relatively small vitelline duct. At the twenty-fifth day the embryo presents a well-developed tail. By the termination of the fourth week the yolk-sac has attained its maximum size, and the presence of the somites is indicated by transverse parallel lines on the dorsal surface of the body.

\section{THE STAGE OF THE FETUS.}

This stage comprises the time between the beginning of the second month and the end of pregnaney.

During the second month the rate of growth is far less rapid than in the preceding stage. The marked curvature of the long axis of the body gradually dimishes, the embryo 
assuming a more erect posture. Owing to the partial disappearance of the cervical flexure, the head becomes raised.

During the fifth week the vitelline duct is seen to be long and slender; the umbilical cord has become longer and more spiral, and may contain a coil of intestine; the abdomen is very prominent, and in the neck-region is a characteristic dorsal concavity. At this time also the nasal pits become conspicuons as depressions situated on either side of the nasofrontal process (Fig. 56). The nasofrontal process mean while undergoes differentiation into the globular processes, which constitute the inner boundaries of the nasal pits, and the lateral frontal processes, which limit these depressions exter-

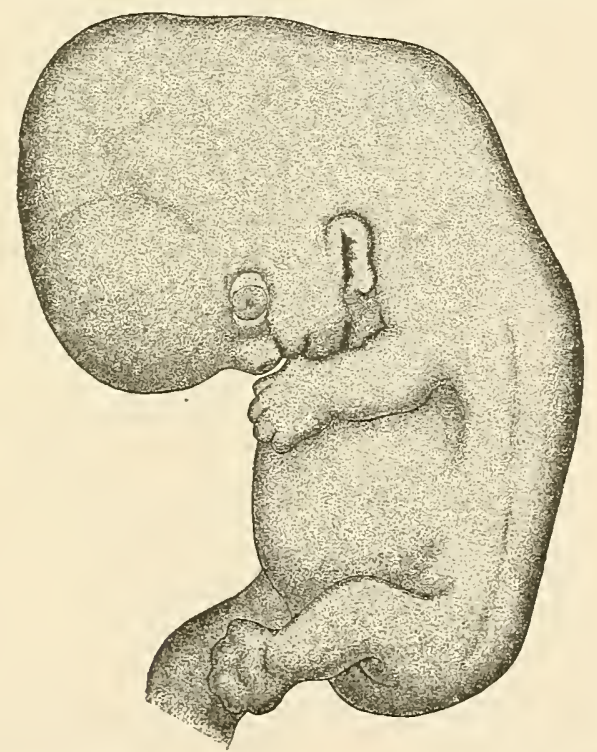

Frg. 52,-Human embryo of about six weeks, enlarged five times (His).

nally and separate them from the depressions for the eyer. The nasal pits are still in communication below with the primitive oral eavity. The lacrimal groove is well-marked at this stage, and the extemal anditory meatns is indicated. The mandibles become united mesially at about the thirtyfourth day. The third and fourth gill-clefts have by this 
time disappeared in the cervical sinus. The pardle-like limbbuds have lengthened and present, at first, a division into two segments, of which the distal is destined to become the hand or foot, while the proximal portion undergoes segmentation a little later into the arm and forcarm or thigh and leg; by the thirty-second day, the hand, now showing differentiation into a thicker proximal and a thinner terminal part, exhibits the first traces of digitation, in the form of parallel longitudinal markings which soon berome grooves and, later, clefts. The development of the upper extremities precedes that of the lower by twelve or fonrteen days.

During the sixth week the head assumes more nearly its normal position, and for this reason the apparent length of the fetus is considerably increased, the dorsal concavity in the neck-region being almost obliterated; the rudiments of the eyelids and of the concha lrecome recognizable, and the various parts of the face assume more definite shape. By the fortieth day the oral eavity has become separated from the nasal pits by the union of the nasofrontal process with the maxillary processes, and the external boundaries of the nostrils have become marked out by the meeting of each lateral frontal process with the corresponding maxillary process. Is a result of these changes, the nose, although still very broad, begins to assume characteristic form. During this week also the fingers are seen as separate ontgrowths, while in the seventh week the rudiments of their nails become evident.

Toward the end of the second month-about the fiftieth to the fifty-third day-the toes are just beginning to separate, the protrusion of the intestine at the umbiliens is at its maximum, the palpebral conjunctiva separates from the cornea, and the rudimentary tail begins to disappear.

The eighth week witnesses the total disappearance of the free tail, the formation of the septum that divides the chaca into the rectum and the genito-11rinary passage, and the presence of the projecting genital tuberele with the accompanying genital folds and genital ridges. The external genitals as yet show no distinction of sex. From the end 
of the second month to the time of birth, fetal growth is, in great measure, merely the further development of organs already mapped out; it is held by many authorities, therefore, that if malformations are ever due to maternal impressions, such impressions could be operative only in the event

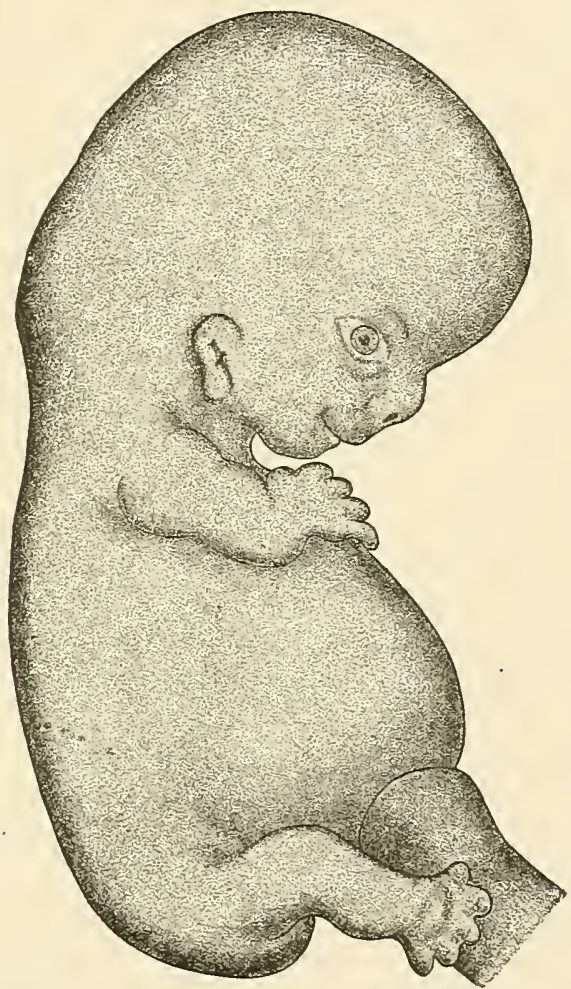

Fig. 53.-Human embryo of about seven weeks, enlarged five times (His).

of having been received prior to the eighth week of gestation.

During the third month, the face, although definitely formed, still presents thick lips, a pointed chin, and a rather broad and triangular nose. At this time the limbs are wellformed and assume a characteristic attitude, and the fingers and toes are provided with imperfect nails. The external 


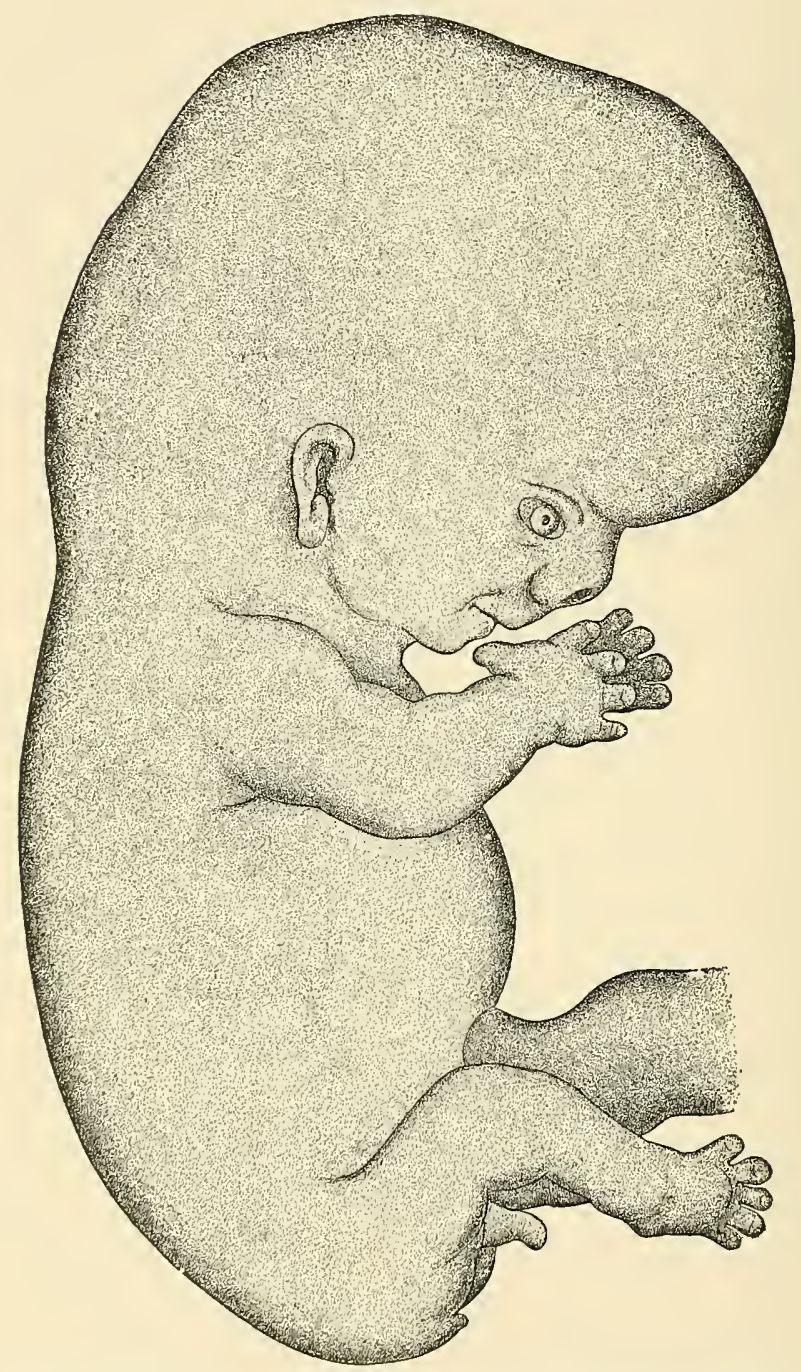

FIG. 54.-Human embryo of about eight and a half weeks, enlarged five times (His).

genitals, which, until the close of the second month, preserver the indifferent type, now begin to show sexual distinction.

In the fourth month, a growth of fine hair, the lanugo, 
appears upon the scalp and some other parts of the body; the anus opens; the intestine recerles within the abdomen; and the external generative organs present well-marked sexual characteristies.

The fifth month marks the inauguration of active fetal movements and the appearance of a more plentiful growth of colorless hair.

In the sixth month the fetal body becomes coated with the vernix caseosa, a modified sebaceous secretion whose function is the protection of the epidermis from maceration in the amniotic fluid. The eyebrows and eyelashes also appear about this time.

The seventh month witnesses the appearance of the lanugo, or embryonal down, upon practically the cntire surface of the body; the testes of the male fetus are in the inguinal canal or at the internal abdominal ring; and the nails break through their epiclermal covering. Children born at the end of the seventh month may survive, but usually they do not.

In the eighth month the lanugo begins to disappear.

In the ninth month the testicles are found in the scrotum, while, in the case of the female, the labia majora are in contact with each other. The contents of the intestinal canal, the meconium, consisting of intestinal and hepatic secretions mingled with epidermal eells and hairs swallowed by the fetus, is now of a dark greenish color. The umbilicus is almost exactly in the middle of the body.

The weight of the fetus at full term is from 3 to 3.5 kilograms (from 6 to 7 pounds), the arerage weight of the male child being abont ten omnees greater than that of the female. While variations from these figures are not uncommon, statements of excessive weight are to be received with reservation, since it has been found, upon eareful observation by competent authorities, that the weight of a new-born infant rarely exceeds ten pounds. The weight of the child, besides depending upon the physical condition of both parents, is influenced by the age of the mother, young women having the smallest, and women between the ages of thirty and thirty- 
five having the heaviest children ; by the number of previous pregnancies, the weight being greater with each succeeding pregnancy, provided the successive children are of the same sex and are not born at too short intervals; and also by the weight (Gassner) and height (Frankenhaiisen) of the mother, the ratio being a direct one. Minot believes that these various inflnences operate chiefly by prolonging or abbreviating the period of gestation, and that therefore the variations in weight at birth are referable to two principal cansesdifferences in the age at birth, and variations in the rate of intra-uterine growtl.

The length of the fetus at the time of birth is about 50 centimeters (20 inches).

The approximate age of an embryo or fetus may be estimated by the characters peculiar to each stage as above noted, and also by employing the rule formulated by Haase. According to Haase, up to the end of the fifth month, the square of the age in months equals the length in centimeters, while after the fifth montl, the length expressed in centimeters equals the age in months nultiplied by five. Tlus a fetus of four months would have a length of 16 centimeters; while one of six months wonld be 30 centimeters long. Hence, the age in months is the square root of the number expressing the length in centimeters; or, if the length exceeds 30 centimeters, the age in months is one-fifth of the length expressed in centimeters.

Reference has been made in Chapter I., page 37, to the relation between conception and menstruation, and to the manner of estimating the age of the product of gestation, based upon this relation. 


\section{CHA PTER VIII.}

\section{THE DEVELOPMENT OF THE CONNECTIVE TISSUES OF THE BODY AND OF THE LYMPHATIC SYSTEM.}

\section{THE CONNECTIVE TISSUES.}

THE variously modified forms of commective tissue distributed throughont the body, including such diversified tissues as the blood and the lymph, areolar tissue, fibrous and elastic tissue, adenoid tissue, tendon, eartilage, bone, and dentine, as well as the connective-tissue stroma of various organs, all result from alterations affecting the middle germ-layer or mesoderm. As pointed out elsewhere (Chapter III.), the inner and the outer germ-layers are concerned in producing the epithelial structures of the body (with the exception of the epithelium of the greater part of the genital apparatus and of the kidney and ureter), the ectoderm giving rise not only to the epithelium of the surface of the body, but also, by processes of infolding, to such important structures as the central nervous system and the internal ear, while the entoderm differentiates into the epithelial parts of the respirittory and digestive systems with their associated glandular organs.

The proliferation of the cells of the mesoderm goes hand in hand with the differentiations of the inner and outer germlayers, so that even at an early stage of development the middle germ-layer, besides having given rise to the mesothelium of the body-cavity and to the primitive segments, constitutes a lonse aggregation of cells that fill the spaces between the germ-layers and spread abont the developing embryonic organs. This primitive relation of the mesodermic tissue foreshadows its future office as the supporting framework not only of the body, but of the functionally 
active epithelial elements of the glands. Thus, the indifferent mesodermic tissue that comes to surromnd the notochord and the neural canal specializes into the spinal column and the brain-case; while the parts of this tissue into which protrude the epithelial evaginations of the primitive alimentary eanal -as, for example, the evaginations which are the beginnings of its glandular organs, the liver and the pancreas-become intimately associated with these epithelial sacs and tubes to constitute the connective-tissue stroma and the vasenlar apparatus of the completed glands. All organs of the body, therefore, that have a connective-tissue constituent obtain it from the mesoderm. Owing to the varying degree of differentiation of the mesodermic elements in different localities there are formerl tissues of widely different character. The most important factor in the production of these modifications is the alteration of the intercellular substance, as to whether it remains soft and homogeneous, whether it acquires a fibrillar or an elastic structure, or whether it becones dense and hard, as in the case of cartilage and bone. The cells undergo comparatively little change, although, according to the kind of tissue prodnced, they come to be known respectively as connective-tissue cells, tendon-cells, cartilage-cells, or bone-cells.

The slightest degree of specialization results in the production of mucous tissue. In this ease a reticulum is formed by the slender processes which the cells acquire, the spaces of the meshwork being filled with the semifluid or semigelatinons intercellular substance.

A further alteration in the intercellular substance, whereby it aequires greater density and becomes permeated by bundles of fibers, some of which are highly elastic, results in the formation of areolar tissue. Prepronderance of the non-elastic fibrous element produces white fibrous tissue, while elastic tissue, such as the ligamentum nuchæ, is formed if the elastic fibers are in excess. Further inerease in the density of the intercellular material, with its accompanying conversion into bundles of non-clastic fibers having a characteristic regularity of arrangement, produces the structure of tendon. When 
the intercellular substance gives rise to a scant amount of fibrous material and the cells become distended with oily or fatty matter, adipose tissue results.

A still greater degree of density of the intercellular substance gives the matrix of cartilage, the cells being enclosed in spaces, the lacunæ, as the cartilage-cells. Partial differentiation into cither fibrous or elastic bundles confers the character of either fibrous or elastic cartilage upon the product.

Great condensation of the intercellular substance and its permeation with salts of lime, the cells being fixed in small spaces, results in the production of osseous tissue (sce Chapter XVIII.).

Blood and lymph may be looked upon as forms of connective tissue in which the intercellular substance is fluid, constituting the plasma, the cellular elements thus remaining free cells, the blood- or the lymph-corpuscles. The development of both lymph and blood from the mesodermic elements serves to bear out the comparison.

The endothelium of the body is related with the connective tismes genetically as well as anatomically. Reference has been made elsewhere to the changes which occur in the mesodermic cells that bound the borly-cavity-the fissure between the two layers into which the parietal plate of the mesoderm splits-to constitute the mesothelium of the bodyeavity. These changes consist in the flattening of the cells and their assumption of the characters of endothelium. Similarly, when other smaller elefts are formed in the mesodermic tissue, clefts which may be the beginnings of small lymph-spaces, or of blood-ressels, or of bursal or articular cavities, the bordering cells of these cavities also assume the endothelioid type.

The mode of development of the serous membranes and of the elosely allied synovial, bursal, and thecal sacs may be inferred from what has been said abont the origin of the endothelium. The connective-tissue stroma of the menbrane, upon which the endothelium rests, is simply a condensed and differentiated lamella of connective tissue. 


\section{THE DEVELOPMENT OF THE LYMPHATIC SYSTEM.}

The solid elements of the lymphatic system-the "lymphglands," the lymph-follicles, and the diffuse adenoid tissueas well as the thymus body and the spleen, result from the specialization of mesodermic cells, while the lymph-vessels and the various lymph-spaces of the economy-that is, the serous sacs, joint-carities, bursal and thecal cavities, subarachnoid and subdural spaces of the brain and spinal cordare developed by vacuolation or hollowing out of the mesoderm.

Definite knowledge is wanting as to many of the details of the genesis of the lymphatic system. The various lymphspaces precede the ressels and the adenoid tissue in development.

The lymph-spaces result from clefts in the mesoderm, the earliest formed and most conspicuous space of this sort being the body-cavity or cœlom. This large fissure develops, even before the differentiation of the body of the embryo, by the coalescence of numerous small cavities that appear within the middle germ-layer. The body-cavity acquires more definite boundaries by the alteration of the mesodermic cells that border it into flattened endothelioid cells, the mesothelium of the body-cavity. When, in the progress of development, the diaphragm and the pericarlium are formed, the body-cavity is divided into the peritoneal cavity, the pleural sacs, and the pericardium. At a still later period, a diverticulum of the peritoneum protrudes, in the male fetus, through the inguinal canal into the scrotum to constitute the tunica vaginalis testis. The stomata of scrous membranes are merely so many apertures of communication between the serons cavities, which are enormous lymph-spaces, and the lymphatic clefts contained within the stroma of the serous membrane, the elefts themselves being the beginnings of lymph-vessels.

The large lymph-sacs surrounding the brain and spinal cord, the subarachnoid and subdural spaces, as well as the spaces within the eapsule of Tenon and the sheath of the 
optic nerve, and the perilymphatic spaces of the internal ear similarly develop as vacuolations of the mesodermic tissue. The same is true of the joint-cavities, bursal sacs, sheaths of tendons, and the small lymph-clefts found in the areolar tissue and throughout most organs.

The lymphatic vessels apparently develop, after the manner of blood-vessels, from anastomosing cords of cells that are of direct mesodermic origin. These solid cell-cords are afterward hollowed out, and thus become tubes. The endothelial cells lining the vessels are probably the metamorphosed descendants of the cells of the original cords. The earliest lymphatic vessels formed are the subcutaneous vessels, which are present in a human embryo of $2-3$ c.m. ${ }^{1}$ At a somewhat later period the deeper vessels appear.

The lymphoid or adenoid tissue is produced at a later date than the vessels. Observations upon the human lymph glands seem to have been confined to the inguinal and lumbar glands. The first indication of an ingninal gland is seen in a $3 \mathrm{~cm}$. embryo, in the shape of little aggregations of lymphoid cells that have migrated from the lymphatic cords or networks into a space hollowed out of the mesoderm. This nodule of lymphoid cells is isolated from the surrounding mesodermic elements by a fissure or space except at one point, the future hilum of the gland, where strands of embryonal connective tissue connect it with the parent mesoderm. The reticulum of the gland appears later, as does also the capsule, the latter of which results from the condensation of the surrounding mesoderm.

The development of the spleen is considered with that of the alimentary system beeanse of its relation to the evolution of the peritoneum, while the account of the development of the thymus will be found in the chapter on the respiratory system.

1 O. Schultze: "Grundriss der Entwickelungsgeschichte des Menschen und der Säugethiere," Leipzig, 1897. 


\section{CHAPTER IX.}

\section{THE DEVELOPMENT OF THE FACE AND OF THE MOUTH=CAVITY.}

The evolution of the face depends so largely upon the growth of the parts concerned especially in the production of the mouth and nose that any account of its derelopment must deal for the most part with the development of those structures. In tracing the earliest stages of facial growth, it will be well to consider the face as a whole before proceeding to a detailed description of its several parts. If we seek the principles underlying the conformation of the face, we shall find that its apertures and chief carities are merely so many provisions for bringing the central nerrous system and the alimentary tract into relation with the outside world. It will be seen, for example, that certain small depressions appear upon the surface; that one of these, which is destined to become the mouth and the respiratory part of the nasal carities, assumes relationship with the alimentary tract and with its offshoot, the respiratory system; that other depressions, which subsequently develop into the olfactory parts of the nasal chambers, come into relation with outgrowtls from the brain, the olfactory bulbs; and that still another surface-invagination becomes the lens-vesicle, which likewise meets witl an ontgrowth from the brain to become a part of a peripheral sense-organ, the eye.

The first step in the differentiation of the face is the formation of the oral plate, the earliest indication of the future month. The oral plate appears on the twelfth day, and consists of a small area of ectoderm and entoderm, the mesoderm being absent. It is situated on the ventral surface of 
the head-end of the embryo, which already presents the enlargement of the cerebral resieles. The oral plate becomes relatively depressed by the upgrowth of the surrounding tissnes, the fossa thus produeed constituting the oral pit or stomodxum (Fig. 46). The oral plate is now the pharyngeal membrane (Fig. 55). Reference to the sagittal seetion will

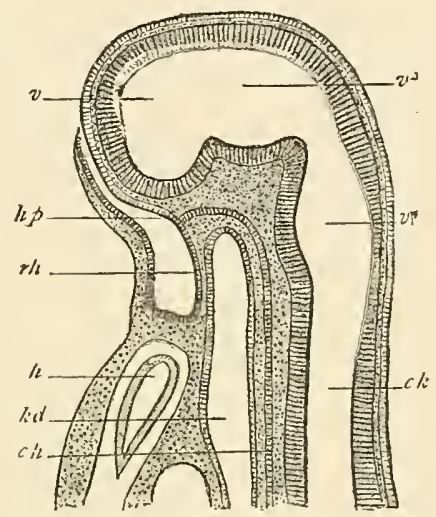

FIG. 55.-Median section through the head of an embryo rabbit $6 \mathrm{~mm}$. long (after Mihalkovies) : $r h$, membrane between stomodæum and fore-gut, pharyngeal membrane (Rachenhaut); $h p$, place from which the hypophysis is developed: $h$, heart; $k d$, lumen of fore-gut; $c h$, chorda; $v$, ventricle of the cerebrum; $v^{3}$, third ventricle, that of the between-brain (thalamencepbalon); $v^{4}$, fourth ventricle, that of the bind-brain and after-brain (epencephalon and metencephalon, or medulla oblongata); $c k$, central canal of the spinal cord.

show that the oral pit corresponds in position to the headend of the gut-tract. The formation of the pit is, in effect, a pushing-in of the surface eetoderm to meet the alimentary entoderm.

A seeond important factor in the development of the face is the appearance of the first and second viseeral arehes, which oeeurs in the third week. As pointed ont in a preeeding section, the first visceral arch divides into the mandibular arch and the maxillary process (Fig. 51), the latter being the smaller and appearing to spring from the mandibular areh. Both the maxillary processes and the mandibular arches grow toward the median line of the ventral surface of the body. Owing to the growth of these struct- 
ures and to the sharp flexion of the head and neek that occurs between the twenty-first and the twenty-third day, the oral pit becomes very much deeper and acquires nore definite boundaries. During the third week it is a fossa of pentagonal outline. Its upper boundary is formed by the unpaired nasofrontal or nasal process (Fig. 56, A), which is essentially a thickening on the ventral wall of the forcbrain vesicle, brought into close relation with the fossa by the flexion above referred to. The lower boundary is formed by the mandibular arches, while the lateral extent of the fossa is limited by the maxillary process of each side.

Soon after the appearance of the oral pit, the future nares are foreshadowed by the development of the two olfactory plates, situated one on each side of the nasofrontal process, widely separated from each other. These epithelial areas, which soon become depressions, the nasal pits, are closely united with the wall of the fore-brain vesicle from the first; they develop subsequently into that part of the nasal mucous membrane which is concerned especially with the sense of smell. This fact becomes very significant when it is remembered that the olfactory bulbs, with which the olfactory epithelium assumes intimate relationship, are outgrowths from the brain.

The nasofrontal process, during the fifth week, becones much thickened along its lateral margins, forming thus the globular processes (Fig. 56, A), which constitute the inner boundaries of the nasal pits. At the same time, there grow downward and forward from the nasofrontal process two ridges, one on each side, the lateral frontal processes, which form the outer boundaries of the nasal pits (Fig. 56, A). In this manner the pits become much increased in depth. The lateral frontal process projects between the nasal pit and the maxillary process, its line of eontact with the latter structure being marked by a groove, the naso-optic furrow or lacrimal groove. This groove later completcly disappears; it is of importance, however, ats indicating the position of the now developing nasal duct, which will be referred to hereafter. The nasal pits are widely in communication with 
the cavity of the primitive mouth. About the fortieth day, however, the extremities of the maxillary processes have grown so far toward the median line that they have met
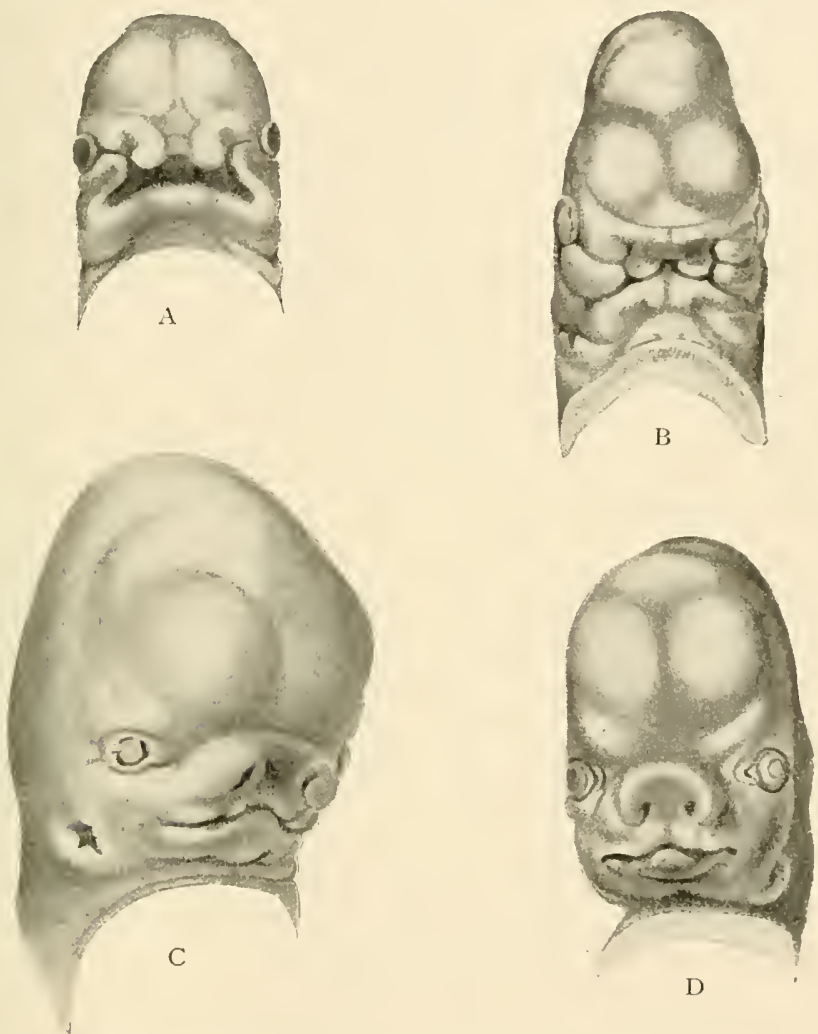

$\mathrm{D}$

FIG. 56.-Development of the face of the human embryo (His) : A, embryo of about twenty-mine days. The nasofrontal plate differentiating into processus globulares, toward which the maxillary proeesses of first visceral arch are extending. B, embryo of about thirty-four days: the globular, lateral, frontal, and maxillary processes are in apposition; the primitive opening is now better defined. $C$, embryo of about the eighth week: immediate boundaries of mouth are more definite and the nasal orifiees are partly formed, external ear appearing. D, embryo at end of seeond month.

and united with the lateral frontal processes and with the nasofrontal process (Fig. 56, $B$ and $C$ ). In this manner the nasal pits become separated from the oral fossa, each of these openings acquiring more definite boundaries. It is 
apparent from this description that the upper boundary of the primitive oral cavity is not identical with that of the adult mouth. The nasofrontal process is the forermnner of the intermaxillary portion of the upper jaw, including the corresponding part of the upper lip and of the nasal septum and bridge of the nose. ${ }^{1}$ The lateral frontal process becomes the wing of the nose. By the completion of the changes here noted the face acquires more distinctive form. It will be seen that the upper jaw proper lesults from the metamorphosis of the maxillary processes. The manner in which its sinus, the antrum of Highmore, is added, as well as the ossification of the jaw, will be considered hereafter.

The development of the eye will be described in connection with that of the sense-organs. In so far as the eyes have relation to the external form of the face, it will be sufficient to say that the surface ectoderm is invaginated in the fourth week to form the lens-vesicle, this sac, which gives rise to the erystalline lens, being covered by two little folds of ectoderm, the primitive eyelids; that the organ is situated on the side of the head, in marked contrast to its position in the mature state; and that the naso-optic furrow, previously referred to, passes from the inner angle of the eye toward the wing of the nose. The development of the face having been pointed out in a general way, the individual parts may be considered separately.

\section{THE MOUTH.}

To review briefly, for the sake of convenience and clearness, the earlier history of the rlevelopment of the mouth, we find the first step to be the appearance, at the twelfth day, of the oral plate. By the enlargement of the anterior end of the neural tube to form the cercbral vesicles, and by

1 Hare-lip is the deformity resulting from failure of union between the nasofrontal and the maxillary processes. Sinee the nasofrontal process is an unpaired structure, in which develop the intermaxillary bones, and which unites on either side with the eorresponding maxillary process-the latter heing the forermner of the upper maxilla proper-we have an explanation of the lateral position of hare-lip. This defect may be, of course, either unilateral or bilateral. 
the development of the visceral arches, this area becomes a depression, the oral pit. The pit is at first bonnded caulad by the cardiac prominence and cephalad by the fore-brain vesicle (Fig. 46). In the third week the oral pit becomes a five-sided fossa, owing to the growth of several new structures. These are the umpaired nasofrontal process, which bounds the fossa above, the mandibular arches, which bound it .below, and the maxillary processes, which form the lateral boundaries (Fig. 56). The mandibular arches do not actually unite with each other until the thirty-fifth day. The angle between the maxillary process and the mandibular arch corresponds to the angle of the future month. In the sixth week-abont the fortieth day-the oral fossa acquires a new upper boundary, which separates it from the nasal pits, by the growth of the maxillary and lateral nasal processes toward the median line to unite with the nasofrontal process.

The primitive oral cavity, as before mentioned, is at first separated from the gut-tract by the pharyngeal membrane (Fig. 55). This structure ruptures at some time during the fourth week, thus bringing the mouth into communication with the upper end of the gut-tract. The exact location of the pharyngeal membrane with reference to the adult pharynx is somewhat difficult to define; it is certain, however, that the primitive mouth includes more than the limits of the adult oral cavity, comprising, in addition to the latter, the anterior part of the adult pharynx. Reference to a sagittal section, as in Fig. 55, shows the relation of the oropharyngeal cayity to the brain-case; in the tissue separating the two the floor of the cranium is subseguently formed. A little evagination from a point (hp, Fig. 55) in the back part of the primitive oral cavity becomes the anterior portion of the pituitary body or hypophysis, the posterior lobe of which develops as an evagination from the floor of the primary fore-brain vesicle. With the development of the floor of the cranim, the hypophysis becomes entirely isolated from the oral carity. A little pouch or recess usually demonstrable in the median line of the roof of the pharyn of the child, 
though not always present in the adult, is the persistent pharyngeal end of the diverticulum that forms the hypophysis; it is known as the pharyngeal bursa or Rathke's pocket.

Very soon after the formation of the upper jaw in the manner above described, the oral surface of the jaw jresents two parallel ridges. Of these, the outer, which is the larger, develops into the upper lip, while the inner smaller ridge becomes the gum. The lip and gum of the lower jaw are produced similarly, at the same time or a little later. So far, the only demarcation between the mouth and the nasal eavity is furnished by the tissue representing the united nasofiontal, lateral nasal, and maxillary processes, the nares opening widely into the cavity of the mouth posterior to this partition.

The formation of the palate, however, effects a separation between the two that gives to each space its permanent limitations. On the inner or oral surface of the mper jaw two shelf-like projections appear, one on each side, which are the rudiments of the future palate. These gradually grow toward each other, the tongue, which has meanwhile been developing, projecting upward between them. In the eighth week, mion of these two lateral halves of the palate begins at their anterior extremities. By the ninth week union has taken place as far back as the extent of the future hard palate, and, by the eleventh week, the constituent halves of the soft palate have united also. As these two halves approach each other the tongue recedes from between them, owing to the growth of the lower jaw, so that, when union ocenrs, that organ occupies its normal position under the palate. Osscons formation within the soft tissue first formed produces the palate processes of the superior maxille and of the palate bones, which processes collectively constitute the hard palate of the adult. The intermaxillary bones are formed within the primitive partition between the mouth and the nares. The completion of the palate definitely marks off the nasal chambers from the mouth, thus dividing the early oral eavity into a lower space, the true mouth, and an 
upper region, which is essentially a part of the respiratory system.

The uvula appears during the latter half of the third month as a small protuberance on the posterior edge of the soft palate. ${ }^{1}$

The Teeth. - The teeth, morphologically considered, are calcified papillæ of the skin, capped by a layer of peculiarly modified and calcified cells of the epidermis. Although in man and the higher mammals the teeth are found only upon the gums, in certain lower types they have a much wider distribution, occurring upon the roof and floor of the mouth and in the pharynx, and also, in selachians, "pon the general skin-surface, in which latter case they are so modified as to constitute scales.

The dentine and cementum of the tooth, as well as its pulp, are derived from the mesoderm ; the enamel is a direct derivative of the overlying ectodermic epithelium. Mammals are sair to be diphyodont, since they develop two sets of teeth; while such groups as sharks, which continue to produce and lose new teeth throughout life, are denominated polyphyodont.

The development of the teeth is inaugurated in the sixth week of embryonic life by the multiplication of the epidermal cells covering the surface of the gums to form a linear ridge. The growth of the ridge is away from the surface, so that the new structure projects into the underlying mesoderm. This horseshoc-shaped ridge, which corresponds in direction and extent to the line of the gum, subdivides into two parallel ridges, of which the outer marks the position of the future groove between the gum and the lip; the inner is the dental shelf or dental ridge, which must be regarded as the carlicst indication of the future teeth. The dental shelf extends into the underlying mesodermic tissue, not directly

${ }^{1}$ Deficiency of union of the halres of the palate, resulting iu a median fissure, constitutes the deformity, cleft palate. This deficiency may be limited to the hard or to the soft palate, or it may affect both, or it may be seen in the urula, either alone-cleft or bifid uvula-or in conjunction with cleft palate. 
downward but in an oblique direction toward the inner or lingual surface of the gum. While the dental shelf is growing, its line of comnection with the surface ectoderm is marked by the superficial dental groove, which at one time was looked upon as being the first evidence of tooth-formation.

Upon the side of the dental shelf opposite the free or oral surface, individual protuberances develop, corresponding in number to that of the teeth of the temporary set-ten for each jaw. Each little projection consists of a mass of ectodermic cells, which soon becomes expanded at its deep extremity, becoming thus elub-shaped and later flask-shaped, and which is called the enamel-sac or primitive enamel-germ, since the enamel of the tooth is developed from it (Fig. 57).
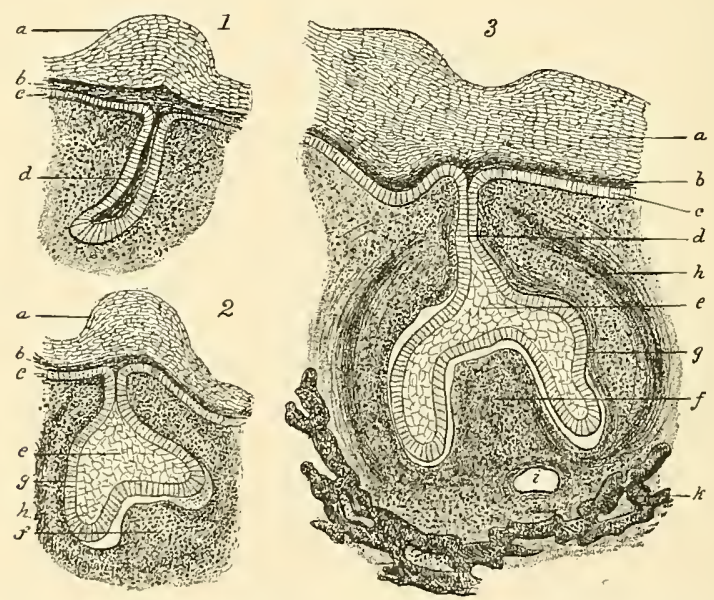

FIG. 57.-Three suceessive stages in the development of a tooth-germ of a pig embryo (after Frey and Thiersch): $a, b, c$, layers of thickened oral epithelium, showing dental groove on surface in $3 ; e$, enamel organ; $f$, dental papilla; $g, h$, internal and external layers of the follicle wall: $i$, blood-vessel $; k$, maxilla; $d$, epithelial ingrowtb, the end of which expands into the enamel-sac.

Meanwhile the continuity of the original dental shelf is broken by the disappearance of the cells in the intervals between the individual enamel-germs, cach germ hecoming thereby isolated from its neighbors. 'The neck of the flask- 
shaped enamel-germ becomes reduced to a slender strand of cells and finally disappears, so that there is no longer any conncetion between the enamel-sac and the ectodermic cells of the frec. surface of the gum. While the enamel-saes for the temporary teeth are growing in this manner, the corresponding structures for the teeth of the permanent dentition bud from the inner side of the dental shelf-that is, the side looking toward the tongue-except those for the three permanent molars, which grow backward toward the articulation of the jaw from the position of the second temporary molar.

As the enamel-germs grow downward in to the mesodermic tissue, the latter sends up a number of conical projections, the dental papillæ, one for each enamel-organ. This dental papilla, of mesodermic origin, is the parent of the dentine and of the pulp of the tooth. When the dental papilla and the enamel-sac meet, the sac becomes invaginated, its under surface assuming a concave form. The enamel-sac at this stage therefore is a double-walled cup which caps the dental papilla. It is at about this time that the connection of the enamel-organ with the surface ectoderm is lost.

The further evolution of the enamel-organ consists essentially in the arrangement of its constituent cells into three layers and the formation, by the deepest of these three layers, of the special elements of the fully-developed enamel-the enamel-prisms. The most supcrficial stratum of the enamelorgan is composed of low columnar or polyluedral cells; the deepest layer, that nearest the papilla, the so-called membrana adamantina, consists of beautifully regular colummar cells, the ameloblasts or adamantoblasts; between the two is a group of less characteristic epithelial elements. The cells of the deep layor, the enamel-cells, are alone concerned in the production of the enamel. The enamel-organ for a time covers the entirc dental papilla. During the course of development, howerer, the growth of that part of it covering the future ront of the tooth aborts, learing the crown alone covered with the enamel.

The first step in the formation of the enamel-prisms by the enamel-cells is that the protoplasm of the deep extremity 
of each cell becomes homogeneous, and a tuft develops on the end of the cell, projecting toward the papilla. By the

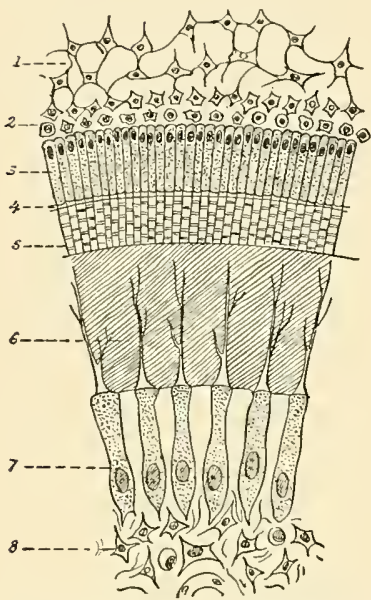

FIG. 58.--Semi-diagrammatic figure showing the several parts of a calcifying enamel-organ (Tourneux): 1 , central cells of enamelorgan; 2 and 3 , cells of inner layer of enamel-organ, 3 being the enamel cells; 4 , zone of young enamel; 5 , enamel prisms; 6 , young dentine traversed by the deutinal fibers; 7 , odontoblasts: 8 , central tissue of dental papilla. calcification of this tuft the formation of an enamel-prism is begun (Fig. 58). The process of caleification continues to advance from the deep or papillary aspect of the enamel-organ toward the surface. From this it eomes about that the newest enamel is next to the enamel-cells, or, in other words, nearest the surface, and also that the enamel-prisms are arranged in a direction generally vertical to the free surface of the tooth. The formation of the enamel of the milk-teeth begins in the latter part of the fourth month. The middle layer of the enamelorgan becomes greatly altered in constitution, owing to the accumulation of fluid and to the reduction of its cells to the form of thin plates, the appearance being rather that of connective tissue than of an epithelial structure. The superficial layer of cells undergoes atrophy, their exact fate not being known.

The atrophic remnant of the enamel-organ is found upon the free surface of the tooth for a variable time after its eruption, constituting the membrane of Nasmyth.

The dental papilla has been referred to as the structure that gives rise to the dentine. It originates from active multiplication of the mesodermic cells. The number of papillie corresponds to the number of enamel-organs. As the papilla grows toward the enamel-organ it early acquires vascularity. The shape of the papilla, whether that of an incisor, of a canine, or of a molar tooth, is determined by the shape which the enamel-organ assumes. The connective- 
tissue cells upon the surface of the papilla assume distinctive character, becoming large and branched, and constitute the so-ealled odontoblasts (Fig. 58). 'They are virtually modified osteoblasts. Forming a continuous layer, they have been styled the membrana eboris. Between this layer of odontoblasts and the enamel-organ a layer of intercellular substance appears, the membrana præformativa. The odontoblasts now send out processes toward the enamel-organ, which are known as the dental processes. Calcification begins upon the surface of the papilla and progresses toward its center, but is not complete. Small uncaleified areas, corresponding to the globular spaces of the completed tonth, remain next the enamel. The dental processes likewise fail to become ealcified, and these are the adult dentinal fibers occupying the dentinal tubules of the finished dentine. The orlontoblasts continue the formation of dentine until the dental papilla is entirely surrounded by it. What remains of the papilla, upon the completion of the tooth, constitutes the pulp, a highly vascular conneetive-tissue substance supporting upon its surface the odontoblasts. The deposition of dentine begins in the latter part of the fourth month.

During the metamorphosis of the dental papilla the mesodermic tissue immediately surrounding it undergoes slight condensation to form the follicle of the developing tooth. As the enamel-organ recedes from the surface, the follicle increases in extent to such a degree as to envelop the entire rudimentary tooth. Only that part of the follicle which covers the future root of the tonth is of subsequent importance, however; undergoing partial transformation into true bony tissue, it gives rise to the cementum or crusta petrosa, while the unossified external fibrous layer constitutes the lining periosteum of the alveolus (Fig. 57).

The development of the permanent teeth is precisely analogous to that of the milk-teeth. The enamel-germs for the permanent teeth, with the exception of the molars, bud from the lingual side of the dental shelf in the screntecuth weck (Fig. 59), the germ for the first permanent molar appearing abont a week earlier at the posterior extremity of the lental 
shelf after the manner of a milk-tooth. The germ for the second molar buds from the neck of the first molar in the third month after birth, while that of the third molar, the wisdom tooth, springs from the neck of the second about the third year. At birth, therefore, the gums contain the

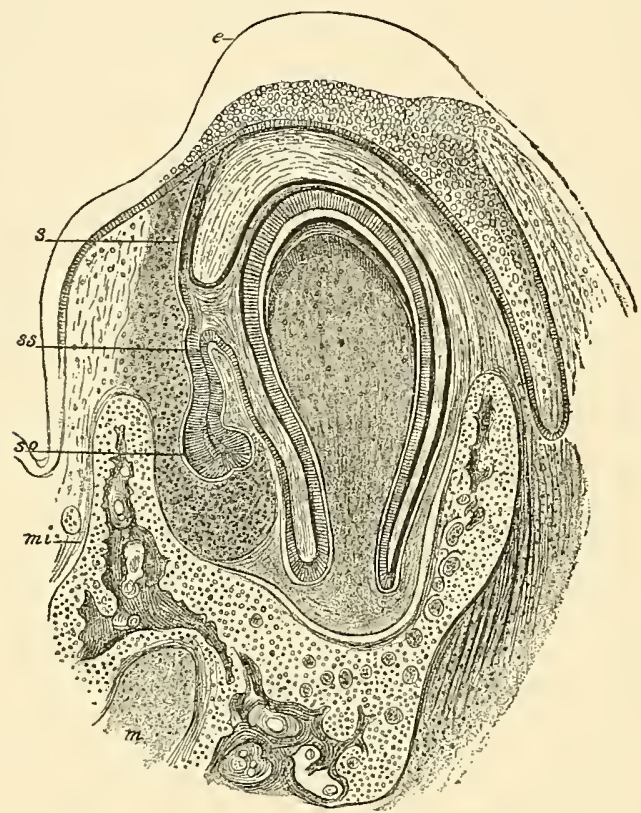

FIG. 59.-Cross-section of the lower jaw of a cat embryo, showing the enamelgerms of a milk-tooth and of a permanent tooth (from Bonnet, after Kölliker): $e$, thickened oral epithelium; so, enamel-organ of permanent tooth, which has grown out at $s s$ from the neck $(s)$ of the enamel-sac of a milk-tooth; mi, lower jaw ; $m$, Meckel's cartilage.

two sets of teeth except the second and third permanent molars.

The eruption of the temporary teeth begins usually at about five and a half months after birth with the appearance of the central incisors, and is complete at from eighteen to thirtysix months, when the second molars are cut. The first teeth of the permanent dentition are the first molars, which are erupted at about the sixth year. The accompanying table shows the time and the order of eruption of the teeth: 
Temporary Dentition.

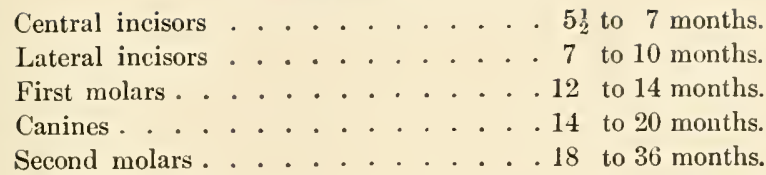

Permanent Dentition.

First molars . . . . . . . . 6th year.

Central incisors ........ 7th year.

Lateral incisors ......... Sth year.

First premolars . . . . . . . 9 9th year.

Second premolars ....... 10th year.

Canines. . . . . . . . 11th to 12 th year.

Second molars. . . . . . . . 12th to 13th year.

Third molars (wisdom teeth) . . . 17th to 21 st year.

The Salivary Glands.-The salivary glands, which in mammals consist of three pairs, the parotid, the submaxillary, and the sublingual, develop as outgrowths of epithelium from the lining mucous membrane of the month. The epithelial elements of the glands are therefore of ectodermic origin. The growth of the submaxillary gland begins in the sixth week, that of the parotid in the eighth week. Each epithelial ontgrowth is at first a solid cylinder, which undergoes repeated branching and acquires a connective-tissue framework and capsule from the surrounding mesoderm. It is not until the middle of the fifth month that the lumen of the gland appears. This is brought about by the moving apart of the epithelial cells composing the cylinders and their branches. The main duct of the gland first becomes hollow, then its branches, and finally the lumina of the alveoli make their appearance. The respective sites from which the several glands grow correspond in a general way to the positions at which the duets of the adult glands open into the month-cavity.

The Tongue.-Although the tongue originates from tissues belonging really to the walls of the pharynx, its development may be conveniently considered in connection with that of the mouth becanse of its relations in the mature organism. This organ, composed chiefly of muscular sub- 
stance, is formed from three originally separate parts, an anterior unpaired fundament, and two posterior bilaterally symmetrical segments. The line of union of these three parts is indicated approximately in the adult organ by the $V$-shaped row of circumvallate papillie on the dorsum of the tongue. The anterior part of the tongue develops from a small unpaired tubercle, the tuberculum impar, which grows from the median line of the floor or anterior wall of the plrarynx between the first, or mandibular, and the second, or hyoid, arch (Fig. 60,6). The posterior segment of the tongue results
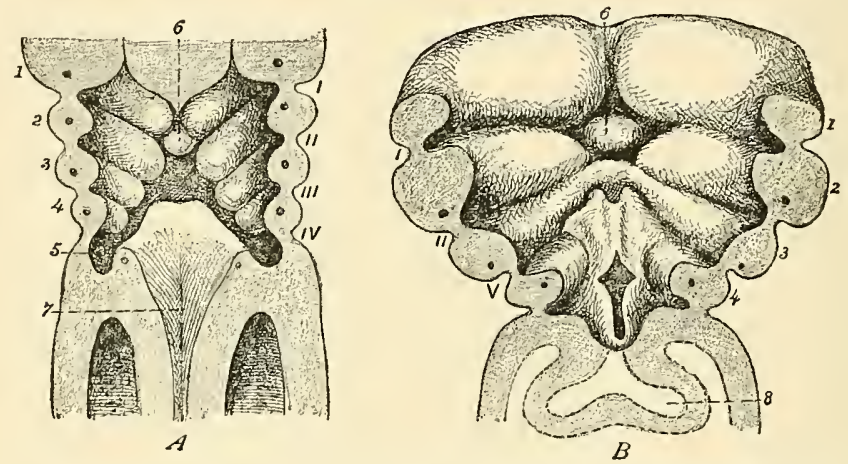

FIG. 60.-Coronal sections of two human embryos, showing ventral wall of pharyngeal end of gut-tract from behind (from Tourneux, after His). $A$, from embryo of $3.2 \mathrm{~mm}$.; $B$, of $4.25 \mathrm{~mm}$. (about 25 to 30 days). I, $I I, I I I, I V$, outer visceral furrows; 1 , sinus præcervicalis, comprising third and fourth outer furrows; $1,2,3,4$, visceral arches, each with its visceral-arch vessel ; 6 , tuberculum impar; 7 , orifice of larynx; 8, pulmonary evagination.

from the growing together of two lateral halves, which develop from the anterolateral walls of the pharynx at the position of the second and third visceral arches, but not from the arches themselves. These ridges are sometimes rlescribed as the fused anterior (ventral) extremities of the arches just mentioned. The unpaired tubercle increases in size to such an extent as to constitute the major part of the organ. In the median line of the anterior wall of the pharynx, immediately behind the tuberculum impar, the epithelial lining of this cavity pouches forward and downward to develop later into the middle lobe of the thyroid body. As the ridges which are to form the posterior part of the tongue lie laterally and 
posteiorly to this median evagination, they completely enclose it in the process of fusing with each other and with the anterior tubercle. In this manner a canal or duct is formed leading from the surface of the tongue at the angle of junction of its three segments down to the middle lobe of the thyroid body, the latter meanwhile having descended from its original position. This canal is the thyroglossal duct or canal of His. During the further progress of development, the canal suffers obliteration, its only restige being the orifice which is known as the foramen cæcum of adult anatomy.

The papillæ of the tongne are found exclusively on the part derived from the tuberculum impar; the line of union between the anterior and posterior parts lies therefore behind the row of circumvallate papillæ. The papillæ begin to make their appearance as early as the beginning of the third month.

Prior to the union of the two lateral halves of the hard palate, by which the primitive oral cavity is divided into the mouth proper and the nasal chambers, the tongue projects upward between the palate-shelves, almost completely filling the primitive mouth. As the palate-shelves approach each other, however, the tongue gradually recedes to its subsequent normal position.

\section{THE DEVELOPMENT OF THE NOSE.}

The nose being an organ of special sense, its derelopment is described in connection with that of the other special-sense organs in Chapter XVI. Owing, however, to its important relation to the other parts of the face, it is desirable to refer to its evolution in this comnection. For a more detailed account, the reader is referred to Chapter XVI.

The first indication of the organ of smell is in the form of the two patches of thickener ectoderm, the nasal areas or olfactory plates, which appear on the headward side of the oral fossa in the third week of development. At the end of the fourth week the areas are depressed and constitute the nasal pits (Fig. 56, A). The nasofrontal process, a mass of thickened mesodermic tissue, lies between them. During the 
fifth week the lateral edges of this process become thick and rounded, forming the two globular processes, while growing outward and downward from the sides of its base are the two lateral nasal or lateral frontal processes. Thus the nasal pits, which correspond with the position of the future anterior nares, become bordered on the mesial side by the globular processes and on the outer side by the lateral nasal processes. Below, the pits are continuous with the oral fossa. Owing to the continued growth of these masses the pits gradually become deeper. The lateral nasal process is separated externally from the maxillary process of the first visceral arch by a groove, the naso-optic furrow. The lower extremities of the maxillary and lateral nasal processes soon unite with each other and advance toward the median line below the nasal pit. In the latter part of the sixth week they unite with the nasofrontal process and thus separate the nasal pits from the oral fossa and furnish the basis of the upper lip. The nasal pits are now the anterior nares, and the nose is represented by the irregular masses of tissue surrounding them. While the orifices of the nares are separated from the orifice of the primitive oral cavity, their deeper parts are continuous with the latter, there being as yet no hard or soft palate.

In the eighth week the nose first acquires definite form, owing to the continued growth of the masses of tissue referred to above. The nasofrontal process forms the bridge of the nose with the nasal septum, and also the intermaxillary part of the superior maxillæ and the connective-tissue parts of the upper lip. The lateral frontal process becomes the ala of the nose. The nose is still very broad and flat in the third month, after which time it gradually assumes its characteristic form. 


\section{CH A PTER X.}

\section{THE DEVELOPMENT OF THE VASCULAR SYSTEM.}

The vascular system, including the blood, the heart, and the blood-vessels, begins its development very early in embryonic life.

While the heart is formed within the body of the embryo, the blood and the earliest blood-vessels have their origin in an extra-embryonic structure, the yolk-sac. It is noteworthy that all parts of the vascular system proceed from mesodermic tissue, the heart and the vessels originating from clefts within this structure, and being lined, therefore, with endothelial cells.

In correspondence with the varying relations which the embryo sustains toward the fetal appendages at different times, its circulatory system is distinguished snecessively by certain special features. Thus, during the activity of the yolk-sac as an organ of nutrition, the vitelline circulation is present; following and supplanting this is the allantoic circulation, which latter, in turn, gives place to, or, in faet, becomes the placental system of vessels.

\section{THE VITELLINE CIRCULATION AND THE ORIGIN OF THE BLOOD.}

The seat of the first formation of the blood-vessels and of the blood is the wall of the yolk-sae, entirely outside of the body of the embryo. The wall of the yolk-sac, the reader may be reminded, consists of the extra-embryonic splanchnopleure eovered with a part of the somatopleure. The mesodermic layer of the sae exhibits-at the end of the first day in the chick-a network made up of cords of cells. Interspersed throughout this network, as part of it, are groups of mesorlermic cells known as the blood-islands of 
Pander. Soon the cords composing the network become hollowed out so as to constitute an anastomosing reticulum of ressels, the cells which are to compose the walls of these vessels meanwhile aequiring the endothelial type. The remaining component cells of the blood-islands coincidentally undergo partial disintegration and liquefaction, by which their nuclei are set free. These nuclei, surrounded by a very small and inconspicuous envelope of protoplasm, are the primitive red blood-corpuscles and are, during the first month, the only corpuscular elements that the fetal blood contains. They differ essentially from the adult red corpuscles in the fact of their being nucleated. Their shape is at first spherical or spheroidal. Subsequently they entirely disappear. Other cells are added to the blood during the second month and afterward. Without discussing the unsettled question of the origin of the adult blood-cells-the red and the white corpuscles and the blood-plaques-it may be pointed out in passing that the liver is a very important source of the red corpuseles during fetal life.

Limiting the first network of vessels on the surface of the yolk-sac is a circular vessel, the sinus terminalis (Plate VI.). Since the yolk-sac is relatively so large that the body of the embryo appears to rest upon it, and since the surrounding somatopleure is translucent, a surface view of the ovum at this stage shows a vascular zone encircling the embryonic area and the later body of the embryo. This zone is the area vasculosa, or vascular area, the seat of the earliest formation of blood and of blood-ressels of the embryo.

The vessels, by a process of budding, grow from the vascular area along the vitelline duct into the body of the eminryo. Here they take their course toward the primitive heart, which has meanwhile been developing. From the anterior and posterior and lateral limits of the vascular area - nsing these terms with reference to the axis of the embryonic body-four pairs of vitelline veins converge toward the vitelline duct and unite to form the two vitelline or omphalomesenteric veins. These veins, after entering the body of the embryo, pass headward along the wall of the 
Plate VI.

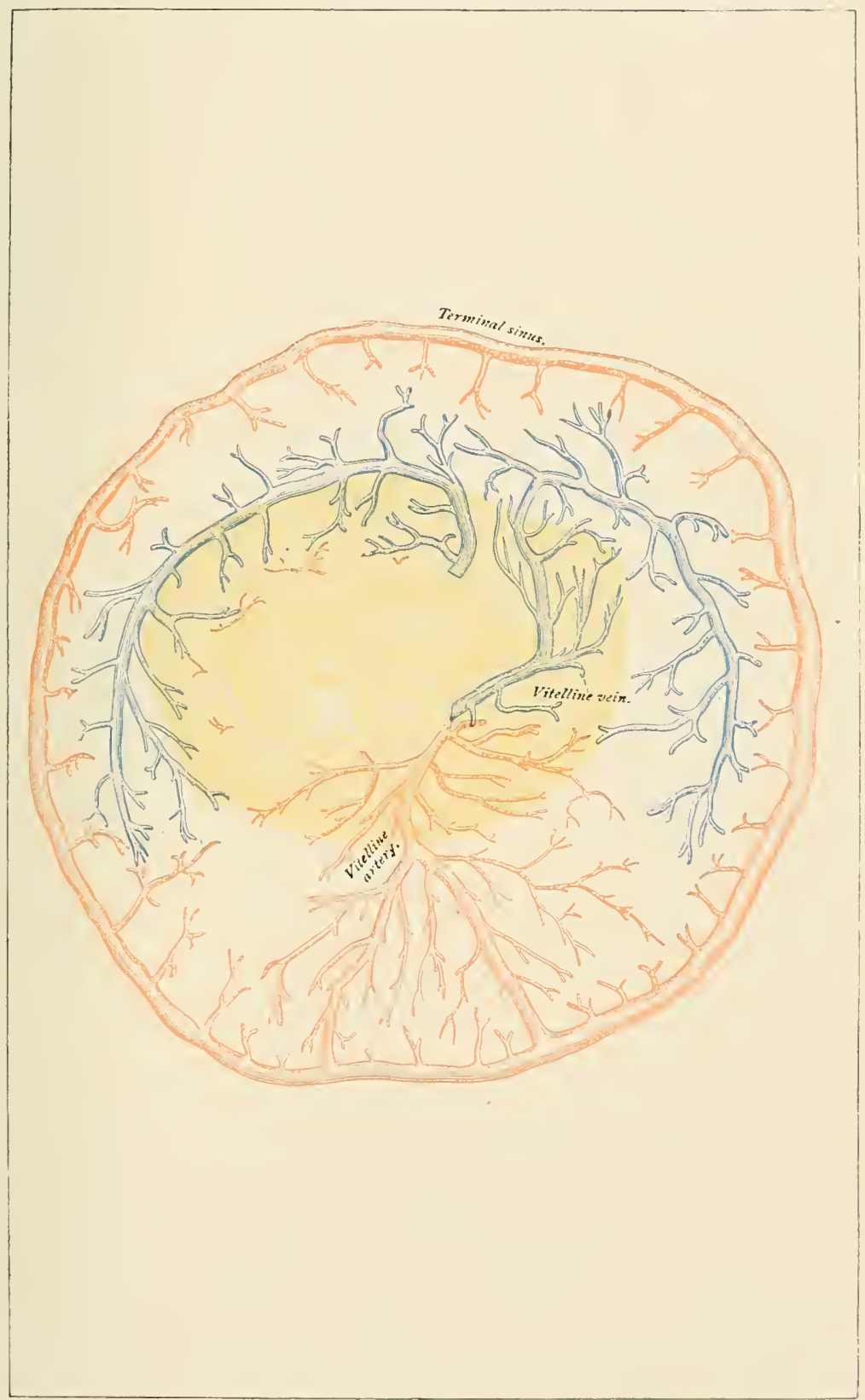

Vascular area of eleven-day rabbit embryo (E. von Beneden and Julin). The capillaries are not shown; the terminal sinus is seen to be arterial. 

intestinal tube and empty into the lower or candal end of the primitive heart. The trunks which are to constitute the vitelline arteries, after entering the body with the vitelline duct, pass upward along the dorsal body-wall, within the dorsal mesentery, to become continuous with large arterial trunks that have proeeeded from the primitive heart.

The large trunks referred to are the visceral-arch vessels, which unite to form the primitive aortre. The risceral-areh vessels (see Fig. 49) are a series of five pairs of arteries that arise by a common stem, the truncus arteriosus, from the upper end of the primitive heart. They pass along the respective visceral arches toward the dorsal surface of the borly where all the vessels of one side unite into a common trunk, the primitive aorta. The two primitive aortre, passing caudalward in the dorsal mesentery, give off, as their largest branches, the two omphalomesenteric or vitelline arteries above referred to. The development and the regression of the visceral-arch vessels correspond with the growth and the decadence respectively of the visceral arches. Not all the vessels are present in a fully-developed condition at any one time, the first pair having begun to atrophy before the fifth pair makes its appearance. The metamorphosis into certain adult vessels of such of them as persist will be considered in a later section.

This system of vessels constitntes the vitelline circulation, the manifest function of which is to convey nutritive material from the yolk-sac to the embryo. While the vitelline circulation is of great importance in any ovum provided with abundant nutritive yolk, snch as that of the bird, it is of comparatively slight consequence in man and the other higher mammals, and it must be regarded as a vestige of the aviau or reptilian ancestry of the mammalian ovum, or, at least, as a reminder that the mammalian ovum was originally provided with an abundant yolk. It must be borne in mind, however, that the mammalian blastodermic vesicle imbibes from the walls of the uterus a richly nutritive albuminous fluid, which may be taken up later and carried to the embryo by the vitelline circulation. This system of yolk-sac 
vessels disappears with the regression and disappearance of the yolk-sac-in the human embryo at about the fifth week.

To render the comprehension of the later phases of the vascular system more simple, their consideration is deferred until the development of the heart shall have been described.

\section{THE DEVELOPMENT OF THE HEART.}

The heart, when studicd in the lower-type animals, is seen to be morphologieally a dilated and specialized part of a vaseular trunk embedded in the ventral mesentery. In man, the first fundament of the heart appears at a very early period-namely, before the splanchnopleure has folded in to

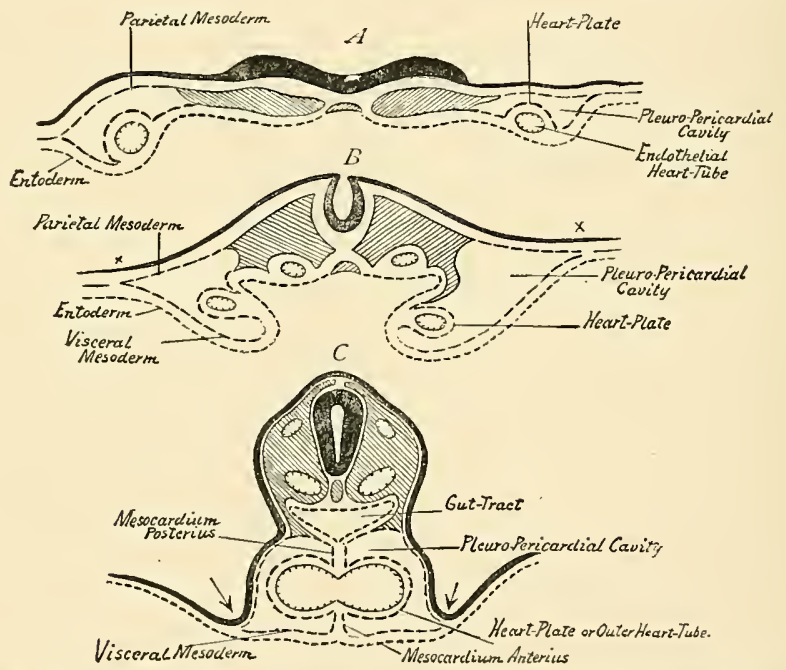

FrG. 61.-Schematic cross-section of rabbit-embryo to show development of heart; $A$, embryonic area with the germ-membranes still spread out; $B$, more advaneer stage, the splanchnopleure partly folded in; $C$, splanchnopleure folded in to form gut-tract, the two heart-tubes fused into one (after Strahl).

form the gut-tract, or, in other words, before the end of the second week. This fundament, in all higher vertebrates, is bilateral, having the form of two tubes produeed by vacuolation of the splanchnic mesoderm and lying widely separated, one in each lalf of the still spread out splanchnoplenre (Fig. 61, A). A transverse section through the future neek- 
region of a sheep- or rabbit-embryo shows the tubes cut across, since their long axes are parallel with that of the body (Fig. 62). With the folding in of the splanchuopleure and the union of the edges of its folds, the tubes are carried toward each other, and subsequently, by the disappearance of the tissue interrening between them, their carities become one (Fig. 61, $B$ and $C^{\circ}$ ). After the formation of the gut-

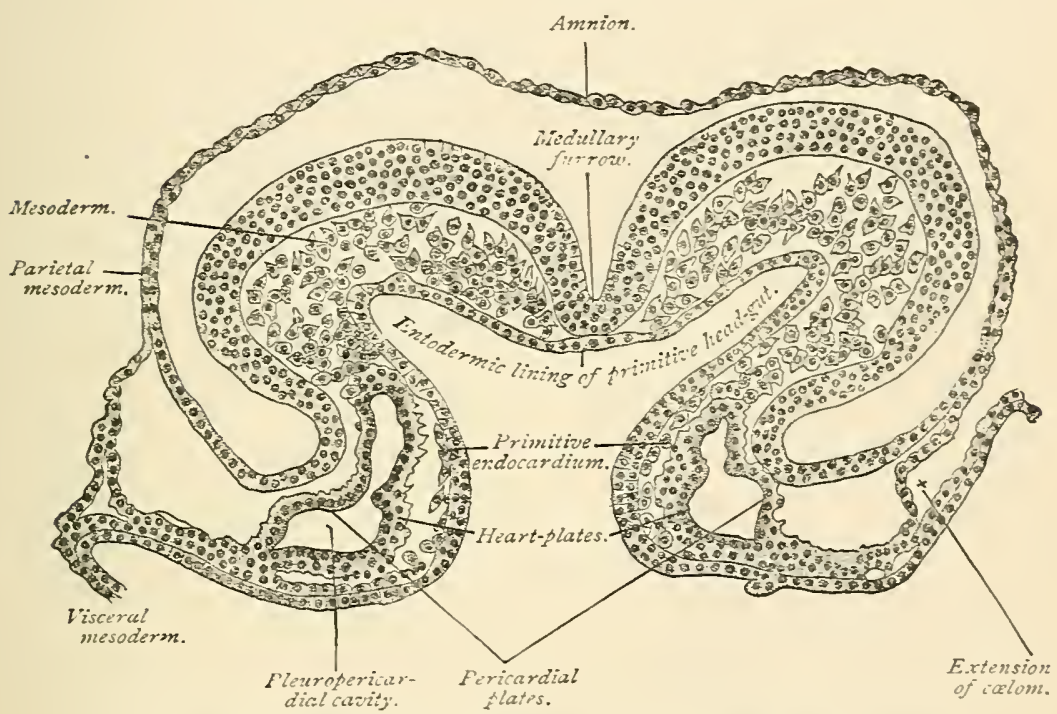

FIG. 62.-Transterse section of a sixteen-and-a-half-day sheep-embryo (Bonnet).

tract, therefore, and the simultaneous appearance of the ventral body-wall, the heart-fundament is a single straight mesodermic tube, situated in the pharrngeal region, in close relation with the ventral wall of the body, between the latter and the fore-gut. Reference to Fig. 61, C, will show that the heart-tube is separated from the body-cavity (or ecelom) on each side by a layer of the mesoderm, and that these two layers connect the heart dorsally with the gut-tract and ventrally with the bodr-wall, forming respectively the mesocardium anterius and the mesocardium posterius. These folds temporarily divide the upper portion of the body-cavity into two lateral parts. 
The disappearance of the stratum of mesoderm immediately surrounding the heart-tube and the differentiation of the tissue limiting peripherally the space thus formed, results in the production of a second larger tube enclosing the first. The cells of the outer tube become specialized into muscle-cells, which are to constitute the future heartmuscle, while those of the inner cylinder flatten and assume the endothelioid type to become the endocardium. The growth of centrally projecting processes from the muscular wall and the outpocketing of the endothelial tube to cover these processes and line the spaces enclosed by them foreshadow the spongy character of the inner surface of the adult heart, with its columnæ carneæ and musculi pectinati. It is significant, as showing the contractility of undifferentiated proto-
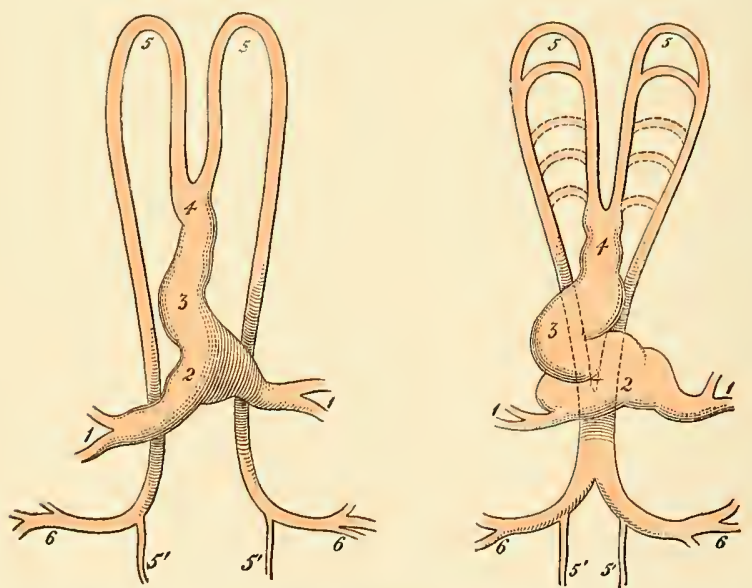

FIG. 63.-Diagrams illustrating arrangement of primitive heart and aortic arehes (modified from Allen Thomson: 1, vitelline veins returning blood from vascular area; 2 , venous segment of heart-tube; 3 , primitive ventricle; 4 , truneus arteriosus; 5,5 , upper and lower primitive aortæ; $5^{\prime}, 5^{\prime}$, continuation of double aortx as vessels to caudal pole of embryo; 6 , vitelline arteries returning blood to vaseular area.

plasmic cells, that the heart begins to pulsate even before the appearance of any muscular tissue in its walls.

The upper end of the heart-tube tapers away into the truncus arteriosus (Fig. 68, 4), a vessel which bifurcates into the first pair of visceral-arch vessels, while its lower ex- 
tremity receives the vitelline veins above referred to. Excessive growth in length, each end of the tube being more or less fixed in position, necessitates flexion or folding, the form which the heart-tube assumes in consequence being that of the letter S placed obliquely (Fig. 64, A). The renous
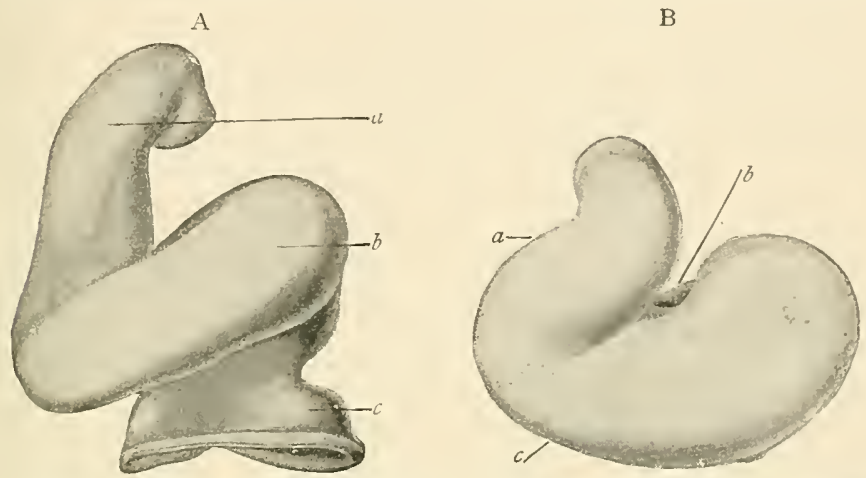

FIG. 6t.-A, heart of human embryo of $2.15 \mathrm{~mm}$. (His) : a, truncus arteriosus ; $b$, primitive ventricle; $c$, venous segment. $\vec{B}$, heart of human embryo of about $3 \mathrm{~mm}$. (His): $a$, truncus arteriosus; $b$, venous segment (behind); $c$, primitive rentricle (in front).

limb of the S lies caudad and toward the left, the arterial segment being direeted headward and toward the right, so that the two lie almost in the same coronal plane. These relations are soon altered by such a rotation around a longitudinal axis that the renous part of the heart comes to lie nearel the dorsal wall of the body, with the arterial portion ventral to it, both being brought at the same time into practically one transverse plane by the headward migration of the venous, and the tailward migration of the arterial, moiety. At this time the heart is relatively so large, and the rentral body-wall covering it so thin, that the organ appears as if situated outside of the embryo's body (Fig. 51, p. 104).

Simultaneously with these alterations in position, the arterial part of the heart is being marked off from the venous segment by a transverse constriction, the forner becoming the ventricle, the latter the auricle or atrium (Fig. 64, A). The narrow communication between the two is the auricular or atrioventricular canal, which soon acquires the primitive 
atrioventricular valves. The truncus arteriosus becomes delimited from the ventricle by a circular constriction, the fretum Halleri, the proximal part of the truncus arteriosus dilating somewhat to constitute the bulbus arteriosus. The truncus arteriosus divides into the visceral-arch vessels, as pointed out in the last section.

\section{The Metamorphosis of the Single into the Double} Heart.-The heart with but one ventricle and one auricle or atrium is found not only during the early periods of development in all air-breathing vertebrates, but is the permanent condition in fishes. In the development of the individual, as in the evolution of the higher vertebrate type, the appearance of the lungs, which replace the branchiæ of fishes as an aërating apparatus, is accompanied by a division of the leart

A

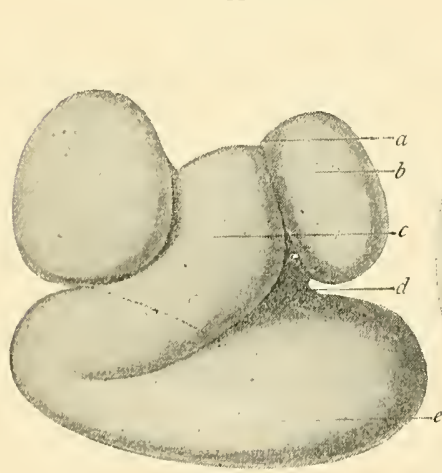

B

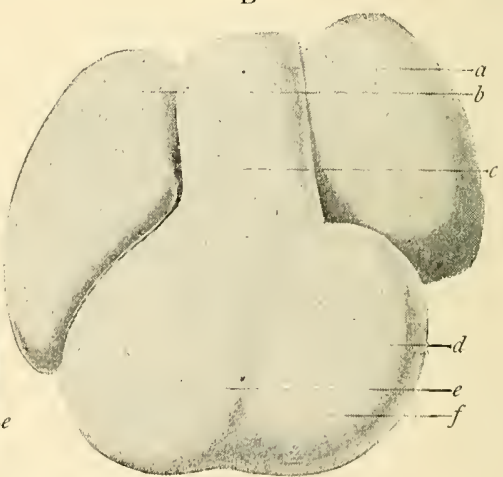

FIG. $65 .-A$, heart of human embryo of about $4.3 \mathrm{~mm}$. (His) : $a$, atrium ; $b$, portion of atrium corresponding with auricular appendage; $c$, truncus arteriosus; $d$, aurieular canal; $e$, primitive ventricle. B, heart of human embryo of about the fifth week (11is) : $a$, left auricle; $b$, right auricle; $c$, truncus arteriosus; $d$, interventricular groove; $e$, right ventricle; $f$, left ventricle.

into right and left halves for the pulmonary and the general systemic circulation respectively.

The division of the hnman atrinm begins in the fourth week with the growth of a perpendicular ridge from its dorsal and cephalic walls (Fig. 66, B), which extends toward the cavity and ultimately divides it into right and left auricles (Fig. 65). 'The atrioventricular canal, with its anterior and posterior 
ridges or valves, shares in this partition, becoming therehy the right and the left auriculoventricular orifices. The separation of the atrium, however, is not complete, since there remains in the septum an aperture, the foramen ovale, which persists until birth or shortly after.

The division of the ventricle, which follows that of the auricle and which is completed by the seventh week, is first indicated by a vertical groove, the sulcus interventricularis, scen on both the dorsal and the ventral surface (Fig. 65).
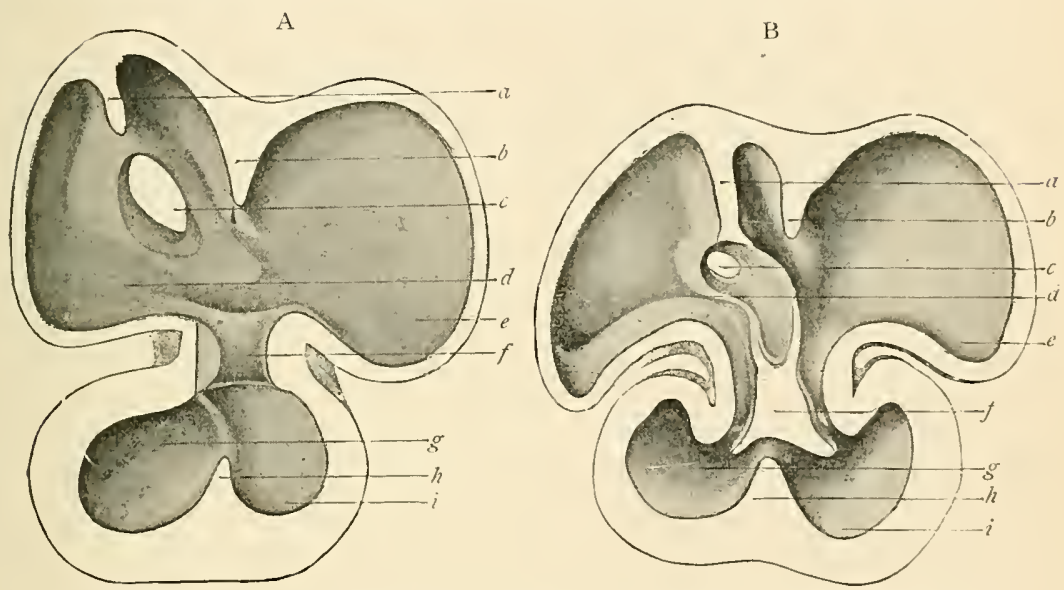

FIG. 66.-A, section of heart of human embryo of $10 \mathrm{~mm}$. (His): $a$, septum spurium; $b$, interauricular septum; $c$, mouth of sinus reuniens; $d$, right auricle; $e$, left auricle; $f$, anricular canal; $g$, right ventricle; $h$, interventricular septum; $i$, left ventricle. $B$, section of heart of human embryo of about the fifth week (His): $a$, septum spurium: $b$, auricular septum; $c$, opening of sinus reuniens (leader passes through foramen ovale); $d$, right atrium; $e$, left atrium; $f$, septum intermedium ; $g$, right ventricle; $h$, ventricular septum ; $i$, left ventricle.

From the internal surface, corresponding to the position of the sulcus, a median centrally projecting ridge appears and develops into a septum, thus producing the right and the left ventricles (Figs. 66 and 67 ).

The truncus arteriosus, after having become somewhat flattened by the growth of a vertical septum, or partition (Fig.

${ }^{1}$ Oecasionally the foramen ovale remains patulous for several weeks or months after birth or even throughout life. As this eondition allows the venous blood to mingle with the arterial, the surface of the body is bluish or cyanotic, and a child thus affected is said to be a "blue baby." 
$67, s)$, is divided into the aorta and the pulmonary artery. Thongh the three septa referred to develop independently of each other there is such correspondence between them, as to position, that the effect is as if they constituted one continuous strueture.

Before the division of the atrium into the anrieles, its walls ponch out on each side to form the auricular appendages, one of which belongs to each future auricle (Fig. 65). While it is still a straight tube, the heart receives at its venous extremity the two vitelline veins. Subsequently this particular part of the atrinm is distingnished as the sinus venosus or sinus reuniens, this being a short thick truuk into which empty, in addition to the vitelline veins, the duets of Cuvier and the umbilical veins. The mouth of the sinus venosus is guarded by a valve composed of two leaflets. In the division of the atrium the simns venosus falls to the right auricle, while emptying into the left auricle is the single pulmonary vein, which is formed by the union of the four pnlmonary veins. Still later, the simus venosus is merged into the wall of the right anricle, and hence the venons trunks above mentioned empty by separate orifices into its eavity.

The left leaflet of the valve at the month of the sinus venosns becomes atrophic; the right divides into two parts, one of which becomes the Eustachian valve at the orifice of the inferior vena cava, while the other forms the valve of Thebesius, or the coronary valve, at the opening of the coronary sinns (the latter being the persistent lower end of the left duct of (nvier). The Enstachian valve serves to direct the blood from the inferior cava through the foramen ovale so long as that aperture is present. The single pulmonary vein is in like manner incorporated in the wall of the left anriele, the four pulmonary veins in eonsequence aecpuring separate openings into that eavity.

The Valves of the Heart.-Before the division of the atrimm and the ventricle into right and left halves, the atrioventricular canal has the form of a transverse fissure, each lip of which is thickened into a ridge (Fig. 67, A). These ridges or endocardial cushions are the primitive valves. 
When the atrial partition grows down and the ventricular septum grows up, their free edges meet and unite with the ridges, each ridge being thereby divided, on its atrial surface by the atrial or interauricular septum, and on its rentricular aspect by the ventricular septum, into a right and a left half (Fig. $67, B$ ). Since the ridges, at their points of mion with
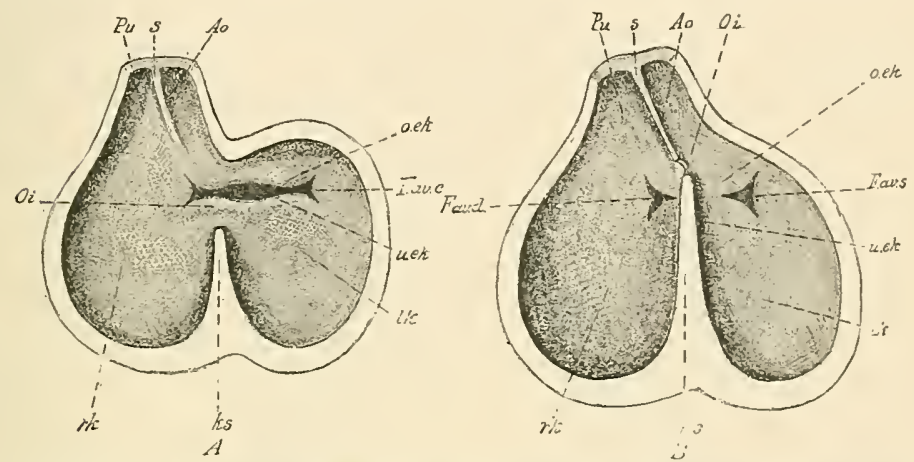

FIG. 67.-Two diagrams (after Born) to elucidate the changes in the mutual relations of the interventricular orifice and the ostium interventriculare as well as the division of the ventricle and large arteries. The ventricles are imagined to have been divided into halves; one looks into the posterior (dorsal) halves, in which, moreover, the cardiac trabeculæ, etc., have been omitted for the sake of simplifying the view. A, heart of an embryo rabbit, in which the head is $3.5-5.4$ $\mathrm{mm}$. long. The ventricle is divided by the ventricular partition $(k s)$ into a left and a right half as far as the interventricular orifice $(O i)$. The right end of the foramen atrioventriculare commune $(F . a v . c)$ extends into the right ventricle; the endocardial cushions $(o . e k, u . e k)$ are developed. $B$, heart of an embryo rabbit, head $7.5 \mathrm{~mm}$. long. The endocardial cushions $(o . e k, u . e k)$ of the foramen atrioventriculare commune are fused, and thereby the foramen atrioventricnlare commune is now separated into a foramen atrioventriculare dextrum $(F . u v . d)$ and sinistrum $(F, a r, s)$. The ventricular partition $(k s)$ has likewise fused with the endocarditl cushions, and has grown forward as far as the partition ( $(\varepsilon)$ of the truneus arteriosus. By the elosure of the remnant of the ostium interventriculare $(O i)$ the septum membranaceum is formed; $r k$, right, $l k$, left ventricle; $k s$, ventricular partition; $P u$, arteria pulmomalis; $A$ o, aorta ; $s$, partition of the truncus arteriosus ; $O i$, ostium interventriculare; $F$. av, $c$, foramen atrioventriculare commune; $F . a v, d$ and $F . a v . s$, formen atrioventriculare dextrum and sinistrum; o.ck, u.ek, upper and lower endothelial or endocardial cushions.

the septa, fuse likewise with each other, the original orifice is bisected into the right and left auriculoventricular apertures, the only valves of which are the ridges or cushions in question.

To trace the further development of the fully formed valves, it will be necessary to ennider the changes which 
now take place in the walls of the heart. It has been seen that the inner surface of the heart acquires a spongy or trabecular structure at a very early stage by the inward projection of muscular processes from the onter tube and the ponching out of the inner endothelial tube to cover these. The wall of the ventriele in consequence is relatively very thick and is made up largely of a network of fleshy columns, the spaces of which network are lined with the endocardium (Fig. 68, A). While the outer stratum of the ventricular
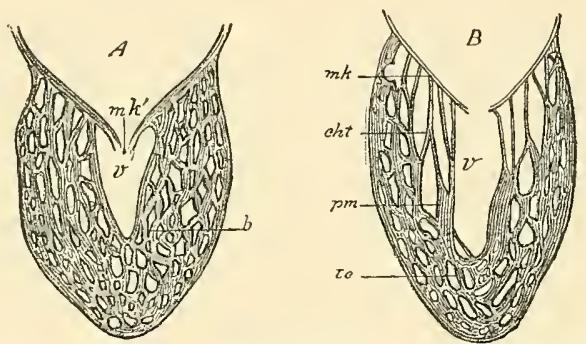

FIG, 68.-Diagrammatic representation of the formation of the atrioventricular valves: $A$, earli $\lrcorner, B$, later condition (after Gegenbaur): $m k$, membranous valve; $m k^{\prime}$, the primitive part of the same; cht, chordæe tendineæ; $v$, cavity of the ventricle; $b$, trabecular network of cardiac musculature; $p m$, papillary muscles; $t e$, trabeculæ carneæ.

wall now becomes more compact by the thickening of the trabeculre-and, to some extent, by their coaleseence-the trabeculæ in the vicinity of the atrioventricular valves diminish in thickness and lose their muscular character, being replaced by thin connective-tissue cords (Fig. 68, B). That part of the ventricular wall which surrounds the atrioventricular orifice and to which the endocardial cushions or primitive valves are attached, likewise becomes deprived of muscle-cells, the remaining connective tissue assuming the form of thin plates. These plates, with the former endocardial cushions attached to their edges, constitute the permanent auriculoventricular valve-leaflets. The strands of connective tissne mentioned above as remaining after the degeneration of certain of the muscle-trabecula are the chordæ tendineæ of the adult heart. Attached at one end to the valve-leaflets, their other extremity is entinuous 
with trabeculæ that have remained muscular, the adult musculi papillares.

The semilunar valves of the aorta and pulmonary artery appear when the trmens arteriosus divides to form those vessels. The orifice of the trmens arteriosus is provided with a valve having four leaflets (Fig. 69, A). By the dirision of this ressel into the pulmonary artery and the aorta (Fig. 69, $B$ and $C$ ), the lateral leaflets are bisected, the anterior half of cach, with the anterior leaflet, going to the anterior vessel-the pulmonary artery-while each posterior or dorsal half, with the dorsal leaflet, falls within the orifice of the aorta. The resulting disposition of the segments of the aortic and pulmonary valves is such that, in the aorta, two leaflets are situated anteriorly and one posteriorly, while in the case of the pulmonary artery these conditions are reversed (Fig. 69, C). In the fully developed leart, however, it is found that the aorta has two posterior leaflets and one anterior, and that the pulmonary artery presents one posterior
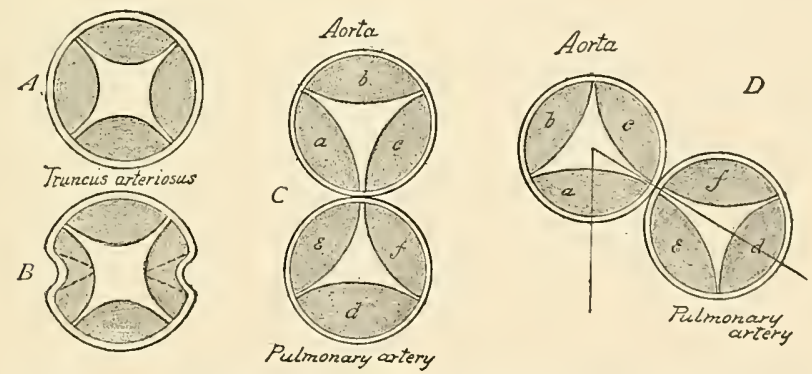

Fig. 69.-Scheme showing division of truncus arteriosus and its valve-leaflets into aorta and pulmonary artery with their leaflets. The division begins in $B$, the lateral leaflets dividing respectively into $a, e$ and $c, f$. Rotation from right to left shown in $D$.

and two anterior segments. In the division of the truncus arteriosus, the anterior half, or the pulmonary artery, fills to the right ventricle, and the posterior trunk, the aorta, to the left ventricle, the two ventricles lying side by side. In order, therefore, that the ventrieles may aequire the relative positions which they hold in the adult there must be such a rotation that the left ventricle comes to lie behind the right. 
This rotation of the heart from right to left necessarily alters the relation of the pulmonary artery, eausing it to lie not direetly in front of the aorta, but in front and to the left. If one conceives of a rotation of the two vessels from right to left through an arc of 60 degrees around a vertical axis, the altered relation of the pulmonary and aortic leaflets beeomes at once intelligible (Fig. 69, $C$ and $D$ ).

\section{The allantoic and THE Placental circulation.}

The development of the allantois and its accompanying system of blood-vessels is simultaneous with the decline of the yolk-sac and the vitelline circulation. Since the allantois is an evagination from the gut-tract (see p. 80), it is a splanchopleuric sac, its walls eonsisting therefore of an entodermie and a mesodermie layer. Blood-vessels develop within the mesodermic stratum as extensions or branches of previously existing intra-embryonie trunks. These vessels are the allantoic arteries and veins. The two allantoic arteries are branches of the primitive aorta and leave the body of the fetus, in company with the neck of the allantois, at the umbilieus. Having reached the peripheral part of the allantois, they break up into a capillary plexus, the extension of which into the villous proeesses of the false amnion eompletes the union of that structure with the allantois to form the true ehorion (Plate III.).

The two allantoic veins develop pari passu with the arteries and convey the blood from the chorion to the fetus. Entering the body of the fetus through the still large umbilical aperture, they find their way along the intestinal tube to the septum transversum - which structure may be regarded as the primitive diaphragm-to the region of the heart, where they open into the duets of Cuvier. Fach duct of Cuvier (Fig. 72, A) is formed by the union of the primitive jugular vein with the cardinal vein of its own side, the cardinal and the jugular veins returning the blood respectively from the lower and upper parts of the trunk. This system of bloorl-vessels constitutes the allantoic circulation; it is of great importance in any orum theit is developed outside of 
the body of the mother, as in the case of birds, reptiles, and fishes, in which classes the allantois is the organ of nutrition from the time that the yolk-sic ceases to perform that function until development is complete. In man, however, as in all other mammals except the monotremes and marsupials, the allantoic circulation may be looked upon as, in a measure, rudimentary, since it serves to convey nutriment from the chorion to the fetus only until the formation of the placenta.

The placental system of blood-vessels, appearing in the third month with the development of the placenta, includes the principal trunks of the former allantoic system, the allantoic arteries and veins having becone the umbilical vessels. The two umbilical arteries convey impure blood from the fetus to the placenta, where it cireulates through the capillaries of that organ and receives oxygen and nutriment from the blood of the mother. As before stated, there is no intermingling of the fetal and the maternal blood, the two currents being separated by the very thin walls of the capillaries, through which osmosis oceurs. The purified blood returns to the fetus through the umbilical veins and reaches the right auricle through the inferior vena cava, a portion of it having passed through the liver. 'The two umbilical veins which are present for a time fuse subsequently to form a single vein. The complicated details of the arterial and the renous trunks, and the relation of the latter to the development of the liver and its special system of vessels, may be advantageously considered in separate sections.

\section{THE FETAL ARTERIAL SYSTEM.}

The truncus arteriosus, the large artery which arises from the, as yet, undivided ventricle of the heart, bifurcates into two trunks, the first pair of visceral-arch vessels (Fig. T0, 4). These first visceral-arch ressels, also sometimes called the first aortic arches, rum from the ventral surface of the body along the first visceral arches, toward the dorsum, whele they curve downmard and pass caudalward, one on each side of the median line, in front of the primitive vertebral column. Very soon there arise from the truncus arteriosus below the 
point of origin of the first vessels, four additional pairs of visceral-arch vessels, which similarly pass dorsad along the corresponding visceral arches, and which unite with the dorsal part of the first pair to form the primitive aorta of each sicle. Each primitive aorta results, therefore, from the confluence of all the visceral-arch vessels of its own side
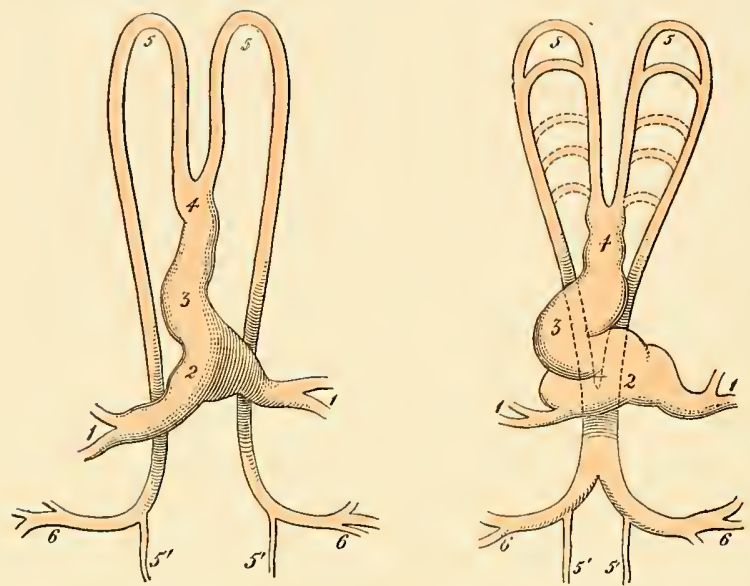

FIG. 70,-Diagrams illustrating arrangement of primitive heart and aortic arches (modified from Allen Thomson: 1, vitelline veins returning blood from vascular area; 2 , venous segment of heart-tube; 3 , primitive ventricle; 4 , truncus arteriosus; 5,5 , upper and lower primitive aortæ; $5,5^{\prime}$, continuation of double aortæ as vessels to caudal pole of embryo; 6 , vitelline arteries returning blood to vascular area.

(Fig. 70). The two aortæ afterward become merged into a single trunk. At first the principal branches of the aorta are the vitelline arteries. As these latter vessels become inconspicuous, the allantoic or umbilical arteries come into prominence as the chief branches. Indeed, the umbilical arteries may be said to be the continuation of the aorta, since the largest part of the blood-stream is diverted into them. The aorta proper continnes in the median line as the caudal aorta, which latter is represented in the adult by the middle sacral artery.

So fir the arterial system of the fetus presents an absolutely symmetrical arrangement (Fig. 70). Changes very soon occur, however, which lead to the asymnetrical condition 
found in the adult. These changes are due to the atrophy of some trunks and the preponderance of others. From the point where the dorsal extremity of the fourth arch joins the fifth, a branch passes to the rudimentary arm (Fig. 71 ).

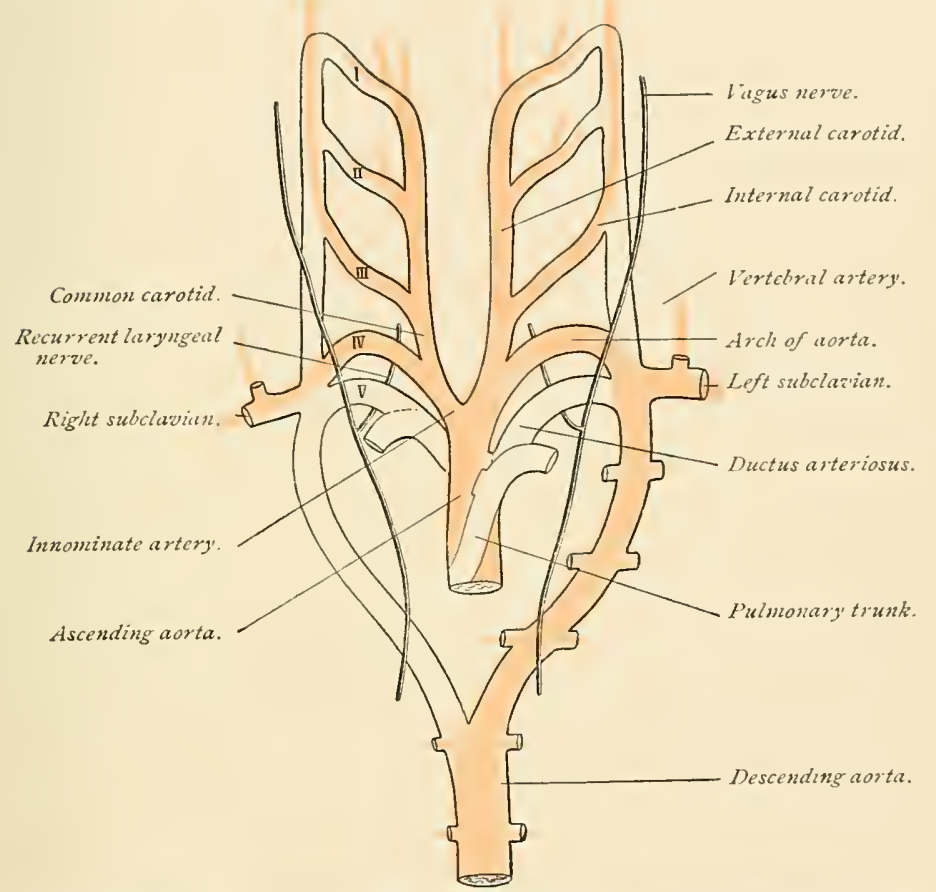

FIG. 71.-Diagram illustrating the fate of the aortic arches in mammals and man (modified from Rathke).

The first and second arches, except their ventral and dorsal limbs, undergo atrophy. The ventral limbs of the first and second arches persist and become the external carotid artery, while their dorsal extremities, with the third visceral-arch vessel, become the internal carotid artery. The ventral stem of the third arch constitutes the common carotid. The right fourth-arch vessel becomes the right subclavian, its stream of blood being conveyed to the arm by the branch which has taken its origin from the point of junction of the dorsal ends of the fourth and fifth arches. This latter branch is there- 
fore the continuation of the subclavian. The ventral segment of the right fourth arch would be represented in the adult by the innominate artery. The fourth arch of the left side assumes a lower position ; sinking into the thorax, it becomes the arch of the aorta. Since the right fifth arch becomes atrophic, the dorsal end of the right fourth-arch vesselthe future right subclavian artery-loses its comnection with the primitive aorta, and the latter now appears as the continuation of the left fourth areh. The ventral stem of the left third arch, which beeomes the futme left common carotid, and also the left subclavian, which arises from the posterior or dorsal end of the left fourth areh, are now branches of the arch of the aorta. When the truncus arteriosus becomes divided into the aorta and the pulmonary artery, the left fifth-arch vessel is the only one of the branches of the truncus that falls to the pulmonary artery, all the other visceral-arch vessels being connected with the aorta. The left fifth visceral-arch vessel therefore is represented in the adult by the pulmonary artery. The fetal lungs being impervious, only a very small part of the blood of the pulmonary artery is sent to them. The larger portion of the blood passes from the pulmonary artery to the aorta through a communicating trunk, the ductus arteriosus, which becomes impervious after birth with the establishment of the proper pulmonary circulation.

These transformations afford an explanation of the different relations of the recurrent laryngeal nerves of the two sides. At first they are symmetrically arranged. The pneumogastrie nerve, as it crosses the fourth visceral-areh vessel, gives off the recurrent laryngeal nerve, the latter winding around the artery from before backward on its way to the larynx. When the left fourth arch becomes the arch of the aorta and sinks into the chest, the nerve is carried with it; hence after this time, the left nerve is found winding around the areh of the aorta.

Anomalous arrangements of the branches of the aortic arch, as well as of the arch itself, are referable to anomalous development of the original system of visceral-arch vessels. 
For example, if the right fourth arch, which usually becomes the right subclavian artery, be suppressed from its origin to the point where the artery for the right upper extremity is given off, the blood must find its way into the latter vessel through the dorsal stem of the fourth arch, and this dorsal stem will then become the right subelavian artery. In such ease, the right subclavian of the adult will be found to arise from the left extremity of the arch of the aorta and to pass obliquely upward to the right side of the neck behind the trachea and the esophagus.

\section{THE FETAL VENOUS SYSTEM.}

The venous system of the embryo presents several successive phases, corresponding in part with the various stages in the evolution of the arterial system. The first trunks to appear are the vitelline veins. These vessels have their origin in the vascular area on the wall of the yolk-sac in the manner already described in connection with the vitelline circulation. The two vitelline or omphalomesenteric veins, which result from the convergence of all the venous trunks of the vascular area, follow the vitelline duet into the body of the embryo through the still widely open umbilical aperture and take their course headward along the intestinal canal to open into the caudal end of the primitive heart-tube (Fig. 70, 1, 1). At a later period they open into the sinus venosus of the heart, and still later, when the sinus venosus becomes a part of the general atrial cavity, into the atrium itself. Near their termination these reins eommunicate with each other by anastomosing trunks that encircle the future duodenal region of the intestinal tube. As the yolk-sac diminishes in size and importance, the vitelline reins decrease in caliber, and the umbilical veins, conveying blood from the allantois and subsequently from the placenta, functionally replace them. The proximal parts of the vitelline veins have an important connection with the circulation of the liver, as will be seen hereafter.

The umbilical veins, which are developed in the mesorlermic tissue of the allantois, pass from the placenta along the umbilical cord and, entering the fetal body at the umbilieus, 
run at first along the lateral, and later along the ventral, wall of the abdomen toward the heart. Meanwhile there have been established a pair of venous trunks, the primitive jugular veins (Fig. $72, A$ ), to return the blood from the head and the upper part of the trunk; and a second pair, the cardinal veins, which bring the blood from the lower part of the trunk, and especially from the primitive kidneys. The primitive jugular vein-which represents the external jugular of the adult-passing downward along the dorsal region of the neck, meets the cardinal rein of its orm side and unites with it near the heart, the short thick trunk thus formed being the duct of Cuvier. The right and left duets of Cuvier converge and open together into the sinus venosus (sinus reuniens) of the heart, which also now receives the vitelline veins and the umbilical veins. Upon the development of the upper and the lower limbs, the eardinal vein appears as if formed by the confluence of the internal and external iliac veins, while the primitive jugular below the entrance of the subclavian vein is designated, with the duct of Cuvier, the superior vena cava, since, owing to the preponderance of the jugular over the cardinal vein, the Cuvierian duct appears to be a direct continuation of the jugular. At this time, then, there are two superior venæ cavæ, the terminal parts of which, however, are not exactly symmetrical, since the left passes around the dorsal or posterior wall of the atrium, owing to the rotation of the heart from right to left.

The lower venous trunks likewise present a symmetrical arrangement. The bilateral symmetry of this stage of the venous system, while permanent in fishes, becomes modified in man to produce the familiar asymmetrical condition of the adult venous trunks by two factors principally-first, the development of an unpaired ressel which is to constitute a part of the inferior vena cava, and second, the atrophy of certain vessels and parts of vessels with a consequent diversion of the major part of their blood-stream into other channels. Associated with these alterations is the evolution of a special set of blood-vessels, the portal venous system, for the supply of the developing liver. The development of the 
portal system, however, may be deferred for separate consideration (see page 161).

When the sinus venosus beeones a part of the atriumconstituting that part of the wall of the adult auricle which is destitute of musculi peetinati-the two ducts of Cuvier, or the superior cavæ, as well as the veins from the abdominal viscera, open by separate orifices into the atrial cavity. An unpaired vessel now develops below the heart in the tissue be-

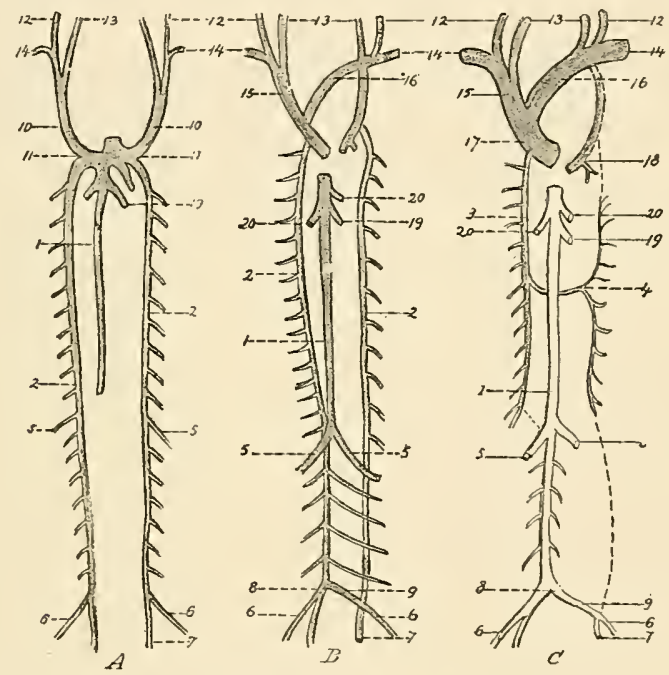

FIG. 72.-Schematic representation of the human venous system, with three successive stages of development (after Hertwig): 1, vena cava inferior; 2 , cardinal veins; 8 , vena azygos major ; 4 , vena azygos minor; 5 , renal veins ; 6 , external iliac vein; 7 , internal iliac vein; 8 and 9 , common iliac veins; 10 , early superior venæ cavæ; 11, ducts of Cuvier; 12 , primitive jugular vein; 13 , internal jugular; 14 , subclavian vein; 15 and 16 , right and left innominate veins; 17 , vena cava superior; 18, coronary vein; 19 , duct of Arantius; 20, hepatic veins.

tween the primitive kidneys (Fig. $72, A, 1$ ). This constitutes the upper or carliac segment of the inferior vena cava. 'The lower extremity of this trunk anastomoses by two transverse branches with the right and the left cardinal veins (Fig. 72, B). The cardinal veins of the two sides are further connected by a transverse trunk at their lower extremities and by one that passes across the vertebral column just below the heart. In like manner the two superior vense cave commu- 
nicate with each other by a transverse vessel, the transverse jugular vein, at the upper part of the thorax, above the arch of the aorta. With the exception of the mnpaired trunk which is destined to constitute the upper part of the inferior vena cava, the arrangement of the veins at this time is absolutely symmetrical. The apparently meaningless asymmetry of the adult venous trunks is easily accounted for if one notes the alterations in the course of the blood-current which now occur.

The blood-stream of the left superior vena cava gradually becomes entirely diverted into the right cava through the transverse jugular vein, and the part of the left cava below this point, being now functionless, shrivels to an impervions cord (Fig. 72, $C$ ). This cord or strand of tissue, the remnant of the left superior cava, is found in postnatal life, in front of the root of the left lung, embedded in a fold of the serous layer of the pericardium, the so-called vestigial fold of Marshall. Since the left superior vena cava receives, near its termination in the auricle, the large coronary vein, which returns the greater part of the blood from the heart-wall, this proximal extremity of the left cava persists as the coronary sinus of the heart. The transverse communicating trunk-the transverse jugular vein-and the part of the left cava above it now constitute the left innominate vein, the course of which from left to right is thus explained. The left superior vena cava of the fetus is represented in the adult, therefore, by the sinus coronarius, by the atrophic impervious cord lying in Marshall's vestigial fold, by the vertical part of the left innominate vein and by a part of the left superior intercostal vein.

The lowest connecting branch between the cardinal veins enlarges and conveys to the right cardinal vein the blood from the left internal and external iliac veins (Fig. 72), in consequence of which the part of the left cardinal vein below the kidney undergoes atrophy and, finally, complete obliteration. 'The newly-formed transverse trunk is the left common iliac vein. The part of each carlinal vein above the renal region suffers an arrest in growth, in consequence 
of which the blood is diverted from these veins into the transverse anastomosing branches before mentioned as connecting the respective cardinal veins with the lower end of the unpaired caval trunk (Fig. 72, $B$ and $C, 5$ ). As a result, the lower half of the right cardinal vein, now receiving at its distal end the two common iliac veins, becomes directly continuous with the unpaired caval trunk, and with it constitutes the inferior vena cava. The inferior vena cava, therefore, is partly an independently formed structure and is partly the greatly developed lower half of the right eardinal vein. The upper half of the right cardinal vein, conveying now a relatively small part of the blood-stream, becomes the vena azygos major, the termination of which in the superior vena cava is explicable when it is borne in mind that the cardinal and the primitive jugular veins, by their confluence, form the duct of Curier.

While no part of the right cardinal vein suffers complete effacement, the left one, in a part of its course, entirely disappears. All the blood of the left external and internal iliac veins being transported to the right side of the body through the lowest transverse trunk-that is, the newly-formed left common iliac vein-the part of the left cardinal vein below the kidney retrogrades and disappears. The part of the left cardinal above the renal region lagging behind in growth, the blood from the left kidney is eonveyed to the inferior vena cava by the transverse trunk that connects the cardinal veins in the renal region; this transverse trunk becomes, therefore, the left renal vein. Since the spermatic veins originally emptied into the cardinal veins, it is found, after these transformations, that the right spermatic opens into the inferior rena cava, while the left spermatic is a tributary of the left renal vein. Some anatomists, indeed, regard the left spermatic vein as the representative of the lower part of the left earlinal vein of the fetus.

As the left renal vein develops into the channel for the major part of the blood from the left kidney, the portion of the left cardinal rein above this point remains an inconspienons ressel, and that part of it intervening betreen the 
duct of Cuvier and the cross branch (Fig. 72, $C, 4$ ) situated immediately below the heart undergoes total obliteration. 'The blood ascending through the persisting part of the left cardinal vein must therefore pass across to the upper part of the right cardinal vein, now the vena azygos major; and the pervious portion of the left cardinal vein, with the transverse trunk referred to, constitutes the vena azygos minor.

\section{THE FORMATION OF THE PERICARDIUM, THE PLEURA, AND THE DIAPHRAGM.}

The development of the pericardium is so intimately related with that of the pleuræ and of the diaphragm that an account of it involves a description of the evolution of those structures. By way of facilitating a comprehension of the rather complicated details of the process, the reader is reminded that the tube which constitutes the primitive heart is formed by the coalescence of the two tubes produced within the splanchnic mesoderm, and that this tube and also, for a time, the heart resulting from it, are embedded within the ventral mesentery; and, further, that the part of the ventral mesentery connecting the heart with the ventral
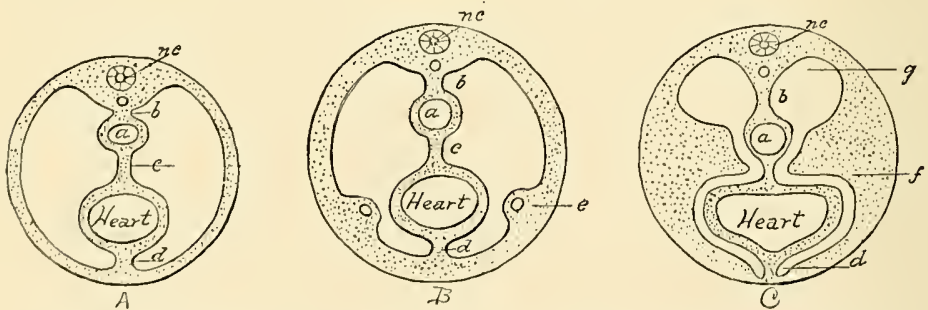

Fig. 73.-Diagrammatic cross-sections of the body of the embryo in the region of the heart at level of future diaphragm : $a$, esophageal segment of gut-traet; $b$, dorsal mesentery; $c$, mesocardium posterius; $d$, mesocardium anterius; $e$, beginning of septum transversum, containing vitelline and allantoic veins; $f$, septum transversum ; $g$, thoracic prolongation of abdominal cavity; $n c$, neural canal.

borly-wall is the mesocardium anterius, while the fold passing from the heart to the gut-tract is the mesocardium posterius (Fig. 73, A, and Fig. 61, C). The space between the heart and the body-wall is a part of the body-cavity or coelom (throat-cavity of Koilliker, parietal cavity of His). The 
first indication of the separation of this space from the future abdominal cavity is furnished by the appearance of a transverse ridge of tissue growing from the ventral and lateral aspects of the body-wall. This mass is the septum transversum. It bears an important relation to the course of the vitelline and the umbilieal veins. As the veins diverge from the body-wall to reach the heart, they carry with them, as it were, the parietal layer of the mesoderm in which they are embedded, forming on each side a fold that projeets mesially and dorsally (Fig. 73, $B$ and $C$ ), the two folds approaching and finally meeting with the rentral mesentery in the median plane. The septum transversum thus formed contains in the region nearer the intestine a mass of embryoual connective tissue which is called the liver-ridge or prehepaticus from the faet that the developing liver grows into it. Since the septum transversum, exclusive of the so-ealled liver-ridge, is the primitive diaphragm, it will be scen that the liver, in the early stages of its growth, is intimately associated with the anlage ${ }^{1}$ of the diaphragm. The septum transversum partially divides the body-carity into a perieardiothoracic and an abdominal part, as shown in Fig. 73, $B$ and $C$. Near the dorsal wall of the trunk, on each side of the intestine and its mesentery, the septum is wanting, and thus the two spaces communicate with each other by openings that are known as the thoracic prolongations of the abdominal cavity. At this stage, then, the four great serous sies of the body, the two pleural, the pericardial, and the abdominal, are indicated, but are still in free communication with each other.

The pericardial cavity is the first one of these to be closed off; subsequently the pleural sacs are delimited from the abdominal space. Just as the transverse septum, which partly forms the floor of the thoracie carity, holds an inportant relation to the course of the vitelline and the umbilical veins on their way to the heart, so is a vertical septum

1 Anlage, a German word signifying groundwork, or, in embryology, the first crude outline of an organ or part, has come into use in English writings upon the subject hecanse there is no exact English equivalent for it. 
(Fig. 74, $A, b$ ) which separates the pericardial space from the pleural spaces associated with the position of a large vein. This vein, the duct of Cuvier, formed in the upper part of the thorax by the confluence of the cardinal and the jugular veins, lies at first near the dorsal body-wall and then along its lateral aspect. In the latter position it encroaches upon the pleuropericardial space and is covered by the somatic or parietal mesoderm (Fig. 74, A). It is this inwardly project-

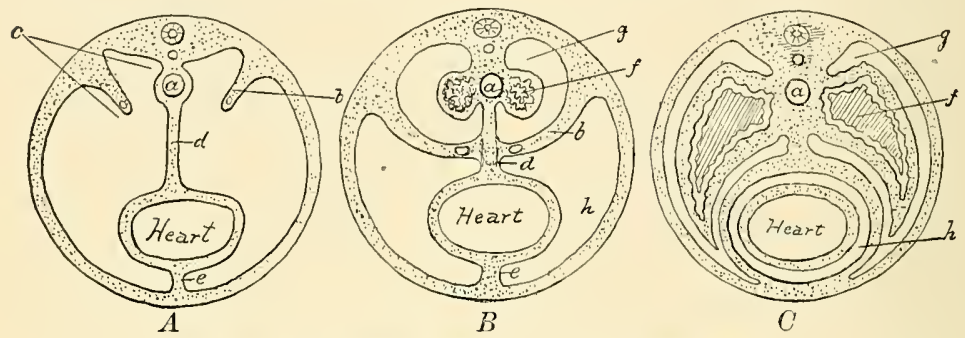

FIG. 74.-Diagrammatic cross-sections of the body of the embryo in the region of the heart entirely above the level of the diaphragm: $a$, esophagus : $b$, pleuropericardial fold containing duct of Cuvier; $c$, pleuropericardial space; $d$, mesocardium posterius; $e$, mesocardium anterius; $f$, lung; $g$, pleural cavity; $h$, pericardial cavity.

ing vertical fold of serous membrane containing the duct of Cuvier which constitutes the pleuropericardial fold and the appearance of which initiates the division of the thoracic cavity into two spaces, one for the heart and one for the lungs. The pleuropericardial fold continues to grow toward the median plane of the body until it meets the mesocardium posterius (Fig. 74, B), with which it fuses, thus completing the pericardial sac $(h)$ and isolating it from the pleural space $(g)$.

The heart is still relatively very large and occupies the greater part of the thoracic cavity, leaving only a comparatively small space, situated dorsally, for the accommodation of the developing lungs. This latter space, as previously mentioned, remains for a long time in communication with the abdominal cavity by the two thoracic prolongations of the latter, which lie one on each side of the intestinal tube and its mesentery (Fig. 73, $C$, and Fig. 74, A, B). Reference to Fig. $74, \dot{B}$, will show that these tube-like spaces are enclosed completely by serous membrane and that they are 
entirely distinct from each other. It is evident also, that the mesial wall of each space is constituted by the mesocardium posterius and the dorsal mesentery. The lungs first appear as two little sacs, connected by a common pedicle, the future trachea, with the upper end of the esophagus. As they grow downward in front of the esophagns and in contact with it, they push the serons membrane before them carrying it away from the esophagus (Fig. $\varangle 4, B$ ), and thus they acquire an investment of serous membrane, which is the visceral layer of the pleura. The layer of serous membrane in contact with the body-wall is the parietal layer of the pleura. The lower extremities of the lungs at length come into relation with the upper surface of the liver, from which organ they are finally separated by the growth of two folds, the pillars of Uskow, from the dorsolateral region of the body-wall. These folds or ridges project forward and unite with the earlier formed septum transversum to complete the diaphragm. So far, howerer, the diaphragm is merely connective tissue, the muscular condition being acquired later by the ingrowth of muscular substance from the trunk. Occasionally the dorsal or younger part of the diaphragm fails to unite with the ventral or older fundament on one side of the body, leaving an aperture through which a portion of the intestine may pass into the thoracic carity. Such a condition constitutes a congenital diaphragmatic hernia.

The heart and its pericardial sac occupy the greater part of the thoracic cavity, while the lungs are merely narrow elongated organs lying in the dorsal part of this space as shown in Fig. $74, B$. As the lungs increase in diameter, they spread out rentrally and gradually displace the parietal layer of the pericardium (Fig. $74, B$ ) from the lateral wall of the chest, crowding the pericardium forward and toward the median plane of the borly (see Fig. $7 t, C^{\prime}$ ) until finally the adult relationship of these structures is established.

\section{THE PORTAL CIRCULATION.}

The circulation of the adnlt liver is peculiar in that the organ is supplied not only with arterial blood for its nutrition 
but receives also venous blood larlen with certain products of digestion obtained from the alimentary tract, the spleen, and the pancreas. This venous blood enters the liver through the portal vein and is designed to supply to the gland the materials for the performance of its special functions.
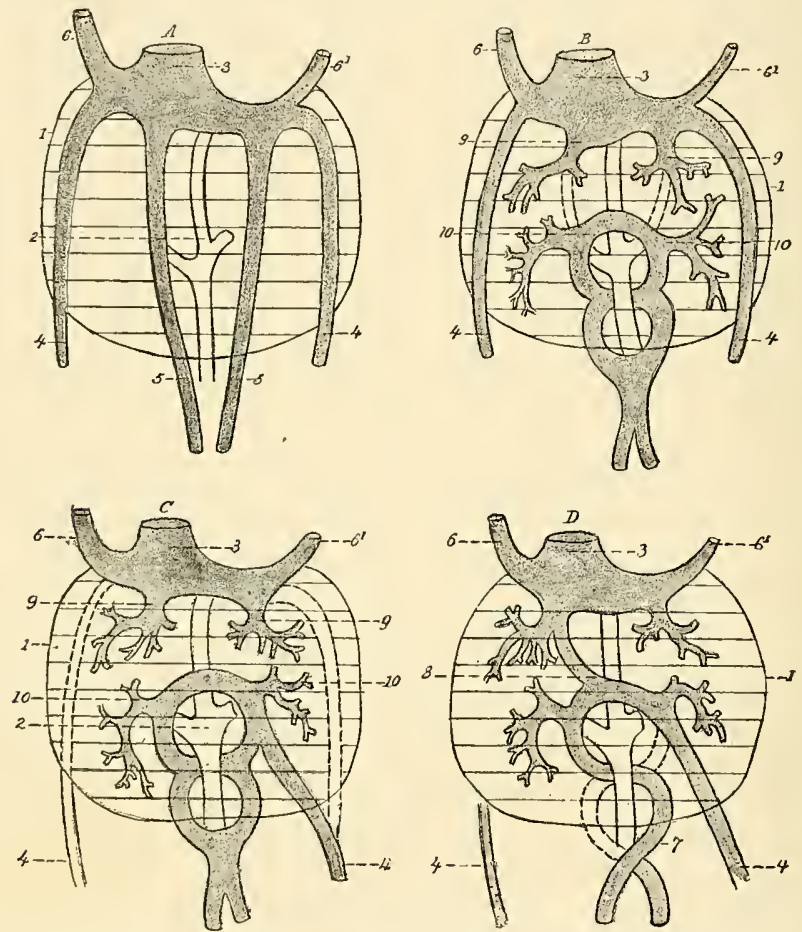

FIG. 75.-Four snecessive stages in the development of the portal venous system (from Tourneux, after His) : 1, outline of liver; 2 , duodenum ; 3 , sinus venosus; 4,4 , umbilical veins; $5,5, A$, vitelline veins, which in $B$ and $C$ are conneeted by the annular sinus; 6 , superior vena cava: 6 , coronary vein; 7 , portal vein; 8 , ductus venosus; 9,9 , venæ hepaticæ revehentes; 10 , 10, venæ hepatica advehentes.

As might be expected from the fact that the liver is an appendage of, and a direct ontgrowth from, the intestinal canal, it receives its blood-supply, in the early stages of its development, from the vessels that supply the primitive intestine, that is, from the vitelline veins. These veins, on their way to the heart, pass along the intestinal eanal and are eonnected with each other in the region of the future 
duodenum by trunks that encircle the bowel, these connecting vessels collectively constituting the annular sinus (Fig. $75, B$ and $C$ ). The liver originates from a small rliverticulum which is evaginated from the ventral wall of the intestinal canal. Growing forward between the folds of the ventral mesentery, this little tubular sac divides and subdivides so as to produce a gland of the compound tubular type. The developing liver is from the first in close relation with the vitelline veins and their ring-like anastomosing branches, and receives its blood-supply from the latter through vessels that are known as the venæ hepaticæ advehentes (Fig. 75, 10, 10). These afferent vessels break up within the liver into a system of capillaries, from which the blood passes through the efferent vessels, the venæ hepaticæ revehentes, into the terminal parts of the vitelline veins. Thus a part of the blood of the vitelline veins is diverted to the liver and, after eirculating through that organ, is returned to them further on to be conveyed to the heart. As the liver, with its increasing development, requires more and more blood, the entire blood-stream of the vitelline veins passes to it, and the parts of these veins between the venæ hepatice advehentes and the venæ hepatice revehentes become obliterated (Fig. 75, B and C). The vitelline veins, therefore, leave the intestinal canal at the duodenal region and traverse the liver on their way to the heart. In this early stage of the development of the liver, then, it receives its nutrition from the yoll-sac, through the vitelline veins.

When the yolk-sack undergoes retrogression, as it does about the fiftl weck, the liver must draw upon the allantoic and the placental vessels for its mutrition. To do this it must acquire connection with the nmbilical veins. The latter vessels pass upwarl from the umbilieus along the rentral wall of the body and empty into the sinns venosus of the heart above the site of the liver (Fig. $75,4,4,4)$. The two umbilical veins fuse to form one, and this one effects communications beneath the liver with the vene hepatice advehentes from the vitelline veins. As the needs of the liver exceed the capacity of the vitelline veins, more and more of the blood of 
the umbilical vein is sent to it, until finally all the blood of the latter vein passes into the liver and reaches the heart through the terminal part of the left vitelline vein. (The left vitelline vein very early begins to predominate over the right.) The part of the umbilical vein above the liver undergoes atrophy and disappears. Although, meanwhile, the yolk-sac has dwindled, the vitelline veins persist, in part, since they receive blood from the walls of the alimentary tract. The liver nou, in this second stage of its development, receives blood from two sources, the abdominal viscera and the placenta.

As previonsly indicated, the proximal half of the inferior vena cava develops as an unpaired vessel connected with the primitive heart. It opens above into the left vitelline vein. In a short time it far ontstrips the latter in growth and, with its extension downward, the point of union of the two vessels is carried downward toward the liver, the vitelline vein becoming larger and constituting now the hepatic vein. Meanwhile the volume of blood flowing through the umbilical vein has increaserl to such an extent that the liver is no longer able to transmit it to the inferior vena cava, and consequently a communication is established between these two vessels on the under surface of the liver. The connecting branch is the ductus venosus or ductus Arantii. The blood of the umbilical vein is divided, therefore, into two streamsone that enters the inferior vena cava directly through the duetus venosus and one that traverses the liver on its way to the eava.

The portal vein results from the persistence of a part of the vitelline veins. The vitelline veins, as we have seen, anastomose with each other by two ring-like branches that encircle the duodenum. The right half of the lower ring and the left half of the upper one atrophy, so that the bloor of the vitelline veins makes its way to the liver through the left half of the lower ring and the right half of the upper one (Fig. 75, D). This single vessel constitutes the portal vein, and its conrse, therefore, is backward alround the left side of the duordenum and then to the right. So long as the yolk-sac is present, the vein receives blood both from it and 
from the walls of the intestine. After the disappearance of the yolk-sac, the intestinal and the visceral veins are the sole tributaries of the portal vein.

\section{THE FINAL STAGE OF THE FETAL VASCULAR SYSTEM.}

The eireulation of the fetus at birth and the ehanges ensuing immediately thereafter may now be easily understood. The fetal blood being sent to the plaeenta through the hypogastrie or umbilieal arteries, receives oxygen there and is returned to the body of the fetus through the umbilical vein. The latter vessel takes its course upward along the ventral wall of the abdomen to the under surface of the liver, lying here in the anterior part of the longitudinal fissure. In this position the blood-stream of the umbilical vein is divided into two parts, one of which unites with the fetal portal vein to enter the liver, while the other passes through the ductus renosus directly to the inferior vena cava. The blood which enters the liver, after traversing that organ, reaches the inferior vena eava through the hepatic veins. Thus, in the one ease directly, in the other case by passing through the liver, all the placental blood reaches the inferior vena eava and passes on to the right auriele of the heart.

From the right auricle the blood passes through the foramen ovale to the left auricle, and thence, through the mitral orifice, to the left ventricle. Being driven from the left ventricle into the aorta, it is conveyerl through the branches of the aortic areh to the head and the upper extremities. Finding its way into the veins of these parts, it is returned, through the superior vena eara, to the right auricle, from whieh eavity it passes, through the tricuspid orifiee, into the right ventricle. From the right ventricle it goes into the pulmonary artery. Since the lungs are not as yet pervious, or but very slightly so, the current is reflected almost entirely through the ductus arteriosus to the descending aorta instead of going to the lungs. Some of the blood of the descending aorta is distributed to the various parts of the body below the position of the heart, while some of it is sent through the hypogastrie or umbilieal arteries to the pla- 


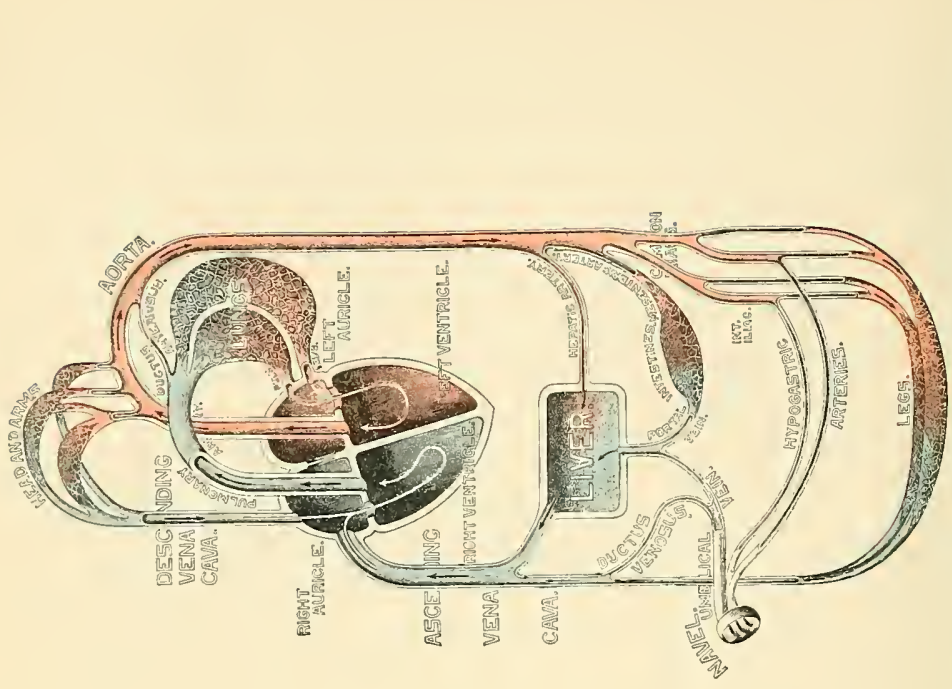

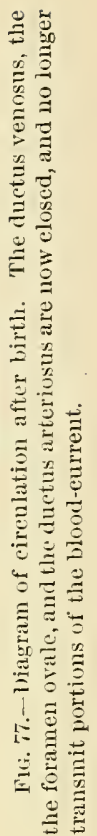

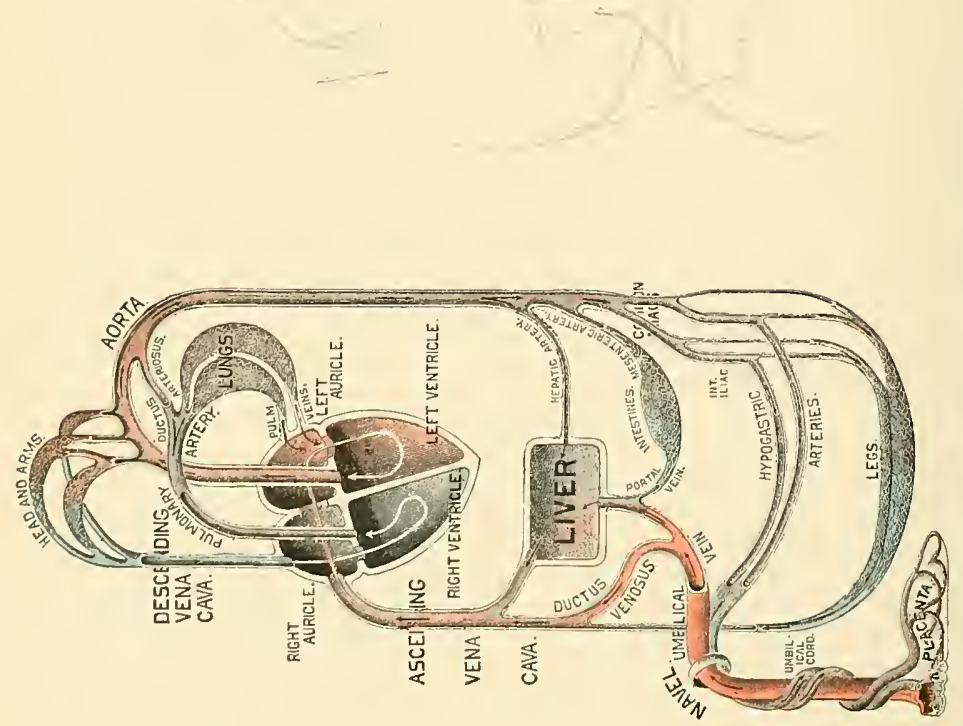

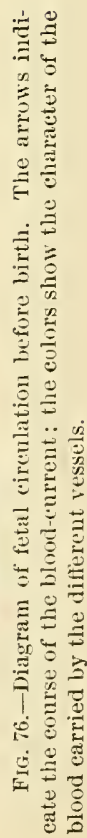


centa for aëration. It is evident that no part of the fetal blood, exeept that in the umbilieal vein, is entirely pure, the venous and the arterial blood being always more or less mixed.

With the detachment of the placenta at birth, several marked alterations occur. The eireulation through the umbilieal rein eeases, that part of this ressel which intervenes between the umbilieus and the portal fissure of the liver beeoming, in eonsequence, an impervious fibrous cord, the round ligament of the liver. The duetus renosus likewise suffers obliteration. Since the lungs now assume their proper function of respiration, the eommunication between the right and the left sides of the heart and also that between the pulmonary artery and the aorta cease. Hence, the respeetive arenues for these communieations, the foramen ovale and the ductus arteriosus, become obsolete. There being no further need for the hypogastrie (umbilical) arteries, the circulation through them ceases, and they become mere cords of fibrons tissne, whose presence is evideneed by two ridges in the peritoneum on the inner surface of the anterior wall of the abdomen. The proximal parts of these arteries persist, however, as the superior resieal arteries. 


\section{CHA P T E R X I.}

\section{THE DEVELOPMENT OF THE DIGESTIVE SYSTEM.}

THE adult digestive system consists of the mouth with its accessory organs, the teeth, the tongue, and the salivary glands; of the pharynx, the esophagus, the stomach, and the small and the large intestine, including also the important glandular organs, the liver and the pancreas. Notwithstanding the apparent complexity of its structure, the alimentary tract may be regarded as a tube, certain regions of which have become specialized in order to adapt them to the performance of their respective functions, the salivary glands, the liver, and the pancreas being highly differentiated evaginations of its walls. While in man and in the higher vertebrates the tube is thrown into coils by reason of its excessive length, in the lower-type animals it is much more simple in its arrangement. For example, in certain fishes and in some amphibians the alimentary tract has the form of a slightly flexuous tube, the deviations from the simple straight canal being few and insignificant, and the stomach being represented by a local dilatation of the tube.

The simple condition obtaining in the representatives of the animal kingdom referred to above suggests the likewise simple fundamental plan of the luman embryonic gut-tract. There is, in fact, a period in development when the gut-tract of the human embryo has the form of a simple straight tube. The processes incident to the formation of this tube mark the earliest stages of the development of the alimentary system, the tube itself acquiring definite form simultaneously with the production of the body of the embryo.

The first indication of the alimentary canal appears at a very early period of development, being inaugurated in fact by those important alterations that serve to differentiate the 
blastodermic vesicle into the body of the embryo and the embryonic appendages. It will be remembered that, after the splitting of the parietal plate of the mesoderm into its two lamellæ, and the union of the outer of the layers with the ectoderm and of the inner with the entoderm to form respectively the somatopleure and the splanchnopleure, these two double-layered sheets undergo folding in different directions. Before the folding occurs, the germ is a hollow sphere whose cavity is the archenteron and whose walls are the somatopleure and the splanchnopleure. ${ }^{1}$ While the somatopleure in a zone corresponding with the margin of the embryonic area becomes depressed and is carried under that area to form the lateral and ventral body-wall of the embryo (Plate II., Figs. 2, 3, and 4), and also more distally folds up over the area to produce the amnion and the false amnion, the splanchnopleure, likewise in a line corresponding with the periphery of the embryonic area, is depressed and carried inward from all sides toward the position of the future umbilicus. This folding in of the splanchnopleure effects the division of the archenteron into two parts, a smaller cavity falling within the body of the embryo, which latter is forming at the same time, and a larger extra-embryonic compartment, which is the yolk-sac or umbilical vesicle. The intra-embryonic cavity is the gut-tract. The constricted communication between the two is the vitelline duct. While the vitelline duct is still a rather wide aperture, the anterior and posterior parts of its intestinal orifice are designated respectively the anterior and the posterior intestinal portals.

As the somatopleure closes in around the vitelline duct, it forms the wall of the abdomen, the opening left, which is traversed by the duet, being the umbilical aperture.

It is evident therefore that the lining of the gut-tract is constituted by the innermost germ-layer, the entoderm, and that all its epithelial elements are consequently of entodermic origin. The folding in of the splanchnopleure begins at about the end of the second week, and is so firr aldranced

${ }^{1}$ Strictly speaking, the somatopleure and the splanchuopleure are not formed before the folding occurs, but the processes go on at the same time. 

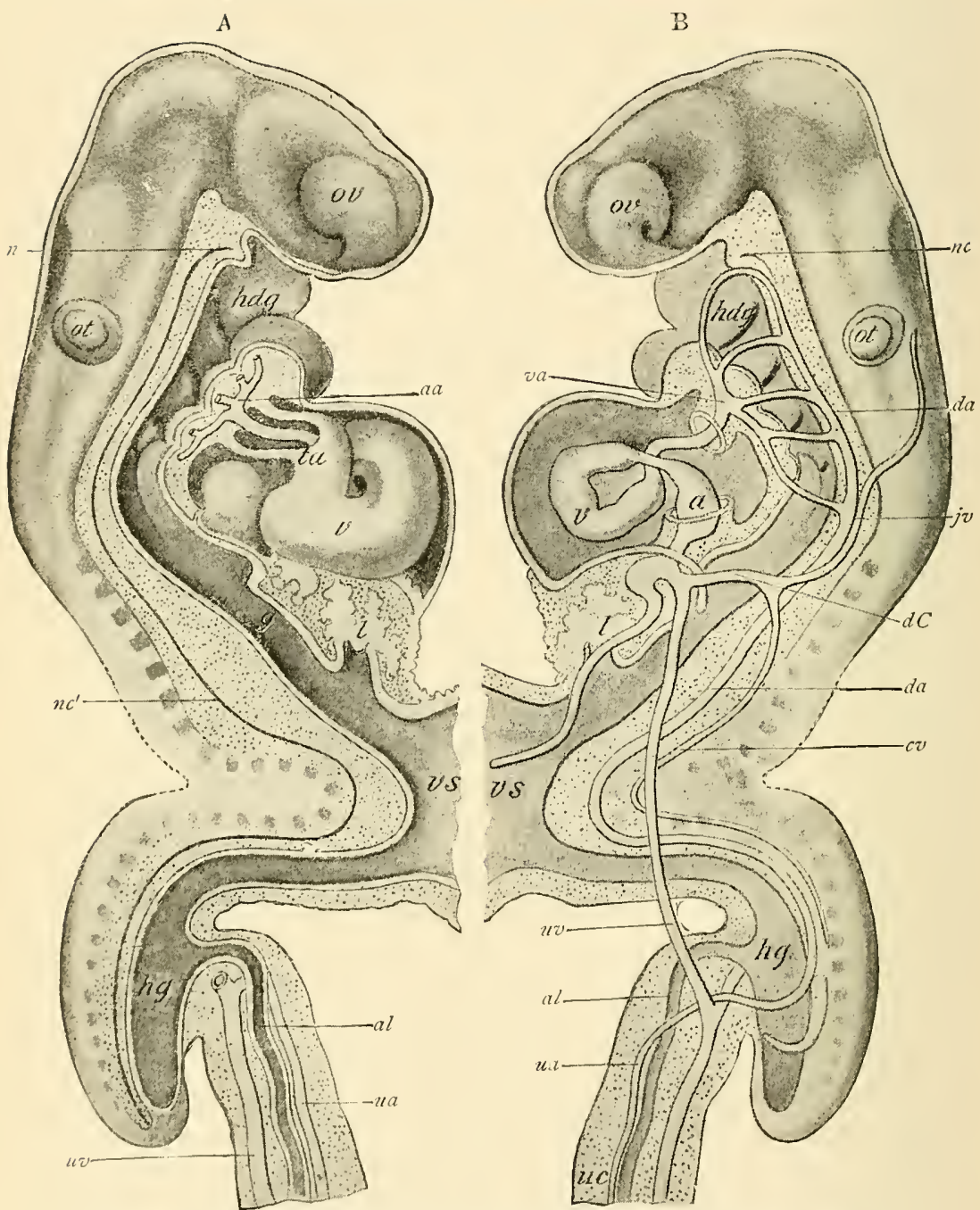

FIG. 78.-Reconstructions of human embryo of about seventeen days (His): ov, optic and ot, otic vesicles : $n c, n c^{\prime}$, notochord; $h d g$, head-gut; $g$, mid-gut ; $h g$, hindgut; $v s$, vitelline sac; $l$, liver; $v, t a$, primitive ventriele and truncus arteriosus; $v a, d a$, ventral and dorsal aortx; $\alpha a$, aortic arehes; $j v$, primitive jugular vein; $c v$, cardinal vein; $d C$, duct of Cuvier; $u v, u a$, umbilical vein and artery; al, allantois : $u c$, umbjlical cord.

before the end of the third week that the archenteron is definitely divided into the gut-tract and the yolk-sac. 
In its earliest definite form, then, the gut-tract is a tube extending from one end of the embryonic body to the other, which opens widely at the middle of its ventral aspect into the vitelline duct, but which is chosed at both ends. It is usual to speak of the primitive gut-tract as consisting morphologically of three parts, the head-gut, which is the region on the headward side of the orifice of the vitelline duct; the hind-gut, which is the part near the tail-end of the embryo; and the mid-gut or intervening third portion (Fig. 78).

The closed head-end of the gut-tube corresponds with the floor of the primitive mouth-cavity, the two spaces being separated by a thin veil of tissue, which consists of the entoderm and the ectoderm and is caller the pharyngeal membrane (Fig. 79). A considerable proportion of the so-

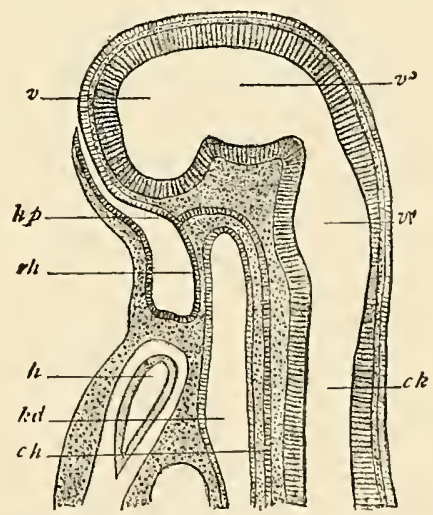

FIG. 79.-Median section through the head of an embryo rabbit $6 \mathrm{~mm}$. Iong (after Mihalkovies): $r h$, membrane between stomodæum and fore-gut, pharyngeal membrane (Rachenhaut); $h p$, place from which the hypophysis is developed; $h$, heart; $k d$, lumen of fore-gut; ch. chorda; $v$, ventriele of the cerebrum; $v^{3}$, third ventricle, that of the between-brain (thalamencephalon); $v^{4}$, fourth ventricle, that of the hind-brain and after-brain (epencephalon and metencephalon, or medulla oblongata); $c k$, central canal of the spinal cord.

called head-gut constitutes the primitive pharynx. This region of the tube has a relatively large caliber, and presents on its lateral and ventral walls the series of recesses or eraginations known as the throat-pockets or pharyngeal pouches (Fig. 60). 
While the inner, entodermic layer of the gut-tube becomes the intestinal mucosa, the outer, mesodermic stratum produces the muscular and the connective-tissue parts of the bowelwall, the most superficial layer of the latter with its mesothelial or endothelial cells forming the visceral layer of the peritoneum. Since the mesodermic layer of the splanchnopleure of each side is continuous with the corresponding mesodermic layer of the somatopleure on either side of the embryonic axis, the primitive intestinal canal has a broad area of attachment with the dorsal wall of the body-cavity (Fig. 80). The ventral wall is likewise connected with the

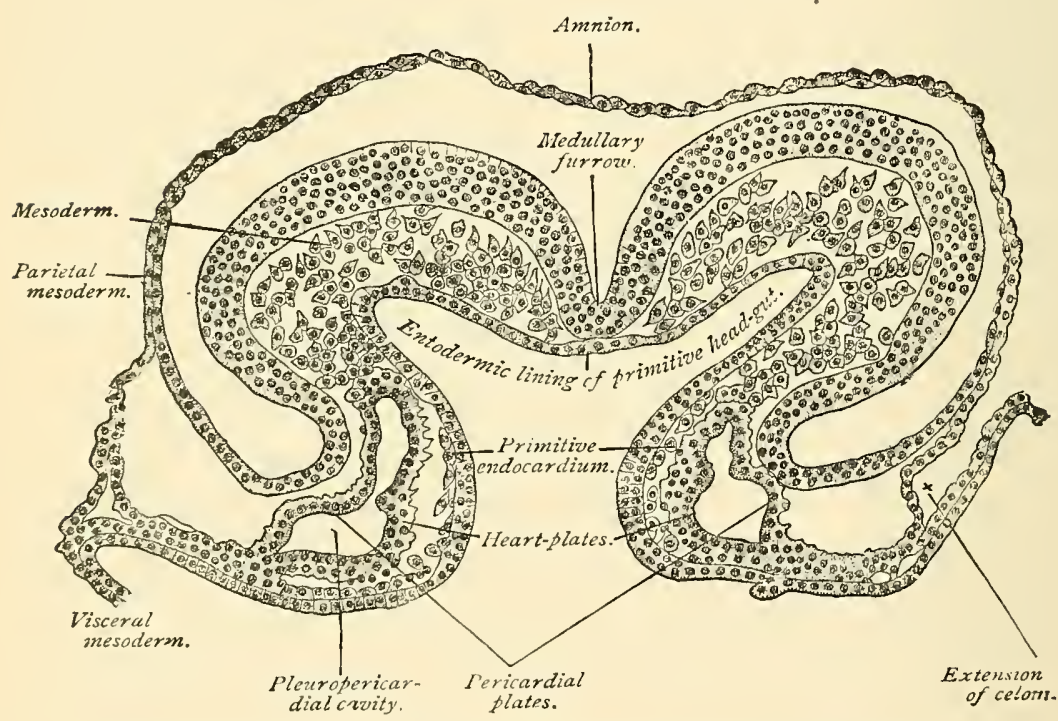

FIG. 80.-Transverse section of a sixteen-and-a-half-day sheep-embryo (Bonnet).

ventral body-wall throughout the anterior or upper part of its extent by the continuity of the splanchnoplenric mesoderm of each side with the somatopleuric mesoderm of the same side. As development advanees, the body-cavity increases in ealiber more rapirlly than does the intestinal tube, so that the interval between the two is angmented, in consequence of which the masses of connective tissue miting the dorsal and the ventral surfaces of the gut with the corre- 
sponding walls of the body-carity become drawn out so as to constitute in each case a median vertical fold consisting of two closely approximated layers of serous membrane with a little connective tissue between them. These folds are the dorsal and the ventral mesenteries (Fig. 81). While the
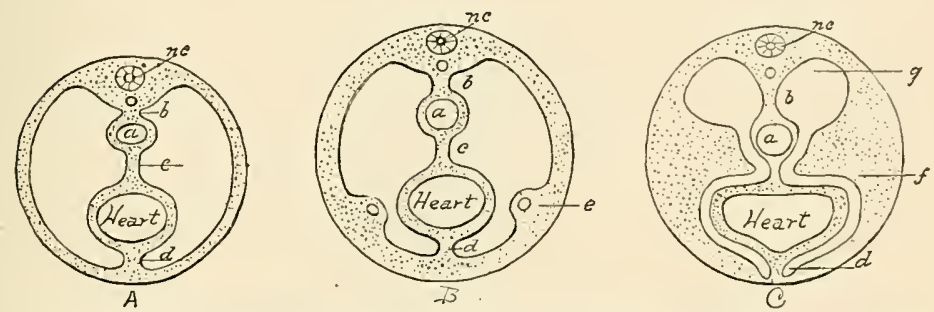

Frg. 81.-Diagrammatic cross-sections of the body of the embryo in the region of the heart at level of future diaphragm : $a$, esophageal segment of gut-tract; $b$, dorsal mesentery; $c$, mesocardium posterius; $d$, mesocardium anterius; $e$, beginning of septum transversum, containing vitelline and allantoic veins; $f$, septum transversum; $g$, thoracic prolongation of abdominal cavity; $n c$, neural canal.

dorsal mesentery extends throughout the entire length of the canal, the ventral fold is present only at its anterior or upper part, corresponding in the extent of its attachment to the digestive tube to that portion representing the future stomach and upper part of the duodenum (Fig. 82). The ventral mesentery at first is present throughout the entire extent of the canal, but very early undergoes obliteration except in the situation abore noted. Concerning the reason and the method of its disappearance nothing is definitely known.

The intestinal tube, at a comparatively early stage, presents on its rentral surface near the posterior or caudal end a small evagination that enlarges to form the allantois (see p. 80). While a part of the intra-embryonic portion of the allantois dilates and develops into the bladder, the part between this latter and the intestine is known as the urogenital sinus. The part of the gut-tube posterior to, caudad of, the origin of the allantois, is a blind ponch known as the cloaca. The latter is, therefore, the common termination of the urinary and the intestinal tracts.

To repeat, we have now, in the third week of development, the alimentary canal represented by a single straight tube 
(compare Fig. 78), closed at each end, but with mouth-cavity and anus both indicated, the tube lying within a larger tube, the body-cavity, with the walls of which latter it is connected by the dorsal and ventral mesenteries. Along the dorsal wall

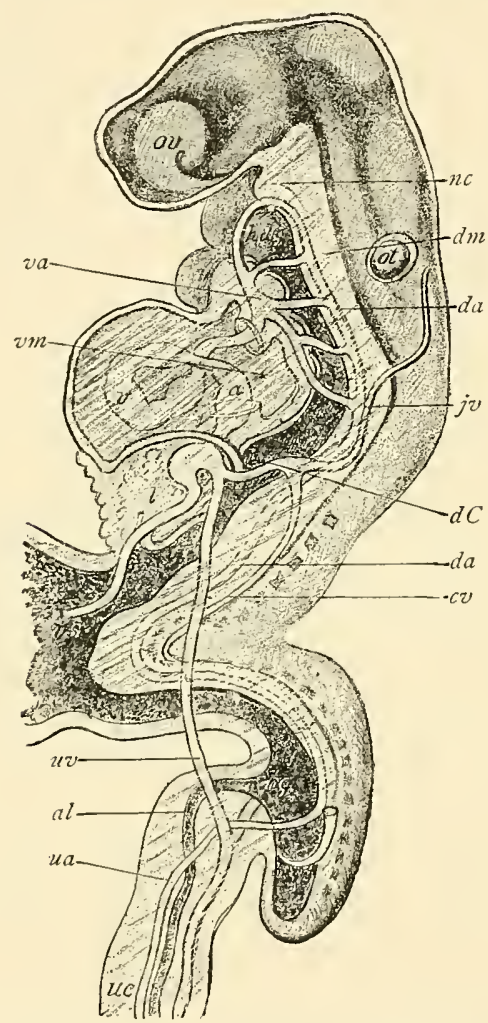

FIG. 82.-Reconstruction of human embryo of about seventeen days (after His) : $o v$, optic and ot, otic vesicles; $n c$, notochord: hd $g$, head-gut; $g$, mid-gut; $h g$, hindgnt; $v s$, vitelline sac; $l$, liver; $v$, primitive ventricle; $v a, d a$, ventral and dorsal aorte; $j v$, primitive jugular vein; $c v$, cardinal vein; $d C$, duet of Cuvier; $u v, u a$, umbilical vein and artery; $a l$, allantois ; $u s$, umbilical cord.

of the body-cavity, dorsad to the parietal peritoneum, pass the two primitive aorte, and later, the single aorta which results from the fusion of these two. Between the two folds of the dorsal mesentery pass the blood-vessels that nourish the walls of the gut. Within the ventral mesentery are the 
vitelline veins, which bring the bloor from the yolk-sac and convey it to the primitive heart. On the rentral wall of the gut is the wide aperture of the vitelline duct. Farther caudad, also on the rentral surface of the bowel, is the orifice of the allantois. These conditions may be better understood by reference to Figs. 78 and 82 . Before tracing the further development of the abdominal part of the alimentary system, it will be proper to note certain very important processes pertaining to its anterior or head-extremity, and also to consider the formation of the anus.

\section{THE MOUTH.}

The development of the mouth, the tongue, the teeth, and the salivary glands has been fully described on pages 122131. In this connection, therefore, it will be necessary to call attention to only a few of the salient features of their evolution.

The oral cavity is produced by a folding in of the surfaceectoderm, the fossa thus formed becoming deeper until it meets the head-end of the gut-tract. From the walls of this fossa the salivary glands are developed as evaginations, in the manner already described, while the teeth are specialized growths of its ectodermal lining and of the underlying mesoderm (vide p. 125). The first intimation of this infolding is apparent at the twelfth day in the form of a localized thickening of the surface-cells on the ventral surface of the body of the embryo near the head-end. The thickened area is the oral plate, which speedily becomes depressed, producing the oral pit or fossa. By the third week, the oral fossa or stomodeum is a well-marked pit of pentagonal ontline, its boundaries being the nasof rontal process above, the maxillary processes laterally, and the mandibular arches below. The original oral plate, having receded farther and farther from the surface and forming the posterior limit of the monthcavity, now separates that cavity from the pharyngeal region of the gut-tube and comes into contact with the anterior wall of the latter. It is called the pharyngeal membrane (Fig. 79). 
Its disappearance occurs at some time during the fourth week, by which event the gut-tube is brought into communication with the mouth.

The exact position of the pharyngeal membrane is not easily definable. It is certain, however, that it falls farther back than the posterior limit of the adult oral cavity, since the primitive month includes the anterior part of the adult pharynx. For example, the diverticulum that gives rise to the anterior lobe of the pituitary body belongs to the primitive mouth, yet its vestige, the pharyngeal bursa or Rathké's pocket, is found in the pharynx of the adult. The primitive oral cavity, by the growth of the palate, becomes divided into the adult mouth and the nasal cavities. The hard palate is completer in the ninth week and the soft palate in the eleventh week.

\section{THE PHARYNX.}

The pharynx is represented in the embryo by the expanded cephalic end of the primitive gut-tract. It is of greater relative length in the earlier stages of development than later, including as it does, almost half the length of the gut-tube in the fourth and fifth weeks. The primitive pharyngeal cavity is widest at its anterior or cephalic extremity and narrowest at the opposite end, tapering here into the esophagus. Until the breaking down of the pharyngeal membrane, which takes place in the fourth week, this structure marks the anterior limit of the pharynx and separates it from the oral cavity.

The pharyngeal pouches or throat-pockets have been referred to in connection with the visceral arches on page 100 . They are out-pocketings or evaginations of the entorlermal lining of the pharynx, there being four furrows on each lateral wall, and they pass from the ventral toward the forsal wall of the cavity, each pouch lying between two adjacent visceral arches. The entoderm of the ponches comes into close relation with the ectoderm of the outer visceral furrows (Fig. 60). The mesodermic stratum being 
absent from the pharyngeal pouches, the ectoderm and the entoderm are in contact, and constitute the closing membrane. As previously mentioned, this closing membrane ruptures in aquatic vertebrates, in consequence of which the pharyngeal cavity in such animals acquires a number of openings. In man, as in other mammals, and in birds, such rupture probably never oceurs. Since the visceral arches and elefts are fully considered in Chapter VII., it will be necessary in this connection to refer only to such derivatives of them as pertain direetly to the pharynx.

The first inner cleft or pharyngeal pouch becomes elosed off from the pharyngeal eavity, its dorsal end giving rise to the tympanic cavity or middle ear, while the remaining part constitutes the Eustachian tube. Hence, the tympanum and the Eustachian tube are to be regarded as differentiated portions of the primitive pharyngeal eavity. The dorsal part of the closing membrane of this cleft persists as the tympanic membrane.

The third pharyngeal pocket or third inner visceral cleft, by an evagination of its entodermal epithelium, gives rise to the epithelial parts of the thymus body, the connectivetissue elements of this "gland" being furnished by the mesodermic cells which surround the epithelial diverticulum and ultimately enclose and isolate its branching processes. In a similar manner, the fourth pocket produces the lateral lobes of the thyroid body.

The ventral wall of the pharynx, between the anterior extremities of the second throat-pockets, evaginates into an entodermic tube which extends caudalward to develop subsequently into the median lobe of the thyroid body.

The tongue (p. 131) also is developed from the walls of the pharyux, the anterior unpaired segment, the tuberculum impar, growing from the median line of the ventral wall, just. below the level of the first visceral arch, while the two symmetrical segments that form the posterior third of the organ proceed from the ventrolateral walls at the ventral extremities of the second and third visceral arehes.

The tonsil develops as masses of lymphoid tissue about 
an evagination of the lateral wall of the pharynx. In the third month the lateral pharyngeal wall pouches out to form

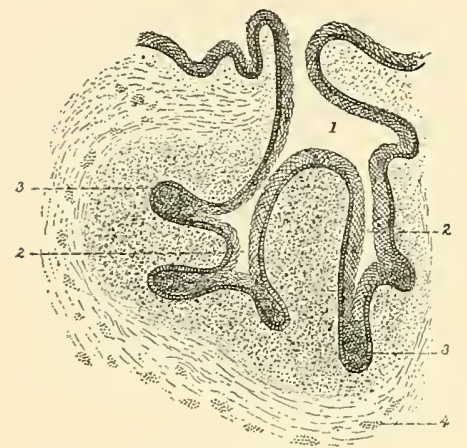

FIG. 83.-Section through anlage of tonsil of a human fetus (Tourneux) : 1, tonsillar pit, continuous with mouthcavity ; 2 , secondary diverticula; 3 , solid epithelial buds ; 4 , striped muscular fiber.

a little fossa (Fig. 83, 1) which is situated between the second and third visceral arehes, the fossa being lined with stratified squamous epithelimm continuous with that of the pharyngeal eavity. Little solid epithelial buds (Fig. 83) proceed from this divertieulum into the surrounding connective tissue, the buds subsequently becoming hollowed out. Wandering leukocytes from the neighboring blood-vessels infiltrate the connective tissue around the young erypts, and these cells becoming aggregated into eondensed and isolated groups give rise to the lymphoid follicles peculiar to the tonsil. The separate and well-differentiated condition of the follicles is not attained until some months after birth. The place of origin of the tonsil between the seeond and third visceral arches explains the position of the adult organ between the anterior and posterior palatine arehes, since the latter struetures represent the deep extremities of the former.

\section{THE ANUS.}

The early stages of the development of the anus are similar to those of the mouth. The so-called anal membrane is produced by the growing together of the ectoderm and the entoderm, the mesoderm being crowded aside. The site of the anal membrane, or anal plate, is in the median line of the dorsal surface of the embryonic body, at its posterior or caudal extremity. It makes its appearance in the third week. Since the tissue immediately in front-that is, headward, of the anal plate projects and develops into the primi- 
tive tail, and sinee the axis of the body becomes ventrally curved, the anal plate is earried around somewhat toward the ventral aspeet of the body. During the following fortnight the anal plate becomes depressed so as to form a small fossa, which is often designated the anal pit or proctodeum. The position of the anal pit does not correspond, in any vertebrate, to the end of the intestine, but to a point short of it ; the gut, therefore, extends beyond the position of the anus. This portion of the bowel is the postanal gut of vertebrate morphology. Ultimately it entirely disappears.

While the anal pit is forming, the allantois is growing forth as a diverticulum from the rentral wall of the gut (Fig. 84). The intra-embryonic part of the allantois is

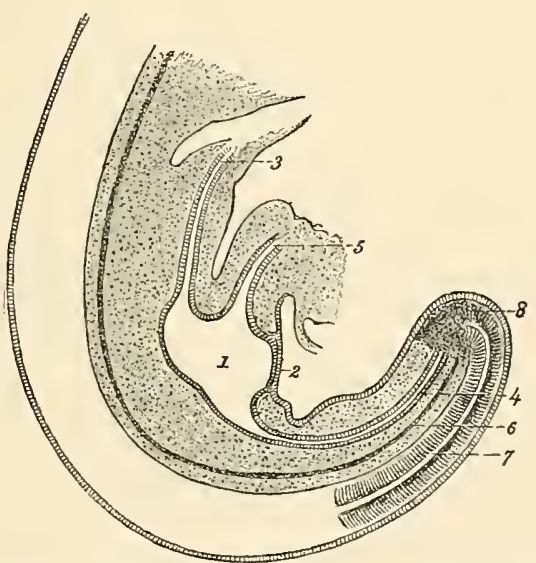

FIG. 84.-Sagittal section of caudal extremity of cat embryo of $6 \mathrm{~mm}$. : 1, cloaca ; 2 , cloacal membrane; 3 , intestine; 4 , post-anal gut; 5 , allantoic canal; 6 , chorda dorsalis; 7 , medullary canal (Tourneux).

transformed ehiefly into the urinary bladder, but it gives rise also, by its proximal extremity, to a short wide duet, the urogenital sinus, which is an arenue of communication with the bowel. The part of the gut on the candal side of the aperture of the urogenital sinus is the cloaca, which is the common termination, therefore, of the genito-urinary system and of the intestinal canal.

The surface depression referred to above as the anal pit is 
often called the cloacal depression during the time that the eloaca is present. In the lowest mammals, the monotremes, as also in the Amphibia, in reptiles, and in birds, the cloaca is a permanent structure. By the breaking down of the membrane between it and the cloacal depression, it acquires an outlet, throngh which the feces, the urine, and the genital products find egress. In all higher mammals, however, including man, the cloaea suffers division into an anterior or ventral passage-way, the urogenital sinus, and a posterior canal, the rectum and canal of the anus. This division is effected by the growth of three ridges or folds, of which one grows from the point of union of the urogenital sinus and the gut, while the other two proceed, one from each lateral wall of the eloaca. The three folds eoalesce to form a perfect septum. The division is complete at about the end of the second month (or, according to Minot, at the fourteenth week). The cloacal depression or anal pit shares in this division, so that at about the tenth week, it is separated into the anal pit proper, or the proctodeum, and the orifice of the urogenital sinus. The newly-formed septum continues to thicken, especially near the surface of the body, until it eonstitutes the pyramidal mass of tissue known as the perineal body, or perineum.

The anal pit deepens, the anal membrane being thereby approximated to the end of the bowel, and in the fourth month the anal membrane breaks down and disappears. Persistence of the anal membrane after birth constitutes the anomaly known as imperforate anus.

\section{THE DIFFERENTIATION OF THE ALIMENTARY CANAL INTO SEPARATE REGIONS.}

The fourth week marks the beginning of certain important clanges in the simple straight alimentary tube. The reader is again reminded that this tube is connected with the dorsal body-wall by the dorsal mesentery and with the ventral wall, for a part of its extent, by the ventral mesentery; that the canal is, as yet, without communication with the exterior; and also that the vitelline duet and the allan- 
tois are connected with its ventral surface (Fig. 82). The umbilical vesicle having reached the limit of its development in the fourth week and having begun to shrink, the vitelline dnet likewise begins to retrograde and very soon becones an inconspicuous structure.

The dorsal wall of the tube at a point nearer the head-end begins to bulge toward the dorsal borly-wall, forming a somewhat spindle-shaped enlargement (Figs. 85, 86). This di-

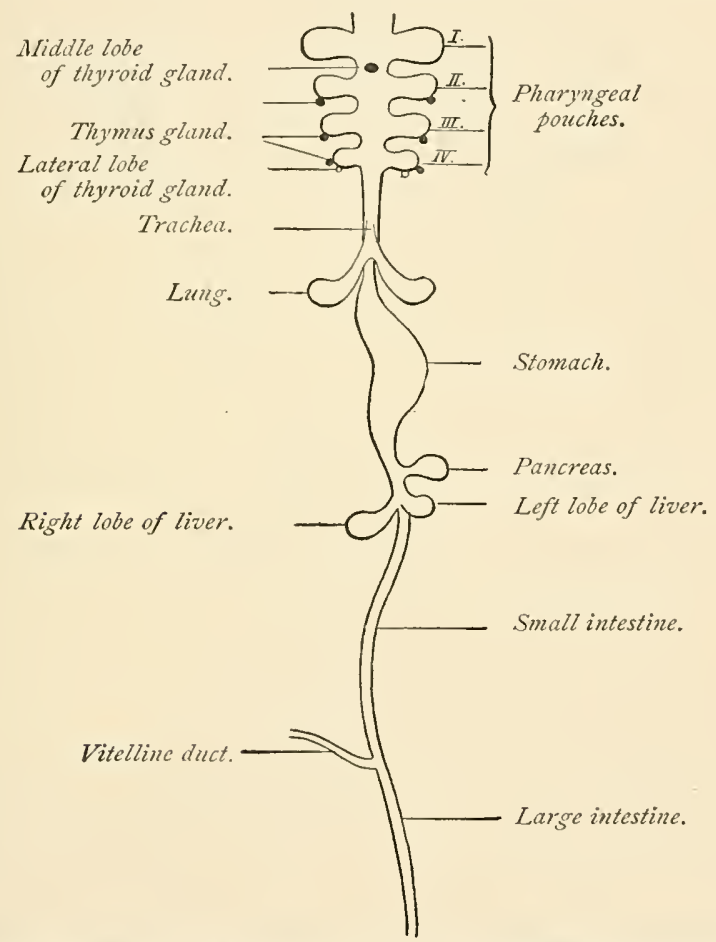

Fig. 85.-Scheme of the alimentary canal and its accessory organs (Bonnet).

latation is the beginning of the future stomach. The part of the canal on the cephalic side of the stomach lags belind somewhat in growth, corresponding in this respect with the relatively smaller size of the adult esophagus. The esophagus begins to lengthen in the fourth week. At this time, also, the beginning of the liver is indicated by a small diver- 
ticulum which pouches ont from the ventral wall of the intestine just posterior to (below) the stomach-the future duodenal region therefore-and which grows into the ventral mesentery. Very soon after the appearance of the hepatic evagination, a similar out-pouching from the dorsal wall of

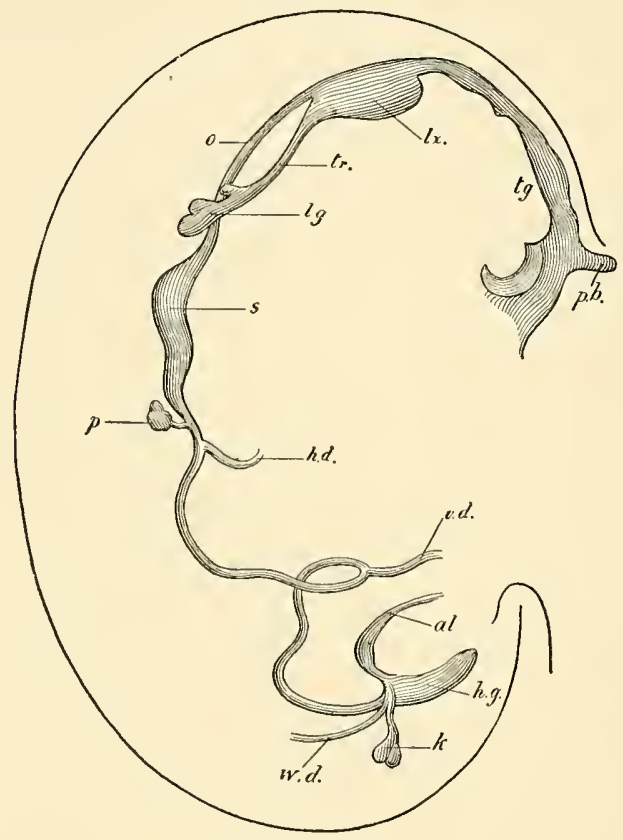

FIG. 86.-Outline of alimentary canal of human embryo of twenty-cight days (His) : $p b$, pituitary fossa ; $t g$, tongue ; $l x$, primitive lary nx; $o$, esophagus ; $t r$, trachea ; $l g$, lung; $s$, stomach ; $p$, pancreas ; $h d$, hepatic duct ; $v d$, vitelline duct ; al, allantois ; $h y$, hind-gut; $W d$, Wolffian duct; $k$, kidney.

the future duodenal region of the intestine indicates the beginning of the development of the pancreas.

In the latter part of the third week or in the beginning of the fourth, the esophagus presents a longitudinal groove on the inner face of its ventral wall. This groove increases in depth and caliber and finally becomes constricted off from the esophagus, with which it retains connection only at its pharyngeal end. The tube or tubular sac thus formed is the first step in the development of the lungs and the trachea. 
It may be said then that the gut-tract has now, in the fourth week, reached the stage of differentiation into the pharynx, the esophagus, the stomach, and the intestine, with the liver, the pancreas, the respiratory system, and the allantois fairly begun.

As heretofore pointed ont (p. 81), the allantois-which grows directly from the primitive gut-tract, and which con-

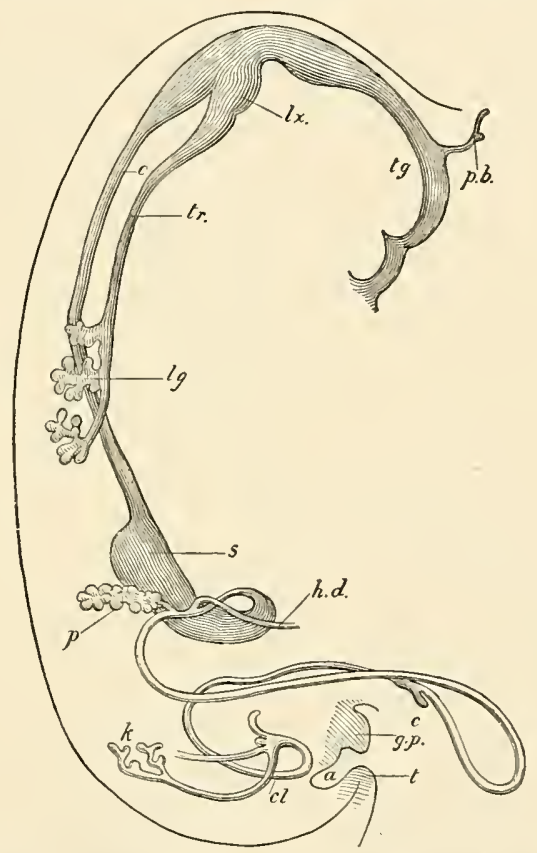

FIG. 87,-Outline of alimentary canal of human embryo of thirty-five days (His): $p b$, pituitary fossa; $t g$, tongue; $l x$, primitive larynx; 0 , esophagus: $t r$, trachea; $l g$, lung; $s$, stomach; $p$, pancreas; $h d$, hepatic duct ; $c$, cæcum ; $c l$, cloaca ; $k$, kidney ; $a$, anus; $g p$, genital eminence; $t$, caudal process.

sists therefore of the entoderm and the visceral mesodermalthough destined to produce in part the permanent bladder, functionates for a time, after its union with the false amnion to form the chorion, as an organ of respiration; while the permanent respiratory system, as we have seen, likewise develops from the entodermal epithelinm of the guttract. The entoderm, therefore, sustains an important re- 
lation to the nutrition of both the embryonic and the adult organism.

\section{Increase in I,ength and Further Subdivision.-} The intestinal canal grows in length much more rapidly than does the embryonic body. It is in consequence of this disproportionate growth that the tube becomes bent and thrown into coils or convolutions. During the fifth and sixth weeks a conspicuons flexure appears at some distance below the stomach. Here the bowel assumes the form of a U-shaped tube, the closed end of the $U$ projecting toward the ventral body-wall (Fig. 88). In other words, the redundant portion

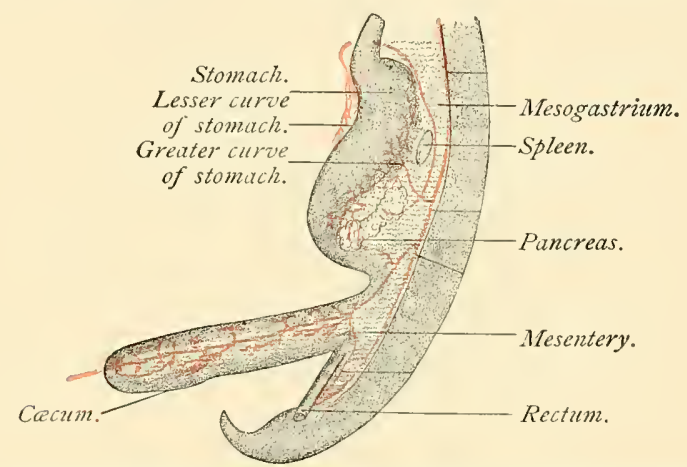

FIG. 88.-Intestinal eanal of human embryo of six weeks (Toldt).

of the gut is pulled away, as it were, from the dorsal wall of the body-cavity and, as a consequence, the dorsal mesentery is lengthened in this region to a corresponding extent (Fig. 88). The vitelline duct is attached to the part of the bend nearest the ventral wall (Fig. 86). At a point on the lower limb of the $\mathbf{U}$ the bowel abruptly acquires increased caliber. This dilated part is the beginning of the cæcum or head of the colon, and its appearance initiates the distinction between the large and the small intestine, since the part of the bowel on the distal side of the point in question becomes also of larger caliber and forms the colon.

During the succeeding weck or fortnight, the character of the colon and of the cxeum becomes better established. The remaining part of the lower limb of the U-loop, with all of 
the tube included between the loop and the stomach, is the small intestine, which presents a slight dorsal flexure at its proximal extremity. The stomach meanwhile has increased in size and has almost attained its characteristic shape. By the end of the sixth week, then, the alimentary canal has not only increased in length but has so far differentiated as to have acquired stomach, duodenum, small intestine, cæcum, and rectum.

Alteration in the Relative Position of Parts, and Further Development.-The most important modification of the alimentary tube as it exists at the end of the sixth week is effected by certain changes of position of some of its parts. The stomach and the large intestine are the portions of the tract most conspicuously affected. The lower limb of the U-segment of bowel, which consists chiefly of the rudimentary cæecum and a part of the colon, is lifted, as it were, over the upper limb and comes to occupy a position above it (Fig. 89, A), the cecum assuming a position in the right

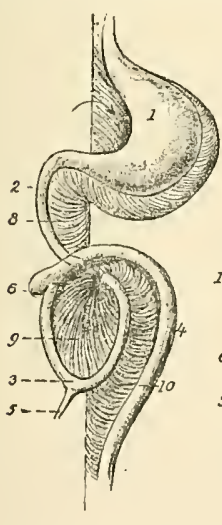

$A$

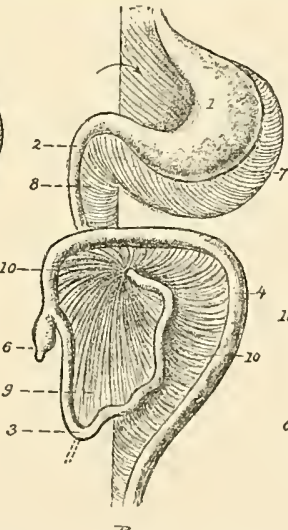

$\not B$

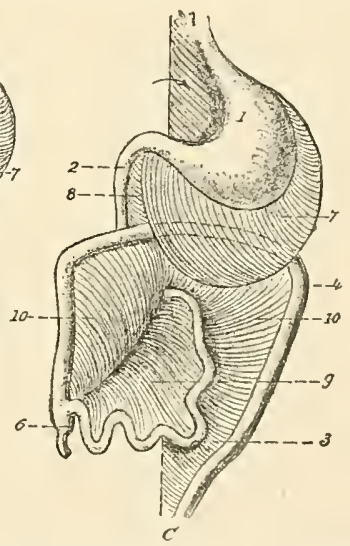

$c$

FIG. 89.-Three successive stages showing the development of the digestive tube and the mesenteries in the human fetus (modifiod from Tourneux): 1, stomach ; 2 , duodenum; 3 , small intestine ; 4 , colon ; 5 , vitelline duet ; 6 , cxeum; 7 , great omentum; 8, mesoduodenum; 9, mesentery : 10, mesocolon. The arrow points to the orifice of the omental bursa. The ventral mesentery is not shown.

hypochondriac region, and the colon passing thence transversely across the abdomen rentrad to the duodenum.

This shifting of position on the part of the colon brings 
about important complications in the arrangement of the mesentery, since the part of the dorsal mesentery that pertains to the upper part of the colon correspondingly alters its position and line of attachment, becoming adherent to the peritoneum on the ventral surface of the duodenum. The part of the mesentery in question becomes the transverse mesocolon (Fig. 89, B). 'The large intestine, after this change of position, presents cæcum, transverse colon, descending colon, and rectum, the ascending colon being still absent.

The vermiform appendix in the third month has already acquired the form of a slender curved tube projecting from the cxeum. At the time of its first appearance and for some weeks afterward, the appendix has the same caliber as the cæeum. Subsequently the cæcum outstrips the appendix in growth, the latter appearing in the adult state as a relatively very small tube attached to the much larger cæcum.

The cæcum soon begins again to change its position, gradually moving downward toward the right iliae fossa (Fig. 89). The downward migration of the crecum is due to the growth of the colon in the same direction. In this manner the ascending colon is gradually produced, it having developed to such an extent in the seventh month that the creum lies below the right kidney, while in the eighth month it passes the crest of the ilium. Corresponding with the growth of the ascending colon, the mesentery shifts its parietal attachment and increases in extent until the ascending mesocolon is produced; and with the descent of the cæeum, the terminal part of the small intestine necessarily alters its position to a like degree.

The stomach, up to the third month, is a localized dilatation of the intestinal tube, bulging most in the dorsal direction and having its long axis parallel with that of the body (Fig. 88). In the third month, however, it undergoes an important alteration in position, rotating about two axes. First, it turns about a longitudinal axis, whereby the left side comes to face toward the ventral surfice of the body (anteriorly) and the right surface looks toward the spinal column. In addition to the longitudinal rotation, the stomach also rotates upon a dorsoventral (anteroposterior) axis, 
by which the lower or pylorie extremity moves somewhat upward and to the right, and the cardiac end goes tailward (downward) and to the left (Fig. 89). By this double rotation the stomach is made to assume approximately its adult position. The longitudinal rotation of the stomach, in which the lower portion of the esophagus takes part, explains the relation of the vagus nerves in the adult. The nerves, before the rotation, lie one on each side of the esophagus and stomach, but since the left surfaces of both turn forward and the right surfaces turn backward, the left vagus lies on the anterior surface of the esophagus and of the stomach, while the right nerve is in relation with their posterior surfaces.

The relations of the mesogastrium are influenced in an inportant manner by the rotation of the stomach. As long as the stomach retains its original position and relations, with its greater curvature facing dorsad (or posteriorly), the mesogastrium is a vertical mesial fold of peritoneum (Fig. 88), while the ventral mesentery similarly connects the future lesser eurvature or rentral surface of the stomach with the ventral body-wall. At the very beginning of the process of rotation, the mesogaster becomes somewhat redundant and sags toward the left (Fig. 89, A). As this increases in extent, there is formed, between the stomach and the dorsal body-wall, a pouch or poeket, the omental bursa, whose opening is toward the right (Fig. 89). In the third and fourth months the original mesogaster, lengthening more and more, and being affected by the increasing torsion of the stomach, projects in the form of a sac considerably below the level of the stomach, in front of (ventral to) the small intestine and the transverse colon. It ultimately becomes the great omentum. The mesogastrium, from having been a rertical mesial fold, is now become a transverse fold, so redundant as to be folded upon itself and to constitute a bag.

In like manner the ventral mesentery (Figs. 8:2 and 90), which eonnects the anterior or ventral surfice of the stomach with the ventral body-wall, and in which the liver develops, is altered from a mesial fold to a transverse fold by the rotation of the stomach. As the liver migrates to a position 
above the stomach, the part of the ventral mesentery which connects the liver with the body-wall becomes its falciform ligament and coronary ligament, while that portion of this mesentery that connects the originally ventral surface of the stomach, now its lesser curvature, with the liver is the lesser or gastrohepatic omentum. The lesser omentum, therefore, is the anterior or ventral boundary of the orifice of the omental bursa referred to above.

The small intestine begins to exhibit flexures as early as the fiftl week, and by the end of the sixth week the dnodenum is well indicated as a segment of the gut-tube passing from the pyloric end of the stomach toward the dorsal bodywall. From this time the development of the small intestine, aside from its histological characters, consists chiefly in increase in length with consequent modification of its mesentery. A striking feature of lmman development is that, with the growth in length of the small bowel, it is gradually extruded from the abdominal carity into the tissues of the umbilical cord. The extent to which extrusion takes place increases until the tenth week, after which period the intestine is gradually withdrawn into the abdomen. In the fouth month it lies entirely within the abdominal carity. Failure of complete restoration of the gut to the cavity of the abdomen constitutes congenital umbilical hernia.

The histologica1 alterations incilent to the development of the alimentary tube, from the beginning of the esophagus to the end of the rectum, consist in the differentiation of the constituent elements of its walls from the two strata, the entoderm and the visceral mesoderm, which compose the walls of the early gut-tube. As an initial step in the process, the cells of the mesodermic stratum nndergo multiplication and arrange themselves in a narrow loose inner zone and a thicker outer lamella. The inner layer subsequently becomes the submucosa of the fully formed state, while the eells of the outer layer undergo differentiation into unstriped muscular tissue, and constitute the muscular coat of the canal. In the case of the esophagns and stomach, at least, this muscular tunic, in the fourth month, exhibits the 
distinction between inner circular, and outer longitudinal, layers. The surface-cells of the mesodermic stratum of the primitive stomach and bowel become the endothelium of the serous coat.

The glands of the entire canal are products of the inner, entodermic stratnm, and therefore they are intimately related genetically, as well as histologically, with the mucous menbrane.

The glands of the stomach, both the peptic aud the pyloric, originate from small cylindrical cell-masses that have been produced by local multiplication and aggregation of entodermal cells. By the hollowing ont of the cylinders and the branching of the tubes thereby formed, the two varieties of gastric glands are evolved. Both sets make their appearance in the tenth week. Until the fourth month the peptic glands contain cells of but one type; at this period, however, certain cells of these glands become altered by the gradual accumulation of granules within their protoplasm, by which they are transformed into the characteristic acid or parietal cells of these glands.

The glands and villi of the intestine are likewise products of the entodermal lining of the gut. Their evolution begins in the second month, and they are fairly well formed by the tenth week. As in the ease of the gastric glands, the glands of the bowel develop from eylindrical masses of entodermal cells which are at first solid, bnt which later become hollowed ont to form tubular depressions or follicles. In the region corresponding to the upper part of the small intestine many of these follicles branch to give rise to the glands of Brunner, while unbranched, simple, tubular depressions distributed throughout the entire length of the bowel become the glands of Lieberkiihn. While the surface entoderm is thus growing into the inderlying mesodermic tissue to form the glands, it becomes elevated into minute projections between the mouths of the gland-ducts, forming the villi of the intestinal mucosa. The connective-tissue corc of the vilhus is derived from the underlying mesodermic tissne, the cells of which, proliferating, grow forth into the cntoxlerm. The villi at first are 
present throughout the large and the small intestine alike, being well developed by the fourth month. While the villi of the small bowel continue their development, those of the large intestine, after the fourth month, begin to retrograde. At the time of birth they are still discemible, but at the end of the first month after birth they are completely obliterated.

Meckel's Diverticulum.--The vitelline duct, it will be remembered, is the avenue of communication between the early gut-tube and the umbilical vesicle. In the sixth week the umbilical vesicle has already begun to retrograde, and the vitelline duct is attached to the ventral extremity of the U-loop of the bowel present at this stage. The vitelline duct in most cases suffers complete obliteration in the later stages of fetal life. In some instances, however, its proximal extremity persists in the form of a small blind tube varying in length from one to several inches, which is known as Meckel's diverticulum. Since the site of attachment of the vitelline duct is not far from the termination of the small intestine, Meckel's diverticulum, when present, is connected with the lower part of the ileum, at a point from one to three feet from its termination. Should this tube remain attached to the umbilical aperture and retain a patulons orifice, there would result a congenital fecal fistula. ${ }^{1}$

\section{THE DEVELOPMENT OF THE LIVER.}

The essential features of the development of the liver will be more easily apprehended if the rearler will not lose sight of the fact that the organ is a compound tubular gland, and if, further, he will recall the method by which glands in general are developed-that is, as evaginations of the wall of the cavity or organ to which they pertain.

The first step in the evolution of the liver is the growth of a diverticulum from the ventral wall of the gut-tube at a point corresponding to the region of the future duodenum. This oceurs in the third week, since His found the diver-

${ }^{1}$ Meckel's diverticulum is of interest clinically, since by contracting adhesions to adjacent coils of intestine or by entanglement, it may produce acute obstruction of the bowel. 
ticulum in a human embryo of $3 \mathrm{~mm}$. The single diverticulum ${ }^{1}$ very speedily bifureates at its distal extremity (Fig. 85). The very short time that elapses between the first appearance of the eragination and its division into two branches explains the statement made in some text-books that two diverticula are present from the first. The hepatic diverticulum is said to grow into the septum transversum (vide Development of the Diaphragm, p. 158). The dorsal part of the septum transversum or primitive diaphragm, the region just ventral to the bowel, contains a mass of young connective tissue, rich in cells and blood-ressels, which has been designated the prehepaticus, and the liver-ridge, by His and Kölliker respectively (Fig. 78). It is into this vasenlar and cellular mass that the liver diverticulum inserts itself. The septum transversum is united in the median piane of the body with the ventral mesentery, and since the ventral mesentery is comnected with the region of theintestine from which the hepatic diverticulum is evaginated, the latter passes between the two layers of the mesentery to reach the liverridge (Fig. 90). This fact constitutes the key to the topographical relations of the liver and its peritoneal "ligaments," as will appear hereafter.

The two diverticula resulting from the division of the original single evagination embrace between them the two vitelline veins, and by repeated branch-

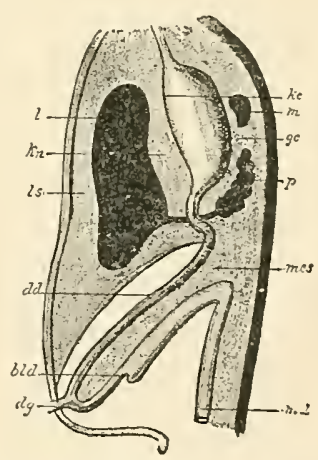

FIG. 90.-Diagram to show the original positions of the liver, stomach, duodenum, pancreas, and spleen, and the ligamentous apparatus pertaining to them. The organs are seen in longitudinal section : $l$, liver ; $m$, spleen; $p$, pancreas ; $d d$, small intestine; $d g$, vitelline duct; bld, ceeum; $m$ d, rectum : $k e$, lesser curvature; $g c$, greater curvature of the stomach; mes, mesentery; $k n$, lesser omentum (lig. hepatogastricum and hepatoduodenale); $l s$, ligamentum suspensorium hepatis (Hertwig). ing produce the right and the left lobes of the liver. Before branching, the diverticula become greatly thickened at their distal extremities by

${ }^{1}$ Single, according to His, Kölliker, Hertwig, Minot, and Piersol. 
abundant cell-proliferation. The numerous branches into which they divide are not tubes, but solid eylinders of cells, the hepatic cylinders. The sceondary branches of these cylinders unite with corresponding branches of adjacent systems, producing thereby a network of inosenlating cell-cords, the meshes of which are oceupicd by young connective-tissue cells and the developing bloodvessels. The comnective and vaseular tissue of the liverridge, thus surromnding and permeating the epithelial cellcords, produces all the connective-tissue parts of the liver, while the liver parenchyma-the proper hepatic cells-and the epithelium of the bile-ducts originate from the primitive entodermic evagination. The cords of cells are in part hollowed out to form the bile-ducts and bile-capillaries, and in part become the cells of the lobules. The cylinders that are to produce the bile-duets acquire their lumen by the fourth week.

Until the middle of the fourth month, the right and left lobes of the liver are of equal size, but after this period the right lobe outstrips the left in growth. The liver grows very rapidly and is relatively of much greater size in the fetus than in the adult, almost filling the body-cavity at the third month. In the later months of pregnaney it reaches almost to the umbilicus, while at birth it makes up oneeighteenth of the body-weight.

The ga11-bladder develops as an evagination from the original diverticulum. It is present in the second month. The perlicle of this evagination lengthens somewhat and becomes the cystic duct. The stalk of the hepatic evagination itself beeomes the ductus communis choledochus.

The ligaments of the liver, save the round ligament, are simply folds of the peritonem which connect the organ with the abdominal wall. Falling into the same eategory, though not usually designated a ligament, is the gastrohepatic omentum, which connects the liver with the stomach. These various peritoneal folds may be looked upon as parts of the ventral mesentery. Since the liver evagination grows between the two layers of the ventral mesentery to reach the 
septum transversum, the liver will be found, in the early stages of its development, embedded between the lamellix of this mesentery, which is a median vertical fold of peritoneum (Fig. 90). The liver is therefore enclosed in the peritoneum and is connected below, by a part of the ventral mesentery, with the lesser curvatne of the stomach, which still lies in the median plane of the body, and above and in front, with the diaphragm and the ventral body-wall by the upper and anterior part of the same structure. 'The latter fold is somewhat modified by the intimate association of the early stage of the liver with the primitive diaphragm, the liver having developed within a portion of the septum transversum, the liver ridge. As levelopment advances, a partial separation of the liver and the diaphragm is effected, the peritoneum, as it were, growing between the two from both the ventral and the dorsal edges of the liver. The region which is not invaded by the peritoneum represents the nonperitoneal surface of the adult liver between the lines of reflection of the two layers of the coronary ligament. Since the peritoneum on the under surface of the diaphragm is reflected from that muscle, both in front of and behind this area of contact, to become continuous with the peritoneum on the convex surface of the liver, there are formed two transverse, parallel, but separated, folds which constitute the coronary ligament of adult anatomy. The lateral prolongations of these folds to the lateral wall of the abdomen constitute the lateral ligaments of the liver.

The rotation of the stomach to assume its permanent relations alters the position of the fold that connects its lesser enrvature with the liver, bringing this fold into a plane parallel, approximately, with the rentral wall of the abdomen. This fold is now the lesser or gastrohepatic omentum.

The round ligament of the adult represents the impervious vestige of the umbilical vein. This vessel, entering the fetal body at the umbilieus and passing to the under surface of the liver, diverges from the abdominal wall to reach that organ and, in doing so, carries with it the parietal peritonem. 'The fold thus formed is the falciform or suspensory ligament. 
The special system of blood-vessels belonging to the liver is described in the chapter on the Vascular System, p. 161.

\section{THE DEVELOPMENT OF THE PANCREAS.}

Just as the liver is produced by an evagination from the ventral wall of the future duodenum, so is the pancreas originated by an eragination from the dorsal wall of the same region of the gut-tube (Fig. 86). The diverticulum grows between the two layers of the dorsal mesentery (Figs. 86, 88, and 90), where it encounters embryonic connective tissue, the cells and the blood-vessels of which, becoming associated with the epithelial entodermic evagination, give rise to all the vascular and connective-tissue parts of the gland. The details of development correspond closely with those of the salivary glands, with which the pancreas is practically identical in structure. The stalk of the diverticulum becomes the duct of the mature gland. Although the orifice of the duct, in early stages, is on the opposite side of the bowel from that of the common bile-duct, the two apertures are made to alproach each other and are finally, in most cases, merged into one by the unequal growth of the lateral walls of the intestine. In the adult, therefore, the duct of the pancreas and that of the liver and gall-bladder open into the duodenum by a common orifice.

Since the pancreas develops between the folds of the dorsal mesentery, it has a complete investment of peritoneum in the early stages of fetal life. The alterations by which this condition is changed, making the pancreas a retroperitoneal organ, will be noted in the account of the peritoneum.

\section{THE DEVELOPMENT OF THE SPLEEN.}

Although the spleen does not belong to the digestive system, it may conveniently be considered here because of its position and relations.

This organ is lifferentiated from the mesodermic tissue found between the layers of the mesogastrium in close proximity to the developing pancreas (Fig. 90). Primitively, therefore, it is situated behind the stomach. The 
first step in its development, recognizable at about the end of the second month, is the accumulation of numerous lymphoid cells with large granular nuclei. The mass is angmented by the addition of cells immediately beneath the peritoneal surfaces of the mesogastrium, which cells elongate until they are spindle-shaped and then become aggregated into fusiform masses. Blood-vessels penetrate the fundament in the third month and become surrounded by cells of the same spindle-shaped type. From both the cells surrounding the blood-ressels and from those of the fusiform aggregations, processes grow out and unite with each other, and from the network thus formed the trabecular framework of the organ is ultimately erolred. Accumulations of small nucleated cells, forming dense masses along the arteries, furnish the chief constituent of the pulp. The delicate intercellular substance which makes up the remainder of the pulp is filled with blood-corpuscles. The Malpighian corpuscles appear before the end of the fourth month. By the sixth month, the spleen attains its characteristic shape and the fibrous capsule is clearly indicated.

The spleen undergoes a change of location coincident with the rotation of the stomach and the alteration of the mesogastrium. The organ being from the first embedded within the mesogastrium, it follows that peritoneal fold to the left side of the abdominal carity. Here it lies close to the cardiac end of the stomach, between the two lavers of the mesogastrium, but projecting toward the left. The part of the mesogastrium which intervenes between the spleen and the stomach is the gastrosplenic omentum; while the part that passes from the spleen to the posterior wall of the abdomen, representing the parietal attachment of the mesogastrium, constitutes the phrenicosplenic omentum.

\section{THE EVOLUTION OF THE PERITONEUM.}

The arrangement of the peritoneum being subordinate to the position and relations of the viscera contained within the abdomen, the development of this complex membrane can be properly described only by tracing the growth of the digestive 
system. As the formation of the early gut-tube by the infolding of the splanchnopleure has been pointed out (pp. 169 and 171), we may begin at once with the period when the tract has the form of a straight tube connected with the

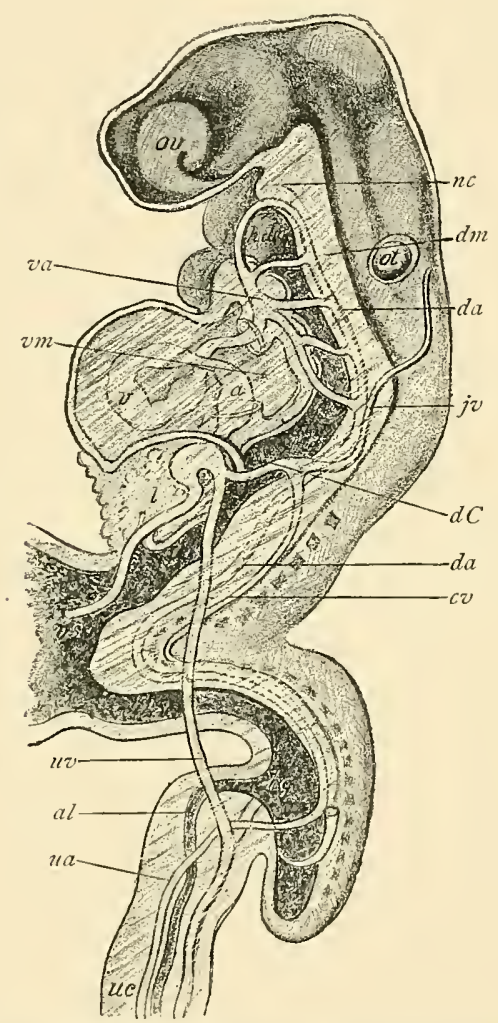

FIG. 91.-Reconstruction of human embryo of about seventeen days (after His): $o v$, optic and ot, otic vesicles; $n c$, notochord: $h d g$, head-gut; $g$, mid-gut; $h g$, hindgut; $v s$, vitelline sac; $l$, liver; $v$, primitive ventricle; $v a$, da, ventral and dorsal aorta; $j v$, primitive jugular vein; $c v$, cardinal vein; $d C$, duct of Cuvier; $u v, u a$, umbilieal vein and artery ; al, allantois ; $u s$, umbilieal cord.

dorsal and the ventral body-wall respectively by the dorsal and the ventral mesentery (Fig. 91). Covering the tube as a constituent part of its wall, is the splanchnic or visceral layer of the mesoderm, while the somatopleuric or parietal layer of the latter lines the wall of the body. Obviously these 
two lamellæ of the mesoderm are continuous with each other throngh the medium of the mesenteries mentioned above (Fig. 92, $A$ and $B$ ). The space thus enclosed by the mesodermic strata is the body-cavity or cœlom or pleuroperitoneal eavity. The surface-cells of both strata flatten and assume the character of mesothelial, the later endothelial, cells. If,
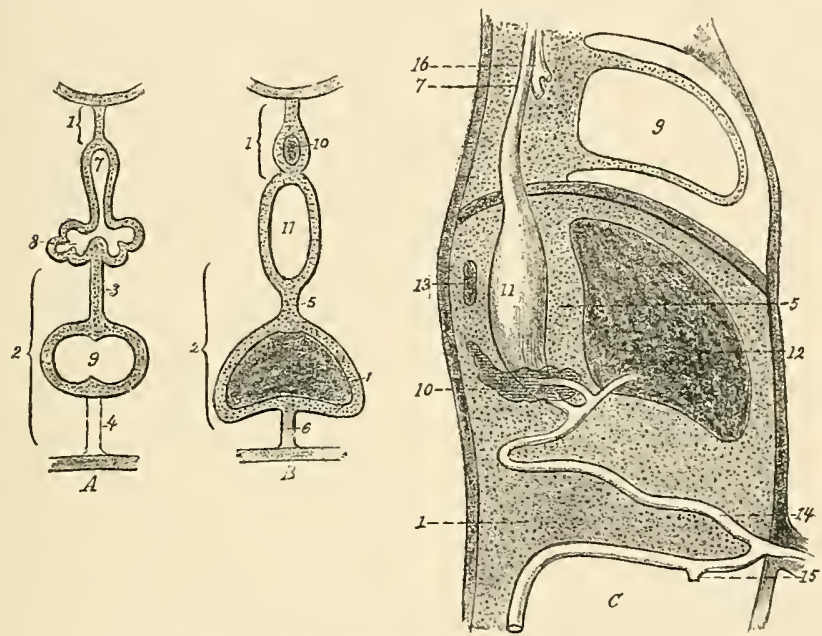

Fig. 92. $-A, B$, two transverse sections, $A$ through thoracic, $B$ through abdominal region; $C$, sagittal section (Tourueux) : 1 , dorsal mesentery ; 2 , veutral mesentery ; 3 , mesocardium posterius; 4, mesocardium anterius; 5 , lesser omentum; 6 , suspensory ligament of liver; 7 , esophagus; 8 , lungs ; 9 , heart; 10 , pancreas ; 11 , stomach; 12 , liver; 13 , spleen; 14 , loop of intestine with vitelline duct; 15 , cæcum; 16 , trachea.

at this stage, one begins at any point to trace the mesothelial lining of the body-cavity, that lining is found to form practieally one continuous sheet.

This simple arrangement of the primitive peritoneum is transformed into the complieated membrane of the adult, primarily, by the increase in length and consequent tortuosity of the alimentary tube; and, secondarily, by the fuct that certain opposed portions of the serous membrane, which have been brought into contact by the altered relations of the bowel and the stomach, undergo eoncrescence or fusion with each other. Sinultaneously with these alterations, the original pleuroperitoneal cavity suffers division into the ab- 
dominal or peritoneal cavity and the thoracic part of the body-cavity by the development of the diaphragm. This is described on p. 158.

The first modification of the original arrangement is effected by the development of the stomach as a spindle-shaped dilatation of the gut-tube, differentiating the tube into the stomach and the intestine, and the common dorsal mesentery into the mesogastrium and the intestinal mesentery. The drawing out of the U-shaped loop of the intestine from the dorsal body-wall, which is the preliminary step to the distinction between the small intestine and the colon, increases the length of the intestinal mesentery to a corresponding extent (Fig. 92, C). As heretofore indicated, the lower limb of the loop presents an enlargement which is the beginning of the development of the large intestine.

An important stage in the evolution of the peritoneum is marked by the rotation of the stomach and by the migration of the proximal part of the large intestine to a new location. The change of position on the part of the colon may perhaps be best expressed by saying that the U-loop of intestine rotates upon an oblique dorsoventral axis, whereby the lower limb of the loop, in other words, the termination of the small bowel and the beginning of the colon, is carried to a position above, cephalad to, the upper limb (Fig. 89, A). This rotation brings the beginning of the colon into the right hypochondriac region of the abdomen, from which point the transverse colon passes across the abdominal eavity, rentrad to the proximal end of the small intestine or duodenum. As a consequence of the altered situation of the transverse part of the colon, its mesentery shifts its area of attachment by fusing with the peritoneum of the dorsal wall along a horizontal line and also with that of the ventral surface of the duodenum. The descending colon having meanwhile moved to the left, its mesentery likewise acquires a new area of attachment by conerescence with the parietal peritoneum of the dorsal wall of the abdomen on the left side. During the progress of these alterations, the small intestine increases in length, and its mesentery becomes correspondingly more 
voluminous both in the extent of its intestinal border and in length. The convolutions of the small intestine now ocenpy the space below the transverse colon and its mesentery.

The duodenum, which in the early stage shares with the gastro-intestinal tube in the possession of the common dorsal mesentery, loses its mesenterial connection with the abdominal wall and becomes thereby a fixed part of the intestine. Nention was made above of the fusion of the transverse mesocolon with the peritoneum of the ventral surface of the duodenum. At about the same time, the duodenal mesentery (Fig. 89, A) fuses with the parietal peritoneum of the posterior abdominal wall, the result being that the lower layer of

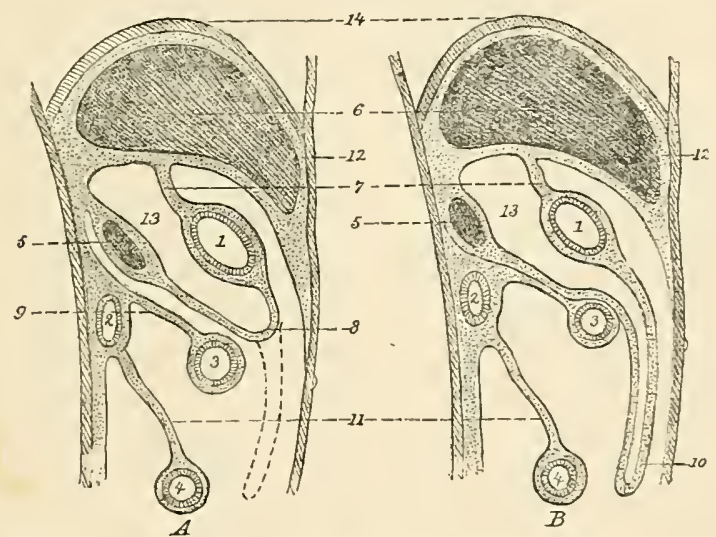

FIG. 93.-A, B. Two successive stages of the development of the mesenteries (schematic representation showing sagittal axial section of trunk, after Gegenbaur and Ilertwig): 1, stomach ; 2 , duodenum; 3, transverse colon; 4 , small intestine ; 5 , pancreas ; 6 , liver; 7 , lesser omentum ; 8,10 , different stages of great omentum ; 9 , transverse mesocolon; 11 , mesentery ; 12 , suspensory ligament of liver; 13 , cavity of omental bursa or lesser peritoneal sae; 11 , diaphragm.

the transverse mesocolon, as it passes downward, is now contimous with the parietal peritoneum, there being no longer any serous membrane between the transverse part of the duodenum and the abdominal wall (Fig. 93, B). This part of the duodenum therefore becomes retroperitoneal, there being an investment of serons membrane only on its anterior or ventral surface. 
The second modifying factor in the eomplication of the peritoneum, the rotation of the stomach, initiates alterations in its mesogastrium. The latter membrane, it will be remembered, is a vertical median fold of peritonetum continuous with the mesentery of the duodenum (Fig. 92, C). As the stomach moves about its two axes of rotation, the mesogastrium begins to sag toward the left (Fig. 89), so that now it constitutes a pouch or fossa, the omental bursa, situ-

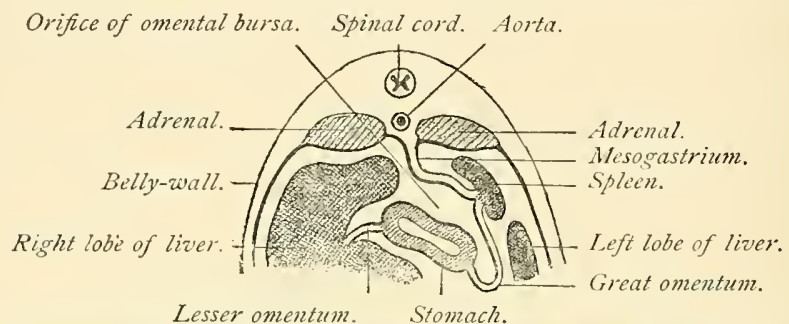

FIG. 94.-Schematic cross-section through body of mammalian embryo in region of stomach, to show development of omental bursa.

ated between the stomach and the dorsal body-wall, the opening of which looks toward the right side of the body (Figs. 93, $A$ and 94). With the rapidly increasing redundancy of the mesogastrium, the omental bursa becomes more and more capacious. In correspondence with the progressive rotation of the stomach, what was at first the left surface of the mesogastrinm comes into contact with the peritoneum of the dorsal abdominal wall and fuses with it, thus changing its area of parietal attachment from a median vertical line to a transverse one. This change is completed by the time the stomach has attained its normal adult position. The omental bursa now has the position and relations shown in Fig. 93, A, 8. A still further increase in the size of the bursa results in its protrusion downward in front of, ventrad to, the transverse colon and the small intestine. Reference to Fig. 93, $B$ will show that the dependent part of the bursa very nearly corresponds with the fully formed great omentum. It will be seen, however, that the deeper layer of the bursa, the layer nearer the intestines, may be traced above the transverse colon and its mesentery to the 
dorsal wall of the abdomen, where its two lamellse separate to enclose the panereas, one lamina passing over the ventral surface of the pancreas to become continuous with the parietal peritoneum, while the other layer passes between the pancreas and the abdominal wall. The latter layer is in continnity here with the parietal peritoneum, which almost immediately leaves the abdominal wall to form the upper layer of the transverse mesoeolon.

The further alterations necessary for the attainment of the completed condition consist in the concrescence of certain opposed peritoneal surfaces. As a conspicnons example of such conereseence, the deeper lamella of the layer of the omental bursa just deseribed fuses with the ventral peritoneal surface of the transverse colon and with the upper layer of the transverse mesocolon (Fig. 93, A), after which event this deeper lamella is practically continuons with the lower layer of the mesocolon, while the superficial lamella is in continuity with the upper layer of the mesocolon (Fig. 93, B). Thus the transverse colon appears as if enclosed between the two lamellæ of the deeper layer of the great omentum, while its mesocolon is constituted by a part of the same structure. In other words, the adult transverse mesocolon includes not only the primitive membrane of that name but also a part of the early mesogastrium. Similarly, the opposed surfaces of peritonenm between the panereas and the dorsal abdominal wall nndergo fusion (Fig. 93), the effect of which, after the concreseence of the mesocolon with the deeper layer of the omental bursa, is to make the lower layer of the mesoeolon continuous, over the transrerse part of the duodenum, with the parietal peritoneum.

The great omentum of descriptive anatomy, resulting from the downwardly projecting process of the omental bursa, consists originally of two layers of membrane, each one having two serous surfices. At the time of birth these two layers are still separate-the permanent condition in some mammals-but during the first year or two after birth they become adherent, the great omentum thus eoming to comprise but a single layer. 
It remains to note the metamorphosis of the ventral mesentery, which, prior to the rotation of the stomach, is a vertical median fold counecting the lesser curvature of that viscus with the ventral abdominal wall. Since the evagination of the gut-tube that gives rise to the liver grows between the layers of the ventral mesentery to reach the septum transversum, the liver is not only enclosed by the mesentery, but is connected by it with the stomach and with the ventral wall of the abclomen and also with the primitive diaphragm (Fig. 92). By the rotation of the stomach, the vertical median fold which connects that organ with the liver becomes so altered in position as to lie in a plane approximately parallel with the ventral surface of the body. This fold is now the gastrohepatic or lesser omentum. As reference to Fig. 93 will show, it is the anterior boundary, above the position of the stomach, of the sac described above as the omental bursa.

That part of the ventral mesentery that connects the liver with the abdominal wall and with the diaphragm, while originally occupying the median plane, is modified by the relation of the developing liver to the primitive diaphragm. These organs are intimately united with each other (p. 159) in the early stage of their growth, but with their completion a separation takes place. Upon the two separated surfaces, execpt in a region near the dorsal wall, the cells assume the endothelial type, the opposed surfaces thus acquiring the characters of serons membrane. The peritoneum on the under surface of the diaphragm is continnous with that on the upper surface of the liver, both in front of and behind the non-peritoncal area of contact. Therefore, in the completed condition of the liver and the diaphragm, these two structures are connecterl by two layers of peritoneum separaterl from each other by a region containing only areolar tissue. These layers constitute the coronary ligament of the liver. If now Fig. 93 is inspeeted, it will be seen that the posterior layer of the lesser omentum, and the upper layer of the transverse mesocolon, together with that part of the peritoneum with which they are in direct continuity, enclose 
a sac which is the so-called lesser bag of the peritoneum or the lesser peritoneal cavity. All other parts of the peritoneum taken togethcr constitute the greater peritoneal cavity. The communication between the two, the foramen of Winslow, situated behind the free right border of the lesser omentum, is the constricted orifice of the early omental bursa.

The position of the kidneys and the ureters as retroperitoneal structures and the relations of the bladder and of the uterus to the peritoneum, encroaching as they do upon the parietal layer of this membrane, and being, therefore, invested by it to a greater or less extent, are easily accounted for when it is recalled that all these organs develop from the somatic or outer layer of the mesoderm.

The peritoneum does not acquire all the characteristic features of a serous membrane until about the third month. The histological alterations begin in the fourth week, from which time until the sixth week the superficial cells, the mesothelium, pass through various phases of transition to reach the condition of somewhat flattened elements. By the eighth week they have acquired the form of true endothelium. It is not, however, until the third month that the subjacent tissue has attained to the condition of a fullyformed basement membrane. 
CHAPTER XII.

\section{THE DEVELOPMENT OF THE RESPIRATORY} SYSTEM.

Although the nasal chambers and the pharyngeal carity contribute to the formation of the respiratory system, these

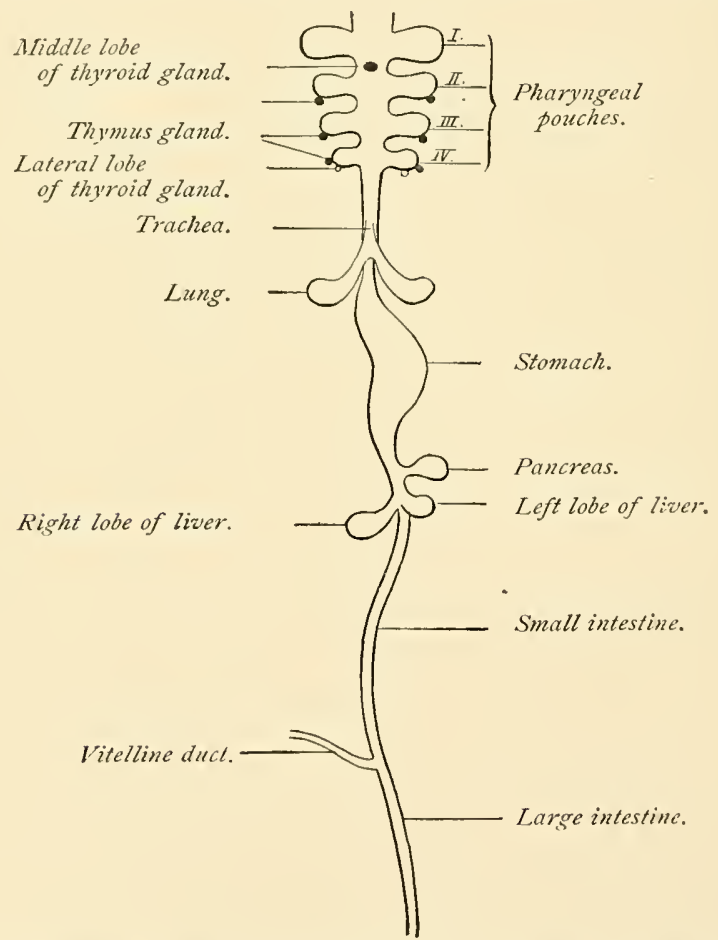

FIr. 95.--Seheme of the alimentary canal and its accessory organs (Bonnet).

parts will not be considered here, since they are described clsewhere. 
Anatomically and aceording to their mode of development, the lungs might be looked upon as a pair of glands having a common duct, the trachea, which latter, through the medium of its dilated proximal extremity, the larynx, opens info the pharyngeal carity. In point of fuct, these organs are developed as an outgrowth from the entodermal alimentary canal in a manner similar to the development of the liver and the pancreas.

The first step in the derelopment of the lungs is the outponiehing of the ventral wall of the esophagns throughout its entire length. The longitudinal median groove thus formed is the pulmonary groove.

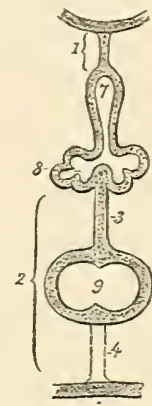

FIG. 96.-Transverse section to show outgrowth of pulmonary anlage from gut-tube (after Tourneux): 1, dorsal mesentery; 2, rentral mesentery including 3 , mesocardium posterius; 4 , mesocardium anterius: $\tau$, esophagus; 8 , diverticulum which becomes the lungs, the trachea, and the larynx; 9 , heart.

It makes its appearance when

the embryo has a length of $3.2 \mathrm{~mm}$. (0.128 ineh) or probably early in the third week. The groove is more pronomeed at its lower or gastric extremity. As the groove deepens, its edges approach and finally meet and fuse with each other. In this manner the groove is convertel into a tube, which gradually separates from the esophagus, the separation beginning at the end toward the stomach and progressing toward the pharyns. The separation, howerer, is not complete, stopping short of the upper end of the groove, so that the tube retains communieation with the pharyngeal end of the esophagus. Even before the constrieting off of this tube or pulmonary diverticulum is completer, its free end bifureates. The pulmonury anlage consists, then, at this stage, of two short wide pouches connected by a common pediele with the primitive pharyn (Figs. 95 and 96), and this eondition is present in the fourth week.

Tery soon after the end of the first month each of the ponches undergocs division, the right one into three branches, 
the left one into two, while at the same time they increase in size (Fig. 97). The further steps toward the attainment

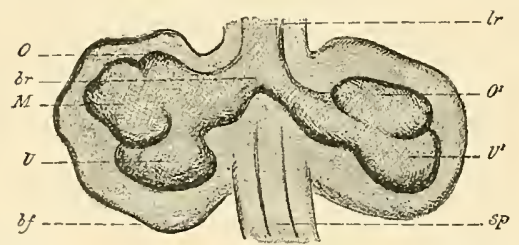

FIG. 97.-View of a reconstruction of the fundament of the lungs of a human embryo (Pr. of His) $10 \mathrm{~mm}$. long, neck measurement (after His) : $l r$, trachea ; $b r$, right bronchus; $s p$, esophagus; $b f$, connective-tissue envelope and serous membrane (pleura) into which the epithelial fundament of the lung grows; $O, M, U$, fundaments of the upper, middle, and lower lobes of the right lung; $O^{1}, V^{1}$, fundaments of the upper and lower lobes of the left lung.

of the completed condition consist largely in the continued repetition of this process of dichotomous division (Fig. 98),

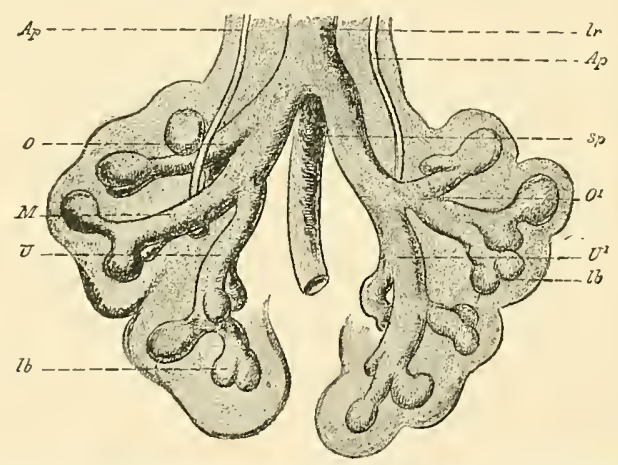

Fic. 98.-View of reconstruetion of the fundament of the lungs of a human embryo (N. of His) older than that of Fig. 97 (after $1 \mathrm{His}$, magnified 50 diameters): $A p$, arteria pulmonalis ; $l r$, trachea ; sp, esophagus; $l b$, pulmonary vesicle in process of division; $O$, upper lobe of the right lung with an eparterial bronehus leading to it; $M, U$, middle and lower lobes of the right lung: $O^{1}$, upper lobe of the left lung with hyparterial bronchus leading $t$ () it; $U^{1}$, lower lobe of the left lung.

which latter goes on intil the sixth month. The original evarination, consisting of entodermal epithelium, gives rise only to the epithelial parts of the lungs and air-passages. 111 the other constituents, the connective tissne, the muscular, vascular, and cartilaginous elenents, are products of the mesodermic tissue into which the divertienlum grows. Upon their first appearance the "tubes" are always solid 
epithelial cylinders, the Iumina being aequired later. At first, the lining entodermal cells of the primitive tubes are tall and eylindrieal, the tubes themselves having a relatively small lumen. In the fourth month the cells acquire cilia. From the anatomical standpoint, the lungs now present the characters of compound saceular glands.

From the sixth month to the end of gestation occur the changes which give to the organs their essential charaeteristies. Upon the dilated extremity of each terminal tube numerous little evaginations develop. These are the air-sacs, or pulmonary alveoli, the terminal tubes from which they are evaginated being the alveolar passages and the infundibula. Their walls renain very thin and their lining epithelium flattens to such a degree as to closely resemble endothelium. The trachea is simply the elongated stalk of the pulmonary diverticulum.

The larynx is the dilated proximal extremity of the pedicle, specially developed to serve as an organ of phonation. One of the earliest changes is the appearance of two ridges at the junction of the primitive trachea with the esophagus. These are elose together in front, ventrally, but separated behind. They are the first indication of the vocal cords. The arytenoid cartilages are indieated in the sixth week and the other cartilages soon after. These are not actually cartilaginous, however, until the eighth or ninth week.

The development of the pleuræ has been deseribed in connection with that of the perieardium and of the diaphragm (p. 158).

\section{THE THYROID AND THE THYMUS BODIES.}

These organs may be eonsidered in this connection, as a matter of convenience and because of their embryological relationship to the respiratory system, being developed, like the latter, from the epithelium of the gut-tract.

The thyroid body, an organ eommon to all vertebrates, genetically consists of two parts, a median lobe and two lateral lobes.

The median portion originates from an evagination of the ven- 
tral wall of the pharynx, in the median line, posterior, candad, to the tuberculum impar, and between the ventral extremities of the first and second visceral arches. This median diverticulum is present in the human embryo of $5 \mathrm{~mm}$. It soon pouches out on either side, assuming thereby the form of an epithelial vesicle connected by the constricted pedicle of the diverticulun with the ventral wall of the pharynx (Fig. 99, 3).

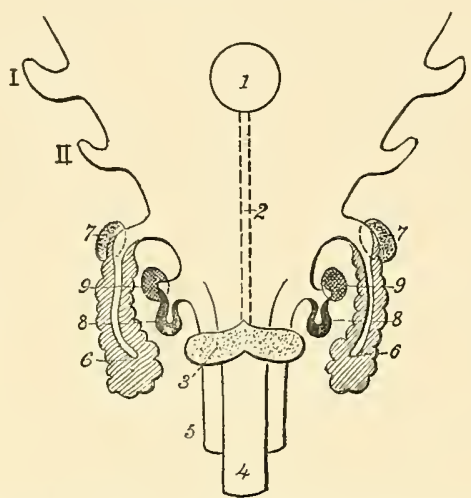

Fig. 99.-Diagrammatic representation of pharynx of human embryo seen from in front (after Tourneux): I, II, first and second pharyngeal pouches; 1 , tuberculum impar; 2, course of thyroglossal duet leading from 3 , median lobe of thyroid gland : 4 , laryngotracheal tube; 5 , esophagus; 6 , thymus; 7 , accessory thymus; 8 , lateral lobe of thyroid; 9 , accessory thyroid.

From the situation of the original point of evagination behind the tuberculum impar and ventromesial to the two halves of the posterior segment of the tongue, the orifice of the perlicle corresponds to the line of junction of the three parts of the tongue. As a consequence, when these parts unite, the perlicle or duct is prolonged upward and comes to open upon the surface of the tongue. The canal is known as the thyroglossal duct or canal of His. In the fifth week it begins to atrophy, and usually by the eighth week has become obliterated. Occasionally it persists throughout life. The foramen cæcum on the dorsum of the tongue is the vestige of the orifice of the duct. Other vestiges of the thyroglossal duct are sometimes present. For example, the lower part of the duet may persist as a short tube, the thyroid duct, leading upward from the median lobe to the 
hyoir bone; and again, according to His, isolated persistent segments of the cluct constitute the little vesicles in the neighborhood of the hyoid bone which are known respectively as the accessory thyroid, and the suprahyoid and prehyoid glands.

The lateral lobes of the thyroid body begin their development somewhat later than does the median lobe. In the embryo of $10 \mathrm{~mm}$., the fourth inner visceral furrow or throatpocket of each side pouches out to form a vesicle (Fig. 99, 8). As the vesicle grows, its pedicle becomes attenuated and finally disappears. After their isolation from the throatpockets, the resicles give out small bud-like processes after the usual manner of the development of glands and gradually approach the median lobe (Fig. 100, B). The three parts
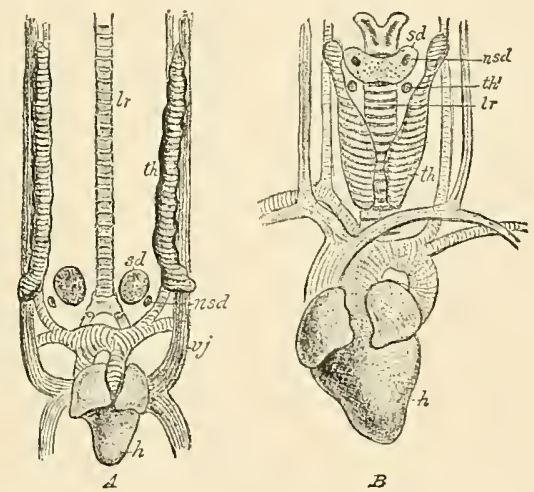

FIG. 100.-Semi-diagrammatic illustrations to show the ultimate position of the thymus, thyroid gland and accessory thyroid gland on the neck of the chick $(A)$ and the calf $(B)$, after de Meuron; $s d$, thyroid gland; $n s d$, accessory thyroid gland; $t h$, thymus; $t h^{\prime}$, accessory thymus; $l r$, trachea; $h$, heart; $v j$, vena jugularis ; $c a$, carotid vein.

unite probably in the seventh week. In the vertebrates below mammals the lateral parts of the thyroid do not unite with the median segment, and in certain animals they remain widely separated from it as the suprapericardial bodies.

After the mion of the three portions of the gland, the latter consists of a network of cords of cells, the meshes of which reticulum are ocenpied by embryonal connective tissue. Subsequently the cords of cells become hollowed ont and exhibit 
alternating enlargements and constrictions. By the increase of the constrictions the continuity of the cell-cords is interrupted at short intervals, and so the network is converted into numerous closed follicles lined with epithelium, the formation of follicles beginning in the eighth week. The follicles later undergo considerable inerease in size on account of the secretion by their epithelial cells of a peculiar colloid material, characteristic of the thyroid body. The embryonal connective tissue, made up necessarily of mesodermic elements, furnishes the connective-tissue framework and the blood-vessels of the organ, while the epithelium originates in the manner indicated from the entoderm of the gut-tract.

The Thymus. - What remains of the thymus after the second year of life is made up ehiefly of lymphoid and connective tissue, embedded in which are characteristic little epithelial bodies, the corpuscles of Hassall.

The epithelial parts of the thymus, in all vertebrate animals, are derived from the entodermal lining of the pharyngeal region of the gut-tract. In the lower groups, such as reptiles, amphibians, and bony fishes, the epithelium of all the inner visceral clefts or throat-ponches shares in the development; while in birds, only two or three clefts take part. In mammals, however, including man, the thymus body is derived probably from but one throat-pocket, the third.

The entodermal epithelium of the third inner ponch becomes evaginated (Fig. 99) to form an epithelial sae whose connection with the pharyngeal cavity is subsequently lost. The isolated and elongated sac soon gives ont small lateral buds or processes at the distal extremity. While the original sac has from the first a eavity, the bud-like branches are solirl masses of epithelium. The branching continues and affects not only the lower or distal extremity of the thymns sac but also the proximal end, the strueture now resembling an acinous gland (Fig. 101). While this growth is taking place, the epithelial mass is being invarled hy lymphoid eells and young connective tissue with developing blood-vessels. The eneroachment by these elements eontinues to such an 
extent that lymphoid tissue becomes the predominant constituent of the thymus, the epithelial parts suffering reduction, relatively, and becoming finally broken up into isolated masses which are the corpuscles of Hassall of the mature gland. The breaking down of the epithelial cords is probably responsible also for the irregular cavities of the thymus. Not until after birth do the glands of the two sides of the body unite to form a single unpaired structure, and the development of the thymus is not completed until the end of the second year of life. Having attained its full development, the organ begins to retrograde, and at the time of puberty has almost disappeared. Although sometimes persistent throughout life, it usually suffers complete obliteration, or at most, is represented by an insignificant vestige. While the epithelial parts of the thymus body, represented in the fully developed organ by the corpuseles of Hassall, are derived from the entodermal epithelium of the third inner visceral furrow, all other parts, the

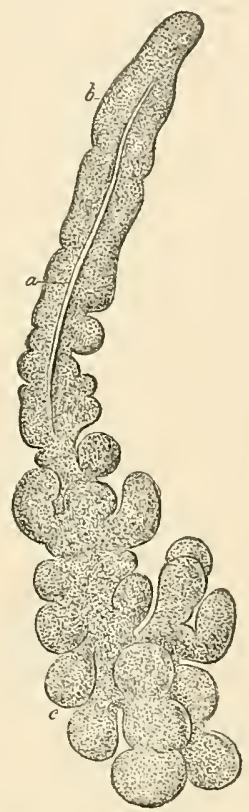

FIG. 101.-Thymus of an embryo rabbit of sixteen days (after Kölliker), magnified: $a$, canal of the thymus; $b$, upper, $c$, lower end of the organ.

lymphoid tissue, connective tissue, and blood-vessels, are products of the surrounding mesoderm. 


\section{CHAPTER XIII.}

\section{THE DEVELOPMENT OF THE GENITO=URINARY SYSTEM.}

Owing to the intimate anatomical and functional association of the generative organs with the mrinary apparatus, it is necessary to discuss the development of these two systems together.

\section{THE DEVELOPMENT OF THE KIDNEY AND URETER.}

The origin of the kidney and ureter of the higher vertebrates is associated with the development of certain fetal structures, the pronephros and the mesonephros, which represent respectively the kidney of larval amphibians and the permanent kidney of fishes. In man and other allied types, the former structure is of little or no importance functionally, while the latter functionates during a part of fetal life as the organ of urinary excretion, prior to the development of the permanent kidney.

The pronephros or head-kidney constitutes the most primitive vertebrate type of a mechanism for the excretion of urine. This structure has its origin in the mesothelium of the bodycavity, and in the following manner: When the paraxial mesoderm, which subsequently divides into the somites, is about to separate from the parietal plate of mesoderm, the two parts are eonnected for a time by an intervening thin band of tissue, the middle plate (Fig. 102, $m p$ ). On the outer side of this middle plate, the mesothelial cells of the parietal layer of the mesoderm beeome invaginated in a line parallel with the axis of the body to form a cord of cells which at several points retains its connection with the surface cells. Further changes bring about the hollowing out of the cell-cords so that there results a long tube, the pronephric or 
segmental duct, which has several short transverse tubules opening into it and communicating by their opposite extremities with the borly-cavity (Fig. 103). The mesothelium in immediate proximity to the free end of each short tube is invaginated by a tuft of capillary blood-ressels from a branch of the adjacent aorta to constitute a glomerulus (Fig. $103,66)$. The pronephric duct passes tailward and opens into the cloaca, a receptacle which receives, in common, the terminal orifice of the primitive bladder and that of the primitive intestine. It is apparent, therefore, that the pro-

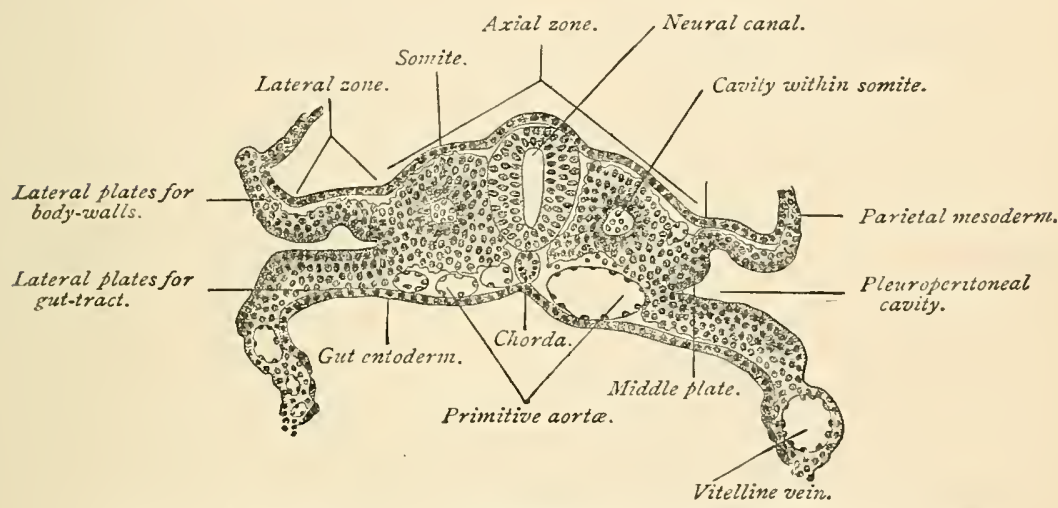

FIG. 102.-Tranverse section of a seventeen-and-a-half-day sheep embryo (Bonnet)-

nephros or head-kidney is anatomically adapted to the function of removing certain substances from the blood by rirtue of the action of the cells surrounding the glomeruli or tufts of capillary blood-ressels, and that these substances may be conveyed away through the duct into the cloaca and thence evacuated from the body. This organ is functionally active, however, only in certain lower classes of vertebrates, as in the Amphibia during the larval stage and in bony fishes. In mammals it is excecdingly rudimentary and very soon gives place to a more important organ, the mesonephros.

The Mesonephros or Wolffian Body.-As in the case of the pronephros, the origin of the mesonephros is to be found in the parietal mesothelium of the borly-cavity or cnelom. Reference has been made, in treating of the primitive segments, 
page 69, to the middle plate (Fig. 102) as a tract of mesodermic tissue connecting the paraxial tract with the parietal plate. When the paraxial mesoderm segments to form the somites, the middle plate likewise undergoes segmentation, each segment being designated a nephrotome. Each nephrotome, in the lower vertebrates, contains a cavity

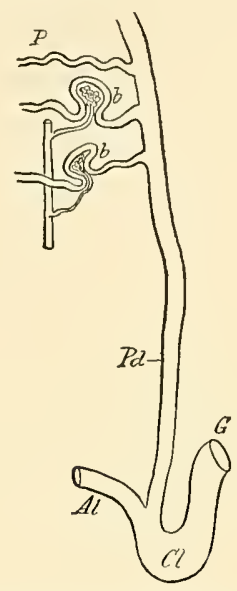

FiG. 103.-Diagram of pronephros $(P)$ and pronephrie duet $(P d)$ : $A l$, allantois; $G$, gut; $C l$, eloaca; $b b$, glomeruli.

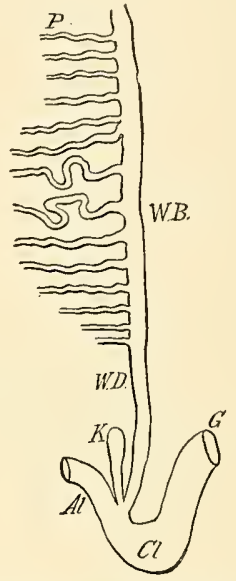

FIG. 104.-Diagram of Wolffian body and duct: $A l$, allantois; $G$. gut; $C l$, cloaca; $\boldsymbol{h}$. kidney evagination.

which communicates with the general body-cavity and which is therefore, in effect, an evagination of the mesothelium of this space. In mammals, however, as well as in reptiles and birds, the nephrotome is a solid cord of cells. By the hollowing out of these cell-cords or nephrotomes, a series of transversely directed tubules is formed, each nephrotome, in fact, becoming converted into a short canal. These tubes acquire connection by their deeper ends with the previously formed pronephric duct (Fig. 103), which is known hereafter, therefore, as the mesonephric or Wolffian duct (Fig. 104). The latter duct and the short transverse tubules which open into it constitute the Wolffian body or mesonephros (Figs. 105 and 106, 1). Hence, in its fully developed condition, which is attained by the seventh week of fetal life in man, the 


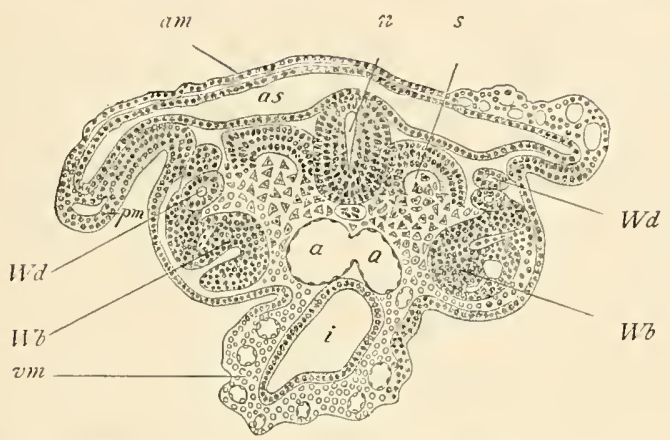

FIG. 105.-Transverse section of seventeen-day sheep embryo (Bonnet): am, amrion; $a s$, amniotic sac; $n$, neural canal; $s$, somite differentiated into muscleplate; $W d$, Wolffian duct; $W b$, Wolffian body; $p m$, parietal mesoderm; $v m$, visceral mesoderm; $a, a$, fusing primitive aortæ; $i$, intestine.

Wolffian body consists of a tube or duct lying behind the parietal layer of the mesoderm, parallel with, and lateral to,

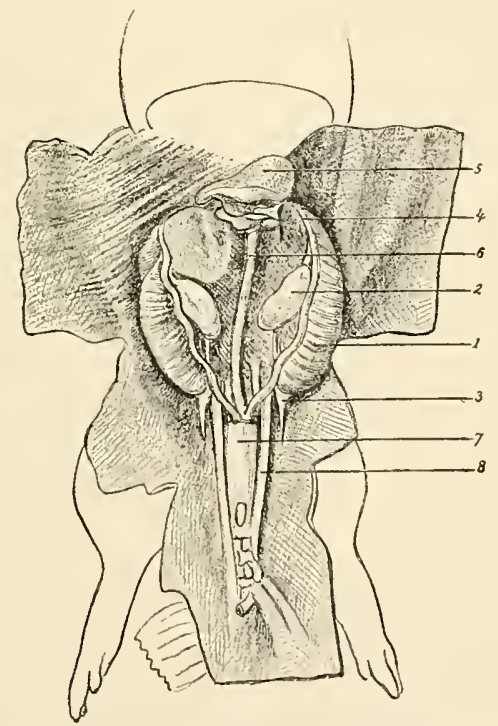

FIG. 106.-Disposition of the genito-urinary organs in the embryo of the hog$5.5 \mathrm{~cm}$ (2.2 in.) long (Tourneux) : 1 , Wolffian body ; 2, orary ; 3 , inguinal ligament ; 4 , diaphragmatic ligament; 5 , stomach ; 6 , intestine ; 7 , bladder ; 8 , umbilical artery.

the primitive vertebral column, and opening at the caudal end of the embryo into the cloaca; and of a series of transverse 
Wolffian tubules opening into the duct and abutting by their opposite ends upon the body-cavity. At the head-end of the Wolffian duct, the now atrophic pronephric tubes are still in connection with it.

It is usual for writers upon embryology to compare the general form of the Wolffian body to a comb, the short tubules representing the teeth, and the duct corresponding to the back of the comb.

As a further step in the development of an organ adapted to the function of the secretion of urine, each Wolffian tubule becomes somewhat saccular midway between its two extremities, and this dilated part of the tubule is invaginated by the capillary branches of an artery from the aorta. In this manner the cells that line the tubules are brought into relation with the blood of the fetus and acquire at the same time the characters of secreting epithelium. Such an invaginating tuft of capillaries, known as a glomerulus, with its enveloping capsule of Bowman, which latter is the invaginated saccular part of the tubule, constitutes a primitive Malpighian corpuscle, a structure analogous to the Malpighian corpusele of the permanent kidney. The complexity of the organ is increased by the development of secondary tubules and Malpighian corpuseles connected with those first formed.

The horizontal or transverse tubules of the Wolffian body are divisible into an anterior or upper series, distinguished as the sexual segment, and a lower set of atrophic tubulesatrophic for reasons that will appear hereafter. In certain vertebrates that are of higher type than those in which the pronephros functionates, such as adult amphibians and fishes, the Wolffian body persists throughout life as an organ of urinary secretion. In birds and mammals, however, its functional activity is but temporary, since it is supplanted, before the end of fetal life, by the permanent kidney. In man it disappears relatively early, retrogression beginning in the eighth week and the Malpighian bodies having almost disappearerl by the fifth month. The presenee of the mesonephros as a temporarily functionating organ in birds and mammals, while it is a permanent structure in certain lower 
members of the vertebrate series, exemplifies the embryological principle elsewhere referred to, that the higher types pass through stages during their development that are permanent in some of the forms below them in the scale of evolution.

The Metanephros or Permanent Kidney.- While the Wolffian body is temporarily performing the office of a kidney, a structure is evolving from its candal extremity which is to form the permanent organ. It has been stated that the duct of the Wolffian body opens into the cloaca. From this cloacal end of the duct, a little diverticulum or evagination (Fig. 104) grows forth and soon lengthens into a tube which extends headward toward the position of the Wolffian body. The upper or anterior end of the tube branches to form a number of smaller tubes (Fig. 107). At the same time, the surrounding indifferent mesodermic tissue (Fig. 108) is altered in character, becoming condensed and vascular. The blind end of each little tube, becoming dilated and saccular, is invaginated by capillary blood-vessels. This transformation produces the Mal-

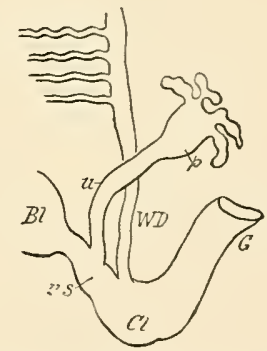

FIg. 107.-Diagram to show extension and branching of kidney evagination and separation of its stalk from the Wolffian duct: $u$, primitive ureter; $p$, pelvis of ureter; $\Pi^{*} d$, Wolffian duet; $B l$, bladder; $u s$, urogenital sinus; $C l$, cloaca; $G$, gut.

pighian corpuscles. The sacenlated end of each tubule is now a capsule of Bowman, while the tuft of capillaries enveloped by it is the glomerulus. It should be borne in mind that the glomernlus is not contained within the cavity of the tubule, bnt that the dilated end of the latter, still a shut sac, folds around the tuft of capillaries, enclosing it within a twolavered wall.

The tubules, assuming tortuons and convolnted form, owing to excessive growth in length, constitute the uriniferous tubules of the adult kidney. According to Minot, the capsule of the kidney, which is produced by the sur- 
rounding mesodermic tissue, exercises an important influence upon the form of the developing tubules, the resistance it offers to their centrifugal extension being the determining factor in producing the foldings and convolutions of the tubules. The progress of these metamorphoses is such that the kidney acquires its eharacteristic features by the end of the second month of fetal life. The original canal-that is,

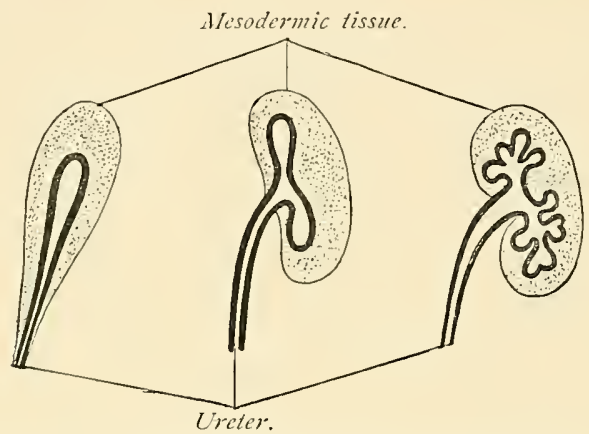

FIG. 108.-Diagrammatic representation of the development of the kidney (after Gegenbaur).

the stalk of the diverticulum-is now the excretory duct of the kidney, the ureter, while the dilated and branched upper part of the latter is the pelvis of the kidney with its calyces and infundibula. The connective-tissue stroma and capsule of the organ, in common with its blood-vessels and lymphatics, are products of the surrounding mesodermic tissue. It is apparent, therefore, that all parts of the kidney and its duct, the epithelium as well as the connective tissue, are derived from the mesoderm, since the Wolffian duct, from which the tubules and the ureter with their epithclium develop, is itself a product of the mesodermic cells, or mesothelium, lining the body-cavity.

\section{THE SUPRARENAL BODIES.}

The development of these structures is still involved in some obseurity. Most observers agree that they are genetically connected with the mesonephros or primitive kidney, but whether the organs, as represented in the adult condition, 
are derived solely from this source is not as yet definitely marle out.

The origin of the suprarenal body is variously ascribed by different investigators-1, to a group of connective-tissue cells found at the upper end of the primitive kidney; 2, to the germinal epithelium of the anterior or head-end of the genital ridge; and 3 , to epithelial outgrowths from the mesonephros or primitive kidney. The last named is regarded by Hertwig and by Minot as being the most probable source. The epithelial outgrowths referred to bud forth from the glomeruli of the primitive kidney and divide, each into two branches, one of which grows into the indifferent sexual gland to produce a part of its structure (as described in the sections on the ovary and on the testis), while the other turns dorsad and spreads out to form eventually the cortical part of the suprarenal body.

The origin of the medullary part of the organ is also a disputed point. On the dorsal side of the primitive kidney chains of small cells grow forth from the embryonic ganglia of the sympathetic system. These latter become surrounded by the cells derived from the mesonephros, as well as by embryonic connective-tissue cells, and are divided into small groups. According to Hertwig, ${ }^{1}$ who follows Balfour, Braun, and Kölliker, the cells budding from the sympathetic ganglia produce the medullary part of the organ. Minot, on the contrary, believes that these cells later entirely disappear and take no part in the formation of the medulla.

In the early stages of fetal life, the suprarenal body is relatively much larger than in the adult condition, and is situated chiefly on the ventral surface of the kidney. At about the third month it begins to assume more nearly its normal position.

The account of the development of the bladder and of the urethra may be deferred until the evolution of the internal sexual system shall have been considered.

${ }^{1}$ Entwickelungsgeschichte, fifth edition, Jena, 1896. 


\section{THE DEVELOPMENT OF THE INTERNAL GENERATIVE ORGANS.}

The Indifferent Type.-The internal generative organs of both sexes, in the course of their development, pass through a stage in which there is to be found no distinction of sex. This stage is designated, therefore, the indifferent type of sexual apparatus.

While the Wolffian body is attaining its full development, there appears in its vicinity a tube, the duct of Muiller (Plate VII., Fig. 1), which lies parallel with, and to the outer side of, the Wolffian duct. The exact mode of origin of the duct of Müller has not as yet been definitely made out. According to one view, its upper or cephalic portion is produced by an invagination of the mesothelium of the body-cavity, while the remaining lower segment results from a fission or longitudinal division of the Wolffian duct. In whatever way the duct may be formed, its lower or caudal end opens into the cloaca, which receptacle receives also the termination of the Wolffian duct. The upper end of the duct maintains a communication with the bodycavity or colom by means of an expanded funnel-shaped mouth. Its lower segment is closely associated with its fellow and with the Wolffian duets, forming thus the genital cord. The function of this canal in lowly organized animals-that of receiving from the body-cavity the female genital products, the ova, and evacuating them from the body-foreshadows its subsequent metamorphosis in most vertebrates.

While the duct of Mirller is forming, the mesothelial cells overlying that part of the free surface of the Wolffian body which looks toward the median plane and somewhat forward, its ventro-mesial aspect, undergo multiplication and thickening (Figr. 109, a), forming an elongated swelling or ridge. This is known as the genital ridge, which produces a projection upon the wall of the body-cavity. 'The genital ridge is still further thickened by the proliferation of the mesorlermic tissue $(E)$ beneath the mesothelial cells. The genital riclges of the human fetus appear in the fiftl week. 

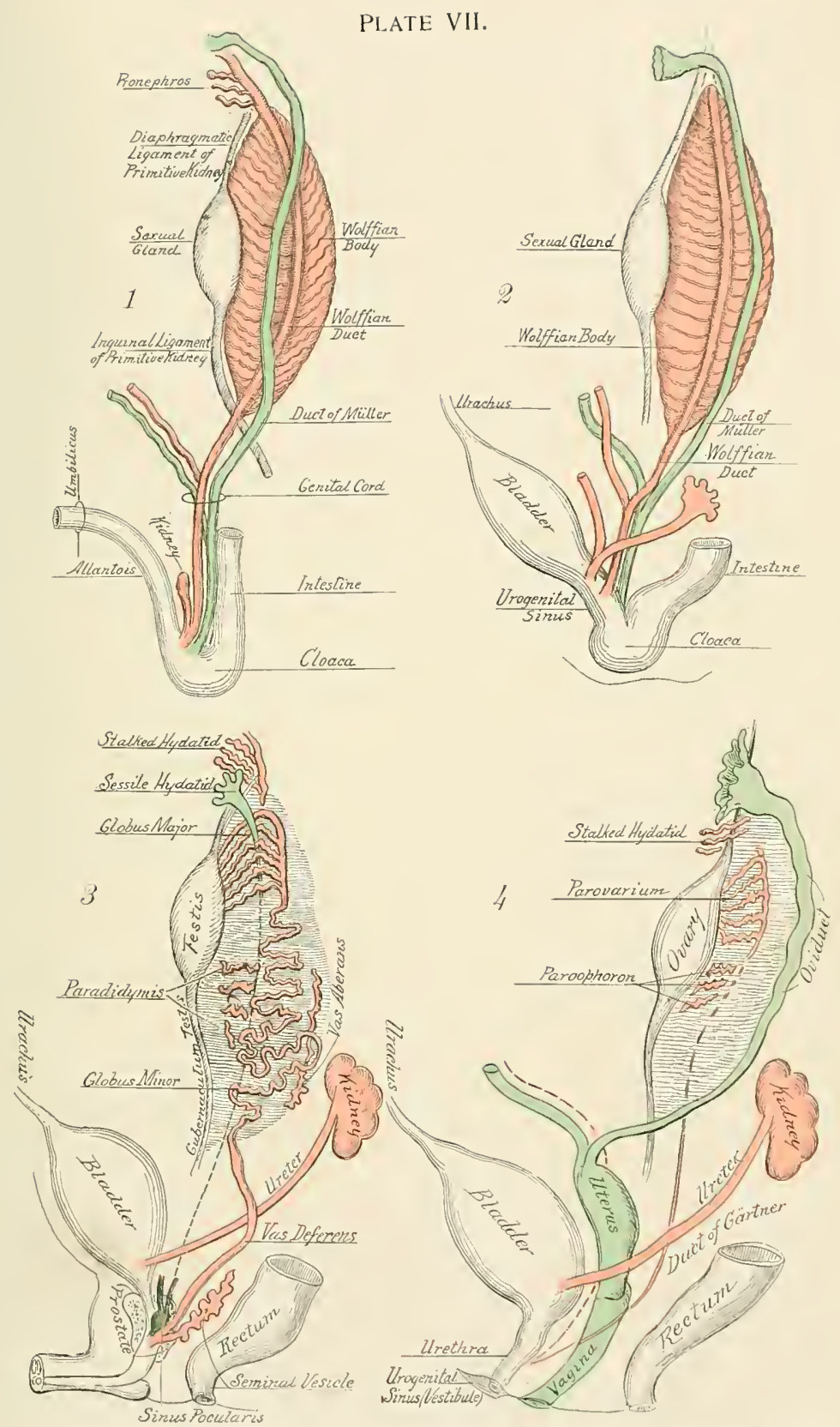

Diagrammatic representation of the development of the genito-urinary system, the Wolffian boly and its derivatives being colored red, the ylüllerian anct and its de. rivatives, green: 1 . Inditlerent tỵe: : Indillerent tỵe, later stage, the Wollian and Millerian ducts and the primitive ureter now opening inte the urogenital sinus: 3 , male type, lower ends of Müllerian ducts fused to form the sinus pocularis; 4 . female type. 

Further differentiation of the genital ridge results in its transformation into the so-called indifferent sexual gland (Plate VII., Fig. 1), a structure common to both sexes at this stage. The essential feature of this process is that the thickened mesothelial cells overlying the genital ridge become modified in character and penetrate the ridge in the form of cords or strands of cells. These mesothelial elements were called by

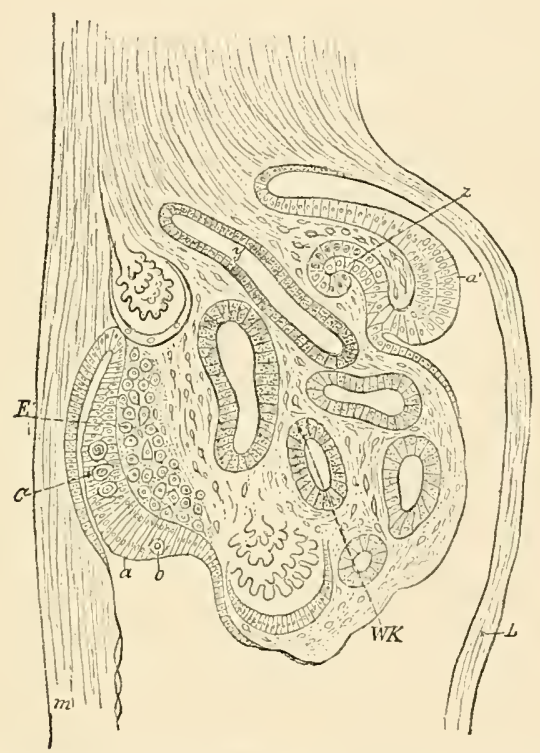

FIG. 109.-Cross-section through the mesonephros, the fundament of the Müllerian duct, and the sexual gland of a chick of the fourth day (after Waldeyer), magnified 100 diameters: $m$, mesentery ; $L$, somatopleure; $a^{\prime}$, the region of the germinal epithelium from which the Müllerian duct $(z)$ has been invaginated; $a_{4}$ thickened part of the germinal epithelium, in which the primary sexual cells, $C$ and $o$, lie; $E$, modified mesenchyme out of which the stroma of the sexual gland is formed; $W K$, mesonephros; $y$, mesonephric duct.

Waldeyer the germinal epithelium, because, after their extension into the interior of the ridge or gland, they give rise to the germ-cells, namely, the ova or the spermatozoa as the case may be. The cell-cords include two kinds of elements, the smaller mesothelial cells and the primitive sexual cells, which latter are larger and less numerous than the mesothelial cells and have large nucleolated nuclei. The primitive sexual 
or seminal cells, or primitive ova, are so called because it has been assumed that they develop either into the ova or the seminal filaments according to the sex of the embryo. The cell-cords have been seen in the indifferent gland of the human embryo as early as the fifth week. At this time, although there are no gross sexual distinctions recognizable, it is possible to determine from the histological characters of the organ whether it is to be a testis or an ovary, the large sexual cells being far less numerous relatively in the former case than in the latter (Nagel).

The indifferent sexual gland comes into an especially close relation with the upper or sexual series of the mesonephros or Wolffian body (Plate VII., Fig. 1), the significance of which fact will appear later.

The elements of the indifferent stage of the sexual apparatus are, therefore, the indifferent sexual gland, the Wolffian duct, and the duct of Müller (Plate VII., Figs. 1, 2). From this asexual stage, either the male or the female type is produced by the metamorphosis of the indifferent glands into the testicles or the ovaries and the formation of ducts to provide for the escape of the sexual elements, the spermatozoa, or the ova, produced by them.

The Male Type of Sexual System.-The differentiation of the indifferent sexual system into the male type is effected by the further development of some parts and the atrophy or the arrested growth of others.

The testicle has a double origin, since the proper secretory part of the organ is produced by the metamorphosis of the indifferent sexual gland, while its system of efferent ducts is furnished by the Wolffian borly. Mention has been made of the cell-cords of the indifferent sexnal glands and of their origin from the mesothelium of the body-cavity, and also of the fact that they consist of the smaller mesothelial cells and the larger and less numerous primitive sexual cells.

The mesothelial cells increase in number and become so grouped as to form cylinclrical masses known as sexual cords, each of which includes some of the primitive seminal or sexnal cells. By the ingrowth of connective tissue from the 
surrounding mesoderm, the sexual cords are divided into roundish masses, each of which is made up of many of the smaller elements and a less number of the large seminal cells. These follicle-like masses become hollowed out to form the seminal ampullæ, which afterward, by undergoing great increase in length, are transformed into the seminiferous tubules. During fetal life, however, and even to the period of puberty, the "tubules" remain solid cords of cells. The exact relation of the two kinds of cells to the production of the spermatozoa, whether or not the small cells give rise to Sertolli's columns, and the primitive seminal cells to the spermatozoa, is still involved in obscurity.

Spermatogenesis, or the development of the spermatozoa from the cells that line the seminiferous tubules of the functionating testicle, has been considered in Chapter $I$.

While the sexual cords are being transformed into the cylinders that become the seminiferous tubules, the surrounding mesodermic tissue penetrates the genital gland and forms the connective-tissue septa that constitute the stroma of the organ and diride it into lobules. At the same time, also, marked changes occur in the Wolffian body. From that part of this structure which has been referred to as the sexual series of transverse Wolffian tubules, cords of cells grow forth and penetrate the genital gland, their ends fusing with the primitive seminiferous tubules. The conversion of these cell-cords into tubes furnishes the initial part of the system of excretory ducts of the testicle, namely, the vasa recta, and the rete testis. Somewhat later, in the twelfth week, the rete testis is extended to form the vasa efferentia, and still later, in the fourth and fifth months, the efferent ressels lengthen and become tortuous, producing thereby the coni vasculosi or head of the epididymis (Plate VII., Fig. e; Fig. 110). The upper part of the Wolffian duct develops into a convoluted tube which eonstitutes the body and tail of the epididymis, while the lower portion becomes the vas deferens, thus completing the system of canals provided for the escape of the spermatozoa. Near the candal end of the ITolffian dnet, a little ponch-like evagination grows from its wall and hecomes 
the seminal vesicle, the lower end of the duct, below the orifice of the seminal vesicle, bcing the ejaculatory duct. Since the

Wolffian duct terminates in the

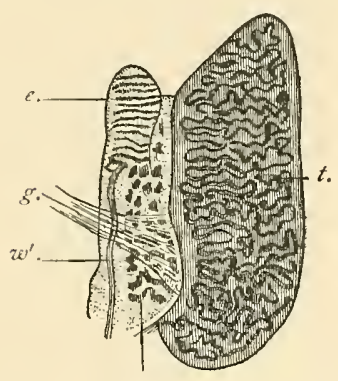

$w$

FrG. 110.- Internal generative organs of a male fetus of about fourteen weeks (Waldeyer): $t$, testicle; $e$, epididymis; $w^{\prime}$, Wolffian duct; $w$, lower part of Wolffian body : $g$, gubernaculum testis. cloaca, and since the anterior part of the cloaca corresponds to a portion of the later urethra, the termination of the ejaculatory duct in the prostatic part of the urethra is accomnted for. Thus it will be seen that while the secreting part of the testicle results from the transformation of the indifferent genital gland, the secretory cells having their origin in the germinal epithelium, the complicated system of ducts with which it is provided is furnished by the mesonephros or Wolffian body.

The series of tubules connected with the upper extremity of the Wolffian duct, the remnant of the pronephros or headkidney, frequently persists as a little pedunculated sac attacherl to the upper part of the epididymis; it is known as the stalked hydatid and sometimes also as the hydatid of Morgagni. The posterior or lower set of Wolffian tubules likewise give rise to an atrophic structure, the paradidymis or organ of Giraldès, which consists of a series of short tubes closed at both ends, lying among the convolutions of the tail of the adult epididymis (Plate VII., Fig. 3).

The duct of Muiller remains atrophic, in the male, throughont its entire extent, and in fact, with the exception of its two extremities, it usmally altogether disappears. Its upper extremity persists as a small vesicle, the unstalked or sessile hydatid, attached to the upper aspect of the testicle. The lower extremity of the duct, uniting with its fellow, becomes converted into the sinus pocularis or uterus masculinus of the prostate gland (Plate VII., Fig. 3). If the intervening part 
of the tube persists to post-natal life and remains patulous, it is known as the duct of Rathke.

The change of location which the testicle undergoes is a conspicnous feature of its development. To understand this clearly, it is necessary to recall the relation of the mesonephros and the genital gland to the peritoneum. Since botl of these bodies originate from the cells of the outer wall of the body-cavity, or, in other words, from what becomes the parietal peritoneum, necessarily they lie between the body-wall and the parietal peritoneum-that is, behind the peritoneal cavity. With the increase in size of these structures, they project toward the peritoneal cavity, the peritonem passing over them and forming a "mesentery," which anchors them to the posterior wall of the abdomen. In the case of the testicle, this peritoneal fold or "mesentery" is called the mesorchium; in the case of the ovary, the mesovarium. It is prolonged upward to the diaphragm as the diaphragmatic ligament of the primitive kidney, and downward to the inguinal region as the inguinal ligament of the primitive kidney (Fig. 106), since this latter organ is the largest constituent of the projecting mass. When the primitive kidney has disappeared as such, the inguinal ligament mentioned seems to commect the ovary or testicle with the inguinal region of the abrlominal wall.

The inguinal ligament contains between its folds connective tissue and unstriped muscular fibers. These become the gubernaculum testis in the male or the round ligament of the uterus in the female. As the body of the fetus continues to grow while the tissues of the ligament remain stationary or grow less rapidly, the testicle is gradually displaced from its position at the side of the lumbar spine, and by the third month reaches the false pelvis. In the fifth and sixth months it is in contact with the anterior abdominal wall, near the imner abdominal ring. In the eighth month it enters the inguinal canal, and near the end of the ninth month, shortly before birth, it leaves the inguinal canal and enters the scrotum. ${ }^{1}$

${ }^{3}$ Non-descent of the testicles, with consequent emptiness and flabbiness 
Before the testicle leaves the abdominal eavity, the parietal peritoneum ponches throngh the inguinal canal into the scrotum, the protruded part being the processus vaginalis. Since the testicle is from the first behind the parietal peritonenm, it passes into the scrotum behind the vaginal process, the latter then folding around it as a shut sac of two layers. Subsequently the eonnection of the sac, now the tunica vaginalis testis, with the abdominal peritoneum is reduced to a slender strand of tissue lying in front of the spermatic cord. ${ }^{1}$

The testicle necessarily carries with it, in its descent, its blood-vessels, the spermatic artery and vein; its duct, the vas deferens; as well as its nerves and lymphatic vessels; and these structures collectively constitute the spermatic cord.

The Female Type of Sexual System.-While the indifferent sexual gland, in the development of the male generative system, undergoes metamorphosis into the testicle, it becomes, in the evolution of the female type, so altered as to constitute the ovary; and while the Wolffian tubules and the Wolffian body become in the male the system of excretory ducts of the testiele, they produce in the female merely atrophic structures. On the other hand, the duct of Müller, which gives rise in the male to atrophic appendages, forms in the female type the Fallopian tube and, by fusing with its fellow of the opposite side, the nterus and the vagina.

The ovary results from alterations in the strneture of the genital gland analogous to those that oecur in the evolution of the testicle. The special features of these changes are better understond, however, than are those of the testicle. As in the case of the development of the testicle, the mesothelial cells on the peritoneal surface of the genital ridge become thickened, these altered cells constituting the germinal

of the scrotum, is designated cryptorchism (hidden testes). The presence of but one testicle in the scrotum is called monorchism.

${ }^{1}$ Occasionally it lappens that the funiculer process of the tunica vaginalis-that is, the stalk of the sac, remains patulous throughont its entire extent, a condition which. allows of the easy and sudden protrusion of a segment of the bowel into the cavity of the tunica vaginalis, constituting the so-called congenital hernia. Or the funicular process may close only at one or the other end, giving rise to other varieties of hernia. 
epithelium (Fig. 109). Coincidentally, the primitive connective tissue-mesodermic tissne-underlying the germinal epithelium proliferates, contributing to the thickness of the genital ridge. By the sixth or seventh week, the germinal epithelium consists of several strata of cells, groups of which begin to penetrate the underlying mesodermic tissue in the form of eordlike processes (Fig. 112, $c$, sch). The indifferent mesodermic tissue at the same time increases in quantity, in turn penetrating between the groups of advancing cells, so that what takes place mighit be described as a mutual intergrowtl. The presence of

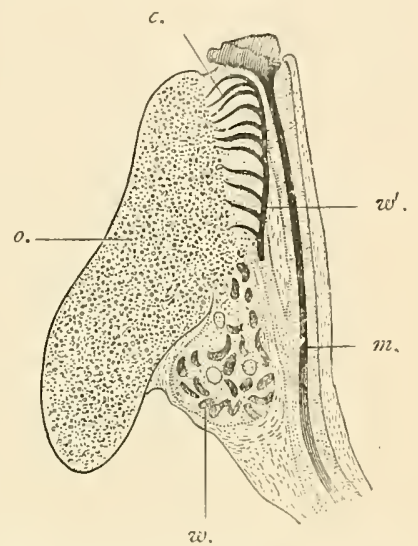

FIG. 111,-Internal organs of a female fetus of about fourteen weeks (Waldeyer): $o$, orary; e, epoöphoron or parovarium; $w^{\prime}$, Wolffian duct; $m$, Irüllerian duet; $w$, lower part of the Wolffian body. the growing connective tissue accentuates the gromping of the cells into cylindrical masses. These latter are the sexual cords or egg-columns (Pflïger's egg-tubes). They contain two special kinds of cells, the large sexual cells or primitive ova (Fig. 112, ue), and the smaller but more numerous mesothelial cells. The connection of the sexual cords with the germinal epithelium is much more obvious in this case than in the case of the developing testicle, and the prinitive sexmal cells are much more abundant. The egg-columns, surrounded by young connective tissue, constitute the nuclens of the cortical part of the future ovary. This mass is later sharply marked off from the free or peritoneal aspect of the gland, the region of the germinal epitheliun, by a zone of proliferating mesodermic cells which become the tunica albuginea of the ovary.

An important change now takes place in the egg-columns; the primitive ova, or large sexual cells, increase in size, their nuclei hecoming especially woll developed, while the small 
mesothelial cells become smaller and less conspicuous. Several of the large cells fuse into a single mass of protoplasm, while one of the nuclei outstrips the others in growth and, with the surrounding zone of protoplasm, becomes the ovum. Each egg-column is now broken up into several groups of cells by the penetration of connective tissue, each group (Fig. $112, e, s^{\prime}$ ) containing a single ovum but many of the smaller

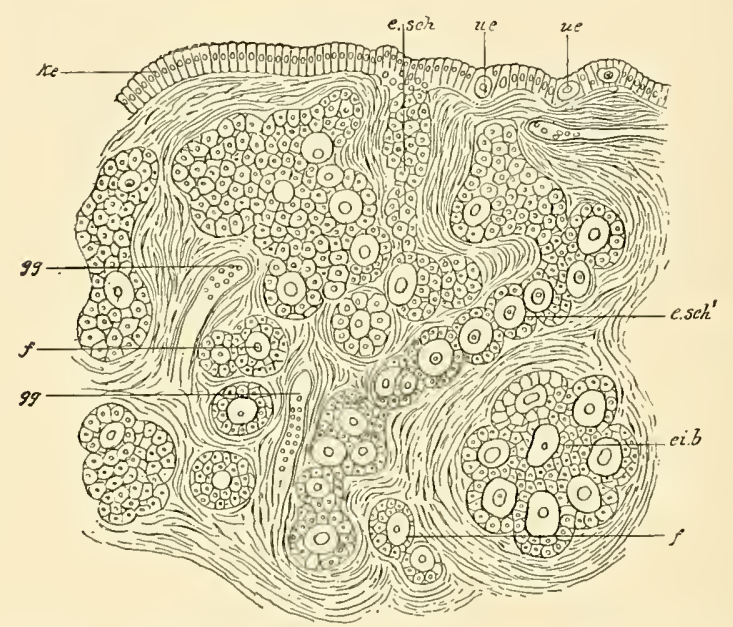

FIG. 112.-Part of sagittal seetion of an ovary of a child just born (after Waldeyer). Highly magnified: $k e$, germinal epithelium; $e, s c h$, Pflüger's egg-tubes; $u e$, primitive ova Iying on the germinal epithelium; $e, s c h^{\prime}$, long Pflüger's tubes, in process of being converted into follicles; $e i, b$, egg-balls (nests), likewise in process of being resolved into follicles; $f$, youngest follicle already isolated: $g g$, blood vessels. In the tubes and egg-nests the primordial eggs are distinguishable from the smaller epithelial cells, the future follicular epithelium.

cells. These groups are the young Graafian follicles of the ovary $(f)$. The enveloping zone of connective tissue becomes the theca of the follicle, while the single large cell constitutes the ovum, and the smaller cells are the membrana granulosa. At first the granulosa cells surround the ovum as a single layer of flattened colls which gradually assume the colnmnar type and become so numerous as to form many layers. They secrete a fluid, the liquor folliculi, which crowds the ovum to one side of the follicle where it is enveloped by a special group of granulosa-cells, the discus proligerus (Fig. 113). 
The question of the origin of the follicular cells is still an unsettled one, though it seems probable that they are derived from the cells of the egg-columns, and Minot believes that they are probably descended from the primitive ova.

The formation of new Graafian follicles, and consequently of ova, begins in the deeper part of the ovary and advances toward the surface. The production of ova and follicles is

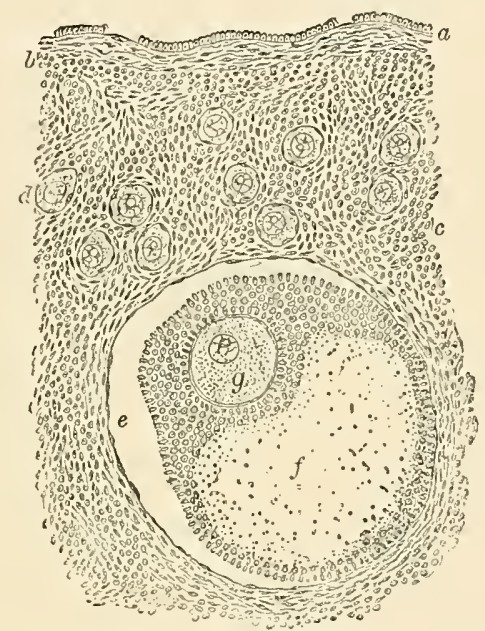

Fig. 113.-Section of human ovary, including cortex : $a$, germinal epithelium of free surface; $b$, tunica albuginea; $c$, peripheral stroma containing immature Graafian follicles $(d)$; $e$, well-advanced follicle from whose wall membrana granulosa has partially separated; $f$, carity of liquor folliculi; $g$, orum surrounded by cell-mass constituting discus proligerus (Piersol).

limited to the fetal stage and to the early part of post-natal life, their formation not occurring, according to Waldeyer, after the second year.

What has been said above refers to the development of the cortex of the ovary. The medulla is produced by the growth toward the egg-columns of cord-like processes, the medullary cords, from the epithelial walls of the Malpighian corpuscles of the primitive kidney or Wolffian body, the cords becoming surrounded by connective tissue and forming a network. The fetal medullary cords are represented in both the cortex and the medulla of the mature ovary by the groups of interstitial cells disposed between the bundles of the stroma-tissue. 
The Oviducts, the Uterus, the Vagina.-The system of passage-ways that constitute the outlets for the ova and the means of nourishing them and evacuating the product of gestation from the body in the event of impregnationnamely, the Fallopian tubes, the uterus, and the vagina-result from the metamorphosis of the ducts of Müller. These ducts, as stated above, lie along the dorsal aspeet of the body-cavity, separated from it by the parietal peritoneum, and parallel with the primitive spinal eolumn (Plate VII.). The probable method of their formation has been pointed out (p. 220). Near the Iower (eaudal) end of the body they approach each other, and finally unite about the second month to form a single duct for the rest of their extent (Plate VII., Fig. 4). The upper, ununited parts of the duets become the Fallopian tubes or oviducts, while the lower portions, now fused into one, become the uterus and the vagina. The upper end of each single duct expands trumpet-like to form the fimbriated extremity of the Fallopian tube.

Until the fifth month there is no distinetion between the vagina and the uterus, the two being represented by a single sac-like structure. The development of a circular ridge in the wall of the sae marks the division between the two organs, the part above the ridge acquiring thick museular walls, while the part below it, the future vagina, remains thin-walled and more eapacious. In the third month the uterus is bifid at its upper extremity, a condition which is permanent in some animals and occasionally in the human subject. ${ }^{1}$

The Wolffian duct, which, in the male, becomes metamorphosed into a part of the epididymis and the vas deferens, remains undeveloped in the female, produeing merely atrophic or vestigial structures (Plate VIT., Fig. 4). The upper series of Wrolfian tubules, the remnant of the pronephros, frequently

3 The formation of the uterus and of the vagina by the coalescence of two parallel tubes affords an explanation of the uterus bicornis or bifid uterus and of the condition of double uterus sometimes met with, as also of the presence of a median septum in the vagina, since by the failure of union of the two tubes in greater or less rlegree one or other of these anomalies would result. 
persists, as in the male, in the form of a small pedunculated sac, the stalked hydatid or hydatid of Morgagni. When present, it is to be found in the broad ligament, in the neighlsorhood of the outer extremity of the ovary. The middle or sexual series of the Wolftian tubules with the adjacent part of the Wolffian duct, which, in the male type, develop into the epididymis, become in the female, an atrophic structure known as the epoöphoron or parovarium, or organ of Rosenmüller (Fig. 111). This structure, which is almost constantly found between the layers of the broad ligament in close proximity to the ovary, consists of a larger horizontal tube representing a segment of the Wolffian duct, and of shorter vertical tubes joining this at a right angle and representing the transverse Wolffian tubules. The lower set of small Wolffian tubules, those which, in the male become the paradidymis, give rise in this ease to a similar atrophic body, the paroophoron. This is also situated in the broad ligament, usually to the inner side of the ovary. The Wolffian duct, with the exception of that portion of it that assists in the formation of the parovarium, usually entirely disappears. Occasionally, howerer, it persists as a small canal traversing the broad ligament close to the uterus and passing on the dorsal side of the upper part of the vagina to be lost upon the wall of the latter or, more rarely, to open near the urinary meatus. When thus persistent, it is known as the duct of Gartner.

The change of position of the ovaries is similar to, though less marked than, that of the testes. The inguinal ligament in the female (Plate VIT.) extends from the primitive position of the ovaries in the lumbar region of the abrlominal cavity to the groin, where it passes through the abdominal wall, traversing the inguinal canal, to terminate in the labium majus. The upper part of this ligament, containing involuntary muscular substance, firmly unites with the ovary. In the third month the ovary descends to the lower part of the abdominal carity and is now connected, by the succeeding portion of the inguinal ligament, with the nterns. This connection may be a fictor in the final change of position of the 
ovary - that is, its descent into the true pelvis. The part of the inguinal ligament that passes from the ovary to the uterus is the permanent ligament of the ovary, while the remaining portion, which passes from the uterus through the inguinal eanal to the labium majus of the vulva, is the round ligament of the uterus. As the inguinal ligament perforates the abdominal wall, a small divertienhm of peritoneum goes with it. Normally this peritoneal pouch subsequently becomes obliterated. Oceasionally, however, it persists and then constitutes the canal of Nuck. Should the canal of Nuek be present, the ovary may pass into or throngh it, thus reaching the labium majus. A patulous canal of Nuek, as in the case of a patulons funicular process of the tunica vaginalis of the male, may permit the sudden oeeurrence of an inguinal hernia in the female.

The aceount of the development of the external genital organs will be deferred until after the consideration of the formation of the urinary bladder and of that part of the urethra that originates from the same embryonic structure.

THE BLADDER AND THE PROSTATE GLAND.

As stated in Chapter V., the urinary bladder and a part of the urethra are derived from the intra-embryonie portion of the allantois. In the same chapter the allantois was described as a sac which developed as a pouching-out of the ventral wall of the gnt-tract near its caudal end (Plate II., 5 and 6). The sac protrudes from the still widely open abdominal cavity, enters the extra-embryonic part of the body-cavity, and reaches the inner surface of the false amnion, with which structure it intimately nnites to form the trne chorion (Plate IIT.). As the walls of the abdomen gradnally close, leaving only the umbilical aperture, it is, necessarily, through this aperture that the allantois protrudes.

We have seen (p. 82) what beeomes of the extra-abdominal part of the allantois-in what degree it contributes to the formation of the placenta and of the umbilical cord. 
Obviously, with the severing of the umbilical cord after birth, all this extra-embryonic part of the allantois disappear's, giving rise to no ádult organ.

Its intra-embryonic portion consists of a tube extending from the candal end of the intestine to the umbilicus (Plate II., 5 and 6). As early as the sceond month, the middle segment of this tube dilates and assumes the form of a spindleshaped sac, which becomes the urinary bladder (Plate VII.). The part of the tube connecting the summit of this sac with the umbilicus remains small, gradually loses its lumen, and constitutes in the adult the (usually) impervious cord known as the urachus. Should the cavity of the urachus persist in its entirety, and should there be at the same time an external opening at the umbilicus, the condition would constitute an umbilical urinary fistula. The proximal part of the allantois -that is, the portion intervening between the bladder and the intestine-is designated the sinus urogenitalis, while the caudal end of the intestine, which is, in effect, a pouch in which both the allantois and the intestine terminate, is known as the cloaca (Fig. 84). The urogenital sinns receives the terminations of both the Müllerian and the Wolffian ducts (Plate TII.).

In the sixth week or slightly earlier, there appears upon the surface of the body, in the region corresponding to the position of the cloaca, a depression, the cloacal depression (Fig. 84), which later, exeept in man and the higher mammals, meets the cloaca, and thus establishes a communication between it and the exterior. In the Amphibia, in reptiles, and in birds, as also in the lowest mammals, the monotremes, the cloaca is a permanent structure, and through it, in these groups of animals, not only the fecal matters and the urine, but also the genital products, the spermatozoa and the ova, are evacuated from the hody. In all mammals, howerer, with the exception of the monotremes, the eloaca undergoes division into a posterior part or anal canal and an anterior urogenital aperture. This division is brought about by the growth of three ridges or folds, of which one springs from each side of the cloaca and one from the point of union of the uro- 
genital sinus and the intestine. These folds coalesce about the eighth ${ }^{1}$ week to form a complete septum, which continues to thicken antero-posteriorly up to the time of birth and constitutes the perineum.

It will be remembered that the ureters originally spring from the terminal parts of the Wolftian or mesonephric ducts (Fig. 104). Owing to alterations brought about by processes of unequal growth, the orifices of the ureters subsequently change their position so as to open into the urogenital sinus (Fig. 107), and still later, by the further operation of the same agency, they come to open into the bladder on its dorsal wall, thus gradually assuming their permanent relations (Pl. VII.). After the division of the cloaca the nrogenital sinus, as stated above, opens independently upon the surface of the borly. In the female it is transformed into a short tube, the urethra, and an expanded terminal recess or fossa, the vestibule of the vulva (Pl. VII.). In the male it becomes the first or prostatic part of the urethra.

In the twelfth or thirteenth week, the future prostatic urethra acquires very thick muscular walls, and the original epithelial tube pouches out into the muscular tissue in the form of little sacs, the lining cells of which assume the characters of secreting epithelium. In this way is produced the aggregation of muscular and glandular tissue known as the prostate gland. This is a well-developed structure by the fourth or fifth month (Tourneux). The recess in the floor of this part of the urethra, the sinus pocularis or uterus masculinus, has been previonsly referred to as the homologue of the uterus, being the persistent caudal extremities of the ducts of Müller (Plate VII.).

THE EXTERNAL ORGANS OF GENERATION.

In the carly stages of the development of the external genital organs no sexual distinctions are apparent.

Reference has been made to the cloacal depression as a superficial fossa which makes its appearance at the candal end of the borly of the embryo in the sixth week (Fig. 84). At

\footnotetext{
1 Fourteenth week, according to Minot.
} 
abont the same period an encircling elevation, the genital ridge (Fig. 114, A, 4), is seen to surround this depression. Within the genital ridge, at the anterior part of the cloncal fossa, a small tubercle, the genital eminence, appears at the same time.
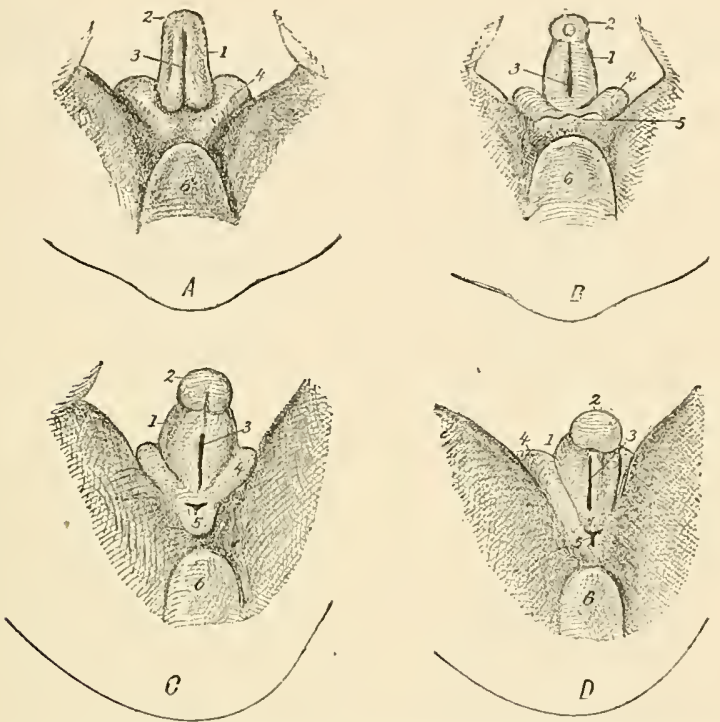

FIg. 114.-Fonr successive stages of development of the external genital organs (indifferent type) of the human fetus of 24 to $34 \mathrm{~mm}$. (0.95 to 1.35 inch) (Tourneux) : 1 , genital eminence or tubercle; 2 , glans; 3 , genital groove; 4 , genital ridge; 5 , cloacal depression; 6 , coccygeal eminence.

On the under aspect of the genital eminence there is soon distinguishable the genital groove (Fig. 114,3), which appears as if a continuation of the fissure-like eloacal depression (5), and the groove very shortly becomes flanked by two ridges, the genital folds, one on each side.

The genital eminence becomes the penis or the clitoris, aceording to the sex of the fetus. It very early acquires a knob-like extremity (2) which is the beginning of the glans penis or of the glans clitoridis, as the case may be. Further development of the glans is brought about by the appearance of a partially encircling groove which serves to differentiate it from the body of the organ.

At this stage of development, the rudimentary organs, as 
described above, are precisely alike in the two sexes. Early in the third month-about the ninth week-sexual distinetions begin to become manifest. Since the female organs exhibit the less degree of deviation from the early indifferent form, they will be first considered.

The External Genital Organs of the Female.-The sexually indifferent genital eminence which, as we have seen, presents

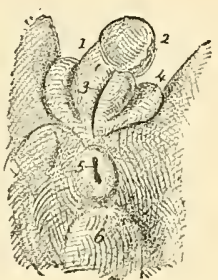

$A$

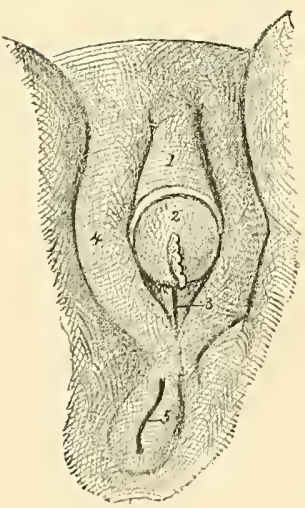

$c$

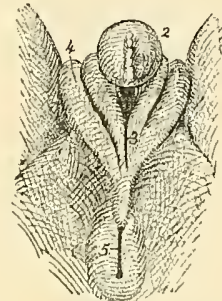

B

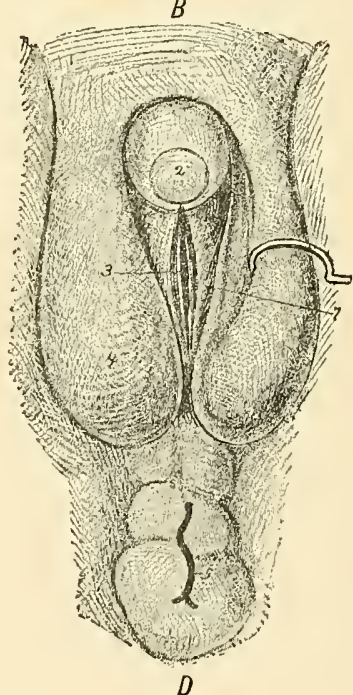

FIG. 115.-Four successive stages of development of the external genital organs of the human female fetus (Tourneux): 1, elitoris; 2 , glans clitoridis; 3 , urinogenital fissure; 4, labia majora; 5 , anus; 6 , eccygeal eminence; 7 , labia minora.

even by the end of the second month a rudimentary glans and an indication of a prepuce, elongates somewhat and becomes the clitoris. The genital folds bounding the genital groove on the under surface of the genital eminence (Figs. 114 and 
115, A) never unite with each other as they do in the male, but become prolonged in the direction of the future anus and constitute, by the fourth month, the lateral boundaries of the orifice of the urogenital sinms, or, in other words, of the vestibule of the vagina (Fig. 115, 3). These folds, continuous over the dorsum of the clitoris with its rudimentary prepuce, are the nymphæ or labia minora (Fig. 115, D, 7) of the fullyformed state. The masses of erectile tissue in close relation with each labium minus, the pars intermedialis and the bulbus vestibuli, are the homolognes respectively of a lateral half of the male corpus spongiosum and its bulb. The genital ridge, which, from the first, encircles the genital emincnce and the cloacal depression, and, consequently, the later clitoris and the aperture of the sinus urogenitalis, increases greatly in thickness. The part of it situated on the ventral side of the clitoris becomes the mons veneris, white the lateral parts of the ridge become the labia majora of the vulva. The several parts of the female genitalia develop to such a degree during the fourth month that their sexual characters at this time are well marked.

The reader is again reminded that in the stage when the cloaca is present, the Müllerian ducts terminate in the sinus urogenitalis (Plate VII.). As previously stated, the sinus urogenitalis becomes the female urethra, its terminal portion expanding into the vestibulum vaginæ. The openings of the Muillerian ducts fall within this latter vestibular region of the sinus. The lower portion of the two ducts by this time, however, have fused to form the uterus and the ragina, and hence is established the permanent relationship of these parts -that is, the opening of the ragina and the urethra by separate orifices into the restibule.

The formation of the hymen begins in the fifth month as a little crescentic fold at the posterior margin of the aperture of the vagina.

The glands of Bartholin develop as evaginations of the wall of the vestibular region of the urogenital sinus.

The Male External Genitals.-The male external organs represent a farther stage of development than the corre- 
sponding female parts. The genital eminence clongates rather rapidly, its length in the tenth week being $1.5 \mathrm{~mm}$. The knob-like extremity becomes better marked and constitutes the glans penis, while the integumentary fold that partially encircles the latter assumes more distinctive character as the prepuce. This fold gradually advances over the glans and adheres to it, the adhesion persisting until, or shortly after, birth. All of the rudimentary penis, exclusive of the glans and of the genital folds, becomes the corpora cavernosa of the adult organ. The characteristic structure of the corpora
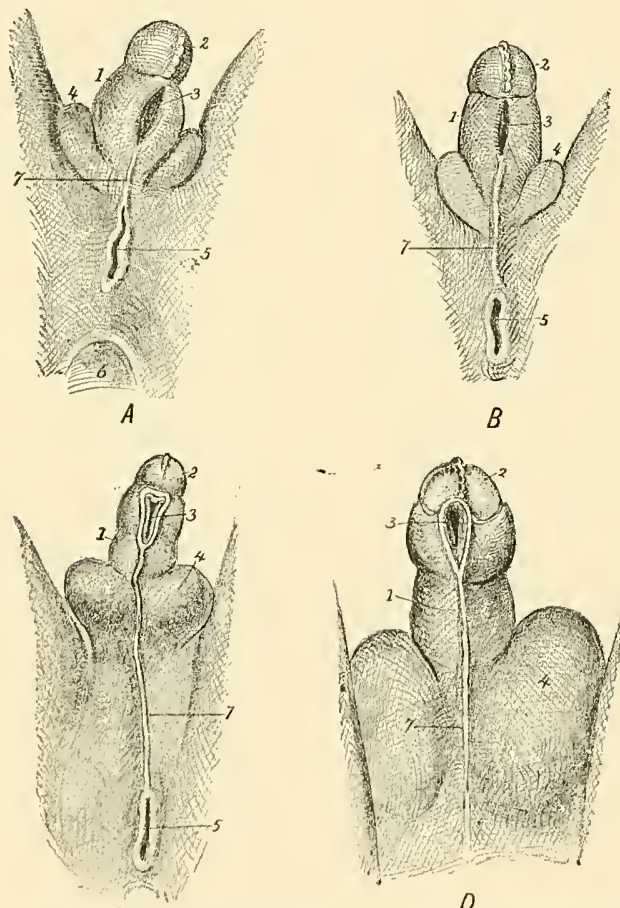

C

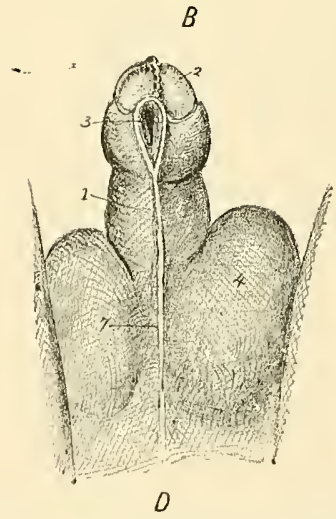

FIG. 116.-Four suceessive stages of development of the human male fetus (Tourneux): 1 , penis; 2 , glans; 3 , genital groove; 4 , serotum ; 5 , anus ; 6 , eoceygeal eminence; 7 , perineoserotal raphe.

cavernosa is foreshadowed as early as the third month by the appearance in the penis of capillary blood-vessels, which, in the sixth month, undergo marked dilatation. 
The groove on the under surface of the penis becomes deeper, and the genital folds, which bound the groove laterally, increase in size. This groove extends from the orifice of the urogenital sinus to the glans penis. The genital folds, which in the female, remain distinct and become the nymphe, unite with each other in the male and convert the groove into a canal, which latter is practically an extension of the urogenital sinus along the entire length of the penis to the glans. The camal thus former is the anterior part of the male urethra, or, in other words, it includes all of the urethra except its prostatic portion, which represents the urogenital sinus. The orifice of this newly-formed canal, situated in the glans, is the meatus urinarius. Failure of union of the genital folds, either wholly or in part, results in total or in partial defieiency of the floor of the urethra, this anomaly being known as hypospadias. If the defective closure involves only the glans, the condition is denominated glandular hypospadias.

The genital folds form not only the sides and the floor of the penile urethra, but by an extension of their growth, also its roof, thus completely surrounding it. Upon the acquisition, by the now united genital folds, of blood-ressels and carcrnous spaces, they become the corpus spongiosum of the penis, and thus is established the permanent or adult relation of these parts.

The genital ridge becomes differentiated into two prominent folds or ponches placed one on either side of the root of the penis. In the fourth month these unite to form the scrotum, the line of union being indicated by the raphe. Failure of mion of the two halves of the scrotum is one of the features of certain forms of so-called hermaphroditism.

The glands of Cowper, which correspond to the glands of Bartholin of the female, are developed, like the latter, as evaginations of the terminal part of the urogenital sinus.

The accompanying tabulation exhibits a comparison of the organs of the two sexes on the basis of their common origin. Male and female parts that develop from the same fetal structure are said to be homologous with each other. 


\section{Homologies of the Sexual System.}

Fetal Structure. Female Organs.

Indifferent sexual gland. Ovary.

Wolffian body-

Its middle series of tu- Short tubules of par- Vasaefferentia, retetestis bules and ovarium and and coni vasculosi.

Corresponding part of Horizontal or long tube Tube of epididymis.

Wolffian duct. of parovarium.

Remainder of Wolffian Usually altogether dis- Tas deferens, seminal duct. appears; if persistent, resicle, and ejaculaGartner's duct. tory duct.

Upper series of short Stalked hydatid of Mor- Stalked hydatid of Mortubules (pronephros). gagni.

Lower series of tubules. Paroöphoron.

\section{Duct of Müller-}

Its upper extremity. Succeeding portion.

Fimbria of oviduct. Oviduct.

Remaining portion, by Uterus and vagina. fusion with its fellow.

\section{External Organs.}

Fetal Structure.

Genital eminence.

Genital folds.

Genital ridge.

Urogenital sinus.
Female Organs.

Clitoris.

Nymphre and bulbi ves- Corpus spongiosum, entibuli.

Labia majora.

Urethra and vestibule, Glands of Bartholin. gagni.

Paradidymis (organ of Giraldès).

Sessile hydatid.

Usually disappears; if persistent, duct of Rathke.

Uterus masculinus.
Male Organs.

Testis. 
temporarily functionating organ, the mesonephros, performs the office of a kidney during a part of fetal life, and this latter is preceded by the pronephros, an organ which, though represented in the higher vertebrates by a vestigial remnant, is functionally active only in larval Amphibia and in bony fishes.

4. The Pronephros.-The mesothelial cells of the onter or parietal wall of the body-cavity become invaginated in a line parallel with the axis of the body, and the cord of cells thus formed becomes hollowed out to constitute the pronephric or segmental duct. At several points this duct retains its connection with the surface-cells by means of cell-cords, which latter become tubes and acquire glomeruli. The long tube and the shorter tubules with their glomeruli constitute the pronephros.

5. The Mesonephros.-The transverse segmentation of the middle plate, which comnects the paraxial mesoderm with the parietal plate, results in the formation of a series of cell-masses, the nephrotomes. Each nephrotome becomes a tube and acquires one or more glomeruli. The deeper ends of the tubes become comnected with the pronephric or segmental duct, which latter is known henceforth as the mesonephric or Wolffian duct. These tubes, with the adjacent part of the Wolffian duct, constitute the mesonephros, which functionates, for a time, even in the human fetus, as an organ of urinary excretion. The entire Wolffian duct, with the pronephric tubules and the mesonephric tubules, constitutes the Wolffian body. The Wolffian duct opens at its lower or caudal extremity into the cloaca.

6. The metanephros or permanent kidney develops from a small diverticulum that pouches ont from the lower or caudal end of the Wolffian duct. The uriniferons tubules and the pelvis of the kidney correspond to the dilated and subdivided fundus of this diverticulum, while the ureter represents its stalk. The surrounding mesodermic tissue furnishes all the component elements of the ureter-walls and of the kidney except the epithelial parts, which latter, as noted above, proceed from the Wolfiim borly. 
7. The suprarenal bodies probably are derived, in part, from epithelial outgrowths which proceed from the mesonephros to form the cortical part of the organ, and, in part, from chains of small cells that bud forth from the embryonic sympathetic ganglia to form its medulla. The surrounding mesodermic tissue contributes the connective-tissue parts of the suprarenal body.

8. The sexual apparatus in its earlier stages presents no distinctions of sex. The elements of this early indifferent type are the indifferent genital gland, the Wolffian duct, and the duct of Müller.

9. The indifferent genital gland originates in the mesothelium of the body-eavity. The mesothelial cells overlying the ventromesial aspeet of the Wolffian body undergo multiplication in the fifth week and thereby produce an elongated elevation, the genital ridge. Further multiplication of its cells and the addition of other elements bring about the transformation of this ridge into the well-defined genital gland, which now lies in close relation with the Wolffian tubules. The mesothelial cells are the "germinal epithelium" of Waldeyer, the cells that produce the ova or the spermatozoa, aceording to the future sex.

10. The duct of Müller makes its appearance soon after the Wolffian duct. It lies parallel with and to the outer side of the Wolffian duet and also terminates in the eloaca. It is of mesodermic origin, being produced either by evagination of the mesothelial cells of the body-eavity, or by a splitting off from the Wolffian duct.

11. The generative systems of both sexes result from the metamorphosis of the three struetures making up the early indifferent sexual apparatus-namely, the indifferent sexual gland, the Wolffian body, and the duct of Müller.

12. The male sexual system is produced by the transformation of the indifferent gland into the testicle, and the eonversion of the Wolffian tubules and the Wolffian duct into the system of excretory ducts for that gland, the short tubules becoming the vasa efferentia and coni vaseulosi, while the Wolffian duct itself furnishes the body and the globus minor 
of the epididymis, the ras deferens, the resieula seminalis, and the ejaculatory duct. The duct of Müller remains undeveloped and is represented in the adult by the atrophic sessile hydatid and the uterus masculinus.

13. The female sexual apparatus is brought about by the development of the indifferent gland into the ovary, and by the metamorphosis of the upper segments of the ducts of Mïller into the Fallopian tubes, and the fusion of the remaining portions of the two ducts to form the uterus and the vagina. The Wolffian duct and tubules give rise to atrophic structures in the female, the most conspicuous of which is the parovarium or epoophoron.

14. Both the male and the female external genitalia are developed from fetal structures common to the two sexes, the genital eminence, the genital ridge, and the genital folds. The genital eminence is situated at the anterior or rentral part of the cloacal depression. The genital ridge is an eleration surrounding this pit and the genital eminence, while the genital folds are on the under surface of the genital eminence, one on each side of a longitudinal groove.

15. The Wolffian ducts and the ducts of Müller open into the cloaca, but when that aperture becomes differentiated into the anus and the urogenital sinus, as it does at the fourteenth week, these ducts fall to the latter apartment. The orifice of the urogenital sinus being at the base of the genital eminence, the sinus comes into continuity with the groove on the under surface of the eminence.

16. The female external genitalia are produced by the further development of the three structures mentioned abore. The genital eminence becomes the clitoris. The genital folds on the under surface of the clitoris become somewhat prolonged to constitute the labia minora. The genital ridge becomes, anteriorly, the mons veneris and laterally the labia majora. The orifice of the urogenital sinus is represented by the vestibule, and since the Müllerian duets near their termination in the urogenital sinus fuse to form the ragina, the latter passage opens in the adult into the restibule. Since, also, the urogenital sinus receives the termination of the 
allantois, which becomes the female urethra, the latter canal likewise opens into the adult vestibule.

17. The male external genitals represent a further development of the embryonic genital eminence, genital folds, and genital ridge than do the female organs. The genital eminence becomes the penis, the genital folds, uniting with each other so as to surround the groove, producing the corpus spongiosum. The groove itself, being thus converted into a canal which extends the now closed urogenital sinus to the end of the penis, constitutes all of the male urethra except the first or prostatic portion. The prostatic urethra represents the proximal extremity of the allantois. Since the Wolffian ducts open into the urogenital sinus after the division of the cloaca, the terminations of those ducts, represented now by the ejaculatory ducts, open into the prostatic urethra; and since the Müllerian ducts also open into the urogenital siuus, the uterus masculinus, which is the representative in the male of the terminal parts of the Müllerian duets, is found likewise in the prostatic urethra. The lateral parts of the genital ridge, which, in the female, become the labia majora, fuse with each other in the male to form the scrotum.

18. The condition of so-called hermaphroditism may be produced either by an unusual degree of development of the female external genitals, resulting in a clitoris resembling a penis and in labia majora which simulate a cleft serotum ; or by the arrested development of male organs, whereby the genital folds and the genital ridges fail to unite, the urethra in consequence opening at the base of the penis. 


\section{CHAPTER XIV.}

\section{THE DEVELOPMENT OF THE SKIN AND ITS APPENDAGES.}

Tre appendages of the skin include the sebaceous and sweat glands, the mammary glands, the nails, and the hairs.

\section{THE SKIN.}

The skin, consisting of the epidermis or cuticle and of the true skin, or derm, or corium, is derived from two sources, the epithelial epidermis being a product of the ectoderm, and the corium originating from the mesoderm. The nails and hairs are outgrowths of the epithelial layer, while the various glands are derived from infoldings or invaginations of the same stratum.

The corium, the connectivetissue component of the skin, is an outgrowth of the cutis plates of the primitive segments or somites (Fig. 117). It first appears in crude form in the second month as a layer of spindle-cells beneath the ectoderm. In the third month, the more superficial part of this layer acquires more definite and distinctive character, the rather loose aggregation of cells having differentiated into a tissne which is a mesh-work of bundles of

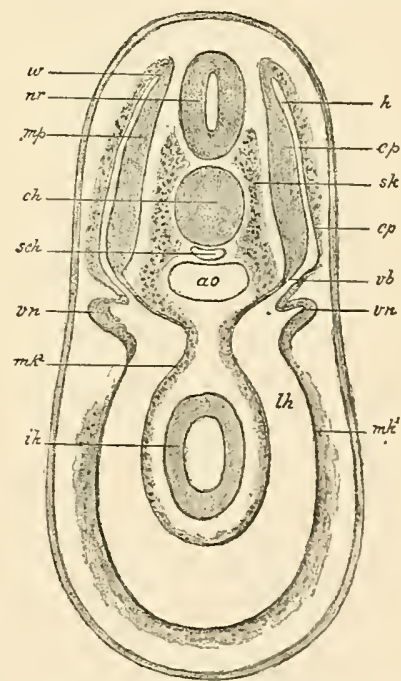

FrG. 117.-Cross-section through the region of the pronephros of a selachian embryo in which the myotomes are in process of being constricted off (Hertwig): $n r$, neural tube; ch, chorda; ao. aorta; $m p$, muscle-plate; $c p$, cutis plate; $2 b$, middle plate; $s n^{n}$, skeletogenous tissue; $\imath n$, pronephros; $m k^{\prime}, m k^{2}$, parietal and visceral mesoderm; $l h$, body-cavity; $i k$, intestinal ectoderm; $h$, cavity of somite. 
white fibrons connective tissne with some intermingled elastic and muscular fibers; this constitutes the corium proper. The deeper layer of cells becomes a loose, subcutaneous areolar tissue containing a few scattered fat-cells. About a month later the external surface of the primitive corium loses its smooth character and presents numerous little elevations, the villi, which project into the overlying epiclermis. The villi, being highly vascular, play an important part in the nutrition of the epidermis and being also freely supplied with nerves they sustain an equally important relation to the sensitiveness of the skin.

From the middle of fetal life onward, the fat-cells in the subcutaneons tissue increase in number to such extent that there is formed a continuous and well-marked subcutaneous layer of fat, the panniculus adiposus.

Certain of the cells of the primitive corium differentiate into unstriated muscular tissne, forming thus the muscles of the hair-follicles, the arrectores pilorum, as well as the subcutaneous muscular tissue of the dartos of the scrotum and penis, and that of the nipple and of the perineum.

The epidermis, consisting of the superficial horny layer and the deeper mucous layer or stratum Malpighii, is entirely an epithelial structure. Its elements are simply the descendants of the carly ectodermic cells specially modified to afford the necessary protection to the more sensitive and delicate corium.

The division into the two strata of the epidermis is indicated as early as the latter part of the first month, at which time the cells of the ectoderm have become arranged into two single layers, a superficial layer of rather large flattened cells and an underlying stratum of smaller elements. The cells of the onter layer, or epitrichium, which probably represents the future stratum corneum, successively undergo degeneration and desquamation, the places of those lost being supplied by the formation of new ones from the deeper layer. As time goes on, both layers increase in thiekness and the hairs and the glands of the skin are gradually formed. With increased proliferation there is increasingly 
active desquamation of superficial cells, and as the degenerate and cast-off cells become mixed with the products of the sebaceous glands, there is formed a sort of cheesy coating of the skin, the vernix caseosa or smegma embryonum. This is first easily recognizable in the sixth month, and first covers the entire surface of the body in the eighth month. It serves to protect the epiclermis of the fetus from maceration in the amniotic fluid.

The completion of the epidermis, aside from the development of its accessory parts, consists simply in further increase in thickness and in the modification of the superficial cells to produce the characteristic scale-like elements of the corneous layer of the skin, accompanied by the differentiation of the deeper cells into those of the rete mucosum or stratum Malpighii. The extent to which these modifications are carried varies in different regions of the body.

\section{THE DEVELOPMENT OF THE APPENDAGES OF THE SKIN.}

The Nails.-The nails have their beginning in little clawlike projections, the primitive nails, that appear upon the tips of the still imperfect fingers and toes in the seventh week. ${ }^{1}$ These result from localized proliferation of the cells of the epidermis, being entirely epithelial structures. The rudimentary nails project from the tips of the digits, instead of occupying the dorsal position of the completed structures.

The claw-like primitive nail, between the ninth and twelfth weeks, becomes surrounded by a groove, which serves to separate it from the general ectodermic surface. These claw-like rudiments of the human nails are quite similar to the prinitive claws of many mammals, the primitive nail in each case including a dorsal part, the nailplate, and a portion which belongs to the rentral surface of the rligit,

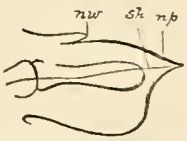

Fig. 118.-Longitudinal seetion through the toe of a Cercopitheeus 2 (after Gegenbaur): $n$ ?, nail-plate; sh, plantar horn (Sohlenhorn); $n u$, nail-wall. called the plantar horn (Fig. 118). The striking difference between the nails of the human adult and the claws and

\footnotetext{
${ }^{1}$ Or nintl week, Minot. ${ }^{2}$ A genus of long-tailed Africun monkeys,
} 
hoofs of many animals is due in great measure to the degree of development to which this ventrally situated plantar horn attains. In the hoofed mammals (Ungulata) and the clawed mammals (Unguieulata), the plantar horn undergoes very great development, whereas in man it retrogrades and leaves no trace except the nail-welt, or the narrow line of thickened epidermis where the distal end of the nailbed merges into the ordinary skin. After the atrophy of the plantar horn, the dorsally situated nail-plate being alone present, the rudimentary nail bears a greater resemblance to the adult condition.

As the nail-plate gradually acquires more distinctive character, the deeper layers of the skin specialize into a structure adapter to its nutrition. This is the nail-bed, a highly vascular and sensitive cushion consisting of the corium and of the stratum Malpighii of the epidermis. It is especially from the proximal part of the nail-bed, representing the matrix of the fully-formed condition, that the nail grows. The rate of growth is such that the ends of the nails protrude beyond the tips of the digits in the eighth month.

The tissue of the fully-formed nail coiresponds to the stratum lucidum of the typical epidermis, developed to an unusual degree. The epitrichium or future stratum corneum, the most superficial layer of the epidermis, does not form a part of the nail, but constitutes a thin covering, the eponychium; this is lost in the seventh month, with the exception of a small band over the root of the nail, which persists for a short time as the perionyx.

The nails of the toes are always somewhat behind those of the fingers in development.

To repeat, the claw-like rudimentary nails appear in the seventh week, the nails are perfectly formed about the twelfth week, and break through their epidermal covering in the seventh month, reaching to or beyond the finger-tips in the eighth month.

The Hair.-Each hair consists of the projecting shaft and the embedded root, with its expanded deep extremity, the hair-bulb, the root being embraced by the hair-follicle. The 
hair is entirely of ectodermic origin, being derived from the epidermal layer of the skin, while the hair-follicle is partly derived from the epidermis and in part is a product of the corium. The hairs are homologous with the feathers and scales of the lower animals.

The development of the hair is initiated in the third fetal month by the appearance of small solid masses of epithelium in the stratum Malpighii of the epidermis. The epithelial plugs or hair-germs grow into the underlying eorium and are met by outgrowths or papillæ of the latter, which develop almost simultaneously. The papillæ are very vascular and serve for the nutrition of the dereloping hair.

The root and the shaft of the rudimentary hair result from the specialization of the axial or central cells of the hairgerm. 'These cells lengthen in the direction of the long axis of the hair-germ and become hard and corneous, thus constituting the root and the shaft, the cells of the deepest part of the hair-germ forming the bulb. The growth of the hair
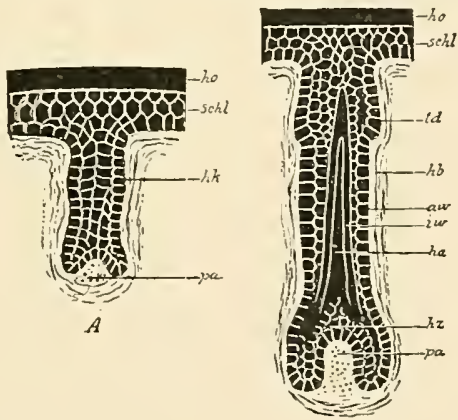

$B$

FIG. 119. - Two diagrams of the development of the hair (Hertwig): $A$ and $B$, two different stages of the development of the hair in human embryos; ho, corneous layer of the epidermis; schl, mucous layer; pa, hair-papilla: $h k$, germ of hair; hz, bulb of hair; ha, young hair; $a w, i w$, outer and inner sleaths of the root of the hair; $h b$, hair-follicle; $t d$, sebaceous gland.

in length is due to the proliferation and specialization of the cells of the bulb. The papilla of the underlying corinm indents the deep surface of the hair-bulb, this close relation of the two structures enabling the papilla the better to fulfil its function of providing nourishment to the bulb. 
The hair-follicle, consisting of an outer connective-tissue portion or fibrous layer and an inner epithelial part, the inner and outer root-sheaths, is partly of mesodermic and partly of ectodermic origin. The inner and outer rootsheaths are produced by the peripheral cells of the luairgerm augmented by cells contributed directly by the stratum Malpighii of the epidermis. The outer fibrous constituent of the follicle results from the mesodermic cells of the corium that immediately surround the hair-germ.

Gradually increasing in length by the addition of new cells from the hair-bulb, the primitive hair at length protrudes from the follicle as free hair. This first growth of hair is umpigmented and is extremely fine and soft, being known as the lanugo or embryonal down. This appears upon the scalp and some other parts of the body in the fourth month, gradually extending orer the entire surface in the succeeding months. In the eighth month the lanugo begins to disappear, but is not lost as a whole nntil after birth, when the permanent growth of hair takes its place. Upon the face, in fact, the lamugo persists thronghont life.

The development of the secondary hair is still a disputed point. It is elaimed by some authorities (Stieda, Fciertag) that they develop from entirely new hair-germs, while others (e.g., Hertwig) hold that the bulb for the new hair buds off from the atrophic bulb of the hair just lost.

The Sebaceous and Sweat-glands.-The sweat-glands, including not only the sweat-glands proper but the ceruminous glands of the external auditory meatus and the glands of Moll of the eyelids, are deriver from the ectorlernic epithelium. The glands are of the simple tubular type. Each gland develops from a small accumulation of cpidermal cells that grows, in the fifth month, from the Malpighian or mucous layer of the epidermis into the underlying corium. The solid ejithelial plugs become tubes in the seventh month by the degeneration and final disappearance of the central cells. The decper part of the tube becomes coiled and its lining epithelium takes on the characteristics of secreting eells. Some of the cells of the original epithelial plug undergo 
specialization into muscular tissue, thus producing the involuntary muscles of the sweat-glands.

The sebaceous glands are developed from solid epithelial processes that originate from the deep layer or rete mucosum of the epidermis in a manner similar to that of the development of the sweat-glands. There is the difference, however, that the epithelial plugs acquire lateral branches and thus usually produce glands of the componnd saccular or acinous variety. There is the further difference that the epithelial outgrowths generally develop from the ectodermic cells of the outer sheath of the root of the hair near the orifice of the follicle (Fig. 119, td ), in consequence of which the ducts of the finished glands usually open into the hair-follicles. In some regions, however-regions devoid of hair, as the prepuce and the glans penis, the labia minora, and the lips-the growth is directly from the stratum Malpighii, as in the case of the sweat-glands.

The Mammary Gland.-The mammary gland represents a number of highly specialized sebaceous glands so associated as to constitute the single adult structure. Its origin, therefore, is to be sought in the cells of the epidermis in common with that of the ordinary sebaceous glands.

The development of the milk-glands is begun as early as the second month. At this time the deep layer of the epidermis, in the sites of the future glands, becomes thickened by the multiplication of its cells, the thickened patch encroaching upon the underlying corium (Fig. 120, A, b). This thickened area enlarges somewhat peripherally and its margins become elevated, owing to which latter circumstance the patch appears relatively depressed $(B)$. The depression is known as the glandular area, and it corresponds with the future areola and nipple.

From the bottom of the glandular area, numerous small masses or bud-like processes of cells grow down into the corium. Some of the buds acpuire lateral branches. By the hollowing out of these cell-buds the latter are transformed into tubes $(c)$, which open upon the glandular area. The branching of the cords begins in the seventh month and is carricd 
on to such a degree that each original cell-cord gives rise to a tubo-racemose gland. The hollowing out of the solid processes begins shortly before birth, but is not completed until after that event. Each cell-cord becomes, in the strict sense, a complete gland, each such individual structure forming a lobe of the mature organ.

This stage of the human mammary gland-that is, a depressed gland-area upon which open individual glands, the
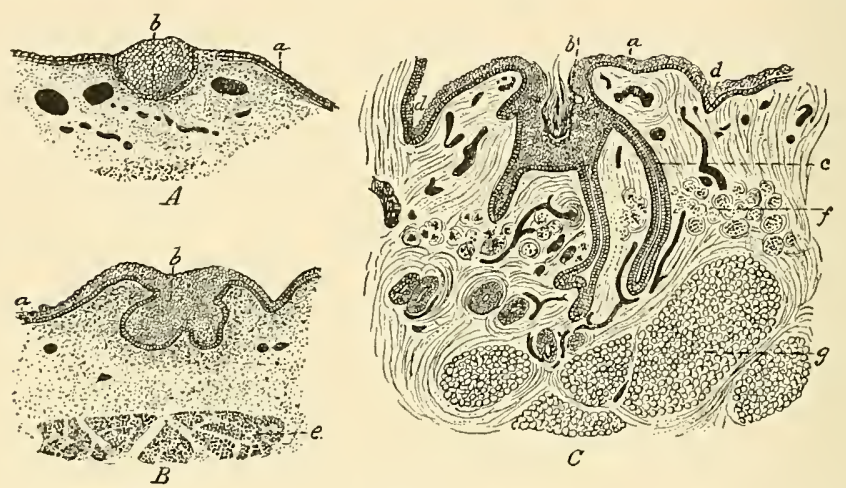

Fig. 120. - Sections representing three successive stages of development of the human mamma (Tourneux) : $A$, fetus of $32.40 \mathrm{~mm}$. (1.3 in.); $B$, of $10.16 \mathrm{~cm}$. (4 in.); $C$, of $24.35 \mathrm{~cm}$. (9.6 in.); $a$, epidermis; $b$, aggregation of epidermal cells forming anlage of gland; $c$, galactophorous ducts; $d$, groove limiting glandular area; $e$, great pectoral muscle; $f$, unstriated museular tissue of areola; $g$, subcutaneous adipose tissue.

nipple being absent-is the permanent condition in some of the lowest mammals, as in the echidna, one of the monotremes. In all higher mammals, however, further metamorphoses oceur in the tissues of the glandular area, and in the human fetus these tissues become the nipple and the surrounding areola.

The nipple is partly formed before birth, but does not become protuberant mitil post-fetal life. The depressed glandular area rises to the level of the surrounding parts, and its central region, which inchules the orifices of the alrearly formed or just forming ducts, swells out into a little prominenee, the nipple. This prominence is a protrusion of the epidermis and includes the terminal extremities of the 
milk-ducts as well as the blood-vessels and connective-tissue elements which surround the ducts. In the dermal constitnent of the rudimentary nipple unstriated muscular tissue develops. The region of the glandular area not concerned in the formation of the nipple becomes the areola.

At birth, as above intimated, the mammary gland is still rudimentary, since many of the ducts have not yet acquired their lumina nor their full degree of complexity. Shortly after birth a small quantity of milky secretion, the so-called witches' milk, may be expressed from the glands-in the male and female infant alike. This is true milk according to Rein and Barfruth, but according to Kölliker, it is merely a milky fluid containing the débris of the degenerated central cells of those rudimentary ducts that were still solid at birth.

So far, the milk-glands are alike in the two sexes, but while in the male they remain rudimentary structures, they continue to increase both in size and in complexity in the female. The increase affects not only the glandular tissue proper but the connective-tissue stroma as well. At the time of puberty the growth of the glands receives a new impetus, which is very materially augmented upon the occurrence of pregnancy. There may be said, therefore, to be several distinct phases in the development of the milk-glands, first, the embryonic stage; second, the infantile stage; third, the stage of maturity beginning at the time of puberty; and finally, the stage of full functional maturity consequent upon pregnancy and parturition. 


\section{CHAPTER X V.}

\section{THE DEVELOPMENT OF THE NERVOUS SYSTEM.}

The nervous system of the adult, including the cerebrospinal axis and nerves, and the sympathetic system of ganglia and nerves, is made up of the essential neural elements, the neurons, together with the supporting framework or stroma. ${ }^{1}$

The neurons and a part of the stroma result from the specialization of the ectodermic layer of the embryo. The ectodermic origin of the nervous system acquires ecrtain interest in view of the conditions that obtain in some of the lowest and simplest organisms. For example, in the ameba, the single protoplasmic eell which constitutes the entire individual possesses the several fundamental vital properties of protoplasm, such as respiration, metabolism, contractility, motility, etc., in equal degree, no single property being more highly developed than the others, and no particular part of the cell exhibiting greater specialization than the other parts. In other words, the protoplasmic substance of the animal is at once a respiratory mechanism, a nervous apparatus, and an organ for the execution of the varions other vital functions.

In somewhat more highly developed ereatures, as the infusoria, although there is no differentiation into separate tissues and probably not even into separate cells, there is seen some progress toward the specialization of certain parts of the organism for the performance respectively of the different functions of life. For example, the central part of the ani-

1 The neurons are the units of which the nervous system is made up. Each neuron consists of a nerve-cell with everything belonging to it - that is, with its various processes, including the axis-cylinder process or neurit, which becomes the axis-eylinder of a nerve-fiber. 
mal has digestive functions, while it is by the superficial portion alone that the creature is brought into relation with the outsicle world, the sensitiveness or irritability of the surface, by which the animal is made responsive to external impressions, being the nearest approach to the function of a nervous system that it possesses.

This primitive function of the surface of the organism is suggestive as to the origin of the nervous system of higher type creatures. It will be seen, indeed, that not only is the nervous system proper derived from the ectodermic cells of the embryo but that the peripheral parts of the organs of special sense, as the olfactory epithelium, the organ of Corti, and the retina, have the same origin.

The alteration of those cells of the ectodermic stratum that are to specialize into nervous elements begins prior to the fourteenth day in the human embryo, in the stage of the blastodermic vesicle. The change consists in a gradual modification of the form of the cells, the cells common to the general surface of the germ assuming the columnar type. The process affects the cells of the median line of the embryonic area in advance of the primitive streak, resulting in the production of a thickened longitudinal median zone. This thickened area is the medullary plate (Fig. 32, p. 62). On each side of the plate-which is apparent at the fourteenth day - the adjoining ectodermic cells become heaped up to form the medullary folds, which latter therefore bound the medullary plate laterally. The medullary plate becomes concave on the surface, forming the medullary groove (Fig. 121). By the deepening of the groove, the lateral edges of the plate approach each other (Fig. 122), and finally they meet and unite, thus producing a tube, the neural tube or canal.

Since the medullary folds similarly meet and unite with each other-their union slightly preceding that of the edges of the plate-the neural tube comes to lie entirely beneath the surface-ectoderm and soon loses all connection with it. The closing of the tube and the union of the medullary folds occur first near the anterior end of the embryonic area, in a position that corresponds with the region of the future neck, 
and from this point it proceeds both cephalad and caudad. Since the medullary folds at their caudal extremity embrace

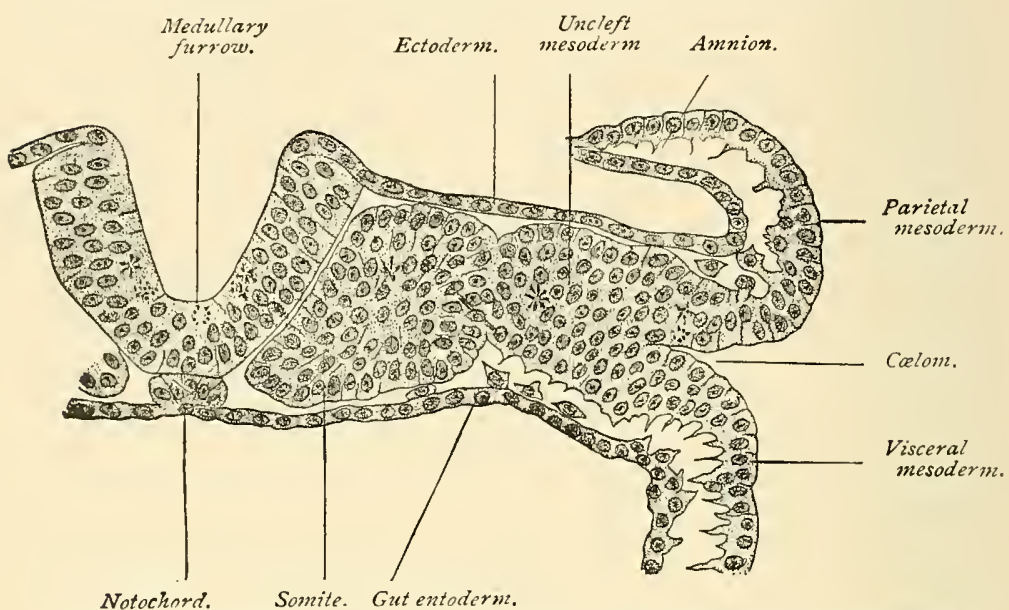

FIG. 121.-Transverse seetion of a sixteen-and-a-half-day sheep embryo possessing six somites (Bonnet).

the primitive streak (Fig. 32, p. 62), the latter structure is included within the caudal end of the neural tube by the

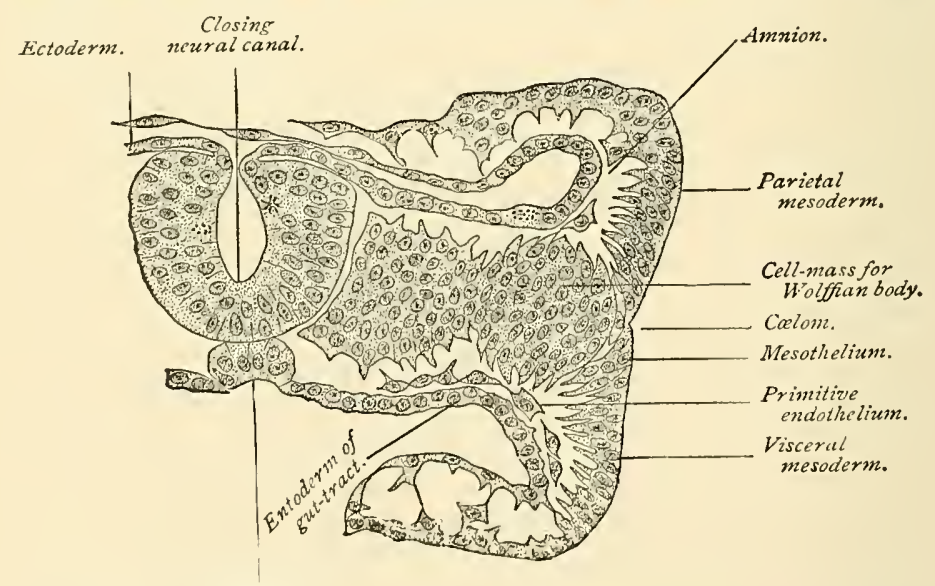

Notochord.

FIG. 122.-Transverse section of a fifteen-and-il-half-day sheep embryo possessing seven somites (Bonnet).

coming together of the folds, and thus the blastopore, which was previously the external aperture of the arehenteron, 
comes to constitute the neurenteric canal, or an arenue of communication betreen the neural canal and the primitive intestine.

The neural canal then is a tube composed of columnar cells, which is formed by the folding in of the ectoderm and which occupies the median longitudinal axis of the embryonic area and consequently of the future embryonic body. From this simple epithelial canal the entire adult nerrous system is evolved.

The evolution of the highly complex cerebrospinal axis from such a simple structure as the neural canal is referable both to the principle of unequal grouth-the walls of the tube becoming thickened by the multiplication of the cellsand to the formation of folds.

The portion of the neural canal-approximately one-halfthat is deroted to the formation of the brain is delimited from the part that produces the spinal cord by the dilatation of the anterior or head-end of the tube, and the subsequent division of this dilated sac-like portion into three communicating saes called respectively the fore-brain, mid-brain, and hind-brain vesicles (Fig. 126). These three resicles give rise to the brain, while the remaining part of the neural canal forms the spinal cord.

\section{THE DEVELOPMENT OF THE SPINAL CORD.}

In the growth of the spinal cord from the spinal portion of the neural canal we have to consider the evolution of a cylindrical mass of nerve-cells and nerve-fibers with the supporting stroma from a simple epithelial tube.

The wall of the neural tube, although consisting at first of a single layer of epithelial cells, is not of uniform thickness throughout its circumference. While the external outline is oval, the lumen of the tube is a narrow dorsoventral fissure (Fig. 36. p. 65). The cavity is therefore bounded on the sides by thickened lateral columns, while the dorsal and ventral walls, which connect the lateral columns with each other, are thimner and are called respectively the roof-plate and the floor-plate. 
After a short time, the walls of the tube having thickened by the multiplication of the cells, the shape of the lumen

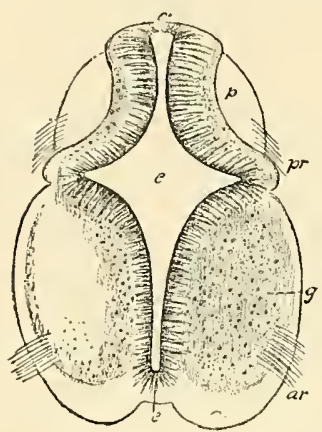

FIG. 123.-Transverse section of the cervical part of the spinal cord of a human embryo of six weeks, $X$ 36 (from Kölliker) : c, eentral canal; $e$, its epithelial lining; at $e^{\prime}$ (superiorly), the original place of closure of the canal; $a$, the white substance of the anterior eolumns; $g$, gray substance of anterolateral horn ; $p$, posterior column; ar, anterior roots; $p r$, posterior roots. alters, two laterally projecting angles being added (Fig. 123). The effect of this change is to partially divide each lateral half into a dorsal and a ventral region. The noural canal at this stage may be said to consist of six columns of cells, the two dorsal zones connected with each other by the roof-plate, and the two ventral zones united by the floor-plate. These regions are also distinguishable, with certain characteristic modifications, in the head-region of the tube. They are important in their bearing upon the further development of the structure, since the dorsal and ventral zones are related respectively to the dorsal or sensory and the ventral or motor roots of the spinal nerves.

The differentiation of the cells of the neural tube into two kinds of elements, one of which gives rise to sustentative tissne or neuroglia while the other produces the nerve-cells, is observed at about the end of the third week. The single layer of cohumuar cells which at first composes the wall of the tube, the long axes of the cells being radially arranged, soon exhibits near the lumen a row of round cells, probably the first offspring of the columnar cells. The round cells are the germ-cells or germinating cells, from which are developed the neuroblasts or young nerve-cells. All the other cells, known as the spongioblasts, are concerned in producing sustentative tissue.

The stroma of the central nervous system includes two constituents-a connective-tissue element, and a part, the neuroglia, which is of epithelial origin, and which is not to 
be regarded, therefore, as eomective tissue. The connectivetissue portion of the stroma is produced by the ingrowth of the pial processes from the pia mater, and is hence of mesodermic origin.

The neuroglia is derived from the spongioblasts, which result from the specialization of the large columnar cells of which the wall of the neural canal is composed. These cells, whose length comprises the entire thickness of the wall of the tube in the earliest stages, undergo partial absorption and disintegration, each eell being transformed into an elongated system of slender processes or trabeculæ, and each such system being a completed spongioblast (Fig. 124). The inner ends of

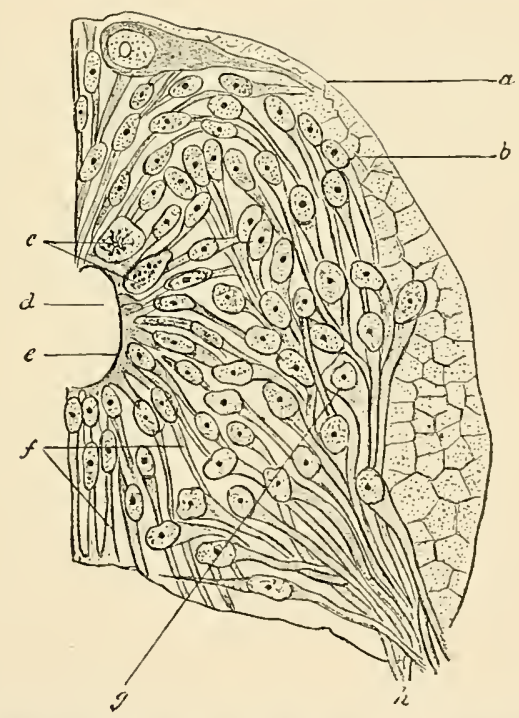

Fig. 124.-Cross-section through the spinal cord of a vertebrate embryo (after IJis): $a$, outer limiting membrane; $b$, outer neuroglia layer, region of future white matter; $c$, germ-cells ; $d$, central canal ; $e$, inner limiting membrane or ependymal layer; $f$, spongioblasts; $g$, neuroblasts (mantle layer); $h$, anterior root-fibers.

the spongioblasts coalesce with each other, forming thus the internal limiting membrane, while the peripheral extrcmities interlace with each other to form a close network. As the walls of the neural tube increase in thickness, the spongioblasts beeome more and more broken up to form the delieate 
neurogliar network with interspersed nucleated glia cells. Such of the spongioblasts as border the eavity of the neural tube become the cells of the later ependyma of the central canal of the spinal cord and of the ventricles of the brain. The cells of the ependyma become ciliated in the human fetus in the fifth week.

The nerve-cells of the spinal cord-as also of the brainare the specialized descendants of the germ-cells referred to above. The proliferation of the germ-cells produces the neuroblasts, or young nerve-cells (Fig. 124). The latter elements move away from the primitive position of the germcells near the lumen of the tube and develop into the nervecells. The transition is effected by the accumulation of the cell's protoplasm on the distal side of the nucleus and its elongation into a process. This process is a neurit or axiscylinder process and is the beginning of a nerve-fiber. The dentrits or protoplasmic processes appear eonsiderably later. Some of the fibers thus produced grow out from the neural tube to constitute the efferent fibers of the peripheral nerves, while others contribute to the formation of the fiber-tracts of the cord.

After the appearance of the neuroblasts and developing nerve-cells, the wall of the neural tube is divisible into three layers (Fig. 124); an inner or ependymal layer, next the lumen of the tube; adjoining this, the mantle layer, made up of neuroblasts; and a peripluerally situated neuroglia layer, which occupies the position of the future tracts of white fibers of the cord.

The altcrations in the form and size of the spinal cord go hand in hand with the histological changes noted above. While those areas that have been mentioned as the dorsal and ventral zones increase greatly in thickness, the floor-plate and the roof-plate-the ventral and dorsal walls of the neural tube-remain thin (Fig. 125). They are never invaded by the nerve-cells but consist of thin layers of neuroglia which later become penetrated by nerve-fiber's that grow from one side to the other. They thus represent the anterior and posterior white commissures of the cord. These plates remain 
relatively fixed in position because of their failure to expand, while the lateral walls of the tube undergo great expansion, in both the rentral and dorsal directions, as well as laterally. In this way a median longitudinal cleft is produced on the ventral wall of the spinal cord and a similar one on the dorsal wall. These are the anterior and posterior median fissures. Since the so-called posterior median fissure is not a true fissure but merely a septum, it differs from the anterior fissure, and it is held by some anthorities that this septum is

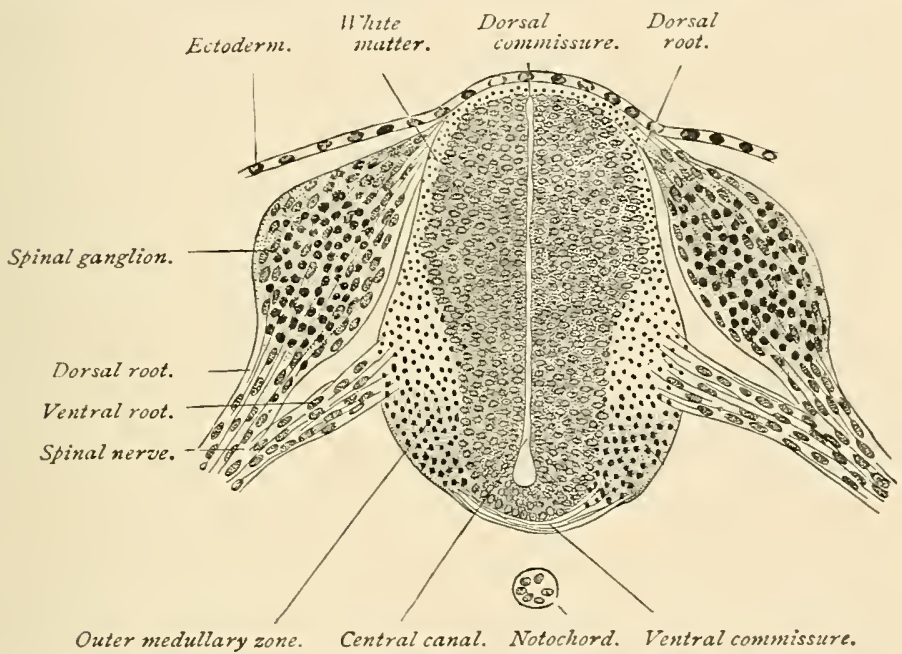

FIG. 125.-Transverse section of developing spinal cord of a twenty-two-day sheepembryo (Bonnet).

formed by the growing together of the walls of the dorsal part of the central canal.

The fiber-tracts or white matter of the spinal cord derelop in the outer or neuroglia layer, each fiber being the elongated neurit of a nerve-cell. Some of the fibers originate from the nerve-cells of the eord while others grow into the cord from the ganglia of the posterior roots of the spinal nerves. The latter methor of origin applies especially to the fibers of the tracts of Burdach and of Goll.

As the walls of the neural canal thicken through the multiplication of the cells, the cavity of the tube is gradually 
encroached upon almost to obliteration. When development is complete, all that remains of the cavity is the small central canal of the spinal cord.

The length of the spinal cord in the fourth fetal month corresponds with that of the spinal column, its lower termination being opposite the last coccygeal vertebra. From this time forward, however, the cord grows less rapidly than does the spinal colmmn, so that at birth, the cord terminates at the last lumbar vertebra, and in adult life at the second lumbar vertebra. This gradually acquired disproportion in the length of the two structures explains the more oblique direction of the lower spinal nerves as compared with those higher up. In the early condition of the cord, each pair of nerves passes almost horizontally outward to the corresponding intervertebral foramina, but as the spinal column gradually outstrips the cord in growth, the lower nerves necessarily pursuc a successively more oblique course to reach their foramina, the lower nerves being almost vertical in direction and constituting, collectively, the cauda equina.

\section{THE DEVELOPMENT OF THE BRAIN.}

The encephalic portion of the neural tube-that part devoted to the production of the brain-after undergoing dilatation, becomes marked off into the three primary brainvesicles, the fore-brain, the mid-brain and the hind-brain, by constrictions in the lateral walls of the tube (Fig. 126). This division occurs at an early stage, before the closure of the tube is cverywhere complete. The vesicles communicate with each other by rather wide openings. As in the spinal part of the neural canal, the walls of the primary brain-vesicles consist of epithelial cells, and it is by the multiplication of these cells in unerpal degree in different regions, and by the formation of folds in certain localities that the various parts of the adnlt brain are developed from these simple epithelial sales.

The stage of three vesicles is soon succeeded by the fivevesicle stage, the primary fore-brain vesicle undergoing divi- 
sion into two, the secondary fore-brain and the inter-brain, and the primary hind-brain vesicle likewise dividing, a little later, into the secondary hindbrain and the after-brain.

The division of the primary fore-brain is preceded by the appearance upon each of its lateral walls of a small bulgedout area which soon assumes the form of a distinct diverticulum. This is the optic vesicle, the earliest indication of the development of the cye (Fig. 126). In the further process of growth the base of attachment of the optic vesicle becomes lengthened out into a relatively slender pedicle, which remains in connection with the lower part of the lateral wall of the brain-vesicle. Following the appearance of the optic resicle, the anterior wall of the primary fore-brain vesicle

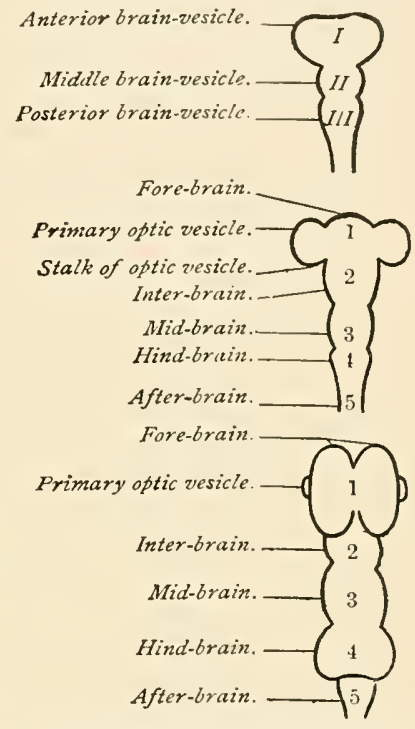

FrG. 126.-Diagrams illustrating the primary and secondary seg. mentation of the brain-tube (Bonnet).

projects as a small evagination, which latter is then distinctly marked off from the parent vesicle by a groove on either side. This anterior diverticulum is the secondary fore-brain vesicle or the vesicle of the cerebrum, and the orignal or primary fore-brain vesicle is now the vesicle of the inter-brain.

The division of the primary hind-brain is effected by the development of a constriction of its lateral wall, this resulting in the production of the secondary hind-brain or the vesicle of the cerebellum, and the after-brain or the vesicle of the medulla oblongata.

While the three primary vesicles at first lie in the sane straight line, they begin to alter their relative positions shortly before division. The change of position is coincident with the flexures of the body of the embryo that oceur at this time. 'Three well-marked flexures appear, the result being 
that the fore-brain is bent over ventrad to a marked degree. The most anterior of these flexures, and the first to develop, is the so-called cephalic flexure (Fig. 127), the primary forebrain, in the advanced state of the curvature, being bent

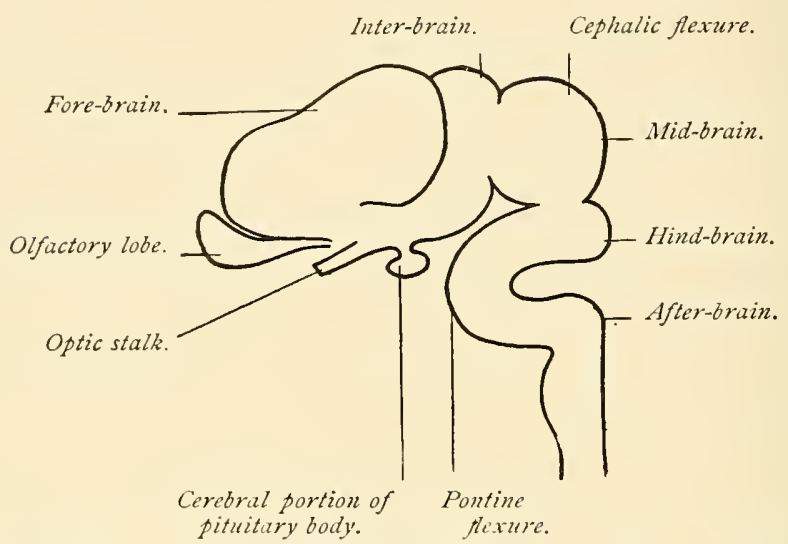

FIG. 127.-Diagram showing relations of brain-vesicles and fiexures (Bonnet).

around the termination of the chorda dorsalis so as to form a right angle, and later, after its division, an acute angle with the floor of the mid-brain. This curvature makes the mid-brain very prominent as regards the surface of the embryonie body, producing the parietal elevation or the prominence of mid-brain.

In the region of the future pons Varolii, on the floor or ventral wall of the secondary hind-brain, is a second wellmarked angularity. This is the pontal flexure. Its convexity projects forward.

A third bend, the nuchal flexure, is a less pronounced eurvature at the juncture of the after-brain with the spinal part of the neural tube.

The Metamorphosis of the Fifth Brain-vesicle.The fifth brain-vesicle, the caudal division of the primary hind-brain, differentiates into the structures which surround the lower half of the fourth ventricle, these struetures eonstituting the metencephalon (Fig. 128). The histological changes correspond essentially with those that ocenr in the spinal segment of the neural tube, the nerve-cells and fibers 
and the neuroglia resulting from the differentiation of the original ectodermic epithelium of which the wall of the tube is composed, and the connective-tissue stroma growing into these from the surrounding mesoderm.

There is a marked disproportion between the rate of growth of the tube in different parts of its circumference. The great thickening of the ventral and lateral walls produces the several parts of the medulla oblongata. In the dorsal wall

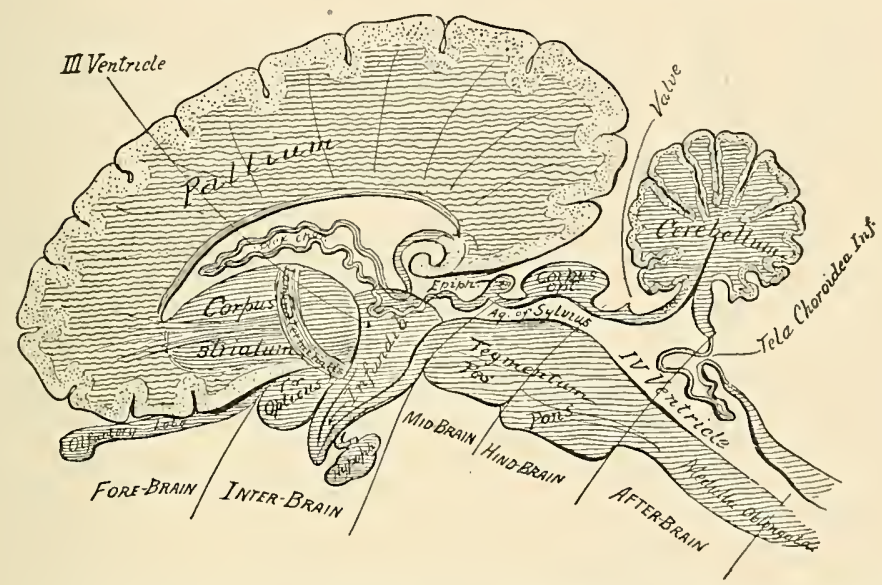

FIG. 128.-Diagram of a sagittal section of the brain of a mammal, showing the type of structure and the parts that develop from the several brain-vesieles (modified from Edinger).

growth occurs to such slight extent that the wall in this region remains a thin layer of epithelium. As a consequence, the cavity of the neural tube is not encroached upon on its dorsal side and the central canal of the spinal cord therefore expands in the metencephalon into a much larger space, the lower half of the future fourth ventricle. This relative expansion of the central canal begins to be apparent in the third weck in the human embryo, from which period it eontimes to increase. A cross-section through the lower part of the developing medulla shows a cavity which is narrow laterally but which has a considerable anteroposterior extent. A section at a higher level diseloses a triangular space, the base of the triangle being the dorsal wall of the cavity. 
At the time when the cavity of the after-brain acquires a distinctly triangular shape-about the third week-each thickened lateral half of the tube is divisible into a ventral and a dorsal segment, these being known respectively as the basal lamina and the alar lamina (Fig. 129).

The first indication of the longitudinal fiber-tracts of the medulla is presented by two bands of fibers which appear upon the surface of the alar lamina and which

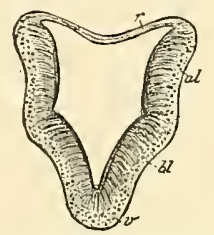

Fig. 129. - Section through npper part (eerebellar region) of the fourth ventricle of an embryo (His): $r$, roof of neural canal: al, alar lamina; $b l$, basal lamina; $v$, ventral border. constitute the ascending root of the fifth nerve and the ascending root (funiculus solitarius) of the vagus and glossopharyngeal nerves. These are later covered in by the folding over of the dorsal part of the alar lamina (Fig. 130) and thus come to occupy their permanent position in the interior of the medulla.

The parts of the alar laminæ that are folded over in the manner referred to differentiate for the most part into the restiform bodies or inferior peduncles. These are distinguishable in the third month. The anterior pyramidal tracts develop fiom the ventral parts of the basal lamine and are recognizable in the fifth month.

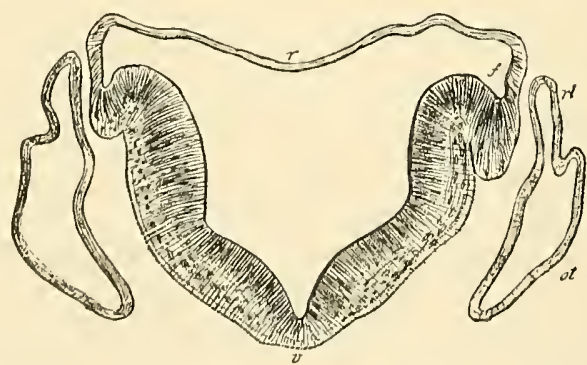

Fis. 130.- Section across the lower half of the fourth ventricle of an embryo, showing gradual opening out of the neural canal, and the commeneing folding over of the alar laminu at $f$ (Jis) : $v$, ventral border; $t$, tenia; ot, otic vesiele; $r l$, recessus labyrinthi.

Coincidentally with the formation of the fibers, the gray matter of the medulla assumes its permanent form and arrange- 
ment. This gray matter, although in part peculiar to the medulla, is in great measure but the continuation of the gray matter of the spinal cord rearranged and differently related because of the motor and sensory decussations and of the dorsal expansion of the central canal. A notable feature of this rearrangement is the presence of masses of gray matter inmediately beneath the floor or ventral wall of the now expanded cavity or fourth rentricle.

As stated above, the dorsal wall of the after-brain resicle remains an extremely thin epithelial lamina, and the cavity in consequence expands toward the dorsal surface. Owing to the excessive delicacy of this dorsal wall of the carity, it is easily destroyed in dissection, with the effect of disclosing a triangular fossa (Fig. 135) on the dorsal surface of the medulla, which in connection with a similar depression on the dorsal surface of the pons, constitutes the rhomboidal fossa, or the fourth ventricle of the brain.

It is often stated in descriptions of the medulla and fourth ventricle that the latter is produced by the opening out of the central canal of the cord to the dorsal surface. It should be borne in mind, however, that the central canal does not, in reality, open out to the surface, althongh it may appear to do so because of the attenuated condition of its dorsal boundary. The thin epithelial roof or dorsal wall of the afterbrain becomes adherent to the investing laver of pia mater, thus forming the tela choroidea inferior, which roofs over the lower half of the fourth rentricle (Fig. 128). The pia mater invaginates the epithclial layer to form the choroid plexuses of the fourth ventricle. Although apparently within the cavity of the ventricle, the choroid plexuses are excluded from it by the layer of epithelium, the morphological roof of the after-brain, which they have pushed before them.

While, for the most part, the roof of the after-brain consists of the thin cpithelial layer referred to above, there are slight linear thickenings, the ligulæ, along its lateral margins, and at its lower angle, the obex. At the upper marcin of the roof, at the place of junction with the hind-brain, there is 
also a thickened area, the inferior medullary velum. These regions of thicker tissne serve to effect the transition from the thin epithelial layer that helps to form the inferior choroidal tela to the more massive boundaries of the rhomboidal fossa.

The Hind-brain Vesicle or Epencephalon.-The epencephalon consists of the pons, the cerebellum with its superior and middle peduncles, and the valve (valve of Vienssens). These structures are produced by the thickening of the walls of the fourth or hind-brain vesicle.

The pons is formed by the thickening of the ventral wall of the vesicle. Its transverse fibers become recognizable during the fourth month.

The cerebellum grows from the posterior part of the roof or dorsal wall of the vesicle (Fig. 128). The first indication of its development is seen as a thick transverse ridge or fold on the posterior extremity of the dorsal wall (Figs. $131,132)$. In the third month the central part of this ridge, now grown larger, presents four deep transverse grooves with the result of dividing the original eminence into five transverse ridges. The grooved part of the ridge is the portion that subsequently becomes the vermiform process or median lobe of the cerebellum, while the smooth lateral portions become the lateral hemispheres. As the vermiform process increases in bulk, two of the ridges come to lie upon its upper surface and three on the inferior aspect. These ridges and furrows persist throughont life as the principal convolutions and fissures of the verniform process (Figs. 133, 134).

The lateral parts of the primary ridge increase in size and eventually, in the human brain, ontstrip the median lobe in growth. They acquire their elief transverse fissures in the fourth or fifth month, and the smaller sulci later.

The thickened cerebellar ridge on the roof of the hindbrain vesicle being continuous with the lateral walls, the continuity of the cerobellar hemispheres with the pons through the mirldle and superior cerebellar peduncles and with the medulla by means of the inferior peduncles, is easily 
understood. These bands of fibers become evident, the inferior in the third month, the middle in the fourth month, and the superior in the fifth month.

While the posterior part of the roof of the hind-brain thickens and develops into the cerebellum, all the remaining part of this roof remains relatively thin and becomes the

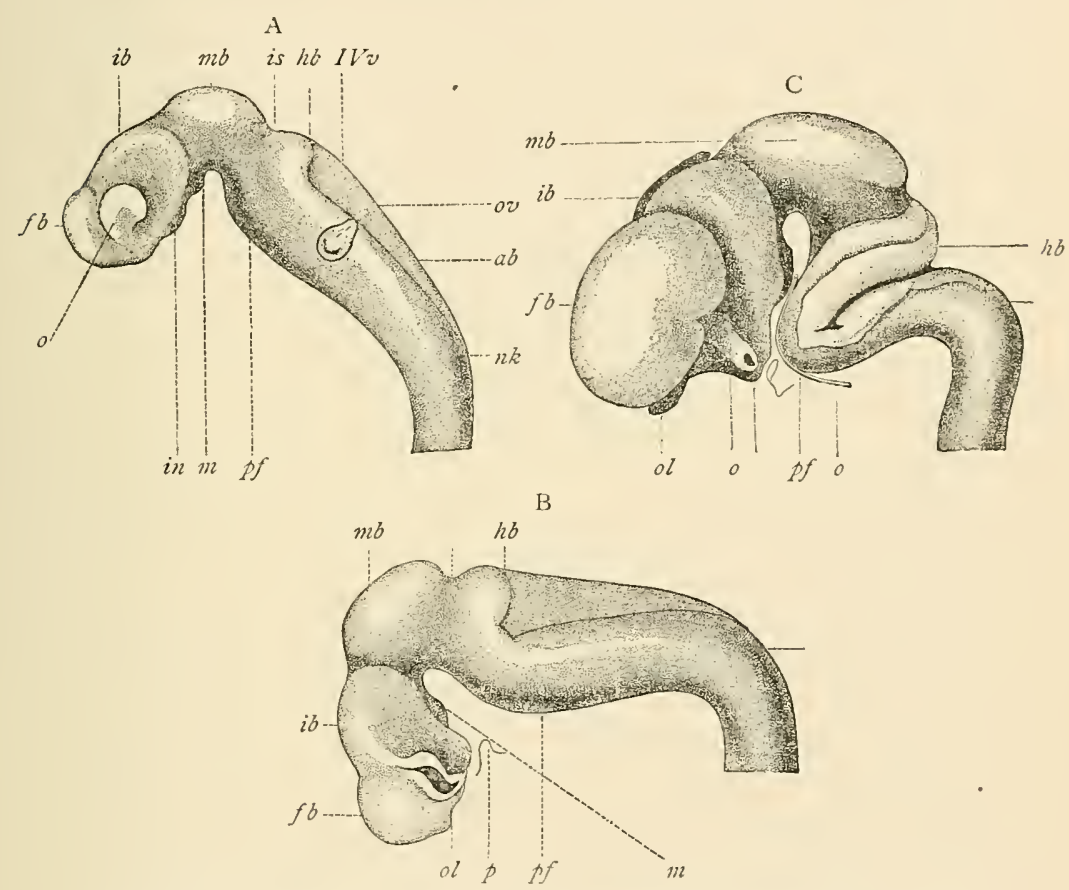

FIG. 131.-Brains of human embryos, from reconstructious by His: A, brain from fifteen-day embryo; $B$, from three-and-a-half-week embryo; $C$, from sevenand-a-half-week fetus: $f b, i b, m b, h b, a b$, fore-, inter-, mid-, hind-, and after-brain vesicles; $o$, optic vesicle; $o v$, otic vesicle; $i n$, infundibulum; $m$, mammillary process; $p f$, pontine flexure; $I$ lv, fourth rentricle; $n k$, cervical flexure; ol, olfactory lobe; $b$, basilar artery ; $p$, pituitary recess.

anterior medullary velum or the valve of Vieussens (Fig. 128). The relations of this structure in the mature brain, stretching across, as it does, from one superior cerebellar peduncle to the other and being continuous posteriorly with the white matter of the cerebellum, are easily explained in the light of the fact that all these parts are but the specialized dorsal and 
lateral walls of the hind-brain vesicle. Since the roof of the hind-brain vesicle is continuous with that of the after-brain or fifth vesicle, it will be seen that the cerebellum must be in continuity with the roof of the medullary part of the fourth ventricle. The transition from the cerebellum to the epithelium of the tela choroidea inferior is effeeted by a pair of thin erescent-shaped bands of white nerve-matter which pass downward from the central white-matter of the cerebellum, and which are collectively known as the inferior or posterior medullary velum. Thus, as the result of unequal growth, there are produced from the continuous dorsal walls of the fourth and fifth vesicles the thin laminar medullary velum or valve, the massive cerebellar lobes, the thin bands known as the inforior medullary velum, and the single layer of epithelium which, with a layer of pia mater, constitutes the inferior choroidal tela.

Although the fourth and fifth brain-vesicles are at first delimited from each other by a constriction, this constriction, as development goes on, disappears, the cavity of the fourth vesicle and that of the fifth together constituting the fourth ventricle of the brain.

The walls of the fourth or hind-brain vesicle then give rise ventrally to the pons, laterally to the superior and middle cerebellar peduncles, and dorsally to the valve and the cerebellum, while its cavity becomes the anterior half of the fourth ventricle.

The Mid-brain Vesicle.-The third brain-vesicle or the vesicle of the mid-brain or mesencephalon gives rise to the structures surromding the aqueduct of Sylvius, the persistent part of the cavity constituting the aqueduct itself.

The thickening of the ventral wall of the vesicle results in the formation of the crura cerebri and the posterior perforated lamina or space included between them. The erura first become apparent in the third montly as a pair of rounded longitudinal ridges on the ventral surface of the vesicle. These remain relatively small until the fifth month, when the longitudinal fibers of the pons begin to grow into them. After this occurrence their increase in size is comparatively 
rapid, their ventral parts or crustæ beconing separated from each other and inchuling between them the posterior perforated lamina.

The roof or dorsal wall of the mid-brain vesicle undergoes considerable thickening (Fig. 131), especially in the Sauropsida (birds, reptiles, fishes). In the fifth week a longitudinal ridge appears upon the dorsal wall, which in the third month is replaced by a furrow. The expansion of the wall on each side of the furrow produces a pair of rounded eminences (Figs. 132-135), which, in birds, attain to a much
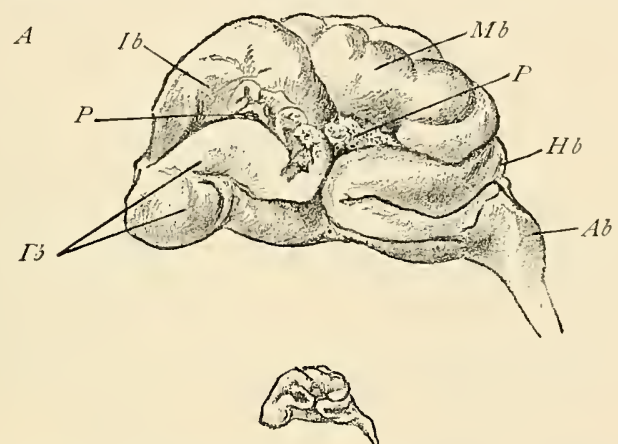

$B$

FIG. 132.-Brain of human fetus of abont eight weeks: $A$, enlarged ; $B$, actual size; $F b$, forobrain ; $I b$, inter-brain ; $A b$, mid-brain ; $H b$, hind-brain; $A b$, afterbrain ; $P$, folds of pia mater.

greater development than in mammals and constitute the corpora bigemina or optic lobes. In the human embryo, each of these elevations is divided into two by an oblique groove, and thus are formed the corpora quadrigemina, which are peculiar to man and other mammals.

The part of the dorsal wall of the resicle that underlies the corpora quadrigemina is the lamina quadrigemina.

The thickening which the walls of the vesicle undergo to produce the several parts of the mid-brain encroaches so much upon its cavity that an exceedingly small canal, the aqueauct of Sylvius, remains. It is scarcely necessary to point out that this canal is a part of the ventricular system of the brain, establishing a communication between the forrth ventricle and the third ventricle or eavity of the inter-brain. 


\section{The Metamorphosis of the Inter-brain Vesicle.-} The inter-brain vesicle results from the division of the primary fore-brain vesicle, comprising what is left of the latter after the ontgrowth from it of the diverticulum that becomes the secondary fore-brain. The thickening of the walls of the inter-brain vesicle produces the structures which surround the third ventricle in the mature condition, and which constitute collectively the thalamencephalon or inter-brain, the cavity of the vesicle persisting as the adult third ventricle. These structures are the optic thalami, which are formed from the lateral walls; the velum interpositum and the pineal body, which develop from the roof; and the lamina cinerea, the
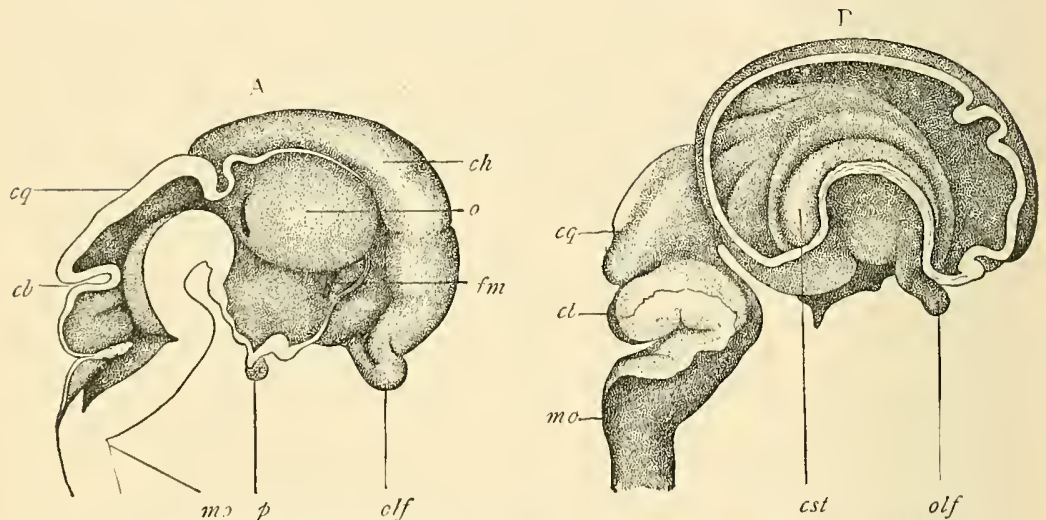

FIG.133.-A, mesial section through brain of a human fetus of two-and-a-half months (His) : ch, eerebral hemisphere; o, optic thalamus; $f m$, foramen of Monro; olf, olfactory lobe; $p$, pituitary body ; mo, medulla oblongata; $c q$. corpora quadrigemina; $c b$, cerebellum. $\mathrm{B}$, brain of human fetus of three months (His): olf, olfactory lobe; $c s t$, corpus striatum; $c q$, corpora quadrigemina; $c b$, cerebellum; mo, medulla oblongata.

tuber cinereum, the infundibulum, the posterior lobe of the pituitary body and the corpora albicantia, which are differentiated from the floor of the vesiele.

The lateral walls of the vesicle mudergo the most marked thickening. The cell-multiplication here is so rapid that cach lateral wall is converted into a large ovoid mass of cells with intermingled hands of fibers, the optic thalamus.

The roof of the inter-brain vesicle, in notable contrast with the lateral walls, remains extremely thin throughout 
the greater part of its extent (Fig. 128). From the back part of the roof, at a point immediately in front of the lamina quadrigemina of the mid-brain, a diverticulum grows out and becomes metamorphosed into the pineal body. With this exception, the roof of the vesicle remains a single layer of epithelium, just as in the case of the roof of the afterbrain. This epithelial layer adheres closely to the pia mater, which covers it in common with the other parts of the brain. As the fore-brain expands, it covers the inter-brain, the under surface of the eerebral hemispheres of the former being closely applied to the roof of the latter. As a consequence, the pia mater on the under surface of the forebrain is brought into contact with and adheres to the pia covering the roof of the inter-brain. Thus the thin epithelial roof of the inter-brain becomes closely united with the two layers of the pia mater to form the velum interpositum or tela choroidea anterior or superior of adult anatomy. Obvionsly, the edges of the velum interpositum rest npon the optic thalami, and its piamatral layers are continned into the cavities of the lateral ventricles (Fig. 134). The space occu-

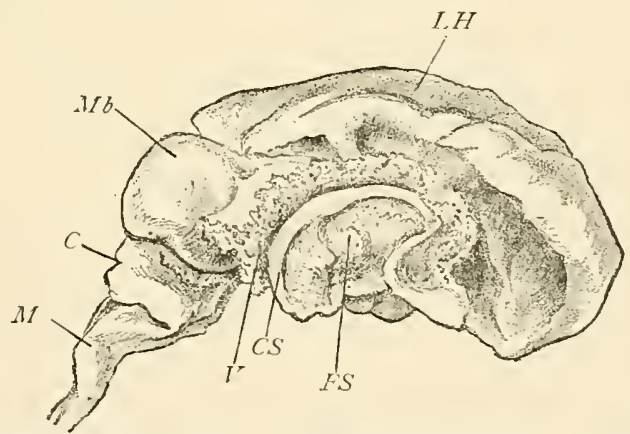

Fig. 134.-Brain of fetus of three months. The outer wall of the right hemisphere has been removed; $L H$, left hemisphere; $C S$, part of corpus striatum; $F S$, site of fossa of Sylvius; $V$, vascular fold of pia mater which has been invaginated through the mesial wall of the hemisphere; $I B$, mid-brain; $C$, cerebellum; $M$, medulla oblongata.

pied by the velum is designated the transverse fissure of the brain, and it is often stated that the pia mater is pushed in from behind, between the optic thalani and the cerebral hemi- 
spheres. As will be seen from the above description, however, its development really begins in front.

The pineal gland or conarium develops from the back part of the roof of the inter-brain at its point of junction with the mid-brain (Fig. 128). This borly is found in all vertebrate animals except the amphioxus, but its form varies greatly in different groups. In all cases it begins as a small pouch-like evagination from the roof of the inter-brain, the diverticulum being directed forward. In the human brain alone the structure is subsequently directed backward, so that it comes to occupy a position just over the corpora quadrigemina. This peculiarity of location is due probably to the greater development of the human corpus callosum, by which the conarium is crowded backward.

In selachians (sharks and dog-fish), the enlarged vesicular end of the diverticulum, which is lined with eiliated columnar cells, lies outside the cranial capsule and is connected with the inter-brain by the long hollow stalk which perforates the roof of the cranium. In many reptiles, the conarium is more highly specialized. In the chameleon, for example, the peripheral extremity has the form of a small closed vesicle which lies outside the roof of the cranium and which is covered by a transparent pateh of skin. The stalk in this case is partly a solid cord and partly a hollow canal, which latter opens into the eavity of the inter-brain. The solid portion lies within a foramen in the parietal bone, the parietal foramen. A further modification of the conarium is presented in lizards, blind-worms, and some other reptiles. In these the vesicle undergoes a marked specialization, its peripheral wall being so modified as to become transparent and to resemble the erystalline lens of the eye, while the opposite deeper wall comes to consist of several layers of cells-some of which beeome pigmented-and acquires a striking resemblance to the retina. 'The stalk of the body, which perforates the roof of the skull and is attached to the roof of the interbrain, bears a eertain likeness to the optic nerve, being solid and composed of fibers and clongated cells. The presence of the transparent epidermal plate which covers the vesicle 
serves to complete the similarity of this particular type of pineal body to the eye of vertebrate animals. It is for this reason that it is often designated the pineal or parietal eye and that it has been looked upon as a third or unpaired organ of vision.

In man and other mammals and in birds the pineal diverticulum does not reach the degree of development that is attained in certain of the Reptilia. The evagination from the roof of the inter-brain begins in the sixth week in the human embryo. The peripheral end of the process enlarges somewhat and small masses of cells project from it into the surrounding mesodermic tissue. These cellular outgrowths, giving off secondary projections, become converted into small closed follicles lined with columnar ciliated cells. The follicles in the case of mammals very soon become solid or nearly so by the accumulation of cells in their interior. Solid concretions of calcareons matter, the so-called brain-sand (acervulus cerebri) are found in the follicles in the adult. By these alterations the pineal body of birds and mammals acquires a structure resembling that of a glandular organ. Since it is only the end of the diverticulum that becomes thus altered, the remaining part constitutes the relatively slender stalk of the pineal body, the stalk being solid at maturity except at its point of attachment to the inter-brain, where a portion of the carity persists as the pineal recess of the third rentricle.

The pineal body of man and the higher vertebrates is therefore a rudimentary structure and is the representative of an organ that is much more highly developed in some of the lower members of the same series. Its true significance is still a matter of conjecture. Although resembling the eye in its structure, and although regarded by some on that account as primitively an organ of vision, it is considered probable by others that in its most highly developed condition it is an organ of heat pereeption.

The floor of the inter-brain vesicle presents several interesting metamorphoses. The anterior part of the floor remains quite thin and becomes the lamina cinerea of the mature brain (Fig. 
128). Immediately posterior to this region, the floor of the vesiele pouches out, this evagination developing into a slender tube, the infundibulum. Behind the point of origin of the infundibulum a second protuberanee indieates the beginning of the tuber cinereum. By subsequent alterations, the tuber cinereum enlarging in eircumference so as to include the point of origin of the infundibulum, the base of attachment of the infundibulum comes to be the center of the tuber cinereum, so that the eavity of the former is a eontinuation of the eavity of the latter. The end of the infundibulum beeomes the posterior lobe of the pituitary body or hypophysis (Figs. 128 and 133). Posterior to the tuber cinereum a small evagination of the floor of the vesicle appears and beeomes divided in the early part of the fourth month into two lateral halves by a median furrow. The two little bodies thus formed become, after further development, the corpora albicantia.

The hypophysis or pituitary body briefly referred to above requires more extended consideration beeanse of its morphological importance. The posterior lobe of this body is the enlarged end of the infundibulum, which is an evagination of the floor of the inter-brain. The eells in the lower end of the infundibulum speeialize into nerve-cells, and nervefibers also develop. In some lower vertebrates these elements are retained throughout life, but in man and the higher-type animals the distinctively nervous eharaeter of the tissnes is soon lost, and the cavity of this part of the infundibulum suffers obliteration. The branched pigmentcells sometimes recognizable in the posterior lobe of the human pitnitary body are the only remnant of the early nerve-cells.

The anterior lobe of the hypophysis is essentially different in origin as well as in structure from the posterior lobe. It is prorluced by an evagination from the posterior wall of the primitive pharynx, lont from that region of the pharynx which is anterior to the pharyngeal membrane and which therefore belongs to the primitive mouth-cavity (Fig. 55, p. 119). The out-pocketing of the pharyngeal wall begins in the fourth 
week, shortly after the rupture of the pharyngeal membrane. The little pouch is the pocket of Rathke. The pouch grows upward and backward toward the floor of the inter-brain and meets the end of the infundibulum. As the pharyngeal diverticulum lengthens, its stalk becomes a slender duct, which for some time retains its connection with the pharynx. As the membranous base of the skull becomes cartilaginous, the duct begins to atrophy, and finally entirely disappears. In selachians, however, it is retained permanently, establishing thus a connection between the hypophysis and the pharyngeal cavity. With the disappearance of the duet the enlarged extremity of the diverticulum becomes a closed vesicle lying now within the cavity of the brain-case, in contact with the end of the infundibulum. From the wall of the vesicle numerous little tubular projections grow out into the enveloping mesodermic tissue, and these, by detachment from the parent vesicle, become closed tubes or follieles. The entire structure becomes converted in this manner into a mass of closed follicles held together by connective tissue, after which event this mass aequires intimate union with the infundibular lobe.

Thus the pituitary body consists of two genetically distinct parts, the anterior lobe being derived from the ectoderm of the primitive pharyngeal or buceal eavity, and the posterior lobe from the ectoderm of the central nervous system. The posterior lobe, developing as it does as an evagination from the floor of the inter-brain, is to be regarded as a small outlying lobe of the brain.

What remains of the cavity of the inter-brain, after its walls have thus developed into the several struetures described, is the third ventricle of the adult brain, and the aperture of communication with the secondary fore-brain vesicles becomes the foramen of Monro. Since the lateral walls become the massive optic thalami, while the dorsal and ventral walls give rise to much thinner structures, the cavity of the resicle is encroached upon to a greater extent on the sides than from above and below, and hence the form of the third rentricle in the mature condition is that of a narrow vertical fissure between the thalami. 


\section{The Metamorphosis of the Fore-brain Vesicle.-} The secondary fore-brain vesicle gives rise to the prosencephalon, which includes the cerebral hemispheres and the structures belonging directly to them. As above indicated, this vesicle grows from the anterior wall of the primary forebrain vesicle as a diverticulum which is at first single, but which soon becomes divided into two lateral halves by the formation of a cleft in the median plane (Fig. 131, $f b$ ). This cleft or interpallial fissure is the early representative of the longitudinal fissure of the adult cerebrum. The two vesicles remain attached at their bases or stalks with the parent vesicle and communicate by a common orifice with its cavity. The vesicles of the secondary fore-brain grow in an upward and backward direction as well as laterally, and their development is so much more rapid than that of the other vesicles that they soon spread over them and partially hide them from view. It is for this reason that the mass resulting from the fore-brain resicles, except their basal ganglia, is known in comparative anatomy as the pallium or mantle (Fig. 128).

The relative rate of growth of the cerebral hemispheres is such that in the third month they completely overlie the inter-brain and by the sixth month they have exteuded so far back as to hide the corpora quadrigemina.

The mesodermic tissue surrounding the developing brain becomes differentiated into the three brain-membranes, which penetrate into the fissure and therefore invest the vesicles on their mesial surfaces as well as elsewhere. The invaginating layers of the dura mater constitute the primitive falx cerebri.

The metamorphosis of this pair of saes into the cerebral hemispheres is brought about by three important processes: first, the multiplication of the cells which eompose its walls to form the masses of nerve-cells and fibers of the hemispheres; second, the formation of folds in the wall whereby are produced the fissures which divide the hemispheres into lobes and convolutions; and third, the development of adhesions within certain areas between the mesial walls of the 
two vesieles, by which the system of commissures of the hemispheres is produced.

The walls of the cerebral vesicles are at first very thin, consisting merely of several layers of spindle-shaped eells. By the rapid multiplication of these cells, the walls are thickened and the cavity of the vesicle is gradually encroached upon until the mature condition of the brain is attained, when the cavity is relatively very much smaller than in the fetus and constitutes the ventricle of the hemisphere or the lateral ventricle. The nerve-cells develop processes or polar prolongations, of which the most conspieuous, the axis-cylinder processes, lengthen out to form the axis cylinders of nerve-fibers. The fibers thus formed are direeted away from the surface and make up the white medullary matter of the hemispheres, while the more superficially placed layers of cells constitute the gray matter of the cortex of the brain.

In addition to the cortical or superficial gray matter there are masses of gray matter within the hemisphere, the basal ganglia, which are likewise collections of nerve-cells. Within a limited area on the lateral wall of each cerebral vesiele, near the lower margin, the cells undergo excessive proliferation resulting in the production of a large ganglionic mass, the corpus striatum, and of two smaller aggregations of cells, the claustrum and the nucleus amygdalæ. These basal ganglia are in reality an infolderl part of the cortex.

Inasmuch as the cortical matter develops more rapidly, as regards superficial extent, than does the medullary substance, the cortex becomes thrown into folds, forming thus the convolutions and fissures of the hemispheres.

Some of the fissures of the brain are produced by an infolding of the entire thickness of the vesicle-wall so that their presence is indieated by corresponding projections in the walls of the ventricles. Such fissures are distinguished as total fissures. Included in this eategory are the fissure of Sylvius, which is represented in the wall of the lateral ventricle by the corpus striatum; the calcarine fissure, the dentate fissure, and the collateral fissure, which are responsible respectively for the ealear aris, the hippocampus major, and 
the collateral eminence of the lateral ventricle; and the great transverse fissure of the brain, the infolded wall in this case being very thin and consisting merely of the layer of epithelium which covers the choroid plexus.

The fissure of Sylvius is the earliest fissure formed and one of the most important. At an early period in the history of the secondary fore-brain, there is a region in the lower part of the lateral wall of the vesicle where expansion is less rapid than elsewhere, this area, as it were, remaining fixed. As the vesicle-wall immediately surrounding this

A
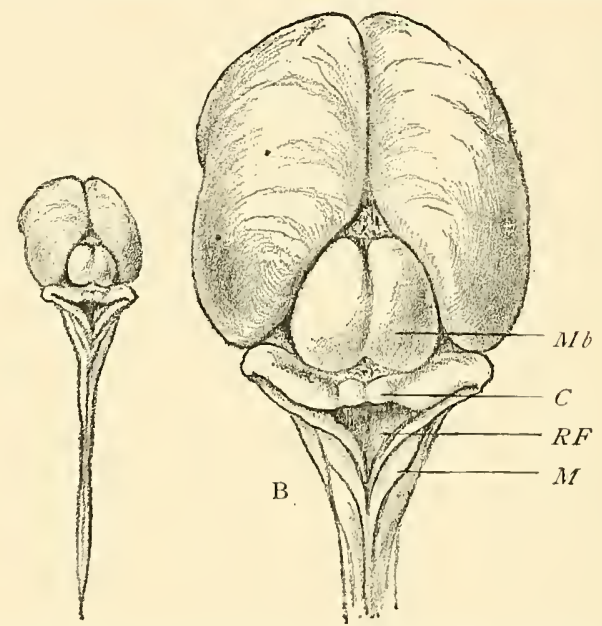

FIG. 135.-Posterior view of brain shown in Fig. 136: $A$, aetual size; $B$, enlargerl ; $M b$, mid-brain ; $C$, cerebellnm ; $R F$, rhomboidal fossa (its dorsal wall having been removed); $\boldsymbol{H}$, medulla oblongata.

spot continues to expand, a dimpling of the wall is produced, the depression being designated the fossa of Sylvius (Fig. 136, $\left.S^{\prime}\right)$. The part of the vesiele-wall behind the fossa advances forward and downward to form the future temporal lobe, and thus the fossa comes to be surrounded by a convolution having the form of an ineomplete ring, open in front-the ring lobe. The floor of the fossa undergoes very considerable thickening to form the basal ganglia - that is, the corpus striatum, the amygrialoid nucleus, and the claustrum. These structures, most conspicuously the corpus striatum, encroach upon the eavity of the vesicle, the melens caudatus of the 
corpus striatum bulging into the floor and outer wall of the adult lateral ventricle.

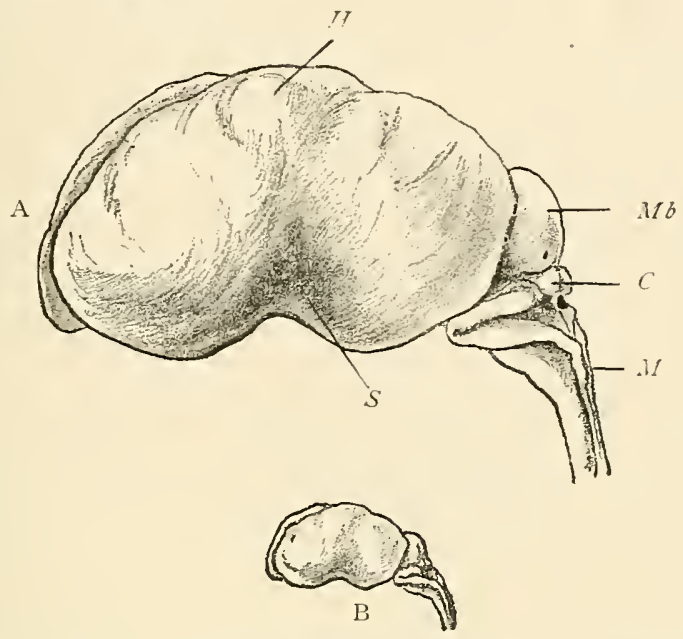

Fig. 136.-Brain of human fetus of approximately three months: A, enlarged; $\mathrm{B}$, actual size; $H$, hemisphere; $M b$, mid-brain; $C$, cerebellum; $N$, medulla oblongata; $S$, fossa of Sylvius.

The cortical matter of the floor of the fossa of Sylvius, being circumscribed by a groove or sulcus, constitutes the

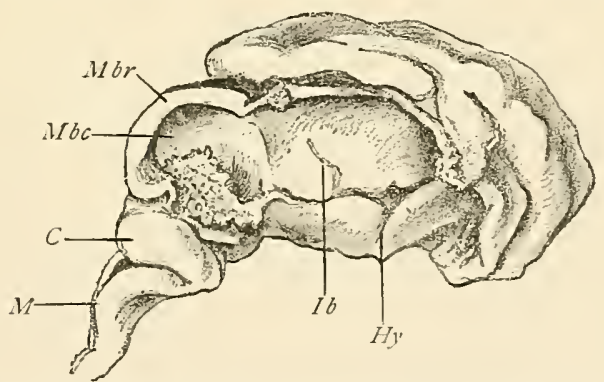

FIG. 137.-Brain of human fetus of three months, with right half of fore-brain, inter-brain, and mid-brain removed: $1 b$, cavity of inter-brain; $H y$, site of hypophysis; $M b r$, mid-brain roof; $M b c$, mid-brain cavity ; $C$, cerebellum; $M$, medulla oblongata.

central lobe or island of Reil, which is subsequently broken up, by secondary fissures, into from five to seven small convolutions. 
By the extension of the fossa of Sylvius backward, and by the inereased growth of the vesicle-wall above and below it, the fossa is converted into the fissure of Sylvius (Fig. 140, B), and the island of Reil is hidden from view. Subsequently the ascending and anterior limbs are added to the chief or horizontal part of the fissure.

The anterior part of the ring lobe corresponds with the future frontal lobe, the posterior part represents the parietal lobe while the lower part of the ring becomes the temporal lobe. A backward extension of the ring lobe produees the occipital lobe.

The cavity of the vesicle is modified in form and extent coincidentally with the formation of the corpus striatum and the alterations in the ring lobe. Just as the ring lobe partially encireles the fossa of Sylvius, so does the eavity of the ventricle partially encirele the corpus striatum. An anterior prolongation of the cavity extends into the completed frontal lobe as the anterior cornu of the ventricle, and an extension downward and forward into the apex of the temporal lobe constitutes the descending cornu, while the posterior horn is gradually protruded into the occipital lobe as the latter develops. From the earliest stage, therefore, until the completed condition is attained, the cavity of the ventricle conforms in a general way to the shape of the hemisphere. The apertures of communication between the vesicles of the eerebrim and the cavity of the inter-brain are the later $Y$-shaped foramen commune anterius or the foramen of Monro.

The mesial surfaces of the hemispheres are much modified in character by the development here of two total fissures, the arcuate fissure and the choroid fissure. These appear in the fifth week while the vesicles are still separate from each other down to their stalks of attachment to the inter-brain, prior to the development, therefore, of the corpus eallosum and the fornix. The two fissures lie close together, paralle] with each other and with the margin of the ring lole, their course conforming to that of the eavity of the ventricle. Beginning near the anterior extremity of the brain, above the 
level of the corpus striatum, they pass backward and then downward and afterward forward to terminate near the anterior extremity of the temporal lobe, thus incompletely encircling the striate body.

The arcuate fissure is the more peripherally placed of the two. Its anterior portion lies just above the region throughout which adhesions subsequently develop between the two hemispheres, or in other words, above the position of the future corpus callosum (Fig. 138, a.f.). This part of the arcu-

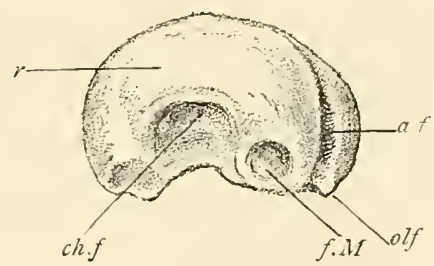

FIG. 138.-Mesial surface of left fore-brain vesicle of brain shown in Fig. $132(F b)$ : $f . M$, foramen of Monro, or opening into inter-brain; a.f, arcuate fissure; $c h . f$, choroid fissure ; $r$ " randbogen," corresponding to future corpus callosum and fornix; olf, olfactory lobe.

ate fissure is the sulcus of the corpus callosum of the mature brain. The posterior segment, that which belongs to the temporal lobe (not present at this stage), is the future hippocampal or dentate fissure. The hippocampal fissure is represented upon the mesial wall of the descending horn of the lateral ventricle by the prominence known as the hippocampus major.

The choroid fissure or fissure of the choroid plexus, forming an incomplete ring within, and parallel with, that described by the arcuate fissure, encircles the corpus striatum more closely (Figs. 138, 139). It begins at the foramen of Monro, and its anterior part lies under the position of the body of the future formix. It then sweeps around into the temporal lobe and terminates near the anterior part of the latter. The fissure of the choroid plexus, like other total fissures, is an infolding of the wall of the cerebral vesicle. It presents the peculiarity, howerer, that the infolded part of the wall is extremely thin, consisting of but a single layer of epithelial 
cells. The pia mater, which everywhere closely invests the surface of the brain, is infolded with the vesicle-wall, the infolded part becoming very rascular and constituting the choroid plexus of the lateral ventricle. The choroid plexus, although within the limits of the ventricle, is excluded, strictly speaking, from its cavity by the layer of epithelium which still covers it and which has been simply pushed before it into that cavity. Since the epithelial layer is very thin and easily ruptured, the choroid fissure is apparently an opening into the carity of the ventricle throngh which the pia enters; in the adult it is called the great transverse fissure of the brain.

The calcarine fissure, another of the total fissures, develops in the latter part of the third month as a branch of the areuate fissure. It bulges into the mesial wall of the posterior horn of the ventricle, producing the elevation known as the calcar avis or hippocampus minor. Since the posterior horn of the ventricle is developed as an extension of the cavity into the backward prolongation of the ring lobe which forms the occipital lobe, the calcarine fissure necessarily is later in appearing than the fissures above described.

The parieto-occipital fissure is added in the fourth month as a branch of the calcarine, effecting the definite demarcation between the parietal and occipital lobes.

The fissure of Rolando develops in the latter part of the fifth month in two parts. The two furrows are at first entirely separated from each other by an intervening area of cortex. Subsequently this part of, the cortex sinks beneath the snrface, as it were, since it expands less rapidly than the adjacent regions, and in this way the upper and lower limbs of the fissure become continuous. The sunken cortical area is to be found even in the adult brain as a deep annectant gyrus embedded in the Rolandic fissure at the position of its superior genu. The development of the fissure of Rolando effects the division between the frontal and parietal lobes.

The collateral fissure appears in the sixth month as a longitudinal infolding of the mesial wall of the hemisphere 
below and parallel with the hippocampal fissure. Being a total fissure, its presence affects the wall of the carity of the vesicle, producing the eminentia collateralis. At about the same time the calloso-marginal fissure makes its appearance, and this is morphologically continuous, through the medium of the post-limbic sulcus, with the collateral fissure (Fig. 141). These three fissures constitute the peripheral bomdary of a region of the mesial wall which is known in morphology as the falciform or limbic lobe.

The longitudinal fissure in the early stage of the growth of the cerebrum separates the two vesicles from each other except at the place where they are attached to the inter-brain; here the two sacs are united by that part of their common anterior wall which is immediately in front of the apertures of communication with the inter-brain and which is called the lamina terminalis.

The development of adhesions between the mesial surfaces of the hemisphere vesicles throughout certain definite areas marks the beginning of the corpus callosum and the fornix. The fusion of these areas begins in the third month in the region corresponding to the anterior pillars of the fornix, the septum lucidum and the genu of the corpus callosum; in the fifth and sixth months adhesion occurs in the position of the body of the fornix and of the body and splenium of the corpus callosum.

Although the central white medullary matter of the cerebral hemisphere is covered almost universally by the cortical gray matter, there is a limited area of the mesial surface from which the gray matter is absent, leaving the white matter exposed. The area of uncovered white matter has the form of a narrow band, which begins at the base of the hemisphere, in front of the opening into the inter-brain, extends upward along the anterior wall of the inter-brain, then passes backward along its roof and enrves downward and outward behind, and then forward under it, to terminate at the front part of the temporal lobe. Thus this white band, which is known as the fimbria, and which represents the lower mesial edge of the hemisphere, almost encircles the inter-brain. The fimbria 
runs between the arcuate fissure and the fissure of the choroid plexus (Fig. 139, f). It holds such a close relation to the lat-

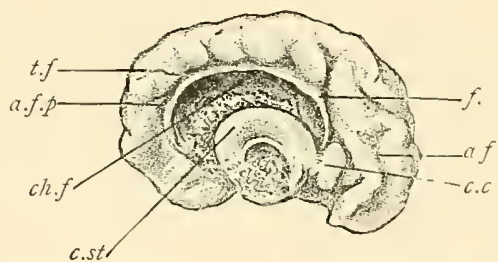

FIG. 139.-Mesial surface of left hemisphere, brain of fetus of three months (enlarged) : f., fornix; c.c., beginning of corpus callosum; c.st., part of corpus striatum arching around fossa of Sylvius; a.f., anterior, and a.f.p., posterior parts of arcuate fissure; ch.f., choroid fissure, the concavity between which and the corpus striatum accommodates the inter-brain, which has been removed. The fissure is occupied by the pia mater.

ter fissure, being placed on its peripheral side, that it constitutes the edge of the apparent opening into the eavity of the vesiele through which the pia mater, bearing blood-vessels, is reflected into the interior, and which, as pointed out above, is the transverse fissure of the brain. The opening is only apparent, however, since the wall is still unbroken, although reduced to a single layer of epithelium. The pia mater, forming, with its blood-vessels, the choroid plexus of the lateral ventricle, pushes the layer of epithelium before it, and although the plexus is said to be within the eavity of the ventricle, it is still covered by the layer of epithelium, the ependyma, which lines that cavity.

The part of the fimbria that immediately overlies the roof of the inter-brain becomes intimately united, as noted above, with the corresponding part of the fimbria of the other hemisphere, these fused portions of the two fimbrix forming a flat triangular sheet, the body of the fornix. The anterior and posterior portions of the fimbria, which diverge from the merlian plane, represent respectively the anterior and posterior limbs of the fornix.

Noting the relation of the anterior part of the fimbria to the aperture of communication between the inter-brain and the cerehral vesicles, it becomes apparent that the anterior pillar of the fornix forms the anterior and upper boundary of 
the foramen of Monro. When, further, one considers the relation of the fimbria to the apparent opening into the ventricle, through which the pia mater is invaginated (the transverse fissure), it is explained why the edge of the fornix appears as a narrow white band, not only as viewed from within the ventricular cavity, but also in a mesial section of the brain (Fig. 140, C).

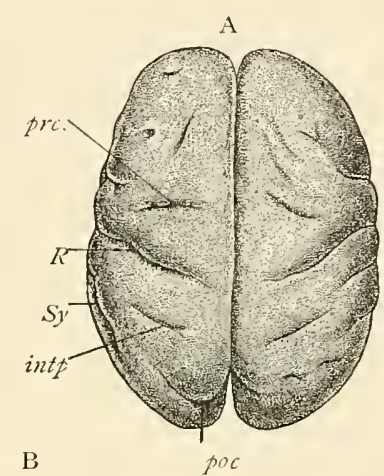

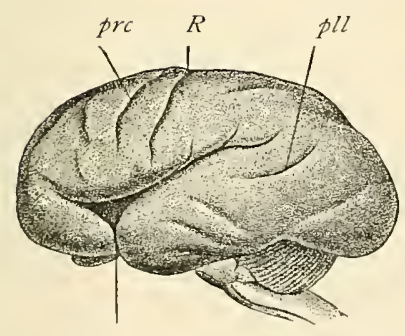

Sy

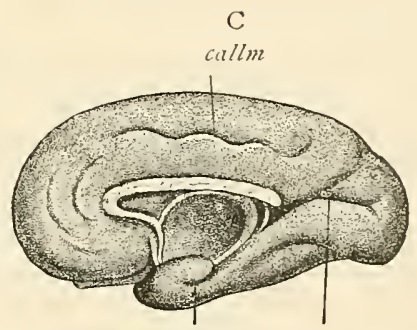

ainc

calc

FIG. 140.-Fetal brain at the beginning of the eighth month (Mihalkovies): $A$, superior, B, lateral, C, mesial surface: $R$, fissure of Rolando; prc, precentral fissure; Sy, Sylvian fissure; intp, interparietal fissure ; poc, parieto-oceipital fissure : $p l l$, parallel fissure; callm, eallosomarginal fissure; unc, uneus; calc, ealcarine fissure.

Another important region of fusion of the opposed mesial surfaces of the hemispheres is that corresponding to the future corpus callosum. Thronghout this area the hemispheres closely unite with each other. The line of fusion begins. at the bases of the vesieles, some little distance in front of the anterior parts of the fimbrix (Fig. 139, c.c.), and after passing upward and forward, curves horizontally backward 
in close relation with the fused portions of the fimbriæe, now the body of the fornix. The adhesion begins at the anterior part in the third month, and affects the region of the body and splenium of the future corpus callosum in the fifth and sixth months. Fibers penetrate from one hemisphere to the other throughout this zone of contact, intimately uniting the cerebral hemispheres. The corpus callosum is therefore a great commissure between the two halves of the cerebrum, and is necessarily composed of fibers having a transverse direction.

While the back part of the corpus callosum lies over the body of the fornix and is in close contact with it, the front part of the body of the corpus collusum, as also its genu or curve and its rostrum or ascending part are at some clistance from the front parts of the fimbriæ. In other words, while the great longitudinal fissure extends at first to the bases of the cerebral vesicles, this fissure is made relatively less deep by the adhesions which occur between the mesial walls and which result in the development of the corpus callosum ; and the space below the anterior part of the corpus callosnm, between it and the anterior parts of the fimbria (Fig. 140, C), is an isolated part of the great longitudinal fissure. This space is bounded on either side by that part of the wall of the corresponding cerebral vesiele or hemisphere which is limited above and in front by the corpus collusum, and behind by the anterior part of the fimbria or anterior limb of the fornix. The space is the so-called fifth ventricle of the adult brain. The eircumscribed parts of the mesial walls of the hemispheres, which form the lateral walls of the space, together constitute the septum lucidum. The parts of the hemisphere walls that become the septum lucidum do not participate in the process of fusion mentioned above. Their surfaces are in contact, however, and do not develop the typical gray cortieal matter, such as appears clsewhere upon the surface of the cerebrum. Cortical gray matter is produced here, but only in rudimentary form.

From what has been said, it will be seen that the two layers of the septum lucidum are circmscribed and opposed 
parts of the mesial walls of the hemispheres; that the fifth ventricle is not a true ventricle but an isolated part of the longitudinal fissure having no connection whatever with the system of ventricular cavities; and that this so-called ventricle is not, like the true ventricles of the brain, lined with ependyma, but with atrophic gray cortical matter.

The limbic lobe has been referred to as that part of the mesial surface of the hemisphere which is eircumscribed by the calloso-marginal fissure, the post-limbic sulcus, and the collateral fissure. It is limited centrally by the fissure of the corpus callosum and the hippocampal fissure, which are represented in the fetal brain by the single uninterrupter arcuate fissure. Hence the limbic lobe would include the gyrus formicatus, the isthmus, and the gyrus uncinatus, which constitute morphologically a single ring-like convolution. Scliwalbe, however, includes with this so-called limbic lobe all the surface of the mesial wall of the hemisphere included between the arcuate fissure and the fissure of the choroid plexus (Fig. 138), designating it the falciform lobe (Fig. 141).

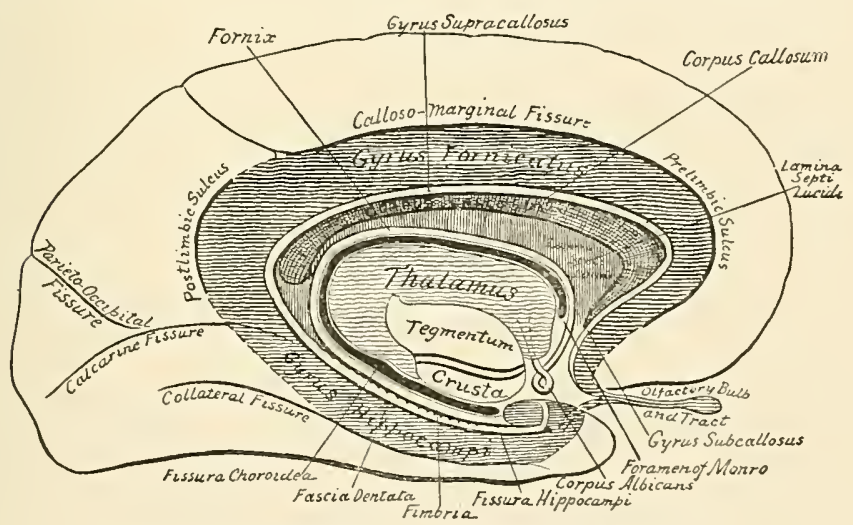

Fig. 141.-Diagram of the limbic lobe (after Quain).

The falciform lobe therefore consists of two ring-like convolutions, one within the other, the two being separated from each other by the arcuate fissure (the adult callosal and dentate fissures) and being limited centrally by the fissure of the choroid plexus (the great transverse fissure of the adult 
brain). While the outer of these concentric convolutionsthe limbic lobe of Broca-develops into the fornicate or callosal, the isthmian, and the uncinate gyri, the inner ring differentiates but slightly, its cortical matter remaining atrophic. The atrophic condition of the cortex here is associated with those alhesions between the mesial walls of the hemispheres that result in the formation of the corpus callosum and the septum lucidum. By these adhesions the continuity of the immer concentric convolution is broken, and it is therefore represented, after the development of the corpus callosum, by the atrophic gray matter of the septum lncidum, by the gyrus dentatus, and by the lateral longitudinal strix on the free surface of the corpus callosum, the latter being an atrophic or rudimentary convolution. Since the transverse fissure of the brain is the centric homndary of the ring, the fornix is also a part of the falciform lobe. To sum up, the falciform lobe includes the gyrus fornicatus, the isthmus, the gyrus uncinatus, the lateral longitudinal striæ or tænia tectæ of the corpus callosum, the gyrus dentatus, the laminæ of the septum lucidum and the fornix.

The olfactory lobe or rhinencephalon is an outgrowth from the vesicle of the cerebral hemisphere. Its development begins in the fifth week by the pouching-ont of the wall of the vesicle near the anterior part of its floor (Figs. 131 and 133). This diverticulum, which contains a cavity continuous with that of the vesicle, grows forward and soon becomes somewhat elub-shaped. In the selachians (sharks and dog-fish) the projection attains a great relative size, the olfactory lohes in these animals being one of the most conspicnous parts of the brain. In all mammals except man it is well developed, and in the horse its eavity persists throughout life. In man the cavity soon becomes obliterated and the lobe itself in part aborts. The protruled portion, becoming more distinctly club-shaped, differentiates into the olfactory bulb and the olfactory tract, the position of the original eavity being indicated by a more or less central mass of neuroglia conspicuous in cross-sections of those structures. 'The proximal portion of the olfactory lobe is represented in the adult 
human brain by the gray matter of the anterior perforated lamina (or space), and by the trigonum olfactorium and the area of Broca, as well as by the inner and onter roots of the olfactory tract (note olfactory lobe of dog's brain, Fig. 142).

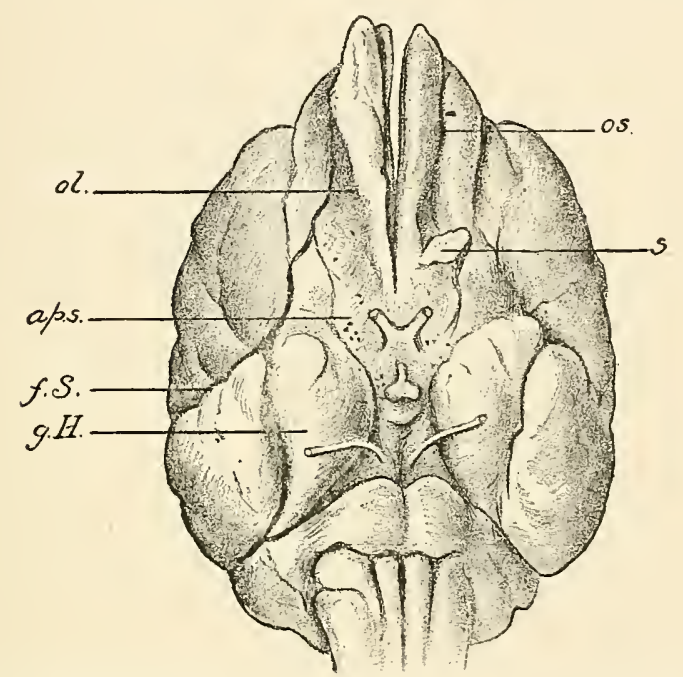

FIG. 142,-Base of dog's brain: ol., olfactory lobe ; a.p.s, region corresponding to anterior perforated space, which is included in the olfactory lobe; f.S., fissure of Sylvius; g.h., hippocampal gyrus, developed to a greater degree than in human brain; s, sectional surface of olfactory lobe ; os, olfactory sulcus.

Because of the relation of the place of evagination of the olfactory lobe to the fossa of Sylvius, it happens that a part of this lobe, the anterior perforated lamina, is situated at the commencement of the fissure of Sylvins and that it is in continuity with both extremities of the ring lobe; hence, the olfactory lobe is connected with both extremities of the falciform lobe. To express it in the language of human anatomy, the outer or lateral root of the olfactory tract is connected with the gyrus uncinatus, while the inner or mesial root may be traced to the fore part of the gyrus fornicatus.

After what has been said, the realer need scarcely be reminded that the olfactory bulb and tract, often erroneons ly referred to as the olfactory nerve, are parts of a lobe of the 
brain, a lobe which in man is rudimentary but which in all other mammals is well developed.

Tabulated Résume of the Derivatives of the Brain-vesicles.

\begin{tabular}{|c|c|c|c|c|}
\hline $\begin{array}{l}\text { BRAIN- } \\
\text { VESICLES. }\end{array}$ & FLOOR. & Roof. & LATERAL WALLS. & Cavity. \\
\hline $\begin{array}{l}\text { After- } \\
\text { brain } \\
\text { vesicle. }\end{array}$ & $\begin{array}{l}\text { Medulla } \\
\text { oblongata. }\end{array}$ & $\begin{array}{l}\text { Tela choroidea } \\
\text { inferior. }\end{array}$ & $\begin{array}{l}\text { Inferior pedun- } \\
\text { cles of cerebel- } \\
\text { lum. }\end{array}$ & \multirow[b]{2}{*}{$\begin{array}{c}\text { Fourth } \\
\text { ven- } \\
\text { tricle. }\end{array}$} \\
\hline $\begin{array}{l}\text { Hind- } \\
\text { brain } \\
\text { vesicle. }\end{array}$ & Pons Varolii. & $\begin{array}{l}\text { Posterior medul- } \\
\text { lary velum. } \\
\text { Cerebellum. } \\
\text { Anterior me- } \\
\text { dullary velum. }\end{array}$ & $\begin{array}{l}\text { Middle and supe- } \\
\text { rior peduncles } \\
\text { of cerebellum. }\end{array}$ & \\
\hline $\begin{array}{l}\text { Mid-brain } \\
\text { vesicie. }\end{array}$ & $\begin{array}{l}\text { Peduncles of cer- } \\
\text { ebrum. Poste- } \\
\text { rior perforated } \\
\text { space. }\end{array}$ & $\begin{array}{l}\text { Corpora quadri- } \\
\text { gemina. Lam- } \\
\text { ina quadrigem- } \\
\text { ina. }\end{array}$ & $\begin{array}{l}\text { Brachia. Inter- } \\
\text { nal geniculate } \\
\text { bodies. }\end{array}$ & $\begin{array}{l}\text { Aqueduct } \\
\text { of Syl- } \\
\text { vius. }\end{array}$ \\
\hline $\begin{array}{l}\text { Inter- } \\
\text { brain } \\
\text { vesicle. }\end{array}$ & $\begin{array}{l}\text { Corpora albican- } \\
\text { tia. Tuber ci- } \\
\text { nereum, infun- } \\
\text { dibulum, and } \\
\text { part of hypo- } \\
\text { physis. Optic } \\
\text { chiasm. }\end{array}$ & $\begin{array}{l}\text { Pineal body. Pos- } \\
\text { terior commis- } \\
\text { sure. Epithe- } \\
\text { lium of velum } \\
\text { interpositum. }\end{array}$ & Optic thalami. & $\begin{array}{l}\text { Third } \\
\text { ven- } \\
\text { tricle. }\end{array}$ \\
\hline $\begin{array}{l}\text { Secondary } \\
\text { fore- } \\
\text { brain } \\
\text { vesicle. }\end{array}$ & $\begin{array}{l}\text { Anterior perfo- } \\
\text { rated lamina. } \\
\text { Corpus stria- } \\
\text { tum. Island of } \\
\text { Reil. Olfactory } \\
\text { lobe. }\end{array}$ & \multicolumn{2}{|c|}{$\begin{array}{l}\text { Convolutions of cerebral hemi- } \\
\text { spheres. Corpus callosum. For- } \\
\text { nix. Septum lucidum. }\end{array}$} & $\begin{array}{l}\text { Lateral } \\
\text { ven- } \\
\text { tricles. }\end{array}$ \\
\hline
\end{tabular}

\section{THE DEVELOPMENT OF THE PERIPHERAL NERVOUS} SYSTEM.

The development of the peripheral nervous system is still involved in some degree of obscurity. In general terms it may be stated that the peripheral nervous apparatus is derived as an extension of the central cerebro-spinal axis.

In the case of the spinal nerves, each nerve-trunk is composed of both motor and sensory fibers, the former being in continuity with the spinal cord throngh the medium of the anterior or motor roots, and the latter through the posterior or sensory roots, each sensory root possessing a ganglion. The cranial nerves exhibit a less regular composition. While the trigeminal nerve, for example, arises by two roots, after the manner of a spinal nerve, some others correspond in relative position and in morle of development to the ventral or motor roots of the spinal nerves, and still others are equivalent to the sensory spinal roots. 
The development of the sensory nerve-fibers is dependent upon and is preceded by that of the ganglia of the posterior roots of the spinal nerves, and of several ganglia of the head region which are related to the development of certain of the cranial nerves. Hence the consideration of the genesis of
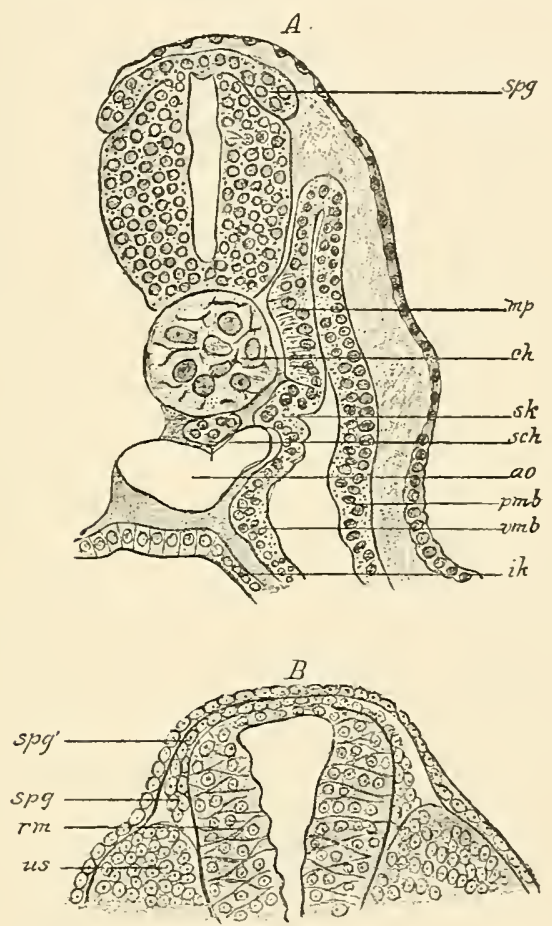

FIG. 143.-A, cross-section through an embryo of Pristiurus (after Rabl). The primitive segments are still connected with the remainiug portion of the middle germ-layer. At the region of transition there is to be seen an out folding ( $s k$ ) from which the skeletogenous tissue is developed; $c h$, cliorda; spg, spinal ganglion; $m p$, muscle-plate of the primitive segment; sch, subchordal rod; $a o$, aorta; $i k$, inner germ-layer; $p m b$, parietal, $2 m b$, visceral middle layer, $B$, cross-section through a lizard embryo (after Sagemehl): $r m$, spinal cord; $s p g$, lower thickened part of the neura! ridge: $s p g^{\prime}$, its upper attenuated part, which is continuous with the roof of the neural tube; us, primitive segment.

the ganglia must precerle the account of the growth of the sensory nerve-fibers.

The origin of the ganglia is connected with the early history of the evolution of the neural tube. Just after the 
sides of the medullary plate (vide p. 255) have united with each other to form the neural tube, there appear two ridges of cells between the tube and the epidermis, one on each side of the raphe or line of union of the sides of the tube. These ridges are the neural crests (Fig. 143). They first appear in the region of the hind-brain and advance from this point both headward and tailward. The ganglia develop from these neural crests. The cells of the neural crest are usually described as growing ont from the neural tube, though according to His it is probable that they originate singly from the ectoderm.

The mass of cells composing the neural crest grows outward and then rentrad along the wall of the neural tube, and very soon undergoes segmentation into a number of cellmasses which are the rudimentary ganglia. In the spinal region the number of segments corresponds to the number of future spinal nerves. In the head region there are four segments. These latter, the cephalic ganglia, will be referred to subsequently.

The segmentation of the neural crest corresponds in the main with the segmentation of the paraxial plate of the mesoderm, whereby the myotomes are produced, and each segment lies upon the inner side of a myotome. The connection of the segments with the nemal tube beeomes reduced in each case to a slender strand, the point of continuity of which with the tube is shifted further away from the median line, as development progresses, to correspond with the dorsolateral position of the sensory nerve-roots in the mature condition.

The cells of the ganglia aequire axis-cylinder processes, each such process, upon further elongation, becoming the axis cylinder of a future nerve-fiber. The cells being bipolar, each one gives origin to two nerve-fibers, one passing to the spinal eord and one going to the periphery of the body as a sensory nerve-fiber. Thus the ganglia are made up of cells which are interpolated in the course of the sensory nerve-fibers, and these cells may be regarded as having migrated from the developing cerebrospinal axis, or, if the 
view of His be accepterl, from the region of the ectoderm from which the tube originates, their connection with the axis being maintained by the gradually lengthening out axiscylinder process.

The development of the motor nerve-fibers differs from that of the sensory. These fibers, or at least, the axis cylinders of the fibers, are the elongated neurits of nerve-cells of the spinal cord and brain. The neuroblasts of the thickened neural tube, as they become fully differentiated nerve-cells, migrate from their central position into the mantel layer, or superficial stratum (Figr. 124). On the distal side of the uuclens of the cell, the protoplasm first becomes massed and then lengthens ont to form an axis-eylinder process or neurit, which in all vertebrate animals grows out from the cerebrospinal axis to form a motor nerve-fiber.

Although, in the ease of the spinal nerves, the motor and sensory fibers are separated from each other at their origin from the cord, they soon intermingle to constitute a spinal nerve-trunk. In certain lower types, as eyclostomes and anphioxus, the motor and the sensory fibers permanently pursue separate routes to their peripheral distribution.

The envelopes of the nerve-fiber are acquired at a relatively late period. The appearance of the neurilemma precedes that of the white substance of Schwann. Both these investments are derived from the mesoderm. The cells of the latter apply themselves to the nerve and, penetrating between the fibers, become arranged as an enveloping layer upon each axis cylinder, ultimately forming a complete sheath, the neurilemma. The persistent nuclei of these cells, scantily surrounded with protoplasm, constitute the nervecorpuscles of the neurilemma. The medulla, or white substance of Schwann, is formed at a considerably later period within the neurilemma. The deposit of the medullary sheath varies as to time for different groups of fibers-although the time is constant for each group-and proceeds always in a direction away from the cell from which the fiber originates, or, differently expressed, in the direetion in which the fiber conveys impulses. Thus, in the spinal cord, groups of afferent 
fibers may be distinguished from those that are efferent by observing the direction in which the medullary sheath develops-that is, whether the sheath appears first at the upper end of the fiber or at the lower end.

The cranial nerve-fibers in their development follow in the main the same general principles that govern the growth of the spinal nerves. That is to say, the motor fibers grow out as extensions of the axis-cylinder processes of nerve-cells of the cephalic part of the neural tube and the sensory fibers proceed from the cells of outlying ganglia, or in the case of at least one nerve, the olfactory, from infolded and highly specialized cells of the ectoderm.

The cephalic ganglia, four in number, have been referred to as resulting from the segmentation of the head-region of the neural erest. As previously stated, the neural crest begins to grow first in the region of the hind-brain and extends from this point both forward and backward, oceupying a position upon the roof or dorsal wall of the hind-brain. The part of the neural crest belonging to the hear-region then divides into the four masses or head-ganglia which are designated respectively the first or trigeminal, the second or acusticofacial, the third or glossopharyngeal, and the fourth or vagal, ganglia.

The trigeminal ganglion, which is very large, becomes divided into a smaller anterior portion, the ophthalmic or ciliary ganglion, and a larger posterior segment, the trigeminal ganglion proper. These two become widely separated during the progress of development, since they constitute respectively the later ciliary and Gasserian ganglia, the ciliary ganglion belonging to the ophthahmic division of the fifth nerve, while the trigeminal belongs to the superior maxillary division and the sensory part of the inferior maxillary division of the fifth. Their nerve-cells give rise to the sensory fibers of these trunks in the same manner that the cells of the spinal ganglia produce the sensory fibers of the spinal nerves. By some observers, the sphenopalatine (Meckel's) ganglion and the otic, and possibly the submaxillary ganglia, are to be regarded as offishoots from the Gasserian ganglion. 
The acusticofacial ganglion, after its migration from its original position on the dorsum of the hind-brain, lies just in front of the otic vesicle. This ganglion subsequently divides into the facial and the acoustic ganglia. The facial ganglion, the geniculate ganglion or intumescentia ganglioformis of the facial nerve, situated in the facial canal of the temporal bone, althongh described as a ganglion upon a motor nerve, the facial, is, in reality, connected mainly with the pars intermedia, a bundle of sensory fibers issuing from the nucleus of origin of the glossopharyngeal nerve. It is equivalent therefore to a spinal ganglion.

The acoustic portion of the acusticofacial ganglion divides still further to become the ganglion on the vestibular part of the auditory nerve, and the ganglion spirale of the cochlear division of the auditory, which latter is situated in the spiral canal of the modiolus. It is considered probable that the lateral accessory auditory nucleus, which is connected with the cochlear fibers of the auditory nerve and lies on the outer side of the restiform borly, is also a part of the acoustic ganglion. From the cells of the vestibular ganglion, which is situated in the internal meatus, centrifugal fibers develop to form the vestibular nerve, while other centripetally growing fibers become the ventral or mesial (vestibular) root of the auditory nerve. The cochlear ganglion in the same way gives rise to the cochlear branch of the nerve and to its dorsal or lateral root. Thus the auditory nerve and its ganglia correspond respectively to the sensory root of a spinal nerve and to a spinal ganglion.

The third cephalic ganglion becomes the ganglion of the glossopharyngeal nerve, undergoing segmentation to form the upper or jugular and the lower or petrous ganglia of this nerve, while the axis-cylinder processes of its cells lengthen out to become the sensory fibers.

The fourth cephalic ganglion similarly becomes the two ganglia of the pneumogastric nerve and gives rise to its sensory fibers.

While the motor fibers of the cranial nerves derelop by the outgrowth of the axis-cylinder processes of the motor 
nerve-cells of the brain, and thus correspond in manner of development with the spinal motor fibers, there is a modification as to their point of emergence from the central axis. Instead of issuing in line with the spinal motor roots, there are two sets of cranial motor roots, the ventral and the lateral. Both arise from the cells of the ventral zone of the neural tube and thus correspond in point of origin with the spinal motor fibers, but the cells from which proceed the fibers of the ventral roots are situated in the ventral part of this zone, whereas the parent cells of the lateral roots lie near its dorsal edge, close to the deep connections of the sensory fibers. It happens therefore that the lateral roots emerge in elose proximity to the dorsal or sensory bundles, the two apparently constituting one nerve-trunk. The motor fibers of the fifth, seventh, ninth, and tenth nerves have this lateral position, and are so elosely idlentified with the sensory fibers that the two sets form one trunk in each case.

The ventral motor nerve-roots emerge in line with the ventral or motor roots of the spinal nerves. The only cranial nerves which represent persistent ventral motor roots are the abducens and the hypoglossal.

A still further modification in the eranial nerres is presented by their relation to the segmentation of the head. As pointed out above, the segmentation of the spinal part of the neural crest is in correspondence with the segmentation of the trunk, and each spinal nerve therefore may be regarded as belonging to a particular segment of the trunk. In the case of the cranial nerves, however, there is no such regular correspondence, since in some instances, several nerves are referred to one head-segment, while in others, one nerve belongs to several sogments. An example of the latter is furnished by the hypoglossal, which arises from the side of the medulla by a series of bundles of fibers which are referable to several segments.

As will be scen later, in the account of the development of the nose and of the eye, the olfactory and optic nerves exhibit rertain peculiarities which set them apart from the other cranial nerves. 
From what has been said, it will be apparent that the cranial nerres develop in a far less regular manner than the spinal nerves, and that eonsequently their trunks consist in some cases of only sensory fibers, in other cases of only motor fibers, and in still others, of both varieties. Typically, each cranial nerve would have a dorsal sensory root with a ganglion, and two motor roots, one lateral and the other ventral. But by the suppression of one or two of these typical roots there will be produced a nerve, for example, representing only the ventral root, as the sixth and twelfth nerves, or a trunk containing sensory and lateral motor fibers, as the vagus, or a nerve consisting solely of sensory fibers, as the auditory.

By way of recapitulation the eranial nerves may be briefly considered seriatim :

First Pair.-The olfactory nerve-filaments grow centripetally from the olfactory epithelium of the nasal mucous membrane.

Second Pair.-The optic nerve is not a true nerve (see Chapter XVI.).

Third Pair.-The oculomotor nerve represents a persistent lateral motor root of the first head-segment (the ophthalmic division of the fifth nerve being the sensory root of the same segment).

Fonrth Pair.-The trochlear nerve represents a lateral motor root and belongs to the second head-segment.

Fifth Pair.-The trifacial or trigeminal nerve, containing sensory and motor fibers, represents a persistent lateral motor root and a dorsal sensory root. The ophthaluic portion of the sensory root belongs to the first head-segment, while all the remaining fibers, with the fourth nerve, are assigned to the second segment.

Sixth Pair.-The abducens develops as a ventral motor root and belongs to the third and possibly to the fourth segments.

Seventh and Eighth Pairs.-The aeusticoficialis nerve, or the facial and anditory nerves, develop as a single nerve with several roots. The anditory nerve and the sensory fibers of 
the facial-that is, the pars intermedia-correspond to a dorsal sensory root, the division of the acusticofacial gangiion into the several ganglia of the auditory nerve and the geniculate ganglion of the facial accounting for the division of the root into the auditory trunk and the pars intermedia. (The sensory tibers of the facial pass off through the chorda tympani to go to the tongue as special-sense fibers.) The motor fibers of the facial develop as a lateral motor root, originating from cells in the ventral zone. These two nerves, with the sixth, belong to the third and possibly to the fourth headsegments.

Ninth Pair.-The glossopharyngeal nerve, made up largely of sensory fibers, represents a dorsal sensory root and a lateral motor root, the fibers of which latter grow out from cells in the dorsal part of the ventral zone of His, the later nucleus ambiguus. It belongs to the fifth head-segment.

Tenth Pair.-The vagus develops in the same manner as the glossopharyngeal.

Eleventh Pair.-The spinal accessory represents in part motor spinal roots and in part probably the lateral motor and dorsal sensory roots of the eranial nerves.

Twelfth Pair.-The hypoglossal develops as the ventral motor roots of several segments, being identical in mode of origin with the anterior roots of the spinal nerves. This nerve and the vagus belong to the head-segments from the sixth to the tenth inclusive.

\section{THE DEVELOPMENT OF THE SYMPATHETIC SYSTEM.}

There are two views as to the origin of the sympathetie system. One theory, based upon the investigations of Paterson, is that the gangliated cord of the sympathetic is differentiated from mesodermie cells, the cell-cord thus formed acpuiring, secondarily, connections with the spinal nerves, and presenting still later the enlargements which constitute the ganglia.

The more generally accepted view, based upon the researches of Balfour and the later work of Onodi and His, is that the sympathetic ganglia develop as offishoots from the 
ventral extremities of the spinal ganglia. Each little mass, which has budded off from a spinal ganglion, moves somewhat toward the ventral surface of the body, its bond of union with the parent spinal ganglion being drawn out to a slender cord, the representative of the future ramus communicans. Each primitive sympathetic ganglion sends out two small processes, one growing tailward from its lower extremity, and one in the opposite direction from its upper end, the approaching processes from each two adjacent ganglia meeting and uniting and thus secondarily establishing the connection between the different ganglia of one side of the body and forming the gangliated cord of the sympathetic. From these ganglia migrating cells probably pass out to develop into the secondary ganglia of certain viscera, as His has shown to be the mode of origin of the ganglia of the heart. 


\section{CHAPTER XVI.}

\section{THE DEVELOPMENT OF THE SENSE ORGANS.}

In the organs of the senses we have to do with peripheral nervous mechanisms of greater or less degrees of complexity, the essential elements of which are elaborately modified or specialized neuro-epithelial cells. These neuro-epithelial structures are specialized cells of the ectoderm, derived from it either directly, by the infolding of patches of ectodermic epithelium, as in the case of the olfactory cells, or indirectly, by growth ontward from the central nervons system, as in the case of the retina. The organs of the sense of touch, the tactile corpuscles of the skin and mucous membranes, are distributed somewhat irregularly, while such highly specialized structures as the organs of the special senses of vision, hearing, smell, and taste are provided with special protective and accessory apparatuses.

\section{THE DEVELOPMENT OF THE EYE.}

It will perhaps facilitate the comprehension of the general principles involved in the development of the eye if its function as the organ of vision is kept in mind, and if, therefore, the retina and the optic nerve are recognized as the essential parts of the organ, and the other structures as accessories. The retina and the optic nerve are an outgrowth from the brain, the rod-and cone-visual colls of the former being epithelial cells so specialized as to serve as percipient elements, while the optic nerve-fibers are the conducting medium. 'To allow of the penetration and refraction of the rays of light, the overlying epirlermis differentiates into a transparent and refractive medium, the crystalline lens, and the necessary protection and means of nourishment 
are provided by the other constituents of the eyeball. Further protection is furnished by two folds of modified skin and subcutaneous tissue, the eyelids, and lastly for the lubrication and still further protection of the exposed part of the eyeball, there is formed still another set of aecessory organs, the lacrimal apparatus.

The first step in the development of the eye is the growth of a diverticulum from the side of the primary fore-brain vesicle (Fig. 144). These optic eraginations are quite large
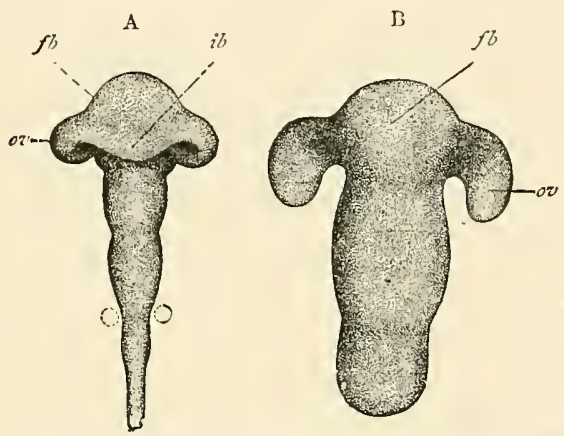

FIG. 144.-A, brain of two-day chick-embryo; B, brain of human embryo of three weeks (His). Shows the development of the optic vesicles and brain-resicles; $f b$, fore-brain; $i b$, inter-brain; ov, optic vesicles.

as compared with the brain-vesicle. They begin to be evident even before the neural tube is completely closed. As the attached part of the diverticulum expands less rapidly than the distal portion, the evagination soon assumes the form of a sac or resicle, the optic vesicle, connected by a hollow stalk with the primary fore-brain. When the secondary fore-brain vesicles grow out anteriorly from the primary vesicle, the region of the latter that becomes in consequence the inter-brain is the part to which the stalk of the optic resicle is attached. Hence the optic vesicle is an appendage of the inter-brain or thalamencephalon and its point of attachment to the latter is at the lateral part of the base, in front of the region of the infundibulum (Fig. 131, A and C).

The optic vesiele expands laterally and dorsally until it lies immediately beneath the epidermis, forming a promi- 
nence on the side of the head (Fig. 51). The ectoderm at the point of contact with the optic vesicle becomes thickened and depressed, the differentiation of this lens-area being the starting point of the crystalline lens. The depressed patch of ectoderm, sinking more deeply, is eonverted into a sae, the lens-vesicle, the comnection of which with the surfacecells is soon lost. The distal wall of the optic vesicle, upon coming into contact with the lens-resicle, undergoes invagination, this wall sinking in until the eavity of the vesicle is almost obliterated. Thus the vesicle is converted into the double-rvalled optic cup, the opening of which looks laterally toward the surface of the head, and is oceupich by the lensvesicle.

The invaginated wall of the vesicle-that is, the layer nearer the center of the enp-becomes the retina, except its pigment-layer, the latter resulting from the outer layer of the cup. The stalk of the eup beeomes the optic nerve. The surrounding mesodermic tissue grows into the openings referred to above, and gives rise to the vitreous humor, while the mesodermic cells that elosely envelop the optic cup produce the uveal tract and the sclera and cornea.

Having traced briefly the development of the organ, its several parts may now be considered in detail.

The Retina and the Optic Nerve.-These two structures, as stated above, are directly derived from the optic vesicle and its stalk.

To repeat, for the sake of eontinuity, some points already mentioned, the optic vesicle grows forth as a divertienlum from the side of the primary fore-brain veciele, its appearance being foreshadowed by a lateral bulging of this vesicle even before the neural canal is eompletely closed. When the primary fore-brain vesicle divides into the secondary fore-brain vesicles and the vesicle of the inter-brain, the region of origin of the optic vesicle falls to the latter, the print of attachment being at the outer edge of the base of the vesiele in front of the infundibular evagination. The optic nerve is to be regarded therefore as springing from the inter-brain or thatamencephaton. 
The onter extremity of the diverticulum expanding more rapidly than its base of attachment assumes the form of a vesicle with a narrow stalk (Fig. 145), the stalked condition

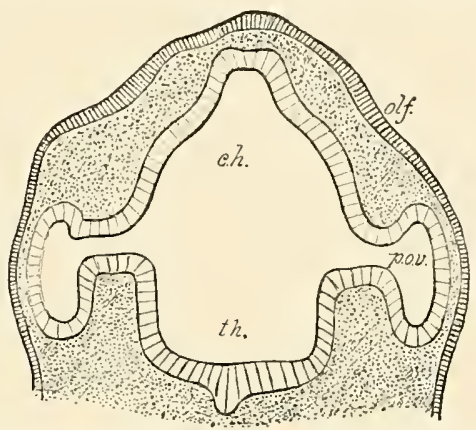

Fig. 145.-Part of a section through the head of an early human embryo, showing the connection of the primary optic vesicles with the fore-brain (His): olf, olfactory area of epiblast; $c . h$. , part of fore-brain which gives rise to eerebral hemispheres; th, thalamencephalon; p.o.v., primary optic vesicles.

being present in the fourth week. The resicles grow in the outward direction and form a prominence on each side of the head. There being no brain-case at this time, they lie imme-

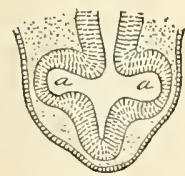

1

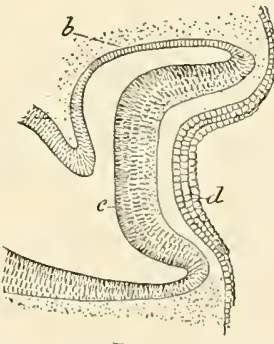

$B$

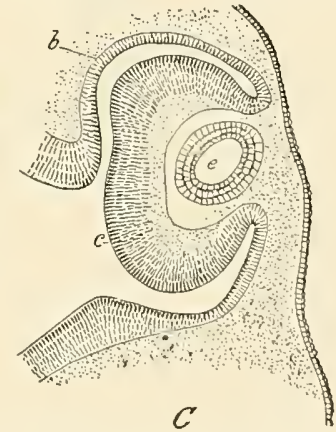

$C$

FIG, 146.-Three successive stages of development of the eye, showing formation of secondary optic cup and crystalline lens in human embryos of $4 \mathrm{~mm}$. (A), $6 \mathrm{~mm} .(B)$, and $8 \mathrm{~mm} .(C)$, (Tourneux) : $a, a$, primitive optic vesicies; $b$, external layer of secoudary optic cup (future pigment-layer of retina) ; $c$, immer layer of cup (retina proper); $d$, lens-pit (thickened and depressed ectoderm) ; $e$, lens-vesicle.

diately under the epidermis, separated from it by only a thin layer of embryonal connective tissne. This lateral position of the optic vesicles is characteristic of the early stages of derelopment. After the end of the first month the eyes 
gradually move forward and downward toward their permanent position, which is approximately attainced probably early in the third month.

Shortly after the fourth week the distal or lateral wall and the under surface of the optic vesicle bceome invaginated. The invagination begins when the vesicle comes into contact with the lens-resicle (Fig. 146). When the infolding is complete, the vesicle has become the secondary optic cup, which latter consists therefore of two layers, an inner and an outer. The mouth of the eup, which faces away from the median plane of the head, is oecupied by the lens-vesicle. Since the under surface of the vesicle participates in the invaginating process (Fig. 147) there is also in this wall of the eup an aperture, which is known as the choroidal fissure. The invagination likewise affects the under surface of the tubular stalk of the vesiele so that it is converted into an inverted donble-layered trough. These invaginations bear an

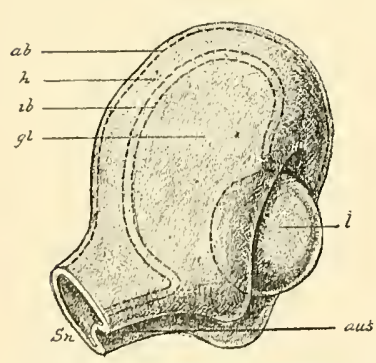

Fig. 147.-Plastic representation of the optic eup with lens and vitreous body (Hertwig): $a b$, outer wall of the eup; ib, its inner wall; $h$, eavity between the two walls, whieh later disappears entirely; Sn, fuudament of the optie nerve (stalk of the optie vesicle with a furrow on its lower surfaee); aus, optie (ehoroid) fissure; $g l$, vitreous body; $l$, lens. important relation not only to the further metamorphosis of the optie vesicle and its stalk into the retina and the optic nerve, but also to the development of the vitreons body and of the eentral artery of the retina. Thus, the vitreous body is produced by the mesodermic tissue that finds access to the cup through the choroidal fissure, and the arteria centralis retine is developed in the vasenlar mesodermie tissue that invaginates the under surface of the stalk of the vesicle.

The ehoroidal fissure gradually contracts after the entrance of the mesorlerm, and in the last month of fetal life it entircly closes. The month of the optic eup embratees the lens, its rim being always on the distal side of, or superficial to, that strueture. This opening represents the pupil of later stages. 
The further metamorphosis of the optic cup includes alterations peculiar to each of the two layers and also to the different regions of the cup. The mouth of the cup contracts somewhat by increased growth of the wall, and thus there is a zone bordering this orifice which is anterior to the lens, holding the same relation to the latter body that the future iris holds. A second zone corresponds with the periphery of the lens, while a third region, the fundus of the cup, includes all the remaining part of its wall.

The fundus of the cup undergoes much greater specialization than the other regions. The outer layer of the cup remains thin, consisting of a single layer of cells which assume the cuboidal form and become infiltrated with pigment-granules. This forms the pigment-layer of the retina. The inner lamina of the cup thickens, by the multiplication of its cells, and soon consists of numerous spindle-shaped cells. The thickened fundus is marked off from the zone that surrounds the periphery of the lens by a slight groove which corresponds in position with the future ora serrata. These early spindle-cells give rise to two kinds of elements, the stroma of the retina, or Müller's fibers, and the various nerve-cells, including the highly specialized rod- and cone-visual cells.

The principal sustentacular elements, or Müller's fibers, like the spongioblasts of the neural tube, are radially arranged and extend throughout the entire thickness of the retina. Their inner expanded extremities, in close contact with each other, form the inner limiting membrane, while their outer ends, in the same way, constitute the outer limiting membrane, which latter is in contact with the pigmentlayer. The stroma of the retina receives a small contribution from the mesodermic tissue, which grows into it throngh the choroidal fissure to furnish the raseular supply.

Of the nerve-cells, those near the pigment-layer undergo great alteration in form and become the sensory epithelium -that is, the rod-and conc-visual cclls. At first these lic entirely internal to the external limiting membrane, which separates them from the pigment-layer. After a time, however, processes grow out-that is, away from the center of 
the eyeball-and perforate the external limiting membrane to penetrate between the cells of the pigment-layer. These processes are the rods and cones, and collectively constitute the layer of rods and cones of the adult. The bodies of the

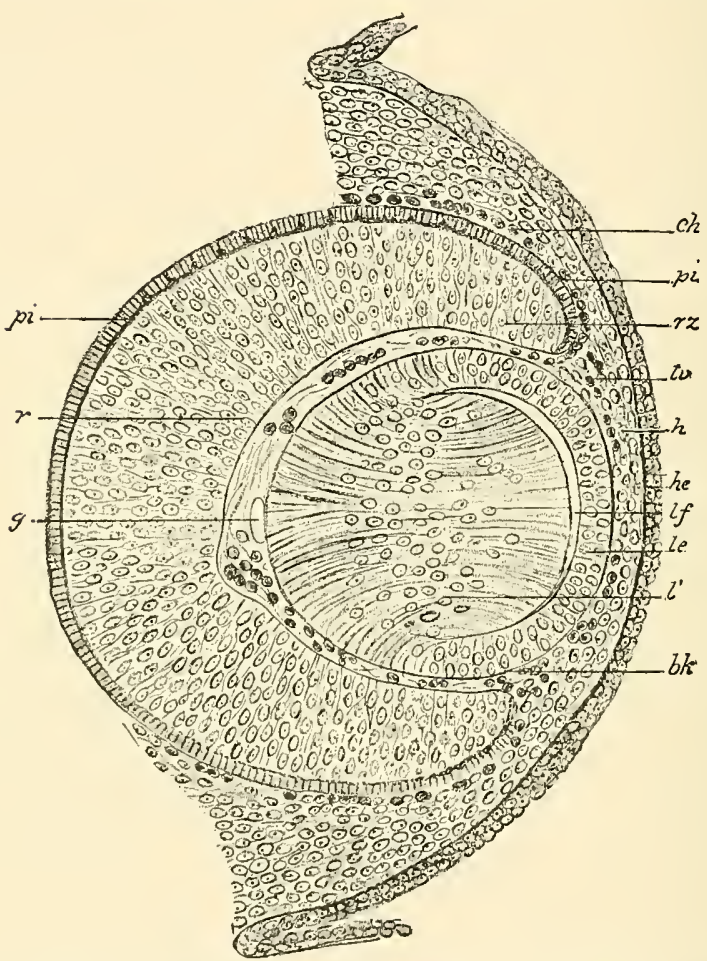

FIG. 148.-Section through the optie fundament of an embryo mouse (after Kessler): $p i$, ligmented epithelium of the eye (outer lamella of the optic cup, or secondary optic vesicle) ; $r$, retina (inner lamella of the optic cup); rz, marginal zone of the optic eup, which forms the pars ciliaris et iridis retinx; $g$, vitreous body with blood-vessels; $t v$, tunica vasculosa lentis; $b k$, blood-eorpuseles; $c h$, choroidea ; lf, lens-fibers; le, lens-epithelium; $l^{\prime}$, zone of the lens-fiber nuclei; $h$, fundament of the cornea; he, external corneal epithelium.

rod-and cone-visnal cells, sitnated on the inner side of the membrana limitans externa, are clongated into narrow elements, the position of the nuclei being indicated by slight anlargements. They constitnte the outer nuclear layer of the mature retina. The outer nuclear layer and the layer of 
rods and cones are to be regarded, therefore, as one layer of highly specialized neuro-epithelium, made up of the rodvisual cells and the cone-visual cells, the inner segments or bodies of the cells being only apparently isolated from the outer segments, the rods and cones respectively, by the fact that the latter project through minute apertures in the external limiting membrane. The axis-cylinder processes of these cells pass toward the center of the eyeball.

The neuro-epithelium of the retina is the last of its elements to develop. In man and in many mammals, it is present at birth. In the cat and the rabbit, the rod-and cone-risual cells develop after birth, and hence the new-born of these species are blind. The macula lutea is developed after birth.

The cells of the inner part of the retina differentiate into the remaining nervous elements, some becoming the bipolar and other cells of the inner nuclear layer-the ganglion retine-while others form the large ganglion cells of the ganglion-cell layer. The axis-cylinder processes of the ganglion cells are directed inward to form the nerve-fiber layer, the fibers of this layer converging from all parts of the inner surface of the retina toward the optic disk or papilla. Here they perforate the retina, as well as the choroid and selera, to pass, as optic nerve-fibers, to the brain.

This part of the optic eup, the fundus, produces then, in the manner described above, the functionating portion of the retina, or the pars optica retinæ, the anterior termination of which is indicated by the orra serrata.

The lenticular zone of the optic cup, which is in relation with the periphery of the lens, undergoes comparatively slight specialization. Its outer lamella is pigmented, as in the fundus of the cup. Its inner layer remains very thin and consists of cells which at first are cuboidal, but which later become cylindrical. At the end of the second month, or the beginning of the third, the two layers of the lentienlar zone become plicated, owing to excessive growth in superficial extent. The folds are nearly parallel and are arranged radially with reference to the lens, the margin of which they surround. These folds are the first indication of the ciliary 
processes. The mesodermic tissue immediately external to the optic cup differentiates into the uveal tract, the part corresponding with the lenticular zone of the cup furnishing the ciliary body. The young growing connective tissue penetrates between the folds of the lenticular zone of the enp, aequiring intimate union with the pigment-layer, and thus provides the connective-tissue basis of the ciliary processes. This lenticular zone of the two layers of the optic cup, therefore, constitutes the lining, or intemal covering, of the ciliary body, and must necessarily be regarded as the continuation of the retina. It is known as the pars ciliaris retinæ of the fully developed eyc.

The marginal zone of the optic cup, or the region bordering its orifice, is also related in its further growth with the uveal tract. Although in the earlier stages of development the lens lies in the month of the cup, as time goes on the relation is so altered that the aperture and the zone which borders it oceupy a position in front of the lens. In this marginal zone both lamellæ of the eup become pigmented and acquire union with the layer of mesodermic tissue which is differentiating into the iris, and they therefore contribute to the formation of that structure, constituting its pigmentlayer. The pigment-layer of the posterier surface of the iris is, therefore, an extended but rudimentary part of the retina. It is called the pars iridica retinæ.

From what has been said, it will be apparent that the retina forms a complete tunic with an anterior perforation, the pupil, and that it consists of the functionally active part, or retina proper, the pars optica retinæ; of the pars ciliaris retinæ, marked off from the latter by the ora serrata; and of the pars iridica retinæ, which terminates at the margin of the pupil.

The evolution of the optic cup or secondary optic vesicle may be thus summarized :

I. Marginal or most anterior region of cup.

II. Lenticular zone of cup.

The thin atrophic pars iridica retinæ, or pigment-layer of the iris.

Par's ciliaris retina, covering inner surface of ciliary body. 
III. Fundus of cup.

A. Outer layer.

B. Inner layer.
Functionating part of retina, or pars optica retinæ, including :

A. Pigment-layer of retina.

B. 1. Neuro-epithelial layer, made up of layer of rods and cones (the processes of the rod-and cone-visual cells) ; membrana limitans externa; outer nuclear layer (the bodies of the rodand cone-cells).

2. Cerebral layer (representing an interpolated ganglion with connecting fibers), consisting of :

Outer reticnlar layer;

Inner nuclear layer;

Inner reticular layer;

Ganglion-cell layer;

Nerve-fiber layer.

The optic nerve is the metamorphosed stalk of the optic vesicle. When the distal and under surfaces of the vesicle suffer invagination, the stalk participates in the process, its under surface being marked by a groove which is a prolongation of the ehoroidal fissure of the optic eup (Fig. 147). By this infolding, the cavity of the stalk is obliterated and the stalk is converted into a double-walled tube enclosing mesodermic tissue which follows the in raginating ventral wall. In this mesodermie tissue is developed the arteria centralis retinæ. In mammals the invagination affeets only the distal part of the stalk, the segment included between the eyeball and the point corresponding in the adult to the place of entrance into the nerve of the eentral artery. It must be apparent that the outer layer of the tube thus formed is directly continuous with the outer layer of the optie cup, while the invaginated lamina is the prolongation of the inner wall of the cup or of the part that beeomes the retina proper, since not only the distal wall of the optic vesicle is invaginated, but its under or rentral wall as well.

The primitive optic nerve at this stage consists of layers of spindle-shaped cells, with a central core of vascular eonnective tissue.

The manner in which the nerve-fibers are developed is 
still a matter of controversy. According to His and Kölliker, the fibers grow ont from the ganglion-cells of the optic thalami and the anterior corpora quadrigemina, while Müller believes that they are the prolonged axis-eylinder processes of the ganglion-cells of the retina. In either case the cells of the optic stalk would furnish only the snstentative tissue of the nerve. There is also a contribution of sustentative tissue or stroma from the mesoderm, as in the case of the central nerrous system.

The Crystalline Lens.-The lens, exelusive of its capsule, is, like the retina, of ectodermic origin. The first step) in its development is the formation of a thickened and depressed patch of the ectoderm on the lateral surface of the head, this area being situated at the place where the optic vesicle is nearest the surface (Fig. 146, $B, d$ ). The depression is the lens-pit. It soon becomes converted into a closed sac, the lens-vesicle, by the gradual approximation and union of its edges. The pit receding from the surface as its lips come together, the completed vesicle lies under the surface ectorlerm, with which it is for a time connected by the slender stalk of the invagination. Upon the disappearance of the strand of cells constituting the stalk, the lensvesicle is completely isolated from the outer germ-layer (Fig. 146, C, e).

The lens-vesicle in birds is a hollow epithelial sac several layers thick, but in mammals the central cavity contains a mass of cells, which latter disappear in the later stages of development.

Upon the invagination of the optic vesicle to form the secondary optic eup, the lens-vesiele is embraced by the lips of the cup and still later eomes to lie within the cup, near its orifice (Fig. 148).

The further alterations in the vesicle are dependent primarily upon changes in its deep and superficial walls respectively, each of which eonsists of several layers of eylindrical eells. The cells of the superficial wall alter their form, beerming cuboidal, while the posterior or deeper eells lengthen so as to becone fibers. Thus the deeper wall of 
the vesicle thickens at the expense of the eentral earity-the central mass of eells at the same time disappearing-while the superficial layer remains thin. The two strata are continuons with each other at the equator of the lens, one form gradually merging into the other at this region, which is a zone of transition (Fig. 148).

The lens at this stage is composed, therefore, of a thin superficial or anterior stratum of cuboidal epithelial cells and a much thicker posterior or deep layer of so-called fibers, the latter being simply the greatly elongated cells of the posterior wall of the vesicle. Between the two laminæ is a small remnant of the cavity of the vesicle. The epithelial layer persists throughout life as the epithelium of the lens, while the fibrous layer is the basis of the lens-fibers of the mature condition. The eavity sometimes persists as a small space containing a few drops of fluid, the liquor of Morgagni.

The next important stage in the development of the lens is the formation of additional lens-fibers. These result from the proliferation of the cells of the epithelial or anterior layer. The lens-fibers are formed in suceessive layers, as may be made evident by the maceration of a lens. Each fiber extends from the anterior to the posterior surface of the lens. The ends of the fibers meet each other along regular lines, producing thus the characteristic three-rayed figures or stars of the lens, one of which belongs to each surface. Hence, while the lens-fibers first formed are the elongated cells of the posterior layer of the lens-vesiele, the fibers of later growth originate from the cells of the anterior wall. The epithelial charaeter of the lens-fibers is evinced by the presence of a nueleus in each fiber of a young lens.

The lens-capsule results from the differentiation of the mesodermic tissue which surrounds the lens. It is from this enveloping vascular lamina, the tunica vasculosa lentis, that the growing lens derives its nutrition. The capsule is well marked in the seeond month. Its blood-ressels are derived from those of the vitreous body. At the end of the serenth month this well-dereloped, highly vascular membrane begins to undergo retrograde alterations, the final result of which is 
its transformation into the thin, non-vascular, transparent capsule of the mature lens. ${ }^{1}$ The most active growth of the lens itself occurs prior to the degeneration of the tunica vasculosa lentis, so that even before the end of fetal life the lens has nearly attained its full size. Thus the weight of the lens of the new-born child is 123 milligrammes, while that of the adult lens is but 190 milligrammes (Huschke).

Hence the crystalline lens has a double origin, the lens-substance or lens proper being derived from the ectoderm, while the capsule originates from the mesoderm.

The Vitreous Body.-The vitreous body, representing a comparatively slightly differentiated form of connective tissue, is derived from the middle germ-layer. The mesodermic tissue, already in the stage of embryonal connective tissue, gains access to the optic cup through the choroidal fissure (Fig. 147), its ingrowth in fact accompanying the invagination of the under surface of the optic vesicle. Since the inferior surface of the stalk of the vesicle-the future optic nerve-participates in the invagination, the mass of mesodermic tissue which gives rise to the vitreous is continuous with that which invaginates the primitive optic nerve to produce the central artery of the retina. As a consequence, the blood-vessels which soon develop so plentifully in the vitreous body are extensions from the central artery of the retina, the latter itself being continued forward as the hyaloid artery. The terminal branches of the hyaloid artery pass on through the vitreous body to terminate in the vascular capsule of the growing lens, constituting the blood-supply of that structure.

The intercellular substance of the young tissue undergoes but little differentiation, while the cells become gradually reduced to a few stellate elements which ultimately entirely disappear. The peripheral part of the tissue develops into

'It sometimes happens that parts of the fetal lens-capsule persist. 'The most common example of such persistence is the so-called membrana pupillaris sometimes present at birth, producing congenital atresia of the pupil. This results from the persistence of that part of the fetal capsule which is situated on the anterior surface of the lens, behind the pupil. 
the hyaloid membrane, which anteriorly acquires union with the capsule of the lens.

The blood-vessels of the vitreous disappear during the last two or three months of fetal life. The hyaloid artery persists, although in reduced form, for a longer time than the smaller vessels. Upon its final degeneration it is replaced by a canal, the hyaloid canal, or canal of Stilling, which is present in adult life.

The Middle or Vascular and the Outer or Fibrous Tunics of the Eye.-The outer fibrous coat of the eye, including the sclera and the cornea, and the middle tunic or uveal tract, comprising the choroid, the ciliary body, and the iris, are structures of mesodermic origin, being directly produced by the mesodermic tissue surrounding the optic cup. The richly cellular mesoderm applies itself to the exterior of the eup and differentiates into the two layers in question, the changes involving on the one hand the metamorphosis of the mesodermic cells chiefly into muscular and vascular elements, and on the other hand the evolution of a tissue essentially fibrous in structure. These two tunies are distinguishable in the sixth week.

The cornea is formed from the thin layer of mesoderm that penetrates between the lens-vesicle and the surface ectoderm. The lens-vesicle lies very near the surface, and the thin stratum of mesoderm that is interposed between the two is the anterior layer of the lens-capsule (Fig. 148). This anterior layer thickens by the immigration of other cells and subsequently splits into two laminæ, a superficial one which produces the cornea (Fig. 148, h), and a deeper, which is now the proper anterior wall of the lens-capsule. Thus a space filled with fluid appears between the primitive cornea and the lens, which corresponds with the future anterior and posterior chambers of the eye, the division of the space into these two chambers being effected subsequently by the development of the iris. The further development of the cornea consists simply in the differentiation of the mesodermic cells and the intercellular substance into the several characteristic elements of the adult structure. 
The uveal tract closely corresponds in extent with the two layers of the optic cup. The choroid is differentiated from that portion of this primitive uveal tract which envelops the pars optica of the retina. In this region the enveloping layer of mesodermic cells develops into the several elements of the choroid, the most conspicnous of which are an inner layer of capillary vessels, the choriocapillaris, and an outer layer of larger vessels, the stroma-layer of the choroid. The development of the choroid bears a certain relation to the choroidal fissure of the optic cup. This fissure has been referred to as a gap in the under surface of the cup corresponding with the line of invagination through which the mesodermic tissue, of which the developing choroid is a part, grows into the cup to produce the vitreous. Althongh normally this fissure in the retina entirely disappears, its site becomes pigmented later than other regions of the pigmentlayer of the retina, and hence there is, for a time, a clear streak in this part of the retina which has the appearanee of a fissure in that membrane. As the pigment-layer of the retina was formerly assigned to the choroid, this streak appeared to be a breach of continuity of the choroid; hence the term choroidal fissure. In some cases, however, the choroidal fissure fails to close, and as the development of the choroid is largely dependent upon or is govemed by that of the retina there remains a corresponding gap in the choroid. This defect enables the sclera to be seen from the interior in a line extending forward from the optic nerve entrance. It is known as coloboma of the choroid.

The ciliary body is developed immediately in advance of the choroid and from the same layer of mesodermic tissue. The leeper parts of the tissue in this region correspond with the plications of the ciliary part of the retina, sending processes into and hetween the radial folds of this part of the two layers of the optic cup, with which latter the highly vascular mesodernic tissne acquires firm union. This results in the formation of the eiliary processes. Some of the cells of the more peripheral part of this zone are converted into unstriated muscular tissue, thus producing the ciliary muscle. 
All the characteristic or important elements of the eiliary body are, therefore, derived from the mesoderm, while the thin layer of tissue on its inner surface, representing an undeveloped part of the optic cup, the pars ciliaris, is of ectodermic origin.

The iris, the most anterior zone of the uveal tunic, is produced from the same mesodermic tract that gives rise to the

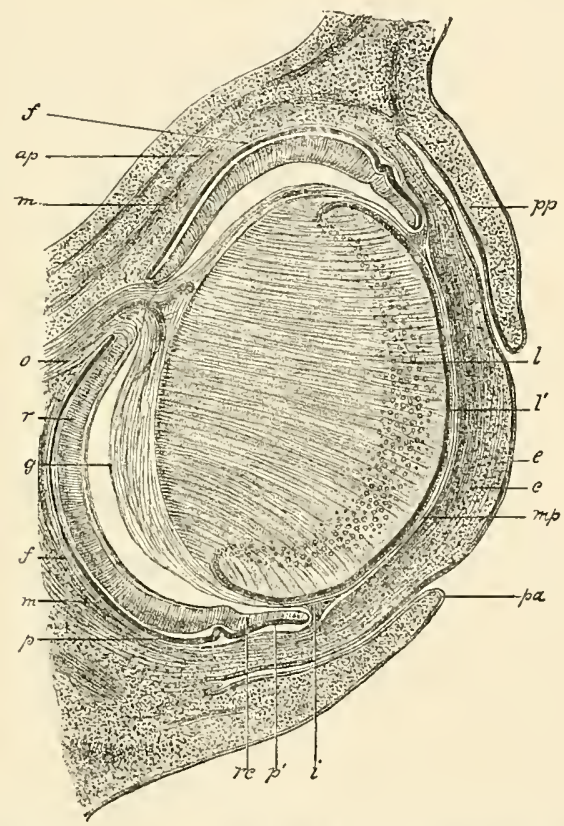

Frg. 149.-Sagittal section through the eye of an embryo rabbit of eighteen days $\times 30$ (Kölliker): o, optie nerve; $p$, hexagonal pigment-layer; $r$, retina; $r$, eiliary part of the retina; $p^{\prime}$, forepart of the optie cup (rudiment of the iris-pigment); $g$, vitreous, shrunk away from the retina, except where the ressels from the arteria centralis retinæ enter it; $i$, iris; $m p$, membrana pupillaris; $c$, cornea with epithelium $e$; $p p, p a$, palpebræ; $l$, lens ; $l$, lens-epithelium ; $f$, sclerotic ; $m$, reeti muscles.

choroid and to the ciliary body. As stated above, soon after the lens-resicle becomes constricted off from the surface ectoderm, it is enveloped by a mass of mesodernic cells which constitute its primitive eapsule, and the layer of these cells lying between the lens-resicle and the surface ectoderm splits into an anterior layer, which becomes the cornea, and a pos- 
terior stratum which is the anterior wall of the lens-capsule. This produces a space between the lens and the cormea. The lens now recedes farther from the surface, and the margins of the optic cup advance, so that the lens now lies within the cup, the marginal zone of the cup being in front of the lens, between it and the cornea, while its equator is in close relation with the ciliary regions of the cup and of the uveal tract. Thus the space between the lens and the cornea is divided into an anterior compartment, the anterior chamber, and a posterior space, the posterior chamber, the orifice of the cup being a means of communication between the two and representing the pupil of a later stage. The marginal zone of the cup furnishes the guiding line for the development of the iris. The mesodermic tissue in relation with the outer surface of the marginal zone of the cup differentiates into the vascular, muscular, and connective-tissue elements of the iris proper, while its posterior pigment-layer is constituted by the slightly specialized layers of the most anterior part of the optic cup, the part that is known as the pars iridica retinæ.

Since the anterior and posterior chambers of the eye are spaces hollowed out of the mesorlerm, they represent a lymph-space and are, as such, lined with endothelial cells.

The cleft in the inferior wall of the optic eup referred to above as the choroidal fissure necessarily affects the marginal zone of the eup as woll as the region posterior to it. If this part of the fissure persists, as it sometimes does, it may be accompanied by a corresponding defieieney in the tissues of the iris proper. Such a congenital defect, appearing as a radial cleft in the lower half of the iris, is known as coloboma of the iris.

The Eyelids and the Iacrimal Apparatus.-The eyelids are developed from folds of the primitive epidermis that form over the superficial part of the developing eyedall (Fig. 149, $p$, and $p a$ ). After the separation of the lons-vesicle from the surface ectoderm, the latter ponches out into two little transverse folds for the upper and lower lids respectively. Fach fold includes al certain quantity of 
mesodermic tissue, from which are produced the connectivetissue elements of the lids, as the tarsal plates, ete. After the folds attain to a certain degree of development their edges approach each other and become adherent, thus enclosing a space between the primitive lids and the front of the eyeball. The infolded ectodermic layers lining this space acquire the characteristic features of mucous membrane and constitute the epithelium of the conjunctiva, the part of this membrane that covers the cornea adhering closely to that structure as its anterior epithelial layer. The union of the edges of the lids begins in the third month and lasts until near the close of fetal life. A short time before birth the permanent palpebral fissure begins to form by the breaking down of the adhesions.

A part of the mesodermic tissne of the lids undergoes conversion into fibrous connective tissue, thus producing the tarsal plates of the upper and lower lids, with the palpebral fasciæ and tarsal ligaments by which the plates are attached to the margins of the orbit.

During the period when the edges of the lids are adherent, the Meibomian glands and the eye-lashes are formed. The glands develop from solid cords of epithelial cells that grow from the deepest or Malpighian layer of the primitive epidermis into the tarsal plates. The cords become hollow tubes by degeneration of their central cells.

In addition to the two principal folds that produce the lids, a third, vertical fold appears at the inner, nasal side of the conjunctival space, beneath the lids. This fold remains quite small in man and forms the plica semilunaris, but in most other vertebrates it attains much greater size as the third eyelid or nictitating membrane. A small part of this third fold develops sebaceous glands and a few hair-follicles and becomes the lacrimal caruncle.

The lacrimal gland is developed in the same mamner as the Meibonian glands, by the growth of solid epithelial cords from the conjunctiva. 'The cords grow into the underlying mesoderm at the outer part of the line of reflection of the conjunctiva from the inner surface of the upper lid to the 
front of the eyeball. The cords acquire lateral branches and then become hollowed out to form the secreting tubules and efferent ducts of the gland, the connective-tissue stroma of which is contributed by the surrounding mesodormic tissue. The orifices of the adult efferent ducts in the upper outer part of the conjunctival sac correspond with the points from which the primitive cell-cords first grow forth.

The efferent lacrimal apparatus, consisting of the nasal or lacrimal duct and the canaliculi, is related genetically to the growth of the nose and the upper jaw. Soon after the appearance of the nasofrontal process, a lateral projection, the lateral nasal process, grows from its side near the base and advances downward so as to form the outer boundary of the nasal pit and consequently of the future nostril (Fig. 56, A, B). This lateral nasal process is separated from the maxillary process of the first visecral arch by an oblique furrow, the naso-optic groove, which extends from the inner angle of the orbit to the outer side of the nostril, or, before the separation of the nasal pit from the primitive month, to the upper boundary of the latter orifice. The naso-optic groove indicates the situation of the lacrimal duct. By some authorities-Coste and Kölliker-it is believed that the duct results from the union of the edges of the groove. Later investigations seem to indicate, however, that the duct is formed by the hollowing out of a solid cord of epithelial cells that appears at the bottom of the furrow. In either case the epithelial lining of the duct is an cetodermic involution. When the nostrils are separated from the oral aperture by the union of the nasofrontal, the lateral nasal, and the maxillary processes (p. 121), the lower end of the furrow is obliterated, and the partially formed duet is made to terminate in the masal cavity.

The canaliculi, representing the bifurcated upper extrenity of the duct, result, according to one view, from the division of the upper end of the epithelial cord into two limbs, one for each lirl, and their subsequent hollowing-out; aceording to another, from the continuation of the cell-cord into the upper lid and the later addition of a limb for the 
canaliculus of the lower lid. The lacrimal sac is merely an expanded part of the duct.

\section{THE DEVELOPMENT OF THE ORGAN OF HEARING.}

As in the case of the other sense-organs, the auditory apparatus consists of highly specialized neuro-epithelium, connected by nerve-fibers and interpolated ganglia with the central nervous system, and of protective and auxiliary structures. The neuro-epithelial structures, including the organ of Corti and the cells of the cristæ and maculæ acusticre, result from the specialization of certain of the epithelial cells which line the membranous labyrinth. The perilymphatic space, which is a lympl-space, together with its bony walls, the osseous labyrinth, serve for the protec-

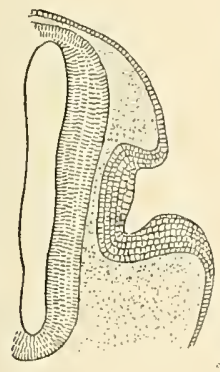

$A$

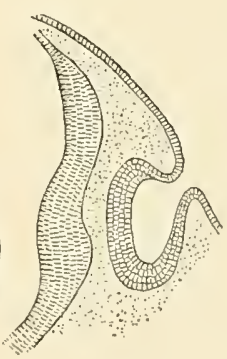

B

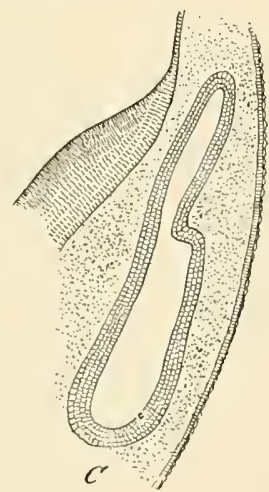

C

FIG. 150.-Three transverse sections showing development of otic vesicle of human embryo (Tourneux): $A$, from embryo of $3 \mathrm{~mm}$, showing auditory pit; $B$, from embryo of $4 \mathrm{~mm}$, showing the transformation of the pit into the otic resicle; $C$, from enbryo of $6 \mathrm{~mm}$, showing otic resicle detached from surface ectoderm, and presenting a posterior diverticulum, the recessus vestibuli.

tion of the delicate nemral elements, while the middle ear and the external ear act as media for the conduction of sonorous vibrations.

The internal ear being the essential part of the organ of hearing and being also the part first formed may properly receive first consideration.

The Internal Ear.-The membranous labyrinth of the 
internal ear is the oldest part of the organ of hearing. Its origin is from a thickened circular patch of ectoderm on the dorsolateral surface of the head-region of the embryo near the dorsal termination of the first outer visceral furrow. The thickened area sinks below the surface, forming thus the auditory pit, which is present in the third week (Fig. 150, A). The pit becomes decper, its edges approach each other and finally meet and unite to form the otic vesicle or otocyst. This little epithelial sac gradually recedes from the surface ectoderm. At this stage of development there is no eranial capsule other than the indifferent mesodermic tissue which surrounds the brain-vesicles; hence, the otic vesicle, em-
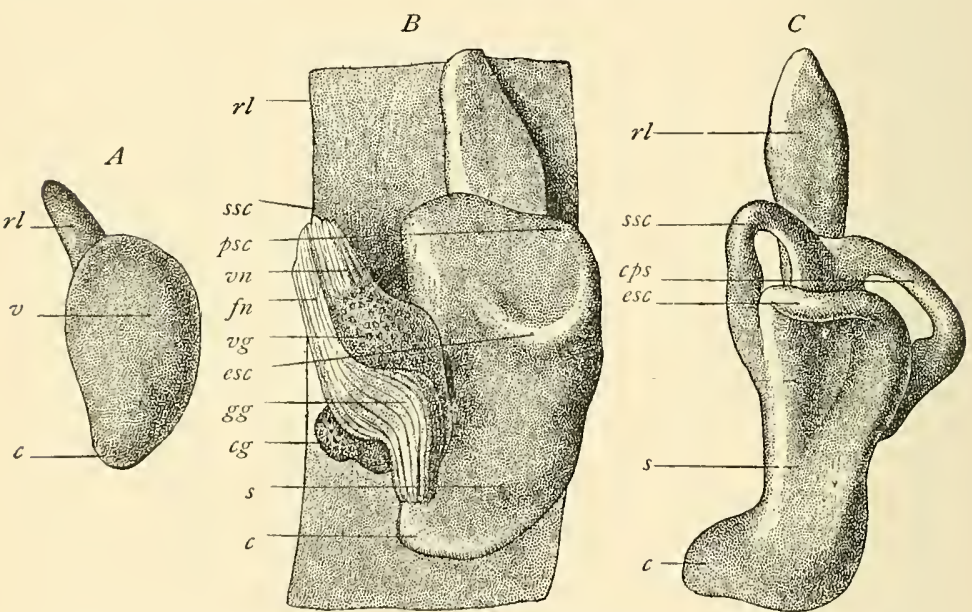

FIG. 151.-Development of the membranous labyrinth of the human ear (W. His, $J$ r.): $A$, left labyrinth of embryo of about four weeks, outer side; $v c$, vestibular and cochlear portions; $\%$, recessus labyrinthi. $B$, left labyrinth with parts of facial and auditory nerves of embryo of about four and a balf weeks ; $r l$, recessus labyrinthi : sse, psc, $c s c$, superior, posterior, and external semicircular eanals; $s$, saceule; $c$, cochlea; $v n, f n$, vestibular and ficial nerves; $v g, r g, g g$, vestibular, coehlear, and genieulate ganglia. C, left labyrinth of embryo of about five weeks, from without and below; labelling as in preceding figure.

bedded in this tissue, lies in elose proximity to the afterbrain, and eomes into relation with the acusticofaeial ganglion (p. 297). The vesiele, at first spherical, soon becomes pear-shaped owing to the protrusion of its dorsal wall. This dorsal projection, the recessus vestibuli or labyrinthi (Fig. 
$150, C)$, lengthens out into a slender tube, the ductus endolymphaticus (Fig. 152), the slightly dilated end of which, the saccus endolymphaticus, is found in the adult occupying the aqueductus vestibuli of the temporal bone.

The opposite, anterior or ventral extremity of the otic vesicle also bulges out into a small evagination, which gradually elongates until it is a tapering tube, slightly eurved inward toward the median plane. This lengthens still more and becomes spirally coiled, forming the cochlear duct or scala media of the future cochlea (Fig. 152). The vesicle itself becomes constricted in such manner by an inward projection of its wall as to indicate its division into an upper larger and a lower smaller sac, the terms upper and lower referring respectively to the head-end and the tail-end of the embryonic body. Before the constriction occurs, the wall of that part of the resicle which is to become the future upper or utricular division presents two pouched-out areas (Fig. 151, B). One of these gives rise to the external semicircular canal, while from the other are formed the superior and posterior canals. The pouch that produces the external

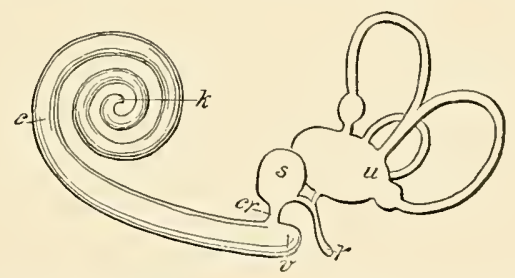

FIG. 152.-Diagram to illustrate the ultimate condition of the membranous labyrinth (after Waldeyer) $: u$, utriculus; $s$, sacculus; $c r$, canalis reuniens; $r$, ductus endolymphaticus; $c$, cochlea; $k$, blind sac of the cupola; $v$, restibular blind sac of the ductus cochlearis.

canal is semicircular in form and flat, lying in the horizontal plane, its upper and lower walls being in contact with each other. The opposed walls fuse, except at the periphery of the pocket, and hence all that remains of its carity is a small marginal tube or channel, corresponding with its border and opening at each end into the earity of the vesicle. Throughout the region of fusion of the walls, the latter be- 
come thin and finally disappear, being replaced by connective tissue. Thus a semicireular epithelial tube is formed, which is the horizontal or external semicircular canal. One end of the tube being dilated, the ampulla of the canal is produced.

The superior and posterior semicircular canals are formed in a somewhat similar manner by the other evaginated pouch or pocket, which is irregularly globular. To produce this result, the walls of the pocket contract adhesions throughout two regions, which correspond with the respective spaces enclosed by each of the two future canals in question. The fusion of the walls takes place in such manner as to leave two narrow channels or tubes, one of which almost encircles the inner or mesial aspect of the pocket, while the other bears the same relation to its posterior wall, the inner limb of the latter semicircle coinciding with the posterior limb of the former. The result of this arrangement is that two vertical semicireular canals are formed with their planes at right angles to each other, the two communicating with the otic vesicle by three openings, one of which is common to both canals. The other two apertures, being dilated, are the ampullated individual orifices of the posterior and superior canals.

The constriction in the otic vesicle referred to above inereases until this sac is divided into two parts, a larger, which includes the region from which the semicircular canals have developed and which is now the utricle, and a smaller vesicle, the saccule, comprising the part from which the cochlear duct was evaginated (Fig. 152). The line of division coincides with the middle of the orifiee of the duetus endolymphaticus, the proximal end of which participates in the division. 'Thus the ductus endolymphaticus becomes a Y-shaped tube, and affords the only bond of connection between the saccule and the utricle (Fig. 152).

The beginning of the eochlear duct, failing to keep pace in growth with the other parts, appears as a smaller tube relatively, and is known as the canalis reuniens (Fig. 152, $(r)$. 
The structures so far considered-the utricle, the saccule, the semicircular canals, and the cochlear duct-being the product of the ectodermic otie vesicle, represent simply the adult epithelial linings of those carities. The fibrous layer of the membranons labyrinth, in common with the walls of the bony labyrinth, is a product of the enveloping mesodermic tissne. While the cells of the otic resicle thus for the most part constitute the walls of the sereral sacs and canals of the primitive internal ear, some of the cells specialize into neuro-epithelium. The most marked specialization of this sort occurs in the cochlear duct, where most of the cells on that wall of the duct which may be called its floor-the part corresponding to the future membrana basilaris-undergo such profound modification in form as to produce the most highly specialized neuro-epithelial cells anywhere to be found, the elements that constitute the organ of Corti.

In the utricle and the saccule, as well as in the ampnllæ of the semicircular canals, there is a similar but less marked specialization of epithelial cells to produce in the former case the maculæ acusticæ, and in the latter, the cristæ acusticæ of the ampullæ. While, therefore, the cells of the otic resicle which are to serve as the lining mucous membrane of the membranous labyrinth become flattened polyhedral cells arranged as a single layer, those cells which are to functionate as the peripheral part of the acoustic mechanism become the specially modified columnar cells, many of them with cilium-like appendages, of the maculæ, the cristæ, and of the organ of Corti.

From the first the otic vesicle lies in close relation with the acusticofacial ganglion (Fig. 151, B). As pointed out in a preceding chapter (p. 297), this ganglion subsequently divides into two parts, corresponding with the two divisions of the auditory nerve. This dirision of the ganglion and of the nerve is correlated with the separation of the otic resicle into a cochlear part, the cochlear duct, and the two restibular resicles, the saccule and the utricle. W'hile the cochlear duct is still a short, slightly curved tube, the cochlear part of the ganglion lies in close proximity to the tube, in the concavity 
on its inner side. As the duct lengthens and becomes more coiled, the ganglion likewise lengthens into a band which follows the spiral course of the duct, lying parallel with the latter and on the side toward the axis about which it is coiled. After the formation of the bony parts of the cochlea, this ganglion occupies the spiral canal of the modiolus and is known as the ganglion spirale. It belongs to the cochlear division of the auditory nerve, which is distributed to the cochlea.

The remaining part of the acoustic ganglion becomes rather widely separated from the spiral ganglion, coming to occupy a position in the internal auditory meatus, and the part of the auditory nerve with which it is connected aequires relation with the macular regions of the utricle and saccule as well as with the cristre of the ampulle of the semicircular canals. These nerve-fibers constitute the vestibular division of the anditory nerve, while the ganglion is the vestibular ganglion or intumescentia ganglioformis of Searpa.

The development of the bony labyrinth of the internal ear, as well as of the comnective-tissue parts of the membranous labyrinth, is effeeted solely by the differentiation of the mesodermic tissne which surrounds the epithelial structures above considered. As previonsly stated, at the time when the otic vesicle is first formed there is no indication of a cranial capsule, the brain-resicles being surrounded and separated from the ectoderm by indifferent mesodermic cells. During the progress of the alterations in the otic vesicle, this tissue undergoes condensation and alteration to form the membranous primordial cranium, and shortly thereafter the petrous portion of the temporal bone is ontlined in cartilage by the further specialization of a portion of this primitive comnective tissue. The formation of cartilage does not affeet all of the tissue which is afterward represented by the petrosa, the region that borders the semicirenlar canals, the cochlear duct, the saccule, and the utricle remaining soft combryonal connective tisine. There is thus a cartilaginous ear-capsule produced which is more than large enough to contain the primitive epithelial labyrintl, and the walls of 
which are separated from the latter by embryonal connective tissue.

The bony semicircular canals are almost exact reproductions, on a larger scale, of the epithelial canals, and they are formed by the ossification of the eartilaginous petrosa. Even before this ossification occurs the soft connective tissue between the cartilage and the epithelial semicircular canals differentiates into three layers. The inner layer, becoming more condensed, is converted into fibrous tissue, and, adhering to the epithelial walls of the canals, furnishes the connective-tissue component of the completed membranous canals. Its blood-ressels scrve for the nutrition of the canals. The outer layer also undergoes condensation and forms a fibrovascular membrane, the perichondrium, which later becomes the internal periosteum of the bony canals. The middle layer, on the contrary, beeomes softer-by the liquefaction of the intercellular substance and the degeneration of the cells-so that gradually increasing, fluid-filled cavities make their appearance, and these latter becoming larger and many of them coalescing, a space is formed around the membranous canals which is filled with fluid, the perilymph. This perilymphatic space is bridged across at intervals by connective-tissue processes that serve for the conreyance of blood-ressels to the membranous canals.

The vestibule of the internal ear is formed in practically the same manner as the bony semicircular canals, the epithelial saccule and utricle acquiring their connective-tissue constituents in the same way. There is the difference, however, that the bony restibule does not conform to the shape of the vestibular parts of the membranous labrrinth, since it is a single undirided carity enclosing the two little resicles, the saccule and the utricle.

The bony cochlea, while developed upon the same general plan as the other parts of the bony labyrinth, presents certain conspicuous modifications. The epithelial cochlear duct, as stated above, in its early stage is a short, tapering, and slightly curred tube. While it is still in this condition, chondrification of the petrous bone occurs, whereby the 
duct acquires its cartilaginous capsule (Fig. 153, kk). This capsule is open at the proximal end of the duct and through this opening the cochlear branches of the auditory nerve gain access to the capsule, being connected with the cochlear division of the auditory ganglion, which, owing to its previously having assumed a position beside the duct, comes to be enclosed by the capsule as the latter is formed (Fig. 153, ne, gsp). It is only after the chondrification that the cochlear duct lengthens out and becomes spirally

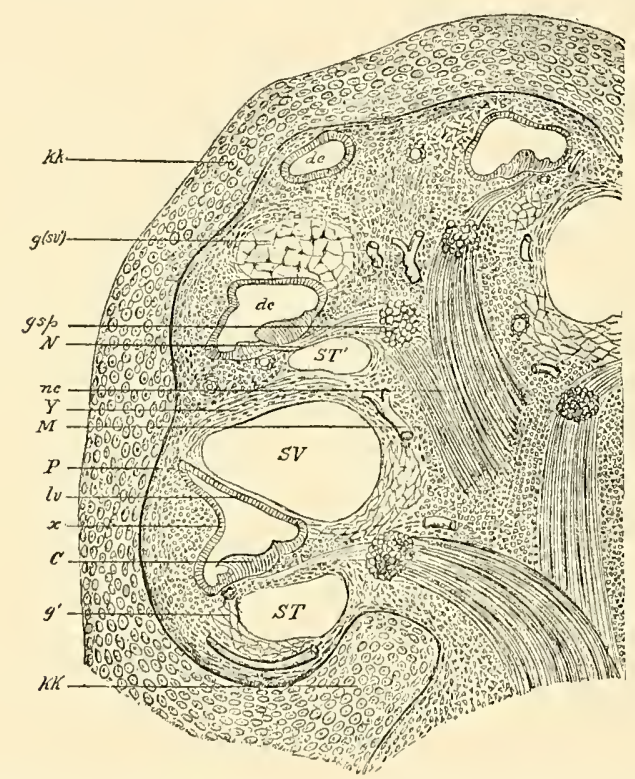

Frg. 153.-Part of a section through the eochlea of an embryo eat, $9 \mathrm{~cm}$. (3.6 in.) long (after Bocttcher): $k \cdot k$, cartilaginous capsule, in which the cochlear duet describes ascending sfiral turns; $d c$, duetus eochlearis; $c$, organ of Corti; $l v$, lamina vestibularis; $x$, outer wall of the membranous ductus cochlearis with ligamentum spirale; $S T$, seala vestibuli ; $S T, S T^{\prime}$, scala tympani; $g$, gelatinous tissue, which still fills the scala vestibuli $\left(s v^{\prime}\right)$ in its last turns; $g^{\prime}$, remnant of the gelatinous tissue, wlich is not yet liquefied; $M$, firm connective tissue surrounding the cochlear nerve $(n c)$; gsp, ganglion spirale; $N$, nerve which runs to Corti's organ in the future lamina spiralis ossea; 1 , eompact connective-tissue layer, which becomes ossified and shares in bounding the bony eochlear duct; $P$, perichondrium.

coiled. The coiling is in such manner that the cochlear nerve is surrounded by the duet-that is, it lies in the axis 
about which the duct is spirally wound. Within the cartilaginons capsule, filling all the space not oceupicd by the spirally coiled duct and the cochlear nerve with its lengthened-out ganglion, is the embryonic connective tissue of which formerly the entire cartilaginous petrosa consisted. The cochlea consists now of a spirally coiled epithelial tube lying within an elongated cavity in the cartilaginous petrosa, a cavity, the walls of which are, therefore, cartilaginous. The peripheral wall of the coiled tube is in contact with the inner surface of the wall of the cartilaginous capsule (Fig. $153, x)$, a fact which has an important bearing upon the further stages of growth.

The embryonal connective tissue within the capsule now undergoes important modifications, which vary greatly in different regions. That portion of this tissue which immediately envelopes the cochlear nerve becomes first dense connective tissue, which is afterward directly converted into bone, constituting the modiolus, or axis, of the cochlea. The processes of condensation and subsequent ossification extend outward from the modiolus in a spiral line, which corresponds with the intervals between the successive turns of the cochlear duct, until they meet the wall of the original capsule, thus producing the bony cochlea. That is, by the development of this spiral plate and its connection internally with the modiolus and externally with the wall of the capsule, a tube at first partly membranous and partly cartilaginous, and at a later stage osseous, is prodnced, which encloses the much smaller cochlear duct, and like it is wound spirally around the modiolus. To repeat, the original simple cavity of the cartilaginous capsule is subdivided by the growth of the modiolus and of the spiral shelf in such manner as to become a spirally coiled tube.

The cochlear nerve, enclosed within the coil of the cochlear duct, sends branches (Fig. 153, N) in a continuous spiral line to the duet, and the soft tissue surrounding and supporting these branches condenses to form a connectivetissue plate which extends outward from the modiolus to the cochlear duct and which, therefore, las a spiral course 
about the modiolus, its entire inner edge being attached to that central axis, while its outer border is, throughout its entire extent, in continuity with the inner wall of the duct. At a later stage this spiral plate undergoes direct ossification to form the two lamellæ of the bony lamina spiralis. Thus it is that the ganglion spirale and the successive terminal branches of the cochlcar nerve come to be enclosed within the spiral lamina. Recalling the condition of the cochlea before the growth of the spiral lamina, it will be seen that the latter, in connection with the epithelial cochlear duct, divides the tube into two parts (Fig. 153, $S Y, S^{\prime} T$ ). It will be evident, too, that the epithelial cochlear duct now holds a relation to the larger tube of the future bony cochlea which is similar in principle to the relation of the membranous semicircular canals to the bony canals, but with the difference that the outer wall of the epithelial duct is in close contact with the onter wall of the future bony canal at $x$, and that the inner walls of the two are connected by a spiral plate, the lamina spiralis.

The cochlear duct, then, is surrounded by undifferentiated mesodermic tissue, except on the side farthest from the modiolus, where its wall is in contact with and finally adheres to the wall of the cartilaginons capsule. The lamina spiralis divides this tissue into two parts which respectively occupy the positions of the future scala vestibuli and scala tympani. This soft embryonal tissue, as in the case of the corresponding tissue of the semicircular canals, develops differently in different regions. The innermost stratum, which is in relation with the epithelial cochlear duet, becomes fibrous connective tissue and constitutes the fibrous layer of the adult cochlear duct; that is, on the side of the duct toward the scala tympani, it becomes the connective-tissue layer of the membrana basilaris, while on the side toward the scala vestibuli it forms the fibrous stratum of the membrane of Reissner (Fig. 153). The peripherul zone of indifferent tissne, that in contact with the now cartilaginous wall of the future brony cochlea, as well as that which lies against the lamina spiralis, also undergoes condensation and forms a fibrous, 
or fibrovascular, membrane, the internal perichondrium or future periosteum. The tissue intervening between these two layers retrogrades, the cells degenerating and the intercellular substance liquefying, mntil finally the spaces known as the scala vestibuli and the scala tympani are hollowed ont. These channels are lymph-spaces and the fluid they contain is the perilymph. This perilymphatic space is in communication with that of the vestibule. Therefore, while the cochlear duct or scala media encloses an epithelium-lined space, as do the saccule, the utricle, and the membranous semicircular canals, and in common with those structures contains the so-called endolymph, the scala vestibuli and the scala tympani are in the same category with the perilymphatic spaces of the other parts of the internal ear.

The Middle and the External Ear. - The middle ear, consisting of the tympanic cavity and the Eustachian tube, is developed from the back part or dorsal end of the first inner visceral furrow. The external ear, comprising the external anditory meatus and the auricle, comes from the dorsal extremity of the first outer furrow and the tissue about its margins, the tympanic membrane representing in part the closing membrane which separates the inner furrow from the onter.

The first inner visceral furrow, in common with the other inner furrows, is an evagination of the lateral wall of the primitive pharyngeal cavity, or head-end of the guttract. The ventral end of this groove suffers obliteration, but the dorsal segment, designated the tubotympanic sulcus, becomes converted into a tube by the growing together of its edges. The tube is composed therefore of entodermic epithelial cells. It elongates in the dorsal and outward direction, and its dorsal extremity becomes enlarged to produce the eavity of the tympanum, the remaining part of the canal becoming the epithelial lining of the Eustachian tube. The canal being formed before the development of the cranium, and approximately its posterior half heing surrounded by the mesodermic embryonal comnective tissue that afterward becomes the petrosa of the temporal bone, the 
tympanic cavity and a part of the Eustachian tube eome to be enclosed within that bone, while the connective tissue encasing the anterior part of the tube differentiates into the curved plate of cartilage that forms the cartilaginous part of the Eustachian tube.

Since the posterior end of the primitive epithelial tube insinuates itself between the otic vesicle and the surface, the tympanum comes to occupy its normal position on the outer side of the internal ear. The tympanum, being derived from the back part of the first visceral cleft, is in close relation with the first and second visceral arches, and the ossicles of the middle ear are derived from the dorsal extremities of the cartilaginous bars of these arches in the manner described in Chapter XVIII. Necessarily the primitive ossicles are exterior to the primitive epithelial tympanic sac, as is also the chorda tympani nerve, which passes along its outer side. After the ossification of the temporal bone, these structures are embedded within the abundant soft eonnective tissue which is between the epithelial sac, now the mucous membrane, and the bony walls of the tympanum. This mass of soft tissue undergoes very eonsiderable diminution, owing to which the mucous membrane comes into eontact with the bony walls, and as a result the ossicles and the chorda tympani are enclosed in folds of the mucons membrane and seem to lie within the tympanic eavity. They are excluded, however, from the true cavity of the tympanum, since they are exterior to the epithelial or mucous-membrane layer.

The external auditory meatus is simply the persistent posterior part of the first outer visceral furrow or hyomandibular cleft (sec pp. 101, 105), this eleft closing completely everywhere but in this region. The closing plate of the first cleft becomes the tympanic membrane. Hence the outer layer of this membrane is of ectodermic origin, while the inner layer is entodermic, being continuous with the epithelial tympanic lining, and the middle fibrous layer is derived from the mesoderm. The relation of the malleus to the membrane and of the latter to the bony tympanic plate 
which forms part of the wall of the meatus is dealt with in the chapter on the development of the skeleton.

The auricle is derived from the tissue around the margin of the unclosed back part of the first outer eleft (Fig. 155, C). Six little elevations make their appearance here, the projections being mesodermic tissue corered with ectoderm. The mesodermic component of the elevations differentiates into the cartilaginous and other comnective-tissue parts of the auriele. The nodules marked 2 and 3 in Fig. 154 beeoming a continu-
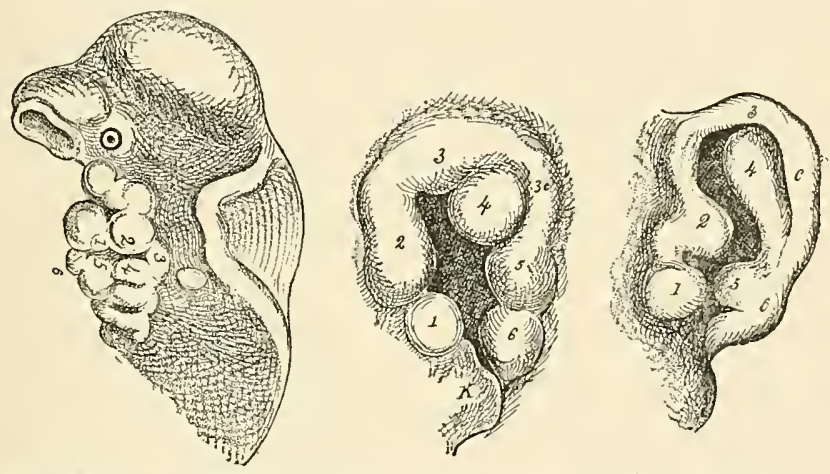

Fig. 154.-Showing the gradual development of the parts of the external ear from prominenees upon the mandibular and hyoidean visceral arches (His), variously magnified: 1, 2, prominences on mandibular arch; 3 , prominence between the two arehes, prolonged posteriorly in second figure to $3 c ; 4,5$, and 6 , prominences on hyoidean or second viseeral arch; $K^{*}$, lower jaw. Prominenee 1 forms the tragus ; $2,3,3 c$, the helix ; 4 , the antihelix ; 5 , the antitragus ; 6 , the lobule.

ous ridge, produce the helix, while nodule 4 becomes the antihelix. The tragus and antitragus develop respectively from the projections 1 and 5 . At the end of the second month, these parts are so far advanced as to be easily distinguishable, and the connective-tissue basis of the ridges and projeetions and the continuous plate-like mass to whieh they all are attached begin to undergo chondrification. From the third month onward, this primitive anricle, by eontinued growth and greater separation from the side of the head, assumes more and more the characters of the fully formed member. The lobule, however, which results from the growth of the little elevation marked 6, lags behind the other parts in development and is rather indistinct mntil the 
fifth month, after which time it increases in size and gradually aequires its normal proportions.

\section{THE DEVELOPMENT OF THE NOSE.}

The nose is primarily a special sense-organ, although a part of its cavity serves, in air-breathing vertebrates, as an adjunct to the respiratory system. The evolution of the mature organ of smell may be epitomized by the statement that the olfactory epithelium, the essential part of this senseorgan, is a patch of depressed or infolded ectoderm, the cells of which are highly specialized and are brought into relation with the central nervous system by means of the ontgrowth from the latter of a part of its mass, the olfactory lobe.

Very early in intra-uterine life-before the end of the third week-the olfactory plates appear as localized thickenings of the ectoderm situated just in front of or above the oral fossa. These nasal areas are the forerumners of the future olfactory epithelium. It is worthy of note that the olfactory plates are in very close relation with the primary fore-brain vesicle, being, in reality, on the onter surface of the cetodermic covering of its ventral wall.

Owing to the rapid outgrowth of the surrounding tissue, the olfactory plates become relatively depressed, constituting now the nasal pits, which are distinguishable at about the twenty-eighth day. The pits are separated from each other by a broad mass of tissue, the nasal or nasofrontal process (Fig. $155)$, which is, as it were, a localized thickening of the mesodermie tissue on the ventral wall of the primary fore-brain vesicle; and this process makes its appearance in the third week. During the fifth week the nasofrontal process thickens greatly along its lateral margins, the thick edges being known as the globular processes (Fig. 155, A, B). At the same time the lateral nasal processes bud out from the nasofrontal process, one on each side, above the nasal pits, and, growing downward, form the external boundaries of the pits, each of which depressions is bomded on its inmer side by the corresponding globular process. 'The nasal pits, therefore, have well-marked 
walls on every side except below, where they are directly continuous with the oral fossa.

In the latter end of the sixth week the nasofrontal process, which, it will be remembered, constitutes the upper
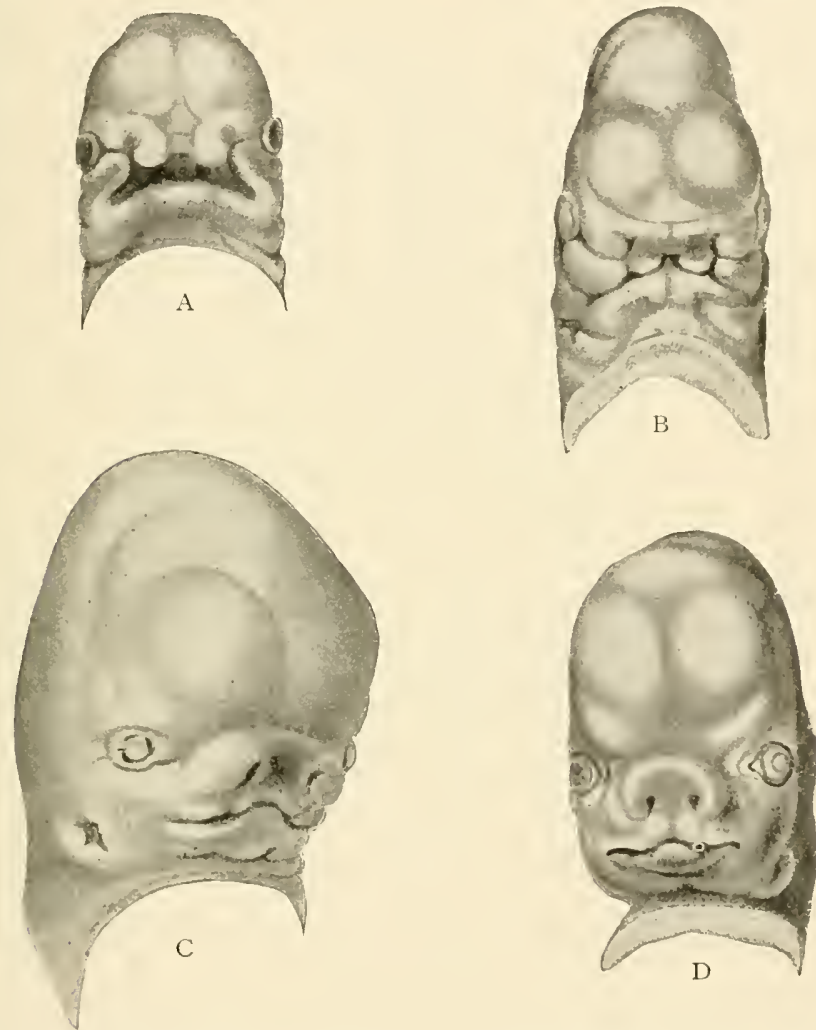

Fig. 155.-Development of the face of the human embryo (His) : A, embryo of about twenty-nine days. The nasofrontal plate differentiating into processus globulares, toward which the maxillary processes of first visceral areh are extending. $B$, embryo of about thirty-four days: the globular, lateral, frontal, and maxillary processes are in apposition; the primitive opening is now better defined. $C$, embryo of about the eighth week: immediate bonndaries of mouth are more definite and the nasal orifices are partly formed, external ear appearing. D, embryo at end of second month.

limit of the oral fossa, is joined on each side by the united maxillary, and lateral nasal, processes. This effects a division between the oral fossa and the nasal pits, and forms, 
though as yet crudely, the external nose, and the upper lip as well. The definite formation of the external nose may be said to be indicated about the eighth week. The orifices of the nasal pits are now the anterior nares, while the pits themselves have become short canals, opening by their deep orifices, the posterior nares, into the primitive mouth-eavity above the palatal shelves. The nares are separated from each other by the still broad nasofrontal process. That portion of the nasofrontal process that separates the nares gradually becomes thinner and produces the septum of the nose, while its external or superficial part gives rise to the bridge and tip of the organ.

The growth of the palate-shelves (Fig. 156) toward the median line, resulting in their union with each other and

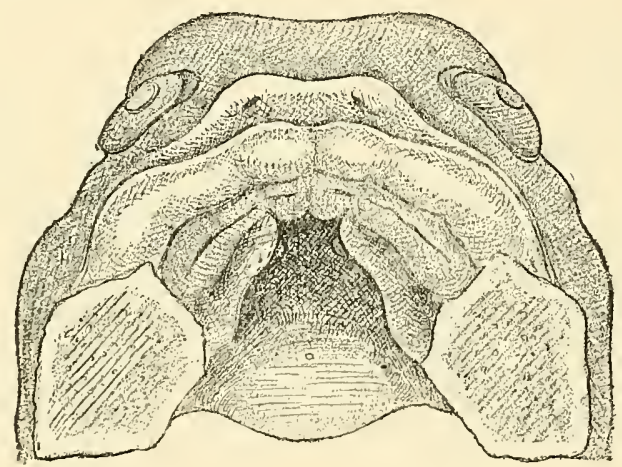

FIG. 156.-Roof of the oral cavity of a human embryo with the fundaments of the palatal processes (after 11 is), $\times 10$.

with the recently-formed septum, definitely divides the nasal chambers from the eavity of the mouth, the posterior nares now opening into the pharynx. This separation is completed toward the end of the third month.

The complexity of the adult nasal cavities is produced by the formation of ridges and pouclies on the lateral walls of the original nasal pits. Three inwardly projecting horizontal folds of the ectodermic lining of the cavity, the superior, middle, and inferior turbinal folds, appear upon the outer wall of each nasal fossa (Fig. 157). Each fold contains a stratum 
of mesodermic tissue which develops into cartilage and subsequently into bone, forming respectively the three turbinated bones. The cartilaginous character of these folds becomes apparent at the end of the second, or the early part of the third, month. An evagination on the lateral wall of each

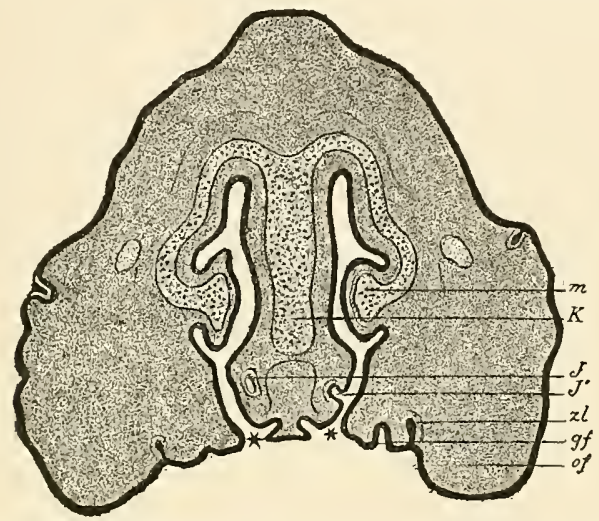

Fig. 157.-Cross-section through the head of an embryo pig $3 \mathrm{~cm}$. (1.2 in.) long, crown-rump measurement. The nasal cavities are seen to be in communication with the oral cavity at the places designated by a $: K$, cartilage of the nasal septum ; $m$, turbinal cartilage; $J$, organ of Jacobson; $J^{\prime}$, the place where it opens into the nasal cavity; $g f$, palatal process; of, maxillary process; $z l$, dental ridge.

nasal fossa, between the middle and the inferior turbinal processes, becomes the antrum of Highmore; this is formed in the sixth month. Other evaginations produce the ethmoidal, the frontal, and the sphenoidal sinuses, the last two of which are not completed, however, until after birth. Very early in the development of the nose a small invagination appears on the mesial wall of the nasal pit. In the fourth month of gestation this invagination has become a canal in the septum (Fig. 157, $J$ ), rumning from before backward and ending in a blind extremity. It is the so-called organ of Jacobson, which, in man, is merely a rudimentary strueture, but which, in most other mammals, is more highly developed, being surrounded by a cartilaginous eapsule and receiving a special nerve-supply from the olfactory nerve.

The olfactory plates become separated from the fore-brain vesicle and consequently from the later brain and its out- 
growth, the olfactory bulb, by the development of an intervening bony plate, the cribriform lamina of the ethmoid bone. The ectodermic cells of the olfactory plates differentiate into the highly specialized neuro-epithelial elements of the olfactory mucous membrane and their associated supporting cells. The neurits of the neuro-epithelial cells, assuming relationship with the glomeruli of the olfactory bulb, constitute the olfactory nerve-fibers.

The external nose, as previously stated, first acquires definite form about the eighth week by the union of the distal ends of the lateral nasal processes with the nasofrontal process, the former producing the alæ and the latter the bridge and the tip of the nose. In the third month the organ is unduly flat and broad, but from this time on it gradually assumes the familiar characteristic form. From the third month to the fifth each external naris is closed by a gelatinous plug of epithelial cells. 


\section{CHA PTER XVII.}

\section{THE DEVELOPMENT OF THE MUSCULAR SYSTEM.}

THE STRIATED OR VOLUNTARY MUSCLES.

THE voluntary muscular system, genetically considered, is divisible into (1) the museles of the trunk and (2) those of the extremities. The muscles of the trunk include two distinct sets: (a) the muscles of the trunk proper, or the skeletal muscles, and (b) the muscles of the visceral arches or the branchial muscles.

To arrive at a proper comprehension of the evolution of the muscular system it is necessary to revert to an important fundamental cmbryological process, the segmentation of the body of the embryo, or, as it is sometimes expressed, the segmentation of the colom, or body-cavity. As pointed out in Chapter IV., this process of segmentation occurs in all vertebrate animals and in some invertebrates.

The Muscles of the Trunk Proper.-At a very early stage of development the tracts of mesodermic tissue situated one on cach side of the median longitudinal axis of the future embryonic body, the paraxial mesodermic tracts, undergo division or segmentation, in lines transverse to the long axis, into a series of pairs of irregularly cubical masses of mesodermic cells. These masses are the mesoblastic somites or primitive segments, often inappropriately called the protovertebræ. The somite first formed corresponds with the future occipital region, the second one lies immediately in front of the first, while two others, situated still more anteriorly, that is, near the cephalie end of the embryonic area, and seven more, behind the first, are added almost simultaneously. The formation of the primitive segments 
then proceeds tailward until a considerable number have been added. Those in front of the one first formed are denominated the head-segments, while the others are known as the trunk-segments. Each somite is at first triangular in cross-section, the base of the triangle looking toward the chorda dorsalis. Subsequently they assume a more cuboidal shape. In the lower vertebrates-amphibians and fishesthe somite is hollow, its cavity being in these cases a constricted-off portion of the body-cavity (hence the term "seg-

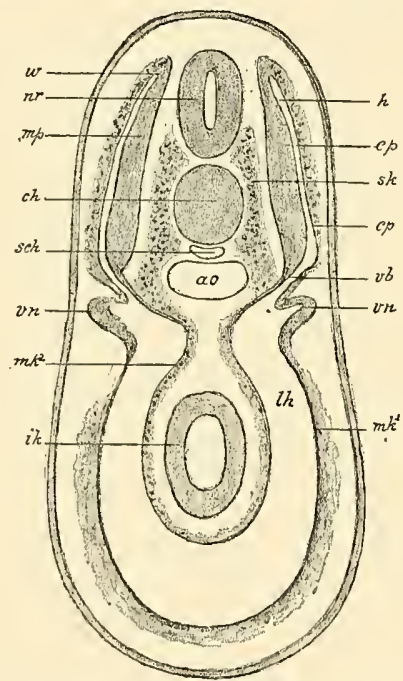

FIf. 158.-Cross-section through the region of the pronephros of a selachian embryo in which the musele-segments (myotomes) $(m p)$ are in process of being constricted off. Diagram (after Wijhe): $n r$, neural tube; $c h$, chorda; ao, aorta; $s c h$, subnotochordal $\operatorname{rod} ; m p$, muscle-plate of the primitive segment; $w$, zone of growth where the muscle-plate bends aronnd into the cutis-plate $(c \rho)$; $v b$, tract connecting the primitive segment with the body-cavity, out of which are developed, among other things, the mesonephric tubules; $s k$, skeletogenous tissue which arises by a probiferation from the median wall of the eonnecting tract $v b$; $v n$, pronephros; $m k^{1}, m k^{2}$, parietal and viscerul middle layer, from whose walls mesenchyme is developed ; $l h$, body-cavity ; $i k$, entoblast.

mentation of the ecelom" to express this process). In the higher vertebrates, however, the cavity is obliterated by the encroachment of the cells of the walls of the somite.

The eclls of the somites soon undergo differentiation and rearrangement. It is usually stated that, preparatory to the 
segmentation of the paraxial mesodermic tract, this tract has become separated from the remaining lateral plate of the mesoderm. The separation is not complete, however, and therefore, after the appearance of the primitive segments, each segment is connected with the more laterally placed lateral plate-by the separation of which latter into two lamellæ the colom is formed-by a smaller mass of tissue, the nephrotome, also called the middle plate, or intermediate cell-mass (Fig. 158, vb). As development progresses the distinction between the primitive segment proper and the nephrotome becomes more sharply expressed, and the former is designated the myotome. The primitive segment on its mesial surface, near the point of union with the nephrotome, sends forth cells which form a mass called the sclerotome (Fig. 158, sk). The sclerotomes spread out and blend with each other, forming a continuous mass of tissue which envelops the chorda and the neural canal, and which, being concerned in the production of the permanent vertebræ, has no further interest in this connection.

What remains of the primitive segment after the formation of the nephrotome and of the sclerotome is the myotome proper or the muscle-plate. Although, as previously stated, the primitive segments of the higher vertebrates contain no cavity, the myotome and the nephrotome each enclose a space, that belonging to the former being known as the myocœl. The myotomes or muscle-plates are so called because they give rise to the voluntary museulature of the trunk. But not all of the cells of the muscle-plate undergo transformation into muscular tissue. While the cells on the mesial or chordal side of the myocol are going through eertain alterations preparatory to their metamorphosis, the cells nearer the body-wall become rearranged to form a characteristic layer which is known as the cutis-plate from the fact that it contributes to the formation of the corium of the skin (Fig. 158, cp). The eutis-plate and the remaining part of the muscle-plate are contimuous around the myocel, the transition from one to the other being more or less gradual. To summarize, the primitive segment is differentiated 
into the nephrotome, the sclerotome, the myotome or muscleplate, and the cutis-plate.

The Metamorphosis of the Muscle-plate.-By the term muscle-plate is meant here the thickened layer of cells on the chordal or mesial side of the myotome proper, which layer constitutes what remains of the myotome after the differentiation of the cutis-plate. These eells having proliferated and increased in size, and having eneroached thereby upon the eavity of the myotome, next undergo alteration in shape, becoming cylindrical, with their long axes parallel with that of the body of the embryo. The length of each eylindrical cell equals the thickness of the primitive segment, at least in the Amphibia and probably also in the chick. The next step in the transformation is the aequisition of the transverse striation characteristic of vertebrate voluntary musele. Soon after this the protoplasm of the cell undergoes longitudinal division into minute fibrillæ-which latter do not necessarily correspond, however, with the primitive fibrillæ of mature muscle-and the cell-nuclens likewise divides. The metamorphosis of the now fibrillated protoplasm into musenlar tissue is first completed at the periphery of the fiber, so that a young musclefiber contains a central core of undifferentiated material, including the daughter-nuclei resulting from the division of the original nuclens. Soon after the appearance of striation and the fibrillation of the fiber, the fibers begin to separate from each other, and developing connective tissue with young blood-vessels penetrates between them, the fibers now showing aggregation into bundles. For some time longer the fibers are naked, sinee the sareolemma is not aequired until considerably later. The differentiation into muscular tissue gradually extends from the periphery of the fiber to its corc, the process being complete in the human embryo at about the end of the fifth month for the muscles of the upper extremities and in the seventh month for those of the lower. The embryonic muscle-fibers are smaller than the mature elements and increase in size until the third month.

It is eonsidered highly probable by most embryologists 
that musele-fibers undergo multiplication during embryonic life. There are several theories as to the method of this multiplication. The most generally accepted view is that put forth by Weismann, the essential feature of which is that the fibers multiply by longitudinal division or fission. Reference was made above to the repeated division of the nucleus of the cell as one of the initiatory steps in the formation of the muscle-fiber. According to the fission theory, there is one class of fibers in which the nuclei are arranged in a single row, and the fibers of this class do not undergo fission; while there is another class, the fibers of which have their nuclei arranged in several rows. Fibers of the latter type divide longitudinally into as many daughter-fibers as there are rows of nuclei.

Although many of the details of the development of the muscular system are still involved in obscurity, it is a generally accepted fact that each fiber is derived from a single cell, the protoplasm of which develops the function of contractility to the subordination of the remaining vital properties of protoplasm. With this specialization of function there is necessarily a concomitant alteration of structure.

The muscular mass resulting from the transformation of each myotome grows in the ventral direetion between the ectoderm and the parietal leaf of the mesoderm, or in other words into the somatopleure, to produce the muscular structures of the ventrolateral body-wall. It grows also and to a greater extent in the dorsal direction, eovering, and acquiring points of attachment to, the vertebral column, which has meanwhile been forming. In addition to the ventral and dorsal extension of the musele-plates, each one grows both forward and backward-cephalad and caudad-in such manner that overlapping and intermingling result.

What has been said above concerning the evolution of the trunk-musculature from the primitive segments refers to those muscles that are developed from the segments of the trunk. As to the evolution of the head-segments comparatively little is definitely known. It is gencrally accepted that in elasmobranchs-at group including sharks and rays- 
there are nine primitive segments in the region of the future head. The number present in mammalian embryos has not been clearly worked out. In the lower vertebrates each segment contains a cavity lined with flattened cells, the mesothelium, the metamorphosis of which into muscular tissue may be inferred to be essentially as already outlined above. The first head-segment, which lies in contact with and partially envelops the optic vesicle, gives rise to the superior rectus, the inferior rectus, and the inferior oblique muscles of the eyeball; the second segment produces the superior oblique, and the third, the external rectus. The fourth, fifth, and sixth segments abort and hence produce no adult structures; while the seventh, the eighth, and the ninth segments become metamorphosed into the muscles that connect the skull with the shoulder-girdle.

From recent studies ${ }^{1}$ it would appear that individual muscles undergo peculiar and significant migrations during their development, and that the origin of the nerve-supply of a muscle indicates the location of the particular myotome or myotomes from which it originated, since the segmental nerves are connected with their respective myotomes and supply the muscles derived from such myotomes. For example, the serratus magnus, being innervated by branches of the cervical nerves, develops from myotomes in the neck region, and subsequently moves down to become attached to the scapula and the ribs.

The Branchial Muscles.-This term embraces the muscles of mastication and the various muscles connected with the hyoid bone, with the jaws, and with the ossicles of the middle ear. They result from the metamorphosis of the mesothelium of the visceral arches and acquire connections with structures that have arisen from the so-called mesenchymal cells of these arches or, in other words, from the embryonal connective tissue which makes up the chief part of their bulk. For an account of the growth of the visceral arches the reader is referred to Clapter VII. From this

"Sce "Development of the Ventral Abdominal Walls in Man," Franklin P. Mall, Johns Hopkins Papers, vol. iii., 1898. 
account and from that found in Chapter IV., it will be seen that the formation of the visceral arches and clefts is in reality the segmentation of the ventral mesoderm of the headregion of the embryo, or to express it in another way, it is the segmentation of the rentral colom of that region. It is interesting to note that whereas in the trunk the segmentation of the mesoderm is restricted to the dorsal part of the body, in the head-region the ventral mesoderm also participates in the process. Hence the visceral arches, as might be expected, consist of so many masses of mesodermic tissue, each arch containing a small cavity lined with mesothelium, which cavity is a constricted-off part of the body-eavity or cnelom. It is these mesothelial cells that produce, by their differentiation, the museles under consideration. While so much concerning the origin of this group of muscles is praetically assured by observations upon the embryos of the lower vertebrates, the details are still obseure. His assumes the origin of the palatoglossus, the styloglossus, and the levator palati from the second or hyoid arch; of the stylopharyngeus, perhaps the palatopharyngeus, the hyoglossus and the superior constrictor of the pharynx from the third arch; and of the midale and inferior pharyngeal constrictors from the fourth arch. Further, it is held by Rabl that the museles of the face, including those of the scalp and the platysma-the muscles of expression-originate from the mesothelium of the hyoid arch in the form of a thin superficial sheet, which, gradually spreading out from the place of origin, breaks up into the individual museles.

The Muscles of the Extremities.-Of the development of these there is little to be said. Enough is known of the development of the limb-muscles to establish two important facts : that these museles develop as buddings from the muscle-plates of the trunk, and that the muscles of each extremity arise not from one but from several myotomes, the exact number being uncertain. The observations have been chiefly upon selachians (sharks, etc.), and in these embryos each myotome gives off two buds, each of which 
divides into two others, while the main part of the myotome continues its growth into the somatopleure.

THE INVOLUNTARY OR UNSTRIATED MUSCULAR TISSUE.

This variety of muscular tissue, like that considered above, is of mesodermic origin. But while the voluntary muscles arise from the flattened or mesothelial cells of the primitive segments, involuntary muscle results from the transformation of the embryonal connective-tissue elements, the mesenchymal cells, of the mesoderm. It is for this reason that some authors speak of the voluntary muscles as the mesothelial muscles and designate the involuntary muscular tissue as mesenchymal muscle.

While it is a generally accepted fact that each of the fibercells which make up unstriated muscle is a metamorphosed mesenchymal or connective-tissue cell, the details of the process have not been accurately worked out. One may assume that necessarily the young connective-tissue cell elongates and that its protoplasm must undergo such differentiation as will fit it for the exereise of its future function, contractility.

\section{THE CARDIAC MUSCLE.}

The account of the development of the heart-muscle will be found in Chapter $\mathrm{X}$. 


\section{CHA P'TER X VIII.}

\section{THE DEVELOPMENT OF THE SKELETON AND OF THE LIMBS.}

Although the skeleton is the framework of the body in the anatomical or mechanical sense, it is not so embryologically, since its development is not begun, at least not to any important extent, until nearly all the principal organs are well differentiated, and its growth is largely subsidiary to that of the structures which, in the mature state, it supports and protects. Morphologists speak of the exoskeleton and the endoskeleton, the former having reference to the hard structures found superficial to the soft parts, for whose protection they serve, such as the carapace of the lobster, and the hard scales of certain fishes; while the latter term signifies the cartilaginous or bony structures found within the bodies of most vertebrate animals. Even in the highest vertebrates, certain bones, such as those of the vault of the cranium, are usually considered by morphologists as being the representatives of part of the exoskeleton of lower types.

The skeleton, using the word in its ordinary sense, consists of the axial skeleton and the appendicular skeleton, or skeleton of the limbs. The former, including the head and the trunk, is common to all vertebrates; the latter is not found in the lowest members of this class and hence is to be regarded as a later acquisition in the evolution of the skeleton.

In studying the development of the skeleton, as in considering that of other systems and organs, clearer conceptions of the growth of the individual may be obtained by comparing it with the evolution of the type. For example, the simplest form of skeletal apparatus is that of the amphioxus. In this animal the only representative of the skeleton is the 
notochord, a cylindrical rod composed of cellular or gelatinous tissue in which neither chondrification nor ossification ever takes place. Such an animal furnishes an example of the notochordal stage of the skeleton. The surrounding of the chorda with a sheath of embryonal connective tissue, by which it is strengthened and thereby better fitted to scrve as the body-axis, furnishes the membranous type of skeleton, a stage a little farther advanced than the preceding. The next higher type of skeleton is the cartilaginous form. In this case the embryonal connective tissue has undergone transformation into cartilage, at which point development is arresterl, the stage of ossification never being attained. The eartilaginons type of skeleton is illustrated by that of the selachian (sharks and $\operatorname{dog}$-fish).

The third and highest type of skeleton is the osseous. This results from the replacement of the cartilaginons tissue by bone. The process of ossification does not, however, affect every part of the cartilaginous skeleton, there being some portions of the latter which remain permanently unossified. As there are, thronghout the vertebrate series of animals, varions gradations in the degree of differentiation of the skeleton, so in the course of development does the osscous system of every higher vertebrate pass through these stages from the simplest condition, that of the notochordal skeleton, to the highest form of the almost completely ossified skeletal apparatus.

\section{THE AXIAL SKELETON.}

The axial skeleton, as stated above, includes the bones of the trunk and those of the hearl. Logically the development of the former will first claim attention.

The Development of the Trunk.

The Stage of the Chorda.-The formation of the chorda dorsalis or notochord is the earliest indication of the axis of the embryonic body and it will be recalled that it is also one of the earliest embryological processes. The mode of development of the chorda from the entodermal epithelium has been described at p. 65 . The chorda serves the pur- 
pose, as it were, of an axis about which the permanent vertcbral column and a part of the skull are, at a much later date, built up. The anterior or headward termination of the chorda corresponds to the position of the later hypophysis, or pituitary body, and thus the chorda is coextensive, not only with the vertebral column, but also with a portion of the cranium. The cells of the chorda enlarge and become distended with fluid, the protoplasm of each cell being reducerd to a thin layer. The peripheral cells, however, constituting a distinct layer, the chordal epithelium, remain small, and it is by their proliferation that the chorda increases in size. In the amplioxus the chorda is the only "skeleton" that is ever acquired, and in this animal it is a permanent structure. In all other vertebrates it becomes surrounded by embryonal connective tissue, mesenchyme, which latter undergoes chondrification, and in the higher types ossification also. While in some of the lower vertebrates, as in certain classes of fishes, the chorda persists as a structure of more or less importance, in the ligher members of the series, birds and mammals, it retrogrades as the processes of chondrification and ossification go on, until finally it is represented only by the pulpy centers of the intervertebral disks.

The Membranous Stage.-The notochordal stage of the development of the vertebral column is succeeded by the membranous stage. The transformation is effected by the appearance of an ensheathing mass composed of embryonal connective-tissue cells which surround not only the chorda but also the neural canal or fundament of the nervous system (Fig. 158, sk). The source of this embryonal connective tissue or mesenchyme bears an important relation to the primitive segments. As the development of the primitive segments was described in the last chapter, and also in Chapter IV., it will suffice to remind the reader that each primitive segment undergoes differentiation into the myotome or muscleplate, the cutis-plate, the nephrotome, and the sclerotome (Fig. 158), the sclerotome oceupying the mesial surfice of the segment and lying in close proximity to the chorda.

While the myotome originates from the flattened or meso- 
thelial cells of the primitive segment, the sclerotome is made up of cells of the type characteristic of young-growing connective tissue-that is, of the mesenchymal part of the primitive segnents as distinguished from their mesothelium. Owing to the rapid multiplication of its cells, each selerotome spreads out headward and caudalward, and dorsad and ventrad, surrounding both the chorda and the neural canal, until both these structures become enclosed in a common, continuous sheath of embryonal connective tissue. That part of this tissue which surrounds the chorda is often designated the skeletogenous sheath of the chorda and also the membranous primordial vertebral column. The cells of the sclerotomes not only surround the chorda and the neural canal, but they also spread out laterally into the intervals between the muscle-segments to constitute the ligamenta intermuscularia or the bands or strips of connective tissue whieh separate adjacent muscle-

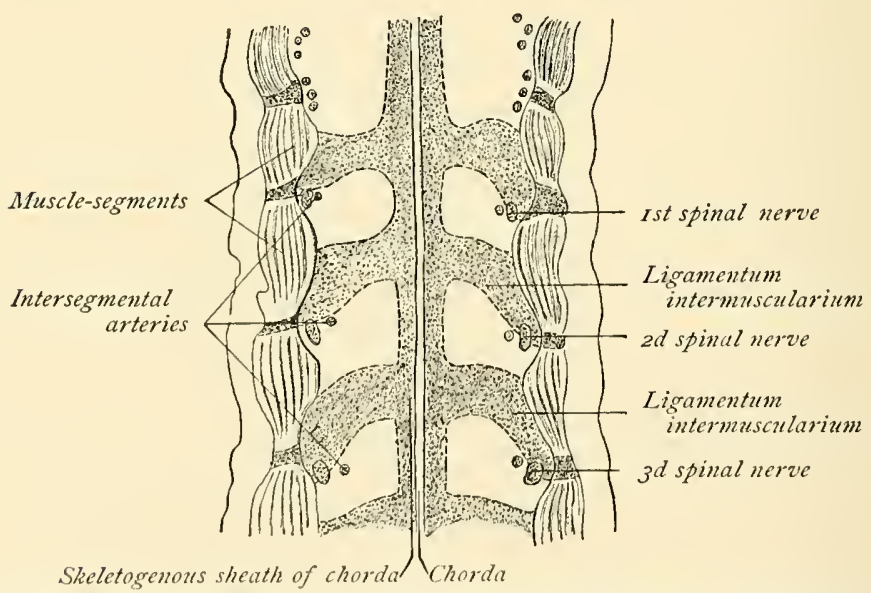

FrG. 159.-Frontal projection from a series of sections through a cow embryo of $8.8 \mathrm{~mm} .(0.35 \mathrm{in}$.). (From Bonnet, after Froriep.)

segments from cach other (Fig. 159). It is worthy of note that while this skeletogenous sheath of the ehorda originates from segmented structures, the somites or primitive segments, and is to that extent related to the segmentation of the body, it now presents no trace of segmentation. 
The Cartilaginous Stage.--This stage of the development of the spine is brought about by the metamorphosis of parts of the membranous vertebral column into the cartilaginous vertebræ. Other and alternating parts of the same structure furnish the intervertebral disks and the ligaments that bind together the individual elements of the spine. The histological changes necessary to effect the transformation of the embryonal connective tissue into cartilage are, briefly, the moving apart of the cells and the modification of both the cells and the intercellular substance, the latter acquiring the characteristic qualities of the matrix of cartilage.

As a preliminary step to the formation of the eartilaginous vertebre, the ensheathing membranous tissue exhibits, at regular intervals, areas of condensation of its connectivetissue elements. It is in these condensed areas that the process of cartilage-formation begins, and each such area, which has the form of a somewhat obliquely placed bow or half-arch, corresponds approximately but not accurately to a future vertebra. This half-arch of condensed mesenchymal tissue is called the primitive vertebral bow by Froriep, whose

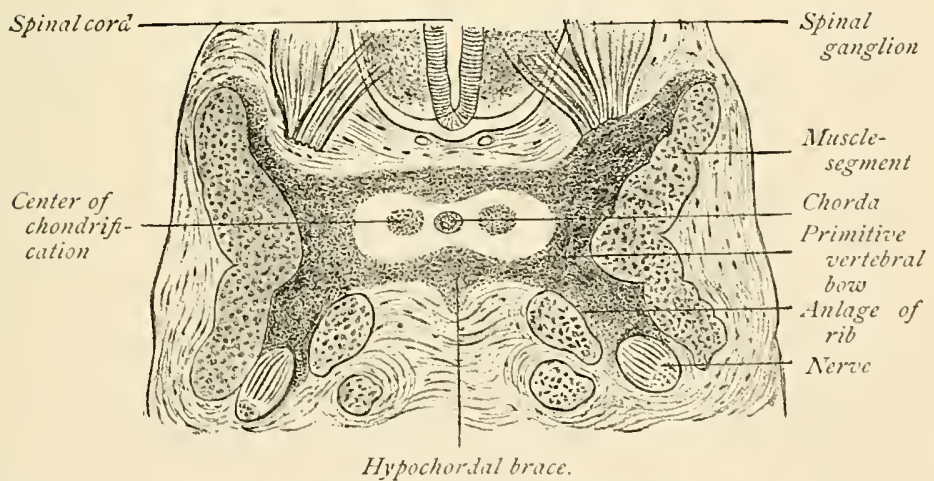

FIG. 160,-Cross-section through the anlage of the third cervical vertebra of a cow embryo of $12 \mathrm{~mm}$. (1/2 in.) (Bonnet).

investigations established many of the ficts known concerning the development of the skeleton (Fig. 160). The merlian part of the bow is on the rentral side of the chorda and is known as the hypochordal brace. The extrenities of the bow 
abut against the corresponding muscle-segments, each extremity becoming bifurcated. The dorsal limb of the bifurcation spreads over the dorsal or superficial surface of the primitive spinal cord, forming the membranous forerunner of the neural arch of the vertebra; while the ventral limb advances ventrad, foreshadowing the hemal arch or costal process of the vertebra, or, as regards the thoracic region of the body, the future rib. ${ }^{1}$ The lateral parts of the bow become the processes of the vertebra, but the median part of each bow, the hypochordal brace, remains unchondrified in mammals and becomes a part of the intervertebral ligament, except in the case of the first cervical vertebra, or atlas, the anterior or ventral arch of which it furnishes. The membranous anlage of the cartilaginous body of the vertebra is found in a special condensation of the ensheathing tissue of the chorda just caudad of the hypochordal brace.

For each vertebral body there are two centers of chondrification, one on each side of the chorda within the mass of tissue referred to above (Fig. 160). The formation of cartilage begins in the second month. The two centers are soon connected with each other by a third, which lies on the ventral side of the chorda, the three forming now a cartilaginous halfcylinder which is later completed by the development of cartilage on the dorsal side of the chorda (Fig. 161). At the time when the chorda is completely eneased in cartilage the spinal cord is still ensheathed by merely membranous tissue. Before the end of the second month the neural arches of the vertebræ are indicated by small isolated masses of eartilage which develop in the connective tissue surrounding the spinal cord, the lateral parts of the membranous vertebral bows. In the eighth week these fuse with the bodies and appear then as projections from them. By the end of the third month the processes, or neural arehes, have grown sufficiently to meet

${ }^{1}$ Morphologically, each vertebra is possessed of a neural areh, for the protection of the spinal cord; and a hemal arch for the protection of the organs of circulation, respiration, and digestion, the rils of man and the higher vertebrates being the persistent hemal arches in the region of the tliorax. 
with their fellows on the dorsal side of the spinal cord, and in the fourth month the corresponding arches of the two sides become united, thus completing the cartilaginous sheath of the cord.

The masses of comnective tissue occupying the intervals between the vertebral bodies are known as the intervertebral

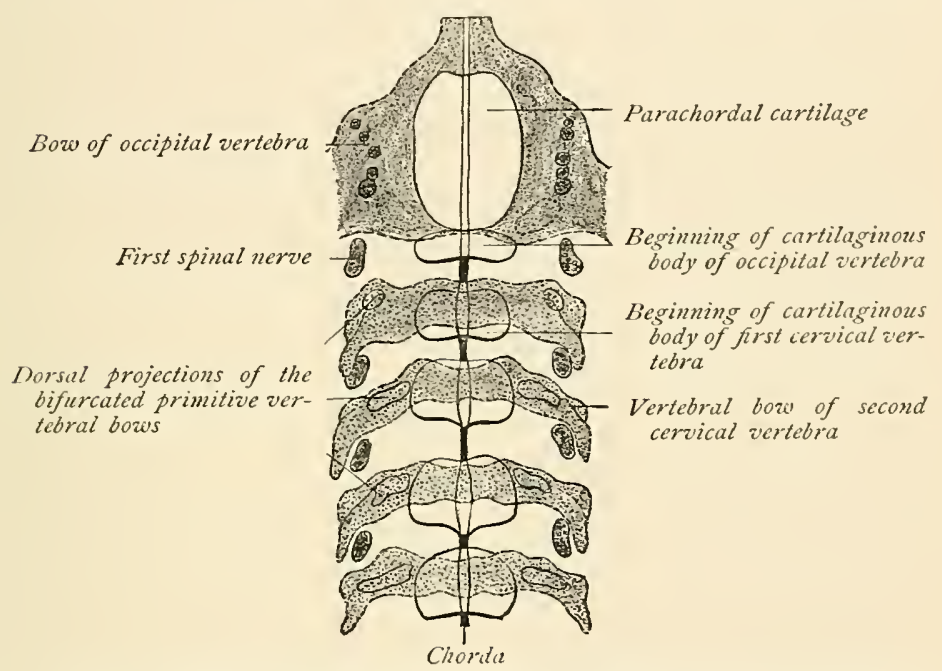

Fig. 161.-Frontal projection from a series of sections through a cow embryo of $17 \mathrm{~mm}$. (0.67 in.), dorsal view (from Bonnet, after Froriep): Connective tissue stippled; cartilage white.

ligaments. Subsequently they become the intervertebral disks. The tissue between the cartilaginous arches becomes differentiated into the ligamenta subflava.

While the unsegmented skeletogenous sheath of the chorda is gradually differentiating into the separate elements of the cartilaginous vertebral colmmn, the chorda itself begins to retrograde. Within the bodies of the vertebra its development is completely arrested, while those portions of it contained within the intervertebral disks continue to grow. The chorda at this stage consequently shows alteruating enlargements and constrictions. In certain fishes it persists as a structure of more or less importance. In verteblates above cartilaginous fishes, all traces of the parts of the chorda 
within the vertebral bodies are lost as soon as ossification nceurs, while in the intervertebral disks parts of it persist as the soft pulpy cores of the latter.

The cartilaginous trunk is completed by the chondrification of the ligamenta intermuscularia to form the cartilaginous thorax.

The Osseous Stage.-The process of ossification begins in certain parts of the trunk at the end of the second month, before the work of chondrification is entirely completed. As the histological details of bone-formation are to be found in the text-books of histology, it will not be necessary to enter into the subject here. The places in any individual cartilage where ossification begins are called the centers of ossification. The process is one of substitution, the cartilage becoming broken down and absorbed as the formation of bone goes on.

The ossification of each vertebra is begun at three centers, one in the body and one in each arch. The centers for the arches appear in the seventh week. The centers for the bodies appear a little later and are found first in the dorsal vertebræ, appearing successively later in the vertebræ farther up and farther down. The ossified arehes unite with each other luring the first year of life, but their union with the body of the vertebra takes place between the third and eighth years. At a much later period five accessory centers of ossification are added to each vertebra. Two of these belong to the body and give rise to two annular plates of bone, the epiphyses, one for the upper or cephalic surface and one for the opposite or caudal surface. The remaining three centers belong respectively to the spinous process and the two transverse processes. The epiphyses do not acquire osseons union with the vertebra proper until about the twenty-fifth yeatr.

The so-called transverse process of a cervical vertebra, enclosing a foramen, and consisting of an anterior and a posterior part, includes more than the transverse process proper, since its anterior or ventral portion is the rudiment of a cervical rib. Iuring the time of the fusion of this rudimentary rib with the transverse process, the vertebral artery, which passes 
between them, is surrounded by the two processes, and thus the adult cervical transverse processes differ from those of the other vertebræ in the possession of a foramen.'

The atlas and the axis, being strikingly modified cerrieal vertebre, require special mention. The atlas contains less and the axis more than an ordinary vertebra, since that which corresponds to the body of the atlas never unites with it but fuses with the body of the axis to constitute its odontoid process.

The atlas presents two centers of ossification for its neural arches-the so-called posterior arch-just as other vertebræ do. Unlike other vertebræ, these centers do not unite with the body but become joined to each other on the ventral side of the position of the chorda by a piece of cartilage which results from the chondrification of the hypochordal brace, referred to on page 352. 'This forms the cartilaginous ventral or anterior arch of the atlas, which, in the first year of life, develops a center of ossification. The areh aequires bony union with the lateral parts between the fifth and sixth years.

The axis or epistropheus develops from the usual centers of ossification and from an additional one for its odontoid process. Bony union of the odontoid process with the proper body of the axis occurs in the seventh year. The odontoid process, in common with every other vertebral body, is traversed in the cartilaginous stage by the notochord.

The transverse processes of the lumbar vertebræ, like those in the cervical region, include not only the transverse process proper but also the rudiment of a rib.

The sacral vertebræ each present the usual oscific centers. Inasmuch as they become articulated firmly with the pelvie bones and undergo fusion to form a single adult bone, the sacrum, their form is much modified during the course of development. 'The transverse processes of each side coalcsec to form the lateral mass of the sacrum. Fich transverse process

${ }^{1}$ The point is made by some authorities, an Minot, that the bone does not grow around the artery, but that the artery grows through the ossifying tissue. 
consists, as in the cervical and the lumbar vertebræ, of the transverse process proper and a rudimentary rib, the center of ossification for the latter being quite distinct during early stages of development. The intervertebral disks of the sacral vertebræ begin to ossify in the eighteenth year, the process being completed in the twenty-fifth year.

The coccygeal vertebræ are quite rudimentary. Each one is ossified from a single piece of cartilage, and usually from but a single center of ossification. Occasionally the first piece of the coccyx develops from two ossific eenters, the process beginning at birth. Ossification begins in the second vertebra between the fifth and the tenth years; in the third, shortly before puberty; in the fourth, soon after puberty. The lower three picces fuse into one before middle life, and this unites with the first, and the latter with the sacrum, at variable periods thereafter.

\section{The Development of the Ribs and Sternum.-} Reference has been made in the preceding pages to the ligamenta intermuscularia as strips or bands of embryonal connective tissue lying between adjacent muscle segments, which have originated, in common with the sheath of the chorda, from the cells of the sclerotomes. The ligamenta intermuscularia become invaded by the costal processes of the primitive vertebral bows, the costal process, which is the ventral division of the tip of the bow, growing ventrad and penetrating the substance of the ligament to constitute a curved rod of connective tissue, the forermmer of the future rib. Thus there are formed connective-tissue representatives of the ribs, each of which is embedded in the looser connective tissue of the corresponding intermuscular ligament. It is by the development of cartilage within these curved rods of condensed mesenchyme, the membranous ribs, that the cartilaginous ribs are produced. The process of chondrification commences in the second month, but does not involve the proximal ends of the ribs, the tissue here beconing ligamentous and serving to bind together the ribs and the vertebre. Ribs are formed throughont the entire extent of the vertebral column, except in the coceygeal region, but while in 
the lower vertebrates the entire series goes on to mature development, in mammals, including man, their growth is arrested in the cervical, lumbar, and sacral regions. In the case of man and mammals only the thoracic ribs persist and become adult structures.

As the distal (ventral) extremities of the ribs advance toward the ventral median line, the tips of the first five, six, or seven each exhibit an enlargement. These broadened ends soon coalesce, thus forming on either side of the median line a continuous strip of cartilage, the anlages of the sternum. The other ribs remain free at their ends. The sternum is therefore produced from two lateral halves, a circumstance that explains some of its anomalies, as for example, cleft sternum, which is a condition due to arrested development or deficiency of union.

The ossification of the ribs begins in the second month of fetal life and from a single center for each. The process does not involve the entire rib, a portion near the distal extremity remaining cartilaginous and becoming the adult costal cartilage. Accessory centers of ossification for the head and tubercle appear between the eighth and fourteenth years of life.

The ossification of the sternum proceeds from numerous centers. There is one for the manubrium and from six to twelve for the gladiolus. The ensiform acquires a center of ossification in the early years of life, but for the most part remains cartilaginous.

Although, as stated above, the ribs of adult human anatomy are limited to the thoracie region, their rudimentary representatives are found throughout the other regions of the vertebral column. In the cervical, lumbar, and sacral regions each rudimentary rib becomes blended with the transverse process of the corresponding vertebrit to form the transverse process of human anatomy. It is from the persistence of the seventh rudimentary cervical rib and its failure to fuse with the corresponding transverse process that the anomaly of a free cervical rib results; while the presence of a thirteenth or lumbar rib, as occasionally met with, is due 
to the unusual development of the first lumbar rudimentary rib.

\section{The Development of the Head Skeleton.}

Just as the skeleton of the trunk consists of a dorsally situated bony case for the protection of the spinal corr and a series of ventral or hemal arches for the protection of the organs of circulation and respiration; so does the head skeleton comprise a bony case for the accommodation of the brain with smaller accessory osseons compartments for the organs of special sense, as the orbits and the nasal chambers; and also a ventrally situated apparatus which constitutes both a receptacle for the oral and the pharyngeal parts of the digestive system and a mechanism for the mastication of

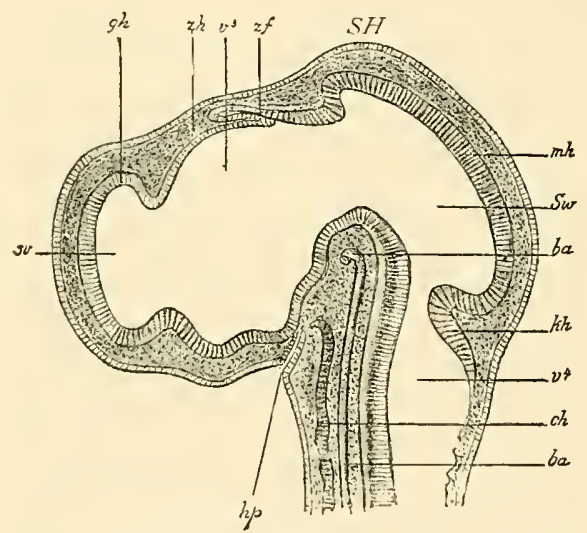

FIf. 162.-Median sagittal section through the head of a chick incubated four and a half days (after Hihalkovics) : $S H$, parietal (mid-brain) elevation; $s v$, lateral ventricle of the brain; $v^{3}$, third ventricle: $v^{4}$, fourth ventricle; Sw, aquednetus Sylvii; gk, cerebral vesicle; $z h$, between-brain (thalamencephalon); $m h$, midbrain; lih, cerebellum; $z f$, pineal process; $h p$, hypophyscal (or Rathke's) pocket; ch, chorrla; be, basilar artery.

food. The former part, the cranial capsule, or brain-case, is developer to a great extent from the connective tissue surrounding the head-end of the chorda, its origin thus being similar to that of the spinal column. On the other hand, the ventral parts, as the jaws and the hyoid bone and relater structures, constituting the so-called visceral skeleton, develop from the mesorlermic tissue of the visceral arches. As in the 
case of the trunk skeleton, the cranium is first outlined in membranous tissue resulting from the differentiation of the embryonal connective tissue which ensheatlis the head-end of the chorda, and also of the connective tissue of the visceral arches, this differentiation prodncing the membranous primordial cranium. The metamorphosis of the membranons cranium into cartilage brings about the cartilaginous stage of the cranium, while the replacement of the cartilage by bone is the final step in the process.

Bones that develop from centers of ossification in previonsly formed masses of cartilage are styled primordial bones, while those that are produced independently of cartilage, either in the skin covering the membranous cranium, or in the mucous membrane lining indentations in its walls, are known as covering or dermal bones. The development of bone is therefore said to be either endochondral or membranous. For the most part, the bones of the base of the skull are of endochondral formation, while those of the vault are dereloped in membrane. The membranous or dermal bones are similar in point of origin to the exoskeletonplacoid and ganoid scales-of certain fishes.

The Membranous Cranium.-The membranous braincase is differentiated from the young comnective tissue which ensheaths the anterior or head-end of the chorda. As previonsly stated, the anterior end of the chorda is at a point ventrad to the mid-brain vesicle, in the angle formed by the latter with the fore-brain, at a position corresponding with that of the pituitary borly (Fig. 162). The skeletogenous sheath of the chorda, in this situation as elsewhere, results from the multiplication of the cells of the sclerotomes, since this region of the body undergoes segmentation in common with the trunk. The number of head-segments is uncertain. According to recent investigations upon shark embryos, there are at least nine primitive segnents formed in the leadregion.

'The skeletogenous sheath of the chorda spreads out dorsarl to cover the brain-resicles. From the terninal point of the chorda, beneath the inter-brain, the sheath advanees ante- 
riorly to invest the fore-brain, which latter at this stage is bent over ventrad. From the part investing the fore-brain, a protuberant mass, the nasofrontal process, extends toward the primitive mouth-cavity, constituting the anterior or upper boundary of the latter. Meanwhile the mesenchymatic tissue of the visceral arches-that is, that part of the mesodermic tissue of these structures which does not form muscular tissue-is undergoing similar transformation into membranous tissne. The first visceral arch divides into an anterior or upper part, the maxillary process, and a posterior or lower mass, the mandibular arch, these being the membranous jaw arches. The four jaw arches, with the nasofrontal process, form the boundaries of the primitive monthcavity, the mandibular arches of the two sides having united in the median line to form its lower border, and the maxillary arches having fused with the lateral nasal and the nasofrontal processes to eonstitute its upper boundary.

The membranous primordial cranium, then, consists of a complete comnective-tissue investment for the brain-vesieles, of the membranons jaw arches, and of the hyoid and the branchial arches, and presents in its walls the indications of the cavities for special-sense organs in the shape of the surface invaginations which constitute respectively the otic vesiele, the lens-vesicle, and the nasal pits.

The Cartilaginous Cranium.-By the further differentiation of the membranous cranium the cartilaginons stage is attained. The development of cartilage begins in the second month. While the membranous cranium furnishes a complete capsule for the brain, the cartilaginons brain-case is deficient, since the process of chondrification does not affeet the regions of the future parietal and frontal bones. This is true at least of man and the higher vertebrates. In those cases where the skeleton remains permanently cartilaginous, as in selachians (sharks, log-fish, ete.), the entire brain-case participates in the chondrifying process. As the skull extends very much farther forward than the end of the chorda - which latter terminates at the position of the future sella turcica-the regions of the primitive skull are designated 
respectively chordal and prechordal (Kölliker), or vertebral and cvertebral (Gegenbater), according as they fall behind or in front of the end of the chorda.

The formation of cartilage begins in the region corresponding to the base of the future skull. On each side of the end of the chorda a mass or bar of cartilage is formed, extending forward and backward, this pair of parallel bars being designated the parachordal cartilages (Fig. 163,1). Farther forward,
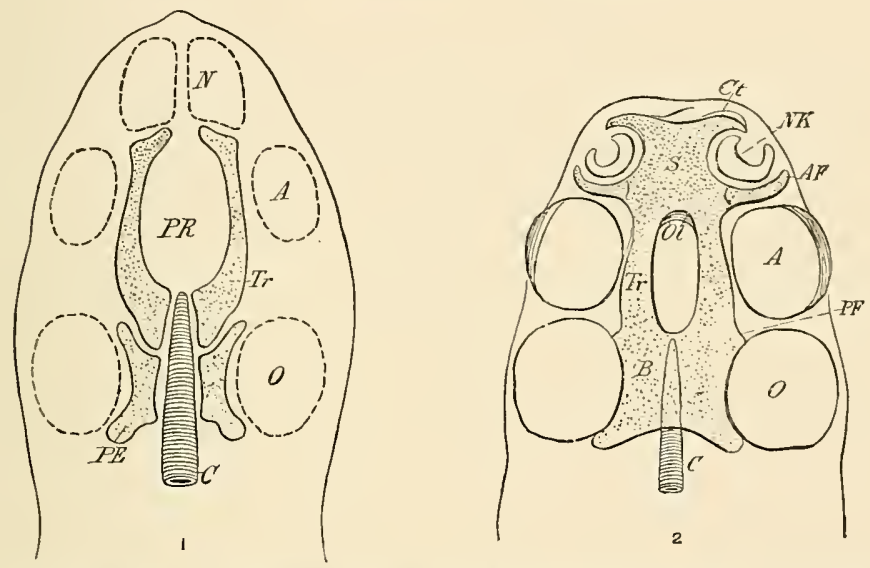

FIG. 163.-First fundament of the cartilaginous primordial cranium (from Wiedersheim): 1. First Stage: $C$, chorda ; $P E$, parachordal cartilage; $T r$, Rathke's trabeculæ cranii; $P R$, passage for the bypophysis; $N, A, O$, nasal pit, otic resicle, otocyst. 2. Second Stage: $C$, chorda; $B$, basilar plate; $T r$, trabeculæ cranii, which have become united in front to constitute the nasal septum $(S)$ and the ethmoid plate; $C t, A F$, processes of the ethmoid plate enclosing the nasal organ ; $O l$, foramina olfactoria for the passage of the olfactory nerves; $P F$, postorbital process; $N K$, nasal pit; $A, O$, otic and labyrinthine resicles.

in the prechordal region, another pair of cartilaginons masses is produced, known as the trabeculæ cranii. The latter are not straight bars, but have somewhat the form of a pair of calipers. In a short time the cranial trabeenle unite with each other, but not throughout their entire extent, an aperture being left at the position of the pituitary body. It is through this aperture that the oropharyngeal diverticulum, which forms the anterior lobe of the pituitary body, projects to come into relation with the diverticulum from the inter-brain, which produces the posterior lobe. At a later period ossifi- 
cation occurs here, as elsewhere in the hase of the skull, thus completely isolating the pituitary body from the wall of the pharynx. The parachordal cartilages also fuse with each other and with the cranial trabeculre, the four pieces now forming one mass. The process of chondrification extends to other parts of the membranous cranium so as to produce a cartilaginons brain-case, just as, in the case of the vertebral column, the dorsal extension of cartilage-formation gives rise to a case or canal for the spinal cord. As before stated, however, the chondrifying process does not affect the entire membranous cranium in the higher vertebrates, chondrification occurring around the position of the foramen magnum and in the lateral walls of the cranial capsule, while parts of the vault remain membranous. The anterior extremities of the united cranial trabeculæ become so modified in form as to constitute the plate of the ethmoid and the nasal capsule for the lodgement of the olfactory epithelium. In each lateral region the cartilaginous ear capsule is differentiated.

Meanwhile the cartilaginous visceral skeleton is developing from the membranous structures of the visceral arches. As in the case of the brain-capsule, the chondrifying process does not involve all parts of the membranous visceral skeleton, parts of the latter being replaced later by dermal or covering bones-that is, bones that develop in membrane without having been previously mapped out in cartilage.

In the first visceral arch, the formation of cartilage oceurs only in the mandibular portion, the maxillary process contimuing membranous. The cartilage of the mandibular arch appears in the form of a curved bar rumning ventrodorsally. This bar divides into a smaller proximal or dorsal piece, the palatoquadratum of comparative anatomy, and a longer distal or ventral segment, Meckel's cartilage. The palato-quadratum subsequently divides into two parts, the cartilaginous anlages respectively of the palato-pterygoir plate and the incus. Meckel's cartilage likewise undergoes division, there being separated from the chief mass a small proximal segment called the articulare, which is the forerunner of the future malleus. Thus the cartilaginous har of the mandibular arch 
has to do with the formation of certain of the ossicles of the middle ear as well as, to a limited extent, with the development of the mandible.

In the second visceral or anterior hyoid arch, chondrification also occurs, but not throughout its entire extent. A bar of cartilage, the hyoid bar or Reichert's cartilage, is produced in this arch and undergoes division into three segments, of which the proximal or dorsal is the forerumner of the future stapes of the middle ear, while the other two pieces represent respectively the styloid process and the lesser horn of the hyoid bone. The tissue intervening between the position of the styloid process and the lesser hyoid cornu does not chondrify in man but remains membranous and becomes the stylohyoid ligament (see Fig. 169).

In the third visceral arch, or the posterior hyoid arch, a rod of cartilage develops which represents the greater cornu of the future hyoid bone. Ventral to this, there is formed a merlian unpaired piece of cartilage, the copula, belonging to the arches of the two sides, which later develops into the body of the os hyoides.

To summarize, the head skeleton in the cartilaginous stage of development presents an imperfect cartilaginous brain-case, capsules for the organs of smell, sight, and hearing, and a cartilaginous visceral skeleton, the several parts of which map out the lower jaw, the hyoid bone, the styloid process, and the ossicles of the middle ear.

The Osseous Stage.-The bony condition of the head skeleton is brought abont in part by the development of bone from centers of ossification in the cartilages described above, and in part by the growth of covering or dermal bones in the integument covering those areas which are deficient in cartilage; in other words, by both endochondral and membranous ossification. It may be stated in general terms that the bones of the base and of the sides of the skull, including the auditory ossicles, the ethmoid, and the inferior turbinated bone, are produced by ossification in cartilage and are hence called primordial bones; and that the bones of the rault of the cranium, and for the most part of the face, result from the membranous method of 
ossification, and are therefore styled dermal or covering bones. Some of the individual bones, however, are partly of car-

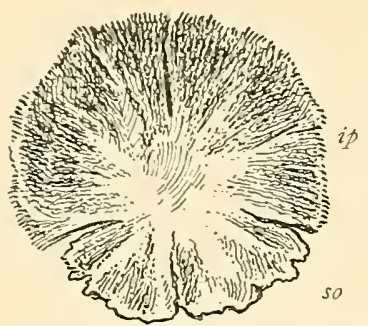

F1G. 161.-Tabular part of occipital bone of about fifth fetal month, inner surface: ip, interparietal, which is ossified in membrane; so, supra-occipital, ossified in cartilage. tilaginous and partly of membranous origin, the several portions remaining permanently distinct in certain lower vertebrates, but in man uniting so intimately with each other as to present no trace of their previously separate condition.

The occipital bone consists of two genetically distinet parts, the superior or interparietal portion, which is a dermal bone, and the occipital bone proper, which is of cartilaginous origin. The ossification of the latter occurs from four centers, one on each side of the foramen magnum for the condylar portions, one in front of the foramen for the basilar process, and one posterior to that aperture for all the tabular portion of the bone not belonging to the interparietal segment. Ossification begins in these centers early in the third fetal month and proceeds at such rate that at the time of birth the bone consists of four bony parts which are separated from each other merely by thin layers of cartilage. Sinee in some animals these parts remain separate throughout life, they are designated by morphologists, respectively, the exoccipitals, the basi-occipital, and the supra-occipital (Fig. 165). The supra-occipital is augmented by the mnion with it of the interparietal portion, a eovering or dermal bone that ossifies from two centers, and that begins to fuse with the supra-occipital near the end of the third month of fetal life. Consisting at birth of four distinet parts, separated by eartilage, the occipital leecones a single bone by the end of the third or fourth year by the bony union of the separate segments.'

The temporal bone is made up of three genetically distinet

${ }^{1}$ In some cases the union of the interparietal with the supra-occipital is incomplete, the adult bone then presenting two transverse fissures which pass, one from each lateral angle, toward the median line. 
parts, the squamosal or squamozygomatic, the petrosal or petromastoid or periotic, and the tympanic. At the time of birth these three elements of the bone are still separate from each other, the tympanic being an incomplete ring, and the petro-
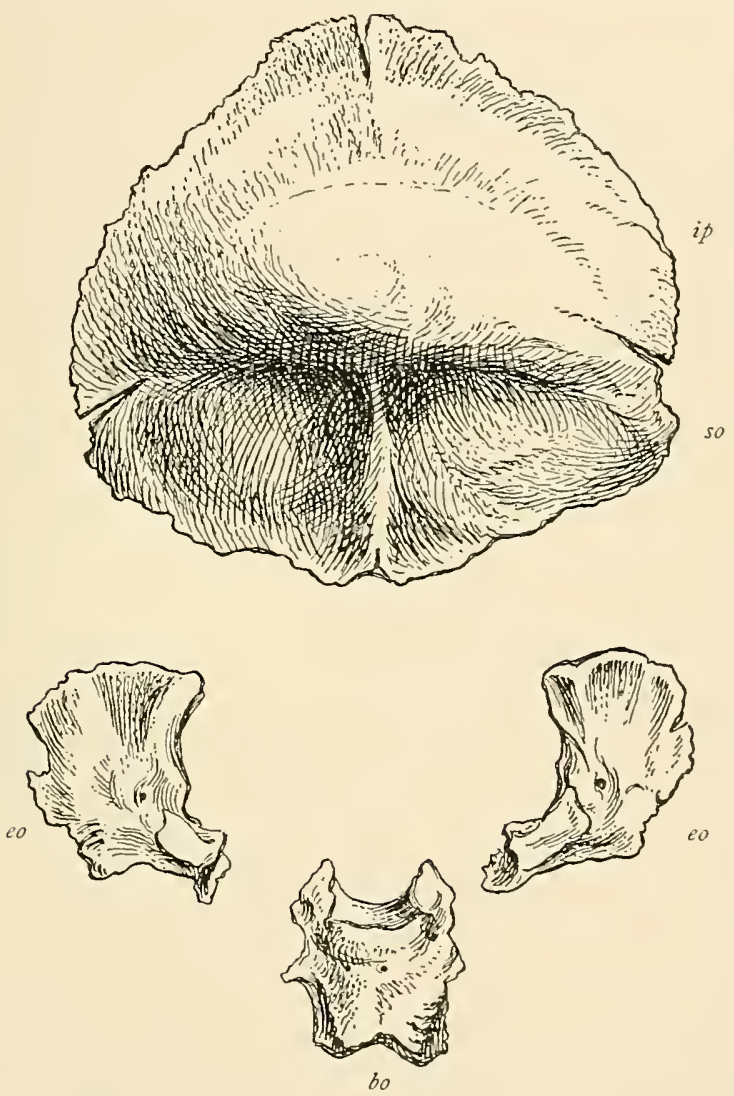

FIG. 165.-Occipital bone at birth, external surface: ip, interparietal; so, supraoccipital; $\epsilon o$, exoccipitals; bo, basi-occipital.

mastoid being still withont a mastoid process. The petromastoid is the only part of the temporal bone that is outlined in cartilage, the squamozygomatic and the tympanic being represented in the eartilaginous stage of the cranium by membranous tissue.

The squamozygomatic (Fig. 166) is ossified in previously 
formed membrane from a single eenter of ossification, which appears in the lower part of this segment at about the seventh week. The process of bone-formation extends in all direc-

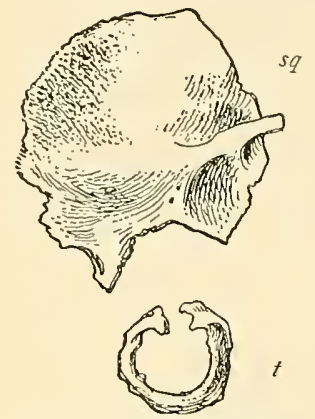

FIG. 166.-Squamozygomatic ( $s q)$ and tympanic $(t)$, of temporal bone at wirth. tions from this center, but especially upward into the squamosa and outward and forward into the zygoma.

The periotic or petromastoid results from the ossification of the cartilaginous ear-capsule, which latter constitutes a part of the cartilaginous portion of the early cranium. It should be remembered that the essential part of the organ of hearing, the internal ear, is differentiated from a small poneh of epithelium, the otic vesicle, which is produced by an infolding or invagination of the surface ectoderm, and that it is the cartilaginous tissue enelosing the otic vesicle and its outgrowths, the semicircular canals and the cochlea, that constitutes the cartilaginous ear-capsule.

The ossification of the periotic is usually deseribed as proceeding from three centers. The first of these, the opisthotic, makes its appearance in the latter part of the fifth month on the outer wall of the capsule, at a point corresponding to the position of the promontory, whence the formation of bone spreads in such manner as to produce that part of the petrosa which is below the internal auditory canal. A second center, the pro-otic, appears a little later over the superior semicireular canal and gives rise to that part of the petrosa above the internal auditory meatus, and also to the inner and upper part of the mastoidea. The third nucleus, the epiotic, arises in the neighborhood of the posterior semicircular canal. Ossification proceeds rapidly, the three parts speedily uniting to form one bone, the periotic or petromastoid. The petrous portion of the periotic is the more important and the more constant. The mastoid is of variable size in different animals, and in the human species, at birth, it is flat and devoid of the mastoid process which is so conspieuous in the mature 
condition of the skull. The mastoid process develops during the first two years of life, but its air-cells do not appear until near the age of puberty.

The pars tympanicus, or the tympanic (Fig. 166), which constitutes the bony part of the wall of the external auditory meatus, is ossified in membrane from a single center of ossification. This center appears in the third fetal month in the lower part of the membranous wall of the external canal, from which point the process of bone-formation extends upward on either side so as to form an incomplete bony ring, open above. This tympanie ring is situated external to both the ear capsule and the ossicles of the middle ear and gives attachment to the periphery of the tympanic membrane. The further growth of the tympanic ring being in the outward direction, it beeomes a curved plate or imperfect eylinder of bone which constitutes the bony wall of the external anditory canal. At birth, the pars tympanieus still has the form of the incomplete ring, its further development taking place during the first few years of life. The extremities of the ring unite with the squamozygomatic before birth. The tympanic unites also with the petrosa except in a region adjacent to the proximal end of Meckel's cartilage, where an aperture is left which is the petrotympanic or Glaserian fissure. Since upon the part of Meckel's cartilage which is thus enelosed by the union of the two bones is formed the long process of the malleus, the presence of this process in the Glaserian fissure is accounted for.

The styloid process of the temporal bone belongs to the visceral-arch skeleton. It ossifies in two parts in small masses of cartilage that belong to the anterior liyoid arch. One, the tympanohyal, gives rise to the base of the process (Fig. 170); it begins to ossify before birth and soon unites with the temporal. The other segment, the stylohyal, undergoes ossification later and joins with the trmpanohyal only after adult age is reached. Sometimes it remains separate throughout life.

The sphenoid bone is for the most part ossified in cartilage. The body of the bone is represented in the fetus by two 
separate parts, the posterior body or basisphenoid (Fig. 167, $b s)$, which includes all that part of the body of the mature bone which is posterior to the olivary eminence and to which belong the greater wings; and an anterior body or presphenoid $(p s)$, situated in front of the olivary eminence, to which belong the lesser wings. The ossification of the basisphenoid proceeds from two centers placed side by
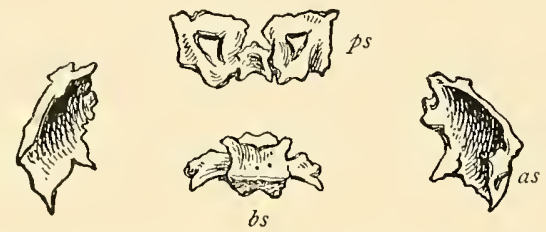

Fig. 167.-Sphenoid bone, fifth or sixth fetal month; seen from above: $p s$, presphenoid or anterior body, with lesser wings; as, greater wings; $b s$, basisphenoid or posterior body.

side, which appear in the eighth week. Two months later two secondary centers appear for the lateral parts of the body. The presphenoid likewise develops from two centers, which are apparent in the ninth week. The union of the presphenoid with the basisphenoid oceurs in the seventh or eighth month. Each greater wing develops from a single center of ossification, which is present in the eighth week. The process of ossification spreads from this center to produce not only the greater wing but also the external pterygoid plate. The greater wings remain separate from the body until some time during the first year after birth. Each lesser wing ossifies from a center that appears about the ninth week. The lesser wings unite with the presphenoid in the sixth fetal month.

The internal pterygoid plate differs from the other parts of the sphenoid in that it does not ossify in cartilage but in membrane. It is therefore a covering bone. Its center or centers of ossification appear in the fourth month in the connective tissue in the lateral watls of the orophlaryngeal cavity. In many animals this plate acquires no connection with the external pterygoid plate but remains throughout 
life a distinet bone, the pterygoid. In man it fuses with the external plate in the fifth month.

The presphenoid with its attached lesser wings, and the basisphenoid, to which are united the greater wings and the pterygoid plates, remain permanently separate bones in some animals. In man, as noted above, the two parts of the borly of the bone unite shortly before birth, although the greater wings remain separate intil some months after that event.

The ethmoid bone and the inferior turbinate are formed in cartilage, resulting from the ossification of the posterior portion of the cartilaginous nasal capsule (Fig. 168, $m$ ). 'The

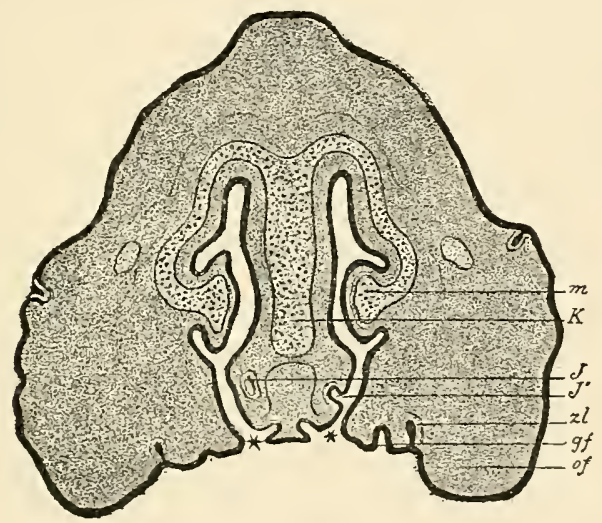

Fig. 168.-Cross-section through the head of an embryo pig $3 \mathrm{~cm}$. (1.2 in.) long, crown-rump measurement. The nasal carities are seen to be in communication with the oral cavity at the places designated by a $*: K$, cartilage of the nasal septum ; $m$, turbinal cartilage; $J$, organ of Jacobson; $J^{\prime}$, the place where it opens into the nasal carity; $g f$, palatal process; of, maxillary process; $z l$, dental ridge.

latter represents the anterior extension of the cartilaginons trabeculie cranii so modified as to constitute a receptacle for the olfactory epithelium. The anterior part of this capsule remains cartilaginous throughout life as the septal and lateral cartilages of the nose. By the ossifieation of the posterior part of the nasal capsule the ethmoid and the inferior turbinate bones are produced. Ossification, beginning in the fifth month, involves the lower and the middle turbinals and a part of the lateral masscs. The ossification of the superior turbinal, of the vertical plate, of the erista galli, and of the 
remaining parts of the lateral masses is effeeted after birth. The bony union of the lateral masses with the median plate is completed between the fifth and seventh years.

The frontal bone is a covering or dermal bone, being ossified in membrane from two centers of ossification, one for each lateral half. These centers are situated above the orbital arehes and are first apparent in the seventh week. At birth, the two halves of the bone are still separate, their union not occurring until during the first year of life. Sometimes the union fuils to take place, the condition of the persistent frontal or metopic suture being known as metopism. Metopism is considerably more common in European skulls than in those of lower type.

The parietal bone is also ossified in membrane. It develops from two nuclei which soon eoalesce. Their position corresponds to that of the future parietal eminence.

The bones of the face are for the most part dermal bones. Of these, the upper and the lower maxille and the palate bones belong to the visceral-arch skeleton. The others develop in the membranous wall of the ermial eapsule.

The nasal and lacrimal bones ossify each from a single center, which appears in the eighth week.

The malar is ossified in membrane from three nuclei, the process beginning in the eighth week.

The palate bone is formed in mucous membrane from a single center which is situated at the junction of the vertical and the horizontal plates.

The vomer develops from two centers of ossification which appear at the back part of the cartilaginons nasal septum. Fach center gives rise to a lamina of bone, the two lamine grarlually uniting with each other from behind forward, and embracing between them anteriorly the septal eartilage.

The vomer and the palate bone are examples of the formation of bone in mucous membrane. The eenters of ossifieation first appear in the eighth weck in each cace.

The skeleton of the visceral arches includes the upper and lower maxillae, the hyoid bone with a part of the styloid process, the car ossicles, and the palate bones. The palate 
bones have been referred to above. These bones of the visceral-arch skeleton are partly primordial and partly membranous.

The superior maxilla comprises two parts, the superior maxilla proper and the intermaxillary bone. Ithile these intimately unite in man, in some animals, as the dog, they are permanently distinct, the intermaxillary bone constituting the important and conspicuous premaxilla of the dog. The superior maxilla ossifies in membrane-within the membranous maxillary process of the first visceral arch-from an uncertain number of centers. It scems probable that there are three nuelei of origin, one for the palate process, one for the malar part of the bone, and one for the portion internal to the infra-orbital foramen and a part of the nasal wall. The formation of the antrum begins in the fourth month by the development of a recess or fossa on the inner or nasal wall of the bonc.

The palate process is formed by the growth, on the inner aspect of the bone, of a shelf-like projection which advances toward the median line until it meets and unites with its fellow of the opposite side (Fig. 156). The horizontal plate of the palate bone develops similarly and very shortly after, and thus is produced the hard palate, which separates the nasal chambers from the month. 'The two halves of the hard palate unitc first in front, their union being completed by the twelfth week. If union is incomplete, the anomaly of cleft-palate results. The intermaxillary segment begins its development in the seventh or eighth week upon that part of the nasofrontal process which lies between the nasal apertures. In the fifth month the intermaxillaries fuse with the maxillæ, the line of union being inclicated by a suture which is apparent upon the oral surface of the palate processes. The intermaxillaries contain the germs of the four incisor teeth. As previonsly mentioned, deficiency of union between the maxilla and the intermaxillary results in the deformity of hare-lip. Obvionsly, the hiatus in hare-lip will be found to be not median, but lateral, corresponding to the position of the line of nornal nnion. 
The lower jaw or mandible is intimately associated in its derelopment with that of the malleus and incus of the middle ear. Inasmuch as these three bones are differentiated from the cartilaginous and membranous visceral skeleton of the first visceral arch it is desirable to consider their development together.

As described above, the membranous jaw-arches form the lateral and lower boundaries of the month-cavity, the first visceral arch dividing into the maxillary process and the mandibular arch. There appears in the mandibular arch a bar of cartilage which abuts by its proximal extremity upon the outer wall of the auditory labyrinth. This cartilaginous

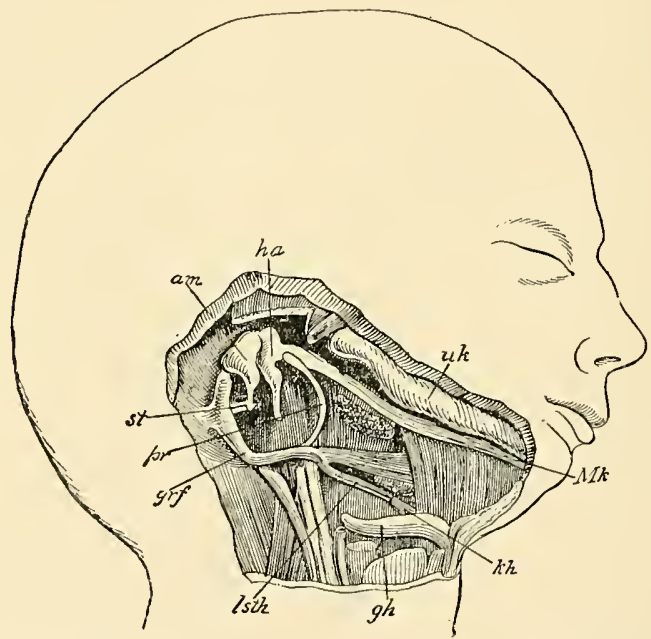

Fig. 169.--Head and neck of a human embryo eighteen weeks old with the viseeral skeleton exposed (after Kölliker), magnified. The lower jaw somewhat depressed in order to show Meckel's eartilage, which extends to the malleus. The tympanic membrane is removed and the annulus tympanicus is visible: ha, malleus, which passes uniuterruptedly into Meckel's cartilage, $M k$; $u k$, bony lower jaw (dentale), with its condyloid proeess artieulating with the temporal bone; am, ineus; st, 'stapes; $p r$, annulus tympanieus; $g r f$, proeessus styloideus; $l s t h$, ligamentum stylohyoideum; $k h$, lesser cornu of the hyoid bone; $g h$, its greater cornu.

rod segments into a distal portion, Meckel's cartilage (Fig. $169, M K k$, and a smaller proximal picee, which is called, in comparative anatomy, the palatoquadratum. From the palatoquadratum a process, the palatopterygoid process, 
grows toward the roof of the month-carity and becomes a separate segment. The piece of cartilage remaining, which represents the proximal end of the original bar, undergoes ossification, becoming the incus (Fig. 169, am). The posterior or proximal extremity of Meckel's cartilage, becoming a partly separated cartilage, the articulare, ossifies to produce the malleus (Fig. 169, ha). Though the form of the malleus is recognizable, it is still in direct continuity with Meckel's cartilage. In the opposite direction it is articulated with the incus. As the tympanic ring develops, and the interval below, between this ring and the petrosa, is gradually narrowed to the petrotympanic or Glaserian fissure, the malleus comes to lie within the tympanic cavity, being continuous, through the fissure, with Meckel's eartilage. Upon the separation of the malleus from the curtilage of Meckel, the long process of the malleus represents the former bond of union and therefore occupies, in the mature state, the Glaserian fissure. The joint between the malleus and the incus represents the primitive vertebrate jaw articulation. In the shark, for example, the mandibular joint is between the two pieces into which the cartilaginous bar of the first visceral arch divides-that is, between the palatoquadratum and the represcntative of Meckel's cartilage, the mandibulare. In mammals, however, the malleus, as we have seen, loses its connection with the mandible, the joint between the latter and the skull, the temporomaxillary articulation, being secondarily acquired in a manner to be pointed ont hereafter. While the malleus develops for the most part by ossification in cartilage, its long process develops in membrane as a small covering or dermal bone, the angulare.

The membranous lower jaw with its enclosed bar of cartilage becomes osseous, not by the ossification of the cartilage, but by the development of a easing of bone within the surrounding membrane. In other words, the lower jaw develops chiefly by the intramembranous method of boneformation. Several centers of ossification appear, and from these the process of bone production extends rapidly, forming, by the fourth month, a covering or dermal bone, the 
dentale (Fig. 169, uk), which is situated mainly on the outer side of Meckel's cartilage. A smaller plate appears on the inner side. Thus the cartilage comes to be surrounded by an irregular cylinder of bone. The cartilage of Meckel plays a comparatively unimportant part in the ossification of the lower jaw-bone and begins to degenerate in the sixth fetal month. Its distal extremity, however, undergoes ossification, thus aiding in the formation of a small part of the mandible near the symphysis; while a posterior segment, with the fibrous tissue encasing it, which extends from the temporal bone to the inferior dental foramen, persists as the internal lateral ligament of the lower jaw. With these exceptions, Meckel's cartilage entirely disappears. The angle of the mandible and a small part of the ramus are also ossified in cartilage, which latter is developed independently of Meckel's cartilage. From the posterior part of the dentale the condyloid process develops and becomes articnlated with the glenoid fossa of the temporal bone, thus establishing the temporomaxillary articulation. This joint, as previously stated, is a secondary one and replaces in mammals the primitive articulation between the mandibulare and the palatoquadratum of the lower vertebrates.

At birth, the two lateral halves of the inferior maxilla are united at the symphysis by fibrons tissue; bony union occurs during the first or second year after birth.

To summarize, the inferior maxilla develops as a part of the visccral-arch skeleton and is chiefly a covering bone, since, with the exception of the angle, a portion of the ramus, and a smail part near the symphysis, which are of cartilaginous origin, it is formed by the membranous method of ossification. The two other products of the mandibular areh, the mallens and the ineus, are ossified from cartilage, with the exception of the processus gracilis of the malleus, which is of membranous origin.

The development of the hyoid bone, of the styloid process of the teinporal bone, and of the stapes was referrert to in considering the cartilaginons visecral-arch skeleton, but for the sake of elearness and completeness it may not be amiss to 
repeat, in this connection, some points previously mentioned.

The membranous anterior hyoid or second visceral arch, at a certain stage of development, presents, in its interior, the dorsoventral cartilaginous bar known as Reichert's cartilage. This is parallel with Meckel's cartilage, and, like it, is in contact by its dorsal or eranial end with the onter wall of the auditory labyrinth. A shorter bar of cartilage appears in the third visceral arch, which latter is known also as the posterior hyoid arch. Together, these two cartilaginous elements furnish the stapes of the middle ear and the hyoidean apparatus, the latter consisting of the hyoid bone, the stylohyoid ligaments, and the styloid processes. In man the

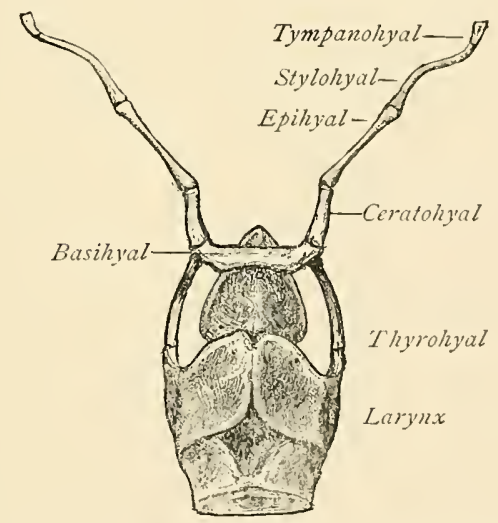

FIG. 170.-Hyoidean apparatus and larynx of dog.

hyoidean apparatus is somewhat rudimentary, but in the dog and many other mammals it is present in its typical form (Fig. 170). In such animals the stylohyoid ligament of human anatomy is represented by a bone, the epihyal, the hyoid bone being, therefore, connected with the skull by a series of small bones articulated with each other. All the elements of the hyoidean apparatus, save the body and the greater cormua of the hyoid bone, are produced by Reichert's cartilage; the hyoid body, known in comparative anatomy as the basihyal, and the greater cornua, or the thyroliyals, ossify 
from the cartilage of the third arch, the cartilage for the body being a median unpaired segment known as the copula.

Reichert's cartilage undergoes division into five segments. The segment at the cranial end, upon ossification, becomes the stapes.' This ossicle, by the closing of the walls of the tympanic eavity, is isolated from the other segments. The second piece, the tympanohyal, ossifies to form the base of the styloid process and ankyloses firmly with the temporal bone at the point of junction of the periotic portion of that bone with its tympanic plate. The third portion, the stylohyal, forms the lower part of the styloid process. It undergoes ossification later than the tympanohyal and does not aequire osseous union with it until the time of adult age. It sometimes remains separate throughout life. The fourth segment, the epihyal, does not even become cartilaginous in man, but remains fibrous, constituting the stylohyoid ligament. In most mammals it ossifies, to form a distinct bone, the epihyal. The ventral extremity of the cartilage of Reichert, the ceratohyal, produces the lesser cornu of the hyoid bone.

\section{THE DEVELOPMENT OF THE APPENDICULAR SKELETON.}

The upper and lower limbs articulate with the trunk through the merlium respectively of the pectoral and pelvic girdles, the former being constituted by the scapula and the clavicle, and the latter by the ossa innominata. As in the case of the axial skcleton, the bones of the limbs in their development pass successively through a membranous and a cartilaginous stage.

The general development of the upper and lower extremities is described in a later section. As stated in that account, each limb-bud is to be regarded as an ontgrowth from several primitive segments, the tissue composing the little bud-like process subsequently differentiating into the muscular, cartilaginous, and connective-tissue clements of the member. The origin of each limb from more than one primitive segment has been established chicfly by embryologieal investi- 
gations upon the lower vertebrates, and is borne out by the fact that each extremity receives its nerve-supply from a series of spinal nerves instead of from the nerre-trunk of any one segment.

The Development of the Pectoral and the Pelvic Girdles.-The pectoral or shoulder girdle consists in its earliest stage of a pair of curved bars of cartilage, each of which is made up of a dorsal limb occupying approximately the position of the future spine of the scapula and approaching but not touching the spinal column, and a rentral segment lying near the rentral surface of the trunk. At the angle of union of the dorsal and rentral parts is a shallow depression, an articular surface, which represents the point of articulation with the future humerus.

The scapula is developed, except its coracoid process, from the dorsal part of the primitive shoulder-girdle. This soon acquires a form resembling that of the adult scapula with the infraspinous portion of the bone very much shortened. Ossification begins at the neek of the scapula about the eighth week, and in the third month extends into the spine. The ventral part of the cartilaginous shoulder-girdle extends almost to the median line of the chest-wall. It divides into two diverging bars, the lower one of which undergoes ossification in birds and in some other vertebrates to form the conspicuous coracoid bone. In mammals, however, it aborts and gives rise to a smaller element, the coracoid process of the scapula. At birth the human scapula is but partially ossified, the coracoid process, the acromion, the edges of the spine, the base, the inferior angle and margins of the glenoid cavity being cartilaginous. The coracoid process ossifies from a single center and acquires osseous union with the body of the bone at about the age of puberty. The acromion ossifies from two or three nuclei and joins the spine between the twenty-second and twentyfifth years. Still other centers of ossification appear from time to time. Thus there is an accessory center for the base of the coracoid and the adjacent part of the glenoid cavity, 
and one at the inferior angle of the bone, from which latter ossification extends along the vertebral border.

The clavicle does not develop from the primitive shouldergirdle, but is formed in membrane, for the most part, as a dermal bone. Its ossification begins in the sixth or seventh week, before that of any other bone in the body. Subsequently, cartilaginous epiphyses are added, one at each end. It is by means of the epiphyses that the bone grows in length.

The cartilaginous pelvic girdle consists of a pair of cartilages, which are united with each other by their ventral extremities, and each of which, by its dorsal end, is artieulated with the sacral region of the cartilaginous spinal column. At about the middle of each cartilage, on its outer surface, is a depression representing the future acetabular fossa. Anterior to the depression is a large aperture, the thyroid foramen, the upper and lower boundaries of which are respectively the pubic and ischiatic rods or bars, which make up the ventral portion of the cartilage, while posterior to the fossa is the iliac segment, which has a somewhat irregular plate-like form. Ossification begins in the third month, proceeding from three centers, one for each of the three divisions of the innominate bone. At the time of birth a large proportion of the original cartilage is still present, the os pubis, the ischium, and the ilinm being separated from each other up to the age of puberty by strips of cartilage. The isehium and the pubes nnite first, and later aequire osseous union with the ilium. In addition to the three primary centers of ossification, other and seeondary nuclei appear at a later date in the crest of the ilium, the tuberosity of the ischium, and in the various spines and tubercles.

The skeleton of the free portions of each extremity, consisting at first of a eontinuous mass or rod of partially metamorphosed mesenchymal tissue, undergoes division into segments which represent the skeleton of the alm or of the thigh, of the forearm or of the leg, and of the land or of the foot. This segmentation corresponds with that of the entire mass 
of the limb, both as to extent and order of appearance (sec page 380). Nuclei of chondrifieation now appear, one in the center of each skeleton-piece, from which eartilage formation extends toward either end. The several cartilaginous elements thus produced present approximately the respective forms of the future bones. The larger eartilages are present in the upper extremity in a six weeks' embryo, but not until somewhat later in the lower limb. All the bones of the extremities are of endochondral origin.

The long bones develop in a fairly uniform manner. The shaft or diaphysis ossifies from a single center, while the two epiphyses each present several centers. The centers for the diaphyses appear at about the eighth week, ossification proceeding at such rate that at birth only the ends of the long bones are cartilaginous. 'The centers for the epiphyses appear at varions times after birth. Osseous union between the diaphysis and the epiphyses does not ocemr mntil the growth in length of the bone is completed. As the details concerning the time of appearance and the number of these centers are to be found in the text-books of anatomy, they are omitted here.

- Each bone of the carpus and of the tarsus ossifies from a single center, exeept the os calcis, which has two ossific nuclei. The bones of the carpus are entirely cartilaginous at birth, their ossification beginning in the first year with the appearance of a center in the scaphoid. The pisiform bone is the last of the series to ossify, its ossification beginning in the twelfth year.

The bones of the tarsus begin to ossify earlier than those of the carpus. The os calcis and the astragalus present osseous nuclei in the sixth or serenth fetal month, and the cuboid shortly before birth. With these exceptions the tarsal bones undergo ossification between the first and the fourth years.

The metacarpal and the metatarsal bones and the phalanges present each a center of ossification for the shaft and one epiphyseal center. In the case of the phalanges and of the metacarpal bone of the thumb and of the great toe, the epiphyseal center is at the proximal extremity, while in the 
remaining metatarsal and metacarpal bones it is at the distal end. ${ }^{1}$ The ossification of the shaft begins in the eighth or ninth week of fetal life; of the epiphyses, not until several years after birth. The development of the ungual or distal phalanges-of the hand, at least-is peculiar in that the ossification begins at the distal extremity, instead of in the middle of the shaft.

\section{THE DEVELOPMENT OF THE LIMBS.}

The limbs of vertebrates develop from little bud-like processes (Fig. 51) that spring from two lateral longitudinal ridges, situated one on each side of the body. 'These ridges are not exactly parallel with the merlian plane of the body, but converge somewhat toward that plane as they approach the caudal end of the embryo. It results from this cireumstance that the posterior limbs are placed closer together than the anterior. In man, the limb-buds appear soon after the third week. Each bud contains a basis of primitive eonnective tissue contributed by several somites, as well as muscular strueture, which is the offshoot from the muscle-plates of a less number of primitive segments.

The assumption of the origin of each limb-bud from more than one primitive segment is borne out by the nerve-supply of the fully-formed limb, each extremity being innervated by a number of spinal nerves (compare page 344 ). The connective tissne of the limb-bud produces the bony structures of the limb, while the outgrowths from the muscle-plates contribute their musculature.

In the fifth week each limb-lnd becomes divided, by a transverse groove, into two segments (Fig. 48, 12, 13), of which the distal part becomes the hand or foot, while the proximal portion very soon afterward divides into the forearm and arm or leg and thigh. Even as early as the thirty-second day, the digitation of the limb-buds-in the ease of the upper extremities-is indieated by four longitudinal parallel lines or grooves on the distal extremity

'Quain's Anatomy, 10th edition. 
of each (Fig. 48, 14). By the conversion of these grooves into clefts, the fingers appear, in the sixth week, as separate outgrowths. The development of the upper extremities precedes that of the lower by twelve or fourteen days, so that, when the fingers are present as distinct projections, the toes are just being marked off in the manner noted above for the fingers. The toes begin to separate, by the deepening of the intervening clefts, from the fiftieth to the fifty-third day. By the end of the eighth week, the fingers are perfeetly formed, with the exception of the nails. The nails have their beginning in the seventh or eighth week, in little claw-like masses of epidermal cells, which are attached to the tips of the digits instead of to the dorsal surfaces. Subsequent transformations result in bringing the nail into its normal position on the dorsal surface of the distal phalanx. The nails are well formed by the fifth month, at which time the covering of modified epidermal cells begins to disappear. The extremity of the nail, however, does not break through so as to projeet beyond the finger-tip until the seventh month. A more complete aceount of the development of the nails will be found in connection with the origin of the skin (page 247).

The Position of the Limbs.-The paddle-like limbbuds at first projeet laterally almost at right angles with the axis of the trunk. At this time the future dorsal surface of each limb looks toward the back of the fetal body (dorsad), the future flexor surface toward its anterior aspect (ventrad), while the first digits-the future thumb and great toe-and consequently the radius and tibia, occupy the side of the member that is direeted headward or cephalad, the future little tinger and fifth toe with the ulua and fibula looking caudad. As the limbs enlarge and differentiate into their respective segments, they apply themselves to the ventral surface of the body, this change in position being facilitated by the occurrence of the future elbow- and knee-flexions, which cause the flexor surfaces of the forearm and leg, respectively, to approach the corresponding surfaces of the upper arm and thigh. At about the same time, the distal segments, the hand and foot, become bent in the opposite 
direction, producing the condition of the limbs that is permanent in the Amphibia-that is, the condition in which the dorsal surfaee of the proximal segment of the limb faces in the same direction as the dorsal surface of the trunk, while the middle segment is flexed and the distal is extended. To establish the permanent eondition of the human limbs, there ocenr an outward rotation of the arms and an inward rotation of the lower extremities, on their long axes. The thumb and radius, therefore, instead of looking eephalad, are now direeted dorsad-with the forearm in the supine position and the arm outstretehed-or laterarl, away from the median plane of the body, if the arm hangs by the side in the anatomieal position. By the inward rotation of the lower limb, the great toe and the tibia eome to lie toward the median plane of the body, eausing the extensor surface to look ventrad, the flexor surfaee, dorsad. 


\section{TABULATED CHRONOLOGY OF DEVELOPMENT.}

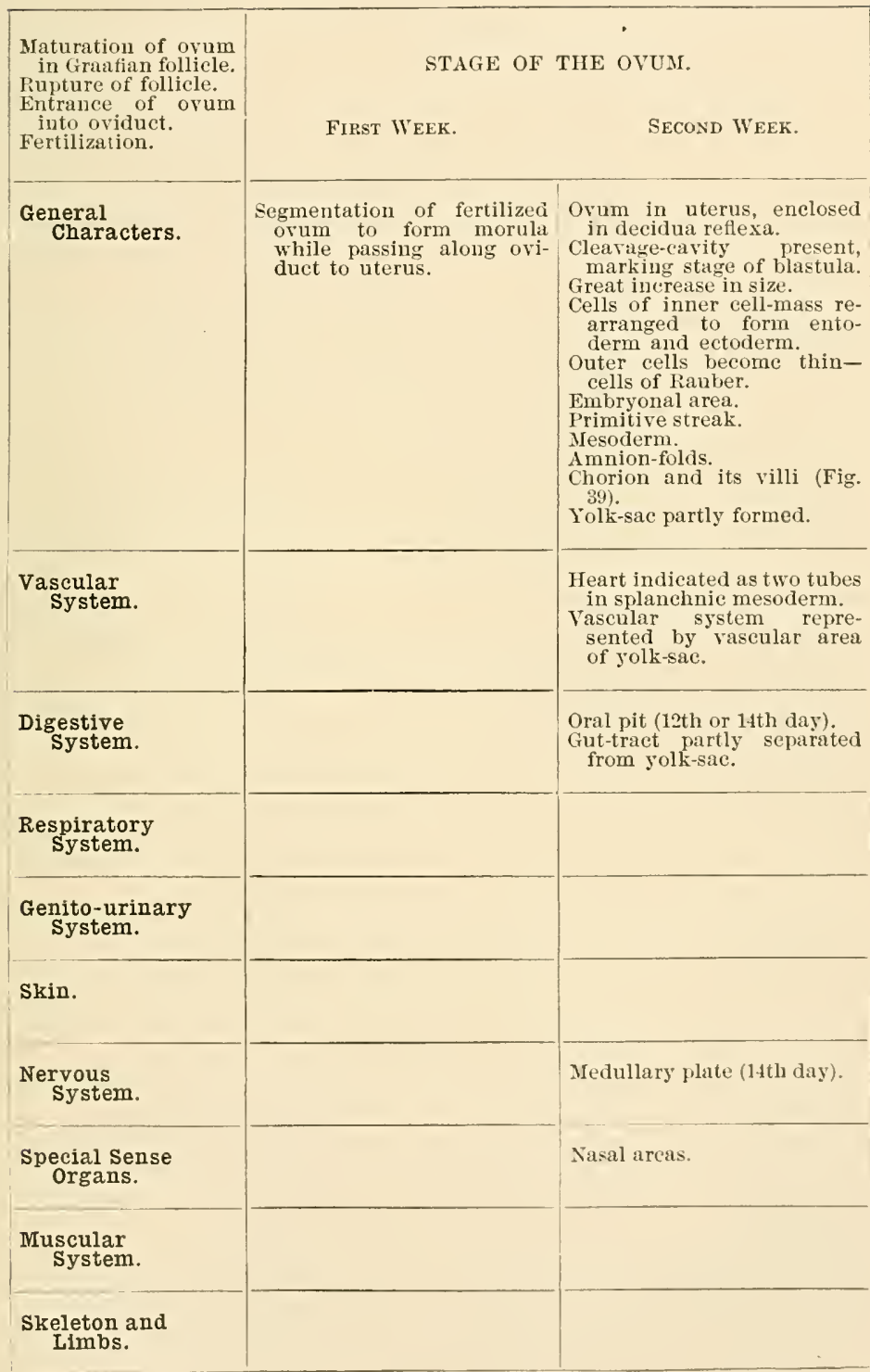


Tabulated Chroxology of Development (Continued).

\begin{tabular}{|c|c|c|}
\hline & \multicolumn{2}{|c|}{$\begin{array}{l}\text { STAGE OF THE EMBRYo. } \\
\text { THIRD WEeK. } \\
\text { Fourth WeEk. }\end{array}$} \\
\hline $\begin{array}{l}\text { General } \\
\text { Characters. }\end{array}$ & $\begin{array}{l}\text { Body of embryo indicated. } \\
\text { Dorsal outline concave. } \\
\text { Vitelline duct (21st day). } \\
\text { Amnion. } \\
\text { Segmentation of paraxial } \\
\text { mesoderm begins. } \\
\text { Visceral arches and elefts } \\
\text { begin to appear. } \\
\text { Nasofrontal process. } \\
\text { Allantoic stalk (Fig. } 46 \text { ). }\end{array}$ & $\begin{array}{l}\text { Marked flexion of body (21st } \\
\text { to } 23 d \text { day); gradual un- } \\
\text { coiling after } 23 \text { day day } \\
\text { Visceral arches and yolk-sac } \\
\text { attain greatest develop- } \\
\text { ment (2oth day). } \\
\text { Somites well formed. } \\
\text { Well-marked tail ( } 25 \text { th day). } \\
\text { Lining cells of celom begin } \\
\text { to fiatten. } \\
\text { Inereased growth of allan- } \\
\text { tois. } \\
\text { Cephalic flexures. }\end{array}$ \\
\hline $\begin{array}{l}\text { Vascular } \\
\text { System. }\end{array}$ & $\begin{array}{l}\text { Heart witl single cavity } \\
\text { present, soon dividing into } \\
\text { atrium and ventricle. } \\
\text { Vitelline circulation begun. } \\
\text { Visceral-arch vessels begin } \\
\text { to appear. }\end{array}$ & $\begin{array}{l}\text { Division of atrium begins. } \\
\text { Completed condition of vitel- } \\
\text { line circulation. } \\
\text { Aliantoic vessels developing. }\end{array}$ \\
\hline $\begin{array}{l}\text { Digestive } \\
\text { System. }\end{array}$ & $\begin{array}{l}\text { Gut-tract a straight tube con- } \\
\text { nected with yolk-sac by a } \\
\text { wide aperture. } \\
\text { Liver-evagination present. } \\
\text { Oral pit a five-sided fossa. } \\
\text { Anal plate. }\end{array}$ & $\begin{array}{l}\text { Alimentary canal presents } \\
\text { pharynx, esophagus, stom- } \\
\text { ach, and intestine. } \\
\text { Pancreas begun. } \\
\text { Liver-diverticulum divides. } \\
\text { Bile-ducts acquire lumina. } \\
\text { Pharyugeal membrane } \\
\text { breaks down. }\end{array}$ \\
\hline $\begin{array}{l}\text { Respiratory } \\
\text { System. }\end{array}$ & $\begin{array}{l}\text { Pulmonary anlage as a longi- } \\
\text { tudinal protrusion of ven- } \\
\text { tral wall of esophagus, } \\
\text { afterward becoming a } \\
\text { stalked sac. }\end{array}$ & $\begin{array}{l}\text { Pulmonary anlage bifur- } \\
\text { cates, the two pouches } \\
\text { being connected by a ped- } \\
\text { icle, the primitive trachea, } \\
\text { with the pharynx. }\end{array}$ \\
\hline $\begin{array}{l}\text { Genito-urinary } \\
\text { System. }\end{array}$ & Wolffian bodies reeognizable. & \\
\hline Skin. & $\begin{array}{l}\text { Segmentation of paraxial } \\
\text { mesoderm. }\end{array}$ & $\begin{array}{l}\text { Somites or primitive seg- } \\
\text { ments. } \\
\text { Cutis-plate. }\end{array}$ \\
\hline $\begin{array}{l}\text { Nervous } \\
\text { System. }\end{array}$ & $\begin{array}{l}\text { Neural canal: its cells show } \\
\text { differentiation into spon- } \\
\text { gioblasts and germ-cells. } \\
\text { Fourth ventricle indicated. } \\
\text { Fore-braiu, mid-brain, and } \\
\text { hind-brain vesicles, soon } \\
\text { dividing into five vesicles. }\end{array}$ & $\begin{array}{l}\text { Walls of cerebral vesicles } \\
\text { thicken. } \\
\text { Ventral roots of spinal } \\
\text { nerves. } \\
\text { Anterior lobe of hypophysis } \\
\text { begins. }\end{array}$ \\
\hline $\begin{array}{l}\text { Special Sense } \\
\text { Organs. }\end{array}$ & $\begin{array}{l}\text { Auditory pit followed by otic } \\
\text { resicle. } \\
\text { olfactory plates. } \\
\text { Optic vesicles begin. } \\
\text { Lens-vesicles. }\end{array}$ & $\begin{array}{l}\text { Otic vesiele with recessus } \\
\text { labyrinthi. } \\
\text { Nasal pits distinet. } \\
\text { Optic vesicle stalked and } \\
\text { transformed into optic cup. }\end{array}$ \\
\hline $\begin{array}{l}\text { Muscular } \\
\text { system. }\end{array}$ & $\begin{array}{l}\text { Segmentation of paraxial } \\
\text { mesoderm. }\end{array}$ & $\begin{array}{l}\text { Somites or primitive seg- } \\
\text { ments. } \\
\text { Myotomes. }\end{array}$ \\
\hline $\begin{array}{l}\text { Skeleton and } \\
\text { Limbs. }\end{array}$ & $\begin{array}{l}\text { Segmentation of paraxial } \\
\text { mesoderm. } \\
\text { Notochord. }\end{array}$ & $\begin{array}{l}\text { Somites or primitive seg- } \\
\text { ments. } \\
\text { Skelctogenous sheath of } \\
\text { chorda. } \\
\text { Limb-buds apparent (about } \\
\text { 21st day). }\end{array}$ \\
\hline
\end{tabular}




\section{Tabulated Chronology of Development (Continued).}

\section{STAGE OF THE FETLS.}

Fifth Week.

SIXTH WEEK.

Body shows dorsal concavity in neckregion.

Globular and lateral nasal processes.

Lacrimal groove.

Third and fourth gill-clefts disappear in sinus præcervicalis.

Umbilical cord longer and more spiral. Umbilical resicle begins to shrink.

Length of fetus $1 \mathrm{~cm}$. (z $\mathrm{z}$ inch).

Primitive aorta divides into aorta and pulmonary artery.

The only corpuscular elements of the blood during the first month are the primitive nucleated red blood-cells.

Intestine shows flexures, notably the U-loop, inaugurating the distinetion between large and small bowel Anal pit.

Right and left bronehi divide into three and two tubes respectively (5th to 7 th week).

Genital ridges appcar on wall of bodycavity and soon become the indifferent genital glands.

Ducts of Müller appear.

Enidermis present as two layers of cells.

Olfactory lobe begins.

Arcuate and choroidal fissures on me. sial surfaces of fore-brain vesicles.

Cells of central canal of cord ciliated.

Ridge-like thickening of roof of midbrain.

Semicircular canals indicated.

Eyes begin to move forward from side of head.

(a)

Tasofrontal, lateral nasal, and maxillary processes unite.

Umbilical vesicle shrunken.

Amnion larger.

Vitelline eirculation atrophic and replaced by allantoic circulation.

First indication of teeth in the form of the dental shelf

Submaxillary gland indicated by epithelial outgrowth.

Duodenum well formed; cæcum; rectum (end of week)

Larynx indicated as dilatation of proximal end of trachea.

Arjtenoid cartilages indicated (though not cartilaginous).

Thyroid and thymus bodies begun.

Genital tubercle, genital folds, and genital ridge (external genitals)

Cells of cutis-plate proliferate and gradually spread out beneath epidermis.

Vembranes of brain and cord indicated. Pineal body begins.

Dorsal roots of spinal nerves.

Some tracts of spinal cord indicated, and its lumen alters (Fig. 123)

Semicircular canals.

Concha of external ear.

Outer fibrous and middle vaseular tunies of eye.

Eyelids
Mandibles unite (35th day).

INeckel's cartilage.

Limb-buds semucnt.

Digitation indieated (32d day) for hand.
Lower jaw berius to ossify.

Clavicle begins to ossify.

Ribs begin to chondrify.

Bodics of vertebræ are cartilaginous.

Fingers as separate outgrowths. 
Tabulated Chronology of Development (Contiued).

\begin{tabular}{|c|c|c|}
\hline & $\begin{array}{l}\text { STAGE OF : } \\
\text { SEVENTH WEEK. }\end{array}$ & $\begin{array}{l}\text { THE FETUS. } \\
\text { EIGHTH WEEK. }\end{array}$ \\
\hline $\begin{array}{l}\text { General } \\
\text { Characters. }\end{array}$ & $\begin{array}{l}\text { Fetal body and limbs well } \\
\text { defined (Fig. } 53 \text { ). } \\
\text { Head less flexed. }\end{array}$ & $\begin{array}{l}\text { Head more elevated (Fig. 54). } \\
\text { Free tail begins to disappear. } \\
\text { Subcutaneous lymph-vessels } \\
\text { present. } \\
\text { Cells lining the colom are } \\
\text { true endothelium. }\end{array}$ \\
\hline $\begin{array}{l}\text { Vascular } \\
\text { System. }\end{array}$ & $\begin{array}{l}\text { Interventricular septum of } \\
\text { heart completed, the beart } \\
\text { now having four chambers. } \\
\text { Other corpuscular elements } \\
\text { added to blood during sec- } \\
\text { ond month. }\end{array}$ & \\
\hline $\begin{array}{l}\text { Digestive } \\
\text { System. }\end{array}$ & $\begin{array}{l}\text { Transverse colon and de- } \\
\text { scending colou indicated. }\end{array}$ & $\begin{array}{l}\text { Parotid gland begins. } \\
\text { True endothelium lines the } \\
\text { body-cavity. } \\
\text { Gall-bladder present ( } 2 \mathrm{~d} \\
\text { month). } \\
\text { Anlage of spleen recogniz- } \\
\text { able (2d month). }\end{array}$ \\
\hline $\begin{array}{l}\text { Respiratory } \\
\text { System. }\end{array}$ & $\begin{array}{l}\text { Median and lateral lobes of } \\
\text { thyroid unite. }\end{array}$ & $\begin{array}{l}\text { Larynx begins to chondrify. } \\
\text { Formation of follicles of } \\
\text { thymus. }\end{array}$ \\
\hline $\begin{array}{l}\text { Genito-urinary } \\
\text { System. }\end{array}$ & $\begin{array}{l}\text { Maximum development of } \\
\text { Wolffian body. }\end{array}$ & $\begin{array}{l}\text { Müllerian ducts unite with } \\
\text { each other. Genital groove. } \\
\text { Bladder present as spindle- } \\
\text { shaped dilatation of allan- } \\
\text { tois. } \\
\text { Suprarenal bodies recogniz- } \\
\text { able. }\end{array}$ \\
\hline Skin. & $\begin{array}{l}\text { Nails indicated by claw-like } \\
\text { masses of epithelium on } \\
\text { dorsal surfaces of digits. }\end{array}$ & $\begin{array}{l}\text { Corium indicated as a layer } \\
\text { of spindle-cells beneath } \\
\text { epidermis. Development } \\
\text { of mammary glands begun. }\end{array}$ \\
\hline $\begin{array}{l}\text { Nervous } \\
\text { System. }\end{array}$ & $\begin{array}{l}\text { Fore-brain vesicles increase } \\
\text { in size disproportionately. } \\
\text { Cerebellum indicated. }\end{array}$ & $\begin{array}{l}\text { Sympathetic nerves discern- } \\
\text { ible. }\end{array}$ \\
\hline $\begin{array}{l}\text { Special Sense } \\
\text { Organs. }\end{array}$ & & $\begin{array}{l}\text { External nose definitely } \\
\text { formed (Fig. 155). } \\
\text { Lens-capsule. } \\
\text { Palpebral conjunctiva sepa- } \\
\text { rates from cornea. }\end{array}$ \\
\hline $\begin{array}{l}\text { Muscular } \\
\text { System. }\end{array}$ & $\begin{array}{l}\text { Muscles begin to be recog- } \\
\text { nizable, though not having } \\
\text { as yet the characters of } \\
\text { muscular tissue. }\end{array}$ & \\
\hline $\begin{array}{l}\text { skeleton and } \\
\text { Limbs. }\end{array}$ & $\begin{array}{l}\text { Ossific centers for vertebral } \\
\text { arches and for vertebral } \\
\text { bodies; ossific centers for } \\
\text { frontal bone and for squa- } \\
\text { mosa. } \\
\text { Membranous primordial cra- } \\
\text { nium begins to chondrify. } \\
\text { Claw-like anlages of nails. }\end{array}$ & $\begin{array}{l}\text { Ribs begin to chondrify. Cen- } \\
\text { ters of ossification of basi- } \\
\text { sphenoid, of greater wings, } \\
\text { of nasal and lacrimal } \\
\text { bones, of malar, vomer, pal- } \\
\text { ate, neck of scapula, diaph- } \\
\text { yses of long bowes and of } \\
\text { metacarpal bones. Fingers } \\
\text { perfectly formed. Toes be- } \\
\text { gin to separate (53d day). }\end{array}$ \\
\hline
\end{tabular}


Tabulated Chronology of Development (Continued).

\section{STAGE OF TIIE FETUS.}

NINTH WEEK.

THIRD MONTH.

Weight, 15 to 20 grams; length, 25 to 30 mm. ( 1 to $1 \frac{3}{6}$ inches).

Hard palate completed.

Free tail has disappeared.

Differentiation of lymph-nodes begins (O. Schultze). Cloaca divided.

Pericardium indicated.

Anal canal formed by division of eloaca.

Weight (end of month), 4 ounces ; length, $2 \frac{3}{3}$ inches.

At first chorion læve and chorion frondosum present; later, formation of placenta (see frontispiece).

\begin{tabular}{|c|c|}
\hline Pericardium indicated. & $\begin{array}{l}\text { Placental system of vessels. } \\
\text { Blood-vessels penetrate spleen. }\end{array}$ \\
\hline \multirow[t]{2}{*}{ Anal canal formed by division of eloaca. } & $\begin{array}{l}\text { Mouth-eavity divided from nose (end of } \\
\text { month). Soft palate completed (11th } \\
\text { week). Papillæ of tongue. Evagina- } \\
\text { tion for tonsil. Intestine begins to re- } \\
\text { eede within abdomen (10th week). Ro- } \\
\text { tation of stomach. Vermiform appen- } \\
\text { dix as a slender tube. Omental bursa. } \\
\text { Gastric glands and glands and villi of } \\
\text { intestine fairly well formed (10th } \\
\text { week). Liver very large. Peritoneum } \\
\text { has its adult histological characters. }\end{array}$ \\
\hline & Epiglottis. \\
\hline \multirow[t]{2}{*}{$\begin{array}{l}\text { External genitals begin to show dis- } \\
\text { tinctions of sex. } \\
\text { Orary and testis distinguishable from } \\
\text { eaeh other. } \\
\text { Kidney has its characteristic features. } \\
\text { Urogenital sinus acquires its own aper- } \\
\text { ture by division of cloaca. }\end{array}$} & $\begin{array}{l}\text { Union of testis with canals of Wolfian } \\
\text { body complete. } \\
\text { Testes in false pelvis. } \\
\text { Ovaries descend. } \\
\text { Prostate begun (12th week). }\end{array}$ \\
\hline & $\begin{array}{l}\text { Corium proper present as distinet layer. } \\
\text { Nails not quite perfectly formed. } \\
\text { Beginning of development of hair as } \\
\text { solid ingrowths of epithelium. }\end{array}$ \\
\hline $\begin{array}{l}\text { Corpus striatum indieated. } \\
\text { Corpora quadrigemina represented by } \\
\text { two elevations on mid-brain roof. }\end{array}$ & $\begin{array}{l}\text { Cerebrum eovers inter-brain. Fornix } \\
\text { and corpus callosum begun. Fissure } \\
\text { of Sylrius. Calcarine fissure. Crura } \\
\text { cerebri. Restiform bodies. Pons. }\end{array}$ \\
\hline $\begin{array}{l}\text { External ear indicated (Fig. 15t). } \\
\text { Ciliary processes indicated. }\end{array}$ & $\begin{array}{l}\text { Eyes nearly in normal position. } \\
\text { Eyelids begin to adhere to each other. }\end{array}$ \\
\hline $\begin{array}{l}\text { Centers of ossification of presphenoid, } \\
\text { of lesser wings of sphenoid, and of } \\
\text { sliafts of metatarsal bones. }\end{array}$ & $\begin{array}{l}\text { Beginning ossification of occipital bone, } \\
\text { of tympanic, of spine of scapula, of } \\
\text { ossa innominata. } \\
\text { Cartilaginous arehes of vertebra close. } \\
\text { Limbs have definite shape; nails almost } \\
\text { perfectly formed. }\end{array}$ \\
\hline
\end{tabular}


Tabulated Chronology of Development (Continued).

\begin{tabular}{|c|c|c|}
\hline & $\begin{array}{l}\text { STAGE OF } \\
\text { Fourth Month. }\end{array}$ & $\begin{array}{l}\text { THE FETUS. } \\
\text { F1FTH MONTH. }\end{array}$ \\
\hline $\begin{array}{l}\text { General } \\
\text { Characters. }\end{array}$ & $\begin{array}{l}\text { Weight, } 73 \text { ounces; length, } 5 \\
\text { inches. } \\
\text { Head constitutes about one- } \\
\text { quarter of entire body. }\end{array}$ & $\begin{array}{l}\text { Weight, } 1 \text { lb.; length, } 8 \text { in. } \\
\text { Active fetal movements be- } \\
\text { gin. Two layers of decidua } \\
\text { eoalesee, obliterating the } \\
\text { space between vera and re- } \\
\text { flexa. Lymphatic glands } \\
\text { begin to appear. }\end{array}$ \\
\hline $\begin{array}{l}\text { Vascular } \\
\text { System. }\end{array}$ & - & Heart very large. \\
\hline $\begin{array}{l}\text { Digestive } \\
\text { System. }\end{array}$ & $\begin{array}{l}\text { Enamel and dentine of milk- } \\
\text { teeth. Germs of permanent } \\
\text { teeth (17th wk); (for 1st mo- } \\
\text { lar, 16th wh). Nuscularis } \\
\text { (longitudinal and eireular) } \\
\text { of stomach and esophagus. } \\
\text { Intestine entirely within } \\
\text { abdomen. Acid eells of } \\
\text { peptie glands. MIalpighian } \\
\text { bodies of spleen. Anal } \\
\text { membrane disappears. }\end{array}$ & $\begin{array}{l}\text { Salivary glands acquire lu- } \\
\text { mina. large intestine begin } \\
\text { Villi of largear. } \\
\text { to disappear. } \\
\text { Liver very large. } \\
\text { Meconium shows traces of } \\
\text { bile (sometimes early in } \\
\text { fourth month). }\end{array}$ \\
\hline $\begin{array}{l}\text { Respiratory } \\
\text { System. }\end{array}$ & $\begin{array}{l}\text { Cells of tracheal and bron- } \\
\text { chial mucous membrane } \\
\text { ciliated. }\end{array}$ & \\
\hline $\begin{array}{l}\text { Genito-urinary } \\
\text { System. }\end{array}$ & $\begin{array}{l}\text { Sexual distinctions of exter- } \\
\text { nal organs well marked. } \\
\text { closure of genital furrow. } \\
\text { Serotum. Prepuce. Pros- } \\
\text { tate well formed. }\end{array}$ & $\begin{array}{l}\text { Distinction between uterus } \\
\text { and vagina. } \\
\text { Hymen begins. }\end{array}$ \\
\hline Skin. & $\begin{array}{l}\text { Papillæ of eorium. Subcuta- } \\
\text { neous fat first appears. La- } \\
\text { nugo or embryonal down } \\
\text { on scalp and some other } \\
\text { parts. }\end{array}$ & $\begin{array}{l}\text { Pannieulus adiposus. } \\
\text { Lanugo more abundant. } \\
\text { Sebaceous and sweat-glands } \\
\text { begin. }\end{array}$ \\
\hline $\begin{array}{l}\text { Nervous } \\
\text { System. }\end{array}$ & $\begin{array}{l}\text { Parieto-oeeipital fissure. } \\
\text { Corpora albieantia. } \\
\text { Transverse fibers of pons. } \\
\text { Middle peduncles and ehief } \\
\text { fissures of eerebellum. } \\
\text { Spinal cord ends at end of } \\
\text { coecyx. } \\
\text { Deposit of myelin on fibers } \\
\text { of posterior roots, extend- } \\
\text { ing to Burdach and Goll. }\end{array}$ & $\begin{array}{l}\text { Fissure of Rolando. Body of } \\
\text { fornix and corp. callosum. } \\
\text { Longitudinal fibers in eru- } \\
\text { racerebri. Superior pedun- } \\
\text { cles. Anterior pyramids of } \\
\text { medulla. Chief transverse } \\
\text { fissures of lateral lobes of } \\
\text { cerebellum. Deposit of my- } \\
\text { elin completed for tract of } \\
\text { Goll and later of Burdach, } \\
\text { and for short commissural } \\
\text { fibers (Tourneux). }\end{array}$ \\
\hline $\begin{array}{l}\text { Special Sense } \\
\text { Organs. }\end{array}$ & $\begin{array}{l}\text { Eyelids and nostrils elosed. } \\
\text { Cartilage of Eustachian tube. }\end{array}$ & Organ of Corti indicated. \\
\hline $\begin{array}{l}\text { Muscular } \\
\text { System. }\end{array}$ & & $\begin{array}{l}\text { Differentiation of muscular } \\
\text { tissue of arms. }\end{array}$ \\
\hline $\begin{array}{l}\text { Skeleton and } \\
\text { Limbs. }\end{array}$ & $\begin{array}{l}\text { Osseous renter for internal } \\
\text { pterygoid plate. } \\
\text { Antrum of lighmore begins. } \\
\text { Ossification of malleus and } \\
\text { incus. } \\
\text { Tympanic ring. }\end{array}$ & $\begin{array}{l}\text { Ossification of stapes and pe- } \\
\text { trosa. Opisthotic and pro- } \\
\text { otie appear. Ossifieation } \\
\text { begins in midcle and infe- } \\
\text { rior turbinals and laterul } \\
\text { masses of ethmoid. Inter- } \\
\text { nal pterygoid plate fuses } \\
\text { with external. Intermax- } \\
\text { illaries fuse with maxilla. } \\
\text { Legs longer than arms. }\end{array}$ \\
\hline
\end{tabular}


Tabulated Chronology of Development (Continued).

\begin{tabular}{|c|c|}
\hline \multicolumn{2}{|c|}{ STAGE OF THE FETLS. } \\
\hline Sixtн Mo:th. & SEVEXTH MONTH. \\
\hline $\begin{array}{l}\text { Weight, } 2 \text { pounds: length, } 12 \text { inches. } \\
\text { Vernix caseosa begins to appear. } \\
\text { Amnion reaches maximum size amni- } \\
\text { otic fluid of maximum quantity. }\end{array}$ & $\begin{array}{l}\text { Weight, } 3 \text { pounds; length, } 14 \text { inches. } \\
\text { Surface less wrinkled owing to increase } \\
\text { of fat. }\end{array}$ \\
\hline $\begin{array}{l}\text { Peyer's patches. } \\
\text { Trypsin in pancreatic secretion (fifth } \\
\text { or sixth month). }\end{array}$ & $\begin{array}{l}\text { Meconium in large intestine. } \\
\text { Ascending colon partly formed. } \\
\text { Cæcum below right kidney. }\end{array}$ \\
\hline \multicolumn{2}{|l|}{ Air-vesicles of lungs begin to appear. } \\
\hline Walls of uterus thicken. & $\begin{array}{l}\text { Testes at internal rings or in inguinal } \\
\text { canals. }\end{array}$ \\
\hline $\begin{array}{l}\text { Veruix caseosa begins to appear. } \\
\text { Eyebrows and eyelashes begin. }\end{array}$ & $\begin{array}{l}\text { Epithelial buds for sebaceous glands ac- } \\
\text { quire lumina. Branching of cords of } \\
\text { milk-glands. Epony chium of nails } \\
\text { lost; nails said to break through. } \\
\text { Lanugo over entire body. }\end{array}$ \\
\hline $\begin{array}{l}\text { Collateral and calloso-marginal fissures. } \\
\text { Body of fornix and corpus callosum } \\
\text { complete. } \\
\text { Hemispheres of cerebrum cover mid- } \\
\text { brain. }\end{array}$ & $\begin{array}{l}\text { Cerebral convolutions more apparent. } \\
\text { Corpora quadrigemina. } \\
\text { Irelination of fibers of direct cerebellar } \\
\text { tracts. (Crossed pyramidal tracts not } \\
\text { until after birth.) }\end{array}$ \\
\hline \multirow[t]{2}{*}{ Lobule of ear more characteristic. } & $\begin{array}{l}\text { Lens-capsule begins to acquire trans- } \\
\text { parency. Eyelids permanenty open. } \\
\text { Pupillary membrane atroplies. }\end{array}$ \\
\hline & $\begin{array}{l}\text { Differentiation of muscular tissue of } \\
\text { lower extremities. }\end{array}$ \\
\hline $\begin{array}{l}\text { Lesser wings unite with presphenoid. } \\
\text { Meekel's cartilage begins to retrograde. } \\
\text { Ossific nuclei of os ealcis and astragalus. }\end{array}$ & $\begin{array}{l}\text { Basisphenoid and presphenoid unite } \\
\text { (7th or 8th month). }\end{array}$ \\
\hline
\end{tabular}


Tabulated Chronology of Development (Concluded).

\begin{tabular}{|c|c|c|}
\hline & $\begin{array}{l}\text { STAGE OF } \\
\text { Eighth Month. }\end{array}$ & $\begin{array}{l}\text { THE FETUS. } \\
\text { NINTH MONTH. }\end{array}$ \\
\hline $\begin{array}{l}\text { General } \\
\text { Characters. }\end{array}$ & $\begin{array}{l}\text { Weight, } 4 \text { to } 5 \text { pounds ; length, } \\
16 \text { inches. } \\
\text { Body more plump. }\end{array}$ & $\begin{array}{l}\text { Weight, } 6 \text { to } 7 \text { pounds; length, } \\
20 \text { inches. } \\
\text { Umbilicus almost exactly in } \\
\text { middle of body. }\end{array}$ \\
\hline \multicolumn{3}{|l|}{$\begin{array}{l}\text { Vascular } \\
\text { System. }\end{array}$} \\
\hline $\begin{array}{l}\text { Digestive } \\
\text { System. }\end{array}$ & $\begin{array}{l}\text { Ascending colon longer. } \\
\text { Cæcum below erest of ilium. }\end{array}$ & Meconium dark greenish. \\
\hline \multicolumn{3}{|l|}{$\begin{array}{l}\text { Respiratory } \\
\text { System. }\end{array}$} \\
\hline $\begin{array}{l}\text { Genito-urinary } \\
\text { System. }\end{array}$ & Testes in inguinal canals. & $\begin{array}{l}\text { Testes in serotum. } \\
\text { Labia majora in contact. }\end{array}$ \\
\hline Skin. & $\begin{array}{l}\text { Vernix easeosa covers entire } \\
\text { body. } \\
\text { Skin brighter eolor. } \\
\text { Lanugo begins to disappear. } \\
\text { Nails project beyond finger- } \\
\text { tips. } \\
\text { Increase of subcutaneous } \\
\text { fat. }\end{array}$ & $\begin{array}{l}\text { Lanugo almost entirely ab- } \\
\text { sent. } \\
\text { Galactopherous ducts of } \\
\text { milk-glands acquire lu- } \\
\text { mina. }\end{array}$ \\
\hline $\begin{array}{l}\text { Nervous } \\
\text { System. }\end{array}$ & & $\begin{array}{l}\text { Spinal cord ends at last lum- } \\
\text { bar vertebra. }\end{array}$ \\
\hline $\begin{array}{l}\text { Special Sense } \\
\text { Organs. }\end{array}$ & & $\begin{array}{l}\text { Ossification of bony lamina } \\
\text { spiralis and of modiolus. } \\
\text { Neuro-epithelial layer of re- } \\
\text { tina completed; macula } \\
\text { still absent. } \\
\text { Choroidal fissure closes. }\end{array}$ \\
\hline \multicolumn{3}{|l|}{$\begin{array}{c}\text { Muscular } \\
\text { System. }\end{array}$} \\
\hline $\begin{array}{l}\text { Skeleton and } \\
\text { Limbs. }\end{array}$ & & $\begin{array}{l}\text { Ossification in lower epiph- } \\
\text { ysis of femur, sometimes } \\
\text { also in upper epiphyses of } \\
\text { tibia and humerus. } \\
\text { Tympanohyal begins to os- } \\
\text { sify. } \\
\text { Ossific nuclei for body and } \\
\text { great horn of hyoid bone. }\end{array}$ \\
\hline
\end{tabular}




\section{INDEX.}

AвDominal cavity, development of, Ampullæ, seminal, 223

198

Accessory thyroid, 209

Acetabular fossa, 378

Achoria, 84

Achromatin, 25

Acid cells, formation of, 189

Acoustic ganglion, 297

Acusticofacial ganglion, 297

Adamantoblasts, 127

Adenoid tissue, development of, 117

Adipose tissue, formation of, 115

After-birth, 93

After-brain, 263

Age of fetus, estimation of, 112

Air-chamber of hen's egg, 27

Air-sacs, development of, 207

Alæ of nose, development of, 338

Allautoic arteries, 81, 148

circulatiou, 81

formation of, 148

$$
\text { stalk, } 76
$$

veins, 81,148

Allantois, 80, 173, 232

function of, 82

respiratory function of, 183

Alar lamiua, 266

Alecithal ova, 24

Alimentary canal, develepment of, 168

differentiation into separate regions, 180

histological alterations in, 188

tract, alteration in positiou of parts, 185

increase in length of, 184

Alveoli, pulmonary, development of, 207

Ameloblasts, 127

Amuion, 73, 74

false, 73

of man, 76

Annion-fold, $72,73,75$

Amniota, 75

Amniotic cavity, $76,7 \tau$

fluid, 76,77

function of, $r \tau$

suture, 75

Amphibiuns, blastula of, 46

Amphioxus, blastula of, 45

skeletal apparatus of, 3.17

Ampullae of semicircular canals, development of, 324
Anal canal, 233

membrane, 178

plate, 178

Anamnia, 75

Animal pole, 25

Animalculists, 18

Anlage, 159

Annular sinus, 163

Anowalous arrangements of aortic arch, 152

Auterior chamber of eye, 318

nares, development of, 134,336

pyramidal tracts of medulla, development of, 266

Antitragus, formation of, 333

Antrum of Highmore, development of, 337

Anus, development of, 178

imperforate, 180

A orta, caudal, 150

development of, 144

primitive, 137,150

Aortic arch, anomalous arrangements of, 152

arches, 149

Appendages of skin, 247

Appendicular skeleton. 347

development of, 376

Aqueduct of Sylvius, development of, 271

Arch, ly yoid, 105

mandibular, 103

maxillary, 103

of aorta, development of, 152

Archenteron. 47, 49

Arches, aortic, 149

branchial, 102

mandibular, 123

visceral, 100

Archiblast, 58

Arcuate fissure, 282, 283

Area, embryonal, 50

glandular, 251

opaca, 51

pellurida, 51

vasculosa, 51, 79,136

Areas, nasal, 133, 334

Areola, development of, 252

A reolar tissue, development of, 114

Arrectores pilorum, 246

Arteria centralis retinæ, development of, 311 
Arterial system, fetal, 149

Arteries, allantoic, 148

umbilica], 91, 149

vitelline, 137

Artery, carotid, common, development of, 151

external, development of, 151

internal, development of, 151

innominate, development of, 152 middle sacral, development of, 150 pulmonary, development of, 152 subelavian, left, development of, 152

right, development of, 151

superior vesical, 166

Arytenoid cartilages, development of, 207

Ascending colon, formation of, 186 mesocolon, formation of, 186

root of fifth nerve, 206 root of vagus, 266

Aster, 41

Atlas, formation of, 355

Atresia of pupil, 314

Atrioventrieular canal, 141 valves, 142

Atrophic tubules of Wolfinan body, 216

Attraction-sphere, 41

Auditory apparatus, development of, 321

meatus, external, formation of, 332 nerve, formation of, 297

nucleus, lateral accessory, 297

yit, 322

Auriele, development of, 333

An ricles, division into right and left, 142

Auricular appendages, 144 canal, 141

Auriculoventricular apertures, 145 va.lves, 146

Axial fiber of spermatozö̈u, 20

skeleton, 347

development of, 348

Axis, development of, 354

Axis-cylinder process, 260

BARTHOLIN, glands of, 237

Basal ganglia, 279, 280

lamina. 266

plate, 91

Basi-oceipital hone, 364

Basisphenoid, 368

Belly-stalk, $; 6$

Bifid uterus, 230

Bile-capillaries, formation of, 192

Bile-ducts, formation of, 192

Bladder, development of, 232

Blastopore, 47

Blastula, stage of, 4is

Blood, development of, 115, 135

Blood-corpuseles, red, primitive, 136

Blood-jslands, of Pander, 135

"Blue baby," 143
Bodies, polar, 31

Body of vertebra, formation of, 352

Body-eavity, 55, 58, 197

Body-wall, development of muscles of, 343

formation of, 71

Bony cochlea, development of, 327 labyrinth, development of, 326

semicircular cauals, $32 \tau$

Bowman, eapsule of, 216, 217

Brain, development of, 262

Brain-case, 358

Brain-membranes, development of, 278

Brain-vesicles, 262

derivatives of, 292

Branchial arches, 102

development of, 344

Bridge of nose, development of, 338

Brunner, glands of, 189

Bulbus arteriosus, 142

vestibuli, 237

Burdach, tract of, myelination of, 388

Bursa, omental, 187, 200 phar'vngea], 124

Bursal sacs, development of, 115

CADucous membranes, 85

Crecum, develpment of, 185, 186

Calcar avis, 284

Calearine fissure, 279, 284

Callosomargiual fissure, 285

Calyces of kidney, formation of, 218

Canal, anal, 233

atrioventrieular, 141

aurieular, 141

liyaloid, 315

medullary, 62

neural, 62, 255, 257

neurenteric, 66,257

of anus, 180

of His, 133, 208

of Nuck, $23 \%$

of Stilling, 315

Canalieuli, lacrimal, development of, 320

Canalis reuniens, 324

Capsule of Bowman, 216, 217

Cardinal veins, 148, 154

Carotid artery, common, development of, 151

extermal, development of, 151

internal, development of, 151

Carpus, development of bones of, 379

Cirtilage, formation of, 115

Meckel's, 105,372

Reichert's, 105

Cartilage-cells, 115

Cartilaginous capsule of cochlea, 328 eranium, 360

ear-capsule, 326

ribs, 356

sheatl of spinal eord, 353

stage of skeleton, 348

of trunk skeleton, 351 
Caudal aorta, 150

Cavity, amniotic, 76 pleuroperitoneal, 58 segmentation, 45

Cell-mass, inner, 45 intermediate, 69 outer, 45

Cells, sexual, 29 mesenchymal, 58

Cementum of tooth, 125 development of, 129

Central canal of cord, formation of, 262

lobe, formation of, 281

Centrolecithal ova, 25

Centrosome, 41

Cephalic flexure, 100, 264 ganglia, development of, 296

Ceratohyal, 376

Cerebellum, development of, 268

Cerebral fissures, development of, 278 vesicles, 262,263

Ceruminous glands, 250

Cervical fistula, 105 flexure, 100 rib, 354,357

Chalaze, 27

Chambers of eye, 318

Chorela dorsalis, 65 formation of, 348 stage of, 348

Chordæ tendineæ, 146

Clordal epithelium, 349 plate, 66 region of primitive skull, 361

Choriata, 84

Choriocapillaris, 316

Chorion, 82 froudosum, 83

læve, 83

primitive, 82

true, 82

Choroid, colohoma of, 316

development of, 316

fissure, 282, 283

plexus, 284

plexuses of fourth ventricle, $26 \%$

Choroidal fissure, 306,316

Chromatin substance, 25

Cicatricula, 26

Ciliary body, development of, 316 ganglion, 296 muscle, development of, 316 processes, development of, 309,316

Cirenlation, allantoic, 148 placental, 135 portal, 161 vitelline, formation of, 135

Claustrum, 279

Clavicle, development of, 378

Cleavage, kinds of, 43 of ovilim, 41

partial discoidal, 44 peripheral, 44

total equal, 43
Cleavage, total unequal, 43

Cleavage-cavity, 45

Cleavage-nucleus, 39

Cleavage-planes, 42

Cleft palate, formation of, 125 sternum, 357 cause of, 74

nvula, formation of, 125

Clefts, visecral, 100

Climacteric, 35

Clitoris, development of, 235, 236

Cloaca, 173, 179, 233

Cloacal depression, 180, 233

Closing membrane, 100, 105, $17 \%$

Cocesgeal curve, 100 vertebræ, ossification of, 356

Cochlea, bony, development of, 327

Cochlear duct, formation of, 323 ganglion, 297 nerve, 329

Colenteron, 47,49

Coelom, 55, 58, 197

Collateral fissure, 279,281

Coloboma of choroid, 316 of iris, 318

Colon, asceuding, formation of, 186 descending, formation of, 184,186 transverse, formation of, 186

Columnæ carneæ, 140

Commissures of brain, development of, 279

of cord, white, 260

Conarium, 274

ulodifications of, 274

Cone-visual cells, $30 \%$

Congenital atresia of pupil, 314 diaphragmatic hernia, 161

fecal fistula, 190

hernia, 226

nmbilical hernia, 188

Coni vasculosi, formation of, 223

Connective tissues, development of, 113

Constructive stage of menstural crele, 35

Copula of hyoid bone, 363

Coracoid bone, $37 \%$ process of seapula, $37 \%$

Cord, spinal, development of, 257 umbilical, 91

Cords of cells, 135

Corimm, development of, 245

('ornea, development of, 315

Corona radiata, 23,29

Coronary ligament, 193 of liver, 202

sinus of heart, 156

valve, 144

Corpora albicantia, 272

bicemiua, 271

cavernosa, formation of, 238

quadrigemina, 27

Corpus callosum, formation of, 285 , 287

hemorrhagicum, 33 
Corpus luteum of, pregnancy, 33,34 false, 34

of meustruation, 34

true, 34

spongiosum, formation of, 239

striatum, 279

Corpuscle of Hassal, 210, 211

Corti, organ of, 325

Costal process of vertebra, formation of, 352,356

Cotyledons of placenta, 88

Covering bones, 359

Cowper, glauds of, 239

Cranial capsule, $35 \overline{8}$

nerve-fibers, development of, 296

Cranium, eartilaginous, 360

membrauous, 359 osseous, 363

Cristæ acusticæ, 325

Crossed pyramidal tract, myelination of, 389

Crura cerebri, development of, 270

Crusta petrosa, 129

Cryptorehism, 226

Crystalliue lens, development of, 312

Cutis-plate, 69, 245, 341

Cuvier, duct of, 148, 154, 160

Cystic duct, development of, 192

DAUGHTER-CELLS, 22

Daughter-wreaths, 41

Decidua menstrualis, 36,84

of pregnancy, 86

reflexa, 86

serotina, 86

vera, 86

Deciduæ, 85

Dendrits, 260

Dental groove, 126

papilla, 127, 128

processes, 129

ridge, 125

shelf, 125

Dentale, 374

Dentate fissure, 279, 283

Dentinal fibers, 129

tubules, 129

Dentine, 125

Dermal bones, 359 navel, 74

Descending colon, formation of, 186

Descent of testicles, 225

Destructive stage of menstrual cycle, 36

Deutoplasm of lien's egg, 26 of ovum, 24

Developnent during eighth month, 111

during eighth week, 108

during fifth month, 111

during fifth week, 107

during ninth mosth, 11 \%

during second month, 106

during seventh month, 111

during sixth month, 111
Development during third month, 109 during third week, 106

length of time necessary for, 18 tabulated chronology of, 383 theories of, 17

Diaphragm, development of, 161

Diaphragmatic hernia, congenital, 161

ligament, 225

Digestive system, development of, $168,385-390$

Digitation of limb-buds, 380

Diphyodont, 125

Direct cerebellar tract, myelination of, 385

Discoidal cleavage, partial, 44

Discus proligerus, 29, 228

Disk, germinative, 26

Dorsal curve, 100 mesentery, 173

Double monster, origin of, 51 uterus, 230

Duct of Cuvier, 148, 154, 160

mesonephric, 214

of Gartner, 231

of Müller, $220,224,230,242$

of Rathke, 225

pronephric, 212

segmental, 213

thy roglossal, 133, 208

thyroid, 208

vitelline, $72,78,169$

Wolffian, 214

Ductus Arantii, 164

communis choledochus, formation of, 192

endolymphaticus, 323

venosus, 91, 164

Duodenum, formation of, 199

EAR, external, development of, 331, 333

internal, development of, 321

middle, development of, 331

Ear-capsule, cartilaginous, 326

Ectoderm, 47, 48

derivatives of, 59

Egg, ultimate origin of, 29

Egg-columns, 29, 2:7

Egg-envelopes, 23

Egg-plasm, 24

Egg-tubes, primary, 29

Eighth month, development during, 111,390

pair cranial nerves, development of, 299

week, development during, 108, 386

Ejaculatory duet, formation of, 224

Elastic tissue, formation of, 114

Eleventh pair eranial nerves, development of, 300

Embryo, differentiation of, 61 of eight-and-a-half weeks, 110 of fifteenth day, 97

of six weeks, 107 
Embryo of thirteenth day, 96 of three weeks, 101 of twenty-eight days, 101 segmentation of body of, 69 stage of, 19,96

Embryology, defined, 17

Embryonal area, 50 down, 250

Embryonjc crescent, 51

Eminentia collateralis, 285

Enamel of milk teeth, formation of, 128

of teeth, 125

Enamel-cells, 127

Enamel-germ, primitive, 126

Enamel-germs of permanent teeth, 129

Enamel-prisms, 127

Enamel-sac, $1 \geqslant 6$

Endocardium, 140

Endochondral bones, 359

Endolymph, 331

Endoskeleton, $34 \%$

Endothelium, formation of, 58, 115

Enterocol, 55

Entoderm, 47, 48

derivatives of, 59

Epencephaion, 268

Ependyma, 286

Ependymal layer, 260

Epiblast, 47

Epidermis, development of, 245, 216 formation of, 223

head of, 223

Epigenesis, doctrine of, 18

Epihyal, 376

Epiotic center of ossification, 366

Epithelinm, germinal, 27, 29,221

Epitrichium, 246

Eponychium. 218

Epoöphoron, 231

Ethmoid bone, ossification of, 369 cribriform plate of, 362

Ethmoidal siuus, development of, 337

Eustachiau tube, development of, 331 . $33:$

formation of, 177 valve, 144

Evertebral region of primitive skull, 361

Exoccipitals, 364

Exoskcleton, 347

Exstrophy of bladder, canse of, 74

External auditory meatus, formation of, 332

ear, development of, 331,333

fertilization, 38

genitals, female, 236,243

male, 237, 241

organs of generation, 234

Exe, development of, 12:, 302

Eyelashes, development of, 319

Eyelid, third, 319

Eyelids, developraent of, 318

primitive, 12:2
FACE, development of, 106,118

Facial ganglion, 297

Faleiform ligament of liver, formation of, 193

lobe, 285,289

Fallopian tubes, development of, 230

False amnion, 73

Falx cerebri, 278

Fecal fistula, congenital, 190

Female cxternal genitals, 236, 243

interual geuital organs, 226

pronucleus, 3 :

sexual system, 243

Fertilization, 38

extermal, 38

internal, 38

Fetal arterial system, 149

membranes, condition of at birth, 93

vascular system, final stage of, 165 venous system, 153

Fetus, lengtl of, at term, 112

stage of, 20, 106

weight of at term, 111

Fiber-tracts of cord, development of, 261

myelination of, 383,389

Fibrillæ of musele, formation of, 342

Fibrous tunic of eye, development of, 315

Fifth brain-vesicle, metamorphosis of, 264

month, development during, 111, 388

pair cranial nerves, development of, 299

ventricle, 288

week, development dnring, 385

Fimbria, 285

Fingers, development of, 381

First pair eranial nerves, development of, 299

week, development during, 393

Fissure, arcuate, 28:, 283

calcarine, 279,284

calloso-marginal, 285

choroid, 282, 283

choroidal, 306

collateral, 279, 284

dentate, 279 , 283

great transverse, 280,284

hippocampal, 283

of choroid plexus, 283

of Rolando, 284

of Sylvius, 279,280

parieto-occipital, 281

Fissures, cerebral, derelopment of, 278,279

median of cord, 261

Fistula, congenital fecal, 190

umbilical urinary, 233

Flexure, ceplıalic, 264

nuchal, 264

pontal, 264

Floor-plate, 257,258 
Fold, pleuropericardial, 160

Folds, medullary, 64

Follicle, Graafian, 27

of tooth, 129

Foramen cæcum, 133, 208

commune anterins, 282

of Monro, 27\%, 282

of Winslow, 203

ovale, 143

Fore-brain, 262, 278

secondary, 263

vesicle, 65

metamorphosis of, 278

Foregut, 73

Formative yolk, 24

Foruis, formation of, 285,286

Fossid of Sylvins, 280 oral, 175

Fourth mouth, development during, 110,388

pair cranial nerves, development of, 299

ventricle, 267

development of, 265,270

week, development during, 384

Fretum Halleri, 142

Frontal bone, ossification of, 370 lobe, 282

sinuses, development of, 337

Funiculus solitarius, 266

GALL-BLADDER, development of, 192 Ganglia, cephalic, 296

spinal, 293

Gangliated cord of the sympathetic, 301

Ganglion, acoustic, 297

acusticofacial, 297

cephalic, fourth, 297

third, 297

ciliary, 296

cochlear, 297

facial, 297

Gasserian, 396

ophthalmic, 296

spirale, 326

trigeminal, 297

vestibular, 326

Ganglion-cell layer, development of, 309

Gartner, duct of, 231

Gasserian ganglion, 296

Gastral mesoderm, 55

Gastrohepatic omentum, 192, 202 formation of, 188

('astrosplenic omentum, 195

Gastrula, 47

mammalian, 48

stage, 47

Generative organs, external, development of, $2: 34$

internal, levelopment of, 220

Genital cord, y20

eminence, $2: 35$

in male, 238
Genital folds, 235

in female, 236

in male, 239

gland, indifferent, 242

groove, 235

ridge, 220,233

in female, 237

ridges, 29

Genito-n rinary system, development of, $212,383-390$

Germ-cells, 221

Germ-disk, 25

Germ-layers, 47

derivatives of, 58

Germinal epithelium, 27, 29, 221

spot, 23, 25

vesicle, 23,25

Germinative disk, 26

Giraldès, orgau of, 224

Glands of alimentary tract, formation of, 189

of Bartholin, 237

of Brunner, development of, 189

of Cowper, development of, 239

of intestine, development of, 189

of Lieberkühn, development of, 189

of Moll, 250

of stomach, development of, 189

Glandular area, 251

hypospadias, 239

Glans elitoridis, formation of, 235 penis, formation of, 235,238

Glaserian fissure, 367,373

Globular processes, 107, 120, 334

Glomerulus of kidney, 213, 216, 217

Goll, tract of, myelination of, 388

Graafian follicle, 27

development of, 228

formation of new, 229

Gray matter of brain, formation of, 279

of medulla, development of, 206

Great omentum, formation of, 18\%, 201

Groove, dental, 126

lacrimal, 107

medullary, 63

naso-optic, 320

primitive, 52

pulmonary, 205

transverse crescentic, 372

Guberuaculum testis, 225

Gum, development of, 124

Gut, postanal, 179

Gut-tract, 72, 73, 169, 171

Gyrus fornicatus, 291

uneinatus, 291

IJAIR, development of, 248

Hair-hulb, 248

development of, 249

Hair-follicle, 218

development of, 249,250

Hair-germs, 249 
Hard palate, development of, 371

Hare-lip, 122, 371

Hassal, corpuseles of, 210,211

Head, muscles of, development of, 343

of epididymis, 223

of spermatozoön, 20

Head-fold, 72

of amnion, 72,75

Head-gut, 171

Head-kidney, 212

Head-process of primitive streak, 51, 62

Head-segments, 340

Head-skeleton, development of, 358

Heart, development of, 138 metamorphosis of single in to double, 142

valves, development of, 144

Helix, formation of, 333

Hemal arch, formation of, 352

Hen's egg, description of, 25

Hensen's node, 51

Hepatic cylinders, 19 ? vein, development of, 164

Hermaphroditism, 239, 244

Hernia, congenital, 2:6 umbilical, 188

Highmore, antrum of, development of, 336

Hilum folliculi, 29

Hind-brain, 262, 268

secondary, 263

vesicle, 65,268

Hindgut, 73,171

Hippocampal fissure, 283

Hippocampus major, 283 minor, 284

His, canal of, 133,208

Holoblastic ova, 43

Homogeneous twins, origin of, 51

Homolngies of the sexual system, 240

Hyaloid artery, formation of, 314 canal, 315

membrane, formation of, 315

Hydatid of Morgagni, 224

sessile, 224

stalked, 22:

mnstalked, 224

Hydramnios, 77

Hymen, formation of, 237

Hyoglossus, origin of, 345

Hyoid arch, anterior, 363 posterior, 363

arches, 105

bar, 363

bone, development of, 363,375

Ityoidean apparatus, 375

HỴomandihular eleft, 105

Hypoblast, 47

Hypochordal hrace, 351

Hypophysis, 276

formation of. 123

Hypospadias, 2:3!

glandular, 239
ILIAC segment of pelvic girdle, 378 vein, left rommon, development of, 156

Imperforate anus, 180

Incus, development of, 362,373

Indifferent genital gland, 24:2 sexual gland, 221

Inferior medullary velum, 268 peduncles of braiu, 266

Infundibula of lungs, development of, $20 \%$

Infundibulum of biain, 272, 276

Inguinal ligament, 225

in female, 231

Inner cell-mass, 45

Innominate artery, development of, 152

Inter-brain, 263, 272

vesicle, metamor phosis of, 272

Intermaxillary bones, formation of, 124,371

Intermedial cell-mass, 69, 341

Internal ear, development of, 321

fertilization, 38

lateral ligament of lower jaw, 374

limiting membrane of spinal cord, 259

Interpallial fissure, 278

Intervertebral disks, development of, 353

formation of, 351

ligament, development of, $35:, 353$

Intestinal canal, formation of, 71

glands, development of, 189

mesentery, 198

mucosa, formation of, 172

villi, formation of, 189

portals, 73,169

Intestine, small, development of, $\mathbf{1 8 5}$, 188

Intestino-body cavity, 47

Intumescentia ganglioformis, 326

Involuntary muscle, development of, 316

Iris, coloboma of, 315

development of, 317

Iscliatic rod, 378

Island of Reil, 281

Jacobsox's organ, development of, 337

Jaw, upper, development of, 122

Jaw-arch, 103

Jelly of Wharton, 92

Joint-eavities, development of, 117

Jugular veiu, primitive, 14s, 154

transverse, 156

KIDNEY, development of, $: 212$

LABIA majora, 237

minolu, formation of, $23 \pi$

Labyrinth, bony, development of, 326 menbranous, development of, 321

Lacrimal bones, ossification of, 3 T0 
Lacrimal canaliculi, development of, Lumbar rib, 357 320

caruncle, 319

duct, development of, 320

gland, development of, 319

groove, 107, 120

sac, development of, 321

Lamina cinerea, 272,275

quadrigemina, 271

spiralis, bony, development of, 330

terminalis, 285

Lanıgo, 250

Larpux, development of, 207

Latebra, 27

Lateral cartilage of nose, 369

folds of amuion, 72

frontal processes, $107,120,122$

in formation of nose, 131

ligaments of liver, 193

nasal process, 320,334

plate of mesoderm, 57

plate of somite, 55

ventricle, development of, 279

Length of fetus at term, 112

Lens, crystalline, development of, 312

Lens-area, 304

Lens-capsule, development of, 313

Lens-pit, 312

Lens-vesicle, 98, 122, 304, 312

Lenticular zone of optic cup, 309

Lesser omentum, 202 formation of, 188

Levator palati, origin of, 345

Lids, union of edges of, 319

Lieberkühn, glands of, 189

Ligament of ovary, 232

Ligaments of liver, formation of, 192

Ligamenta intermuseularia, 350 subflava, 353

Ligulæ, 267

Limb-buds, 108, 380

Limbie lobe, 285, 289

Limb-museles, development of, 345

Limbs, brones of, development, 379

developinent of, 380, 383-390 position of, 381

Limiting membrane, iuner, formation of, 307

outer, formation of, 307

Lip, upper, development of, 124

Liquor ammii, 76,77 function of, 77

folliculi, 29, $2: 28$

of Morgagni, 313

Liver, development of, 190

first rudiment of, 181

liganents of, formation of, 192

Jiver-lidge, 15!), 191

Lobes of liver, 191

bobnle of rar, development of, 333

Longitudinal fiber-tracts of medulla, 266

fissure of braill, 278

Lower jaw, ossification of, 372

vertebræ, ossification of, 355

Lungs, development of, 205

Lymph, formation of, 115

Lymph-clefts, development of, 117

Lymph-saes, development of, 116

Lymph-spaces, development of, 116

Lymphatic system, development of, 116

vessels, development of, 117

Lymphoid follicles of tonsil, 178 tissue, development of, 117

MAcUla lutea, formation of, 309

Maculæ acusticæ, development of, 325

Malar bone, ossification of, 370

Male external genitals, 237, 244

interual genital organs, 222

pronucleus, 39

sexual system, 222,212

Malleus, development of, 362,373

Malpighian corpusele, development of, 195,217 primitive, 216

Mammalia deciduata, 88 indeciduata, 88

Mammals, blastula of, 45

Mammary gland, development of, 251

Mandible, ossifieation of, 372

Nandibular arch, 103, 123, 360

Mantle layer, 260

Marginal sinus, 90

vein, 90

zone of optic cup, 310

Marshall, vestigial fold of, 156

Maturation of ovum, 30 theories of, 32

Maxilla, superior, ossification of, $3 \pi 1$

Maxillary arch, 103

process, 123,360

Meatus, external auditory, formation of, 332

urinarius, male, 239

Meckel's cartilage, 105, 362, 372

diverticulum, formation of, 190

ganglion, 298

Median fissures of cord, 261

lobe of cerebellum, 268

Medulla oblongata, development of, 265

Medullary canal, 62

cords, 229

folds, 64,255

furrow, 63

groove, 63

plate, 62,255

tube, 255

velum, anterior, 269

iuferior, 268, 270

Meibomian glands, development of, 319

Nembrana adamantina, $12 \%$

basilaris of cochlea, formation of, $3: 30$

eboris, 129 
Membrana granuJosa, 29 formation of, 228 præformativa, 129

Membrane, anal, 176 closing, 100, 105, 177 nuclear, 25 of Nasmyth, 128 of Reissner, 330 pharyngeal, $106,119,171,175$ vitelline, 23,24 tympanic, 17\%, 33:

Membranes, caducous, 85 deciduous, 85

Membranous bones, 359 cranium, 359

labyrinth, development of, 321 ribs, 356

stage of skeleton, 348 of trunk, 349

Menopause, 35

Menstrual cycle, 35

Menstruation, 35 relation of, to ovulation and con. ception, 37

Meroblastic ova, 44

Mesencephalon, 270

Mesenchymal cells, 58 muscle, 346

IIesenchyme, 58

Mesenteries, 173

IIesentery, intestinal, 198 ventral, 187 development of, 202

Mesoblast, 54

Mesoblastic somites, 57,67

Mesocardium anterins, 139, 158 posterius, 139,158

Mesocolon, ascending, production of, 186

formation of, 186

Mesoderm, 54

derivatives of, 60

gastral, 55

paraxial, 57

peristomal, 55

somatic, 50

splanchnic, 58

structures developed from, 113 et seq.

Mesogastrium, 187, 198

Mesonepliric duct, 214

Mesonepliros, 213, 241

Mesorchium, 225

Mesothelinm, 58, 115

Mesovarium, 225

Hetacarial bones, development of, 379

Metamorphosis of single into double heart, $14: 2$

Mctanephros, $21 \%, 241$

Metatarsal bones, development of, 379

Metencephalon, 264

Metopice snture, $3 \% 0$

Metopism, 370
Micropyle, 23, 39

Mid-brain, 262, 270

prominence of, 264

vesicle, 65,270

Mid-gut, 171

Middle ear, development of, 177, 331 piece of spermatozoön, 20

plate, $69,212,341$

sacral artery, development of, 150

tunic of eye, development of, 315

Modiolus of cochlea, development of, 329

Moll, glauds of, 250

Monorchism, 226

Mouro, forameu of, 277,282

Mons veneris, formation of, 237

Morgagni, hrdatid of, 224

liquor of, 313

Morula, 41

Mother-cells, 22

Hotor nerve-fibers, development of 295

Month, development of, 122,175

Mucous tissue, formation of, 114

Mulberry-mass, 41

Müller, duct of, $220,224,230,242$

Müller's fibers, 307

Muscle, inroluntary, development of, 3.16

voluutary, development of, 339

IIuscle-plate, 69,341

metamorphosis of, 342

Muscles, branchial, development of, 344

of extremities, development of, 345

of trunk, development of, 339

Muscular coat of intestines, formation of, 188

system, development of, 339, 383-390

Musculi papillares, 147

pectinati, 140

IIyocœ1, 89, 341

Myotome, 69, 341

NAIL-BED, 248

Nail-plate, 247

Nails, development of, 247 of toes, 240

Nail-weIt, 248

Nares, anterior, formation of, 134 development of, 336

Nasal areas, 133,334

bones, ossification of, 370 eapsule, 362

cavities, derelopment of, 336

pits, $107,120,133,331$

process, 1:0, 334

lateral, 320,334

Nismyth, membrane of, 128

Nitsofrontal process, $103,107,120,122$ 331,360

in development of nose, 133

Naso-optic furrow, 1:0, 1:2

in formation of nose, 131

groove, 320 
Nephrotome, 69, 214, 241, 341

Nerve-cells, formation of, 258 of cord, formation of, 260

Nerve-corpuscles of neurilemma, 295

Nerve-fiber, euvelopes of, formation of, 295

layer, derelopment of, 309

Nerve-fibers, cranial, development of, 296

motor, development of, 295

sensory, development of, 293

Nerve-trunk, spinal, development of 295

Nervouls system, development of, 254 , 333-390

peripheral, development of, 292

sympathetic, development of, 300

Neural arch of vertebra, formation of 352

canal, $62,255,257$

crest, segmentation of, 294

crests, 291

tube, 255

Neurenteric canal, 66, 25\%

Neurilemma, formation of, 295

Neurit, 251, 260

Neuroblasts, 258, 260

Neuro-epithelium of retina, development of, 309

Neuroglia, 258, 259

layer, 260

Neurons, 254

Nictitating membraue, 319

Nintl month, development during, 111,390

pair cranial nerves, development of, 300

week, development during, 387

Nipple, development of, 252

Node, Hensen's, 54

Nose, development of, 133, 334

Notochord, 65

Notochordal stage of skeletom, 348

Nnchal flexure, 264

Nuck, canal of, 232

Nuclear juice, 25

layer, of retina, onter, 308

membrane, 25 spindle, 41

Nuclens amygdalæe, 279

cleavage-, 39

of ovnm, 25

segmentation-, 39

Nutritive yolk, 24

Nymplix, formation of, 237

OBEx, 267

Occipital bone, ossification of, 361 lobe, 28\%

Odontoblasts, 129

Glontrid frocess, development of, 35.5

Olfactory bulb, 290

epithelium, 334

lobe, 290
Olfactory nerve-fibers, 338

plates, 120, 133, 331

tract, 290

Omental bursa, 187, 200

Omentum, gastrohepatic, 192, 202 formation of, 188

gastrospleuic, 195

great, formation of, 187, 201

lesser, 202

formation of, 188

phrenicosplenie, 195

Omphalomesenteric veins, 136

Ontogeny, 17

Oogenesis, 27

Ophthalmic ganglion, 296

Opisthotic center of ossification, 366

Optic enp, 304 secondary, 306

lobes, formation of, 271

nerve, development of, 311

thalami, 272

vesicle, 263,303

Ora serrata, 307

Oral cavity, development of, 175

fossa, 175

pit, $98,106,119,123,175$

plate, 118, 122,175

Organ of Corti, 325

of Giraldès, 221

of Jacobson, development of, 337

of Rosenmüller, 231

Osseons craninm, 363

stage of trunk skeleton, 354

tissue, formation of, 115

Ossicles of ear, development of, 332

Ossification of ribs, 357

of skull, 363

of sternum, 357

of vertebræ, 354

Otic vesicle, 98,322

Otocyst, 32:?

Outer cell-mass, 45

Ova, alecithal, 21

centrolecithal, 25

classification of. 24

formation of, 27

holoblastic, 43

meroblastic, 44

plimitive, 29, 222,227

telolecithal, 24

Ovaries, change of position of, 231

Ovary, development of, 226

Ovidnets, development of, 230

Ovists, 18

Ovulation, 32

relation of, to menstruation, 31

Ovum, 22

forluation of, $2: 28$

maturation of, 30

ripeniug of, 30

segmentation of, 41

stace of, 19,95

Parate hone, ossification of, 370

formation of, 121 
Palate process, development of, $3 \pi 1$

Palate-shelves, 336

Palatoglossus, origin of, 315

Palatopharyngeus, origin of, 345

Palpebral fasciæ, 319

fissure, 319

Pancreas, development of, 194

first rudiment of, 182

Pancreatic duct, development of, 194

Pander. blood-islands of, 135

Pander's nucleus, 26

Panniculus adiposus, 246

Papillæ of tongue, formation of, 133

Parablast, 58

Parachordal cartilages, 361

Paradidrmis, 224

Paraxial mesoderm, 57

Parietal bones, ossification of, 370

elevation, 261

eye, 275

foramen, 274

layer of pleura, 161

lobe, 282

zone, 68

Parieto-oceipital fissure, 284

Paroöphoron, 231

Parovarium, 231

Pars ciliaris retinæ, 310

intermedialis, 237

iridica retinæ, 310

optica retinæ, 309

Parthenogenetic eggs, 32

Patulous foramen ovale, 143

Pectoral girdle, development of, $3 \pi \%$

Pelvic girdle, 375

Pelvis of kidney, formation of, 218

Penis, development of, 235

Perforated lamina, anterior, 291 space, posterior, 270,271

Pericardial cavity, 159

Pericardium, development of, 158

Perilymph, 327, 331

Perilymphatic space, 327

Perineal bodr, 180

Perineum, formation of, 180

Perionyx, 248

Perintic bone, 366

Peripheral eleavage, 44 nervous system, development of, 292

Peristomal mesoderm, 55

Peritoneal carity, development of, 198

Peritoneum, development of, 195

visceral layer of, 172

Perivitelline space, 23

Permanent kidney, 217 tectl, development of, 129 eruption of, 131

Petromastoid bone, 366

Petrotympanic fissure, 373

Pflüger's egg-tubes, 22:

Plialanges, development of, 379

Pliaryngeal bursa, 1:24

constrictors, origin of, 345
Pharyngeal membrane, 106, 119, 171, 175

in formation of month, 123

pouches, 100, 171, 176

Pharynx, 176

Phrenicosplenic omentum, 195

Phylogeny, 17

Pial processes, 259

Pigment-layer of retina, 307

Pillars of Uskow, 161

Pineal body. 272

or gland, 273,274

eye, 275

Pit, auditory, 322

oral, 98,106

Pits, nasal, 334

Pituitary body, 276

formation of, 123

Placenta, 87

discoidea, 89

prævia, 91

zonaria, 88

Placental spaces, 90 system of blood-ressels, 149

Planes of cleavage, 42

Plantar horn, 247

Plate, chordal, 66

medullary, 6:

vertebral, 57

Pleura, parietal layer of, 161 visceral layer of, 161

Pleuræ, derelopment of, 158, 159

Pleural sacs, formation of, 15s, 159

Pleuropericordial fold, 160

Pleuroperitoneal cavity, 50, 197

Plica semilunaris, 319

Pocket of Rathke, 277

Polar bodies, 31

striation, 41

Polarity of egg, 25

Pole-corpuscles, 30

Polyphrodont, 125

Polyspermia, 39

Pontal flexure, 261

Polls, formation of, 268

Portal circulation, 154, 161 vein, development of, 161 venous system, 15t, 161

Postanal gut, 179

Posterior ehamher of eje, 318 nares, development of, 336

Post-limbic sulcus, 285

Preformation theory, 18

Prehepaticus, 159, 191

Prehyoid gland, 209

Premaxilla, 371

Prepuce, formation of, 238

Prespluenoid, 368

Primary egg-tubes, 29

Primitive aorta, $13 \%, 150$

chorion, 8:2

enamel-germ, 126

ejelids, 122

groove, 5:

heart-valves, 144 
Primitive jugular veins, 148, 154 Malpighian corpusele, 216 nails, 247 ova, $29,222,227$ red blood-eorpuscles, 136 segment plate, 57 segments, 57,67 sexual cells, $2: 1$ streak, 51 vertebral bow, 351

Primordial bones, 359

Proamnion, $56^{\circ}$

Proeess, lateral frontal, 107, 120, 122 nasal, 120,334

nasofrontal, 103, 107, 120, 122, 334

in formation of nose, 133

Processes, dental, 129 globular, $107,120,334$

nasal, 334

maxillars, 123

of vertebra, development of, 352

Processus vaginalis, $2: 26$

Proehorion, 45, 82

Proctodeum, 179

Pronephric duet, 212

Pronephros, 21:, 241

Pronucleus, female, 32 male, 39

Pro-otic center of ossification, 366

Prosencephalon, 278

Prostate gland, formation of, 234

Prostatie urethra, formation of, 234

Protoplasmic processes, 260

Protovertebra, 55

Pterygoid plate, internal, development of, 368

Pubie rod, 378

Pulmonary alveoli, development of, 207

artery, development of, 144, 152

äiverticulum, 205

groove, 205

Pulp of spleen, development of, 195 of teeth, 125

Pupil, 306

eongenital atresia of, 314

development of, 318

Pyramidal tracts, anterior development of, 266

crossed, of cord, myelination of, 389

RAMUS communicans, 301

Ratlike's jocket, 124, $27 \%$

Rauber's layer, 45, 49

Receptive frominumes, 39

Recessus laby rinthi, 32: vestibuli, $3: 2$

Rectum, 180

Recurrent larringeal nerves, 152

Red blood-corinuscle, primitjve, 136

Reiehert's rutilage, 105, 363, 375

Reil, island of, : $: \times 1$

Reissner, membrane of, $: 330$

Ienal vein, loft, 157
Reproduction, theories of, 17

Respiratory system, development of, 204, 383-390

Restiform bodies, development of, 266

Rete mueosum, 247

testis, formation of, 223

Retina, development of, 304

Rhinencephalon, 290

Rbomboidal fossa, 267

Rib, eervical, 354,357

Iumbar, 357

thirteenth, $35 \%$

Ribs, development of, 356

Ridge, genital, 220

terminal, 50

Ring lobe, formation of, 280

Ripening of orum, 30

Rod-and cone-layer, formation of, 308

Rod-visual cells, 307

Rolando, fissure of, 284

Roof-plate, 25\%, 258

Rotation of stomaeh, 186, 200

Round ligament of liver, 167 formation of, 193 of uterus, 225,232

SACCULE. development of, 324

Saceus endolympliaticus, 323

Saeral vertebre, ossifieation of, 355

Sacrum, formation of, 355

Salivary glands, development of, 131

Sauropsida, blastula of, 46

Seala media of cochlea, development of. 323

tympani, development of, 330,331

vestibuli, developnent of, 330, 331

Scapula, development of, 377

Schwaun, white substanee of, 295

deposit of, upon fibres of tract of eord, 388,389

Selerotome, 69, 341, 350

Serotum, development of, 239

Sebaceous glands, development of, 251

Seeond mouth, development duriug, 106

paireranial nerves, development of, 299

week, development during, 383

Secondary hair, 250

optie cup, 306

Segmental duet, 213

Segmentation of body of embryo, 69 of ovum, 41

Segmentation-eavity, 45

Segmentation-nucleus, 39

Semieireular eanals, bony, 327 development of, 323,324

Semilumar valves, development of, 147

Seminal ampulla, 223

vesicle, formation of, 224

Seminiferous tubmles, formation of, 223

Sense organs, development of, 302, 383-3910

Sensory epithelium of retina, 307 
Sensory nerve-fibers, development of, Spermatic cord, 226 293

Septa placentre, 90

Septal cartilage of nose, 369

Septum lucidum, formation of, 285

transversum, 148, 159

Serosa, 7:3

Serous membranes, development of, 115

Sertoli's, columns, 21, 223

Sessile hydatid, 2:4

Seventl month, development during, 111,359

pair cranial nerres, development of, 299

week, development of, during, 356

Sexual cells, 29

primitive, 221

cords, 29, 2:22

female. $2 \% \gamma$

gland, indifferent, $2: 1$

segment of Wolftian body, 219

system, female, 226,243

homologies of, 240

indifferent type, 220

male, 222,242

Shell of hen's egg, 27

Shell-membrane, $2 \tau$

Shoulder girdle, development of, 377

Sinus, annular, 163

pocularis, 221,231

præcervicalis, 105

reuniens, 144

terminalis, 136

urogenital, 173,233

venosus, 144, 153

Sixth montlı, development during, 111,359

pair cranial nerres, development of, 299

week, development during, 108, 385

Skeletogenous sheath of chorda dorsalis, 350

tissues, 69

Skeleton, appendicular, 313

development of, $376,353-390$

axial, 318

development of, 318

development of, $31 \tau$

of head, development. of, 353

of trunk, eartilaginous stage of 351

chordal stage of 348

development of, 318

membranous stage of, 349

visceral, $35 \mathrm{~s}$

Skin, appendages of, $24 i$

development of, $245,383-390$

Small intestine, development of, 188

Snegma embryonum, 217

Somatic mesoderm, 58

Somatoplemre, 58, 169

Somites, 55, $6 \tau$

mesoblastic, $5 \pi, 6 \pi$

Space, perivitelline, 23

veius, $15 \tau$

Spermatids, 2:2

Spermatoblasts, :2:2

Spermatogenesis, :21

Spermatogenic cells, 21

Spermatozoön, :20

pow'r of locomotion of, 21

vitality of, 21

Sphenoid bone, ossification of, $36 \pi$

Sphenoidal sinus, development of, $33 \tau$

Sphenopalatine ganglion, 296

Spinal cord, development of, 257

Spinous process of vertebra, development of, 354

Splanchnic mesoderm, 58

Splanchnopleure, 5s, 169

Spleen, derelopment of, 194

Spongioblasts, 252,259

Spot, germinal, 25

Squamozygomatic bone, 365

Stage of embrro, 19,96

of fetus, $20,106^{\circ}$

of ovum, 19, 95

of quiescence of menstrual cycle, 36

of repair of menstrual cycle, 36

Stalked hydatid, 2:24

Stapes, development of, 363

Stem-zone, 6\%

Sternum, cleft, $35 \tau$

development of, $35 \tau$

Stigma, 29

Stilling, canal of, 315

Stomach, development of, 186

first rudiment of, 181

glands of, development of, 189

rotation of, 186, 200

Stomodæum, 119, 175

Stratum Malpighii, 247

Streak, primitive, 51

Striated muscles, development of, 339

Stroma-laver of choroid, development of, 316

Strloglossus, origin of, 345

Stṛlohyal, 376

cartilage. $36 \pi$

Stylohyoid ligament, 363

Styloid process of hyoid, 363 temporal, development of, 367

Strlopluarngens, origin of, 345

Subclavian artery, left, development of, 152

right, development of, 151

Snbmaxillars ganglia, 296

Submucosa of intestines, formation of, 188

Sulcus interventricularis, 143

of corpus callosum, 283

Superior maxilla, ossification of, 371

Supralisoid gland, 209

Supra-occipital bone, 364

Sunrapericardial bodies, 209

Suprarenal bodies, development of 218,242 
Suspensory ligament of liver, formation of, 193

Sustentacular cells of seminiferous tubule, 21

Suture, amniotic, 75

Sweat-glands, development of, 250

Srlvius, aqueduet of, 271

fissure of, 279,280

fossa of, 280

Sympathetic nervous system, development of, 300

Synovial saes, development of, 115

TAIL of spermatozoön, 20

Tail-fold, 72

Tarsal ligaments, 319 plates, 319

Tarsus, development of bones of, 379

Teeth, development of, 125

permanent, development of, $1: 9$ eruption of, 131

temporary, development of, 125 eruption of, 130

Tela choroidea, 273

Telolecithal ova, 24

Temporal boue, ossification of, 364

lobe, formation of, 280

Temporary teeth, development of, 125 eruption of, 130

Temporomaxillary articulation, 374

Tendon, development of, 114

Teudon-sheaths, development of, $11 \%$

Teuth pair eranial uerves, development of, 300

Terminal ridge, 50

Testicle, development of, 222 desceut of, 225

Thalameneephalon, 272

Thebesius, valve of, 144

Theea follieuli, $2 \%$

Thecal sacs, development of, 115

Theory of evolution, 17

of unfolding, 17

Third eyelid, 319

month. development during, 109 387

pair cranial nerves, development of, 299

ventricle, formation of, $27 \%$

week, development during, 384

Thirteenth rib, 357

Thoracic prolongations of abdominal eavity, 159

Throat-pockets, $100,171,1 \% 6$

Thymus body, development of, $17 \%$, 210

Thyroglossal duct, 133, 208

Thyroid body, accessory, 209 development of, $17 \%, 207$

duct, $20 \mathrm{~s}$

formmen, 378

Toes, develojment of, 381

Tongue, develojment of, 131, 177

Tomsil, develomment of, 177

Tonsillar jit, 178
Trabeculæ cranii, 361

Trachea, development of, 207

Tragus, formation of, 333

Transverse colon, formation of, 186

erescentie groove, 72

fissure of brain, 273

processes of vertebræ, formation of, 354

Trigeminal ganglion, 296

True chorion, 82

Truncus arteriosus, 102, 137, 140, 149

Trunk, skeleton of, development of, 348 osseous stage of, 354

Trunk-museles, development of, 339

Truuk-segments, 340

Tuber cinereum, 272, 276

Tuberculum impar, 132, 177

Tubotympanic suleus, 331

Tuniea albuginea of ovary, 227

fibrosa, 28

propria, :88

vaginalis testis, 226

vasculosa, 27

lentis, 313

T'urbinal folds, 336

Turbinate bone, inferior, ossification of, 369

Turbinated bones, development of, 337

Twelfth pair eranial nerves, development of, 300

Twins, origin of, 51

Tympanie eavity, formation of, $17 \gamma$ menbraue, 177 development of, 332

portion of temporal bone, development of, 367

Tympanohyal, 376

cartilage, 367

Tympanum, development of, 331

UMmilicAl aperture, 78, 169

arteries, 92,149

cord, 91

hernia, congenital, 189

urinary fistula. 233

vein, $91,149,153$

vesiele, $72,78,169$

function of, 80

human, 80

vessels, 91

Uncinate gyrus, 291

Unstriated muscle, development of, 346

Urachus, 82, 233

Ureter, 218 development of, 212

Urethra, fentale, 234

male, formation of, 239

prostatic, formation of, 234

Urinary fistula, umbilical, 233

Uriniferous tubules, formation of, 217

Urogenital aperture, 233

sinus, 17:3, 179, 233

Uskow, pillars of, 161 
Uterus bicornis, 230

development of, 230

double, 230

masculinus, 224, 234

Utricle, development of, 324

Uveal tract, development of, 316

Uvula, formation of, 125

VAGINA, development of, 230 median septum in, 230

Valve, coronary, 144

Eustachian, 144

of Thebesius, 144

of Yieussens, 269

Valves, atrioventricular, 142

auriculoventricular, 146

of heart, development of, 144

semilunar, development of, 147

Vas deferens, formation of, 223

Vasa efferentia, 223

recta, formation of, 223

Vascular area, 79

system, development of, 135, 383390

fetal, final stage of, 165

tunic of ere, development of, 315

Vegetative jole, 25

Vein, cardinal, 149

hepatic, 164

iliac, left common, development of, 156

portal, development of, 164

renal, left, 155

umbilica], 91

Veins, allantoic, 148

cardinal, 154

ompbalomesenteric, 130

prinitive jugular, 154

spermatic, $15 \tau$

umbilical, 149,153

vitelline, 136,153

Velum interpositum, 272, 273

Veua azygos major, $15 \%$ minor, 158

cava inferior, $155,15 \%$ superior, 154

Venæ hepaticæ advehentes, 163 reveheutes, 163

Venous segment of heart, 141 system of fetus, 153 portal, 154

Ventral meseutery, 173, 18 \% development of, 202

Ventricles, separation of, 143

Vermiform appendix, development of, 1 s6

proress of cerebellum, 268

Vernix caseosa, 78, 247

Vertebre. ossification of, 354

Vertebral bow, primitive, 351

column, development of, 348-35)6 membranous primordial, 350 plate, 57
Vertebral region of primitive skull, 361

Vesicle, germiual, 23, 25

otic, $98,3 \% 2$

umbilical, $72,78,169$

Vesicles, cerebral, 26:2, 263

lens, 98

Vestibular ganglion, 326

nerve, 297

Vestibule of ear, development of, 327 of vagina, 237 of vulva, 234

Vestigial fold of Marslaall, 156

Vieussens, valve of, 269

Villi of chorion, $8: 3$ of intestine, folmation of, 189

Visceral arch, first, fuuction of, 103, 119

arches, 100

metamorphosis of, 103

morphological siguificance of, 102 clefts, 100

layer of peritoneum, 1\%? of pleura, 161

skeleton, 358

Visceral-arch vessels. $10 \%, 137,149$

Vitelline arteries, $13 \tau$

circulation, formation of, 135

duct, $\tau 2, \tau 8,169$

membrane, 23,24

veins, 136,153

Vitellus, 23, 24

Vitreous bodr, development of, 314

Yocal cords, devolopment of, 207

Voluntary muscles, development of, 339

Vomer, ossification of, 370

WEIGHT of fetus at term, 111 at different stages, 386-390

Wharton, jelly of, 9 ?

White commissures of cord, 260 fibrous tissue, formation of. 114 matter of brain, formation of, 279 of cord, developunent of, 261

of hen's egg, 27

substarce of Schwamn, development of, $295,383,389$

Winslow, foramen of, $\supseteq 03$

Witches' milk, 253

Wolftian bodr, 213 duct, $: 215$ in female, 230

Wolff's doctrine of epigenesis, 18

Wreath, 41

YOLK of orum, 23

Yolk-sac, 72, 7s, 169

ZoxA pellueida, 23, 29 radiata. 29

Zone, parietal, 68 stem-, 6 s 



\section{CATALOGUE}

OF THE

\section{MEDICAL PUBLICATIONS \\ OF}

\section{W. B. SAUNDERS,}

\section{No. 925 WALNUT STREET, PHILADELPHIA.}

Arranged Alphabetically and Classified under Subjects.

THE books advertised in this Catalogue as being sold by subscription are usually to be

obtained from travelling solicitors, but they will be sent direct from the office of pub-

lication (charges of shipment prepaid) upon receipt of the prices given. All the other books advertised are commonly for sale by booksellers in all parts of the United States; but books will be sent to any address, carriage prepaid, on receipt of the published price.

Money may be sent at the risk of the publisher in either of the following ways : A postoffice money order, an express money order, a bank check, and in a registered letter. Money sent in any other way is at the risk of the sender.

See pages 30, 31, for a L'st of Contents classified according to subjects.

\section{LATEST PUBLICATIONS.}

American Text-Book of Dis. of Eye, Ear, Nose, and Throat. Page 3. American Text-Book of Genito-Urinary and Skin Diseases. Page 4. American Text-Book of Diseases of Children-Rev. Edition. Page 3. American Text-Book of Gynecology-Revised Edition. See page 4. American Year-Book of Medicine and Surgery. See page 6. Anders' Practice of Medicine-Revised Edition. See page 6. Vierordt's Medical Diagnosis-Fourth (Revised) Edition. See page 29. Kyle on the Nose and Throat. See page 15.

Church and Peterson's Nervous and Mental Diseases. See page 8. Da Costa's Surgery-Revised and Enlarged Edition. See page 10.

Saunders' Medical Hand-Atlases. See page 2.

Griffith on The Baby-Revised Edition. See page 12.

Butler's Materia Medica and Therapeutics-Revised Edition. Page 8. De Schweinitz' Diseases of the Eye-Revised Edition. See page 10. Vecki's Sexural Impotence. See page 28.

Stoney's Materia Medica for Nurses. See page 28.

Penrose's Diseases of Women--Second Edition. See page 18.

McFarland's Pathogenic Bacteria-Revised Edition. See page 17.

American Pocket Medical Dictionary. See page 10.

Stengel's 'Text-Book of Pathology. See page 26.

Hirst's Text-Book of Obstetrics. See page 13.

Grafstrom's Massage and Medical Gymnastics. Page 12.

Saunders' Pocket Formulary-Fifth (Revised) Edition. See page 24.

Stevens' Practice of Medicine-Fifth (Revised) Edition. See page 27. 


\section{SAUNDERS' MEDICAL HAND-A TLASES.}

THE series of books included under this title consists of authorized translations into English of the world-famous Lehmann Medicinische Handatlanten, which for scientific accuracy, pictorial beauty, compactness, and cheapness surpass any similar volumes ever published. Each volume contains from 50 to roo colored plates, executed by the most skifful German lithographers, besides numerous illustrations in the text. There is a full and appropriate description of each plate, and each book contains a condensed but adequate outline of the subject to which it is devoted.

One of the must valuable features of these atlases is that they offer a ready and satisfactory substitute for clinical observation. To those unable to attend important clinics these books will be absolutely indispensable.

In planning this series of books arrangements were made with representative publishers in the chief medical centers of the world for the publication of translations of the atlases into nine different languages, the lithographic plates for ail these editions being made in Germany, where work of this kind has been brought to the greatest perfection. The expense of making the plates being shared by the various publishers, the cost to each one was materially reduced. Thus by reason of their universal translation and reproduction, the publishers have been enabled to secure for these atlases the best artistic and professional talent, to produce them in the most elegant style, and yet to offer them at a price heretofore unapproached in cheapness. The success of the undertaking is demonstrated by the fact that the volumes have a'ready appeared in nine different languages -German, English, French, Italian, Russian, Spanish, Danish, Swedish, and Hungarian.

In view of the striking success of these works, Mr. Saunders has contracted with the publisher of the original German edition for one hundred thousand copies of the atlases. In consideration of this enormous undertaking, the publisber has been enabled to prepare and furnish special additional colored plates, maling the series even handsomer and more complete than was originally intended.

As an indication of the practical value of the atlases and of the favor with which they have been received, it should be noted that the Medical Department of the U.S. Army has adopted the "Atlas of Operative Surgery" as its standard, and has ordered the book in large quantities for distribution to the various regiments and army posts.

The same careful and competent editorial supervision has been secured in the English edition as in the originals, the translations being edited by the leading American specialists in the different subjects.

\section{NOW READY.}

Atlas of Internal Medicine and Clinical Diagnosis. By DR. CHR. JAKOB, of Erlangen. Edited by Augustus A. Eshner, M.D., Professor of Clinical Medicine in the Philadelphia Polyclinic; At. tending Physician to the Philadelplia Hospital. 68 colored plates, and 64 illustrations in the text. Cloth, $\$ 3.00$ net.

Atlas of Legal Medicine. By Dr. E. R. Yon Hofman, of Vienna. Edited by Frederick FErERSoN. M.D. Clinical Professor of Mental Diseases, Woman's Medical College, New York; Chiel of Clinic, Nervous Dept., College of Physicians and Surgeons, New York. With I2o colored ñgures on 56 plates, and 193 beautiful half-tone illustrations. Cloth, $\$ 3.50$ net.

Atlas of Diseases of the Larynx. By Dr. L. Grünwald, of Munich. Edited by Charles P, GRAYSON, N.D., Iecturer on Laryngology and Rhinology in the University of Pennsylvania; Physician-in-Charge, Throat and Nose Department, Hospital of the University of Fennsylvania. With 107 colored figures on 44 plates, and 25 text-illustrations. Cloth, $\$ 2.50$ net.

Atlas of Operative Surgery. By DR. O. ZuckFrkand, of Vienna. Edited by J. Chalmers DACosTA, M.D., Clincal Professor of Surgery, Jefierson Medical College, Philadelphia; Surgeon to the Philadelphia Hospital. With 24 colored plates, and 217 text illustrations. Cloth, $\$ 3.00$ net,

Atlas of Syphilis and the Venereal Diseases. By PROF. DR. FrANz Mraček, of Vienna. Edited by L. BOLTON BANGS, M. D., Professor of Genito-Urinary Surgery, University and Bellevue Hospital Aledical College, New York. With 71 colored plates, 16 black-and-white illustrations, and 122 pages of text. Cloth, \$3.50 net.

Atlas of External Diseases of the Eye. By DR. O. HAAB, of Zurich. Edited by G. E. IDE Schwersti\%, M. L., Professor of Uphthalmology, Jefferson Medical College, Philadelphia. With 76 colored illustrations on 40 plates, and 228 pages of text. Cloth, $\$ 3.00$ net.

Atlas of Skin Diseases. Jyy Prof. Dr. Franz Mracek, of Vienna. Edited by Henry IV. Stelwagon, .1. D., Clinical Professor of Dermatology, Jefferson Nedical College, Philadelphia. 63 colored plates, 39 beautiful half-tone illustrations, and 200 pages of text. Cloth, $\$ 3.50$ net.

\section{IN PREPARATION.}

Atlas of Pathological Histology.

Atlas of Orthopedic Surgery.

Atlas of General Surgery.
Atlas of Operative Gynecology.

Atlas of Psychiatry.

Atlas of Diseases of the Ear. 


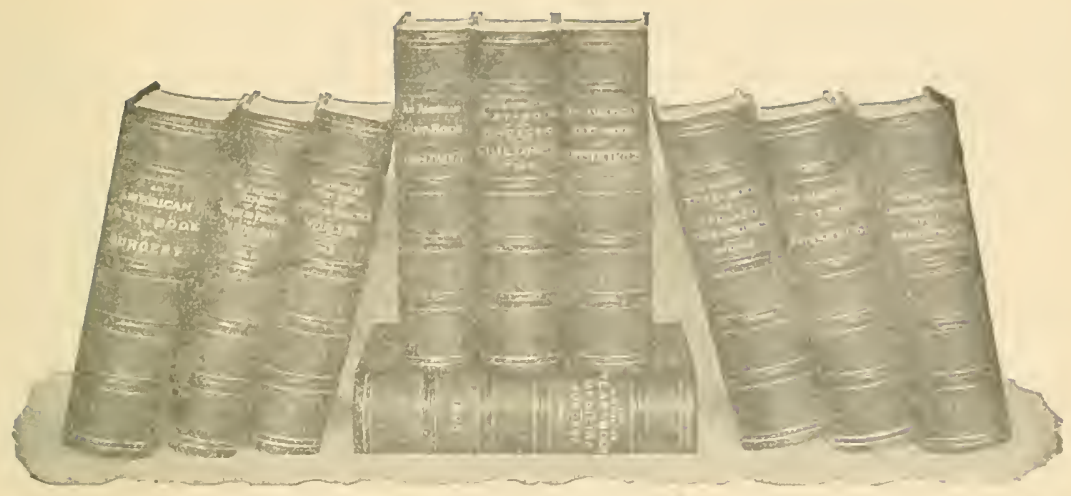

THE AMERICAN TEXT-BOOK SERIES.

\section{AN AMERICAN TEXT=BOOK OF APPLIED THERAPEUTICS.}

By 43 Distinguished Practitioners and Teachers. Edited by JAmes C. IVILSON, M.D., Professor of the Practice of Medicine and of Clinical Medicine in the Jefferson Medical College, Philadelphia. One hand. some imperial octavo volume of 1326 pages. Illustrated. Cloth, $\$ 7.00$ net; Sheep or Half Morocco, \$8.00 net. Sold by Subscription.

"As a work either for study or reference it will be of great value to the practitioner, as it is virtually an exposition of such clinical therapeutics as experience has taught to be of the most value. Taking it all in all, no recent publication on therapeutics can be compared with this one in practical value to the working physician."-Chicago Clinical Revievi.

"The whole field of medicine has been well covered. The work is thoroughly pracical, and while it is intended for practitioners and students, it is a better book for the general practitioner than for the student. The young practitioner especially will find it extremely suggestive and helpful."-The Indian Lancet.

\section{AN AMERICAN TEXT=BOOK OF THE DISEASES OF CHILDREN. Second Edition, Revised.}

By 65 Eminent Contributors. Edited by Louis Stare, M. D., Consulting Pediatrist to the Maternity Hospital, etc. ; assisted by THompSon S. WestcotT, M. D., Attending Physician to the Dispensary for Diseases of Children, Hospital of the University of Pennsylvania. In one handsome imperial octaro volume of 1244 pages, profusely illustrated. Cloth, $\$ 7.00$ net; Sheep or Half Morocco, $\$ 8.00$ net. Sold by Subscription.

"This is far and away the best text-book on children's diseases ever published in the English language, and is certainly the one which is best adapted to American readers. We congratulate the editor upon the result of his work, and heartily commend it to the attention of every student and practitioner." - American Joumal of the Medical Sciences.

\section{AN AMERICAN TEXT=BOOK OF DISEASES OF THE EYE, EAR, NOSE, AND THROAT.}

By $5 S$ Prominent Specialists. Edited by G. E. DE Schweinitz, MI.D , Professor of Ophthalmology in the Jefferson Medical College, Philadelphia; and B. Alexander Randall, M.D., Professor of Diseases of the Ear in the University of Pennsylvania. Imperial octavo, I $25 \mathbf{r}$ pages; 766 illustrations, 59 of them in colors. Cloth, $\$ 7.00$ net; Sheep or Half Morocco, \$S.00 net. Sold by Subscription.

Disstrated Catalogue of the "American Text-Books" sent free upon application. 


\section{AN AMERICAN TEXT=BOOK OF GENITO=URINARY AND SKIN} DISEASES.

By 47 Eminent Specialists and Teachers. Edited by L. BoLron Bangs, M. D., Professor of Genito-Urinary Surgery, University and Bellevue Hospital Medical College, New York; and WV. A. HARDAWay, M. D., Professor of Diseases of the Skin, Missouri Medical College. Imperial octavo volume of I 229 pages, with 300 engravings and 20 full-page colored plates. Cloth, $\$ 7.00$ net; Sheep or Half Morocco, \$S.00 net. Sold by Subscription.

"This volume is one of the best yet issued of the publisher's series of 'American TextBooks.' The list of contributors represents an extraordinary array of talent and extended experience. The book will easily take the place in comprehensiveness and value of the half dozen or more costly works on these subjects which have heretofore been necessary to a well-equipped library." - Neze York Polyclinic.

\section{AN AMERICAN TEXT=BOOK OF GYNECOLOGY, MEDICAL AND SURGICAL. Second Edition, Revised.}

By ro of the Leading Gynecologists of America. Edited by J. M. Baldy, M. D., Professor of Gynecology in the Philadelphia Polyclinic, etc. Handsome imperial octavo volume of 7I 8 pages, with 34I illustrations in the text, and 38 colored and half-tone plates. Cloth, $\$ 6.00$ net; Sheep or Half Morocco, \$7.00 net. Sold by Subscription.

" It is practical from beginning to end. Its descriptions of conditions, its recommendations for treatment, and above all the necessary technique of different operations, are clearly and admirably presented. . . . It is well up to the most advanced views of the day, and embodies all the essential points of advanced American gynecology. It is destined to make and hold a place in gynecological literature which will be peculiarly its own." Medical Record, New York.

\section{AN AMERICAN TEXT-BOOK OF LEGAL MEDICINE AND TOXI- COLOGY.}

Edited by Frederick Peterson, M.D., Clinical Professor of Mental Diseases in the Woman's Medica! College, New York; Chief of Clinic, Nervous Department, College of Physicians and Surgeons, New York; and Walter S. Haines, M.D., Professor of Chemistry, Pharmacy, and Toxicology in Rush Medical College, Chicago. In Preparation.

\section{AN AMERICAN TEXT $=$ BOOK OF OBSTETRICS.}

By I5 Eminent American Obstetricians. Edited by Richard C. NorRIS, M.D.; Art Editor, Robert L. Dickinson, M.D. One handsome imperial octavo volume of IoI 4 pages, with nearly 900 beautiful colored and half-tone illustrations. Cloth, $\$ 7.00$ net; Sheep or Half Morocco, $\$ 8.00$ net. Sold by Subscription.

" Permit me to say that your American Text-Book of Obstetrics is the most magnificent medical work that I have ever seen. I congratulate you and thank you for this superb work, which alone is sufficient to place you first in the ranks of medical publishers." - ALEXANDER J. C. SkENE, Professor of Gynecology in the Long Island College Hospital, Brooklyn, N. Y.

"This is the inost sumptuously illustrated work on midwifery that has yet appeared. In the number, the excellence, and the beauty of production of the illustrations it far surpasses every other book upon the subject. This feature alone makes it a work which no medical library should omit to purchase." -British Medical Journal.

"As an authority, as a book of reference, as a 'working book' for the student or practitioner, we commend it because we believe there is no better." - American Journal of the Medical Sciences.

Illustrated Catalogue of the "American Text-Books" sent free upon application. 


\section{AN AMERICAN TEXT=BOOK OF PATHOLOGY.}

Edited by John Guitéras, M.D., Professor of General Pathology and of Morbid Anatomy in the University of Pennsylvania; and David Riesnian, M.D., Demonstrator of Pathological Histology in the University of Pennsylvania. In Preparation.

\section{AN AMERICAN TEXT=BOOK OF PHYSIOLOGY.}

By io of the Leading Physiologists of America. Edited by William H. Howell, PH.D., M.D., Professor of Physiology in the Johns Hopkins University, Baltimore, Md. One handsome imperial octavo volume of 1052 pages. Illustrated. Cloth, $\$ 6.00$ net; Sheep or Half Morocco, \$7.00 net. Sold by Subscription.

"We can commend it most heartily, not only to all students of physiology, but to every physician and pathologist, as a valuable and comprehensive work of reference, written by men who are of eminent authority in their own special subjects." - London Lancet.

"To the practitioner of medicine and to the advanced student this volume constitutes, we believe, the best exposition of the present status of the science of physiology in the English language." - American Journal of the Medical Sciences.

\section{AN AMERICAN TEXT=BOOK OF SURGERY. Second Edition.}

By I $_{3}$ Eminent Professors of Surgery. Edited by William W. KeEn, M.D., LL.D., and J. William White, M.D., Ph.D. Handsome imperial octavo volume of I 250 pages, with 500 wood-cuts in the text, and 39 colored and half-tone plates. Thoroughly revised and enlarged, with a section devoted to "The Use of the Röntgen Rays in Surgery." Cloth, $\$ 7.00$ net; Sheep or Half Morocco, $\$ 8.00$ net. Sold by Subscription.

"Personally, I should not mind it being called THE TEXT-BOOK (instead of A TEXTBook), for I know of no single volume which contains so readable and complete an account of the science and art of Surgery as this does." -EDMund OwEN, F.R.C.S., Member of the Board of Examiners of the Royal College of Surgeons, England.

"If this text-book is a fair reflex of the present position of American surgery, we must admit it is of a very high order of merit, and that English surgeons will have to look very carefully to their laurels if they are to preserve a position in the van of surgical practice. "London Lancet.

\section{AN AMERICAN TEXT=BOOK OF THE THEORY AND PRACTICE OF MEDICINE.}

By 12 Distinguished American Practitioners. Edited by William Pepper, M.D., LL.D., Professor of the Theory and Practice of Medicine and of Clinical Medicine in the University of Pennsylvania. Two handsome imperial octavo volumes of about rooo pages each. Illustrated. Prices per volume: Cloth, $\$ 5.00$ net; Sheep or Half Morocco, $\$ 6.00$ net. Sold by Subscription.

"I am quite sure it will commend itself both to practitioners and students of medicine, and become one of our most popular text-books." - ALFRED Loomis, M.D., LL.D., Professor of Pathology' and Practice of Medicine, Unizersity of the City' of New Iork.

"We reviewed the first volume of this work, and said: "It is undoubtedly one of the best text-books on the practice of medicine which we possess.' A consideration of the second and last volume leads us to modify that verdict and to say that the completed work is in our opinion the best of its kind it has ever been our fortune to see." - New York Medical Journal.

Illustrated Catalogue of the "American Text-Books" sent free upon application. 
AN AMERICAN YEAR-BOOK OF MEDICINE AND SURGERY.

A Yearly Digest of Scientific Progress and Authoritative Opinion in all branches of Medicine and Surgery, drawn from journals, monographs, and text-books of the leading American and Foreign authors and investigators. Collected and arranged, with critical editorial comments, by eminent American specialists and teachers, under the general editorial charge of GEORGE M. Gould, M.D. One handsome imperial octavo volume of about $\mathrm{I} 200$ pages. Uniform in style, size, and general make-up with the "American Text-Book" Series. Cloth, $\$ 6.50$ net; Half Morocco, $\$ 7.50$ net. Sold by Subscription.

"It is difficult to know which to admire most-the research and industry of the distin. guished band of experts whom Dr. Gould has enlisted in the service of the Year-Book, or the wealth and abundance of the contributious to every department of science that have been deemed worthy of analysis. . . . It is much more than a mere compilation of abstracts, for, as each section is entrusted to experienced and able contributors, the reader has the advantage of certain critical commentaries and expositions . . . proceeding from writers fully qualified to perform these tasks. . . . It is emphatically a book which should find a place in every medical library, and is in several respects more useful than the famous 'Jahrbïcher' of Germany." - London Lancet.

\section{THE AMERICAN POCKET MEDICAL DICTIONARY.}

[See Dorland's Pocket Dictionary, page ı.]

\section{ANDERS' PRACTICE OF MEDICINE. Second Edition.}

A Text=Book of the Practice of Medicine. By James M. Anders, M.D., PH.D., LL.D., Professor of the Practice of Medicine and of Clinical Medicine, Medico-Chirurgical College, Philadelphia. In one handsome octavo volume of I $2 \$ 7$ pages, fully illustrated. Cloth, $\$ 5.50$ net; Sheep or Half Morocco, $\$ 6.50$ net.

"It is an excellent book,-concise, comprehensive, thorough, and up to date. It is a credit to you ; but, more than that, it is a credit to the profession of Philadelphia-to us." James C. Wilson, Professor of the Practice of Medicine and Clinical Medicine, Jefferson Medical College, Philadelphia.

\section{ASHTON'S OBSTETRICS. Fourth Edition, Revised.}

Essentials of Obstetrics. By W. Easterly Ashton, M.D., Professor of Gynecology in the Medico-Chirurgical College, Philadelphia. Crown octavo, 252 pages; 75 illustrations. Cloth, \$1.00; interleaved for notes, $\$ 1.25$.

[See Saunders' Question-Compends, page 2i.]

"Embodies the whole subject in a nut-shell. We cordially recommend it to our read. ers." - Chicago Medical Times.

\section{BALL'S BACTERIOLOGY. Third Edition, Revised.}

Essentials of Bacteriology; a Concise and Systematic Introciuction to the Study of Micro-organisms. By M. V. BaLl, M.D., Bacteriologist to St. Agnes' Hospital, Philadelphia, etc. Crown octavo, 2 r 8 pages; 82 illustrations, some in colors, and 5 plates. Cloth, \$1.00; interleaved for notes, $\$ 1.25$.

\section{[See Saunders' Question-Compends, page 21.]}

"The student or practitioner can readily oltain a knowledge of the subject from a perusal of this book. "The illustrations are clear and satisfactory."-Medical Record, New York. 


\section{BASTIN'S BOTANY.}

Laboratory Exercises in Botany. By Edson S. BAstin, MI.A., late Professor of Materia Medica and Botany, Philadelphia College of Pharmacy. Octavo volume of $53^{6}$ pages, with 87 plates. Cioth, $\$ 2.50$.

"It is unquestionably the best text-book on the subject that has yet appeared. The work is eminently a practical one. We regard the issuance of this book as an important event in the history of pharmaceutical teaching in this country, and predict for it an unqualified success."-Alumni Report to the Philadelphia College of Pharmacy.

"There is no work like it in the pharmaceutical or botanical literature of this country, and we predict for it a wide circulation." - American Joumal of Phamacy.

\section{BECK'S SURGICAL ASEPSIS.}

A Manual of Surgical Asepsis. By CARL BEck, M.D., Surgeon to St. Mark's Hospital and the New York German Poliklinik, etc. 306 pages ; 65 text-illustrations, and $\mathrm{I}_{2}$ full-page plates. Cloth, \$1.25 net.

"An excellent exposition of the 'sery latest' in the treatment of wounds as practised by leading German and American surgeons."-Birmingham (Eng.) Medical Review.

"This little volume car be recommended to any who are desirous of learning the details of asepsis in surgery, for it will serve as a trustworthy guide." - London Lancet.

\section{BOISLINIERE'S OBSTETRIC ACCIDENTS, EMERGENCIES, AND OPERATIONS.}

Obstetric Accidents, Emergencies, and Operations. By L. CH.

Boisliniere, M.D., late Emeritus Professor of Obstetrics, St. Louis Medical College. 38 I pages, handsomely illustrated. Cloth, \$2.00 net.

"It is clearly and concisely written, and is evidently the work of a teacher and practitioner of large experience."-British Medical Joumal.

"A manual so useful to the student or the general practitioner has not been brought to our notice in a long time. The field embraced in the title is covered in a terse, interesting way." - Yale Medical Journal.

\section{BROCKWAY'S MEDICAL PHYSICS. Second Edition, Revised.}

Essentials of Medical Physics. By Fred J. BrochWAr, M.D., Assistant Demonstrator of Anatomy in the College of Physicians and Surgeons, New York. Crown octavo, 330 pages; I 55 fine illustrations. Cloth, \$1.00 net; interleaved for notes, \$1.25 net.

$$
\text { [See Saunders' Question-Compends, page 2r.] }
$$

"The student who is well versed in these pages will certainly prove qualified to com prebend with ease and pleasure the great majority of questions involving physical principles likely to be met with in his medical studies."-American Practitioner and :Vews.

"We know of no manual that affords the medical student a better or more concise exposition of physics, and the book may be commended as a most satisfactory presentation of those essentials that are requisite in a course in medicine. "- lew lork Hedical Junrnal.

"It contains all that one need know on the subject, is well written, and is copiously illustrated." -Medical Record, New York.

\section{BURR ON NERVOUS DISEASES.}

A Manual of Nervous Diseases. By Chdrles W. Burr, M.D., Clinical Professor of Nervous Diseases, Medico-Chirurgical College, Philadelphia; Pathologist to the Orthopedic Hospital and Infirmary for Nervous Diseases; Visiting Phrsician to St. Joseph's Hospital, etc. In Preparation. 
BUTLER'S MATERIA MEDICA, THERAPEUTICS, AND PHARMACOLOGY. Second Edition, Revised.

A Text=Book of Materia Medica, Therapeutics, and Pharma= cology. By George F. Butler, Ph.G., M.D., Professor of Materia Medica and of Clinical Medicine in the College of Physicians and Surgeons, Chicago; Professor of Materia Medica and Therapeutics, Northwestern University, Woman's Medical School, etc. Octavo, 860 pages, illustrated. Cloth, $\$ 4.00$ net; Sheep, $\$ 5.00$ net.

"Taken as a whole, the book may fairly be considered as one of the most satisfactory of any single-volume works on materia medica in the market." - Journal of the American Medical Association.

\section{CERNA ON THE NEWER REMEDIES. Second Edition, Revised.}

Notes on the Newer Remedies, their Therapeutic Applications and Modes of Administration. By David Cerna, M.D., Ph.D., formerly Demonstrator of and Lecturer on Experimental Therapeutics in the University of Pennsylvania; Demonstrator of Physiology in the Medical Department of the University of Texas. Rewritten and greatly enlarged. Post-octavo, 253 pages. Cloth, $\$ 1.25$.

"The appearance of this new edition of Dr. Cerna's very valuable work shows that it is properly appreciated. The book ought to be in the possession of every practising physician." - New York Medical Journal.

\section{CHAPIN ON INSANITY.}

A Compendium of Insanity. By John B. Chapin, M.D., LL.D., Physician-in-Chief, Pennsylvania Hospital for the Insane; late Physician-Superintendent of the Willard State Hospital, New York; Honorary Member of the Medico-Psychological Society of Great Britain, of the Society of Mental Medicine of Belgium. 12mo, 234 pages, illustrated. Cloth, \$I.25 net.

“The practical parts of Dr. Chapin's book are what constitute its distinctive merit. We desire especially to call attention to the fact that on the subject of therapeutics of insanity the work is exceedingly valuable. It is not a made book, but a genuine condensed thesis, which has all the value of ripe opinion and all the charm of a vigorous and natural style."Philadelphia Medical Joumal.

\section{CHAPMAN'S MEDICAL JURISPRUDENCE AND TOXICOLOGY.} Second Edition, Revised.

Medical Jurisprudence and Toxicology. By Henry C. Chapman, M.D., Professor of Institutes of Medicine and Medical Jurisprudence in the Jefferson Medical College of Philadelphia. 254 pages, with 55 illustrations and 3 full-page plates in colors. Cloth, \$I.50 net.

"The best book of its class for the undergraduate that we know of."-Nerw York Medical Times.

\section{CHURCH AND PETERSON'S NERVOUS AND MENTAL DISEASES.}

Nervous and Mental Diseases. By Archibald Church, M. D., Professor of Mental Diseases and Medical Jurisprudence in the Northwestern University Medical School, Chicago ; and Frederick Peterson, M. D., Clinical Professor of Mental Diseases, Woman's Medical College, N. Y.; Chief of Clinic, Nervous Dept., College of Physicians and Surgeons, N. Y. Handsome octavo volume of 843 pages, profusely illustrated. Cloth, $\$ 5.00$ net; Half Morocco, $\$ 6.00$ net. 


\section{CLARKSON'S HISTOLOGY.}

A Text=Book of Histology, Descriptive and Practical. By Arthur Clarkson, M.B., C.M. Edin., formerly Demonstrator of Physiology in the Owen's College, Manchester; late Demonstrator of Physiology in Yorkshire College, Leeds. Large octavo, 554 pages; 22 engravings in the text, and 174 beautifully colored original illustrations. Cloth, strongly bound, $\$ 6.00$ net.

"The work must be considered a valuable addition to the list of available text-books, and is to be highly recommended."-New York Nedical Journal.

"This is one of the best works for students we have ever noticed. We predict that the book will attain a well-deserved popularity among our students." - Chicago Medical Recorder.

\section{CLIMATOLOGY.}

Transactions of the Eighth Annual Meeting of the American Climatological Association, held in Washington, September 22-25, I $89 \mathrm{x}$. Forming a handsome octavo volume of 276 pages, uniform with remainder of series. (A limited quantity only.) Cloth, \$I.50.

\section{COHEN AND ESHNER'S DIAGNOSIS.}

Essentials of Diagnosis. By Solonon Solis-Cohen, M.D., Professor of Clinical Medicine and Applied Therapeutics in the Philadelphia Polyclinic ; and Augustus A. Eshner, M.D., Professor of Clinical Medicine in the Philadelphia Polyclinic. Post-octavo, 382 pages; 55 illustrations. Cloth, \$I.50 net.

\section{[See Saunders' Question-Compends, page 21.]}

"We can heartily commend the book to all those who contemplate purchasing a 'com. pend.' It is modern and complete, and will give more satisfaction than many other works which are perhaps too prolix as well as behind the times." - Medical Review, St. Louis.

\section{CORWIN'S PHYSICAL DIAGNOSIS.}

Essentials of Physical Diagnosis of the Thorax. By ARTHUR M. Corwin, A.M., M.D., Demonstrator of Physical Diagnosis in Rush Medical College, Chicago; Attending Physician to Central Free Dispensary, Department of Rhinology, Laryngology, and Diseases of the Chest, Chicago. 200 pages, illustrated. Cloth, flexible covers, \$I. 25 net.

"It is excellent. The student who shall use it as his guide to the careful study of physical exploration upon normal and abnormal subjects can scarcely fail to acquire a good working knowledge of the subject."-Philadelphia Polyclinic.

"A most excellent little work. It brightens the memory of the differential diagnostic signs, and it arranges orderly and in sequence the various objective phenomena to logical solution of a careful diagnosis." - Journal of Nervous and Mental Diseases.

\section{CRAGIN'S GYNAECOLOGY. Fourth Edition, Revised.}

Essentials of Gynæcology. By EDwin B. CRAGIN, M. D., Lecturer in Obstetrics, College of Physicians and Surgeons, New York. Crown octavo, 200 pages; 62 illustrations. Cloth, $\$ 1.00$; interleaved for notes, $\$ 1.25$.

\section{[See Saunders' Question-Compends, page 21.]}

" $A$ handy volume, and a distinct improvement on students' compends in general. No anthor who was not himself a practical gynecologist could have consulted the student's needs so thoroughly as Dr. Cragin has done."-Medical Record, New York. 


\section{CROOKSHANK'S BACTERIOLOGY. Fourth Edition, Revised.}

A Text=Book of Bacteriology. By Edgar M. CRookshank, M.B., Professor of Comparative Pathology and Bacteriology, King's College, London. Octavo volume of 700 pages, with 273 engravings and 22 original colored plates. Cloth, $\$ 6.50$ net; Half Morocco, $\$ 7.50$ net.

"To the student who wishes to obtain a good résumé of what has been done in bacteriology, or who wishes an accurate account of the various methods of research, the book may be recommended with confidence that he will find there what he requires." - London Lancet.

\section{DA COSTA'S SURGERY. Second Ed., Revised and Greatly Enlarged.}

Modern Surgery, General and Operative. By John Chalmers DaCosta, M.D., Clinical Professor of Surgery, Jefferson Medical College, Philadelphia; Surgeon to the Philadelphia Hospital, etc. Handsome octavo volume of 900 pages, profusely illustrated. Cloth, $\$ 4.00$ net; Half Morocco, $\$ 5.00$ net.

"We know of no small work on surgery in the English language which so well fulfils the requirements of the modern student."-Nedico-Chirurgical Joumal, Bristol, England.

\section{DE SCHWEINITZ ON DISEASES OF THE EYE. Third Edition, Revised.}

Diseases of the Eye. A Handbook of Ophthalmic Practice. By G. E. De Schweinitz, M.D., Professor of Ophthalmology in the Jefferson Medical College, Philadelphia, etc. Handsome royal octavo volume of 696 pages, with 256 fine illustrations and 2 chromo-lithographic plates. Cloth, $\$ 4.00$ net; Sheep or Half Morocco, $\$ 5.00$ net.

"A clearly written, comprehensive manual. One which we can commend to students as a reliable text-book, written with an evident knowledge of the wants of those entering upon the study of this special branch of medical science."-British Mledical Jommal.

"A work that will meet the requirements not only of the specialist, but of the general practitioner in a rare degree. I am satisfied that unusual success awaits it." - WiLL1AM Pepper, M.D., Professor of the Theory and Practice of Medicine and Clinical Medicine. University of Penusylvania.

\section{DORLAND'S DICTIONARY. Second Edition, Revised.}

The American Pocket Medical Dictionary. Containing the Pronunciation and Definition of all the principal words and phrases, and a large number of useful tables. Edited by W. A. Newman Dorlani, M. I., Assistant Demonstrator of Obstetrics, University of Pennsylvania; Fellow of the American Academy of Medicine. 5 I 8 pages; handsomely bound in full leather, limp, with gilt edges and patent index. Price, $\$ 1.25$ net.

\section{DORLAND'S OBSTETRICS.}

A Manual of Obstetrics. By W. A. Newman Dorland, M.D., Assistant Demonstrator of Obstetrics, University of Pennsylvania; Instructor in Gynecology in the Philadelphia Polyclinic. 760 pages; $\mathrm{x}_{3}$ illustrations in the text, and 6 full-page plates. Cloth, $\$ 2.50$ net.

"By far the best book on this subject that has ever come to our notice." - American Medical Review.

"It has rarcly been our duty to review a book which has given us more pleasure in its perusal and more satisfaction in its criticism. It is a veritable encyclopedia of knowledge, a gold mine of practical, concise thoughts." - American Medico-Surgical Bulletiz. 


\section{FROTHINGHAM'S GUIDE FOR THE BACTERIOLOGIST.}

Laboratory Guide for the Bacteriologist. By LANGDON FrothINGHAM, M.D.V., Assistant in Bacteriology and Veterinary Science, Sheffield Scientific School, Yale University. Illustrated. Cloth, 75 cts.

"It is a convenient and useful little work, and will more than repay the outlay neces. sary for its purchase in the saving of time which would otherwise be consumed in looking up the various points of technique so clearly and concisely laid down in its pages." - Ameri. can Medico-Surgical Bulletin.

GARRIGUES' DISEASES OF WOMEN. Second Edition, Revised. Diseases of Women. By Henry J. Garrigues, A.M., M.D., Professor of Gynecology in the New York School of Clinical Medicine; Gynecologist to St. Mark's Hospital and to the German Dispensary, New York City, etc. Handsome octavo volume of 728 pages, illustrated by 335 engravings and colored plates. Cloth, $\$ 4.00$ net; Sheep or Half Morocco, $\$ 5.00$ net.

"One of the best text-books for students and practitioners which has been published in the English language; it is condensed, clear, and comprehensive. The profound learning and great clinical experience of the distinguished author find expression in this book in a most attractive and instructive form. Young practitioners to whom experienced consultants may not be available will find in this book invaluable counsel and help." -THAD. A. ReAmy, M.D., LI.D., Professor of Clinical Gynecology, Medical College of Ohio.

GLEASON'S DISEASES OF THE EAR. Second Edition, Revised. Essentials of Diseases of the Ear. By E. B. Gleason, S.B., M.D., Clinical Professor of Otology, Medico-Chirurgical College, Philadelphia; Surgeon-in-Charge of the Nose, Throat, and Ear Department of the Northern Dispensary, Philadelphia. 208 pages, with I I 4 illustrations. Cloth, $\$ 1.00$; interleaved for notes, $\$ 1.25$.

[See Saunders' Question-Compends, page 2r.]

" It is just the book to put into the hands of a student, and cannot fail to give him a useful introduction to ear-affections; while the style of question and answer which is adopted throughout the book is, we believe, the best method of impressing facts permanently on the mind."-Liverpool Medico-Chimurgical Journal.

\section{GOULD AND PYLE'S CURIOSITIES OF MEDICINE.}

Anomalies and Curiosities of Medicine. By George M. Gould, M.D., and Walter L. Pyle, M.D. An encyclopedic collection of rare and extraordinary cases and of the most striking instances of abnormality in all branches of Medicine and Surgery, derived from an exhaustive research of medical literature from its origin to the present day, abstracted, classified, annotated, and indexed. Handsome imperial octavo volume of 968 pages, with 295 engravings in the text, and I 2 full-page plates. Cloth, $\$ 6.00$ net; Half Morocco, $\$ 7.00$ net. Sold by Subscription.

"One of the most valuable contributions ever made to medical literature. Ii is, so far as we know, absolutely unique, and every page is as fascinating as a norel. Not alone for the medical profession has this volume value: it will serve as a book of reference for all who are interested in general scientific, sociologic, or medico-legal topics." -Brookly ul Ifilical Journal.

"This is certainly a most remarkable and interesting rolume. It stands alone among medical literature, an anomaly on anomalies, in that there is nothing like it elsewhere in medical literature. It is a book full of revelations from its first to its last page, and cannot but interest and sometimes almost horrify its readers."-Americun Medico-Surgical Bulletin. 
GRAFSTROM'S MECHANO=THERAPY.

A Text=Book of Mechano=Therapy (Massage and Medical Gym= nastics). By Axel V. Grafstrom, B. Sc., M. D., late Lieutenant in the Royal Swedish Army; late House Physician City Hospital, Blackwell's Island, New York. I 2 mo, I 39 pages, illustrated. Cloth, \$1.00 net.

\section{GRIFFITH ON THE BABY. Second Edition, Revised.}

The Care of the Baby. By J. P. Crozer Griffith, M.D., Clinical Professor of Diseases of Children, University of Pennsylvania; Physician to the Children's Hospital, Philadelphia, etc. I $2 \mathrm{mo}, 404$ pages, with 67 illustrations in the text, and 5 plates. Cloth, $\$ \mathbf{r} .50$.

"The best book for the use of the young mother with which we are acquainted. . . . There are very few general practitioners who could not read the book through with advantage." - Archives of Pcdiatrics.

"The whole book is characterized by rare good sense, and is evidently written by a master hand. It can be read with benefit not only by mothers but by medical students and by any practitioners who have not had large opportunities for observing children." - American Joumal of Obstetrics.

\section{GRIFFITH'S WEIGHT CHART.}

Infant's Weight Chart. Designed by J. P. Crozer Griffith, M. D., Clinical Professor of Diseases of Children in the University of Pennsylvania, etc. 25 charts in each pad. Per pad, 50 cents net.

A convenient blank for keeping a record of the child's weight during the first two years of life. Printed on each chart is a curve representing the average weight of a healthy infant, so that any deviation from the normal can readily be detected.

\section{GROSS, SAMUEL D., AUTOBIOGRAPHY OF.}

Autobiography of Samuel D. Gross, M.D., Emeritus Professor of Surgery in the Jefferson Medical College, Philadelphia, with Reminiscences of His Times and Contempuraries. Edited by his Sons, Samuer W. Gross, M.D., LL.D., late Professor of Principles of Surgery and of Clinical Surgery in the Jefferson Medical College, and A. Haller Gross, A.M., of the Philadelphia Bar. Preceded by a Memoir of Dr. Gross, by the late Austin Flint, M.D., LL.D. In two handsome volumes, each containing over 400 pages, demy octavo, extra cloth, gilt tops, with fine Frontispiece engraved on steel. Price per volume, $\$ 2.50$ net.

"Dr. Gross was perhaps the most eminent exponent of medical science that America has yet produced. Ilis Autobiography, related as it is with a fulness and completeness seldom to be found in such works, is an interesting and valuable book. He comments on many things, especially, of course, on medical men and medical practice, in a very interest ing way." - The Spectator, London, England.

\section{HAMPTON'S NURSING. Second Edition, Revised and Enlarged.}

Nursing: Its Principles and Practice. By Isabel Adams HanpToN, Graduate of the New York Training School for Nurses attached to Bellevue Hospital ; late Superintendent of Nurses and Principal of the Training School for Nurses, Johns Hopkins Hospital, Baltimore, Md. I 2 mo, 5 I 2 pages, illustrated. Cloth, \$2.00 net.

"Seldom have we peruscd a book upon the subject that has given us so much pleasure as the one before us. We would strongly urge upon the members of our own profession the need of a book like this, for it will enable each of us to become a training school in himself."-Ontario Medical Journal. 
HARE'S PHYSIOLOGY. Fourth Edition, Revised.

Essentials of Physiology. By H. A. HARE, M.D., Professor of Therapeutics and Materia Medica in the Jefferson Medical College of Philadelphia. Crown octavo, 230 pages. Cloth, $\$ 1.00$ net; interleaved for notes, \$I.25 net.

[See Saunders' Question-Compends, page 21.]

"The best condensation of physiological knowledge we have yet seen." - Medical Record, New York.

\section{HART'S DIET IN SICKNESS AND IN HEALTH.}

Diet in Sickness and in Health. By MRS. ERNEST HART, formerly Student of the Faculty of Medicine of Paris and of the London School of Medicine for Women; with an INTroduction by Sir Henry Thompson, F.R.C.S., M.D., London. 220 pages. Cloth, \$I.50.

"We recommend it cordially to the attention of all practitioners; both to them and to their patients it may be of the greatest service." - Nere York Medical Journal.

\section{HAYNES' ANATOMY.}

A Manual of Anatomy. By Irving S. Hareses, M.D., Adjunct Professor of Anatomy and Demonstrator of Anatomy, Medical Department of the New York University, etc. 680 pages, illustrated with 42 diagrams in the text, and I 34 full-page half-tone illustrations from original photographs of the author's dissections. Cloth, \$2.50 net.

"This book is the work of a practical instructor-one who knows by experience the requirements of the average student, and is able to meet these requirements in a very satisfactory way. The book is one that can be commended."-Nedical Record, New lork.

\section{HEISLER'S EMBRYOLOGY.}

A Text=Book of Embryology. By John C. Heisler, M.D., Professor of Anatomy in the Medico-Chirurgical College, Philadelphia. I 2 mo volume of about 325 pages, handsomely illustrated.

\section{HIRST'S OBSTETRICS.}

A Text=Book of Obstetrics. By BARTon Cooke Hirst, M. D., Professor of Obstetrics in the University of Pennsylvania. Handsome octavo volume of 848 pages, with 6 is illustrations, and 7 colored plates. Cloth, $\$ 5.00$ net; Sheep or Half Morocco, $\$ 6.00$ net.

"The illustrations are numerous and are works of art, many of them appearing for the first time. The arrangement of the subject-matter, the foot-notes, and index are beyond criticism. As a true model of what a modern text-book on obstetrics should be, we feel justified in affirming that Dr. Hirst's book is without a rival." - Veav Iork Medical Recort.

\section{HYDE AND MONTGOMERY ON SYPHILIS AND THE VENEREAL DISEASES.}

Syphilis and the Venereal Diseases. By Janes Nevins Hyde, M.D., Professor of Skin and Venereal Diseases, and Frank H. MonTgonery, M.D., Lecturer on Dermatology and Genito-Urinary Diseases in Rush Medical College, Chicago, til. 6 I 8 pages, profusely illustrated. Cloth, \$2.50 net.

"We can commend this manual to the student as a help to him in his study of venereal diseases." - Liverpool Medico-Chiruryical Journal.

"The best student's manual which has appeared on the subject." - St. Louis Medicw" and Surgical Journal. 
JACKSON AND GLEASON'S DISEASES OF THE EYE, NOSE, AND THROAT. Second Edition, Revised.

Essentials of Refraction and Diseases of the Eye. By EDWARD Jackson, A.M., M.D., Professor of Diseases of the Eye in the Philadelphia Polyclinic and College for Graduates in Medicine ; and-

Essentials of Diseases of the Nose and Throat. By E. BALDwin Gleason, M.D., Surgeon-in-Charge of the Nose, Throat, and Ear Department of the Northern Dispensary of Philadelphia. Two volumes in one. Crown octavo, 290 pages; I 24 illustrations. Cloth, $\$ 1.00$; interleaved for notes, $\$ 1.25$.

[See Saunders' Question-Compends, page 2I.]

"Of great value to the beginner in these branches. The authors are both capable men, and know what a student most needs."-Medical Record, New York.

\section{KEATING'S DICTIONARY. Second Edition, Revised.}

\section{A New Pronouncing Dictionary of Medicine, with Phonetic} Pronunciation, Accentuation, Etymology, etc. By JoHN M. Keating, M.D., LL.D., Fellow of the College of Physicians of Philadelphia; Vice-President of the American Pædiatric Society; Editor "Cyclopædia of the Diseases of Children," etc.; and Henry Hanilton, Author of "A New Translation of Virgil's Eneid into English Rhyme," etc.; with the collaboration of J. Chalmers DACosta, M.D., and Frederick A. Packard, M.D. With an Appendix containing Tables of Bacilli, Micrococci, Leucomaïnes, Ptomaïnes; Drugs and Materials used in Antiseptic Surgery; Poisons and their Antidotes; Weights and Measures; Thermometric Scales; New Official and Unofficial Drugs, etc. One volume of over 800 pages. Prices, with Denison's Patent Ready-Reference Index: Cloth, $\$ 5.00$ net; Sheep or Half Morocco, \$6.00 net; Half Russia, \$6.50 net. Without Patent Index: Cloth, $\$ 4.00$ net; Sheep or Half Morocco, $\$ 5.00$ net.

“ I am much pleased with Keating's Dictionary, and shall take pleasure in recommend. ing it to my classes." - Henry M. Lyman, M.D., Professor of the Principles and Practice of Medicine, Rrush Medical College, Chicago, Ill.

"I am convinced that it will be a very valuable adjunct to my study-table, convenient in size and sufficiently full for ordinary use."-C. A. Lindsley, M.D., Professor of the Theory and Practice of Medicine, Medical Dept. Yale University.

\section{KEATING'S LIFE INSURANCE.}

How to Examine for Life Insurance. By JoHn M. KEATING, M. D., Fellow of the College of Physicians of Philadelphia; VicePresident of the American Pædiatric Society; Ex-President of the Association of Life Insurance Medical Directors. Royal octavo, 2 I I pages; with two large half-tone illustrations, and a plate prepared by Dr. McClellan from special dissections; also, numerous other illustrations. Cloth, \$2.00 net.

"This is lyy far the most useful book which has yet appeared on insurance examination, a sul,ject of growing interest and importance. Not the least valuable portion of the volume is Part II., which consists of instructions issued to their examining physicians by twenty-four representative comparies of this comntry. If for these alone, the book should be at the right hand of every physician interested in this special Jranch of medical science." - The Medical Newos. 


\section{KEEN ON THE SURGERY OF TYPHOID FEVER.}

The Surgical Complications and Sequels of Typhoid Fever. By WT. IV. Keex, M.D., LL.D., Professor of the Principles of Surgery and of Clinical Surgery, Jefferson Medical College, Philadelphia; Corresponding Member of the Société de Chirurgie, Paris; Honorary Member of the Société Belge de Chirurgie, etc. Octavo rolume of 386 pages, illustrated. Cloth, $\$ 3.00$ net.

"This is probably the first and only work in the English language that gives the reader a clear view of what typhoid fever really is, and what it does and can do to the human organism. This book should be in the possession of every medical man in America." American Medico-Surgical Bullitin.

\section{KEEN'S OPERATION BLANK. Second Edition, Revised Forn.}

An Operation Blank, with Lists of Instruments, etc. Required in Various Operations. Prepared by WT. W. KEEN, M.D., LL.D., Professor of the Principles of Surgery in Tefferson Medical College, Philadelphia. Price per pad, containing blanks for fifty operations, 50 cents net.

\section{KYLE ON THE NOSE AND THROAT.}

Diseases of the Nose and Throat. By D. Braden Kyle, M.D., Clinical Professor of Laryngology and Rhinology, Jefferson Medical College, Philadelphia; Consulting Laryngologist, Rhinologist, and Otologist, St. Agnes' Hospital. Handsome octavo volume of about 630 pages, with over 150 illustrations and 6 lithographic plates. Price, Cloth, $\$-$ net; Half Morocco, $\$-$ net.

\section{LAINE'S TEMPERATURE CHART.}

Temperature Chart. Prepared by D. T. LAINÉ, MI.D. Size $S \times 13 \frac{1}{2}$. inches. A conveniently arranged Chart for recording Temperature, with columns for daily amounts of Urinary and Fecal Excretions, Food, Remarks, etc. On the back of each chart is given in full the method of Brand in the treatment of Typhoid Fever. Price, per pad of 25 charts, 50 cents net.

"To the busy practitioner this chart will be found of great value in fever cases, and especially for cases of typhoid."-Indian Lancet, Calcutta.

\section{LOCKWOOD'S PRACTICE OF MEDICINE.}

A Manual of the Practice of Medicine. By George RoE Lock. wood, M.D., Professor of Practice in the IVoman's Medical College of the New York Infirmary, etc. 935 pages, with 75 illustrations in the text, and 22 full-page plates. Cloth, \$2.50 net.

"Gives in a most concise manner the points essential to treatment usually enumerated in the most elaborate works." - Massachusetts. Medical Joumal.

\section{LONG'S SYLLABUS OF GYNECOLOGY.}

A Syllabus of Gynecology, arranged in Conformity with "A An American Text=Book of Gynecology." By I. W. LoxG, M.D., Professor of Diseases of Women and Children, Medical College of Virginia, etc. Cloth, interleaved, \$1.00 net.

"The book is certainly an admirable risumé of what every gynecological sturlent and practitioner should know, and will prove of value not only to those who have the 'American Text-Book of Gynecology;' but to others as well."-Brooklyn .Meatical Joumal. 


\section{MACDONALD'S SURGICAL DIAGNOSIS AND TREATMENT.}

Surgical Diagnosis and Treatment. By J. W. MACDONALD, M.D. Edin., F.R.C.S., Edin., Professor of the Practice of Surgery and of Clinical Surgery in Hamline University; Visiting Surgeon to St. Barnabas' Hospital, Minneapolis, etc. Handsome octavo volume of 800 pages, profusely illustrated. Cloth, $\$ 5.00$ net; Half Morocco, $\$ 6.00$ net.

"A thorough and complete work on surgical diagnosis and treatment, free from pad. ding, full of valuable material, and in accord with the surgical teaching of the day." - The Medical Neres, New York.

"The work is brimful of just the kind s. nractical information that is useful alike to studeats and practitioners. It is a pleasure to commend the bock because of its intrinsic valur: to the medical practitioner." -Cincinnati Lancet-Clinic.

\section{MALLORY AND WRIGHT'S PATHOLOGICAL TECHNIQUE.}

Pathological Technique. A Practical Manual for Labolatory Work in Pathology, Bacteriology, and Morbid Anatomy, with chapters on Post-Mortem Technique and the Performance of Autopsies. By Frank B. Mallory, A.M., M.D., Assistant Professor of Pathology, Harvarn University Medical School, Boston; and James H. WRIoHT, A.M., M.D., Instructor in Pathology, Harvard University Medical School, Boston. Octavo volume of 396 pages, handsomely illustrated. Cloth, $\$ 2.50$ net.

"I have been looking forward to the publication of this book, and I am glad to say that I find it to be a most useful laboratory and post-mortem guide, full of practical information, and well up to date."-William IH. Welch, Professor of Pathology', Johns Fopkins Uni. versity, Baltimore, $M d$.

\section{MARTIN'S MINOR SURGERY, BANDAGING, AND VENEREAL} DISEASES. Second Edition, Revised.

Essentials of Minor Surgery, Bandaging, and Venereal Diseases. By Edward Martin, A.M., M.D., Clinical Professor of Genito-Urinary Diseases, University of Pennsylvania, etc. Crexn octavo, I66 pages, with 78 illustrations. Cloth, $\$ \mathrm{r} .00$; interleaved for notes, $\$ 1.25$.

\section{[See Saunders' Question-Compends, page 2r.]}

"A very practical and systematic study of the subjects, and shows the author's familiarity with the needs of students."-Therapeutic Gazette.

\section{MARTIN'S SURGERY. Sixth Edition, Revised.}

Essentials of Surgery. Containing also Venereal Diseases, Surgical Landmarks, Minor and Operative Surgery, and a complete description, with illustrations, of the Handkerchief and Roller Bandages. By Edward Martin, A.M., M.D., Clinical Professor of GenitoUrinary Diseases, University of Pennsylvania, etc. Crown octavo, $33^{8}$ pages, illustrated. With an Appendix containing full directions for the preparation of the materials used in Antiseptic Surgery, etc. Cloth, $\$ 1.00$; interleaved for notes, $\$$ I. 25 .

[See Saunders' Question-Compends, page 2r.]

"Contains all necessary essentials of modern surgery in a comparatively small s" ace. Its style is interesting, and its illustrations are admirable." -Medical and Surgical Reporter- 
McFARLAND'S PATHOGENIC BACTERIA. Second Edition, Re= vised and Greatly Enlarged.

Text=Book upon the Pathogenic Bacteria. By Joseph McFarI.AND, M. D., Professor of Pathology and Bacteriology in the MedicoChirurgical College of Philadelphia, etc. Octaro volume of 497 pages, finely illustrated. Cloth, $\$ 2.50$ net.

"Dr. MicFarland has treated the subject in a systematic manner, and has succeeded in presenting in a concise and readable form the essentials of bacteriology up to date. Altogether, the book is a satisfactory one, and I shall take pleasure in recommending it to the students of Trinity College."-H. B. Anderson, M.D., Professor of Pathology and Bac. teriology, Trinity Medical College, Toronto.

\section{MEIGS ON FEEDING IN INFANCY.}

Feeding in Early Infancy. By Arthur V. MeIgs, M.D. Bound in limp cloth, flush edges, 25 cents net.

"This pampllet is worth many times over its price to the physician. The author's experiments and conclusions are original, and have been the means of doing much good." Medical Bulletin.

\section{MOORE'S ORTHOPEDIC SURGERY.}

A Manual of Orthopedic Surgery. By James E. Moore, M.D., Professor of Orthopedics and Adjunct Professor of Clinical Surgery, University of Minnesota, College of Medicine and Surgery. Octavo volume of $35^{6}$ pages, handsomely illustrated. Cloth, $\$ 2.50$ net.

"A most attractive work. The illustrations and the care with which the book is adapted to the wants of the general practitioner and the student are worthy of great praise." - Chicago Nedical Recorder.

"A very demonstrative work, every illustration of which conveys a lesson. The work is a most excellent and commendable one, which we can certainly endorse with pleasure." St. Louis Medical and Surgical Joumal.

\section{MORRIS'S MATERIA MEDICA AND THERAPEUTICS. Fifth} Edition, Revised.

Essentials of Materia Medica, Therapeutics, and Prescription= Writing. By Henry Morris, M.D., late Demonstrator of Therapeutics, Jefferson Medical College, Philadelphia; Fellow of the College of Physicians, Philadelphia, etc. Crown octavo, 288 pages. Cloth, $\$ 1.00$; interleaved for notes, $\$ 1.25$.

[See Saunders' Question-Compends, page $2 \mathrm{r}$.]

"This work, already excellent in the old edition, has been largely improved by revi. sion." - American Practitioner and Nézos.

\section{MORRIS, WOLFF, AND POWELL'S PRACTICE OF MEDICINE.} Third Edition, Revised.

Essentials of the Practice of Medicine. By Henry Morris, M.D., late Demonstrator of Therapeutics, Jefferson Medical College, Philadelphia; with an Appendix on the Clinical and Microscopic Examination of Urine, by LawRence WolfF, M.D., Demonstrator of Chemistry, Jefferson Medical College, Philadelphia. Enlarged by some 300 essential formula collected and arranged by William M. Powell, M.D. Post-octaro, $48 S$ pages. Cloth, $\$ 2.00$.

[See Sannders' Question-Compends, page 21.]

"The teaching is sound, the presentation graphic; matter full as can be desired, and style attractive."-American Practitioner and Nezus. 


\section{MORTEN'S NURSE'S DICTIONARY.}

Nurse's Dictionary of Medical Terms and Nursing Treat= ment. Containing Definitions of the Principal Medical and Nursing Terms and Abbreviations; of the Instruments, Drugs, Diseases, Accidents, Treatments, Operations, Foods, Appliances, etc. encountered in the ward or in the sick-room. By Honnor Monten, author of "How to Become a Nurse," etc. I6mo, I 40 pages. Cloth, \$I.०0.

"A handy, compact little volume, containing a large amount of general information, all of which is arranged in dictionary or encyclopedic form, thus facilitating quick reference. It is certainly of value to those for whose use it is published." - Chicago Clinical Revieze.

\section{NANCREDE'S ANATOMY. Fifth Edition.}

Essentials of Anatomy, including the Anatomy of the Viscera. By Charles B. Nancrede, M.D., Professor of Surgery and of Clinical Surgery in the University of Michigan, Ann Arbor. Crown octavo, 388 pages; 180 illustrations. With an Appendix containing over 60 illustrations of the osteology of the human body. Based upon Gray's Anatomy. Cloth, \$1.00; interleaved for notes, \$1.25.

[See Saunders' Question-Compends, page 2 I.]

"For self-quizzing and keeping fresh in mind the knowledge of anatomy gained at school, it would not be easy to speak of it in terms too favorable."-American Practitioner.

\section{NANCREDE'S ANATOMY AND DISSECTION. Fourth Edition.}

Essentials of Anatomy and Manual of Practical Dissection.

By Charles B. Nancrede, M.D., Professor of Surgery and of Clinical Surgery, University of Michigan, Ann Arbor. Post-octavo; 500 pages, with full-page lithographic plates in colors, and nearly 200 illustrations. Extra Cloth (or Oilcloth for the dissection-room), \$2.00 net.

"It may in many respects be considered an epitome of Gray's popular work on general anatomy, at the same time having some distinguishing characteristics of its own to commend it. The plates are of more than ordinary excellence, and are of especial value to students in their work in the dissecting room." -Joumal of the American Medical Association.

NORRIS'S SYLLABUS OF OBSTETRICS. Third Edition, Revised. Syllabus of Obstetrical Lectures in the Medical Department of the University of Pennsylvania. By RICHARD C. NORRIS, A.M., M.D., Demonstrator of Obstetrics, University of Pennsylvania. Crown octavc, 222 pages. Cloth, interleaved for notes, $\$ 2.00$ net.

"This work is so far superior to others on the same subject that we take pleasure in calling attention briefly to its excellent features. It covers the subject thoroughly, and will prove invalualle buth to the student and the practitioner." -Medical Record, New York.

\section{PENROSE'S DISEASES OF WOMEN. Second Edition, Revised.}

A Text=Book of Diseases of Women. By Charles B. Penrose, M.D., PH.D., Professor of Gynecology in the University of Perinsylvania; Surgeon to the Gynecean Hospital, Philadelphia. Octavo volume of 529 pages, handsomely illustrated. Cloth, $\$ 3.50$ net.

"I shall value very highly the copy of Penrose's 'Diseases of Women' received. I have alrearly recommcnded it to my class as THE BEST book." - HowARD A. KELLY, Professor of Gynecology and Obstetrics, Johns Hopkins University, Baltimore, Md.

"The bork is to be commended without reserve, not only to the student but to the general practitioner who wishes to have the latest and best modes of treatment explained with absolute clearness." - Therapentic Gazette. 


\section{POWELL'S DISEASES OF CHILDREN. Second Ec̈ition.}

Essentials of Diseases of Children. By Williay M. Powell, M.D., Attending Physician to the Mercer House for Invalid Women at Atlantic City, N. J.; late Physician to the Clinic for the Diseases of Children in the Hospital of the University of Pennsylvania. Crown octavo, 222 pages. Cloth, $\$ 1.00$; interleaved for notes, $\$ 1.25$.

[See Saunders' Question-Compends, page 21.]

"Contains the gist of all the best works in the department to which it relates." American Practitioner and Neres.

\section{PRINGLE'S SKIN DISEASES AND SYPHILITIC AFFECTIONS.}

Pictorial Atlas of Skin Diseases and Syphilitic Affections (American Edition). Translation from the French. Edited by J. J. Pringle, M.B., F.R.C.P., Assistant Physician to the Middlesex Hospital, London. Photo-lithochromes from the famous models in the Museum of the Saint-Louis Hospital, Paris, with explanatory woodcuts and text. In 12 Parts. Price per Part, $\$ 3.00$. Complete in one volume, Half Morocco binding, $\$ 40.00$ net.

"I strongly recommend this Atlas. The plates are exceedingly well executed, and will be of great value to all studying dermatology." -STEPHEN MACKENZIE, M.D.

"The introduction of explanatory wood-cuts in the text is a novel and most important feature which greatly furthers the easier understanding of the excellent plates, than which nothing, we venture to say, has been seen better in point of correctness, beauty, and general merit."-New York Medical Journal.

\section{PYE'S BANDAGING.}

Elementary Bandaging and Surgical Dressing. With Directions concerning the Immediate Treatment of Cases of Emergency. For the use of Dressers and Nurses. By Walter Pye, F.R.C.S., late Surgeon to St. Mary's Hospital, London. Small I 2 mo, with over 80 illustrations. Cloth, flexible covers, 75 cents net.

"The directions are clear and the illustrations are good."-London Lancet.

"The author writes well, the diagrams are clear, and the book itself is small and port. able, although the paper and type are good."-British Medical Joumal.

\section{RAYMOND'S PHYSIOLOGY.}

A Manual of Physiólugy. By Joseph H. Raymond, A.MI., M.D., Professor of Physiology and Hygiene and Lecturer on Gynecology in the Long Island College Hospital; Director of Physiology in the Hoagland Laboratory, etc. $3^{8} 2$ pages, with 102 illustrations in the text, and 4 full-page colored plates. Cloth, $\$ 1.25$ net.

"Extremely well gotten up, and the illustrations have been selected with care. Tke text is fully abreast with modern physiology." - British Medical Journal.

\section{RÖNTGEN RAYS.}

Archives of the Röntgen Ray (Formerly Archives of Clinical Skiagraphy). Edited by SYDNEY Rowland, M.A., M.R.C.S., and W. S. Hedley, M.D., M.R.C.S. A series of collotype illustrations, with descriptive text, illustrating the applications of the new photography to Medicine and Surgery. Price per Part, \$1.00. Now ready: Vol. I, Parts I. to IV.; Vol. II., Parts I., II. 


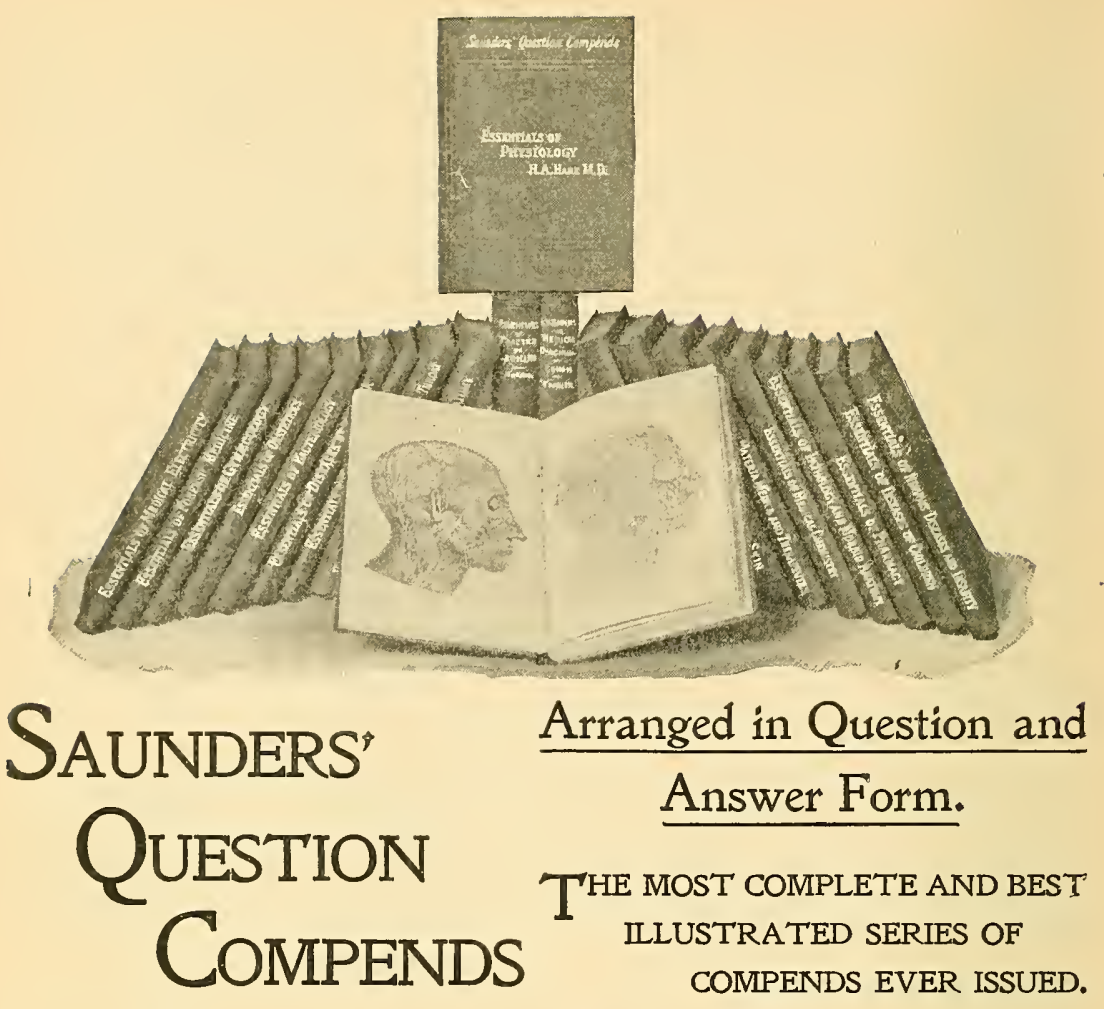

Now the Standard Authorities in Medical Literature ....

with Students and Practitioners in every City of the United States and Canada.

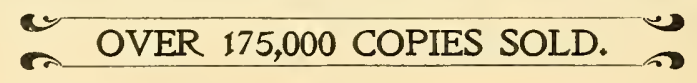

\section{THE REASON WHY.}

They are the advance guard of "Student's Helps"- that Do HELP. They are the leaders in their special line, well and authoritatively written by able men, who, as teachers in the large colleges, know exactly what is wanted by a student preparing for his examinations. The judgment exercised in the selection of authors is fully demonstrated by their professional standing. Chosen from the ranks of Demonstrators, Quiz-masters, and Assistants, most of them have become Professors and Lecturers in their respective colleges.

Each book is of convenient size ( $5 \times 7$ inches), containing on an average 250 pages, profusely illustrated, and elegantly printed in elear, readable type, on fine paper.

The entire series, numbering twenty-three volumes, has been kept thoroughly revised and enlarged when necessary, many of the books being in their fifth and sixth editions.

\section{TO SUM UP.}

Although there are numerous other Quizzes, Manuals, Aids, etc. in the market, none of them approach the "Blue Series of Question Compends;" and the elaim is made for the following points of excellence:

1. Professional distinction and reputation of authors.

2. Conciseness, clearness, and soundness of treatment.

3. Quality of illustrations, paper, printing, and binding.

Any of these Compends will be mailed on receipt of price (see next page for List). 


\section{Saunders' Question-Compend Series.}

Price, Cloth, $\$ 1.00$ per copy, except when otherwise noted. "Where the rork of preparing students' manuals is to end we cannot say, but the
Saunders Series, in our opinion, bears off the palm at present."-New York Medical Record.

1. essentials of Physiology. By H. A. Hare, M.D. Fourth edition, revised and enlarged. (\$1.00 net.)

2. ESSENTIALS OF SURGERY. By Edward Martix, Mi.D. Sixth edition, revised, with an Appendix on Antiseptic Surgery.

3. Essentials of anatomy. By Charles B. Nancrede, M.D. Fifth edition, with an Appendix.

4. ESSENTIALS OF MEDICAL CHEMISTRY, ORGANIC AND INORGANIC. By LAwrENCE WOLFF, M.D. Fourth edition, revised, with an Appendix.

5. ESSENTIALS OF OBSTETRICS. By W. EAsterly Ashton, M.D. Fourth edition, revised and enlarged.

6. ESSENTIALS OF PATHOLOGY AND MORBID ANATOMY. By C. E. ARMANd Semple, M.D.

7. ESSENTIALS OF MATERIA MEDICA, THERAPEUTICS, AND PRESCRIPTION=WRITING. By HENRY MORRIS, M.D. Fifth edition, revised.

8, 9. ESSENTIALS OF PRACTICE OF MEDiCiNE. By Henry Morris, M.D. An Appendix on Urine Examination. By Lawrence WolfF, M.D. Third edition, enlarged by some 300 Essential Formulæe, selected from eminent authorities, by WM. M. Poweld, M.D. (Double number, \$2.00.)

10. ESSENTIALS OF GYNAECOLOGY. By Edwin B. CRAGin, Mi.D. Fourth edition, revised.

11. ESSENTIALS OF DisEases OF THE SKIN. By HEnry W. Stelwagon, M.D. Third edition, revised and enlarged. (\$1.0o net.)

12. ESSENTIALS OF MINOR SURGERY, BANDAGING, AND VENEREAL DISEASES. By EDWARD MARTIN, M.D. Second ed., revised and enlarged.

13. ESSENTIALS OF LEGAL MEDICINE, TOXICOLOGY, AND HYGIENE. By C. E. Armand Semple, M.D.

14. ESSENTIALS OF DISEASES OF THE EYE, NOSE, AND THROAT. By Edward Jackson, M.D., and E. B. Gleason, M.D. Second ed., revised.

15. ESSENTIALS OF DISEASES OF CHILDREN. By Willian M. Powell, M.D. Second edition.

16. ESSENTIALS OF EXAMINATION OF URINE. By LAWRENCE WOLFF, M.D. Colored "VOGEL SCALE." (75 cents.)

17. ESSENTIALS OF DIAGNOSIS. By S. Solis Cohen, M.D., and A. A. Eshner, M.D. (\$1.50 net.)

18. ESSENTIALS OF PRAC'TICE OF PHARMACY. By Lucius E. Sayre. Second edition, revised and enlarged.

20. ESSENTIALS OF BACTERIOLOGY. By M. V. BAle, M.D. Third edition, revised.

21. ESSENTIALS OF NERVOUS DISEASES AND INSANITY. By JohN C. SHAW, M.D. Third edition, revised.

22. ESSENTIALS OF MEDICAL PHYSICS. By Fred J. BRockWAy, M.D. Second edition, revised. (\$I.OO net.)

23. ESSENTIALS OF MEdiCAL ELECTRICITY. By David D. Stewart, M.D., and Enward S. Lawrance, M.D.

24. ESSENTIALS OF DisEases of THE EAR. By E. B. Gleason, M.D. Second edition, revised and greatly enlarged.

Pamphlet containing specimen pages, etc. sent free upon application. 


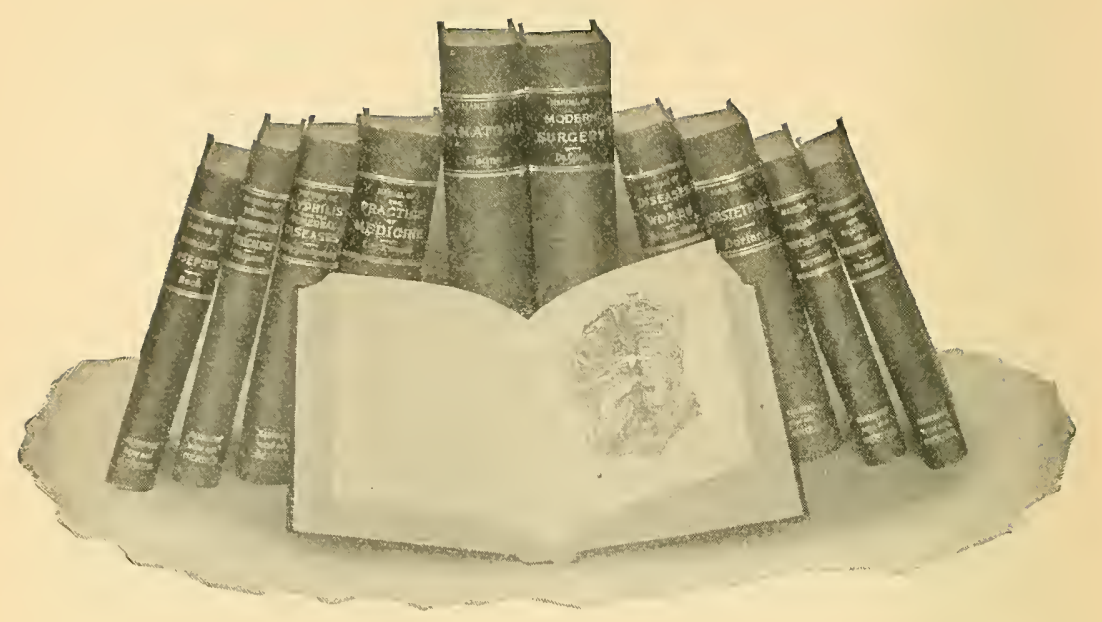

\section{Saunders'}

$\mathrm{N}_{\text {ew }}$ Series of Manuals

\section{for Students}

and

Practitioners.

IHAT there exists a need for thoroughly reliable hand-books on the leading branches of Medicine and Surgery is a fact amply demonstrated by the favor with which the SAUNDERS NEW SERIES OF MANUALS have been received by medical students and practitioners and by the Medical Press. These manuals are not merely condensations from present literature, but are ably written by well-known authors and practitioners, most of them being teachers in representative American colleges. Each volume is concisely and authoritatively written and exhaustive in detail, without being encumbered with the introduction of "cases," which so largely expand the ordinary text-book. These manuals will therefore form an admirable collection of advanced lectures, useful alike to the medical student and the practitioner: to the latter, too busy to search through page after page of elaborate treatises for what he wants to know, they will prove of inestimable value; to the former they will afford safe guides to the essential points of study.

The SAUNDERS NEW SERIES OF MANUALS are conceded to be superior to any similar books now on the market. No other manuals afford so much information in such a concise and available form. A liberal expenditure has enabled the publisher to render the inechanical portion of the work worthy of the high literary standard attained by these books.

Any of these Manuals will be mailed on receipt of price (see next page for List). 


\section{Saunders' New $_{\text {eries of }}$ Manuals.}

VOLUMES PUBLISHED.

PHYSIOLOGY. By Joseph Howard Raymond, A.M., M.D., Professor of Physiology and Hygiene and Lecturer on Gynecology in the Long Island College Hospital; Director of Physiology in the Hoagland Laboratory, etc. Illustrated. Cloth, \$1.25 net.

SURGERY, General and Operative. By John Chalmers LACusta, M.I., Clinical Professor of Surgery, Jefferson Medical College, Philadelphia; surgeon to the Philadelphia Hospital, etc. Second edition, thoroughly revised and greatly enlarged. Octavo, 9 II pages, profusely illustrated. Cloth, \$4.00 net; Half Morocco, \$5.00 net.

DOSE=BOOK AND MANUAL OF PRESCRIPTION=WRITING. BY E. Q. Thornton, M.D., Demonstrator of Therapeutics, Jefferson Medical College, I'hila. delphia. Illustrated. Cloth, \$I.25 net.

SURGICAL ASEPSIS. By CARI. Beck, MI.D., Surgeon to St. Mark's Hospital and to the New York German Poliklinik, etc. Illustrated. Cloth, \$1.25 net.

MEDICAL JURISPRUDENCE. By HENRY C. CHAPIAN, MI.D. Professor of Institutes of Medicine and Medical Jurisprudence in the Jefferson Medical College of Philadelphia. Illustrated. Cloth, \$I.50 net.

SYPHILIS AND THE VENEREAL DISEASES. By JAMES NeTins Hyid, M.D., Professor of Skin and Venereal Diseases, and Fraik H. Montgomerr, M. D., Lecturer on Dermatology and Genito-Urinary Diseases in Rush Medical College, Chicago. Profusely illustrated. Cloth, \$2.50 net.

PRACTICE OF MEDICINE. By GEORgE RoE Lockwood, M.D., Professor of Practice in the Woman's Medical College of the New York Infirmary; Instructor in Physical Diagnosis in the Medical Department of Columbia College, etc. Illustrated. Cloth, \$2. 50 net.

MANUAL OF ANATOMY. By IRving S. HAXxes, M.D., Adjunct Professor of Anatomy and Demoristrator of Anatomy, Medical Department of the New York University, etc. Beautifully illustrated. Cloth, \$2.50 net.

MANUAL OF OBSTETRICS. By W. A. Nemman DORLAND, M.D., Assistant Demonstrator of Obstetrics, University of Pennsylvania ; Chief of Gynecelogical Dis. pensary, Pennsylvania Hospital, etc. Profusely illustrated, Cloth, \$2.50 net.

DISEASES OF WOMEN. By J. Bland Suttox, F. R. C.S., Assistant Surgen to Middlesex Hospital and Surgeon to Chelsea Hospital, London; and ARTrнR E. (illes, M.D., B.SC. lond., F.R.C.S. Edin., Assistant Surgeon to Chelsea Hospitai, London. Handsomely illustrated. Cloth, \$2.50 net.

\section{VOLUMES IN PREPARATION.}

NOSE AND THROAT. By D. BRADEN KrLE, M.D., Clinical Profesior of Iaryngology and Rhinology, Tefferson Medical College, Ihiladelphia ; Consulting Iaryngologist, Rhinologist, and Otologist, St. Agnes' Hospital; liacteriologist to the I'liladelphia Orthopedic Ilospital and Infirmary for Nervous Diseases, etc.

NERVOUS DISEASES. By CHARlfs IV. BuRR, M.D., Clinical Professor of Nerrous Diseases, Medico-Chirurgical College. Philadelphia: Patholngist to the Urthopredic 1 lospital and lufirmary for Nerrous Diseases; Yisiting I'lysician to the st. Joseph llospital, etc.

*** There will be published in the same series, at short intervals, carefully-prepared works on various subjects by prominent specialists.

Pamphlet containirg specimen pages, etc. sent free upon application. 


\section{SAUNDBY'S RENAL AND URINARY DISEASES.}

Lectures on Renal and Urinary Diseases. By RoBERT SAUNdBy, M.D. Edin., Fellow of the Royal College of Physicians, London, and of the Royal Medico-Chirurgical Society; Physician to the General Hospital; Consuiting Physician to the Eye Hospitai and to the Hospital for Diseases of Women; Professor of Medicine in Mason College, Birmingham, etc. Octavo volume of 434 pages, with numerous illustrations and 4 colored plates. Cloth, $\$ 2.50$ net.

"The volume makes a favorable impression at once. The style is clear and succinct. We cannot find any part of the subject in which the views expressed are not carefully thought out and fortified by evidence drawn from the most recent sources. The book may be cordially recommended."-British Medical Joumal.

\section{SAUNDERS' MEDICAL HAND=ATLASES.}

This series of books consists of authorized translations into English of the world-famous Lehmann Medicinische Handatlanten. Each volume contains from 50 to 100 colored lithographic plates, besides numerous illustrations in the text. There is a full description of each plate, and each book contains a condensed but adequate outline of the subject to which it is devoted. For full description of this series, with list of volumes and prices, see page 2.

"Lehmann Medicinische Handatlanten belong to that class of books that are too good to be appropriated by any one nation."-Foumal of Ey'e, Ear, and Throat Diseases.

"The appearance of these works marks a new era in illustrated English medical works." - The Canadian Practitioner.

\section{SAUNDERS' POCKET MEDICAL FORMULARY. Fifth Edition,} Revised.

By William M. Powell, M.D., Attending Physician to the Mercer House for Invalid Women at Atlantic City, N. J. Containing I 800 formulæ selected from the best-known authorities. With an Appendix containing Posological Table, Formulæ and Doses for Hypodermic Medication, Poisons and their Antidotes, Diameters of the Female Pelvis and Fotal Head, Obs̊tetrical Table, Diet List for Various Diseases, Materials and Drugs used in Antiseptic Surgery, Treatment of Asphyxia from Drowning, Surgical Remembrancer, Tables of Incompatibles, Eruptive Fevers, Weights and Measures, etc. Handsomely bound in flexible morocco, with side index, wallet, and flap. $\$ 1.75$ net.

"This little book, that can be conveniently carried in the pocket, contains an immense amount of material. It is very useful, and, as the name of the author of each prescription is given, is unusually reliable." - Medical Record, New York.

\section{SAYRE'S PHARMACY. Second Edition, Revised.}

Essentials of the Practice of Pharmacy. By Lucius E. SAYre, M.D., Professor of Pharmacy and Materia Medica in the University of Kansas. Crown octavo, 200 pages. Cloth, $\$ 1.00$; interleaved for notes, \$1.25.

\section{[See Saunders' Question-Compends, page 2I.]}

"The topics are treated in a simple, practical manner, and the work forms a very useful student's manual." - Boston Medical and Surgical Joumal. 
SEMPLE'S LEGAL MEDICINE, TOXICOLOGY, AND HYGIENE.

Essentials of Legal Medicine, Toxicology, and Hygiene. By C. E. Ariand Semple, B. A., M. B. Cantab., M. R. C.P. Lond., Physician to the Northeastern Hospital for Children, Hackney, etc. Crown octavo, 2 I 2 pages; I 30 illustrations. Cloth, \$1.00; interleaved for notes, $\$ 1.25$.

\section{[See Saunders' Question-Compends, page 2I.]}

"No general practitioner or student can afford to be without this valuable work. The subjects are dealt with by a masterly hand."-London Hospital Gazette.

\section{SEMPLE'S PATHOLOGY AND MORBID ANATOMY.}

Essentials of Pathology and Morbid Anatomy. By C. E. Armand Semple, B.A., M.B. Cantab., M.R.C.P. Lond., Physician to the Northeastern Hospital for Children, Hackney, etc. Crown octavo, I 74 pages; illustrated. Cloth, \$I.00; interleaved for notes, \$1.25.

[See Saunders' Question-Compends, page 2I.]

"Should take its place among the standard volumes on the bookshelf of both student and practitioner."-London Hospital Gazette.

\section{SENN'S GENITO=URINARY TUBERCULOSIS.}

Tuberculosis of the Genito=Urinary Organs, Male and Female. By Nicholas Senr, M.D., PH.D., LL.D., Professor of the Practice of Surgery and of Clinical Surgery, Rush Medical College, Chicago. Handsome octavo volume of 320 pages, illustrated. Cloth, $\$ 3.00$ net.

"An important book upon an important subject, and written by a man of mature judgment and wide experience. The author has given us an instructive book upon one of the most important subjects of the day."-Clinical Reporter.

"A work which adds another to the many obligations the profession owes the talented author." - Chicago . Medical Recorder.

\section{SENN'S SYLLABUS OF SURGERY.}

A Syllabus of Lectures on the Practice of Surgery, arranged in conformity with "An American Text=Book of Surgery." By" Nicholas Sexn, M.D., Ph.D., Professor of the Practice of Surgery and of Clinical Surgery in Rush Medical College, Chicago. Cloth, \$2.00.

"This syllabus will be found of serrice by the teacher as well as the student, the work being superbly done. There is no praise too high for it. No surgeon should be without it." Nero York Medical Times.

\section{SENN'S TUMORS.}

Pathology and Surgical Treatment of Tumors. By N. SEns, M.D., PH.D., LL.D., Professor of Surgery and of Clinical Surgery, Rush Medical College; Professor of Surgery, Chicago Polyclinic; Attending Surgeon to Presbyterian Hospital; Surgeon-in-Chief, St. Joseph's Hospital, Chicago. Octavo volume of 7 IO pages, with 5 I $_{5}$ engravings, including full-page colored plates. Cloth, $\$ 6.00$ net; Half Morocco, $\$ 7.00$ net.

"The most exhaustive of any recent book in Engush on this subject. It is well illustrated, and will doubtless remain as the principal monograph on the subject in our language for some years. The book is handsomely illustrated and printed, and the author has given a notable and lasting contribution to surgery."-Joumal of the American .Medical Association. 


\section{SHAW'S NERVOUS DISEASES AND INSANITY. Third Edition, Revised.}

Essentials of Nervous Diseases and Insanity. Ву Јонм C. Shaw, M.D., Clinical Professor of Diseases of the Mind and Nervous System, Long Island College Hospital Medical School; Consulting Neurologist to St. Catherine's Hospital and to the Long Island College Hospital. Crown octavo, I 86 pages; 48 original illustrations. Cloth, $\$ 1.00$; interleaved for notes, $\$ \mathbf{I} .25$.

[See Saunders' Question-Compends, page 21.]

"Clearly and intelligently written."-Boston Medical and Surgical Journal.

"There is a mass of valuable material crowded into this small compass."-American Medico-Surgical Bulletin.

\section{STARR'S DIETS FOR INFANTS AND CHILDREN.}

Diets for Infants and Children in Health and in Disease. By Louis STARR, M.D., Editor of "An American Text-Book of the Diseases of Children." 230 blanks (pocket-book size), perforated and neatly bound in flexible morocco. \$I.25 net.

The first series of blanks are prepared for the first seven months of infant life; each blank indicates the ingredients, but not the quantities, of the food, the latter directions being left for the physician. After the seventh month, modifications being less necessary, the diet lists are printed in full. Formulæ for the preparation of diluents and foods are appended.

\section{STELWAGON'S DISEASES OF THE SKIN. Third Edition, Revised.} Essentials of Diseases of the Skin. By Henry W. Stelwagon, M.D., Clinical Professor of Dermatology in the Jefferson Medicai College, Philadelphia; Dermatologist to the Philadelphia Hospital; Physician to the Skin Department of the Howard Hospital, etc. Crown octavo, 270 pages; 86 illustrations. Cloth, \$1.00 net; interleaved for notes, \$1.25 net.

\section{[See Saunders' Question-Compends, page 2r.]}

"The best student's manual on skin diseases we have yet seen."-Times and Register.

\section{STENGEL'S PATHOLOGY. Second Edition.}

A Text=Book of Pathology. By Alfred Stengel, M. D., Physician to the Philadelphia Hospital; Clinical Professor of Medicine in the Woman's Medical College; Physician to the Children's Hospital; late Pathologist to the German Hospital, Philadelphia, etc. Handsome octavo volume of 848 pages, with nearly 400 illustrations, many of them in colors. Cloth, $\$ 4.00$ net; Half Morocco, $\$ 5.00$ net.

\section{STEVENS' MATERIA MEDICA AND THERAPEUTICS. Second} Edition, Revised.

A Manual of Materia Medica and Therapeutics. By A. A. Stevens, A.M., M.D., Lecturer on Terminology and Instructor in l'hysical Diagnosis in the University of Pennsylvania; Professor of Pathology in the Woman's Medical College of Pennsylvania. Postoctavo, 445 jages. Flexible leather, $\$ 2.25$.

"The author has faithfully presented modern therapentics in a comprehensive work, and, while intended particularly for the use of students, it will be found a reliable guide and sufficiently comprehensive for the physician in practice." - University Medical Magazine. 
STEVENS' PRACTICE OF MEDICINE. Fifth Edition, Revised.

A Manual of the Practice of Medicine. By $\downarrow$. A. Srevexs, A. M., M. D., Lecturer on Terminology and Instructor in Physical Diagnosis in the University of Pennsylvania; Professor of Pathology in the Woman's Medical College of Pennsylvania. Specially intended for students preparing for graduation and hospital examinations. Postoctavo, 5 I 9 pages; illustrated. Flexible leather, \$2.00 net.

"The frequency with which new editions of this manual are demanded bespeaks its popularity. It is an excellent condensation of the essentials of medical practice for the student, and may be found also an excellent reminder for the busy physician." - Buffalo Medical Journal.

\section{STEWART'S PHYSIOLOGY. Third Edition, Revised.}

A Manual of Physiology, with Practical Exercises. For Students and Practitioners. By G. N. Stewart, M.A., M.D., D.Sc., lately Examiner in Physiology, University of Aberdeen, and of the New Museums, Cambridge University; Professor of Physiology in the Western Reserve University, Cleveland, Ohio. Octavo volume of 848 pages; 300 illustrations in the text, and 5 colored plates. Cloth, $\$ 3.75$ net.

"It will make its way by sheer force of merit, and amply deserves to do so. It is one of the very best English text-books on the subject." - London Lancet.

"Of the many text-books of physiology published, we do not know of one that so nearly comes up to the ideal as does Prof. Stewart's volume."'-British Medical Journal.

\section{STEWART AND LAWRANCE'S MEDICAL ELECTRICITY.}

Essentials of Medical Electricity. By D. D. Stewart, M.D., Demonstrator of Diseases of the Nervous System and Chief of the Neurological Clinic in the Jefferson Medical College; and E. S. Lawrance, M. D., Chief of the Electrical Clinic and Assistant Demonstrator of Diseases of the Nervous System in the Jefferson Medical College, etc. Crown octavo, 158 pages; 65 illustrations. Cloth, $\$ 1.00$; interleaved for notes, $\$ 1.25$.

[See Saunders' Question-Compends, page 21.]

"Throughout the whole brief space at their command the authors show a discriminating knowledge of their subject." -Medical News.

STONEY'S NURSING. Second Edition, Revised.

Practical Points in Nursing. For Nurses in Private Practice. By Emily A. M. Stoney, Graduate of the Training-School for Nurses, Lawrence, Mass.; late Superintendent of the 'Training-School for Nurses, Carney Hospital, South Boston, Mass. $45^{6}$ pages, illustrated with 73 engravings in the text, and 8 colored and half-tone plates. Cloth, \$1.75 net.

"There are few books intended for non-professional readers which can be so cordially endorsed by a medical journal as can this one." - Therapeutic Gasette.

"This is a well-witten, eminently practical volume, which covers the entire range of private nursing as distinguished from hospital nursing, and instrucis the nurse how best to meet the various emergencies which may arise, and how to prepare everything ordinarily needed in the illness of her patient."-American Joumal of Obstetrics and Disenses of Homen and Children.

"It is a work that the physician can place in the hands of his private nurses with the assurance of benefit."-Ohio Nedical Jourmal. 


\section{STONEY'S MATERIA MEDICA FOR NURSES.}

Materia Medica for Nurses. By Emily A. M. StonEy, Graduate of the Training-School for Nurses, Lawrence, Mass. ; late Superintendent of the Training-School for Nurses, Carney Hospital, South Boston, Mass. Handsome octavo volume of 306 pages. Cloth, \$I.50 net.

The present book differs from other similar works in several features, all of which are intended to render it more practical and generally useful. The general plan of the contents follows the lines laid down in training-schools for nurses, but the book contains much useful matter not usually included in works of this character, such as Poison-emergencies, Ready Dose-list, Weights and Measures, etc., as well as a Glossary, defining all the terms used in Materia Medica, and describing all the latest drugs and remedies, which have been generally neglected by other books of the kind.

\section{SUTTON AND GILES' DISEASES OF WOMEN.}

Diseases of Women. By J. Bland Sutton, F.R.C.S., Assistant Surgeon to Middlesex Hospital, and Surgeon to Chelsea Hospital, London; and Arthur E. Giles, M.D., B.Sc. Lond., F.R.C.S. Edin., Assistant Surgeon to Chelsea Hospital, London. 436 pages, handsomely illustrated. Cloth, $\$ 2.50$ net.

"The text has been carefully prepared. Nothing essential has been omitted, and its teachings are those recommended by the leading authorities of the day." - Joumal of the American Medical Association.

\section{THOMAS'S DIET LISTS AND SICK=ROOM DIETARY.}

Diet Lists and Sick=Room Dietary. By Jerone B. Thomas, M.D., Visiting Physician to the Home for Friendless Women and Children and to the Newsboys' Home; Assistant Visiting Physician to the Kings County Hospital. Cloth, \$I.50. Send for sample sheet.

\section{THORNTON'S DOSE=BOOK AND PRESCRIPTION=WRITING.}

Dose $=$ Book and Manual of Prescription $=$ Writing. By E. $Q$. Thornton, M.D., Demonstrator of Therapeutics, Jefferson Medical College, Philadelphia. 334 pages, illustrated. Cloth, \$1.25 net.

"Full of practical suggestions; will take its place in the front rank of works of this sort." - Medical Record, New York.

\section{VAN VALZAH AND NISBET'S DISEASES OF THE STOMACH.}

Diseases of the Stomach. By Wildiam W. VaN ValzaH, M.D., Professor of General Medicine and Diseases of the Digestive System and the Blood, New York Polyclinic; and J. Douglas Nisbet, M.D., Adjunct Professor of General Medicine and Diseases of the Digestive System and the Blood, New York Polyclinic. Octavo volume of 674 pages, illustrated. Cloth, $\$ 3.50$ net.

"Its chief claim lies in its clearness and general adaptability to the practical needs of the general practitioner or student. In these relations it is probably the best of the recent special works on diseases of the stomach."-Chicago Clinical Review.

\section{YECKI'S SEXUAL IMPOTENCE.}

The Pathology and Treatment of Sexual Impotence. By Victor G. VeCKI, M.D. From the second German edition, revised and enlarged. Demi-octavo, about 300 pages. Cloth, $\$ 2.00$ net.

The subject of impotence has seldom been treated in this country in the truly scientific spirit that it deserves. Ir. Vecki's work has long been favorably known, and the German book has received the highest consideration. This edlition is more than a mere translation, for, although based on the German edition, it bas been entirely rewritten in English. 
VIERORDT'S MEDICAL DIAGNOSIS. Fourth Edition, Revised.

Medical Diagnosis. By Dr. Oswald Tierordt, Professor of Medi cine at the University of Heidelberg. Translated, with additions, from the fifth enlarged German edition, with the author's permission, by Francis H. Stuart, A. M., M. D. Handsome royal octavo volume of 603 pages; I9t fine wood-cuts in text, many of them in colors. Cloth, $\$ 4.00$ net; Sheep or Half Morocco, $\$ 5.00$ net.

"A treasury of practical information which will be found of daily" use to every busy practitioner who will consult it."-C. A. LiNDSLEY, M.D., Professor of the Theory and Practice of Medicine, Yale Uiziversity.

"Rarely is a book published with which a reviewer can find so little fault as with the volume before us. Each particular item in the consideration of an organ or apparatus, which is necessary to determine a diagnosis of any disease of that organ, is mentioned; nothing seems forgotten. The chapters on diseases of the circulatory and digestive apparatus and nervous system are especially full and valuable. The reviewer would repeat that the book is one of the best-probably the best-which has fallen into his hands." - University Medicat Magazine.

\section{WARREN'S SURGICAL PATHOLOGY AND THERAPEUTICS.}

Surgical Pathology and Therapeutics. By John Collixs IVARREN, M.D., LL.D., Professor of Surgery, Medical Department Harvard University; Surgeon to the Massachusetts General Hospital, etc. Handsome octavo volume of 832 pages; ${ }^{3} 3^{6}$ relief and lithographic illustrations, 33 of which are printed in colors, and all of which were drawn by William J. Kaula from original specimens. Cloth, $\$ 6.00$ net; Half Morocco, $\$ 7.00$ net.

"There is the work of Dr. Warren, which I think is the most creditable book on Surgical Pathology, and the most beautiful medical illustration of the bookmaker's art, that has ever been issued from the American press."-DR. Roswell PARk, in the Harvard Graduate Magazine.

"The handsomest specimen of bookmaking that has ever been issued from the American medical press." - American Joumal of the Medical Sciences.

"A most striking and very excellent feature of this book is its illustrations. Without exception, from the point of accuracy and artistic merit, they are the best ever seen in a work of this kind. Many of those representing microscopic pictures are so perfect in their coloring and detail as almost to give the beholder the impression that he is looking down the barrel of a microscope at a well-mounted section."-Ammals of Surgery.

\section{WOLFF ON EXAMINATION OF URINE.}

Essentials of Examination of Urine. By LAWRENCE WOLFF, M.D., Demonstrator of Chemistry, Jefferson Medical College, Philadelphia, etc. Colored (Vogel) urine scale and numerous illustrations. Crown octavo. Cloth, 75 cents.

[See Saunders' Question-Compends, page 2r.]

"A very good work of its kind-very well suited to its purpose."-Times and Rigister.

\section{WOLFF'S MEDICAL CHEMISTRY. Fourth Edition, Revised.}

Essentials of Medical Chemistry, Organic and Inorganic. Containing also Questions on Medical Physics, Chemical Physiology, Analytical Processes, Urinalysis, and Toxicology. By LAwrence WolfF, M.D., Demonstrator of Chemistry, Jefferson Medical College, Philadelphia, etc. Crown octaro, 2 I 8 pages. Cloth, \$1.00; interleaved for notes, \$1.25.

\section{[See Saunders' Question-Compends, page 21.]}

"The scope of this work is certainly" equal to that of the best course of lectures on Medical Chemistry. "-Pharmaceutical Era. 
OF THE

\title{
Medical Publications
}

OF

\author{
W. B. SAUNDERS, \\ 925 Walnut Street, Philadelphia.
}

\section{ANA'TOMY, EMBRYOLOGY,} HISTOLOGY.

Clarkson-A Text-Book of Histology, Haynes-A Manual of Anatomy,. . . I 3 Heisler-A Text-Book of Embryology, I3 Nancrede-Essentials of Anatomy, . . I8 Nancrede-Essentials of Anatomy and Manual of Practical Dissection, . . . I8

Semple-Essentials of Pathology and Morbid Anatomy,. . . . . . . 25

\section{BACTERIOLOGY.}

Ball-Essentials of Bacteriology, . . . 6 Crookshank-A Text-Book of Bacteriology, .

Frothingham - Laboratory Guide, . II

Mallory and Wright - Pathological Technique,

McFarland-Pathogenic Bacteria, . . I7

CHARTS, DIET=LISTS, ETC.

Griffith-Infant's WVeight Chart,

Hart_Diet in Sickness and in Health, I 3

Keen-Operation Blank, . . . . . I5

Lainé-Temperature Chart, . . . . . I5

Meigs-Feeding in Early Infancy, . . 17

Starr-Diets for Infants and Children, . 26

Thomas-Diet-Lists and Sick-Room

Dietary, .

\section{CHEMISTRY AND PHYSICS.}

Brockway-Essentials of Medical Physics,

Wolf-Essentials of Medical Chemistry, 29

\section{CHILDREN.}

An American Text-Book of Diseases of Children,

Griffith-Care of the Baby, . . . I

Griffith-Infant's WVeight Chart, . . . I 2

Meigs-Feeding in Early Infancy, . . I 7

Powell-Essentials of Dis. of Children, I9

Starr-Diets for Infants and Children, . 26

\section{DIAGNOSIS.}

Cohen and Eshner-Essentials of Diagnosis,

Corwin-Physical Diagnosis,

Macdonald-Surgical Diagnosis and Treatment,

Vierordt-Medical Diarnosis, * * I6

\section{DICTIONARIES.}

Dorland-Pocket Dictionary,

Keating-J'ronouncincr Dictionary, * Io

Morten-Nurse's Dictionary, . . . I8
EYE, EAR, NOSE, AND THROAT.

An American Text-Book of Diseases of the Eye, Ear, Nose, and Throat, - 3 De Schweinitz-Diseases of the Eye,. Io Gleason-Essentials of Dis. of the Ear, I I Jackson and Gleason-Essentials of Diseases of the Eye, Nose, and Throat, I 4 Kyle-Diseases of the Nose and Throat, I 5

\section{GENITO=URINARY .}

An American Text-Book of Genito.

Urinary and Skin Diseases, . . . . . 4

Hyde and Montgomery-Syphilis and

the Venereal Diseases,. . . . . . I3

Martin-Essentials of Minor Surgery,

Bandaging, and Venereal Diseases, . 16

Saundby-Renal and Urinary Diseases, 24

Senn-Genito-Urinary Tuberculosis, . 25

Vecki_-Sexual Impotence, ..... 28

\section{GYNECOLOGY.}

American Text-Book of Gynecology, 4 Cragin-Essentials of Gynecology, . . 9 Garrigues-Diseases of IVomen, . . . I I Long-Syllabus of Gynecology, . . . I5 Penrose-Diseases of Women, . . . I8 Sutton and Giles-Diseases of Women, 28

MATERIA MEDICA, PHARMACOLOGY, AND THERAPEUTICS.

An American Text-Book of Applied Therapeutics,

Butler-Text-Book of Materia Medica, Therapeutics and Pharmacology, . . . 8 Cerna-Notes on the Newer Remedies, 8 Griffin-Materia Med. and Therapeutics, I2 Morris-Essentials of Materia Medica and Therapeutics, . . . . . . . . I7 Saunders' Pocket Medical Formulary, 24 Sayre-Essentials of Pharmacy, . . . 24 Stevens-Essentials of Materia Medica and Therapeutics, . . . . . . . $2 h$

Stoney-Materia Medica for Nurses, . 28 Thornton-Dose-Book and Manual of Prescription-Writing, . . . . 28

MEDICAL JURISPRUDENCE AND TOXICOLOGY.

An American Text-Book of Legal Medicine and Toxicology, . . . . 4

Chapman-Medical Jurisprudence and Toxicology,

Semple-lissentials of Legal Medicine, Toxicology, and Hygiene, .... 25 


\section{NERVOUS AND MENTAL. DISEASES, ETC.}

Burr-Nervous Diseases,

Chapin-Compendium of Insanity, . 8

Church and Peterson-Nervous and Mental Diseases,

Shaw-Essentials of Nervous Diseases and Insanity, . . . . . . . . . . 26

\section{NURSING.}

An American Text-Book of Nursing, 29 Griffith-The Care of the Baby, . . . I2

Hampton--Nursing, . . . . . . . I2

Hart-Diet in Sicliness and in Health, I3

Meigs-Feeding in Early Infancy, . . I7

Morten-Nurse's Dictionary, . . . . Is

Stoney-Practical Points in Nursing, . 27

\section{OBSTETRICS.}

An American Text-Book of Obstetrics, Ashton-Essentials of Obstetrics,

Boisliniere-Obstetric Accidents, Emergencies, and Operations, . . . . 7

Dorland-Manual of Obstetrics, . . . Io

Hirst-Text-Book of Obstetrics, . . . I3

Norris-Syllabus of Obstetrics,. . . . I 8

\section{PATHOLOGY.}

An American Text-Bcok of Fathology, Mallory and Wright - Pathological Technique,

Semple-Essentials of Pathology and Morbid Anatomy, . . . . . . . . . 25

Senn-Pathology and Surgical Treatment of Tumors, . . . . . . “25

Stengel-Text-Book of Pathology, . . 26

Warren-Surgical Pathology and Therapeutics,

\section{PHYSIOLOGY.}

An American Text-Book of Physiology,... . . . . . . . . 5 Hare-Essentials of Physiology, . . I 3 Raymond-Manual of Physiology, . . I9 Stewart-Manual of Physiology,... 27

\section{PRACTICE OF MEDICINE.}

An American Text-Book of the Theory and Practice of Medicine,

An American Year-Book of Medicine and Surgery,

Anders-Text-Book of the Practice of Medicine,

Lockwood-Manual of the Practice of Medicine,

Morris-Essentials of the Practice of Medicine,

Rowland and Hedley - Archives of the Roentgen Ray,

Stevens-Manual of the Practice of Medicine,

SKIN AND VENEREAL.

An American Text-Book of GenitoUrinary and Skin Diseases, . . . .
Hyde and Montgomery-Syphilis and the Venereal Diseases, . . . . . . I3

Martin-Essentials of Minor Surgery, Bandaging, and Venereal Uiseases, . I6

Pringle-Pictorial Atlas of Skin Diseases and Syphilitic Affections,

Stelwagon-Essentials of Diseases of the Skin,

\section{SURGERY.}

An American Text-Book of Surgery, An American Year-Book of Medicine and Surgery, . . . . . . . . 6

Beck-Manual of Surgical Asepsis, . 7

DaCosta-Manual of Surgery, . . . . Io

Keen-Operation Blank, . . . . . I5

Keen-The Surgical Complications and Sequels of Typhoid Fever, . . . . I5

Macdonald-Surgical Diagnosis and Treatment,

Martin-Essentials of Minor Surgery, Bandaging, and V'enereal Diseases, . I6

Martin-Essentials of Surgery, . . . . I6

Moore-Orthopedic Surgery, . . . . . I7 Pye-Elementary Bandaging and Surgical Dressing, . . . . . . . . I9

Rowland and Hedley-Archives of the Roentgen Ray, . . . . . . . . I9

Senn-Genito-Urinary Tuberculosis, . 25

Senn-Syllabus of Surgery, . . . . . 25

Senn-Pathology and Surgical Treatment of Tumors, . . . . . . . 25

Warren-Surgical Pathology and Ther-

apeutics, 5 6

7

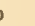

5

5
16

16

6

6

9

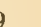

5
5

URINE AND URINARY DISEASES.

Saundby-Renal and Urinary Diseases, 24 Wolff-Essentials of Examination of Urine,

\section{MISCELLANEOUS.}

Bastin-Laboratory Exercises in Botany, . . . . . . . . . 7 Gould and Pyle-Anomalies and Curiosities of Medicine, . . . . . . . I I 5 Grafstrom-Mlassage, . : . , I2 Keating-How to Examine for Life Insurance, . . . . . . I I

Rowland and Hedley-Archives of the Roentgen Ray, . . . . . . . . I9

Saunders' Medical Hand-Atlases, . . 2 Saunders' New Series of Manuals, 22, 23 Saunders' Pocket Medical Formulary, . 24 Saunders' Question-Compends, . . 20, 2 I Senn-Pathology and Surgical Treatment of Tumors, . . . . . . . 25

Stewart and Lawrance-Essentials of Medical Electricity, . . . . . . 27 Thornton-Dose-Book and Manual of Prescription- IVriting, . . . . . . . $2 S$ Van Valzah and Nisbet-Diseases of the Stomach,......... $2 \&$ 


\section{IN PRESS}

\section{FOR PUBLICATION EARLY IN THE FALL OF 1899.}

\section{THE INTERNATIONAL TEXT=BOOK OF SURGERY. In two volumes.}

By American and British authors. Edited by J. Collins WArren, M.D., LL.D., Professor of Surgery, Harvard Medical School, Boston; Surgeon to the Massachusetts General Hospital; and A. Pearce Gould, M.S., F. R. C.S., Eng., Lecturer on Practical Surgery and Teacher of Operative Surgery, Middlesex Hospital Medical School; Surgeon to the Middlesex Hospital, London, England. Vol. I. Handsome octavo volume of about $95^{\circ}$ pages, with over 400 beautiful illustrations in the text, and 9 lithographic plates.

\section{HEISLER'S EMBRYOLOGY.}

A Text=Book of Embryology. By John C. Heisler, M. D., Professor of Anatomy in the Medico-Chirurgical College, Philadelphia. I mo volume of about 325 pages, handsomely illustrated.

\section{KYLE ON THE NOSE AND THROAT.}

Diseases of the Nose and Throat. By D. Braden Kyle, M. D., Clinical Professor of Laryngology and Rhinology, Jefferson Medical College, Philadelphia; Consulting Laryngologist, Rhinologist, and Otologist, St. Agnes' Hospital. Octavo volume of about 630 pages, with over 150 illustrations and 6 lithographic plates.

\section{PRYOR-PELVIC INFLAMMATIONS.}

The Treatment of Pelvic Inflammations through the Vagina. By W. R. Pryor, M. D., l'rofessor of Gynecology in the New York Polyclinic. I 2 mo volume of about 250 pages, handsomely illustrated.

\section{ABBOT'T ON TRANSMISSIBLE DISEASES.}

The Hygiene of Transmissible Diseases: their Causation, Modes of Dissemination, and Methods of Prevention. By A. C. Aввотт, M. D., Professor of Hygiene in the University of Pemnsylvania; Director of the Laboratory of Hygiene. Octavo volume of about 325 pages, containing a number of charts and maps, and numerous iilustrations.

\section{JACKSON-DISEASES OF THE EYE.}

A Manual of Diseases of the Eye. By Edward Jackson, A. M., M. D., late Professor of Diseases of the Eye in the Pliiladelphia P'olyclinic and College for Graduates in Medicine. I2mo volume of over 500 pages, with about $\mathbf{1 7 5}$ beautiful illustrations from drawings by the author. 





This book is due UNIVERSITY LIBRARIES provided by the dibrate period after theated below, or at the the Librarian in charge. DATE BORROWE

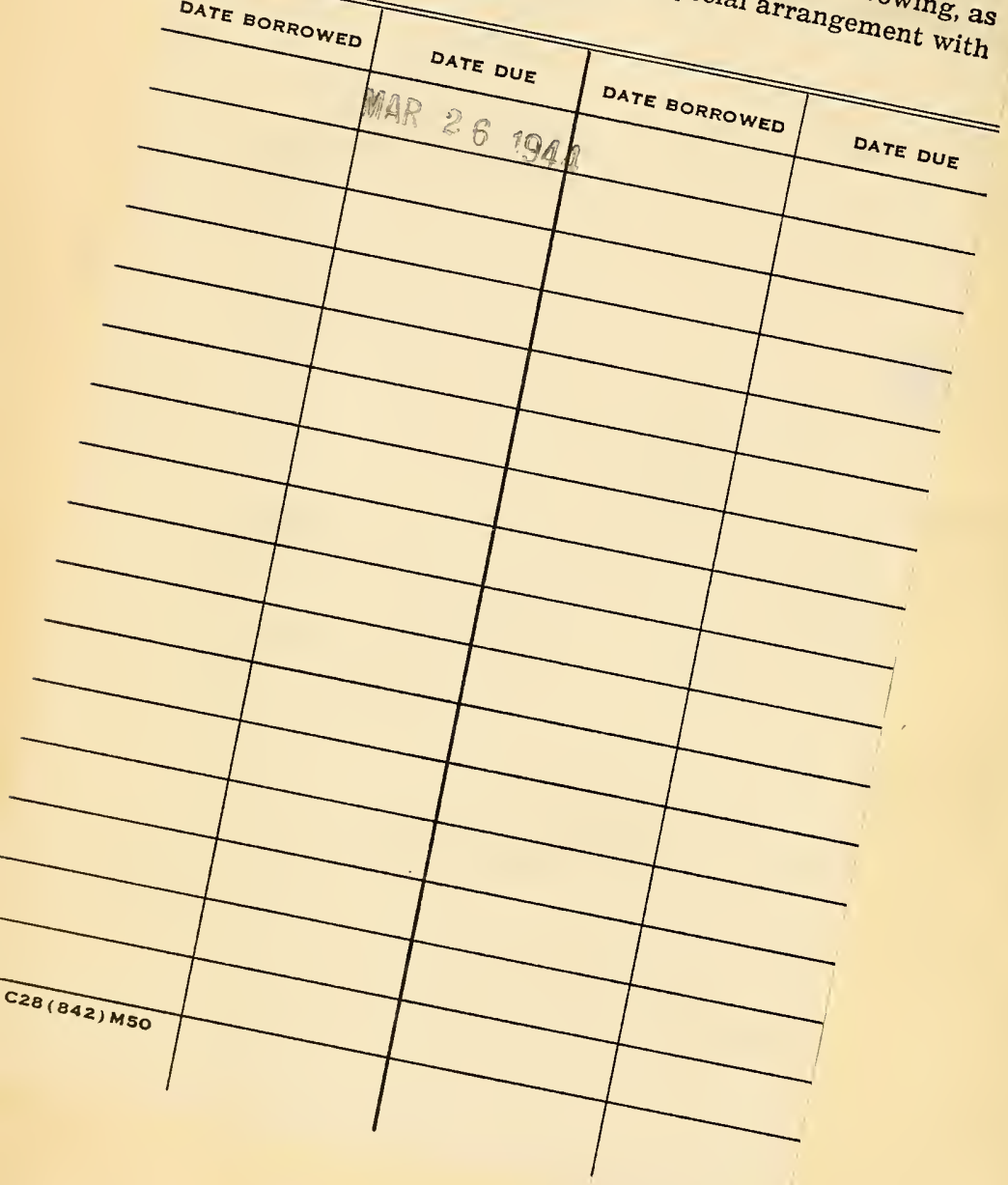


QM601

$+36$

Herster cop.. .

Embryology

- 21 - 20 tanlor 


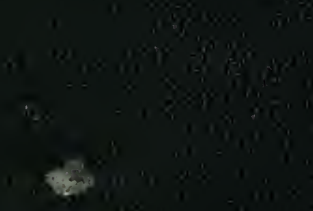

